Universidad Nacional de La Plata (UNLP)

Facultad de Periodismo y Comunicación Social

La escena bonaerense de la música metal: estudio en torno a Hermética como centro de sentidos y disputas

\author{
Trabajo de tesis para optar por el título de \\ DOCTORA EN COMUNICACIÓN
}

\begin{abstract}
Autora: Mg. Manuela Belén Calvo (IEHS/IGEHCS-CONICET)
Directora: Dra. Olga Inés Echeverría (IEHS/IGEHCS-CONICET)

Co Director: Prof. Sergio Alejandro Pujol (FPyCS/UNLP-CONICET)
\end{abstract}

-Cohorte 2013-

La Plata, Abril 2019 
"Se me cumple

hoy el sueño pendejo de ayer. Y fue por rebelde que al metal pesado me aguanté" (Hermética) 


\section{Agradecimientos}

Esta tesis está dedicada a todos aquellos que me tendieron una mano en los caminos y las pendientes que debí atravesar para culminar con la escritura de este trabajo. Los nombres son muchos y es muy difícil no olvidarse de alguien. No obstante, voy a mencionar algunos:

Al Consejo Nacional de Investigaciones Científicas y Técnicas (CONICET) que me permitió llevar a cabo esta investigación otorgándome financiamiento a través de una beca doctoral. A las autoridades del Instituto de Estudios Histórico Sociales (IEHS) y del Instituto de Geografía, Historia y Ciencias Sociales (IGEHCS) por brindarme un espacio de trabajo, de diálogo y de despliegue de creatividad.

Al Doctorado en Comunicación de la Facultad de Periodismo y Comunicación Social de la Universidad Nacional de La Plata por aceptar este proyecto de tesis.

A los miembros de Medios UNICEN y Abra TV por ayudarme a afinar mis preguntas de investigación e invitarme a difundirlas en su programa "Ciencia x científicxs".

A mis amigas, Priscila Orguilia y Annalee Tomsiček; a Bruno Aranha, Luciano Scarrone, María Sol Bruno, Exequiel Núñez, Gito Minore, Ariel Ávila, Aldana Perazzo, Nelson Varas-Díaz y a mis compañeras y compañeros del Instituto de Estudios Histórico Sociales (IEHS) de Tandil, por la ayuda con el rastreo y el aporte bibliográfico.

A Fernando Galicia Poblet, por el asesoramiento en los apartados referidos a la descripción musical. A Lorena La Macchia, por la colaboración en la elaboración de los mapas. A todas las personas y las bandas (Mal Karma, Rotas Cadenas e Instinto DC) que entrevisté, por su amabilidad. Sobre todo a aquellos que cordialmente me abrieron las puertas de sus casas.

A Nicolás Fleming, Oscar Rodríguez y, muy especialmente, a mi compañero, Francisco, por ayudarme a acceder a mis trabajos de campo.

A mi directora, Olga Echeverría y a mi co-director, Sergio Pujol, por estos años de asesoramiento y por invitarme a transitar hermosos caminos bibliográficos a través de sus sugerencias y comentarios.

A mis amigos, amigas y abuelos, por bancarme incondicionalmente a pesar de verme poco, siempre por la excusa de "tener que hacer la tesis".

A mi hermana, mi mamá y mi papá, porque, sin su amor, esta tesis ni la vida tendrían sentido. 


\section{Índice}

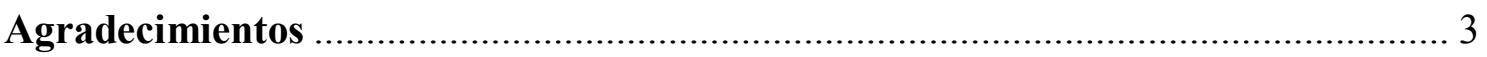

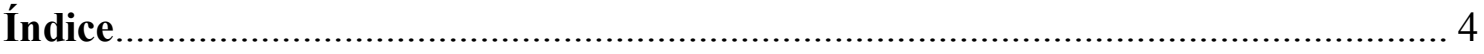

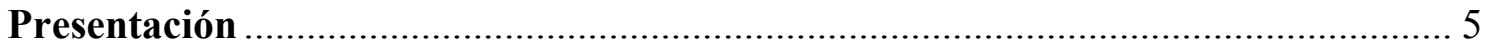

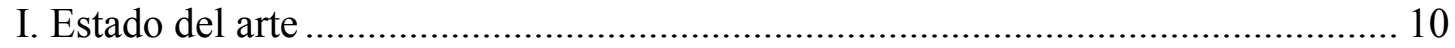

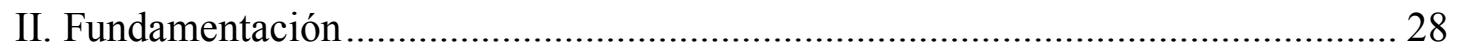

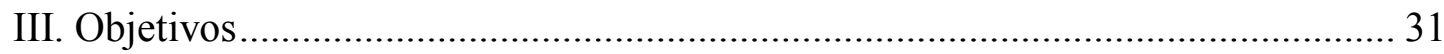

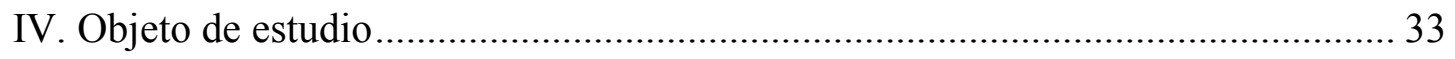

V. Propuesta teórico-metodológica ……................................................................. 59

Parte I: Reconstrucción de la escena metálica bonaerense como semiosfera:

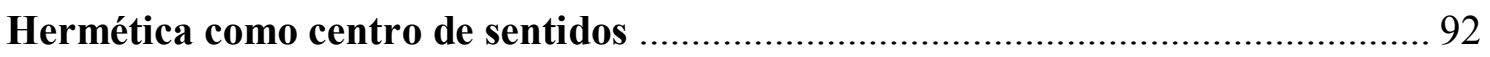

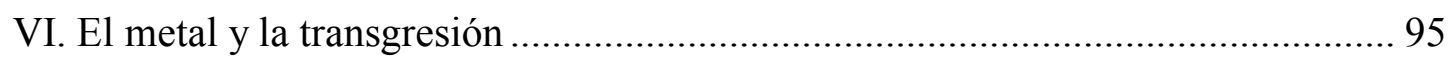

VII. Metal, sexualidad y perspectivas de género................................................. 175

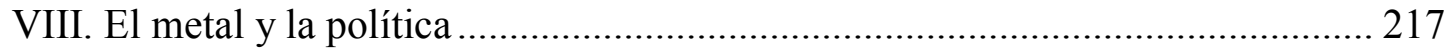

Parte II: Reconstrucción de la escena metálica bonaerense como campo cultural:

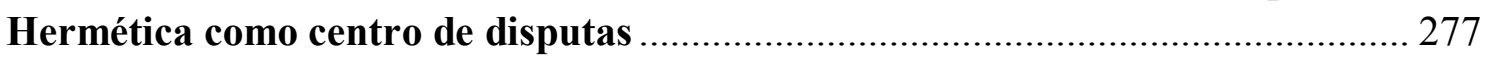

IX. Tensiones espaciales en la escena metálica bonaerense.................................. 278

IX. Tensiones temporales en la escena metálica bonaerense ................................. 315

X. Un nuevo campo intelectual en la escena metálica bonaerense ......................... 335

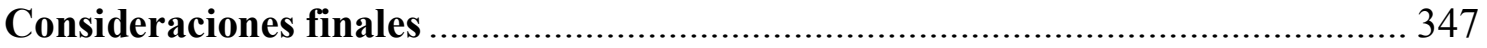

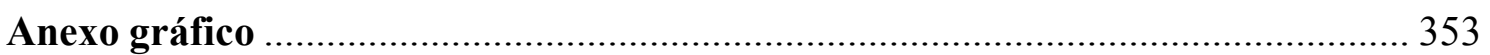

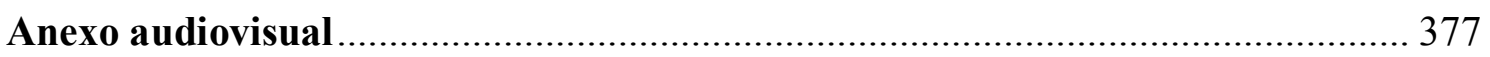

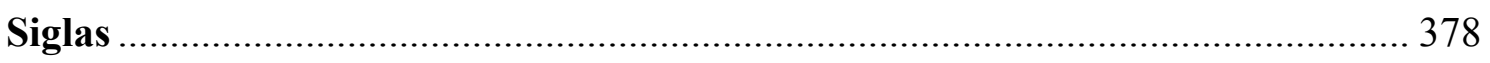

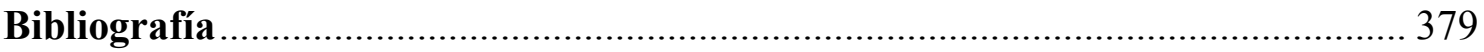

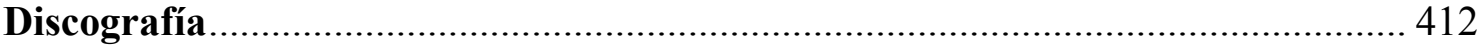

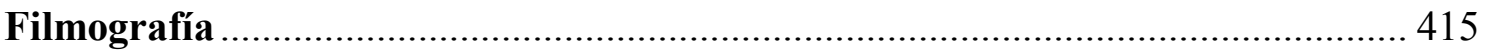




\section{Presentación}

En esta tesis doctoral se presentan los resultados de investigación sobre la escena bonaerense de la música metal ${ }^{1}$ en el período comprendido entre los años 2011 y 2017. Dicha escena musical se conforma como un espacio limitado -pero no completamente cerrado- que permite la producción, la circulación y el consumo de un estilo musical en particular -el metal-, además de la sociabilidad y la formación de cultura en torno a él.

A pesar de que la mirada externa ha descrito a la escena a través de características homogéneas, en su interior se compone de manera diversa. No obstante, dicha heterogeneidad conserva la unidad por medio de la circulación de algunos códigos en común, los cuales aparecen representados en las producciones y en la actividad de la banda, Hermética, una agrupación de thrash metal que estuvo activa entre 1987 y 1994 , fue liderada por Ricardo Iorio y se destacó por otorgarle una impronta argentina a un estilo musical de carácter transnacional.

Por otra parte, de manera explícita, en el imaginario de los aficionados ${ }^{2}$ de la escena metálica bonaerense (y también argentina) prevalece la idea de que ese conjunto musical es el más emblemático del metal argentino, lo que se puede ver en la reactualización de las producciones de la banda por parte de la audiencia y los mediadores.

Sin embargo, se produce una paradoja ya que, a pesar de que los discursos de dicho grupo intentan posicionarse en la perspectiva de los jóvenes de los sectores populares, en la actualidad permiten identificaciones y apropiaciones en un público heterogéneo, que pertenece a diversos sectores sociales, geográficos, etarios, políticos y de identidades de género, lo que acentúa la polifonía y la intertextualidad de dichas producciones.

De esta manera, la hipótesis principal de esta tesis plantea que: por un lado, la escena se construye a través de ciertos códigos específicos que, en su concreción dominante, aparecen plasmados a través de una línea que puede ser denominada "fundamentalista", la cual define lo que es "auténtico" y "legítimo" dentro de la escena y se encuentra representada por Hermética.

\footnotetext{
${ }^{1}$ Más adelante explicaré con más detalle que dicha denominación conceptual abarca geográficamente tanto a la provincia de Buenos Aires como a la Ciudad Autónoma de Buenos Aires.

${ }^{2}$ Es necesario hacer la salvedad de que, a pesar de estar de acuerdo con el lenguaje inclusivo, en esta tesis se utiliza mayormente el genérico tradicional masculino que suele usarse de manera "universal" para facilitar la lectura del texto.
} 
Por otra parte, la presencia recurrente de dicha banda en las prácticas sociales y culturales de la escena metálica argentina -y, en este caso, bonaerense- no solo se debe a la argentinidad de su mensaje, sino también a que en ella se representan los códigos mencionados, por medio de la síntesis musical y extra-musical de diversas tradiciones musicales y culturales vinculadas con el rock, el metal, el tango y el Folklore. En este sentido, tanto dichas producciones como los códigos mencionados se conforman como "híbridos" y "polifónicos".

En otras palabras, en las producciones de Hermética se puede observar la presencia de un conjunto de códigos que es compartido por los agentes de la escena bonaerense de la música metal, un espacio en el cual cohabitan diferencias sociales, geográficas, generacionales, culturales e ideológicas y diversidad de gustos y juicios de valor, los cuales conviven de manera predominantemente pacífica a pesar de las tensiones que esta variedad produce.

Efectivamente, dentro de la escena sus miembros y sus instituciones no solo se presentan de manera heterogénea, sino que también es posible encontrar entre ellos algunas posiciones de desigualdad. De esta manera, dichos agentes se encuentran en una disputa constante que tiene como principal objetivo la búsqueda de autenticidad, legitimación y su posterior consagración como efecto de poder.

Temporalmente, el objeto de estudio fue recortado al período comprendido entre el 2011 y el 2017, tomando como referencia algunos hitos que se desprenden de la historia de los antiguos músicos de Hermética y del impacto que tuvieron en la escena: en el primer año se produce el regreso de Malón ${ }^{3}$ luego de un receso de 10 años y, en el segundo, Ricardo Iorio ${ }^{4}$ alcanza masividad con su carrera solista, la cual posee una impronta ideológica explícitamente nacionalista que, a pesar de comenzar un temprano desarrollo en Almafuerte, en los últimos años se ligó a tendencias de la extrema derecha, las cuales tienen una fuerte presencia simbólica y testimonial en la arena política e ideológica de la Argentina, a pesar de no ser numéricamente significativas en términos de militantes y adherentes.

Como consecuencia de esa vinculación explícita de Iorio con personalidades y agrupaciones filofascistas, se produce una fuerte ruptura en la escena, ya que el público comienza a demostrar reflexividad política y sus manifestaciones generan divisiones

\footnotetext{
${ }^{3}$ Malón es la banda que forman el cantante, Claudio O'Connor; el guitarrista, Antonio "Tano" Romano; y el baterista, Claudio "Pato" Strunz, luego de distanciarse de Hermética.

${ }^{4}$ Ricardo Iorio es el bajista y cantante líder de Hermética que, luego de separarse de este grupo, forma el conjunto, Almafuerte y, luego de este, conforma su banda solista denominada igual que su apellido.
} 
ideológicas y nuevos modos de sociabilidad en torno a la música metal. Esto resulta más evidente en los eventos que proponen discusiones intelectuales, tales como las Feria del Libro Heavy, y entre los agentes que comienzan a conformar una especie de campo intelectual o académico dentro de la escena, el cual es característico del período estudiado y le otorga nuevos rasgos que la distinguen tanto de otros estilos musicales como de sus propios antecedentes históricos.

Por su parte, geográficamente el objeto es delimitado al área bonaerense, compuesta por la provincia de Buenos Aires y su ineludible relación con la Ciudad Autónoma de Buenos Aires (CABA). Esto constituye un recorte "micro" del panorama argentino, ya que en el interior de la escena bonaerense es posible ver dinámicas vinculadas a un policentrismo cultural: por un lado, el Área Metropolitana Bonaerense (CABA y el Conurbano) ocupa el centro de la escena bonaerense. Pero, por otra parte, dicha centralidad se encuentra en constante pugna con las localidades del "interior" que se constituyen como "doble periferia", debido a que Argentina ocupa un lugar periférico dentro del desarrollo global del metal. Estas características acentúan la heterogeneidad de la escena estudiada, mientras que la interconexión se produce por medio del metal como unificador.

\section{Acerca de la autora}

En este apartado también considero necesario presentarme como autora de esta tesis, ya que además de investigadora formo parte del objeto de estudio, no solo porque soy "metalera", sino también agente de la escena metálica bonaerense y dicha pertenencia comenzó muchos años antes de iniciar esta pesquisa, lo que no consistía en un mero fanatismo sino en una filosofía de vida o en un modo de ver el mundo.

Soy hija de una familia de trabajadores que con gran esfuerzo económico apostó por la educación privada, por lo que me escolaricé en un colegio católico para mujeres, al igual que lo fue con mi carrera terciaria. Más tarde, parte de mis posgrados los pude realizar gracias a mi trabajo como docente y diversos empleos "en negro" (Fui portera, ayudante de bibliotecaria, tallerista, vendedora, periodista gráfica y correctora de estilo). Finalmente en el año 2015 comencé a recibir apoyo económico del CONICET a través de una beca doctoral que me permitió dedicarme plena y exclusivamente a esta investigación.

En el año 2012 concluí mi tesis de Maestría en Culturas y Literaturas Comparadas acerca de la banda, Almafuerte, y su público. La elección de este tema 
estuvo motivada por el conocimiento previo que tenía acerca de dicho grupo musical. Al tratarse de un conjunto que me gustaba, lo valoraba de manera positiva, por lo que consideré que sus producciones eran materiales interesantes de analizar. Como Profesora de Lengua y Literatura sabía que los atravesaban gran cantidad de intertextos y diálogos que podían generar un conocimiento más profundo.

Posteriormente, en el 2013, ingresé al Doctorado en Comunicación de la Facultad de Periodismo y Comunicación Social de la Universidad Nacional de La Plata, con un pre-proyecto de tesis que vinculaba a la Argentina con el grupo, Hermética. En dicho momento presupuse que el cántico "La Hache no murió" decía mucho más que lo que objetivamente la frase significaba. Es decir, si Almafuerte me había resultado relevante por los diálogos que la atravesaban, ¿a cuántos sitios más podría llegar si partía de "la banda emblémática del metal argentino"?

A medida que fui cursando los seminarios propios de la carrera empecé a darle varias "vueltas de rosca" al tema y a ver la gran cantidad de problemáticas que lo atravesaban, lo cual era tan vasto que debió ser recortado temporal y geográficamente tal como describí anteriormente. Por otra parte, comencé a generar reflexividad acerca de mi multiplicidad de roles con respecto al objeto de estudio, ya que la elección del tema no solo se debió a mi afición por el metal y a mi conocimiento a priori, sino también al ejercicio de reflexión analítica que había comenzado a realizar durante la Maestría.

En consecuencia, durante esta tesis me ubiqué en una doble posición y en un constante vaivén que constió en observar y analizar tanto desde dentro como desde fuera. Más adelante me explayaré acerca de las herramientas metodológicas, pero brevemente indicaré que "ingresar" al campo consistió simplemente en "vivir" y "salir" de él, en analizar dichas vivencias. Esto implicó un fuerte trabajo de deconstrucción personal que, por momentos, reforzó algunas convicciones y, en muchos otros, modificó varios preconceptos que había naturalizado de manera inconsciente, muchos de los cuales provenían de prejuicios patriarcales.

Podría decir que, antes de iniciar este estudio, me consideraba una "metalera" bastante ortodoxa, pero al comenzar a familiarizarme con el feminismo y las teorías de género empecé a "ablandarme" y abrirme a la escucha y disfrute de otros géneros musicales. Esto también fue consecuencia de la gran cantidad de lecturas que realicé para escribir este trabajo, muchas de las cuales consistían en investigaciones sobre diversas manifestaciones musicales, en las que se citaban innumerables canciones y 
videoclips que me vi tentada a "googlear" y a reproducir en Internet. Al mismo tiempo, mi discografía metálica se amplió notablemente.

Esta implicación personal en la investigación también provocó cambios en mis relaciones interpersonales, generando alejamientos y nuevos acercamientos. Al mismo tiempo, más allá de que por momentos me dediqué a realizar una observación concienzuda, otras veces en las que me proponía "relajar" y disfrutar, tuve cierta sensación de extrañeza con respecto al ambiente que hasta entonces me había sido familiar. A la par de ello, estos cambios internos estaban acompañados por el paso del tiempo, la madurez y el pasaje a la adultez. No obstante, la propia escena también fue mutando (algo que se observará en los próximos capítulos) por lo que tanto yo como el resto de los agentes nos vimos sumergidos en dicha evolución.

Debo admitir que, al igual que otros miembros de la escena, a mí también me dolieron las declaraciones nefastas de Iorio, alguien que en algún momento había sido fuente de inspiración para mí. Sin embargo, intenté realizar un análisis lo más objetivo posible al respecto. Además, en dicho proceso también reflexioné acerca de mi propia práctica política y entendí que la visión "desconfiada” que tenía de ella provenía de mi identificación con las canciones "anti-sistema" de las bandas metálicas que me gustaban, algunas veces cercanas a las filosofías del anarquismo.

Dichas conclusiones no solo forman parte de los resultados de la pesquisa sino que también se convirtieron en recursos personales cuyo uso enriqueció el desarrollo de la propia vida. Con todo esto quiero decir que esta tesis no tiene la intención de ser una defensa del metal realizada por una aficionada, sino más bien, pretende constituirse como el resultado de la problematización y la deconstrucción resultantes de una investigación que utilizó a la objetividad y a la subjetividad de manera complementaria para la construcción del conocimiento. 


\section{Estado del arte}

El problema de investigación de esta tesis se enmarca dentro del campo de la comunicación y la cultura popular; los estudios sociales y culturales de la música popular; los estudios del rock y los estudios metálicos. Por ello, a continuación daré cuenta de las líneas teóricas que se tomaron como referencia y antecedente.

\section{Estudios sobre comunicación y cultura popular}

En la década de los '80, en el contexto del regreso de las democracias en diferentes países de Latinoamérica, se produce una ruptura en el campo de la comunicación, a partir del trabajo de Jesús Martín Barbero (1980), Armand Mattelart (1987) y Héctor Schmucler (1984). En consecuencia, surgen “(...) unas reconceptualizaciones de la comunicación que la ubican en la cultura como aquello que se define en el entremedio de las estructuras materiales de existencia y las dimensiones simbólicas de las mismas." (Saintout, 2003b, p. 84)

Por medio de la labor de Martín Barbero con la publicación de De los medios a las mediaciones (1991) y Procesos de comunicación y matrices de cultura. Itinerario para salir de la razón dualista (1987) se produce un desplazamiento con respecto al dualismo de las tradiciones anteriores que, en términos de Umberto Eco, correspondían a los "apocalípticos" y los "integrados", es decir, la teoría crítica de la Escuela de Frankfurt y el estructural funcionalismo respectivamente, las cuales poseían visiones enfrentadas acerca de los efectos que producían los medios de comunicación masiva sobre las audiencias.

La importancia de Martín Barbero radica en que este propone “(...) el desplazamiento de una teoría centrada en los medios hacia las mediaciones culturales; de la determinante tecnológica a la cultura." (Saintout, 2003a, p. 21) La labor de este autor junto con la de Néstor García Canclini resulta significativa para el desarrollo de los estudios culturales latinoamericanos, los cuales parten de las concepciones de cultura popular de la Escuela de Frankfurt y de la Escuela de Birmingham.

La primera se desarrolla en la década de 1940, en el "Instituto de Investigación Social de la Universidad de Frankfurt, una institución cuya orientación era abiertamente marxista. Sus representantes eran Max Horkheimer, Herbert Marcuse, Jürgen Habermas y Theodor Adorno. Estos académicos se caracterizaron por desarrollar la llamada teoría crítica o del "pensamiento negativo" (Marafioti, 2008, p. 182), debido 
a que consideraban que la industria cultural era una forma en que el capitalismo manipulaba a los individuos de una sociedad.

Por su parte, la otra tradición surge en los años '60, en el Centre of Contemporary Cultural Studies (CCCS) de la Universidad de Birmingham, representada por Richard Hoggart, Raymond Williams, Edward P. Thompson y Stuart Hall. Estos estudios, a pesar de ser una crítica al capitalismo y basarse en las nociones de hegemonía de Antonio Gramsci, se diferencian de la escuela de Frankfurt por rescatar el lugar del receptor como un sujeto activo, cuyas formas culturales eran modos de resistencia a los medios dominantes.

En América Latina, algunos precursores en los estudios culturales fueron Alfonso Reyes, Fernando Ortiz, José Carlos Mariátegui, José Luis Romero y Paulo Freyre (Pineda, 2012). Estos autores se encargaron de revalorizar a las culturas populares latinoamericanas de diferente rango y centralidad con una mirada descolonizadora, rescatando su lugar en confrontación con las ideas de cultura del Viejo Continente, que las vinculaban con el Medioevo y las consideraban opuestas al ideal iluminista de la cultura como "culta", "elitista", "refinada" y "letrada", ligada a las bellas artes, la literatura canónica y la música “seria” (Martín, 2003).

Al igual que la ruptura en el campo de la comunicación, se considera que los estudios culturales como tales emergieron en América Latina a principios de la década de los ' 80 , más precisamente durante las transiciones democráticas. Es en este contexto que se desarrollan los trabajos ya citados de Martin-Barbero $(1987,1991)$ y de García Canclini $(1984,2012)$ que también ponen su foco de atención en las culturas populares.

En Argentina, se describen dos grandes perspectivas: por un lado, la que es nombrada como "sociocultural" y está ligada a la propuesta de Pablo Alabarces (2008), quien se encuentra influido por la Escuela de Birmingham y define las culturas populares como formas de resistencia a la cultura dominante. Por el otro lado, se encuentra la perspectiva "socioantropológica", representada por los estudios de Pablo Semán (2006), y de éste junto a Daniel Míguez (2006), quienes critican el "hegemonicocentrismo" y rescatan la agencia de las culturas populares al considerar que existen mediaciones entre la condición social y sus prácticas culturales (Aliano, 2010).

En una línea similar a la de Semán y Míguez, es posible mencionar el trabajo de Aníbal Ford, Jorge Rivera y Eduardo Romano, Medios de Comunicación y Cultura Popular (1984), en el cual además de revalorizar la agencia del receptor, también se 
rescatan géneros discursivos que habían sido marginados y considerados menores por la academia argentina hasta mediados de los años 70: el radioteatro, las telenovelas y la historieta.

También en el campo de la Historia hay un notable crecimiento de los estudios culturales, especialmente desde la Historia Cultural, los cuales tuvieron un alto impacto en las disciplinas sociales. Algunos ejemplos son los trabajos que abordan a sujetos de los sectores populares de la Argentina de los siglos XVIII y XIX, como los criminales (Fernández, 2007) y los menores (Zapiola, 2007), es decir, "niños, pobres, callejeros, abandonados, delincuentes, analfabetos, abusados, peligrosos, trabajadores ambulantes, inmorales" (Gayol y Madero, 2007, p. 23).

También es posible mencionar el trabajo de Olga Echeverría $(2012,2013)$ en el cual da cuenta de la mirada estigmatizadora que tenían los intelectuales elitistas de Argentina entre fines del siglo XIX y principios del XX sobre el colectivo de sectores populares, integrado por

(...) los "diferentes" (mujeres, inmigrantes, especialmente los judíos y los pobres provenientes de los países de la Europa mediterránea) que merecían ser estigmatizados y repudiados por sus comportamientos vulgares, por ser portadores de una estética errónea y por encarnar valores y prácticas alejadas del buen gusto, del decoro y la decencia. (Echeverría, 2013, p. 12)

\section{Estudios sobre música popular}

Retomando a los autores anteriores, es necesario mencionar que tanto para la Escuela de Birmingham como para la de Frankfurt, la música formaba parte de la cultura, por lo que es posible encontrar en ellas referencias a diversas formas musicales. Dentro de la teoría crítica se encuentran los trabajos Theodor Adorno (2006) quien se encarga de estudiar cuáles son los impactos sociales de las obras musicales a través de una perspectiva socio-musical.

Estos aportes son fundamentales para el rechazo de la música popular como objeto de estudio dentro de los estudios sociales de la música (o la precursora sociología de la música). Los argumentos de Adorno se basaban en menospreciar a las audiencias de la música popular, considerando que no solo no poseían las competencias necesarias para apreciar la música erudita sino que también la música que consumían era un producto de la industria cultural para distraer a los trabajadores de su condición de explotación. 
La concepción de Adorno es criticada primeramente por los estudios culturales de Birmingham, entre los que es posible mencionar el trabajo de Dick Hebdige (2004) sobre la subcultura británica del punk, en donde se rescataba la agencia de las audiencias al considerar que tanto la música como sus prácticas culturales (vinculadas especialmente al "estilo" de su atuendo) eran un modo de resistencia a las formas de dominación.

Otra de las primeras posturas críticas a la perspectiva de la Escuela de Frankfurt fue ocupada por David Riesman (1950) que en su trabajo acerca de las audiencias de música popular se oponía a la consideración del público como pasivo, ya que

(...) no se puede esperar comprender la influencia de cualquier medio, digamos música, sin entender la estructura de carácter total de una persona. A su vez, la comprensión de sus gustos musicales y su uso con fines de conformidad social, progreso o rebelión proporciona pistas reveladoras de su carácter, para ser confirmadas y modificadas por un conocimiento de su comportamiento y perspectiva en muchas otras esferas de vida. (Riesman, 1950, p. 371. T de la A.)

Posteriormente aparecen una multiplicidad de críticas, entre las que se encuentran las de Simon Frith (2014) y Tia DeNora (2004), quienes se desplazan de la visión elitista acerca de la música y de las audiencias, y estudian de qué manera las formas musicales pueden producir efectos emocionales y sociales, generando modos de identificación y de sociabilidad. En este sentido, Frith (2014) considera que

(...) las preguntas que la gente se plantea frente al arte culto y popular son las mismas, que sus placeres y satisfacciones se basan en las mismas cuestiones, en formas similares de relacionar lo que ven o escuchan con lo que piensan y sienten. Las diferencias entre lo alto y lo bajo surgen porque estas cuestiones se inscriben en circunstancias históricas y materiales diferentes, y están enmarcadas, por consiguiente, de manera distinta, y porque las respuestas se relacionan con diversas situaciones sociales, con diferentes parámetros de sociabilidad, de necesidades sociales distintas. (Frith, 2014, p. 52)

La relevancia del contexto frente a las diferentes concepciones de la cultura ya había sido analizada por Lawrence Levine (1988) quien describe el pasaje que se produjo a mediados del siglo XIX de una "cultura pública compartida" a la "bifurcación del la cultura", la cual consiste en

(...) por un lado, un proceso de sustracción que asigna a las diferentes prácticas culturales un valor distintivo de acuerdo a quien fuera el auditórium y, por otro lado, un procedimiento de descalificación-exclusión que expulsa lejos de la cultura 
sacralizada y canonizada las obras, los objetos, las formas de diversión populares. (Echeverría, 2012)

El rechazo hacia la música popular también es advertido por Claudio Díaz (2011) en las universidades latinoamericanas, que la excluían por considerar que esas músicas poseían "falta de valor" y se le adjudicaban rasgos diferentes a la "tradición musical dominante" (Díaz, 2011, p. 195. Cursivas del original). Este autor cita a Juan Pablo González, que afirma que "se ha resistido el ingreso a la academia de una música catalogada de comercial, efímera, impura, simple y corporal” (citado en Díaz, 2001).

No obstante, en Argentina existen una gran cantidad y diversidad de estudios que intentan rescatar el valor de la música popular a través de estudios sobre productores, audiencias y culturas de diversos géneros musicales populares, entre los que se encuentran los respectivos trabajos acerca del rock, la cumbia y el cuarteto, de Pablo Alabarces, Daniel Salerno, Malvina Silba, Carolina Spataro, Daniel Míguez, Pablo Semán, Gustavo Blázquez y Sergio Pujol, entre otros.

Además, en varias universidades de Argentina se dicta la carrera de licenciatura en música popular. Algunas de ellas son la Universidad Nacional de La Plata, la Universidad Nacional de Cuyo, la Universidad Nacional del Litoral, la Universidad Nacional de San Luis, la Universidad Nacional de Villa María y la Universidad Católica Argentina.

Al describir al Metal Extremo, Salva Rubio (2011) considera que se trata de “(...) un tipo de música difícil de apreciar, difícil de digerir y difícil de encuadrar. Nunca será popular, nunca encajará en ciertos ambientes sofisticados, populares o refinados, nunca sonará en las emisoras de moda." (p. 16), debido a que ciertos estilos de música metal dialogan fuertemente con la música clásica pero también con movimientos de artes visuales, cine y teatro que son considerados marginales. Esto lo ubica en un lugar intermedio entre la música de élite y la masiva, ya que cierto elitismo presente en el metal no está vinculado a la clase social sino a la aspiración de "autenticidad".

Frente a ello es posible considerar que la escena metálica bonaerense y, dentro de ella, Hermética, se desarrollan dentro del campo de la música popular, a través del diálogo con otros estilos musicales populares como el Folklore, el tango y el rock. Por otra parte, más adelante se podrá ver que algunos autores consideran que el surgimiento 
de los "estudios metálicos" son deudores en gran parte de las investigaciones acerca de la cultura popular.

\section{Estudios sobre música metal y los "estudios metálicos"}

La música metal (metal music) captó interés académico prácticamente desde sus orígenes, sin embargo la variedad y disparidad de enfoques con que se la estudió permiten que se realice una periodización de los mismos. Un trabajo que recopila la genealogía de los estudios acerca del metal es el del comunicólogo, Andy Brown (2011), en el cual utiliza The Metal Studies Bibliography Database (MSBD) ${ }^{5}$, un sitio web creado por el bibliotecólogo, Brian Hickam, que dispone de un listado ordenado de los trabajos académicos en inglés, francés y alemán, que incluyen al metal y al hard rock y fueron publicados entre 1978 y 2012.

En esa base de datos, Brown encuentra que uno de los primeros trabajos que analizan al metal corresponde a Simon Frith y Angela McRobbie (1978), el cual se titula "Rock and sexuality" y analiza el "estilo masculino" de las performances del cantante Robert Plant y de la banda Thin Lizzy. Además de dicho listado bibliográfico, Brown retoma el trabajo de los franceses, Gérôme Guibert y Fabian Hein (2006), quienes realizan una periodización de las publicaciones acerca del metal y proponen tres orientaciones.

La primera corresponde a los estudios iniciados por la criminología y la psicología, alentados por la asociación, Parent's Music Resource Center (PMRC), aliada con Parent-Teacher Association y American Academy of Pediatrics. Estos se encargaban de estudiar los efectos negativos del heavy metal en los jóvenes, exhibiéndolo como "violento", "satánico", "machista" y promotor de la promiscuidad, la drogadicción y el suicidio, características vinculadas con la idea de pánico moral (Cohen, 2002; Young, 2011; Thompson, 2014).

Estos estudios se caracterizaban por utilizar métodos cuantitativos y experimentales basados en test cognitivos, cuya finalidad era rastrear los efectos de la exposición de la audiencia a los medios de comunicación masivos. Algunos ejemplos de estos trabajos son los de Stephen B. Thorne y Philip Himelstein (1984), y John R. Vokey y J. Don Read (1985), quienes intentaban rastrear el impacto de posibles mensajes subliminales en las grabaciones de rock y heavy metal; y el trabajo de

\footnotetext{
5 Es posible ingresar a dicho sitio web a partir del siguiente link: https://www.ucmo.edu/metalstudies/metal_studies_home.html
} 
Catherine E. Wanamaker y Marvin Reznikoff (1989), en el que pretendían dar cuenta de los efectos del contenido agresivo de las letras de rock y metal.

La segunda orientación que proponen Guibert y Hein (2006) es la que corresponde a trabajos propios de las ciencias sociales, los cuales se muestran en desacuerdo con la causa del pánico moral detectado por las corrientes psicológicas. Para los estudios sociológicos, el heavy metal era resultado de la alienación de los jóvenes por parte de cultura hegemónica dominante y la desigualdad social.

Algunos ejemplos de estos abordajes son el de Jonathon S. Epstein y David J. Pratto (1990) y el de Robert L. Gross (1990) que analizan al heavy metal como una subcultura. En esta etapa, Guibert y Hein también incluyen el trabajo de Will Straw (1984), que estudia al heavy metal como un subgénero del rock que, desde la perspectiva de la industria musical, se populariza en una audiencia conformada por varones blancos provenientes de los sectores suburbanos.

De acuerdo a Guibert y Hein, la tercera orientación se compone por trabajos provenientes del campo de la musicología. Entre ellos se puede mencionar el del musicólogo estadounidense, Robert Walser (2014); la etnóloga alemana, Bettina Roccor (1998); la musicóloga catalana, Silvia Martínez García (1999) y el etnomusicólogo estadounidense, Harris M. Berger (1999).

En esta misma etapa, también incluyen al estudio de la socióloga Deena Weinstein (2000), el cual es considerado la piedra fundamental para los estudios acerca de la música metal, a pesar de que posteriormente es criticado por tratarse de un trabajo propio de la perspectiva de la homología estructural, ya que al considerar al heavy metal como una subcultura, lo observa como una reacción a la dominación material de la infraestructura económica capitalista (Guibert y Hein, 2006, p. 15).

Todos estos estudios convergen, primeramente, en la publicación "Études Metal/Metal Studies: Une bibliographie" (2006), en la cual Fabian Hein y Keith KhanHarris se encargan de hacer un listado bibliográfico sobre los trabajos acerca de la música metal. Dicha labor es continuada por Hickam, en el ya mencionado sitio web, “MSDB". Posteriormente, en octubre del 2008, algunos estudiosos de la música metal se congregaron en Salzburgo, Austria, donde tuvo lugar uno de los primeros congresos internacionales en torno al heavy metal como objeto de análisis, cuyo título fue "Metal Music and Politics: Heavy Fundametalisms". Las presentaciones de este congreso luego fueron publicadas en The Metal Void (2010), editado por Niall Scott e Imke Von Helden. 
A partir de ella comenzaron a realizarse nuevas reuniones en diferentes países (como Alemania, Estados Unidos y República Checa) y a publicarse gran cantidad de artículos académicos y libros dedicados a los estudios de la música metal. Hasta que en el 2011 se realizó un nuevo congreso internacional en Wolverhampton, Inglaterra, como parte del evento denominado "The Home of Metal""

Dicha reunión académica se denominó "Heavy Metal and Place” y concluyó con una publicación especial de la revista científica Journal for Cultural Research, en la cual se publicaron varios artículos que iniciaron un meta-discurso acerca los estudios dedicados al metal, planteando la posibilidad de la emergencia de un nuevo campo de estudios (Spraklen, Brown y Kahn-Harris, 2011; Kahn-Harris, 2011; Weinstein, 2016a).

Previamente a dichas reuniones, se realizaron en Madrid entre 2003 y 2008 las jornadas "Heavy metal en España”, organizadas por el musicólogo, Fernando Galicia Poblet, en la Universidad Complutense de Madrid. Allí hubo charlas, conferencias, mesas redondas y master class de guitarra, bajo y batería por parte de músicos reconocidos de la escena española, entre otras actividades. En la quinta edición, el entonces rector de dicha institución, Carlos Berzosa, entregó a la banda, Obús, una placa conmemorativa por el 25 aniversario del grupo.

En el año 2013, además de que Gérôme Guibert y Jedediah Sklower publicaran "Dancing with the Devil: Panorame des "metal studies"” (2013), se realizó en Ohio el congreso "Heavy Metal and Popular Culture", en el cual se consolidó la International Society for Metal Music Studies (ISMMS), cuyo propósito es reunir, intercambiar y difundir las contribuciones trans e interdisciplinarias de estudiosos de todo el mundo acerca de los procesos y fenómenos relacionados con el metal (Scott, 2012). Allí también se anunció el lanzamiento del sitio web de la ISMMS y la revista académica revisada por pares, Metal Music Studies.

De esta manera, varios autores proponen la formación de los “metal studies” o “estudios metálicos”. De acuerdo a Deena Weinstein (2016a)

Los estudios metálicos no están organizados de acuerdo a un paradigma o método particular o, como la economía, la abstracción de una actividad. Es decir, no es una

\footnotetext{
${ }^{6}$ Este era un proyecto que tenía la intención de crear un archivo hecho por fanáticos y compuesto por merchandising de bandas, entradas de conciertos, tapas de discos y objetos similares. Este evento se realizó en el occidente de la región central de Inglaterra debido a que tanto Black Sabbath como Judas Priest son originarias de Birmingham y dichas bandas son consideradas por los aficionados como las precursoras del heavy metal que, desde allí, se dispersó por el resto del mundo (Brown, Spraklen, KahnHarris y Scott, 2016, p. 1).
} 
disciplina tradicional. Tampoco es transdisciplinaria, como demandaría una forma particular. Ni es interdisciplinaria, combinando dos o más disciplinas en trabajos singulares. Los estudios metálicos son multidisciplinarios, compuestos por una disparidad de abordajes basados en diferentes disciplinas, e incluyen la interdisciplinariedad y un intento de transdisciplinariedad. Contienen abordajes de la musicología, la literatura, los estudios de religión y de género, la antropología, la sociología y otros campos. Los estudios metálicos no son una ciencia paradigmática, sino un área de contenido. Esto es propiamente llamado un estudio, la aplicación de múltiples disciplinas, múltiples métodos y múltiples paradigmas teóricos para un contenido particular. (p. 23. T. de la A. ${ }^{7}$ ).

Weinstein compara a los estudios metálicos con movimientos académicos tales como los estudios feministas, estudios de la cultura negra americana, estudios étnicos y estudios queer, los cuales ingresaron en la academia en 1960 a través de la Teoría Cultural y de los movimientos sociales por la justicia, la igualdad y la democratización de la cultura. Para dicha investigadora, los estudios metálicos forman parte de los estudios culturales, que reivindican el valor intelectual y político de la cultura popular (Weinstein, 2016a, p. 23). Además se caracterizan por ser un fenómeno intelectual posmoderno con una estructura descentrada.

Un rasgo característico de dicho campo de estudios es que emergió a partir de los trabajos de jóvenes investigadores que, además de ser graduados especializados en determinadas disciplinas, formaban parte de la audiencia de música metal, por lo que sin hacer de ello un propósito explícito, propusieron una nueva forma de objetividad debido a que intentaban analizar sus propias prácticas culturales. Es por ello que algunos investigadores hablan de "critical insiders", "aca-fans", "fan-academics" (Brown, 2011, p. 217) y “metallectuals" (Scott, 2012, p. 205).

Sin embargo, a pesar de que sus trabajos contribuyen a darle lugar a temáticas que fueron ignoradas o demonizadas por la academia, Kahn-Harris (2011) y Weinstein (2011a) advierten de los peligros de que dichos investigadores solo intenten legitimar académicamente su fanatismo o que los estudios metálicos se conviertan en un gueto de defensa del estilo musical, en donde los trabajos dedicados a esta temática solo circulen en el interior de dicho campo de estudios.

Efectivamente, en varios trabajos relevados tanto a nivel nacional como internacional, pude observar que los investigadores no daban cuenta de su posición con respecto al objeto de estudio; al mismo tiempo, además de aislar al estilo musical de

\footnotetext{
${ }^{7}$ De ahora en más, la abreviatura "T. de la A." se refiere a "Traducción de la Autora".
} 
otros géneros contemporáneos, era evidente que algunas características eran naturalizadas y no problematizadas.

La publicación, Metal Music Studies, y las reuniones organizadas por ISMMS permiten dar cuenta del carácter global que caracteriza a la música metal, ya que a partir de estos comienzan a visibilizarse trabajos realizados por investigadores que estudian las escenas locales de sus propios países por fuera de Europa y Estados Unidos. Sin embargo, tal como plantea Weinstein (2016a), la limitación idiomática al inglés no permite una total integración (p. 30), por lo que la presencia latinoamericana en dicha asociación es escasa.

En efecto, la diferencia de idioma también se observa en varios trabajos realizados en España que no aparecen integrados a dicha sociedad. Entre ellos es posible mencionar las tesis doctorales del sociólogo, Fernan de Val Ripollés (2014) y la del musicólogo, Fernando Galicia Poblet (2016); además de los libros de este último, Espiritus rebeldes: el heavy metal en España (2005) e Inoxidable. Formación, cristalización y crecimiento del heavy metal en España, 1978-1985 (2017). Lo mismo sucede con varias publicaciones, tanto en español como en catalán, pertenecientes a la musicóloga ya mencionada, Silvia Martínez García (1997, 1999, 2003, 2004 y 2006).

En España en 2018 también se organizó la reunión "Rock and Metal Encounter" en la Universidad de Jaén. Este evento se consagró como hispanoamericano ya que en su organización también colaboraron la Universidad Nacional Autónoma de México (UNAM), el Instituto de Investigaciones Antropológicas de México y la Universidad Internacional de Florida.

La minoridad latinoamericana en las publicaciones provenientes del círculo de ISMMS también aparece en Metal rules the globe. Heavy metal music around the world (2011), editado por Jeremy Wallach, Harris M. Berger y Paul D. Greene. Este libro se presenta como el primer estudio académico que examina el crecimiento mundial de la música metal y su vinculación con la globalización, a través de contribuciones de diversos autores que abarcan las escenas de China, Malasia, Indonesia, Singapur, Nepal, Noruega, Israel, Japón, Malta, Eslovenia y las Islas de Pascua. El caso latinoamericano aparece con el aporte del especialista en literatura, Idelber Avelar, acerca de la banda, Sepultura, y la escena brasileña.

No obstante, en 2018, la revista, Metal Music Studies, publica una sección especial titulada, "Metal in Latin America", coordinada por Nelson Varas-Díaz de la Universidad Internacional de Florida, Daniel Nevárez de la Universidad de 
Massachussets y Claudia Azevedo. Allí la propuesta era darles lugar a investigadores latinoamericanos que, debido al "imperialismo académico", permanecen invisibilizados por las academias norteamericanas y europeas. De esta manera, este dossier se convierte en el primero que, dentro de dicha publicación anglófona, se dedica a América Latina y se compone por artículos en varios idiomas (inglés, español y portugués).

En este número especial los países que fueron analizados son Cuba (por VarasDíaz, Osvaldo González Sepúlveda y Andrés Rivera), Puerto Rico (por Eliut RiveraSegarra, Sigrid Mendoza, Xaymara Díaz y Varas-Díaz), El Salvador (por Christian Pack), Republica Dominicana (por Sigrid Mendoza, Eliut Rivera-Segarra, Varas-Díaz y Carlos Vélez), Perú (por María de la Luz Núñez y Arturo Rivas), Brasil (por Melina Aparecida Dos Santos Silva) y Argentina (por quien escribe esta tesis).

Además de ello, en 2008, previamente a las publicaciones anteriores, el antropólogo canadiense, Sam Dunn, produce el documental Global metal, en el cual se investiga la difusión y producción de música metal en países por fuera de Europa y Estados Unidos. El caso latinoamericano se hace presente también con Brasil y Sepultura.

Este mismo año, también Jeff Brenes e Indira González producen el documental Cadáver exquisito: la cultura metal en América Latina como parte del proyecto de graduación de la Maestría en Estudios Latinoamericanos de la Universidad Nacional de Costa Rica. En dicho material audiovisual se recopilan una serie de entrevistas realizadas en diferentes países de Latinoamérica acerca del metal extremo (especialmente, el black metal). Dentro de ellas aparecen las bandas argentinas, Diadema Tristis y Ecliptic Sunset.

Con respecto a América Latina, es posible encontrar una gran cantidad de artículos académicos, ponencias, libros y tesis de grado y posgrado, en las cuales diferentes investigadores analizan bandas, comunidades y escenas latinoamericanas.

Por ejemplo, se pueden citar los trabajos del comunicólogo e historiador guatemalteco, Mario Castañeda (2005); de los sociólogos chilenos, Maximiliano Sánchez Mondaca (2007, 2014) y Omar Villalobos Albornoz (2015), y de este junto con Alfredo Miranda González (2011); del historiador colombiano, Carlos Arturo Reina Rodríguez (2009); del psicólogo costarriqueño, Gilbert Ulloa Brenes (2013); y de los peruanos, Jimmy Renzo Yépez Aguirre (2013) y José Ignacio López Ramírez Gastón y Giuseppe Risica Carella (2019). 
También las producciones provenientes de Ecuador de la socióloga, Karina Gallegos Pérez (2004); del antropólogo, Juan Pablo Viteri Morejón (2011); de los comunicólogos, Héctor O. Coba Baque y Dayana S. Vinueza Merizalde (2012); y de México, del antropólogo, Sthepen Castillo Bernal (2007); la antropóloga, Olivia Domínguez Prieto (2017); y la psicóloga, Yelotzin Cortés Morales (2018).

Por su parte, Brasil posee una cantidad destacable de producciones académicas en portugués que analizan la música metal. Gran muestra de ello aparece en las actas del congreso de la IASPM-AL del $2012^{8}$ y de los I y II "Congresso Internacional de Estudos do Rock" realizados en la ciudad de Cascavel (Brasil) en 2013 y 2015.

Además, hay varias tesis doctorales y de maestría dedicadas al metal brasileño, como por ejemplo la del comunicólogo, Jeder Janotti Jr. (1994); la del antropólogo, Pedro Alvim Leite Lopes (2006); la del etnomusicólogo, Hugo Ribeiro (2007); la del sociólogo, Leonardo Carbonieri Campoy (2008); y la del historiador, Wlisses James de Farias Silva (2014). Asimismo se pueden mencionar los trabajos de investigación independientes de Avelar (2010), Ribeiro (2010) y Claudia Azevedo (2007a y 2007b).

Por otra parte, también se destaca el trabajo del psicólogo social puertorriqueño, Varas-Díaz, quien estudia al metal latinoamericano a través del formato audiovisual. Junto a su equipo de investigación produjo tres documentales basados en sus estudios principalmente etnográficos: The Distorted Island. Heavy Metal and Community in Puerto Rico (2015), The Metal Islands. Culture, History and Politics in Caribbean Heavy Metal Music (2016) y Songs of injustice: Heavy Metal Music in Latin America (2018).

Los dos primeros examinan las escenas de la música metal de los países caribeños, Puerto Rico, Cuba y República Dominicana; y el último incluye países de América del Sur como Chile y Argentina. Conjuntamente, Varas-Díaz construyó el sitio de Facebook, "Heavy Metal Studies. Latin America" en donde se publican las actualizaciones de dichos trabajos académicos.

\footnotetext{
${ }^{8}$ Las Actas del X Congreso de la Rama Latinoamericana de la IASPM se titulan "Enfoques interdisciplinarios sobre músicas populares en Latinoamérica. Retrospectivas, perspectivas, críticas y propuestas" y se encuentran disponibles en: http://iaspmal.com/index.php/2016/03/02/actas-X-congreso/ Allí es posible ver los trabajos presentados en el simposio "Estudos interdisciplinares sobre rock e metal na América Latina".

${ }^{9}$ Este congreso fue el primer evento académico dedicado al rock en América Latina. Las actas del mismo se pueden ver en la sección "Anais" de su página web: http://www.congressodorock.com.br/evento/annals.xhtml
} 
Además de ello, a partir del 2017 en la Facultad de Música de la Universidad Nacional Autónoma de México (UNAM), se realiza el Seminario Permanente de Estudios sobre Heavy Metal dirigido por el musicólogo, Alfredo Nieves, quien en 2019 lanza el Diplomado “Antropología de la Música: Contextos, Marcos Teóricos y Metodológicos para el Estudio de las Culturas del Rock y Músicas Urbanas" en la UNAM, en cuyo programa tiene como contenido al metal. Por otro lado, en 2018 se realizó la Jornada Académica de Estudios sobre Heavy Metal en la Universidad de Guanajuato.

\section{Estudios sobre rock y metal en Argentina}

En Argentina, el rock posee una vasta producción bibliográfica escrita primeramente por periodistas y críticos musicales en las cuales principalmente se narra la historia del rock en Argentina, a partir de las bandas y músicos más reconocidos, por lo que varias de estas publicaciones consisten en biografías. Entre los libros más reconocidos se encuentran Agarrate. Testimonios de la música joven argentina (1970) de Juan Carlos Kreimer et al. y Cómo vino la mano (1977-2014) de Miguel Gringberg.

Posteriormente, comienza a ser objeto de estudio académico hacia fines de los ' 80 , siendo abordado desde diferentes puntos de vista. Dentro de estas producciones hay principal atención a dos momentos puntuales: el rock durante la última dictadura militar y la masividad adquirida durante los noventa.

Para el primer caso, se puede citar a autores como Pablo Alabarces (1995), Pablo Vila (1985) y Sergio Pujol (2005, 2007a, 2007b, 2013), para quienes el rock actuaba como refugio aglutinador de los jóvenes de esa época. En la línea de los trabajos que estudian esa época histórica hay algunos que hacen referencia al surgimiento del heavy metal en Argentina, como por ejemplo los ya citados de Alabarces, Vila y Pujol (2007a, 2013) y los de Claudio Díaz (2005) y Garriga Zucal y Salerno (2008).

A pesar de no dedicarse específicamente al metal, se puede considerar como pioneros los trabajos de Vila y Alabarces, ya que a través de la etnografía del Área Metropolitana de Buenos Aires dieron cuenta de las audiencias metálicas de dicha época. El primero describe a los "metálicos" (junto con los "rockeros" y los "punks") como uno de los grupos que surgen a partir de la fragmentación del campo rockero en la década de los '80. Y el segundo menciona a los "firestones", los cuales provenían de la zona oeste del Conurbano bonaerense y eran los antecesores del público "metálico", ya que se inclinan de manera predilecta por el rock "duro". 
Posteriormente, en la década de los ' 90 , el rock comienza a ser estudiado desde la perspectiva de las tribus urbanas y de la cultura masiva, en otro contexto histórico. Autores como Pablo Semán (2006) y Pablo Vila (1999), José Garriga Zucal y Daniel Salerno (2008) y Silvia Citro (2008), comienzan a hablar de "rock chabón" y lo definen como un conjunto de estilos musicales que interpelan a jóvenes de una situación social semejante: la que deviene a la crisis económica y social de los noventa. Semán y Vila (1999) mencionan a las bandas de metal, Almafuerte y Hermética, como grupos que en sus líricas desarrollaban temáticas que eran homogéneas dentro del "rock chabón".

En algunos de estos trabajos que abordan el rock argentino, aparece una mirada negativa acerca de la rama metálica. Por ejemplo, Garriga Zucal y Salerno (2008), hacen hincapié en que los "metaleros" de comienzos de los ochenta "[...] hacían de la pelea un signo de identidad" (nota al pie, 2008, p. 77). Afirmación con la que estigmatizan al metal y lo apartan del resto de las corrientes del rock, a las que destacaban por la ausencia de rivalidades como requisitos del concierto. Al mismo tiempo, dicha caracterización solo es mencionada pero no problematizada.

Otro trabajo es el de Alejandro Rozitchner (2003) quien analiza la letra de "Brigadas metálicas" de V8 del año 1982. Por medio de la generalización y la lectura literal de las metáforas, se encarga de calificar a los metaleros como violentos, borrachos, machistas, infantiles y fascistas. Por ejemplo, al afirmar que el heavy metal simpatiza con la dictadura de esa época, solo por utilizar el nombre "brigadas" para referirse a los grupos de aficionados. Esta lectura es errónea, ya que a pesar de provenir del ámbito bélico, dicha denominación no solo fue usada por militares, sino también por gran cantidad de agrupaciones políticas de izquierda y de movimientos artísticos.

No obstante, además de estos trabajos previos, la academia argentina comienza a enfocarse en el metal de manera particular luego del año 2000. Dentro de estas producciones se encuentra una serie de documentales que intentan reconstruir la historia del estilo musical en el país: Heavy Mental Metal Pensado (2010) realizado por el Licenciado en Comunicación, especializado en Medios Audiovisuales (de la Universidad Nacional de Córdoba), Juan Astrain; y Sucio y desprolijo (2014) un documental audiovisual de Paula Álvarez y Lucas Lot Calabró realizado para la tesis de la Licenciatura en Comunicación Social para la Facultad de Periodismo y Comunicación Social de la Universidad Nacional de La Plata ${ }^{10}$.

\footnotetext{
10 Ambas producciones se encuentran fuertemente influenciadas por los documentales Metal: $A$ Headbanger's Journey (2005) y Global Metal (2009), realizados por Sam Dunn, en los cuales se encarga
} 
Además se produjo un fenómeno similar al que originó la ISMMS, ya que en el año 2014 se crea el Grupo de Investigación Interdisciplinario sobre Heavy Metal Argentino (GIIHMA) que, sin ninguna afiliación académica institucional, se propuso reconstruir la historia del metal argentino desde una mirada crítica enfocada en el análisis de las canciones de un recorte arbitrario de bandas del estilo musical, compuestas especialmente por Ricardo Iorio.

Este grupo se conforma a partir de la realización de la primera Feria del Libro Heavy en el año 2013 en el barrio de Boedo de CABA, de la cual deriva la publicación del libro Cultura metálica. Ponencias, debates y exposiciones de la $1^{\circ}$ Feria del libro Heavy de Buenos Aires (2014), compilado por el escritor, Gito Minore, uno de los miembros del GIIHMA.

Una similitud de dicho grupo con la ISMMS es que sus integrantes también son explícitamente fanáticos de música metal ${ }^{11}$. La diferencia es que el GIIHMA se asume como parte de clase trabajadora y sus producciones publicadas en la compilación Se nos ve de negro vestidos (2016), toman la forma de ensayos que militan contra los formatos académicos tradicionales (es decir, papers y artículos científicos) y se centran principalmente en el análisis de las letras de canciones. Otro modo de renunciar a los estándares científicos convencionales es el rechazo explícito a la realización de un estado de la cuestión, por lo que en sus publicaciones prácticamente no aparecen referencias a trabajos previos.

A su vez, en el año 2016 surge el Equipo Interdisciplinario de Estudios Sociales sobre Heavy Metal (EIESHM) el que, de manera similar al GIIHMA, propone fundar un campo de estudios acerca de la música metal, considerando que no existen trabajos anteriores acerca de la temática. Dicho equipo de investigación se ancla principalmente en la Universidad de Buenos Aires y sus trabajos ensayísticos se encuentran publicados en su página web $^{12}$ y en su fanpage de Facebook, de manera que se asemejan al GIIHMA en la elección de formas alternativas de comunicación científica.

Por otra parte, a partir del relevamiento bibliográfico, es posible decir que el metal argentino es objeto de estudio de gran cantidad de artículos académicos,

de documentar la historia y la cultura de la música metal de diferentes países. Además, este es el director del documental Iron Maiden. Flight 666 (2009) -el que muestra una gira entera de la banda británica, Iron Maiden. Dentro de sus viajes se muestra el concierto y la estadía de la agrupación en Argentina- y de la serie del canal VH1, "Metal evolution".

${ }^{11}$ El resto de las tesinas relevadas también presentan dicho aspecto. Es decir, sus autores eran aficionados al metal. Por este motivo considero necesario dar cuenta de ellos como agentes de la escena. Más adelante me referiré a ello.

${ }^{12}$ La dirección de dicha página web es https://eieshm.wordpress.com/ 
ponencias en congresos, tesinas de grado y tesis de posgrado, tanto desde el ángulo de sus producciones (Boffa, 2005; Hertz, 2007, 2008; Plano, 2011; Samiguel, 2011; Calvo, 2012, 2014, 2015, 2016a, 2018 a 2018b; Pascuchelli, 2012, 2014, 2016; Scaricaciottoli, 2012, 2018; Gendler y Prado, 2016; Setton, 2016; Panzini, 2018), como de su circulación (Conte, 2007; Espíndola y Morales, 2013; Calvo, 2016b, 2018c), sus consumos (Arias, 1998; Svampa, 2000; Kropff, 2008a, 2008b; Remedi, 2010; Espíndola y Morales, 2013; Calvo, 2012, 2016, 2018c; Pascuchelli, 2014; Mux, 2016) y su historia (Conte, 2007; Astrain, 2010; Álvarez y Lot Calabró, 2014).

Sin embargo, la mayoría de estos trabajos estudian al estilo musical bajo las nociones de subcultura, tribus urbanas y culturas juveniles, limitándolo a su vez como expresión urbana propia de algunos sectores del Área Metropolitana de Buenos Aires. En algunos pocos casos se menciona al interior del país, pero no se problematizan las diferencias que surgen de esta distribución dispar. Solo un trabajo presenta la noción de escena musical (Vidal Vargas, 2016), pero es utilizada para referirse a las bandas de metal extremo de CABA y el Conurbano bonaerense.

\section{Acerca del aporte de esta tesis}

A partir de la bibliografía académica hallada cuyo objeto de estudio es la música metal de Argentina, se observa que dichos trabajos poseen una multiplicidad de enfoques y miradas provenientes de diferentes disciplinas de las ciencias sociales y las humanidades. Sin embargo, considero necesaria la revisión de los marcos teóricos con que se la abordó y de las confusiones surgidas en torno a la delimitación del objeto, en el sentido de que la mayoría de los casos utilizan el gentilicio "argentino" refiriéndose únicamente a las actividades desarrolladas en el Área Metropolitana Bonaerense, aspecto que sucede con muchas temáticas abordadas por las ciencias sociales y humanas.

Por otra parte, al estudiar a las audiencias se las reduce a una clase social (la obrera), a un sector de la población (la juventud), a un lugar geográfico (los espacios urbanos) y prácticamente no se problematizan cuestiones de género -excepto el ensayo de Noelia Adamo del GIIHMA (2018)- que, paradójicamente, son descritas de manera profunda.

Por otra parte, observé que Hermética es mencionada en la mayor parte de estos estudios como una de las bandas fundamentales de la música metal en el país, lo que permite ratificar la relevancia de dicha agrupación para mi hipótesis. Sin embargo, tanto 
en estos como en otros trabajos ensayísticos (Morandini, 2016; Scaricariottoli et al, 2016), a esta agrupación solo se la destaca y analiza a partir del contenido temático de las letras de sus canciones (el cual es leído en relación homológica con el contexto), al mismo tiempo que se centraliza la cuestión en torno a la figura de Ricardo Iorio.

Esta tendencia también aparece en algunos de los trabajos mencionados, lo que conduce al ocultamiento de la heterogeneidad de bandas, prácticas e ideologías que caracteriza a la escena argentina. A la vez que se pasan por alto los diálogos y las tensiones que surgen entre los actores y las instituciones que forman parte de la comunidad metálica.

Por el contrario, dos investigaciones rompen con estas características generales. En primer lugar, el trabajo de Martín Gendler y Horacio Prado (2016), en el que analizan de manera cuantitativa las temáticas de las canciones de las bandas de Iorio, es decir, V8. Hermética y Almafuerte, y propone a estas como las hegemónicas dentro del campo del metal argentino. Para estos autores la centralidad reside en los tópicos vinculados con la argentinidad y en una forma de exaltar al "verdadero metal". De hecho, los autores afirman que

Hermética logra imponerse sobre las demás bandas derivadas de V8 en su lucha por el capital simbólico del campo, demostrando ser la que más cumple con el resto de los parámetros conceptuales establecidos, teniendo como vital impulso el contexto creciente expansión neoliberal y de un crecimiento exponencial de las injusticias sociales. (Gendler y Prado, 2016, p. 34)

Parcialmente coincido con la postura de Gendler y Prado, pero considero que dicha hegemonía también se ancla en otros ejes (como por ejemplo, la masculinidad) y además es desarrollada en las producciones de la audiencia y los mediadores.

En segundo lugar se encuentra el trabajo de Ariel Panzini (2018) que observa que una de las características del metal argentino es la heterogeneidad. A pesar de ello, el autor se pregunta por qué las propuestas artísticas del movimiento actúan en conjunto. Frente a ello, su respuesta es la descripción del metal argentino como un grupo cohesionado a partir de la experiencia compartida que consiste ocupar un lugar subordinado dentro de la sociedad, más específicamente el de la clase trabajadora. Tal como argumenté anteriormente, en este punto es en el que discrepo.

Otros trabajos que también nombran a Hermética son el de Luis Montanero Vico (2005) -que recorre la historia mundial del estilo musical creado por la New Wave Of British Heavy Metal-, la lista propuesta por el Diccionario de Heavy Metal Latino 
(2005) -una publicación española realizada por la editorial Zona de Obras-, y el estudio realizado por José Gobello y Marcelo H. Oliveri, Tangueces y lunfardismos del rock argentino (2001) -el cual analiza las relaciones entre el tango, el lunfardo y el rock nacional de las décadas de 1980 y 1990, incluyendo el cover que realizó Hermética del tango "Cambalache" de Enrique Santos Discépolo-.

A pesar de la multiplicidad de veces que Hermética es mencionada como un conjunto fundamental para la música metal de Argentina, ningún trabajo cuestiona los factores que posibilitan ello. Tampoco se problematiza la recurrencia de dicha banda en la actualidad, lo cual permitiría ver flujos de continuidad y de cambio dentro del desarrollo histórico de este estilo musical en Argentina.

Al mismo tiempo, no se analiza la apropiación de los discursos de Hermética (los cuales poseen una fuerte perspectiva de los sectores populares) en sectores sociales, político-ideológicos, culturales y etarios diversos y dispares; así como también la identificación de aficionadas mujeres con valores fuertemente masculinistas.

Tampoco aparecen preguntas acerca del contacto de Argentina con la escena global de la música metal, entendiendo que, a pesar de que el surgimiento del metal argentino fue de manera procesual y prácticamente a la par del desarrollo internacional, los antecedentes (el hard rock y el blues) son foráneos y provenientes de los países angloamericanos.

Esto mismo se observa en la ausencia de referencias a la tradición de los estudios metálicos globales en los trabajos realizados en Argentina. Con todo ello, intentaré iluminar algunos de estos puntos que aún no han sido examinados, intentando comprender la producción de sentidos sociales en torno a la comunicación de un estilo musical específico que se vincula de manera directa con la cultura popular de Argentina. 


\section{Fundamentación}

La relevancia del estudio de la música metal reside en que su naturaleza musical la convierte en un medio de comunicación de ideas, emociones y experiencias que permite la interacción social y la formación de cultura. Al mismo tiempo, habilita la circulación de códigos no solo vinculados con lo musical, sino también con lo cultural y lo ideológico.

Es decir que no se trata meramente de música sino también de una gran cantidad de producciones extra-musicales que dan cuenta de un gran trabajo de producción de sentido no solo desde el lugar de las bandas sino también de sus audiencias y sus mediadores. El estudio de la música metal se presenta como una ventana que permite la aproximación a la dinámica cultural de un espacio social y territorial en un período determinado.

A pesar que las características mencionadas también son compartidas con otros géneros musicales, en el caso del metal hay ciertas especificidades que le otorgan rasgos distintivos, como por ejemplo, determinados movimientos corporales realizados por lo músicos y la audiencia que resultan característicos. Estos dependen de determinadas reglas (explícitas e implícitas) que circulan tanto a nivel global como local. Además, se caracterizan por generar identificación entre sus participantes y, muchas veces, rechazo y/o miedo entre quienes observan dichas prácticas de manera externa. Es decir que, mientras que posee una sonoridad irritante para la audiencia ajena a la escena, resulta fortalecedora para sus miembros.

La música metal también se distingue por la fuerte actividad de su audiencia, lo que la posiciona en un medio para la creación de identidades. Esto es posible debido a que, “(...) el vínculo aparentemente especial de la música con las emociones y los sentimientos la hace un sitio particularmente potente para reunir la experiencia privada y la pública." (Helsmondhalgh, 2015, p. 21).

De esta manera, el metal en general constituye un medio a través del cual los participantes de la escena construyen sus propias identidades tanto individuales como colectivas de manera diversa, a la vez que el estilo musical se convierte en vehículo tanto para la integración y la cohesión grupal, como también para la discriminación y la distinción.

Al mismo tiempo, en Argentina, el metal es un ejemplo de cultura híbrida. A través de ella, los aficionados no solo realizan conexiones con las culturas de otros 
países, sino que también reflexionan acerca de su propia identidad local y de los significados otorgados al país como nación a través de diversas construcciones ideológicas. Por lo que se observan una gran cantidad de diálogos e hibridaciones en este doble movimiento geográfico hacia el exterior y hacia el interior. Esto resulta relevante si se tiene en cuenta que dichos contactos se realizan en el contexto de la globalización, lo que conduce a examinar formas de colonización cultural pero también de resistencia.

Como forma artística, el metal se relaciona fuertemente con otras artes: la pintura, la literatura, el teatro y el cine. Además posee fuertes diálogos con una amplia variedad de géneros musicales. Esto la convierte en un arte de gran riqueza, la cual se incrementa al analizar las particularidades de diferentes casos de estudio. Al tomar como ejemplo a la Argentina es posible ver la presencia de producciones artísticas locales en las letras de canciones, portadas de discos y escenografías de gran cantidad de bandas. Mi estudio preliminar ${ }^{13}$ ilustra dicha afirmación con la relación entre la agrupación musical, Almafuerte y el poeta Pedro Bonifacio Palacios, entre otras.

A partir de la investigación mencionada, se pudo rescatar una gran cantidad de material empírico que permitió comprender académicamente la importancia del metal dentro de la Argentina. Como ya se ha podido entrever, este estilo musical, a pesar de haberse originado en la década de 1980, en la actualidad se encuentra muy vigente, aunque no con las mismas características de dicho momento. Esto lleva a considerar una evolución, la cual se relaciona de manera estrecha con el contexto sociopolítico del país.

Por otra parte, la agencia de los sujetos ligados al metal aparece en el hecho de que no es posible hablar de un público homogéneo, sino que justamente lo que lo caracteriza es la gran diversidad no solo con respecto a la posición social de sus agentes, sino también a lo generacional, lo ideológico y a la identidad de género. Tal como menciona Robert Walser (2014), "las lealtades de los fans son complejas y específicas" (Walser, 2014, p. 5. T. de la A.). De manera que la escena se desarrolla como un espacio democrático y de convivencia hacia el interior de la misma.

Para finalizar, se puede decir que el metal se caracteriza por ser un estilo musical que ha recibido fuertes críticas a lo largo de la historia, no solo en los países centrales, sino también en los periféricos, como la Argentina. Además, tal como afirma Keith

\footnotetext{
${ }^{13}$ Me refiero a la tesis realizada para obtener el grado de Magister en Culturas y Literaturas Comparadas, titulada "Un análisis sociosemiótico comparativo de los discursos que conforman el metal pesado argento de Almafuerte".
} 
Khan-Harris (2007), ha escandalizado a sectores ideológicos tanto de derecha como de izquierda por motivos a los que nos referiremos más adelante. Esto parece dar cuenta de la influencia de este estilo musical en la vida cotidiana y de sus repercusiones ideológicas en instituciones del exterior de la escena (especialmente, políticas y religiosas). Acerca de esto, Deena Weinstein (2000) considera que

Los dos oponentes del metal lo distorsionan a su manera, de acuerdo a cómo pueden encajar en las categorías de sus ideologías. Sus posiciones políticas hacia el "problema social" del heavy metal reflejan sus construcciones ideológicas acerca del heavy metal en lugar de lo que es el heavy metal para sus fans, el artista que lo crea, sus mediadores o un etnógrafo. La crítica pública al metal es un caso tan claro como el que puede presentarse en la tendencia de la discusión de la política pública a mal caracterizar sus objetos a través de la proyección de construcciones ideológicas. (Weinstein, 2000, p. 239. T. de la A.)

Esta relación conflictiva con respecto a agentes externos al estilo musical también aparece en la propuesta de Julio Mendívil (2016), quien considera a los seguidores del metal como un ejemplo de comunidad musical que discrimina y menosprecia a otras a las que califican como opuestas e inferiores. En este sentido, el autor afirma que

(...) Es esa capacidad de crear significados sociales e individuales lo que hace de la música un arma puntiaguda para ofender y descalificar -ya sea personal o socialmenteal otro. Mas cabe preguntarse ¿por qué se desprecia un tipo determinado de música? Los desencuentros musicales nacen frecuentemente de nuestra incapacidad para aceptar la alteridad. (Mendívil, 2016, p. 37)

Sin negar la recurrencia de dichas prácticas entre la audiencia del metal, considero que es necesario observar que "Las representaciones outsiders del heavy metal como sitio monolítico se colocan en duro contraste con las perspectivas de los fans, quienes aprecian la diferencia y la especificidad" (Walser, 2014, p. 5. T. de la A. Destacado propio). Ambas situaciones reclaman un análisis que permita dar cuenta la estigmatización que generan visiones externas y parcializadas de la música metal, pero que también contribuya a comprenderla reflexivamente desde adentro. 


\section{Objetivos}

Con todo esto se plantean los siguientes objetivos de investigación:

\section{Objetivo general:}

Analizar la escena de la música metal de la provincia de Buenos Aires entre los años 2011 y 2017 a partir de la centralidad articuladora de la banda Hermética.

\section{Objetivos específicos:}

1. Comprender la posición central de Hermética en la escena de la música metal de la provincia de Buenos Aires.

1.1. Analizar los ejes en los cuales se estructura la producción de significado de Hermética: el thrash metal, la transgresión, la masculinidad y el nacionalismo.

1.2. Desagregar dichos ejes para analizar problemáticas más específicas: las formas en que el tono de denuncia del thrash metal le permitió a Hermética dar cuenta de su contexto social y político; la importancia que tienen el uso del idioma español y de argentinismos en la construcción de una perspectiva identitaria localista; las ideologías y referencias históricas locales y que eligió Hermética y el vaivén con retóricas propias de la tradición metálica angloamericana; el diálogo con géneros musicales propiamente argentinos tales como el tango y el Folklore; la perspectiva de género que se puede identificar en las producciones de la banda; los valores que se transgreden y los que se celebran en las producciones de Hermética.

1.3. Observar los modos en que estos significados son apropiados y/o rechazados por los agentes de la escena metálica bonaerense, tanto desde los roles vinculados al consumo como los referidos a la producción y la circulación.

2. Comprender los modos en que Hermética ocupa un lugar dominante y canónico dentro de dicha escena.

2.1. Analizar el proceso de consagración y de alcance mainstream de los músicos de Hermética, especialmente las particularidades que llevaron a Ricardo Iorio a conformarse como el mayor referente de la escena metálica argentina.

2.2. Observar los modos de resistencia y de celebración hacia la canonización de dichos músicos por parte del circuito underground y del metal extremo, y de los agentes de la escena que se ubican por fuera de la capital porteña. 
2.3. Observar la relación de dichos músicos consagrados con la escena global de la música metal.

2.4. Comprender la importancia de la figura de Ricardo Iorio como referente en los procesos de "intelectualización/academización” y de reflexividad política dentro de la escena.

3. Reconstruir los diálogos y las tensiones que forman parte del entramado que constituye la escena metálica bonaerense y la convierten en una comunidad heterogénea.

3.1. Observar los diálogos y las tensiones que se producen entre los agentes y las instituciones de la escena a nivel geográfico.

3.2. Observar los movimientos y el desarrollo de la escena a nivel temporal.

3.3. Observar los modos en que se conforma un nuevo campo "intelectual" dentro de la escena. 


\section{Objeto de estudio}

Como ya se mencionó, el propósito de esta tesis es reconstruir la escena de la música metal de la provincia de Buenos Aires a partir de la reactualización de la banda Hermética. Por ello es necesario comprender previamente los conceptos que componen la hipótesis: la música metal, Hermética y la provincia de Buenos Aires entre los años 2011 y 2017. A continuación se presentará una descripción de cada uno de los tres elementos.

\section{Historia de la música metal}

\section{La formación: década de 1970}

Tal como plantea el comunicólogo brasileño, Jeder Janotti Jr. (2004), "No es posible establecer una fecha o una genealogía específica para el surgimiento del heavy metal" (2004, p. 19. T. de la A.). Por el contrario, "El heavy metal tiene muchas historias. No hay consenso sobre sus precursores, influencias básicas, primeras canciones y bandas hechas y derechas, o etapas de desarrollo" (Weinstein, 2000, p. 14. T. de la A.).

En general, la mayoría de las historias escritas acerca del metal tienden a delimitarlo a la perspectiva europea y norteamericana proponiendo como conjuntos precursores a Black Sabbath y Led Zepellin de Inglaterra, y a Iron Buterfly y Steppenwolf de Estados Unidos. Algunos trabajos han revisado esto dando cuenta del surgimiento de agrupaciones musicalmente similares y contemporáneas a las mencionadas, por fuera de los países centrales, como por ejemplo la banda Stress de Brasil (Silva da Silva y Silva de Oliveira, 2012).

Para Janotti Jr. el predominio de las agrupaciones angloamericanas en la historia del metal se debe a que el rock “(...) también está impregnado por todos los aspectos que caracterizan los procesos comunicacionales a partir de la mundialización cultural del siglo XX." (Janotti Jr., 2004, p. 21. T de la A.). De todas formas, la mayoría de los académicos, periodistas y críticos musicales coinciden en que el término heavy metal fue utilizado para nombrar a las formas musicales que emergieron como producto de la fusión del rock psicodélico con el blues y que se apoyan principalmente en el sonido distorsionado y amplificado de la guitarra eléctrica y el uso del acorde de potencia. 
Tomando esto como premisa, es posible decir que a fines de la década de 1960 y durante la de 1970, en diferentes lugares del mundo surgieron una gran cantidad de grupos con estas características. En Argentina, las que se caracterizaban de esa manera decían hacer "rock pesado". Algunas de ellas fueron Billy Bond y la Pesada del Rock and Roll, Manal, Pappo's Blues, Pescado Rabioso, Púrpura, La Torre, El Reloj, Mamut, Lulú, Riff y V8. Estas agrupaciones, más allá de la diversidad que existía entre ellas, se caracterizaban por ser innovadoras en lo musical y por componer canciones con letras más crudas que las de las bandas de rock argentino de ese momento, en las cuales predominaba el ideal hippie de paz y amor.

Los músicos de muchos de estos conjuntos eran oyentes de agrupaciones anglófonas como Black Sabbath, Led Zepellin, AC/DC, Quiet Riot, Deep Purple, Blue Öyster Cult, Rush y Aerosmith, las cuales son consideradas precursoras del metal como tal y sirvieron como fuente de inspiración de muchos conjuntos musicales argentinos que, en varios casos, se formaron con motivo de ensayar covers $^{14}$ de ellas. Estos grupos era posible escucharlos a través de programas de radio y de discos de vinilo. Incluso, en el año 1978 hubo proyecciones del film de Led Zepellin, The song remains the same (La canción es la misma).

Además de conformarse mediante las producciones musicales y extra-musicales de las bandas, se comenzó a desarrollar el público del metal. En los '70, en la zona Oeste del Conurbano bonaerense los seguidores de los grupos anteriormente mencionados eran llamados "firestones" (en alusión a la marca argentina de neumáticos). Estos pertenecían a los rockeros "duros" que se contraponían a los "blandos" (los seguidores de, por ejemplo, Almendra) (Alabarces, 1995).

Posteriormente surgieron los "metálicos" en el Área Metropolitana de Buenos Aires, uno de los tres grupos de actores (junto con los "rockeros" y los "punks") en los cuales se fragmentó el campo del rock nacional a principios de la década de los '80 (Vila, 1985). Tanto los “firestones" como los "metálicos" provenían mayoritariamente de sectores obreros.

Para Weinstein (2011), el "heavy metal, como otros géneros de la música popular, existieron antes de tener un nombre" (Weinstein, 2011, p. 36. T. de la A.). Según el musicólogo, Robert Walser (2014) el término heavy metal comenzó a ser usado para referirse a las formas musicales de bandas como MC5 y The Stoogies por

\footnotetext{
${ }^{14}$ En la música popular, un cover o una canción versionada es una nueva interpretación de una canción grabada previamente por otro artista.
} 
parte de periodistas especializados en rock como Lester Bangs y Dave Marshall de la revista Creem de Chicago en la década de 1970. Anteriormente había sido utilizado por la banda Steppenwolf en el tema "Born to be wild" y por William S. Burroughs en la novela, Naked Lunch (1959). En esa época también se lo usaba para referirse al efecto de las drogas pesadas (Fuentes Rodríguez citado en Plano, 2011, p. 89).

De acuerdo a Weinstein (2000), el heavy metal tradicional se cristalizó en la segunda mitad de 1970 con las bandas de la New Wave Of British Heavy Metal (Nueva Ola del Heavy Metal Británico), es decir, Judas Priest, Iron Maiden, Saxon, Def Leppard, Tygers of Pan Tang y Motörhead. Dichos grupos intentaron representar fuerza y potencia en sus dimensiones sonora, visual y verbal, significados que conforman el corazón del metal.

Es así que se caracterizaron por el uso del color negro en su iconografía y su vestimenta, la ropa de cuero con tachas y cadenas, y la referencia a temáticas ominosas y oscuras. A partir de allí el término "heavy metal" empezó a denotar

(...) una variedad de discursos musicales, prácticas sociales y significados culturales, todos los cuales giran alrededor de conceptos, imágenes y experiencias de poder. (...) Y todos estos aspectos de poder provocan fuertes reacciones de los que están fuera del heavy metal, incluyendo el miedo y la censura. (Walser, 2014, p. 2. T. de la A.)

Al mismo tiempo, dicho sentido de poder está vinculado con la idea de poder masculino, el cual se exalta y es representado en las diferentes dimensiones del estilo, tanto en lo musical como en lo extra-musical y en las relaciones sociales de sus músicos, audiencias y mediadores.

\section{La fragmentación, la dispersión y la globalización: década de 1980}

En la década de 1980, "heavy metal” se convirtió en un rótulo utilizado por la industria musical y los medios de comunicación, por lo tanto se produjo el crecimiento comercial y la diversificación como estilo musical. Debido a que circulaba y se producía en gran parte del mundo, aparecieron varios sellos discográficos y medios de comunicación especializados en el tema (principalmente revistas) y se comenzaron a formar diversos subestilos. A los procesos desarrollados en esta época, Weinstein (2000) los describe de dos formas: en primer lugar, la fragmentación y la dispersión; y, por último, la transnacionalización o globalización. 
La fragmentación se produjo a partir del desarrollo de nuevas bandas en dos direcciones que componen dos grandes subestilos: por un lado, el lite metal (también llamado hair metal o glam metal) y, por el otro, el speed/thrash metal. Ambos continuaron los legados de las temáticas que predominaban en el heavy metal: en primer lugar, las dionisíacas, las cuales se desarrollaban en torno al lema "sexo, drogas y rock and roll"; y, en segundo lugar, las caóticas, que se referían principalmente a la muerte y la destrucción (Weinstein, 2000).

De esta manera, el lite metal dio continuidad a los temas dionisíacos y, musicalmente, privilegió la melodía. Algunas de las bandas de esta rama fueron Def Leppard, Van Halen, Poison, Warrant, Twisted Sister, Bon Jovi, Mötley Crue y Cinderella. Estéticamente apostaron por un look que muchas veces simulaba la androginia (Ver Figura 1) y, verbal e iconográficamente, las mujeres eran representadas como objetos de conquista sexual, al mismo tiempo que se populariza la denominación groupie. Este subestilo alcanza gran masividad por lo que muchos críticos y periodistas lo calificaban como "pop metal".

Por el contrario, el speed/thrash metal continuó el legado de las temáticas caóticas y musicalmente privilegió el ritmo por sobre la melodía, creando canciones más veloces, con guitarras más desgarradas, emparentadas con la música del punk rock y el hardcore. Dentro de este subestilo las bandas más populares son las provenientes de la "Bay Area" de San Francisco y Los Ángeles, de las que se destacan las denominadas "Los cuatro jinetes del Apocalipsis": Metallica, Megadeth, Anthrax y Slayer. Temáticamente desarrollaron canciones con tono de protesta que realizaban denuncias sociales por medio de metáforas apocalípticas. Estéticamente, exaltaron la masculinidad del metal (Ver Figura 2) y, a diferencia del lite metal, poseían una ideología ligada a lo underground.

Ambos subestilos generaron divisiones dentro del metal, ya que los seguidores del thrash metal consideraban que el lite metal era "falso metal" y sus cultores, "poseurs", debido a que creían que aquel no poseía autenticidad y no era serio debido a que buscaba el éxito comercial. Además, ligaban el uso de la androginia a la homosexualidad, la cual era excluida por vincularse con la feminidad y, por ende, con la debilidad, opuesta al poder masculino.

La postura de los "thrasheros" es descrita por Weinstein (2000) como "fundamentalista" y por ser culturalmente conservadora. Estos crearon la frase "muerte al falso metal" (Weinstein, 2000, p. 137) y su enfrentamiento con los seguidores del lite 
metal o glam metal también se desarrolló en Argentina en la segunda mitad de la década de 1980, en donde la hostilidad fue una continuación de la anterior oposición entre los rockeros "duros" y los "blandos". Esta división se acentuó en los '80, ya que era el momento en donde el rock argentino se dividió en varios subgéneros, como el punk, el reggae, el pop y el metal, además del llamado "rock nacional", cuyos cultores en ese entonces se convirtieron en "consagrados" (Díaz, 2005).

Un momento en que esto se hizo visible fue durante el festival B.A. Rock que se realizó durante los cuatro sábados de noviembre de 1982 y fue organizado por la editorial Magendra ${ }^{15}$. Aquí se produjeron ciertos incidentes que marcaron la diferencia dentro del rock. Por ejemplo, el público hippie abucheó a las bandas emergentes calificadas como "modernas" (Taxi) y "heavys" (V8). Esta última se encargó de insultar a dicha audiencia, no solo a través de injurias, invectivas y provocaciones dichas a través del micrófono sino también por medio de canciones cuyas letras criticaban fuertemente la ideología pacifista del hippismo.

En cuanto a la dispersión del metal, Weinstein (2000) explica que además de los dos grandes subestilos mencionados (lite metal y thrash metal), aparecen otros nuevos a partir de la acentuación de algunas de las características del heavy metal clásico y sus dos derivados o por medio de la fusión con otros estilos musicales.

Es así que surgieron subestilos como el black metal ${ }^{16}$, el white metal ${ }^{17}$, el death metal $^{18}$, el doom metal ${ }^{19}$, el gothic metal ${ }^{20}$ y el power metal ${ }^{21}$. Cada uno de ellos posee

\footnotetext{
${ }^{15}$ Esta editorial fue dirigida por Osvaldo Daniel Ripoll, quien se encargó de editar la revista de rock de Argentina, Pelo, y más tarde, Pelo Metal y Metal, ambas dedicadas a la música metal en general.

16 El black metal es el subestilo cuyas líricas y estéticas están constituidas expresiones satánicas y anticristianas. Musicalmente, deriva del thrash metal pero acentúa la velocidad de sus tempos y agrega voces guturales agudas. Para algunos críticos, la banda pionera fue la de los británicos Venom, aunque la escena más representativa es la que proviene de Noruega con grupos como Mayhem y Gorgoroth.

${ }^{17}$ El white metal o "metal cristiano" surge como oposición a las expresiones satánicas de bandas como Black Sabbath y Alice Cooper. Musicalmente es similar al resto de subestilos de metal y solo se distingue por incluir líricas y estéticas con contenidos cristianos.

${ }^{18}$ El death metal es, musicalmente, una fusión entre el thrash y el black. Se caracteriza por agregar voces guturales a sus cantos y por sus líricas que utilizan metáforas de muerte como forma de denuncia social. Algunos ejemplos son Morbid Angel, Deicide y Cannibal Corpse.

${ }^{19}$ El doom metal es el estilo que surge específicamente de Black Sabbath y se caracteriza por un sonido demoledor y lento, con letras que contienen la descripción de paisajes oscuros y depresivos. Se puede ejemplificar a través de las bandas Cathedral y Pentagram.

20 El gothic metal se encuentra emparentado musicalmente con el doom, pero se caracteriza por conformarse a través de la fusión con el resto de los subestilos y por tomar como referencia a la cultura gótica. Su lírica contiene caracteres melodramáticos, de horror y existencialismo. Utiliza la técnica de "la bella y la bestia", en la que canta una voz lírica femenina y una gutural masculina. Algunas bandas que son ejemplo de este estilo son Lacrimosa y Theatre of Tragedy.

${ }^{21}$ El power metal es ejecutado a mayor velocidad que el heavy metal clásico y se caracteriza por que en sus letras se relatan acontecimientos propios de la literatura fantástica o, más bien, maravillosa de la Edad
} 
características específicas que los diferencian de los otros. Es por ello que se empezó a hablar de metal como término paraguas que engloba tanto al heavy metal como a los subestilos que nacieron a partir de él. En ese sentido, para Weinstein (2000) el heavy metal clásico sería el centro de significado del metal y los subestilos, la periferia. Por su parte, de la tendencia fundamentalista surge el metal extremo (Kahn-Harris, 2007).

En esta década también se produce la difusión global del metal por el mundo, la cual es descrita por algunos autores como "globalización" del metal. Para Weinstein (2011b) este proceso contó con dos etapas (desarrolladas en las décadas de 1980 y 1990, respectivamente) en las cuales el metal se expandió desde los países económica y tecnológicamente más desarrollados a los de menor desarrollo, tal como lo hizo McDonald's y la televisión (Weinstein, 2011b, p. 44).

Es así que la primera etapa contó con el movimiento desde Reino Unido y Estados Unidos hacia Europa Occidental, Australia, Canadá, Japón y las áreas más ricas y urbanizadas de América Latina, en donde la autora menciona a Brasil y Argentina. Por su parte, en la segunda etapa, el metal se propagó por las islas asiáticas del Océano Pacífico, sectores seculares del Medio Oriente y la mayoría de las ciudades de Latinoamérica (Weinstein, 2011b, p. 44).

La globalización del metal fue posible gracias a la labor de tres actores sociales: músicos, aficionados y mediadores. Como consecuencia, este estilo musical adquiere el carácter de transcultural. Es decir, “(...) el metal no es una música atada a una cultura particular, que la gente en otras culturas suele disfrutar como outsiders; más bien, el metal es la música de un grupo de personas que trasciende otro preexistiendo fronteras culturales y nacionales.” (Weinstein, 2011b, p. 46. T. de la A. Cursivas propias)

Una forma en que la música popular y, dentro de ella, el metal se lograron diseminar por diferentes países fue a través de los viajes realizados por individuos. En Argentina esto se puede ejemplificar con la carrera del guitarrista, Norberto "Pappo" Napolitano. A partir de sus viajes por Europa (especialmente a Inglaterra) a mediados de la década del '70, en los cuales conoció a la Nueva Ola del Heavy Metal Británico (NWOBHM), especialmente bandas como Judas Priest y Saxon, decidió dar origen a Riff la que, a diferencia de su banda anterior, Pappo’s Blues, poseía un cantante con un

Media, o de las épicas de la antigüedad. Algunas bandas representativas de este estilo son Blind Guardian y Stratovarius. 
tono similar al de Bon Scott de AC/DC y dos guitarristas. Además, incorporó un cambio estético, el cual se evidenció en el uso de ropa de cuero color negro, tachas y cadenas.

Es necesario destacar que Riff no fue una banda de covers, sino que realizó sus propias composiciones influenciada por el estilo de los grupos de la NWOBHM. En 1981 editaron su primer disco, Ruedas de metal. A partir de ellos comenzó la denominación "metálicos", ya que sus seguidores eran nombrados por la agrupación como "huestes" u "hordas" metálicas, y sus aficionados se autodenominaban "papperos", en alusión a Pappo, muchos de los cuales ya lo seguían desde sus anteriores conjuntos.

Riff congregó audiencias en todo el país pero, sin embargo, duró poco y tuvo varias idas y vueltas debido a los incidentes de violencia que generaba su público, al punto de ya no poder controlarlos. Esto resulta relevante si se tiene en cuenta que dichos eventos se realizaron posteriormente al regreso de la democracia argentina, un período sensible a los actos de violencia en todos los ámbitos de la sociedad.

A la par de Riff se encontraba la banda, V8, que se destacó por congregar gran cantidad de público y porque trascendió posteriormente a su disolución. En la década de los '80 nombraban a su estilo musical como "heavy metal", aunque los críticos de rock de ese entonces la diferenciaban de las demás por poseer una "actitud punk", ya que mostraban más agresividad y transgresión en sus performances y composiciones. Esto se debía a que, en realidad, el estilo que hacían era thrash metal pero esa denominación aún no se usaba en el país. Su primer disco fue Luchando por el Metal y se editó en el año 1983.

En esa época, los "metálicos", especialmente seguidores de V8, se reunían en grupos denominados "brigadas metálicas", las cuales provenían de diferentes barrios de la ciudad de Buenos Aires y distintos partidos del Conurbano Bonaerense. Entre ellas, se encontraban los "Apaches de Pacheco", los "Hurling Metal" y la "Brigada del Docke".

A pesar de que la denominación "brigada" proviene del ámbito militar, el objetivo de dichos grupos era congregarse para poder asistir a los recitales y movilizarse con el atuendo típico del metal sin ser detenidos por la policía, ya que al circular con esa vestimenta de forma individual eran más vulnerables a los abusos ${ }^{22}$ policiales. Al igual

\footnotetext{
${ }^{22}$ Digo "abusos" porque en el contexto de la transición a la democracia aún quedaban resabios de la represión y el control policial.
} 
que otras agrupaciones que utilizaron la denominación "brigada" -tales como la brigada "Castagnino", conformada por pintores muralistas de ideología de izquierda que homenajeaban a Juan Carlos Castagnino- llevaba una impronta ideológica que, en su caso, estaba vinculada con la oposición al sistema.

De acuerdo a Weinstein (2011b), las estrategias que permitieron el proceso de globalización del metal fueron la circulación de revistas y fanzines y de difusión de música grabada (tanto en formato de discos como cassettes, en medios electrónicos como posteriormente en Internet) y en vivo (a través de tours y festivales internacionales).

También existía una gran interacción a través de correo postal entre aficionados, periodistas y músicos locales con extranjeros. Por ejemplo, se pueden citar los intercambios entre el argentino "Pocho Metalica", integrante de la Brigada de Hurlingham y editor del fanzine, Hurling Metal, con los músicos, Mille Petrozza de Kreator, Max Cavalera de Sepultura, Euronymus de Mayhem; el fan club oficial de Metallica; la revista brasileña, Rock Brigade y la mexicana, Heavy Metal Subterráneo (Cañizares, 2015).

En ese contexto, también fueron importantes las disquerías y rockerías, las cuales se alojaban principalmente en Capital Federal ${ }^{23}$ y debían adquirir el material original a través de viajes al exterior, especialmente a Brasil. Esta misma dificultad para conseguir música metal de la escena internacional, se podía ver en la escasez de estudios de grabación especializados, instrumentos musicales e indumentaria (que en su gran mayoría era confeccionada de manera casera y artesanal).

A pesar de estas trabas, la escena argentina se consolidó a mediados de 1980, en época de democracia. Algunas muestras de ello fueron la grabación del primer compilado del género (Aleación, editado en 1985 por el sello Umbral) y la organización de los Festivales Metálicos de Primavera, el 28 y 29 de septiembre de 1984 en el Estadio Atlanta.

Por otra parte, algunas bandas lograron presentarse en programas televisivos dedicados a diversos géneros de la música popular, como por ejemplo, "Música Total". También surgieron medios de comunicación especializados: programas de radio (“Cuero pesado"), revistas (Metal, Riff Raff, Kiss y Rocker) y fanzines (por ejemplo,

\footnotetext{
${ }^{23}$ Capital Federal se refiere a CABA. Esta última denominación se comenzó a utilizar a partir de 1996.
} 
Metal Command, Rebelión Rock y Hurling Metal). Estos fueron fundamentales para la difusión del estilo musical por todo el país.

Considerando que, para Weinstein (2011b), Argentina entra en la primera etapa de la globalización del metal, se observa que en esa época se produjo un gran contacto de la escena local con la de otros países. Por ejemplo, varios grupos argentinos lograron presentarse en países vecinos como Uruguay, Chile y Brasil. Además, en Argentina (más específicamente, en Capital Federal) se realizaron conciertos de bandas extranjeras como la española, Barón Rojo (en 1984, en el estadio de Obras Sanitarias) y la estadounidense, Quiet Riot (en 1985, en Luna Park).

Por otra parte, resulta de gran relevancia el primer festival Rock in Rio en Brasil, ya que allí asistió gran cantidad de público argentino y fue la oportunidad para que periodistas, cronistas y músicos hicieran contacto con la escena brasileña y pudieran ver en vivo bandas de reputación internacional, como Iron Maiden, Ozzy Osbourne, AC/DC y Whitesnake. A su vez, la grabación audiovisual de dicho evento circuló de manera masiva, por lo que los melómanos asistían a las proyecciones públicas y privadas del mismo.

A fines de esta década ya no se hablaba solo de heavy metal, sino también de thrash, glam, death y black. Un hecho importante fue la disolución de la banda V8 de la cual surgieron Hermética ("metal pesado"), Horcas (thrash metal), Logos (metal cristiano) y Rata Blanca (heavy metal y power metal), las que desde esa época han congregado un público masivo.

Por ejemplo, Rata Blanca se destacaba por reclutar aficionados por fuera del propio metal y por ser reconocidos internacionalmente como una de las agrupaciones más importantes del rock en español, lo que les costó el mote de "caretas" dentro de la escena metálica y "grasas", entre algunos cultores del rock nacional. Por su parte, Hermética de manera inversa adquirió masividad y cobró la misma importancia pero para el interior de la escena argentina. Por su parte, de manera underground se desarrollaba el metal extremo, con bandas como Escabios y Militia.

\section{La supuesta muerte: década de 1990}

La gran mayoría de los críticos y periodistas especializados consideraban que la década de los '90 era sinónimo de la "muerte" del metal, debido a que a diferencia de la década anterior en donde el glam metal había constituido el mainstream del rock, en los años posteriores era reemplazado por la masividad comercial del grunge y del hip hop. 
Es así que ganaron terreno festivales como Lollapalooza, el cual reunía a bandas del denominado "rock alternativo". Metallica formó parte de uno de ellos, dando muestra de su cambio radical: de ser una referente del thrash underground, había pasado a ser un "suceso mega-mainstream" (Weinstein, 2000, p. 293).

Por otra parte, los grupos que se habían consagrado en los '80, como Judas Priest y Iron Maiden, no tenían las formaciones originales y algunos de sus músicos habían abandonado los conjuntos y se los había reemplazado con otros no tan reconocidos. Esto generó gran cantidad de bandas tributo y discos homenaje. Esas disoluciones hicieron que el final de los '90 se caracterizara por las reuniones de las agrupaciones que se habían separado, como por ejemplo, Black Sabbath (Weinstein, 2000).

En esta época también surgió el ñu metal y otros nuevos subestilos a partir de nuevas mixturas con el rap, el hardcore y la música electrónica, como por ejemplo, el metalcore y el metal industrial ${ }^{24}$, los cuales no fueron fácilmente aceptados por los sectores más fundamentalistas, ya que poseían estéticas vinculadas con los estilos de rock que estaban de moda.

En Argentina, un ejemplo de ellos fue la banda de ñu metal, A.N.I.M.A.L. que, a diferencia de sus antecesores, grabó discos con Warner y se destacó a nivel internacional (Lunardelli, 2002). Tal como sucedió con dicha agrupación, también se puede mencionar a los thrasheros, Tren Loco, que llegaron a la final del certamen mundial "Yamaha Band Explosion" de Japón, pero a pesar de ello continuaron gestionando su actividad de manera underground.

El contacto con la escena internacional también se pudo ver en la visita de gran cantidad de bandas extranjeras profesionales al país, facilitadas por las políticas monetarias neoliberales del gobierno de Carlos Saúl Menem. Entre ellas estuvieron Bon Jovi, Faith No More, Sepultura, Ratos de Porão, Kreator, Iron Maiden, Skid Row, Motörhead, Obituary, Guns N' Roses, Exodus, Metallica y Saxon. De acuerdo a Blumetti y Parise (1993) esta gran cantidad de conciertos internacionales hicieron que los "metaleros" bajen su interés por los conjuntos argentinos.

\footnotetext{
${ }^{24}$ El metal industrial es aquel que agrega sonidos y arreglos electrónicos a sus temas musicales. Algunos ejemplos son los alemanes, Rammstein, y la banda solista del estadounidense, Rob Zombie.
} 
Sin embargo, estas continuaban su actividad, lo cual se evidenciaba en los compilados editados en esa década: Metal Vol. I, Latinos y Metálicos ${ }^{25}$ y Thrash, Metal Argentino $^{26}$, producidos por los sellos discográficos, Halley y Radio Trípoli. Además, en 1990 Hermética se convirtió en el primer grupo argentino de metal en grabar en formato Disco Compacto o compact disc (CD) con la edición del disco "Intérpretes". Por su parte, Rata Blanca ofreció un concierto en 1991 en el estadio Vélez Sarsfield junto con Attaque 77, congregando un público de 25000 personas.

En cuanto a los lugares para realizar conciertos, en Capital Federal se destacaban Halley, Cemento y el teatro Arlequines. Estos permitían la presentación tanto de bandas consagradas como del underground. Con respecto a los medios especializados, los más reconocidos en ese momento eran las revistas Madhouse y posteriormente, Epopeya; además del programa de radio "Heavy Rock \& Pop".

Asimismo, a mediados de los '90 comenzó a cobrar importancia Internet, el que no solo permitía la difusión de la información de las bandas y la promoción de sus discos, sino también un espacio de sociabilidad e intercambio a través de los foros de discusión. Incluso, la red permitía la circulación de revistas y programas de radio de manera gratuita a través de e-zines y radios virtuales.

\section{El metal en Argentina después del 2000}

En la actualidad, la escena de la música metal en Argentina trasciende los conceptos que en general se usaron para hablar del rock argentino: juventud y ciudad. En primer lugar, porque actualmente la escena no solo se compone por adolescentes sino también por los viejos seguidores que hoy en día son adultos de alrededor de $50 \mathrm{y}$ 60 años. En segundo lugar, la amplia difusión de la música metal y, especialmente, la labor de Ricardo Iorio hicieron que la escena no sea un fenómeno típicamente urbano, sino que además es posible ver la organización de conciertos en zonas rurales y aficionados provenientes de dichos lugares.

Esta etapa se caracteriza por la difusión de metal a través de Internet, por lo que es más fácil que bandas locales se escuchen fuera del país y agrupaciones extranjeras sean consumidas por el público local. Esto hace que el conocimiento sea tan amplio que

\footnotetext{
25 "El mismo incluye temas de bandas argentinas (Riff, Escocia, Lethal y Alakrán), Españolas (Legión, Fuck Off), uruguayas, chilenas, mexicanas y colombianas." (Blumetti y Parise, 1993, p. 114)

26 "El álbum es doble y contiene a las siguientes bandas: Hades, Vandalis, Relayer, Barbalangs, Chug, Wolfgang, Charmer, Destroyer, Wolf, Reina Aspid, Factor RH, Rocket, Sexton, Metal Azul, Aspeed y El Dragón. Con la excepción de este último, todos los grupos pertenecen al interior del país." (Blumetti y Parise, 1993, p. 120).
} 
Argentina se presente como un lugar propicio para la organización de recitales de grupos que circulan a nivel global, por lo que el país casi siempre es incluido en las giras por Sudamérica o Latinoamérica.

Además, la gran mayoría de las provincias del interior argentino poseen sus propias escenas y sus festivales característicos, como por ejemplo el "Criminal Metal Camp" de la provincia de Córdoba. A pesar de esto, la circulación a lo largo del país continúa siendo dispar, ya que las bandas internacionales se presentan mayoritariamente en la Ciudad Autónoma de Buenos Aires (CABA).

Sin embargo, a partir del 2010 se ha intentado romper con esto y bandas de la talla como Iron Maiden, Metallica y Megadeth se presentaron en las ciudades capitales de provincias del interior argentino como Córdoba, Río Negro y Neuquén. Por el contrario, las agrupaciones extranjeras que circulan globalmente pero se desarrollan de manera underground sí incluyen fácilmente a algunas ciudades del interior además de CABA.

Por otro lado, también es necesario dejar de lado la caracterización del público metálico como proveniente del sector obrero, ya que la audiencia se expande a diferentes sectores sociales y económicos. Sin embargo aparecen nuevas disputas, ya que muchos de los músicos surgidos en la primera etapa se consagran como profesionales, graban sus propios discos y logran que sus bandas sean reconocidas no solo a nivel nacional sino también internacional.

Esto conduce a que un gran número de conjuntos nuevos se desarrollen de manera underground, los cuales contribuyen al desarrollo de los subestilos del metal. Además, muchos están influenciados por los estilos de Hermética y Almafuerte y desarrollan el llamado "metal argento", con líricas referidas al contexto argentino y, a veces, con la fusión del metal con el Folklore argentino.

$\mathrm{Al}$ igual que sucede con la profesionalización de las bandas, algunos mediadores y medios especializados de larga trayectoria se consagran conformando una especie de hegemonía. Pero, a pesar de ello, aún existe la circulación underground de fanzines y de e-zines. Esta etapa también se caracteriza por la edición de libros y biografías especializados en el género musical $y$ en la realización de documentales $y$ rockumentales sobre la música metal en Argentina.

También juegan un rol importante las redes sociales de Internet (como por ejemplo, Facebook e Instagram), las cuales no solo sirven para promocionar los recitales 
y eventos vinculados al metal, sino que también constituyen medios de participación e intercambio al igual que lo eran los foros de Internet de los años anteriores.

En esta etapa, los recitales que se realizan a lo largo del país son numerosos. Especialmente en el Área Metropolitana Bonaerense es posible encontrar conciertos cada fin de semana, los cuales en muchos casos se superponen en fecha y horario. Por otra parte, es posible contar con conciertos de bandas extranjeras al menos una vez al mes y con festivales con varias bandas del mainstream metálico, como por ejemplo, el "Monsters of Rock". Además, las bandas underground pueden acceder a tocar como soportes de bandas extranjeras o profesionales nacionales.

Otra característica relevante de esta época es la creación del teatro y la radio Vorterix por parte de Mario Pergolini, ambos especializados en metal (Scarrone, 2016). También aparece el "Wacken Metal Battle" en Argentina, un concurso que permite que la banda ganadora se presente en el festival "Wacken Open Air" de Alemania, uno de los más importantes de la escena global de la música metal. Al mismo tiempo, se comienzan a realizar los "campamentos metaleros" por diferentes provincias del país en homenaje a los pueblos originarios y el festival "Metal para todos" en donde se presentan solo bandas argentinas.

\section{Historia de Hermética}

Luego de la disolución de V8 en 1987, el bajista, Ricardo Iorio, de 26 años de edad, decidió formar una nueva banda. Para ello le pidió ayuda a su amigo y antiguo manager de V8, Marcelo “Tommy” Moya. De esta manera, éste se contactó con Martín Knye y Leo Marisel, quienes integraban LZ2. Sin embargo esta relación no prosperó, por lo que Moya le presentó al guitarrista Antonio "Tano" Romano (ex integrante de Cerbero), con quien Iorio comenzó componer los primeros temas. Posteriormente, se sumaron Claudio O'Connor en la voz y Fabian Spataro en batería, los cuales habían sido parte del conjunto Mark I.

Con esta formación, Hermética (nombre que ya había decidido Iorio antes de buscar a los músicos) comenzó a ensayar en la casa de Moya situada en Villa Ballester. Este era el punto de encuentro, ya que los miembros provenían de diferentes lugares: Iorio de Villa Devoto, Romano de la zona oeste del Conurbano Bonaerense y O'Connor y Spataro, de zona sur. Además, tuvieron su debut el 23 de abril de 1988 en el Centro 
Cultural Recoleta en una muestra de diversas artes titulada "El Cubo", organizada por Joaquín Amat ${ }^{27}$ y Jorge Pistocchi ${ }^{28}$.

Luego, hicieron un inicio formal con un recital con el formato tradicional, el 7 de mayo de ese año en el pub Helloween, que pertenecía a los músicos de la banda de metal, Retrosatán, y se situaba en la localidad de San Martin, Buenos Aires. Allí asistieron más de 150 personas, la mayoría de los cuales eran antiguos seguidores de V8 y Cerbero. Al poco tiempo, Spataro decidió abandonar la banda por lo que se sumó al grupo, Tony Scotto, que había sido baterista de Motor V y Mephisto. Al año siguiente, con este nuevo miembro y debido al aumento de público, la banda comenzó a presentarse en el Teatro Arlequines, el cual poseía mayor capacidad.

A pesar de las dificultades económicas derivadas del contexto de la hiperinflación, en 1989 grabaron su primer disco, titulado Hermética, con el sello novele, Radio Trípoli. Este estaba conformado por "Chuchu” Fasanelli, Walter Kolm y Pedro Zambón, quien era saxofonista de Todos Tus Muertos y fue el inversor de este trabajo. Como en ese momento aún no tenían un espacio físico formal, el contrato se firmó en un bar y se pactó que la grabación y la producción estaría a cargo de dicho sello discográfico, el cual también mantendría exclusividad para las presentaciones de la banda en Capital Federal. Por su parte, las grabaciones se realizaron en los estudios Sonovisión con el ingeniero de sonido, Álvaro Villagra. En esta época el lema de la banda era "contra el falso metal".

$\mathrm{Al}$ año siguiente, como habían quedado 27 horas extra de grabación, decidieron realizar un $\mathrm{EP}^{29}$ titulado Intérpretes, en el cual solo hicieron covers, por lo que la prensa lo comparó con The \$5.98 E.P.: Garage Days Re-Revisited (1987) de Metallica. Dicho disco de Hermética fue realizado en los estudios Aguilar con el técnico de sonido, Néstor "Pájaro" Randazzo. Los temas que se versionaron fueron "Vencedores vencidos" de Patricio Rey y sus redonditos de ricota, "Ideando la fuga" y "Destrucción" de V8,

\footnotetext{
${ }^{27}$ En palabras propias, "Soy videasta, filmo, la cámara de video es mi instrumento, como la guitarra para un guitarrista. Con mi cámara acompañé movidas culturales, el under, el Centro Cósmico, los subsuelos de la Bond Street, tuve galerías de arte. Mis videos son subjetivos, parciales. (...) En 1987 presenté Canal Cero, un medio de comunicación alternativo, con una video instalación en el Centro Cultural Recoleta." (Amat, 2017, p. 95) Amat también se destaca por su trabajo cultural conjunto con el ya citado, Jorge Pistocchi.

${ }^{28}$ Fue un periodista, escultor e ilustrador argentino, creador de la revista contracultural, El expreso imaginario.

${ }^{29}$ EP es la sigla que se utiliza para nombrar a los discos "Extended play" (reproducción extendida). Estos poseen una duración menor que un "Long Play" (reproducción larga), pero mayor que un "sencillo".
} 
"Cambalache" de Enrique Santos Discépolo, "Porque hoy nací" de Manal y "No class" de Motörhead -único tema en inglés que realizó la banda en toda su carrera-.

En 1991 comenzaron a tocar en Cemento, ya que cada vez reunían más seguidores. A pesar de ello, aún no podían vivir de la música, por lo que los músicos tenían otros trabajos. Por ejemplo, ese año Joaquín Amat les prestó dos locales de la galería Bond Street de Capital Federal a O'Connor y Iorio. Es así que el primero abrió el acuario, "Nautilus", junto al fotógrafo, Andres Violante; y el segundo, emprendió un negocio de compra, venta y canje de instrumentos musicales, llamado "El perro de hierro", el cual se sumaba a sus trabajos en el rubro frutihortícola. Ambos negocios duraron un corto período de tiempo.

Ese año también se produjo el reemplazo de Scotto por Claudio "Pato" Strunz, antiguo baterista de Heinkel, el cual demostraba más profesionalismo que el anterior. Al mismo tiempo, era el dueño de la sala en donde la banda ensayaba. Con este nuevo integrante grabaron el disco Ácido argentino en los estudios Aguilar, nuevamente con el ingeniero Randazzo. También formaron parte del compilado editado por la revista, Metal, y Radio Trípoli junto a las bandas Riff, Horcas, Lethal, Kamikaze, Alakrán, JAF, El Dragón, Tarzen, El Reloj y 2112. También editaron Hermética e Intérpretes juntos en formato $\mathrm{CD}$.

Además de la difusión a través de revistas especializadas en rock y metal, tuvieron su participación en televisión, más específicamente en el programa "Siglo XX Cambalache" ${ }^{30}$, transmitido por Telefé, que conducía Teté Coustarot y Fernando Bravo. Allí realizaron el playback ${ }^{31}$ del cover metálico del tango, "Cambalache". Como a esa canción la cantaba Iorio, O'Connor salió a escena simulando ejecutar una segunda guitarra eléctrica. Además de esta presentación, les hicieron un reportaje en el programa "la Movida del '90"32 y el año siguiente, en "Crema americana"33 del canal América TV.

El año 1992 fue relevante para la banda por varios acontecimientos. En primer lugar, porque participaron de un festival organizado por SADAIC y Radio Nacional a beneficio las familias de las víctimas de un alud que se produjo en la localidad de San Carlos Minas de la provincia de Córdoba. Este concierto tuvo lugar en el estadio

\footnotetext{
${ }^{30}$ Programa de interés general, con una impronta "familiar" y de corrección.

${ }^{31}$ El término se refiere a la sincronía de labios o fonomímica, proceso que consiste en la sincronización de movimientos labiales con vocales habladas o cantadas para simular el cantar o hablar en vivo.

32 Programa emitido por ATC, conducido por la vocalista de la banda de pop punk, Trixi y los maniáticos.

${ }^{33}$ Era un programa de verano emitido por América TV y conducido por Juan Castro y Ari Paluch.
} 
Chateau Carreras y en él también participaron la banda de rock, punk y reggae, Todos Tus Muertos y el folklorista, José Larralde, quien comenzó a entablar una larga amistad con Iorio y un vínculo concreto con el nacionalismo, ya que Larralde tenía larga trayectoria en lo que podría denominarse "nacionalismo popular", ya que su música consiste en una especie de defensa del peón rural y de lo nacional.

Este contacto con lo autóctono también se evidencia en la participación de Hermética en la muestra artística realizada por los ya mencionados, Joaquín Amat y Jorge Pistocchi, titulada "La revancha de América", con motivo de los 500 años de la colonización de América. Allí, dentro de los artistas plásticos, músicos y dirigentes de pueblos originarios, también participó Hermética ejecutando el tema musical que llevaba el mismo nombre que la muestra.

Por otro lado, la banda tuvo la posibilidad de telonear a los grupos británicos de rock y metal, Black Sabbath y Motörhead, en su visita a la Argentina, los cuales eran de gran influencia para ellos. En estas ocasiones, Iorio le regaló un cassette de Larralde a Tony Iommi, guitarrista del primer conjunto, y una campera de cuero a Lemmy Kilmister, bajista del segundo. Esta prenda de vestir resulta significativa para la cultura metálica en la mayor parte del mundo.

El gran crecimiento de la banda no solo se veía en la cantidad de público que congregaba sino también a nivel profesional, lo que marcó la necesidad de modificar la estructura para agregar dos managers: Por un lado, Eduardo "el chancho" Christiani se encargaría de las presentaciones en Gran Buenos Aires y, por el otro, Marcelo Caputo, de los conciertos en el interior del país. Por su parte, Marcelo Tommy Moya quedó en el puesto de coordinador general.

De esta manera, en 1993 realizaron la gira "Atravesando todo límite-Evitando el ablande", con la cual se presentaron en más de 50 shows a lo largo de 13 provincias. La forma de viaje era similar a las de las bandas profesionales: en el micro no solo iban los músicos y los managers, sino también asistentes, sonidistas e iluminadores. De esta manera llegaron a provincias como Tierra del Fuego, Chubut, Salta y Tucumán. Estas presentaciones significaron un crecimiento de público, lo que se tradujo en aumento de ventas discográficas, por lo que recibieron disco de oro.

En este mismo año realizaron su primer concierto en Stadium frente a más de 4000 personas. Ese show fue grabado audiovisualmente y con dicho material posteriormente se editó el primer disco en vivo de la banda y un video en formato VHS titulado Hermética en vivo, 1993, Argentina. Aquí se incluyó el cover de la canción de 
protesta, "Si se calla el cantor", del folklorista, Horacio Guarany. El disco fue grabado y mezclado por el ingeniero Álvaro Villagra en los estudios móviles Del Abasto y editado por el sello Radio Trípoli,

Otro show importante de ese año fue el concierto realizado por Alejandro Taranto (responsable de Armenia Rock Producciones y del sello Tommy Gun Records) en el Penal $N^{\circ} 1$, "Lisandro Olmos", a beneficio de la radio que manejaban los internos. En dicho recital también se presentaron las bandas argentinas de punk Attaque 77, Pilsen y Massacre; los metálicos, Lethal y A.N.I.M.A.L.; y los punks norteamericanos, UK Subs. Este evento quedó registrado en el disco "Radio Olmos", editado el año siguiente, para el cual Hermética colaboró con los temas "Robó un auto" e "Ideando la fuga".

En 1994 editaron el disco Víctimas del vaciamiento, el cual se había comenzado a grabar el año anterior. Nuevamente contaron con la colaboración del ingeniero, Villagra, y los estudios Del abasto. La novedad es que en esta producción, a diferencia de las anteriores, se realizó una pre-producción. Durante este trabajo, Iorio se rapó, lo que resultó un acontecimiento importante ya que marcó una nueva tendencia dentro de los "metaleros". En las entrevistas realizadas en ese momento, Iorio explicaba que el nuevo look se debía a que la moda del cabello largo ya no era exclusiva del metal y la habían adoptado cantantes melódicos como Diego Torres y Guillermo Fernández. La cabeza rapada posteriormente incluyó el cabello como una cresta.

Este año se produjo una desgracia para el grupo. El 18 de febrero en un concierto en el local, Morón 90, murió José Luis Damián, un joven de 16 años que, por querer alcanzar unas púas arrojadas al público desde el escenario, se abalanzó sobre una potencia de sonido, de la cual sufrió una descarga eléctrica que le produjo un paro cardiorrespiratorio. De acuerdo a los cronistas de la revista Efecto Metal (2014), "La banda asistió al Velatorio (pagó los gastos) y además le cedió la recaudación de un show en Stadium a los familiares." (Violante, 2014, p. 38).

Posteriormente hubo un juicio, pero de todos los implicados (el dueño del lugar, el sonidista, el iluminador y los músicos), el único afectado fue Iorio, a quien se le aplicó una medida cautelar con un embargo en su cuenta en SADAIC. Según la biografía de Iorio, el resto de los músicos declararon ser empleados de él para no ser enjuiciados, hecho con el que comenzaron las diferencias en el grupo (Torres, 2008). Más tarde, la banda le dedicó el siguiente disco al joven fallecido. 
En 1994 hubo varios shows destacables. Por ejemplo, el 18 de abril se presentaron en la cárcel de Caseros gracias a una amistad que tenía en ese momento Iorio con el convicto, Sergio Schocklender. Nuevamente se produjo el acercamiento de la banda a los reclusos, posiblemente porque se trataba de un tipo más de varones marginales.

También formaron parte del primer festival Monsters of Rock hecho en Argentina en el estadio River Plate, junto a Gatos Sucios, Slayer, Kiss y Black Sabbath. El crecimiento del grupo musical hizo que se presentara como única banda en el estadio Obras Sanitarias, cuya capacidad quedó colmada en el show del 12 de noviembre. En ese concierto nuevamente recibieron disco de oro por las ventas de Víctimas del vaciamiento.

El contacto de Hermética con la causa de los pueblos originarios se produjo en varias ocasiones. Por ejemplo, durante un show en Stadium el 6 de mayo de ese año, una delegación aborigen subió al escenario, realizó rituales a la Pachamama con música autóctona con quenas, charangos y bombos, y nombró a los músicos como "Nuevos indios de América", colocándoles vinchas con plumas. Sin embargo, los relatos periodísticos no especifican de qué comunidad eran dichos nativos.

De acuerdo a la crónica de Andrés Violante (1994) en la revista Madhouse, durante una presentación en Salta, los miembros de la cooperativa "Wichi Ka Puchi Hi" de los aborígenes wichi de Santa Victoria Este, Salta, se acercaron a saludar a la banda y a contarles que usaban la canción "La revancha de América" en las charlas que daban en las escuelas rurales de su comunidad. De acuerdo a una entrevista realizada a Iorio en ese momento (1994) en la revista Rock N Shows, dicha cooperativa se había manifestado en el Congreso en Buenos Aires para reclamar por sus derechos.

Hermética no solo se presentó en Argentina, sino que también participó de un concierto en Bolivia en 1994, dos en Uruguay (uno en 1988 y otro en 1994) y un show fallido en Paraguay (se suspendió debido a un desacuerdo con los organizadores). Sin embargo la intención de la banda siempre fue llegar a nuestro país. Esto no solo se demostró en la cantidad de provincias argentinas que visitaron, sino también en algunas decisiones, como por ejemplo, rechazar la propuesta de editar un disco con el sello europeo, Roadrunner. Solo llegaron a grabar la versión en inglés del tema "Desterrando a los oscurantistas", la cual no se dio a conocer ya que no estuvieron conformes con el resultado. 
El último concierto de la banda fue en la discoteca, Go!, de Mar del Plata el 18 de diciembre de 1994. Luego de ello, Iorio ordenó cancelar un show que estaba pactado en Obras con la excusa de haber contraído hepatitis B. Posteriormente, el 6 de enero de 1995 en un reportaje para el suplemento, Si!, del diario Clarín, el bajista afirmó que la enfermedad había sido falsa y, en realidad, Hermética se había separado. De acuerdo a la crónica de Efecto Metal (2015), el resto de los músicos se enteró de la decisión de Iorio a través de esa entrevista.

Los verdaderos motivos de la separación aún permanecen en secreto y circulan diferentes versiones de los hechos, casi como una leyenda, muchas de las cuales se desprenden de las canciones que produjeron posteriormente Iorio con Almafuerte y O'Connor, Romano y Strunz con Malón, las cuales demuestran rivalidad entre las dos bandas, cuyo apéndice está en la separación del público de Hermética entre los “almafuerteros" y los "maloneros".

En 1995 O'Connor, Romano y Strunz editaron el disco Lo último a través del sello DBN con el material grabado del concierto realizado en el estadio Obras Sanitarias el 12 de noviembre del año anterior. Este mismo material fue usado y retocado posteriormente por Iorio en 1996 para editar el disco doble, En concierto parte $I \& I I$, también por medio del sello DBN. Esta edición contiene más temas musicales que la versión del otro disco.

\section{El espacio bonaerense entre el 2011 y el 2017}

Como ya mencioné anteriormente, es prácticamente imposible pensar a la escena metálica bonaerense sin considerar tanto a la provincia de Buenos Aires como a CABA. De hecho, el Conurbano bonaerense forma junto con esta el Gran Buenos Aires ${ }^{34}$. Es por esto que bajo el gentilicio "bonaerense" se tendrá en cuenta a la provincia y a la Capital Federal en interrelación, a pesar de que algunas veces los adjetivos "porteño" y "porteña" se refieran a la segunda.

La provincia de Buenos Aires, ubicada en el centro-este de la Argentina, no solo constituye la más poderosa política y económica sino también la más poblada del país.

\footnotetext{
${ }^{34}$ El Gran Buenos Aires se compone por la Ciudad Autónoma de Buenos Aires y 40 municipios de la provincia de Buenos Aires: Almirante Brown, Avellaneda, Berazatagui, Berisso, Brandsen, Campana, Cañuelas, Ensenada, Escobar, Esteban Echeverría, Exaltación de la Cruz, Ezeiza, Florencio Varela, General Las Heras, General Rodríguez, General San Martín, Hurlingham, Ituzaingó, José C. Paz, La Matanza, Lanús, La Plata, Lomas de Zamora, Luján, Marcos Paz, Malvinas Argentinas, Moreno, Merlo, Morón, Pilar, Presidente Perón, Quilmes, San Fernando, San Isidro, San Miguel, San Vicente, Tigre, Tres de Febrero, Vicente López, y Zárate.
} 
De acuerdo a los datos del último Censo Nacional de Población, Hogares y Viviendas realizado por el INDEC en el 2010, la provincia posee 18.515.235 habitantes, los cuales representan el 46\% del total de la población de Argentina.

Por su parte, el Área Metropolitana de Buenos Aires o Gran Buenos Aires está compuesto por la Ciudad Autónoma de Buenos Aires (CABA) -que tiene 2.890.151 habitantes- y el Conurbano bonaerense, -de 9.916.715 habitantes-. Juntos se caracterizan por ser el principal aglomerado urbano del país.

La provincia posee en total 135 municipios o partidos, de los cuales la ciudad de La Plata es la capital. Esta se encuentra dentro de los principales centros urbanos, a la que se le suman Mar del Plata y Bahía Blanca-Ingeniero White. La primera por ser un centro turístico y pesquero relevante para el país y, la otra, por ser una zona portuaria, poseer un polo petroquímico y además, por ser la que limita con la región patagónica.

Además de la gran cantidad de habitantes, la importancia del área bonaerense con respecto al país se debe a la relevancia otorgada a la región que ocupa. Tal como explica Hugo Ratier (2009)

La región pampeana reviste inusitada centralidad en Argentina. Nuestra ciencia económica distingue entre economía pampeana y economías regionales. Esto implicaría que la pampa no es una región, más bien sería la Nación. También se habla de pampeano y extra-pampeano. Especies agrícolas no tradicionales en el país, son llamadas no pampeanas. En el territorio nacional existiría, entonces, un sector central definitorio del que se excluiría, bajo una denominación residual y unificadora, todo lo extra. Es más, cuando la economía capitalista de mercado avanza en una región, se habla de su pampeanización. (Ratier, 2009, p. 21. Cursivas del original)

Sin embargo, esta centralidad no impide que el área bonaerense (provincia y Capital) se componga de manera heterogénea (con zonas industriales y agrícolaganaderas; con diferencias entre el interior y el Área Metropolitana; los partidos del conurbano y CABA, etc.) y, al mismo tiempo, exista dentro de ella un alto grado de desigualdad y diversidad de modelos económicos, densidad poblacional, identidades, etc.

CABA se distingue por ser la capital del país, por lo que se constituye en sede de las instituciones del poder político, económico y cultural nacional, a la vez que en ella se concentran los principales medios de comunicación. Al mismo tiempo que es exaltada mediáticamente y se la convierte en expositora de la cultura argentina para el exterior, también es anfitriona de gran cantidad de visitantes y migrantes extranjeros. Geográficamente se identifica por la hiperurbanización y por la presencia de 
desigualdades socioeconómicas, las cuales se pueden observar en el contraste de los lujosos countries o barrios cerrados y las villas de emergencia.

Por su parte, los partidos del Conurbano bonarense albergan la mayor cantidad de habitantes de la provincia. Este sector históricamente se conformó a partir de la industrialización y de las diversas migraciones internas -de pobladores rurales y de habitantes de las provincias del interior a la capital-, y externas -de extranjeros provenientes de países vecinos (como Perú, Paraguay Bolivia)-.

A la par de que los medios de comunicación construyen una mirada negativa sobre este sector, los habitantes de esta región suelen ser trabajadores en CABA, por lo que diariamente deben hacer uso de transportes como trenes y colectivos para asistir a sus empleos, aunque la infraestructura vial no tenga las condiciones adecuadas.

Las ciudades intermedias son aquellas que poseen entre 50000 y menos de un millón de habitantes y se sitúan entre "lo metropolitano" y "lo rural". Entre ellas, se puede mencionar a Mar del Plata, Bahía Blanca, Tandil y Olavarría. Tal como expresa Ariel Gravano (2015), algunas de ellas son identificadas como centros urbanos y turísticos, al mismo tiempo que sus identidades se construyen históricamente: muchas de ellas constituyeron "ciudades de frontera" en el siglo XIX entre la campaña militar y los pueblos originarios y, posteriormente, naturalizaron el carácter étnico blanco a partir de la inmigración europea. De esta manera, la "negritud" es adjudicada a los barrios "mancha" (Gravano, 1996) que ocupan lo que antes era llamado "toldería".

Finalmente, los pueblos bonaerenses son aquellos que poseen menos de 50000 habitantes y, de acuerdo a Ratier (2009) pueden ser descritos a través de la economía agropecuaria; los paisajes de campo "abierto", con la presencia de calles y caminos que a veces no son referenciados en los mapas, además de ferrocarriles cerrados; la ruralidad presente en la actividad de baquianos y chacareros; la cultura gauchesca de los "paisanos"35; y la sociabilidad construida a través de instituciones como la cooperadora de la escuela, la sala de primeros auxilios, las comisiones de los clubes sociales y deportivos (y la actividad futbolística), las peñas folclóricas y las actividades organizadas por iglesias de diversas confesiones.

Al tener en cuenta estas escalas es posible acceder a la heterogeneidad que caracteriza a la provincia. En el caso de la escena estudiada estas diferencias se plasman en el desarrollo de un centro (el Área Metropolitana de Buenos Aires) y una periferia (el

\footnotetext{
${ }^{35}$ Este término es utilizado en la provincia de Buenos Aires para referirse a los trabajadores rurales.
} 
interior constituido por las ciudades intermedias y los pueblos). Dar cuenta de este último nivel es relevante porque, tal como expresa Ana Teresa Martínez, "Analizar la producción de un autor extracéntrico es también descubrir por entre medio de su palabra lo invisible para el centro, es decir aquello que se desprende de la particularidad del lugar." (Martínez, 2013, p. 177. Cursivas del original)

En el período comprendido para esta investigación (2011 a 2017), la provincia estuvo gobernada hasta el 10 de diciembre de 2015 por Daniel Scioli del Partido Justicialista, durante la presidencia de Cristina Fernández de Kirchner del Frente para la Victoria. El jefe de gobierno de la ciudad de Buenos Aires era Mauricio Macri y la vicejefa, María Eugenia Vidal, ambos del partido, en ese entonces, Propuesta Republicana (PRO).

A partir de dicha fecha hasta la actualidad, la gobernación de la provincia quedó a cargo de Vidal y Macri fue electo como presidente de la nación, los cuales forman parte del partido, Cambiemos. De manera que la jefatura de gobierno de la ciudad comenzó a estar a cargo de Horacio Rodríguez Larreta y Diego Santilli como vicejefe. El cambio de gobierno a nivel provincial significó la transformación radical de modelos político-económicos e ideológicos.

Con respecto a la cultura, de acuerdo al Atlas Cultural realizado en el 2013 por la Secretaría de Cultura de la Presidencia de la Nación y la Dirección Nacional de Industrias Culturales, basado en los datos aportados por el Sistema de Información Cultural de la Argentina ${ }^{36}$ (SInCA), es evidente la concentración de actividad cultural de CABA, a tal punto que "El nivel de aglomeración observado en esta área constituye una variable insoslayable para analizar cualquier aspecto de la realidad cultural regional y nacional" (Atlas Cultural, 2013, p. 170).

Esto se presenta, en primer lugar, en el presupuesto de la gestión pública cultural, el cual es mayor en CABA que en la provincia. Esto se debe a que

\footnotetext{
“(...) la primera posee un potencial económico que le permite recaudar una proporción elevada de recursos propios, mientras que la provincia debe responder a una enorme población distribuida en un inmenso territorio, con lo cual no sólo el gasto en cultural, según cantidad de habitantes es comparativamente menor, sino que también lo es en cualquier otra área." (Atlas Cultural, 2013, p. 164)
}

\footnotetext{
${ }^{36}$ Organismo dependiente del entonces Ministerio de Cultura de la Nación.
} 
Sin embargo, en los cordones más pobres del Gran Buenos Aires es pronunciado el déficit de cobertura e integración cultural, debido a la sobrepoblación, el hacinamiento y las malas condiciones de servicios públicos urbanos (Atlas Cultural, 2013, p. 162). A su vez, la provincia posee un total de 25 universidades públicas, de las cuales, 19 se ubican en el Área Metropolitana Bonaerense. También se destaca la influencia mediática de CABA por sobre la provincia, especialmente a través de la televisión y los periódicos. Por su parte, la radio y las estaciones repetidoras son los medios de comunicación que poseen mayor cobertura provincial.

Asimismo, Internet, otro modo expansivo de consumir capital cultural, se caracteriza por presentarse a través de 342 conexiones cada 1000 habitantes. Este número es casi 10 veces más que el registrado en el 2001. El acceso a Internet no solo se da por medio de la conexión fija residencial, sino también a través del acceso móvil por telefonía de datos y, en la actualidad, a través del sistema wi-fi. De acuerdo a los datos del 2013, CABA poseía más de una conexión a Internet por habitante.

En cuanto a los espacios de exhibición cultural, dentro de los cuales se encuentran los teatros, se destaca La Plata, CABA, Mar del Plata y Bahía Blanca. Con respecto a las fiestas y celebraciones populares, la distribución varía de acuerdo a la temática: los eventos cívicos e históricos se presentan en ciudades que poseen una fuerte historia colonial y poscolonial, como La Plata y CABA; las fiestas de tipo productivo se distribuyen más homogéneamente y se relacionan con la diversidad de producciones agropecuarias e industriales de la región; por su parte, las fiestas folclóricas que se realizan en Gran Buenos Aires se relacionan con los migrantes del interior del país y de países limítrofes, y las que se hacen en la costa atlántica son características de la temporada turística de verano.

En resumen,

La CABA cosmopolita, es el epicentro de las vanguardias estéticas y culturales, pero también capital de las bellas artes. El conurbano profundo es escenario de hibridación de valores y tradiciones populares de migrantes internos y de países limítrofes. El interior de la provincia, más detenida, aunque sin escapar de la modernidad cultural, es baluarte de tradiciones folclóricas y rurales. (Atlas Cultural, 2013, p. 162)

Con respecto a la música, de acuerdo a la Encuesta de Consumos Culturales y Entorno Digital realizada en el 2013 también por el SInCa, la provincia de Buenos Aires fue incluida dentro del diseño muestral correspondiente a la región Centro (junto con Córdoba, Entre Ríos y Santa Fé) y, por su parte, el Gran Buenos Aires fue vinculado a 
la región Área Metropolitana de Buenos Aires (AMBA). Esta encuesta fue realizada a habitantes de más de 12 años, residentes de ciudades de más de 30.000 habitantes. De acuerdo a estos datos, tanto AMBA como la región centro (que incluye a la provincia de Buenos Aires) se destacan por la escucha de rock extranjero y la asistencia a recitales internacionales.

\section{La conformación de un objeto de estudio}

A partir de los datos anteriormente descritos y una variada y amplia cantidad de fuentes y materiales empíricos, intentaré reconstruir la escena bonaerense de la música metal entre los años 2011 y 2017, anclándola en la circulación de algunos significados en común, representados en las producciones discursivas y performativas de la banda Hermética. Los códigos que plantea dicha agrupación se vinculan de manera directa con los que proponen el rock y el metal a nivel global, pero también con los significados provenientes de otras formas culturales argentinas.

En el primer caso, como ya mencioné, de acuerdo a Weinstein (2000) y Walser (2014) lo que caracteriza al metal es la expresión de poder, la que se enlaza mayormente con diferentes formas de poder ligadas a lo masculino. Para dicha autora, este significado se representa tanto en la dimensión musical, como en la visual y en la verbal.

En la primera de ellas, a través del volumen alto, la estridencia de la guitarra eléctrica, el estruendo de la batería, la pesadez del bajo eléctrico y la capacidad de la voz expresar emocionalidad (Weinstein, 2000, p. 27). En la segunda, por medio de las tipografías angulosas de los logotipos, la predominancia del color negro y las portadas de los discos con imágenes que sugieren caos o representan algo ominoso, inquietante o grotesco (Weinstein, 2000, p. 29). Y en la última, mediante los nombres de las bandas y los títulos de los discos que aluden a imágenes ominosas y con las temáticas de las canciones que Weinstein separa en dionisíacas y caóticas.

Hermética no solo hace uso del código del heavy metal tradicional tal como lo describe Weinstein, sino que además forma parte de la tendencia fundamentalista del metal y, por medio del thrash metal, acentúa algunos aspectos de dicho conjunto de significados, los cuales serán analizados con mayor profundidad en el desarrollo de esta tesis. Por otro lado, la banda se caracteriza por la conformación de discursos que, más allá de dar cuenta del carácter transcultural del metal, intentan exaltar una forma de identidad local argentina. Esta conexión geográfica permite que se permeen contenidos 
políticos, los cuales a su vez están vinculados con el contexto histórico de su momento de producción.

El período elegido comienza en el 2011, año en que se vuelve a reunir Malón, agrupación que fue formada por O'Connor, Romano y Strunz junto al bajista Carlos Cuadrado, luego de la disolución de Hermética. Con esta formación el grupo duró hasta 1998, período en el cual grabaron dos discos: Espíritu Combativo (1995) y Justicia o resistencia (1996). En el 2001 tuvieron un regreso temporal con Eduardo Ezcurra como cantante. Sin embargo, no tuvieron éxito, por lo que cada uno siguió su carrera de manera individual. A pesar de ello, en el año 2011 decidieron volver a reunirse y mantener su carrera hasta la actualidad, ahora sí logrando la masividad.

Por su parte, Iorio formó Almafuerte ni bien se separó Hermética junto el guitarrista Claudio Marciello y el baterista Claudio Cardaci. Con una variación de miembros (lo que incluye un bajista, ya en que en cierto momento Iorio decidió dedicarse exclusivamente a la composición y al canto) y la edición de 8 discos de estudio, 5 en directo, uno recopilatorio y un DVD, el grupo se separó en el año 2016 luego de diferencias entre Iorio y el manager, Marcelo Caputo.

De manera inmediata, el cantante armó su banda solista, en la cual incluyó a los hermanos Walter y Rubén Martínez, en batería y guitarra (ambos ex integrantes de Vórax); los hermanos Alejo y Facundo León, en guitarra y bajo; la tecladista, Joana Gieco, y la guitarrista invitada, Carina Alfie.

En esta banda la intención de revalorizar la identidad argentina que había comenzado con Hermética y se había desarrollado con Almafuerte, se agudiza al punto de tomar connotaciones del nacionalismo de derecha, las cuales se presentan principalmente en los elementos extra-musicales vinculados con la escenografía de los shows en vivo y los modos de difusión y, principalmente, con el propio Iorio, en su canal de YouTube y sus declaraciones en entrevistas en medios radiales y televisivos.

El año 2017, en el cual finaliza el período de análisis, resulta crucial por dos eventos: en primer lugar, Iorio aparece en una fotografía saludando al líder político filonazi del partido Bandera Vecinal, Alejandro Biondini. Este hecho despierta un fuerte repudio en el público, así como también un gran apoyo, el cual se incrementa en el momento en que la organización del festival B.A. Rock decide quitar a Iorio de la programación, debido a amenazas de escrache realizadas por organizaciones políticas vinculadas a la lucha por los derechos humanos y de ideología de izquierda. 
En segundo lugar, los miembros de Malón deciden realizar una gira de shows por el 30 aniversario del disco Ácido Argentino, lo cual despierta tanto elogios como críticas por parte del público, pero también un gran respaldo por parte de los medios hegemónicos especializados. Ambos sucesos marcan una fuerte división dentro de la escena metálica, especialmente los relacionados con Iorio, ya que tienen una connotación explícitamente política ${ }^{37}$. A continuación, daré cuenta del marco teórico metodológico en el cual me basé para el análisis.

${ }^{37}$ Más adelante, me detendré en la explicación del lugar y la forma que ocupa lo político dentro de la escena. 


\section{Propuesta teórico-metodológica}

\section{Principales líneas teóricas}

\section{Los estudios sociales y culturales de la música}

La música como objeto de estudio posee diversas formas de ser abordada. En primer lugar, la musicología se encarga principalmente de analizar los elementos compositivos. Por su parte, la etnomusicología surgió de manera posterior a partir de la necesidad de estudiar a la producción de manera situada, es decir, en determinadas culturas y etnias, contemplando así a las músicas no occidentales, las cuales hasta entonces habían sido ignoradas por la musicología.

Más tarde, fue la sociología la que comenzó a estudiar a los elementos extramusicales y su relación con el contexto, debido a que, tal como plantea Antoine Hennion (2002), la música se presenta como un objeto de estudio problemático porque resulta “(...) imposible de fijar materialmente. Obligada una y otra vez a hacer que aparezca, acumula intermediarios, intérpretes, instrumentos y soportes, necesarios para su presencia en medio de músicos y oyentes” (Hennion, 2002, p. 15).

Dentro de los principales estudios sociales de la música popular, en apartados previos fueron destacadas las investigaciones provenientes de los Estudios Culturales las que a partir de la noción de "estilo" dieron cuenta de la agencia de los oyentes. En esta línea, también se encuentran los trabajos de la socióloga, Tia DeNora (2000, 2003), quien toma la noción de affordance ("habilitación”) del psicólogo, J.J. Gibson (1966), para mostrar cómo

La música puede, en otras palabras, invocarse como un aliado para una variedad de actividades creadoras de mundos, es un espacio de trabajo para la actividad semiótica, un recurso para hacer, ser y nombrar los aspectos de la realidad social, incluidas las realidades de la subjetividad y el yo (...) (DeNora, 2000, p. 40)

Esta autora se encarga así de rescatar la agencia de los oyentes ${ }^{38}$, al intentar comprender cuáles son los usos que hacen de la música y cómo entran en acción por medio de ella en contextos específicos. De esta manera, “(...) la música es mucho más que un 'reflejo' estructural de lo social" (DeNora, 2003, p. 57), ya que se trata de un

\footnotetext{
${ }^{38}$ Esta perspectiva se encuentra en consonancia con los estudios de la recepción tanto desde el campo de la Comunicación como de la Literatura.
} 
poderoso agente social que en circunstancias específicas actúa sobre los oyentes provocando conductas y permitiendo la creación de identidades y subjetividades (DeNora, 2000).

Desde la perspectiva de los estudios de la Comunicación, la música resulta significativa tanto por su capacidad de actuar como medio para la interacción social, así como también por su función de producir sentido cultural y por la industria cultural que la rodea. James Lull (1985) afirma que

La música es comunicación en el sentido de que la música grabada o ejecutada públicamente habla directamente a la sociedad como una forma cultural. Las expresiones musicales son mensajes simbólicos significativos. La música también afecta la comunicación. Facilita la interacción diádica y de grupos pequeños, en grandes reuniones sociales como fiestas, en la danza social y en las relaciones sexuales, entre otros contextos. Las capacidades de la música de alterar el estado anímico pueden intensificar o reducir de diversas maneras la actividad personal o social. (Lull, 1985, p. 364. T de la A. Cursivas del original)

Para este autor, la música no solo es una fuente de entretenimiento, sino que también cumple el rol de agente de utilidad social. Esto resulta similar a los postulados del comunicólogo español, Miguel de Aguilera (2008), quien considera que la música ha sido “(...) expresión de colectivos sociales, manifestación cultural de modos de vida (...)” (de Aguilera, 2008, p. 36). Esta caracterización de la música como medio de expresión social y cultural, conduce a buscar marcos conceptuales que den cuenta de ello.

\section{La teoría de la escena musical}

Entre los enfoques teóricos socio-culturales de la música, se puede mencionar a la noción de escena musical, acuñada primeramente por el comunicólogo canadiense, Will Straw $(1991,1997,2006,2013)$. La primera versión de esta teoría fue presentada en el congreso "The Music Industry in a Changing World", realizado en el otoño de 1990 por el Centro de Investigación en Cultura y Sociedad de la Universidad de Carleton en Ottawa, Canadá.

Las discusiones de dicha reunión académica giraban principalmente en torno a la globalización y sus consecuencias, tales como las migraciones, las diásporas, la intensificación de los medios de comunicación, la conexión entre las culturas locales y el mundo global, y la circulación en red de la música. Estas temáticas se encontraban estrechamente vinculadas con su contexto, el cual se caracterizaba por la presencia tanto 
de movimientos localistas de resistencia frente al orden global, como de afirmaciones cosmopolitas.

Posteriormente, en 1991, los trabajos allí presentados fueron publicados en un número especial dedicado a la música popular de la revista, Cultural Studies. Dicho volumen fue co-editado por John Sphered y Will Straw. Allí fue publicado por primera vez el trabajo de Straw titulado "Systems of articulation, logics of change: communities and scenes in popular music". Luego, en 1997, una versión más sintética de esta ponencia fue incluida en el libro The Subcultural Reader, dirigido por Ken Gelder y Sarah Thornton.

En estas primeras formulaciones de la teoría, Straw se basa en los aportes de Barry Shank, quien utilizó al concepto "escena" de manera académica para referirse a la comunidad del rock de Austin. Sin embargo, Straw encuentra ciertas limitaciones a la idea de "comunidad", por lo que prefiere definir a la escena musical como un espacio cultural demarcado geográfica e históricamente en el cual coexisten prácticas musicales que interactúan de múltiples formas, a través de diversas trayectorias de cambio y enriquecimiento mutuo (Straw, 1991).

Con esta definición, Straw intenta proponer que el sentido de comunidad es consecuencia de la actividad de la escena. Además, el autor hace hincapié en las formas de comunicación que se producen allí y las caracteriza a través de la unión afectiva entre las prácticas musicales contemporáneas y la herencia musical (Straw, 1991, p. 373). Esta variación en lo histórico se apoya en las tensiones geográficas que suponen el vaivén entre lo local y lo global. Straw aclara que:

(...) esta distinción simplemente concreta dos presiones compensatorias dentro de los espacios de actividad musical: una hacia la estabilización de las continuidades históricas locales y otra que trabaja para interrumpir tales continuidades para cosmopolitizar y relativizarlas. (Straw, 1991, p. 373. T. de la A.)

De esta manera, utiliza diversas teorías para proponer que las escenas se encuentran inmersas en el contexto de la globalización, el cual es referido por Edward Said (1990) como un "creciente sistema universal de articulación” que transformaba el estado de lo local en las sociedades contemporáneas.

Por otra parte, las escenas se articulan con tres lógicas de cambio: una, derivada de la perspectiva bourdieana de campo que manifiesta que las contradicciones ideológicas se resuelven en favor de unas sobre otras; otra, que utiliza las nociones de 
Bernard Miège para explicar el valor de los productos culturales en el proceso de canonización; y por último, la que deriva del concepto de lógica de Michel de Certau y da cuenta de dos procesos sociales: la lucha por el prestigio y las transformaciones en las relaciones sociales y culturales.

En el artículo titulado "Scenes and sensibilities" (2006), Straw caracteriza a la escena musical como un concepto abstracto y anti-esencializante que permite etiquetar unidades culturales que poseen límites variables. Esto les permite a los investigadores dar cuenta de una determinada coherencia entre ciertas prácticas culturales por medio de un marco teórico flexible, a diferencia de nociones anteriores más estáticas como clase o subcultura (Straw, 2006). En este sentido, el autor destaca que "Al mismo tiempo, la escena parece capaz de evocar tanto la intimidad de la comunidad como el cosmopolitismo fluido de la vida urbana” (Straw, 2006, p. 248. T. de la A.).

De esta manera, la escena se define a través de: a) la recurrente congregación de personas en un lugar particular; b) el movimiento de esa gente entre ese lugar y otros espacios; c) las calles o zonas en las cuales se produce ese movimiento; d) todos los lugares y actividades que rodean y nutren una preferencia cultural particular; e) el fenómeno más amplio y más geográficamente disperso de las cuales ese movimiento o esas preferencias son ejemplos locales; f) las redes de actividad microeconómica que permiten la sociabilidad y ligan esa escena a la ciudad (Straw, 2001).

En este nuevo trabajo, Straw hace hincapié en el carácter urbano del concepto escena musical. Es por ello que aclara que "A través de ella, es posible vislumbrar una cartografía de las regiones sociales de la ciudad y su interconexión. En este sentido, 'escena' es un recurso en la elaboración de una gramática de ordenamiento cultural" (Straw, 2006, p. 250. T de la A.). Pero la teoría no se limita a la descripción de una ciudad, sino que su flexibilidad le permite estudiar tanto grupos de escala local como global, así como el contacto cara a cara como la interacción mediatizada (Straw, 2006, p. 248).

En el 2013, Straw publica "Cenas Culturais e as consequências imprevistas das políticas públicas", el cual se encuentra incluido en el libro Cenas Musicais (2013), editado por los brasileños, Simone Pereira de Sá y Jeder Janotti Junior. En este capítulo, Straw vuelve a destacar el carácter urbano del término escena, pero realiza una apertura al utilizarlo para todas las unidades culturales no solo las que están relacionadas con la música. Por el contrario, ésta solo constituye la forma con la que más comúnmente se identifica a la escena en tanto concepto teórico. De esta manera, 
Escena constituye y designa determinados conjuntos de actividad social y cultural sin especificación en cuanto a la naturaleza de las fronteras que los circunscriben. Las escenas pueden ser distinguidas de acuerdo con su localización (como en la escena de St. Laurent en Montreal), el género de la producción cultural que les da coherencia (un estilo musical, por ejemplo, como en las referencias a la escena electroclash), o de la actividad social vagamente definida en torno de la cual ellas toman forma (como las escenas urbanas de juego de ajedrez al aire libre). Una escena nos invita a mapear el territorio de la ciudad de nuevas maneras en tanto, al mismo tiempo, designa ciertos tipos de actividad cuya relación con el territorio no es fácilmente demostrada (Straw, 2013, p. 12. T de la A. Cursivas del original).

En esta nueva formulación, Straw le presta atención a la interacción realizada en el interior de las escenas como formas de "interacción urbana móvil" (Straw, 2013, p. 14) y en su acción transformadora sobre las ciudades. Es por ello que se encarga de estudiar las tensiones que se producen con las políticas públicas de dichos lugares. Sobre esto finalmente concluye en que las escenas, al surgir como formas de vida colectiva, aprovechan los espacios de las ciudades de manera activa por medio de la búsqueda creativa de oportunidades. De esta manera, cualquier tipo de política pública va a colaborar de alguna manera en la conformación de esos lugares (Straw, 2013, p. 22).

A la teoría de la escena musical se le han realizado gran cantidad de críticas, las cuales conducían a dos caminos: por un lado, las que solo señalaban las confusiones y limitaciones de la categoría teórica (Hesmondhalgh, 2015, p. 184); y por el otro, las que a partir de observaciones similares proponían una reformulación. En esta senda se encuentran numerosos estudios que ponen en la balanza diferentes aspectos de la teoría formulada inicialmente por Straw.

En primer lugar, la preocupación se extendió desde lo geográfico hacia el desarrollo virtual de las escenas. Los primeros en dar cuenta de ello fueron Andy Bennett y Richard Peterson (2004). Desde una perspectiva tricotómica, estos autores examinan la vida musical y sus formas de producción y consumo. Para ello proponen tres tipos generales de escenas: las escenas locales, que se refieren a las formas de agruparse en torno a un foco geográfico específico; las translocales, que son escenas locales diseminadas que se comunican en torno a un estilo de música particular; y las virtuales, que se constituyen como formas emergentes en las que las personas dispersas en grandes espacios físicos crean el sentido de escena de Internet y otros medios alternativos como los fanzines. 
En esta primera perspectiva, Bennett y Peterson (2004) limitaban a las escenas virtuales a la comunicación que se daba únicamente de manera online entre fans que se encontraban dispersos geográficamente alrededor del mundo (2004: 10). Sin embargo en el trabajo publicado en el 2016 por Bennett junto a Ian Rogers, titulado Popular Music, Scenes and Cultural Memory, se reconoce que la hipótesis anterior no era correcta, ya que en este nuevo estudio lograron aproximarse a las escenas virtuales como intersecciones entre las locales y las translocales y como extensiones de la comunicación cara a cara.

Para ello tomaron como ejemplo la plataforma, YouTube y la red social, Facebook. De acuerdo a los autores, la primera funcionaba como un espacio para archivar grabaciones y como un índice de videos, tal como la televisión. Por su parte, la sección de eventos de la segunda servía como un mecanismo de promoción de conciertos y recitales y como un recordatorio de dichas actividades.

De esta manera, la comunicación virtual no reemplazaba la personal, sino que la coordinaba. En este número, Bennett y Rogers también utilizan las nociones de memoria cultural y geografía emocional para abordar los aspectos intangibles de la escena (vinculados con lo afectivo) y la forma en que las características del presente se articulan con las del pasado.

De manera similar al trabajo de Bennett y Rogers (2016), la comunicóloga brasileña, Simone Pereira de Sa (2013) considera a Internet como un ambiente, de manera que “(...) las escenas musicales pueden ser mejor entendidas como redes sociotécnicas, constituidas por múltiples mediadores que atraviesan incesantemente las fronteras del mundo offline y online" (Pereira de Sa, 2013: 37. T. de la A. Cursivas propias). Otro aporte de esta autora fue tomar la teoría de Straw (2006) de las escenas musicales como gramáticas urbanas y considerar que dentro de ellas también trabajan las reglas de los géneros musicales, las cuales allí no solo son enseñadas sino también actualizadas.

Otras reformulaciones provenientes de América Latina vienen de la mano de Julio Mendívil y Christian Spencer Espinosa (2016), quienes consideran que aquí las escenas musicales poseen ciertas particularidades que las diferencian de las anteriores perspectivas anglo-americanas. Un ejemplo de ellas es que las escenas no solo se desarrollan en espacios metropolitanos sino también en comunidades rurales, en donde la música también se conecta con modos de socialización previos a la urbanización. Además, aquí también aparecen formas económicas alternativas y el uso del lenguaje 
nativo para la creación de la estética local. Por otra parte, los autores consideran que además de estudios etnográficos del presente, las escenas latinoamericanas requieren que también sean observados sus cambios históricos (Mendívil y Spencer Espinosa, 2016).

De manera similar, los brasileños, Jorge Cardoso Filho y Luciana Xavier de Oliveira (2013), hacen hincapié en los cambios producidos dentro de las escenas a lo largo del tiempo. Para ello proponen el uso de las nociones historiográficas de Reinhart Koselleck (2006), espacio de experiencia y horizontes de expectativas, entendidas como categorías metodológicas que permiten entender a la escena musical como fenómeno configurado a partir de expectativas, propuestas y proyecciones en el largo plazo que son resultado de experiencias anteriores.

Por su parte, Jeremy Wallach y Alexandra Levine (2013) proponen una teoría general que consideran que puede ser utilizada para estudiar la formación de todas las escenas de la música metal a lo largo del planeta. Estos autores utilizan la noción de "replicación" de Greg Urban (2001) para afirmar que mediante este mecanismo todas las escenas metálicas del mundo poseen las mismas dinámicas escénicas e instituciones. Este proceso se vincula de manera estrecha con la circulación cultural en el mundo global, tal como lo planteaba Straw. Sin embargo, es necesario revisar si tal procedimiento solo conduce a una mirada etnocéntrica del fenómeno al utilizar la noción de replicación con el sentido de "imitación”.

Tomando todas estas trayectorias, considero que el uso de la categoría escena musical es pertinente para esta investigación, debido a que permite realizar una delimitación histórica y geográfica del objeto de estudio. Pero es necesario destacar que a lo largo del trabajo empírico logré construir mi propia reformulación: la escena de la música metal de la provincia de Buenos Aires no se limita a sus fronteras geopolíticas, sino que se encuentra en permanente diálogo con otras ciudades, provincias y otros países, por lo que se trata de una escena translocal.

Por otra parte, no solo da cuenta de una cartografía urbana de los circuitos de producción, circulación y consumo del género musical, sino que también permite ver de qué manera se desarrollan diferentes lógicas vinculadas con la idea de intercambio de capital cultural. En ese sentido, la escena parece emerger tanto cuando se encuentran dos o más agentes e interactúan en torno al metal, como cuando un miembro escucha o ejecuta metal en la intimidad de su casa. Esto se podría conectar con la aplicación de la noción de escena para el estudio del metal extremo que realizó Keith Kahn-Harris 
(2007), en la cual investiga a las instituciones, la infraestructura, los participantes de la escena y sus relaciones como un todo, es decir, mediante una concepción holística ${ }^{39}$.

De manera similar a las afirmaciones de Mendívil y Spencer Espinosa (2016), la escena metálica bonaerense no se limita al desarrollo urbano, sino que también dialoga fuertemente con la cultura rural; y además de desplegarse de manera virtual, utiliza en gran medida formas de comunicación pre-urbanas como el boca en boca y medios alternativos como los fanzines en versión impresa.

Por otra parte, las lógicas de la escena que podrían considerarse como centro y periferia, no solo se observan en la forma de distribución económico-cultural que caracteriza al área bonaerense, sino también en los códigos que la estructuran. De esta manera, la gramática que proponía Straw no solo podría trazarse como una cartografía sino también como una red de sentidos que configuran a la escena como una unidad cultural que se visibiliza a partir de la acción y la interacción de sus agentes. Los cuales también pueden ser analizados como miembros centrales y periféricos al tener en cuenta sus diversos desarrollos y aportes personales.

Es por ello que se postula la necesidad de articular la teoría de las escenas musicales con las nociones de semiosfera de la Semiótica de la Cultura de Iuri Lotman (1996) y de campo cultural de Pierre Bourdieu (1995). A continuación sintetizaré los principales postulados de ambas teorías que apoyan esta investigación

\section{La semiosfera y la Semiótica de la Cultura}

La teoría del semiólogo ruso proveniente de la Escuela de Tartu, Iuri Lotman, resulta productiva para este estudio porque de manera similar al concepto de escena, la noción de semiosfera se define como un espacio cerrado de carácter abstracto pero no metafórico. Según Lotman (1996), sólo dentro de él “(...) resultan posibles la realización de los procesos comunicativos y la producción de nueva información" (Lotman, 1996, p. 11). Es decir, que solo dentro de ella es posible la existencia de la semiosis.

La semiosfera posee dos rasgos distintivos: primero, tiene un carácter delimitado con respecto al espacio extrasemiótico o alosemiótico que está a su alrededor. Por ello

\footnotetext{
${ }^{39}$ La perspectiva holística le permite al autor estudiar al metal extremo como un todo. De esa manera "El holismo proporciona una perspectiva que reconoce la interconexión entre los diferentes elementos de los fenómenos sociales y que evita la fragmentación del área temática que han sufrido los estudios del metal. (...) en términos holísticos, el metal extremo debe ser considerado como el lugar para una gran variedad de prácticas interconectadas, textos, instituciones y fenómenos sociales." (Kahn-Harris, 2007, p. 11. T. de la A)
} 
es importante el concepto de "frontera", la cual "(...) es un mecanismo bilingüe que traduce los mensajes externos al lenguaje interno de la semiosfera y a la inversa" (Lotman, 1996, p. 14). De cierta manera, su función es la de separar lo propio de lo ajeno, para filtrarlo, traducirlo y elaborarlo para adaptarlo al lenguaje interno. En este sentido, Lotman (1996) afirma que "La cultura crea no solo su propia organización interna, sino también su propio tipo de desorganización externa” (Lotman, 1996, p. 15).

El segundo rasgo distintivo de la semiosfera es la irregularidad semiótica. Esto significa que "El espacio semiótico se caracteriza por la presencia de estructuras nucleares (con más frecuencia varias) con una organización manifiesta y de un mundo semiótico más amorfo que tiende hacia la periferia, en el cual están sumergidas las estructuras nucleares" (Lotman, 1996, p. 16). A pesar de esta división, para Lotman no existe jerarquía dentro de los niveles, sino que ellos se chocan y mezclan.

Pero aclara que "En el núcleo se disponen los sistemas semióticos dominantes" (Lotman, 1996, p. 17). Estos realizan una autodescripción, es decir, funcionan como un metalenguaje que describe a la totalidad de la semiosfera -que incluyendo el espacio periférico- y construye la unidad ideal de ella (Lotman, 1996, p. 16).

De esta manera, "La diversidad interna de la semiosfera presupone la integralidad de esta. Las partes no entran en el todo como detalles mecánicos, sino como órganos de un organismo" (Lotman, 1996, p. 17). Esto demuestra la propiedad del isomorfismo, mediante el cual los niveles “(...) son al mismo tiempo parte del todo y algo semejante a él” (Lotman, 1996, p. 18). Esto reemplaza la noción de transmisión entre niveles, por la de intercambio.

De esta manera, es posible considerar que en la escena metálica bonaerense aparecen estructuras nucleares y periféricas. Esta idea de un centro de significado en torno al cual gravita la producción, circulación y consumo de la música metal es similar al postulado de Deena Weinstein (2000), quien considera que el corazón del metal se constituye no solo de manera musical, sino también visual y verbalmente. Dicho código central se caracteriza por la representación social y cultural de conceptos, imágenes y experiencias de $\operatorname{poder}^{40}$ (Walser, 2014, p. 2; Weinstein, 2000).

Esto permitiría postular la primera hipótesis: en la escena metálica bonaerense las estructuras nucleares de significado parecen estar articuladas en las producciones musicales, verbales y visuales de la banda Hermética. Las mismas podrían sintetizarse

\footnotetext{
${ }^{40}$ Sobre estas construcciones me explayaré más adelante.
} 
en torno a algunos ejes fundamentales para la estructuración de la escena: el thrash metal (y, por lo tanto, la corriente fundamentalista del metal); la masculinidad y la ética patriarcal; y la evocación de ideologías nacionalistas. Además, dicho núcleo es desarrollado por los músicos, productores e intermediarios consagrados (canónicos) y alzado como estandarte por los participantes más conservadores y ortodoxos de la escena.

Por su parte, las estructuras periféricas están constituidas por los participantes de la escena que dialogan con otras semiosferas, tales como el Folklore argentino; el rock; las culturas nórdicas y medievales; el tango; las culturas gótica y emo; la música electrónica; las prácticas deportivas del skate y el BMX; las artes marciales; los comics y el manga; el cine, las series y las literaturas de terror, fantástica y de ciencia ficción; los juegos de rol y videojuegos; etc. Dicha periferia en gran parte de los casos está constituida por los agentes más novatos de la escena que, en muchos casos, son los más jóvenes. $^{41}$

De acuerdo a esta teoría, para Lotman (1996) la cultura se caracteriza por ser políglota, en el sentido de que no es homogénea. Se compone por múltiples lenguajes y el diálogo entre sus diversos niveles. El autor sugiere que la comunicación es el mecanismo por medio del cual se produce cultura. Los textos, entonces, no solo son mediadores sino que también se caracterizan por ser polisémicos, por sus relaciones intertextuales y por no solo transmitir significados sino también generarlos a través de la presencia necesaria de un interlocutor. Esta caracterización resulta pertinente para el abordaje del objeto como una escena musical, la que tampoco se compone de manera homogénea y también emerge a través de la interacción entre sus agentes y sus producciones.

\section{El campo cultural}

Por su parte, el sociólogo francés, Pierre Bourdieu (2005) explica que el campo "(...) no es ni un $<<$ medio $>>$ en el sentido vago de $<<$ contexto $>>$ o de $<<$ social background $>>$ ”, es decir el "(...) universo de relaciones personales entre los artistas o los escritores" (Bourdieu, 1990, p. 2. Cursivas del original). Más bien, lo define como

\footnotetext{
${ }^{41}$ Los elementos de las semiosferas que dialogan con la escena del metal son traducidos e incorporados a esta en su propio lenguaje. Este proceso de re-significación se puede vincular con las ideas de "bricolage cultural" de Levi-Strauss (1995), "estilo" de Dick Hebdige (2004), "hibridación" de Néstor García Canclini (2012) y Motti Regev (2013); y "performance” de Richard Schechner (2011).
} 
(...) un campo de fuerzas que se ejercen sobre todos aquellos que penetran en él, y de forma diferencial según la posición que ocupan (...), al tiempo que es un campo de luchas de competencia que tienden a conservar o a transformar ese campo de fuerzas. Y las tomas de posición (obras, manifiestos o manifestaciones políticas, etc.), que se pueden y deben tratar como $<<$ sistema $>>$ de oposiciones para las necesidades del análisis, no son el resultado de una forma cualquiera de acuerdo objetivo, sino el producto y el envite de un conflicto permanente. Dicho de otro modo, el principio generador y unificador de este $<<$ sistema $>>$ es la propia lucha. (Bourdieu, 2005, p. 345)

De esta manera, un campo cultural es definido por el capital cultural que está en juego en esa lucha de posiciones que, en este caso, es la música metal. Bourdieu aclara que "Para que funcione un campo, es necesario que haya algo en juego y gente dispuesta a jugar, que esté: dotada de los habitus que implican el conocimiento y reconocimiento de las leyes inmanentes al juego, de lo que está en juego, etcétera." (Bourdieu, 2002, p. 120. Cursivas del original.) Esas luchas se producen tanto por la legitimación de dicho capital, como por la conservación o la subversión de la distribución de dicho capital:

Aquellos que, dentro de un estado determinado de la relación de fuerzas, monopolizan (de manera más o menos completa) el capital específico, que es el fundamento del poder o de la autoridad específica característica de un campo, se inclinan hacia estrategias de conservación -las que, dentro de los campos de producción de bienes culturales, tienden a defender la ortodoxia-, mientras que los que disponen de menos capital (que suelen ser también los recién llegados, es decir, por lo general, los más jóvenes) se inclinan a utilizar estrategias de subversión: las de la herejía. (Bourdieu, 2002, p. 121. Cursivas del original)

Es así que las oposiciones que se dan dentro de un campo, de acuerdo a Bourdieu (2005) pueden representarse como "dominante/dominado, consagrado/novato, ortodoxo/hereje, viejo/joven, etc.” (p. 355).

En el caso de la escena metálica bonaerense, lo que está en juego no solo es el capital cultural (que posee un mercado específico) sintetizado en la música metal, sino también el capital social (la interacción social) y el capital simbólico (el que supone reconocimiento y consagración, además de la legitimidad que otorgan ciertas formas de “autenticidad metálica").

Al tener en cuenta que el campo se caracteriza por la distribución desigual del capital y por la lucha entre posiciones dominantes y dominadas, es posible ver que en el objeto de estudio de esta tesis dichos lugares no solo se encuentran ocupados por los productores (por ejemplo, los músicos), sino también por los consumidores y los 
mediadores. Inclusive, estos puestos se presentan de manera dinámica, ya que los agentes no ocupan dichos roles de manera fija y, en muchos casos, lo hacen con más de uno.

De acuerdo a Bourdieu,

El envite de las luchas de definición (o de clasificación) consiste en fronteras (entre los géneros o las disciplinas, o entre los modos de producción dentro de un mismo género) $\mathrm{y}$, con ello, en jerarquías. Definir las fronteras, defenderlas, controlar las entradas, significa defender el orden establecido en el campo. (2005, p. 334)

Esta idea de fronteras es similar a la propuesta de semiosfera de Lotman. Según Bourdieu, los campos culturales se encuentran en constante redefinición y

Una de las propiedades más características de un campo es el grado en que sus límites dinámicos se extienden tan lejos como alcanza el poder de sus efectos, son convertidos en frontera jurídica, protegida por un derecho de entrada explícitamente codificado (...). Un alto grado de codificación de ingreso en el juego, va parejo con la existencia de una regla del juego explícita y de un consenso mínimo sobre esta regla; por el contrario, a un grado de codificación débil corresponden unos estados de los campos donde la regla de juego está en juego dentro del juego. (2005, p. 335)

En el caso de la escena metálica bonaerense, existe un alto grado de codificación. Sin embargo, posee límites dinámicos tal como Bourdieu propone en su idea de campo. Debido a esto, se puede trazar un paralelo con la noción de traducción de la semiosfera y de flexibilidad de la escena musical. De manera que los tres conceptos permiten dar cuenta del carácter dinámico del objeto de estudio, a pesar de que el núcleo de la escena se caracteriza por ser conservador y porque, en el caso del metal, la vigilancia de dichas fronteras es más intensa que las escenas de otros géneros musicales (Wallach y Levine, 2013, p. 124). Esta intención se puede vincular con el grado de autonomía del campo.

También es necesario precisar que el corte temporal elegido (2011 a 2017), permite dar cuenta de modificaciones en el interior de la escena, de las cuales una de ellas corresponde con el pasaje de la reflexividad propia de los críticos musicales y periodistas especializados hacia una reflexividad que se caracteriza por ser "académica" o "intelectualizada":

La evolución del campo de producción cultural hacia una mayor autonomía va acompañada así de un movimiento hacia una mayor reflexividad, que lleva a cada uno de los $<<$ géneros $>>$ a una especie de retroceso crítico sobre sí mismo, sobre su propio 
principio, sus propios presupuestos (...) A medida que el campo se cierra sobre sí mismo, el dominio práctico de las experiencias adquiridas específicas de toda la historia del género, están objetivizadas en las obras pasadas y registradas en ellas, canonizadas por todo un cuerpo de profesionales de la conservación, y de la celebración, historiadores del arte y de la literatura, exegetas, analistas, forma parte de las condiciones de ingreso en el campo de producción restringida. (Bourdieu, 2005, p. 360)

Este abordaje de la escena como un campo se inspira, en parte, en el trabajo ya citado de Kahn-Harris (2007), quien observa a ambos términos de manera análoga y considera que el campo es una “(...) herramienta para examinar las múltiples formas en las cuales el poder es reproducido a través de la infraestructura de la escena del metal extremo" (Kahn-Harris, 2007, p. 69. T. de la A.)

Mediante el concepto de campo, el autor logró dar cuenta de cuáles eran las posiciones dominantes dentro de la escena global del metal extremo. Con respecto a los participantes, estaban principalmente ocupadas por hombres blancos heterosexuales, pero dicho lugar no estaba determinado por diferencias económicas. Al mismo tiempo, al tener en cuenta la distribución del capital de las escenas de diversos lugares del mundo, observó un centro y una periferia que se vinculaba con diferencias de construcción y estructura pero que no reproducían las desigualdades inherentes del capitalismo global (Kahn-Harris, 2007, p. 97).

Otro autor que es deudor de la teoría bourdieana y cuyos postulados resultan operativos para esta investigación es Motti Regev (2013), quien utiliza la noción de campo para comprender las formas de reconocimiento y prestigio que se presentan dentro de la producción del pop-rock ${ }^{42}$.

En primer lugar, afirma que los actores de esta forma musical son movilizados a sí mismos para ocupar de manera simultánea dos campos de producción cultural: la del campo global del pop-rock y la del campo de la cultura nacional en la que se sitúan, lo que genera como consecuencia la existencia del cosmopolitismo estético (Regev, 2013, p. 13), una cultura mundial. En este sentido,

\footnotetext{
${ }^{42}$ Regev (2013) define al pop-rock como la “(...) música conscientemente creada y producida mediante el uso de amplificación, instrumentos eléctricos y electrónicos, sofisticados equipos de grabación (incluyendo samplers), mediante el empleo de ciertas técnicas de expresión vocal supuestamente sin experticia, principalmente aquellas que significan inmediatez de expresión y espontaneidad, y filtrando todo esto a través de la edición de sonido, modificación y dispositivos de manipulación. (...) La música pop-rock es principalmente una creación de maquinarias de grabación en estudios y otros lugares, destinada principalmente a fonogramas (y su mutación como archivos de computadora). El uso de este conjunto de prácticas convierte a todos los estilos de los participantes del pop-rock en un solo idioma sónico, en un solo sistema semiótico." (p. 18)
} 
(...) cosmopolitización estética refiere a la formación en marcha, en la modernidad tardía, de la cultura mundial como una entidad interconectada complejamente, en cuyas agrupaciones sociales de todos los tipos alrededor del mundo comparten cada vez más amplios campos comunes en sus percepciones estéticas, formas expresivas y prácticas culturales. Cosmopolitismo estético refiere a la cultura mundial singular ya existente, al estado de asuntos alcanzado siguiendo lo anterior (Regev, 2013, p. 3. T. de la A. Cursivas del original.)

Por otra parte, el autor percibe varios subcampos que son los que corresponden a los géneros musicales: el hip hop y el R\&B, la música electrónica, el metal, el indie o alternativo, y el campo central, que es el que se refiere a los llamados "clásicos" y suele vincularse con el canon mainstream y los públicos masivos (Regev, 2013, p. 84). La teoría del campo también le permite afirmar que la narrativa histórica, la ideología artística y el mundo canónico del campo global del pop-rock se encuentran dominados por la tradición anglo-americana (Regev, 2013, p. 89).

Con todo esto, la segunda hipótesis puede sintetizarse en que la escena metálica bonaerense se estructura mediante posiciones dominantes y marginales que podrían describirse por pares de opuestos cuyas lógicas se refractan desde el exterior hacia el interior de la escena (lo global-lo local y nacional; la capital-el interior; la ciudad-el campo; el mainstream-el underground; varones heterosexuales-mujeres y colectivo LGTBQ) y otras que dan cuenta de luchas producidas en el interior (thrash-glam, "verdadero metal"-"falso metal", Hermética-Rata Blanca, Almafuerte-Malón, metal extremo-Iorio, la celebración-la intelectualidad). Sin embargo, dichas disputas se producen al mismo tiempo que la aparente convivencia de diversidades vinculadas a ideologías políticas y religiosas, y a la integración de minorías tales como las étnicas y las conformadas por personas con discapacidades.

\section{El público como agente}

Siguiendo los postulados de Weinstein (2000), los participantes de la escena pueden ser divididos de acuerdo a su rol dentro de ella: primero, los músicos, encargados de la producción artística; segundo, la audiencia que la consume; y tercero, los mediadores, que podrían identificarse con la circulación (en el caso de los medios de comunicación) pero también con la producción como parte de la industria cultural.

Esta postura es diferente a la de Hennion (2012) que considera que

No existe por un lado la música, por el otro el público y, entre ambos, los medios a su servicio: todo se desarrolla en cada ocasión en el medio, en un enfrentamiento 
determinado con los intérpretes, a través de mediadores materiales concertos: instrumentos, partituras, candilejas escénicas olector de discos, que separan, según cada caso, a estrellas y públicos, <<piezas $>>$ y aficionados, obras e intérpretes, repertorios y melómanos, emisiones y oyentes, catálogos y mercados... (Hennion, 2012, p. 19)

No obstante, se tendrá en cuenta la clasificación que propone Weinstein para poder caracterizar las diferentes posiciones de los agentes, pero se considerará a estas de manera móvil e intercambiable, regidas por la interacción social y cultural.

Debido a que la escena se caracteriza por el dialogo entre sus miembros y por la producción de sentido en todos los roles que ocupan, considero pertinente dar cuenta de ellos en tanto aficionados, ya que a pesar de que algunos ocupan el lugar de la producción, esta se encuentra mayormente motivada por el gusto y el consumo del estilo musical. De esta manera, la audiencia se convierte en un referente conceptual útil para este estudio.

Como ya se mencionó anteriormente, la Escuela de Frankfurt se caracterizó por una mirada apocalíptica sobre la cultura de masas que consideraba que los medios de comunicación masivos eran formas alienantes de control de la población. En este marco, la sociología de la música de Adorno caracterizaba al oyente de música como pasivo. Tal como se explicó, la mayoría de los académicos que reaccionaron a dicha postura intentaron rescatar la agencia del público (Riesman, 1950).

Entre los aportes que se tienen en cuenta para esta investigación, se encuentra el estudio de James Lull (1987b) acerca de la audiencia de la música popular, cuya postura parte de la teoría de los usos y las gratificaciones postulada por Elihu Katz, Jay G. Blumler y Michael Gurevitch en 1974. Teniendo en cuenta a la música popular como un medio de comunicación, Lull le otorga relevancia al estudio de los usos y las interpretaciones que realizan los oyentes de ella, sin dejar de lado que la industria musical también repercute en ello.

El autor analiza diferentes "culturas de gusto" y afirma que

Las funciones de la música en cualquier cultura están integradas en las operaciones sociales fundamentales de su gente y estas circunstancias varían de una cultura a otra. No obstante, los oyentes crean usos imaginativos personales y sociales de la música en todos los contextos culturales. En parte, esto se debe a que la música está disponible en muchas variedades y se puede experimentar fácilmente en un gran número de situaciones. Las audiencias participan en la música popular de formas físicas (cantando, tocando, aplaudiendo, bailando, por la excitación sexual, etc.); emocionales ("sentir" la música, rememorar, romantizar, lograr un "alto" espiritual, y similares); y cognitivas 
(procesar información, aprender, simular pensamientos, contribuir a la memoria, enmarcar percepciones, etc.) (Lull, 1987b, p. 141. T. de la A.).

Esta postura es similar a la perspectiva que toman, en el campo de la Comunicación, Jesús Martín-Barbero (1991) con la idea del receptor como coproductor, y Manuel Castells con la noción de "audiencia creativa" (2009).

Por su parte, Antoine Hennion (2012) considera que es necesario "rehabilitar" al oyente “(...) para rehacer esta relación entre la música como arte y la música como gusto, a partir de la reconsideración de sus soportes" (Hennion, 2012, p. 366). Es por ello que define a los melómanos como "usuarios de la música”, los cuales son “(...) practicantes activos del amor por la música, ya sea por tocar instrumentos, formar parte de un grupo, asistir a conciertos o escuchar discos o la radio", los cuales evidencian que "no hay razones para afirmar que algunas formas son de mero consumo pasivo" (Hennion, 2012, p. 214).

Esta caracterización, a su vez, se asemeja a la idea de "habilitación" (affordance) propuesta por Tia DeNora (2012):

(...) hablar de la música como estructura habilitante no equivale en absoluto a hablar de la música como "causa" o "estímulo" de la acción, el pensamiento o la respuesta emocional. Por el contrario, el concepto de "habilitación" hace avanzar la teoría de la recepción al poner de relieve el hecho de que los efectos de la música dependen de las respuestas y los actos de apropiación, lo cual equivale a decir que, si bien es posible anticipar las cosas que habilita la música, estas no pueden predeterminarse sino que dependen de cómo los "usuarios" enlacen la música con otras cosas, de cómo interactúen con la música y a su vez actúen sobre ella en la medida en que la han activado. (p. 193)

Además, para esta autora, "La música es, en definitiva, un material que los actores usan para elaborar, llenar y rellenar, para sí mismos y para otros, modos de agencia estética y, con ella, posiciones subjetivas e identidades" (DeNora, 1999, p. 54. T. de la A.).

Entonces, para poder dar cuenta de la producción de sentido y la circulación de significados en la escena, es necesario atender la subjetividad de sus miembros. Al pensar en la audiencia, uno de los primeros conceptos que aparecen en torno a la cultura de masas es el de los fans.

Para el caso de la música popular, según Roy Shuker (2009), estos "son personas que siguen ávidamente la música y las vidas de intérpretes y géneros musicales en 
concreto, y las historias de los géneros musicales, con diversos grados de entusiasmo y compromiso" (Shuker, 2009, p. 132). Pero distingue de estos a los aficionados, que

(...) son aquellos que se consideran como devotos $<<$ serios $>>$ de unos estilos musicales o intérpretes en especial. Los aficionados son fans por lo que se refiere al origen de la palabra $<<$ fanático $>>$, aunque su implicación emocional y física difiere de la de $\operatorname{los}<<$ fans $>>$ corrientes, al igual que lo hacen las situaciones sociales de consumo en las que se mueven. El apasionado interés de los aficionados se sitúa habitualmente en un nivel más intelectual y se centra en la música per se más que en la persona de/los intérprete/s. Los aficionados prefieren describirse a sí mismos como interesados en géneros e intérpretes en especial, y a menudo exhiben un conocimiento impresionante sobre ellos. Se caracterizan por lo que podría definirse como <<implicación secundaria $>>$ en la música: la búsqueda de raras ediciones discográficas, como los pictures discs y los pirata; la lectura de fanzines además de las revistas de música comerciales; la asistencia regular a conciertos; y el interés por los sellos discográficos y los productores además de los intérpretes. (...) También pueden estar involucrados en subculturas alrededor de la música. (Shuker, 2009, p. 133)

De esta manera, utilizaré el concepto de "aficionados" para referirme a la mayor parte de los miembros de la escena metálica bonaerense. Este término tiene como sinónimo en lengua francesa a amateur, el cual es utilizado por Hennion (2009) para hacer referencia a las prácticas de afición que definen tanto el amor por la música como la actividad que se realiza en torno a ella, dentro de la cual es posible incluir la que es llevada a cabo por músicos y productores no profesionales, muchas veces calificados como "amateurs".

Es necesario aclarar que se reconoce que no todos los actores de la escena estudiada son aficionados ya que algunos de ellos son profesionales y otros no gustan del estilo musical pero participan dentro de la escena a partir de sus actividades. Entre ellos es posible mencionar a los sonidistas, el personal de seguridad y a los empresarios de las discográficas. Sin embargo, en este caso, una de las principales características es que la mayor parte de los agentes son movilizados por el gusto y la pasión por el metal, al punto de que para algunos es algo similar a una religión o un estilo de vida. Es decir que constituye el rasgo identitario en torno al cual organizan su vida y articulan sus cosmovisiones.

Por otra parte, dentro de los aficionados es posible encontrar a los que se autodenominan "metaleros" y los que no se reconocen de tal manera sino simplemente como oyentes o admiradores del estilo musical. En el primer caso, el compromiso con el metal es mayor que en el segundo. Debido a que "metalero" constituye un término 
nativo, se decidió utilizar los adjetivos "metálico" y "metálica" para hacer referencia de manera conceptual a los objetos, instituciones y agentes vinculados a la música metal.

\section{Principales líneas metodológicas}

\section{La transdisciplinariedad y la interdisciplinariedad}

Puesto que esta investigación requiere de la observación y el análisis de elementos de materialidades y naturalezas diversas, considero pertinente usar como base para este estudio al paradigma de la transdiciplinariedad, cuyos principales referentes son Edgar Morin y Barasab Nicolescu. De acuerdo a la conceptualización de Miguel Martínez Miguélez (2007), este paradigma epistemológico es útil para el abordaje de la escena musical, debido a que esta se constituye de acuerdo a los pilares propuestos por dicho enfoque: se trata de una realidad compleja (está constituida por una multiplicidad de nexos, relaciones e interconexiones) y poliédrica (posee varias caras).

En primer lugar, es compleja porque el consumo de las producciones de Hermética (la banda que constituye el centro de significado de la escena) no se realiza de manera unidireccional. Es decir, la audiencia no se presenta como pasiva, sino que colabora activamente con el desarrollo de la escena. Este consumo tampoco es históricamente lineal, ya que se produce constantemente un retorno a producciones más antiguas para reactualizarlas. La circulación tampoco es simple, ya que no solo está a cargo de medios de comunicación, sino también de los propios artistas y aficionados. Se le da un lugar importante a la comunicación cara a cara y a los valores que surgen en torno a ella.

En segundo lugar, es poliédrica porque el producto que se vende y se consume es, a su vez, medio de comunicación. Este producto/medio es la música, la que no solo se compone por su naturaleza musical sino que también se constituye de manera verbal (letras de canciones) y visual (soportes materiales, como los discos y las escenografías, que poseen un diseño estético especial). Por otra parte, los modos sociales de consumo implican prácticas que dan cuenta de las formas de recepción y de la respuesta de la audiencia, muchas de las cuales se realizan de manera corporal (movimientos, gestos y formas de baile).

Además, la escena metálica bonaerense no solo se constituye por sus participantes, sino también por la industria cultural de la música metal (la producción, la 
circulación y el consumo) y las instituciones y formas de organización y participación que derivan de ello. Todos estos elementos constituyen una cara más de la investigación. Y, tal como expresa Daniel Annoni Binnoto (2004),

La música es, por lo menos, un buen sistema de revelación de realidades, mientras posee niveles de realidad y de organización inmanentes a su vocación. Su constante movimiento dialéctico de acción y percepción, expresión y reflexión, garantizan la creación y percepción de procesos transdisciplinarios de raciocinio. (Annoni Binnoto, 2004, p. 124)

Por otra parte, si se tiene en cuenta que esta investigación se constituirá como un aporte al campo de investigación de la Comunicación, es relevante la postura de Jesús Martín-Barbero (2003), quien afirma que:

La conciencia creciente del estatuto transdisciplinar del campo no hace sino dar cuenta de la multidimensionalidad que en nuestra sociedad revisten los procesos comunicativos y su gravitación creciente sobre los movimientos de desterritorialización e hibridaciones que en Latinoamérica cataliza y produce la modernidad. Transdisplinariedad que en modo alguno significa la disolución de los problemas-objeto del campo de la comunicación en los de otras disciplinas sociales, sino la construcción de las articulaciones e intertextualidades que hacen posible pensar los medios y las demás industrias culturales como matrices de desorganización y reorganización de la experiencia social y de la nueva trama de actores y estrategias de poder. (MartínBarbero, 2003, p. 3)

Sin embargo, para Miguel García Angelo (2006), "El enfoque transdisciplinario trata de romper fronteras disciplinarias y articular ciencias y conocimientos en pos de resolver los problemas de la sociedad de una manera más integral $\mathrm{y}$ participativa."(García Angelo, 2006). Tomando las consideraciones de los dos autores, propongo un abordaje holístico -al igual que el que se plantea desde la teoría de la escena musical- que toma como base tanto algunos postulados de la transdisciplinariedad como de la interdisciplinariedad, permitiendo el diálogo entre metodologías de diferentes disciplinas.

Por ello considero que, más allá de utilizar elementos del paradigma transdisciplinario, esta investigación puede constituirse como un aporte al campo de la Comunicación debido que toma como base teórico-metodológica a la comunicación en sí misma, utilizando tanto marcos conceptuales como métodos que propician el diálogo. Para ello fueron necesarias herramientas cualitativas y cuantitativas, utilizadas en de manera complementaria. A continuación se reflexionará acerca de las posibilidades que 
ambas metodologías ofrecen para el análisis de los diferentes elementos de la escena musical.

\section{Metodología cualitativa}

Como ya fue mencionado, la escena musical que compone el objeto de estudio de esta investigación no solo consiste en las acciones e interacciones entre sus participantes, sino también en el mercado de la música metal y las formas de organización que surgen de ello. Los que, además, se encuentran inmersos en un contexto histórico-espacial específico: el área bonaerense entre los años 2011 y 2017. Esta pluralidad de elementos amalgamados requiere de una organización.

Para ello, será necesario utilizar métodos cualitativos que permitan estudiar aquellos elementos referidos a la producción y consumo de la música metal y los códigos que surgen de ella. La adhesión a estas convenciones estará relacionada con la identidad tanto individual como grupal de los agentes de dicha escena musical. Tal como expresa Simon Frith (2014), “(...) la música nos proporciona un intenso sentido subjetivo del ser social “(p. 471). Es por eso que uno de los objetivos será arribar a la categoría científica de la subjetividad.

Según Armando Capote González (1999), esta es una refracción de la realidad, ya que el sujeto interactúa con la realidad, la cual es construida con el aporte de la interioridad de aquel. Es así que la subjetividad es producto de la relación entre elementos psicológicos y sociales. Estas nociones permiten estudiar la forma en que se conforma un aficionado al metal, no solo a través de su gusto íntimo sino también a partir de la identificación con los grupos que conforman la escena y con los cuales interactúa.

Por otra parte, “(...) la Subjetividad no debe ser considerada como un producto definitivamente terminado, sino en permanente elaboración, pero con períodos de cierta estabilidad en el tiempo que la hacen accesible al conocimiento" (Capote González, 1999, p. 19). Esta idea permite analizar las dinámicas de identificación de los aficionados al metal, las cuales se caracterizan principalmente por trascender generacionalmente: en la mayor parte de los casos, no ocupan este rol en una época específica de su vida (como por ejemplo, durante la juventud), sino que comienzan en determinada edad y en la mayoría de los casos la identificación continúa de por vida, aunque modifican las prácticas y la continuidad de estas con el paso del tiempo. 
Este desarrollo temporal también se acerca a la noción de que "(...) en la Subjetividad, el pasado se actualiza en la valoración del presente, en tanto sirve de referente para evaluar lo actual, contexto donde siempre se realiza el comportamiento" (Capote González, 1999, p. 19). Esto se debe a que "Tiempo y espacios psicológicos no son tiempo y espacios objetivos" (Capote González, 1999, p. 20). Esta dinámica permitiría entender la reactualización que hacen los aficionados de las producciones de Hermética.

$\mathrm{Si}$ “(...) la Subjetividad se expresa tanto en formas de actuar, como en formas de pensar y de sentir" (Capote González, 1999, p. 21), es necesario considerar que en el caso de la música metal estas acciones se dan mayormente de manera comunal. Por eso será necesario tener en cuenta que

(...) no hay posibilidad de afirmación de la subjetividad sin intersubjetividad, y por ende, toda biografía, todo relato de la experiencia es, en un punto, colectiva/o, expresión de una época, de un grupo, de una generación, de una clase, de una narrativa común de identidad. (Arfuch, 2010, p. 79. Cursivas del original)

Entonces la conformación de la escena se produce en la interacción y la influencia mutua de lo individual y lo colectivo; además, la comunicación del código específico de la escena metálica bonaerense se realiza de manera intersubjetiva. Este carácter relacional es fundamental para la escena musical, ya que la misma se construye a partir de la interacción y el diálogo entre sus actores.

Como ya se mencionó, los métodos apropiados para el abordaje de este objeto serán todos aquellos que propicien el diálogo tanto en la escena como productora de significados, como en ella como campo de disputas. Entonces, se pueden dividir los elementos escénicos en dos: por un lado, los que dan cuenta de la construcción de significados, en torno a los cuales se conforma a escena; y por el otro, las disputas que se producen en su interior, las cuales no solo se generan por motivaciones que surgen desde dentro, sino que también atraviesan la escena desde el exterior y provienen del contexto histórico, social y político, y de otros campos culturales. Esta doble división será la que se tomará como referencia para la organización de esta tesis.

El corpus se compone por las producciones realizadas tanto desde el lado de la producción, como de la circulación y del consumo. Las cuales pueden ser detalladas de la siguiente manera: 
1) Producciones: las de Hermética (su música, sus letras, las portadas de sus discos, el video de uno de sus conciertos editado en formato VHS y algunos elementos tales como volantes y afiches que fueron publicados posteriormente en revistas homenaje); las de algunas bandas reconocidas y no reconocidas que permiten compararlas y contrastarlas. De algunas de ellas logré acceder a sus discos, demos y LP, y de otras solo pude escuchar algunas canciones en diversos sitios web.

2) Circulación: primeramente, algunos números de las revistas especializadas reconocidas a nivel nacional y de origen porteño (tales como Metal, Madhouse, Rock N Shows, Efecto Metal y Jedbangers), y algunos números de fanzines tales como La espada Sagrada, Metálica, Revelaciones, Lider Metalero, Resistiré y Enterrado Vivo. Dentro de las publicaciones impresas se tuvieron en cuenta a la colección de libros Cultura Metálica, en los cuales se publican resúmenes, ponencias, debates y reseñas de lo acontecido en las diferentes Ferias del Libro Heavy. Al mismo tiempo, se relevaron las producciones académicas argentinas dedicadas al metal tanto en su formato científico tradicional como alternativo.

En segundo lugar, se tuvieron en cuenta los videos subidos a la red en canales especiales de YouTube, tales como Malón, IORIO oficial, Iorio channel y canalcero. Además de algunos videos de grabaciones caseras de varios shows de Hermética subidos a la plataforma por aficionados.

Finalmente, el lugar predominante lo ocupó la red social, Facebook. De ella se tomaron registros de las publicaciones que no solo consistían en discursos lingüísticos, sino también en la acción de compartir imágenes y videos. Algunas de estas publicaciones provenían de las revistas y los fanzines anteriormente mencionados, así como también de algunos programas radiales (por ejemplo, "Dos horas para la medianoche", "Tiempos violentos", "La noche de las gárgolas", “Artillería pesada", “Esquilación", "Vorterix Metal”, “Toro y Pampa" y "Estrella del Camino").

También se indagaron las publicaciones de la página oficial de la banda solista de Iorio y de grupos tales como "Monsters of Rock Argentina", "Revista MADHOUSE", "metal-tandil pogo-mosh-eslam", "Mujeres Del Metal Argentina!! [Unidas,Somos Mas]", "IORIO_oficial”, "AYACUCHO METAL (culture underground) - Ayacucho", "Metaleros de Olavarría y la Zona", "MALON LO MAS GRANDE DEL HEAVY LATINOAMERICANO”, "IORIO LO MAS GRANDE DEL HEAVY NACIONAL", "La llaga" y "sociedad de metaleros suipacha, mercedes y chivilcoy", entre otras. 
Además, se investigaron fanpages, como "Las Plazas por A salto.”, "Glamnation Party", "Iorio Frases", "Resistencia Heavy Punk", "Frente Heavy Metal”, "Pogopedia", "Equipo Interdisciplinario de Estudios Sociales sobre Heavy Metal”, "B.A.Rock", “Congreso Unico de Culturas Metaleras", “Juarez Heavy Rock Fest”, "El Pancho del Metal", "Megadeth Argentina", "Una Silla para Walter", "Graffitis Pesados", "Metallica - Argentina for all", "Malón Oficial”, “Archivo Hermetica”, "La Hache”, "Feria Metalera", "Prefiero a Ricardo Iorio Que Al Che Guevara", “Anti-Iorio", "Grupo de Investigación Interdisciplinaria sobre el Heavy Metal Argentino", "Feria del libro Heavy Metal” y "Metaleros Anti Iorio".

3) Consumo: para ello se tuvieron en cuenta a los participantes de la escena y a los diálogos que mantuve con ellos al interactuar también como agente de la escena, no solo en eventos específicos como recitales, viajes y ferias, sino también en la convivencia en la vida cotidiana. En algunos casos donde no había un contacto interpersonal a priori, se realizó el acercamiento mediante entrevistas a agentes específicos, teniendo en cuenta especialmente el género y la edad.

Cada uno de estos tres ejes se compone por discursos de diversa materialidad: musicales, verbales e icónicos. De manera que cada caso demanda una metodología particular, pero que en general dan cuenta de la interdiscursividad de las producciones realizadas en la escena. A continuación detallaré los diversos métodos empleados:

-Análisis del discurso social

Marc Angenot (2012) define como discurso social

(...) a la totalidad de la significación cultural: no solamente los discursos, sino también los monumentos, las imágenes, los objetos plásticos, los espectáculos (desfiles militares, banquetes electorales, kermeses) y, sobre todo, la semantización de los usos y las prácticas en su aspecto socialmente diferenciado (kinésico, proxémico, vestimentario) y, por lo tanto, significante. (Angenot, 2012, p. 47)

Esta idea del discurso como una producción que trasciende lo lingüístico/verbal, le permite “(...) tomar en su totalidad la producción social del sentido y de la representación del mundo" (Angenot, 2012, p. 22). Dicha noción entonces resulta útil para poder analizar al conjunto de producciones artísticas de Hermética (sus canciones en tanto música y palabras; sus discos y sus portadas; la edición de uno de sus conciertos en formato video VHS; sus afiches y volantes) y del resto de las bandas de la escena que fueron analizadas. Todas estas producciones se componen de múltiples 
materialidades: musicales, verbales, visuales y corporales, de manera que los postulados de Angenot resultan productivos para el análisis.

Por otra parte, el corpus de esta investigación también se compone por las producciones de los mediadores y la audiencia del metal, en el área bonaerense. Por lo que igualmente se tuvieron en cuenta producciones tales como las revistas especializadas, los fanzines, los ensayos académicos, los flyers, los volantes, los memes, las ilustraciones, las artesanías, las publicaciones en fanpages y grupos de Facebook, los videos subidos a YouTube, y las formas corporales y gestuales de interacción con el metal. De manera que dichas producciones también se componen por materialidades diversas.

Más allá de que todos fueron considerados discursos sociales, en las producciones de materialidad verbal, el análisis se centró principalmente en los tópicos, los tropos y el nivel léxico-semántico. Los primeros también fueron observados en las producciones de materialidad visual y corporal, tanto desde lo denotativo como de lo connotativo, para lograr arribar a la resignificación realizada por los agentes.

Aquí se tuvo en cuenta el postulado de Angenot de que la discursividad social da cuenta de "lo decible" (Angenot, 2012, p. 21) en una sociedad dada. Entonces se investigaron los procedimientos por medio de los cuales se transgredieron y se revalorizaron tópicos hegemónicos, además de los diálogos con otras semiosferas -en términos de Lotman (1996)- o las relaciones interdiscursivas -de acuerdo a Angenot (2012)-.

\section{-Etnografía}

Dentro de las principales metodologías utilizadas se encuentran las etnográficas, las que me permitieron dialogar con los agentes de la escena y arribar a su propia voz y puntos de vista, como por ejemplo la percepción que tenían de la escena bonaerense en tanto objeto geográfico ${ }^{43}$. La diversidad de actores hizo posible reconstruir la polifonía que caracteriza a la escena musical. De acuerdo a Joaquín Guerrero Muñoz (2014),

\footnotetext{
${ }^{43}$ Para ello, utilicé la metodología de la deriva situacionista (Debord, 2010). Debido a que en términos de factibilidad era imposible recorrer cada ciudad del área bonaerense, decidí asistir a eventos y a entrevistar a agentes de ciudades de acuerdo a la información que iba recolectando a partir de las entrevistas y los diálogos de la observación participante. Esto demostraba la relevancia y el funcionamiento de algunos circuitos en el interior de la escena de acuerdo a la perspectiva de sus agentes. Por otra parte, en varios casos las redes sociales de Internet permitieron sortear las barreras de la distancia física.
} 
La etnografía nos permite describir a un grupo humano en su contexto, a partir de la vida cotidiana, en el entorno natural en el que tienen lugar las diferentes interacciones sociales, reguladas por instituciones, sistemas de creencias y valores, normas y patrones de comportamiento incorporados por cada uno de los miembros que configuran esa colectividad a través de un proceso de enculturación. (Guerrero Muñoz, 2014, p. 237)

Aquí la etnografía constituye el llamado "trabajo de campo" y se presenta por medio de diferentes formas, que “(...) no solo reportan el objeto empírico de investigación -un pueblo, una cultura, una sociedad- sino que constituyen la interpretación/descripción sobre lo que el investigador vio y escuchó." (Guber, 2001, p. 12) El principal vehículo de esta metodología es el lenguaje, ya que no solo le permite al estudioso describir la situación, sino también a los miembros de la sociedad hablar acerca de ellos e interactuar en conjunto.

Por otra parte, es relevante la presencia de la reflexividad en el trabajo de campo:

Si los datos de campo no vienen de los hechos sino de la relación entre el investigador y los sujetos de estudio, podría inferirse que el único conocimiento posible está encerrado en esta relación. Esto es sólo parcialmente cierto. Para que el investigador pueda describir la vida social que estudia incorporando la perspectiva de sus miembros, es necesario someter a continuo análisis -algunos dirían 'vigilancia'- las tres reflexividades que están permanentemente en juego en el trabajo de campo la reflexividad del investigador en tanto que miembro de una sociedad o cultura; la reflexividad del investigador en tanto que investigador, con su perspectiva teórica, sus interlocutores académicos, sus hábitus disciplinarios y su epistemocentrismo; y las reflexividades de la población en estudio. (Guber, 2001, p. 25)

En este proceso, "El desafío es, entonces, transitar de la reflexividad propia a la de los nativos" (Guber, 2001, p. 26). ¿Pero qué sucede cuando mi lugar previo en la escena era el de una nativa y, en el tránsito de la vida, me convirtí en investigadora de dicha comunidad? Parte de esta problemática la pude resolver mediante el uso de la técnica de la observación participante, la cual

(...) consiste en dos actividades principales: observar sistemática y controladamente todo lo que acontece en tomo del investigador, y participar en una o varias actividades de la población. Hablamos "participar" en el sentido de "desempeñarse como lo hacen los nativos"; de aprender a realizar ciertas actividades y a comportarse como uno más. La "participación" pone el énfasis en la experiencia vivida por el investigador apuntando su objetivo a "estar adentro" de la sociedad estudiada. En el polo contrario, la observación ubicaría al investigador fuera de la sociedad, para realizar su descripción con un registro detallado de cuanto ve y escucha. La representación ideal de la observación es tomar notas de una obra de teatro como mero espectador. Desde el ángulo de la observación, entonces, el investigador está siempre 
alerta pues, incluso aunque participe, lo hace con el fin de observar y registrar los distintos momentos y eventos de la vida social. (Guber, 2001, p. 29)

La participación, no solo es importante como forma de investigación, sino también porque “(...) es la condición sine qua non del conocimiento sociocultural”, debido a que “(...) una cultura se aprende viviéndola” (Guber, 2001, p. 29). De manera que esta metodología me permitió reconstruir a la escena metálica bonaerense "desde adentro". En mi caso, empleé el "rol del participante pleno", en donde el observador se mimetiza con los nativos de su campo de estudio.

Sin embargo, esta posición no sería suficiente ya que aquí el investigador debe ocultar su rol a los nativos de su campo y en mi caso no solo debí dar cuenta de mi papel de investigadora en la mayoría de los casos, sino que también formé parte del proceso de "intelectualización” o "academización" de la escena bonaerense del metal, lo que además devino en capital cultural y en posiciones de prestigio frente a muchos de mis interlocutores. Esta situación, resulta similar a la que plantea Keith Kahn-Harris (2007) en su investigación sobre el metal extremo:

Siempre he sido un fanático ambivalente del metal extremo, pero como sociólogo he tratado de usar mi ambivalencia con fines productivos. Como estudiante de maestría y luego estudiante de doctorado, profundicé cada vez más en la música y la cultura del metal extremo, yendo y viniendo de un critical insider [interno crítico] a un sympathetic outsider [externo comprensivo]. Este movimiento continuo ofrece, creo, el punto de vista ideal (cambiante) desde el cual llevar a cabo la investigación. Para mi cambio continuo entre los puntos de vista de fanático e investigador, agregué el punto de vista del crítico cuando comencé a escribir para la revista británica Extreme Metal 'Terrorizer' en 1997. Completé mi tesis doctoral sobre metal extremo en 2001 (Harris 2001) pero nunca fui bastante capaz de "dejar el campo". (Kahn-Harris, 2007, p. 5. T. de la A. Cursivas propias)

Si hago una autodescripción de mi lugar dentro de la escena bonaerense del metal, encuentro que en el período que me propongo investigar (2011 a 2017) cumplí una gran cantidad de roles que no puedo pasar por alto, ya que no solo el ser parte de la escena resulta complejo sino también el tener diversas perspectivas del mismo objeto podría resultar productivo.

Entonces, puedo describir mi actividad como la de una aficionada. Comencé a escuchar metal en los primeros años de la adolescencia y, en el tránsito que significó adentrarme en el estilo musical a través de la escucha, la participación y la adquisición de conocimiento, me comencé a autorreconocer como "metalera". En ese momento, no 
solo me identifiqué con las letras que parecían gritar el dolor de los marginados sino también con la rabia que expresaba esa sonoridad que me permitía sentirme más fuerte.

Asimismo, después de esta investigación, comprendí que gran parte de mi afiliación provenía del hecho de haber encontrado en la masculinidad característica del metal formas de desafiar las feminidades que se valoraban en el colegio católico para mujeres en que estudiaba: allí mis pares aspiraban a ser mujeres "bellas", "cools" y "refinadas", adjetivos ligados a estándares provenientes de familias burguesas, de élite y a modelos mediáticos, a los cuales no podía acceder debido a mis diferentes atributos físicos, mi condición de "traga-libros" 44 y mi desigual proveniencia social.

A mediados de dicha etapa, es decir, desde el año 2006, formé parte de los intermediarios con un programa de radio de transmisión alternativa, lo que me generó cierto reconocimiento en la escena local y regional. Posteriormente, en el año 2012 comencé a considerar al metal de manera académica mediante la elaboración de una tesis de maestría acerca de Almafuerte y sus seguidores. Y en el 2013 empecé a formar parte de la "academización" 45 argentina del metal mediante la participación activa como disertante en las Ferias del Libro Heavy.

Esto logró trascendencia nacional e internacional, por lo que el capital cultural se expandió y, en muchos casos, modificó el capital social, es decir, las relaciones personales con el entorno. Como consecuencia, la interacción con miembros de la escena dejó de circunscribirse a la zona centro-sudeste de la provincia, como en los años anteriores, y se trascendió a otras provincias e, incluso, a otros países.

\footnotetext{
44 Forma peyorativa de describir a las personas excesivamente interesadas en el estudio y el conocimiento. También son llamadas "nerds".

${ }^{45}$ Esta forma de aporte que realiza un investigador al campo musical analizado fue referido por Ian Maxwell (2002) en un trabajo en donde debate la posición objetiva del sociólogo de la música en oposición a lo que menciona como la "maldición del fan". De esta manera, ve una fuerte dicotomía entre la posición outsider del investigador y el intercambio de opiniones de los aficionados (insiders).

Sin embargo, mediante su trabajo etnográfico acerca del hip hop en los suburbios de Sydney, logra dar cuenta del movimiento que se produce en el desarrollo de la investigación: se pasa de una objetivización propia del trabajo sociológico a una subjetivización, en la medida en que se fue convirtiendo en un participante del campo al participar de disertaciones en paneles realizados por aficionados y productores del género musical, en donde se discutían cuestiones intrínsecas al hip hop. Esto mismo sucedió con el metal y los estudios metálicos.

Pero, en mi caso, la investigación partió desde dentro del campo, por lo que esta posición es problematizada en otro sentido: de insider a critical insider. En este punto se puede trazar un paralelo con la investigación de Claudio Benzecry (2012) sobre los fanáticos de la Ópera, en la cual el autor se ubica en el lugar de "antropólogo nativo" (en términos de James Clifford), al cual ve como un sitio privilegiado: "No he tenido que sortear interminables obstáculos para tener acceso a la comunidad en cuestión, ni tuve que aprender la lengua nativa, y mi presencia no provocó alteraciones significativas en la vida cotidiana del grupo. Todo esto me permitió reconocer con mayor precisión las categorías y las razones locales." (Benzecry, 2012, p. 36)
} 
De manera paralela, en estos años fui vocalista invitada en una banda de death metal, lo que también significó la adquisición de nuevo capital cultural y social, pero que en este punto me llevó a realizar otras reflexiones. Esto sucedió una vez que bajé del escenario y un varón del público me preguntó: “¿Cómo una 'mina’ pueda cantar con voz de 'chabón'?”.

Entonces, a diferencia de Kahn-Harris, yo soy mujer y me reconozco como tal y, además, no provengo de un país del primer mundo, sino que soy latinoamericana y dentro de Argentina, un país periférico, soy parte de una ciudad intermedia del “interior". De manera que estas cuestiones son ineludibles a la hora de observar y participar en la escena. ¿Cómo investiga una mujer una escena en la que los miembros son mayoritariamente varones y la masculinidad es uno de sus principales rasgos? Esa pregunta me llevó a deconstruir mi lugar como participante y activar mi propia reflexividad de género.

Por otra parte, en este proceso de deconstrucción y durante la investigación (y la interacción en el trabajo de campo) surgieron nuevas preguntas, las cuales me permitieron indagar sobre mi propia experiencia pasada y comprender que, como aficionada, había naturalizado los parámetros de la autenticidad metálica y con ellos había juzgado tanto a la música como a los actores, los objetos y las instituciones tanto del interior como del exterior de la escena.

Como consecuencia, la etnografía tal como la plantea Guber no me resultó suficiente, por lo que consideré la posibilidad de agregar a mi investigación el método autoetnográfico, el cual se caracteriza por mostrar la influencia del investigador y la propia identidad cultural en su trabajo (Ellis et al., 2015). Según Heewon Chang (2008):

\footnotetext{
Al igual que la etnografía, la autoetnografía persigue el objetivo final de la comprensión cultural subyacente a las experiencias autobiográficas. Para lograr este propósito etnográfico, los autoetnógrafos se someten al proceso habitual de recopilación de datos, análisis/interpretación de datos y redacción de informes. Recopilan datos de campo por medio de participación, observación, entrevista y revisión de documentos; verifican datos triangulando fuentes y contenidos de múltiples orígenes; analizan e interpretan datos para descifrar los significados culturales de eventos, comportamientos y pensamientos; y escriben etnografía. Al igual que los etnógrafos, se espera que los autoetnógrafos traten sus datos autobiográficos con ojos críticos, analíticos e interpretativos para detectar los trasfondos culturales de lo que se recuerda, se observa y se cuenta. Al final de un autoexamen exhaustivo en su contexto cultural, los autoetnógrafos esperan obtener una comprensión cultural de sí mismos y de los demás directa e indirectamente conectados con sí mismos. (Chang, 2008, p. 49. T. de la A.)
} 
Esta metodología no solo me permite dar cuenta de mis múltiples lugares dentro de la escena, sino también de las perspectivas que se construyen en cada uno de estos roles, pero haciéndolo de una manera crítica e interpretativa. Además, la actividad etnográfica concienzuda comenzó en el 2012 a través de la investigación realizada para la tesis de maestría. Por lo que, teniendo en cuenta que el período del presente objeto de estudio comienza en el 2011, fue necesaria la utilización de la memoria aubiográfica como complemento del relevamiento archivístico.

La actividad investigativa se constituyó entonces como un ir y venir entre un sutil distanciamiento para deconstruir de manera crítica el entorno y las actividades a los que estaba habituada y, otras, en el "Antropological Groove" que proponen Blázquez y Liarte (2017), es decir, en una epistemología de la inmersión. De acuerdo a estos investigadores, en algunos de sus trabajos de campo,

La puesta consistía en tratar de capturar el vaivén continuo y contradictorio del vivir que compartíamos con quienes nos encontrábamos en las diferentes salidas nocturnas. Como parte de ese proceso sentimos vergüenza, danzamos frenéticamente, nos extasiamos y excitamos, e incluso experimentamos cómo se disolvía, momentáneamente, el binomio sujeto investigador/sujetos investigados. (Blázquez y Liarte, 2017, p. 211)

Este supuesto epistemológico no solo me permitió reflexionar críticamente sobre las emociones que me causaba la música, sino también la interacción de esta con mi propio cuerpo y el del resto de los participantes, y de las actividades que implicaban la participación en la escena.

Por ejemplo, poder describir el dolor físico posterior a una noche de fuerte headbanging y de los golpes causados por la inmersión en un pogo agresivo y/o masivo, repleto de participantes sudorosos; el cansancio corporal de largos viajes a conciertos en la capital porteña o ciudades semi-aisladas con poca accesibilidad de transporte; el temor al asistir sola a eventos nocturnos en lugares alejados o considerados "inseguros"; la adrenalina de subirse al escenario ya sea para cantar como para disertar académicamente; la tristeza de la discriminación y la alegría de la integración por el hecho de ser mujer; la intensidad de disfrute y camaradería al compartir con otros participantes tanto la música como la ingesta de varias cervezas.

Asimismo, para el caso específico del pogo se tuvo en cuentra a la "moshografía", método etnográfico propuesto por Gabrielle Riches, Brett Lashua and Karl Spracklen (2014), el cual consiste en la observación participante del pogo o moshpit. Es decir, una metodología que efectivamente consiste en una práctica de inmersión 
si se tiene en cuenta que algunas veces el pogo visualmente se parece a una "marea humana".

Sin embargo, el método autoetnográfico no es el central, ya que en realidad el objetivo es la comprensión total de la escena. Podría decirse entonces, que la autoetnografía solo es una parte de los métodos etnográficos utilizados en la investigación, de los cuales tiene un gran peso la observación participante y se utilizan como apoyo las entrevistas etnográficas para contrastar los datos.

De acuerdo a Guber (2001), la entrevista es una estrategia,

(...) una situación en la cual una persona (el investigador-entrevistador) obtiene información sobre algo interrogando a otra persona (entrevistado, respóndeme, informante). Esta información suele referirse a la biografía, al sentido de los hechos, a sentimientos, opiniones y emociones, a las normas o standards de acción, y a los valores o conductas ideales.

(...) La entrevista es una situación cara-a-cara donde se encuentran distintas reflexividades pero, también, donde se produce una nueva reflexividad. Entonces la entrevista es una relación social a través de la cual se obtienen enunciados y verbalizaciones en una instancia de observación directa y de participación. (Guber, 2001, p. 36)

En esta investigación utilicé entrevistas semi estructuradas (con un cuestionario pactado con anterioridad) y no directivas (que se componían por preguntas que surgían del contexto). En el primer caso, dotaban a la instancia de un aspecto formal y permitían el acercamiento a participantes de gran trayectoria o de difícil acceso, ya sea por su reticencia a prestar declaraciones o por el desconocimiento previo de mi persona. En otros casos, las entrevistas no directivas también se realizaban a personas desconocidas y también surgían como forma de acercamiento, sobre todo en los casos en que viajé a eventos más alejados del radio en que habitualmente me movía. Allí las preguntas surgían a partir de esos contextos que, en muchos casos eran recitales.

De todas formas, es necesario destacar que las entrevistas solo constituyeron un soporte al resto de las metodologías, ya que se mostraban como un método muy limitado en comparación con la observación participante. Por ejemplo, porque muchos participantes se negaron a responder preguntas en una situación de entrevista, pero que durante la observación participante desarrollaban diálogos de gran riqueza temática. Incluso, se podría decir que mediante el empleo de esta técnica logré arribar a interacciones entre participantes en la vida cotidiana, por fuera de eventos estrictamente metálicos y a cuestiones de gran intimidad que en algunos casos incluso mencionaban (o, al mismo tiempo, realizaban) actividades y consumos que no son legales. 
Este último punto, demanda que dé cuenta de la ética relacional del trabajo etnográfico y, principalmente, el autoetnográfico, debido a que el uso de mi propia experiencia personal implica de manera indirecta a mis cercanos e íntimos (Ellis et al., 2015). Es por esto que decidí conservar el anonimato de los aficionados citados (excepto en los casos de los ex integrantes de Hermética) para resguardar su intimidad. Además, esta estrategia permite que no se individualicen las declaraciones, sino que permitan describir un panorama más amplio.

A los participantes con los que interactué los puedo describir como varones y mujeres argentinos y argentinas; en su mayoría heterosexuales; de entre 15 y 60 años; provenientes de CABA y diferentes ciudades de la provincia de Buenos Aires; algunos desempleados y otros con ocupaciones diversas como tareas domésticas y servicios de limpieza, estudiantes escolares y universitarios, propietarios y empleados de comercios, propietarios de PyMEs, peones de albañil, peones rurales, guardias penitenciarios, docentes, analistas en sistemas informáticos, editores, chef, artesanos, enfermeros, investigadores, herreros, camioneros, mecánicos, empleados administrativos, empleados bancarios, tatuadores, veterinarios, empleados estatales, estilistas, profesores de diversos deportes, maquilladores, etc; que, en algunos casos, también eran músicos reconocidos y del circuito underground de variados subestilos de música metal, productores y periodistas especializados.

Es necesario destacar que esta gran diversidad de ocupaciones también se refleja en una importante variedad de ideologías políticas (personas con inclinaciones por políticas de derecha, de izquierda, anarquistas y apolíticos), religiosas (católicos, protestantes, evangélicos, judíos, satanistas, agnósticos, ateos y simpatizantes de creencias orientales tales como el budismo y el taoísmo, entre otras), así como también de gustos y consumos culturales alternativos al metal.

Retomando las metodologías, otra técnica etnográfica empleada fue la que corresponde a la netnografía. Esta es

(...) una etnografía que amplía su objeto de estudio por medio de las posibilidades que ofrece tener acceso a ese nuevo campo: el ciberespacio, donde se produce sociabilidad y crean vínculos y relaciones sociales entre personas y grupos o comunidades. (del Fresno, 2011, p. 82)

Este método otorga nuevas posibilidades: permite investigar grupos que comparten “(...) un objetivo, afinidad o necesidad como eje vertebrador de la 
conformación de una comunidad online que puede tener su nacimiento en el contexto social offline y online" (del Fresno, 2011, p. 82), ya que la interacción online no ocurre de manera separada de la offline, sino que es una forma "sociabilidad ampliada" (del Fresno, 2011, p. 44).

Además, permite a los investigadores acercarse a comunidades remotas sin necesidad de desplazarse físicamente hacia ellos. De esta manera, ambas ventajas resultaron beneficiosas para esta investigación, ya que dicho método no solo fue utilizado como una forma de triangular la información obtenida por medio de la observación participante y la autoetnografía, sino también de comenzar o continuar el contacto cara a cara con agentes de la escena que habitaban lejos de mi ubicación física.

Dentro de las plataformas online analizadas estuvieron la red social, Facebook, y el sitio web, YouTube. Ambos fueron considerados de la misma manera que Bennett y Rogers (2016): del primero se tuvieron en cuenta algunos grupos, fanpages y eventos ${ }^{46}$, de los cuales se realizó la descripción no participante (del Fresno, 2011), es decir, no se realizó interacción sobre los diálogos y las publicaciones realizadas por otros participantes para no intervenir en sus intercambios y poder acceder a discursos de diversas ideologías, por ejemplo, de quienes defendían los ideales derechistas de Ricardo Iorio y de quienes lo criticaban por esa razón.

También se hicieron entrevistas semiestructuradas y cuestionarios con informantes privilegiados y se tuvieron conversaciones informales por medio del chat con agentes con quienes también me contacté de manera offline, tanto a priori como $a$ posteri. Por su parte, YouTube, fue descrita de manera no participante y de dicho sitio no solo se tuvieron en cuenta videos de contenido archivístico sino también los canales de los ex integrantes de Hermética y los comentarios realizados por los aficionados sobre los contenidos subidos a la red.

\section{Metodología cuantitativa}

Tal como expone Baranger (2009), “(...) en gran parte de la práctica de la investigación social lo cualitativo y lo cuantitativo no son términos excluyentes sino más bien complementarios y, por lo general, ambos necesarios" (iv). En esta

\footnotetext{
${ }^{46}$ En muchos casos actué de manera encubierta aplicando la opción "asistiré" a pesar de que no iría realmente. Esto me permitió agendar eventos que resultaban relevantes para la escena y poder analizar los modos de participación y de difusión. Lo mismo sucedió con las páginas a las que comencé a seguir a través de la opción "me gusta", lo que solo implicaba una decisión metodológica objetiva. De cierta manera, se intentó utilizar las redes de manera productiva, tratando de expandir los usos restringidos propuestos por sus directivas nominales.
} 
investigación considero que ambas metodologías son útiles. En este caso, los métodos cuantitativos me permitieron abordar los elementos objetivos que componen la escena musical.

Teniendo en cuenta que "un dato es el producto de un procedimiento de medición, y medir supone predicar una propiedad" (Baranger, 2009, p. 2. Destacado del original), considero que la mayor cantidad de información objetiva (datos) que se puede medir de la escena musical es aquella que aparece en Internet y puede ser relevada de manera estadística.

Una de mis hipótesis es que la escena no se conforma de manera homogénea en toda el área bonaerense, sino que hay una gran disparidad entre el Área Metropolitana y el interior "profundo". Estas desigualdades no solo pueden ser representadas mediante las derivas situacionistas, sino que también es posible determinarlas de manera cuantitativa e inciden en las características cualitativas de la escena.

Entonces, la metodología cuantitava fue utilizada a partir de aquellos datos que podían extraerse de manera objetiva, por lo que en este sentido Internet fue la principal fuente de información. De esta manera, se trianguló la información cualitativa descrita mediante la etnografía con los datos objetivos publicados en la web, como por ejemplo, la frecuencia de recitales en determinados puntos de la provincia de Buenos Aires.

De este modo, a partir de la organización que propuse anteriormente, a continuación desarrollaré el análisis en dos grandes apartados: primero, se tendrá en cuenta a la escena bonaerense del metal en tanto espacio de producción, circulación y consumo de sentido (semiosfera) y, luego, como campo de luchas y disputas de diversa índole. Por último, se expondrán las consideraciones finales a las cuales se arribó en esta investigación. 


\section{Parte I: Reconstrucción de la escena metálica bonaerense como semiosfera: Hermética como centro de sentidos}

En su análisis discursivo cuantitativo, Gendler y Prado (2016) proponen a V8, Hermética y Almafuerte como las bandas que representan la hegemonía del campo del metal argentino y, en consecuencia, a la figura de Ricardo Iorio como centro, ya que

Los conceptos principales en las letras de las canciones de estas tres bandas centrales expresan la condición de posibilidad y los contenidos mínimos que las demás bandas de este género deberán tener en sus canciones, o en otras palabras, expresan cuáles son las reglas de juego para la lucha por el capital simbólico del "metal argentino legítimo". (p. 33)

De acuerdo a los autores, esto se debe a que en las producciones de las tres agrupaciones se propone un régimen de verdad ligado a definiciones del modo de ser "un heavy argentino". De manera que, "Esta producción de sujetos metaleros verdaderos resulta significativa puesto que es la que ha logrado ocupar lugar hegemónico del campo del heavy argentino, desplazando a otras configuraciones posibles.” (Gendler y Prado, 2016, p. 7. Cursivas del original)

Al mismo tiempo, explican que Hermética, además de “(...) imponerse sobre las demás bandas derivadas de V8 en su lucha por el capital simbólico del campo (...)" (Gendler y Prado, 2016, p. 34), se destaca porque en sus canciones la principal conceptualización se produce en torno a las referencias a un "nosotros metalero". Por lo que es posible deducir que dentro de la discursividad de Hermética se puede encontrar una fuerte intencionalidad de definir lo que es el metal y lo que no lo es.

Al enfocarse en los contenidos y las conceptualizaciones de estos grupos, se estaría considerando a los significados que producen. $\mathrm{Y}$, si ellos son los conjuntos hegemónicos, la significación que construyen sería la central para la escena. Entonces, resulta operativo considerar a la escena metálica bonaerense como semiosfera. Lo que, además, permite dar cuenta de “(...) la separación de lo propio respecto de lo ajeno" (Lotman, 1996, p. 14) como un modo de construcción de identidad, al mismo tiempo que, en tanto espacio semiótico, solo dentro de la semiosfera es posible la producción de sentido y, por ende, la formación de cultura.

A su vez, internamente la semiosfera se organiza en núcleo y periferia: 
En el núcleo se disponen los sistemas semióticos dominantes. Sin embargo, mientras que el hecho de esa división es absoluto, las formas que reviste son relativas desde el punto de vista semiótico y dependen en considerable medida del metalenguaje de descripción escogido. (Lotman, 1996, p. 17)

Entonces, mi hipótesis es que Hermética, al construir un discurso que alude fuertemente a un modo de ser "metalero", construye una forma de identidad metálica y produce un metadiscurso acerca del metal y de la propia escena argentina. Esto la sitúa en el centro de la semiosfera metálica bonaerense. A su vez, dicha construcción identitaria se caracteriza por definir al "verdadero" o "auténtico" metal y por ubicarse en la línea fundamentalista del metal (Weinstein, 2000), ya que identifica (y se opone) al glam metal como "falso metal".

Para Gendler y Prado (2016), “(...) la producción de subjetividad metalera está asociada indisolublemente a la problemática de la argentinidad (...)” (p. 36). A ello es posible sumarle las discusiones vinculadas con las configuraciones en torno a la idea de poder hegemónico y de masculinidad. Lo que, además, no solo se halla en las letras de canciones de Hermética sino también en todos aquellos elementos que constituyen los planos verbal, musical y visual de sus producciones.

Tomando como referencia al estudio del heavy metal angloamericano realizado por Deena Weinstein (2000), se analizaron las producciones de Hermética como "textos artísticos" (Lotman, 1996) constituidos por los tres planos anteriormente mencionados. A partir de allí fue posible encontrar tres significados centrales: primero, aquellos que se vinculan con modos de transgresión; segundo, los que dan cuenta de la construcción de diversas formas de masculinidad; y finalmente, aquellos que discuten diferentes perspectivas en torno al localismo y la política.

A continuación, desarrollaré un capítulo para cada uno de estos tres significados centrales. Además de analizarlos en las producciones de Hermética, daré cuenta de la resignificación que realizan de ellos los agentes de la escena metálica bonaerense en el período estudiado (2011-2017), ya que "El texto como generador del sentido, como dispositivo pensante, necesita, para ser puesto en acción, de un interlocutor." (Lotman, 1996, p. 69) Esto supone una operación dialógica entre todos los componentes de la semiosfera estudiada.

Por otra parte, “Además de la función comunicativa, el texto cumple también una función formadora de sentido, interviniendo en este caso no en calidad de embalaje pasivo de un sentido dado de antemano, sino como generador de sentidos." (Lotman, 
1996, p. 60) Por lo que, al observar los modos en que los miembros de la escena estudiada reconstruyen los tres significados centrales de la escena, intentaré rescatar su agencia dentro de dicha semiosfera. Tal como expresa Martín Barbero (1991), “(...) el receptor no es un mero decodificador de lo que en el mensaje puso el emisor, sino un productor también" (p. 228).

Entonces a continuación se verá de qué manera los agentes de la escena metálica bonaerense construyen la identidad cultural metálica a partir de sus propios trabajos de subjetividad, los cuales se apegan y/o se alejan de la corriente fundamentalista representada por Hermética. 


\section{El metal y la transgresión}

A pesar de que la escena metálica bonaerense se caracteriza por componerse de manera heterogénea, es posible encontrar en ella determinados caracteres aglutinantes que son compartidos por la mayor parte de los miembros que la integran. Como expliqué anteriormente, Hermética representa el centro unificador que propone un "nosotros" en relación con la identidad metálica, la cual no solo es construida mediante la selección de determinados rasgos elegidos como "propios" sino también de los que son excluidos como "ajenos" y de los que sus participantes se pretenden diferenciar. Aquí la identidad se presenta como

\footnotetext{
(...) la (auto y hetero) percepción colectiva de un "nosotros" relativamente homogéneo y estabilizado en el tiempo (in-group), por oposición a "los otros" (out-group), en función del (auto y hetero) reconocimiento de caracteres, marcas y rasgos compartidos (que funcionan también como signos o emblemas), así como de una memoria colectiva común. Dichos caracteres, marcas y rasgos derivan, por lo general, de la interiorización selectiva y distintiva de determinados repertorios culturales por parte de los actores sociales. (Giménez Montiel, 2002, p. 90. Cursivas del original)
}

Al analizar las producciones de Hermética se puede observar la identificación de la banda con ciertos grupos de víctimas/dominados frente a otros que parecen ocupar el lugar de victimarios/dominantes. Mientras que los primeros están representados con los jóvenes y niños, los pobres, los trabajadores, el pueblo y las comunidades originarias, que forman parte del "nosotros"; los segundos están constituidos por la policía y los políticos, quienes ocuparían el lugar de "los otros".

Frente a dicho contexto (referido mayormente a las consecuencias de las políticas neoliberales implementadas en Argentina por el gobierno de Menem en la década de los '90) descrito de manera apocalíptica, Hermética propone diversas maneras de hacer justicia, dentro de las cuales el metal es considerado como una forma de resistir esos modos de dominación y como un camino a seguir o una forma de vida.

Al tener en cuenta que tanto para Walser (2014) como para Weinstein (2000) el metal se caracteriza por recrear y representar formas de poder de diversas maneras, y a partir del análisis léxico-semántico y de los tópicos y los tropos de las producciones de Hermética es posible ver que, más que demostraciones de poder, se leen diversas propuestas de empoderamiento.

La perspectiva adoptada por Hermética puede ser considerada como contrahegemónica, ya que proviene de la tradición del rock como contracultural y como 
discurso en contra del "sistema" (Díaz, 2005; Pujol, 2007a). De acuerdo a Keightley (2006), el rock norteamericano e inglés posterior a 1964 se constituyó como una cultura juvenil que se oponía a la sociedad de masas, la cual era identificada con el mundo adulto. La necesidad de diferenciarse hizo que dichos jóvenes sientan afinidad hacia las culturas marginales y la puesta en movimiento de las llamadas minorías.

Las contraculturas, al igual que las subculturas, para Clarke et al. (2010) se definían por su oposición a la cultura dominante, la cual

(...) se representa a sí misma como la cultura. Trata de definir y contener todas las demás culturas dentro de su rango inclusivo. $S u$ visión del mundo, a menos que sea desafiada, permanecerá como la cultura más natural, universal, que todo lo abarca. Otras configuraciones culturales no sólo estarán subordinadas a este orden dominante: entrarán en lucha con él, buscando modificar, negociar, resistir o incluso derrocar su reinado -su hegemonía-. (Clarke et al, 2010, p. 72. Cursivas del original.)

El metal es heredero de esta tradición contracultural y contra-hegemónica mediante la cual el rock se oponía al orden establecido (Ochoa, 2002). De hecho, forma parte de las expresiones juveniles puestas bajo la lupa del "pánico moral"-“una espiral en la que los grupos sociales que ven amenazada su posición y mundo identifican un $<<$ enemigo responsable $>>$ y emergen como los guardianes vociferantes de los valores tradicionales: empresarios morales" (Clarke et al, 2010, p. 161)- tanto por la cultura dominante como por los "guardianes morales" (Clarke et al., 2010).

Esto se debe a que durante la década de los '80 dicho estilo musical fue percibido como ofensivo y peligroso (Hjelm et al., 2013). Lo que dio como resultado que la controversia se convierta en una parte integral del metal, el cual ha usado a la polémica como una herramienta de identidad y como estrategia de marketing (Hjelm et al., 2013, p. 5).

Por esto, "el metal tiende a estar dominado por un compromiso distintivo con temas y musicalidad "transgresores"” (Hjelm et al., 2013, p. 10. T. de la A.), en donde la "transgresión” consiste en “(...) la práctica de cruzar límites, simbólicamente y/o prácticamente; la práctica de cuestionar y romper tabúes; la práctica de cuestionar los valores establecidos." (Hjelm et al., 2013, p. 10. T. de la A.)

En este sentido, resulta operativo estudiar las producciones del metal como transgresoras teniendo en cuenta los postulados de Marc Angenot (2012), quien 
considera que existe una hegemonía discursiva ${ }^{47}$ que impone aceptabilidad y formas y grados de legitimidad, por medio de la imposición de dogmas, fetiches y tabúes. Dicha hegemonía se define como

(...) el conjunto complejo de las diversas normas e imposiciones que operan contra lo aleatorio, lo centrífugo y lo marginal, indican los temas aceptables e, indisociablemente, las maneras tolerables de tratarlos, e instituyen la jerarquía de las legitimidades (de valor, distinción y prestigio) sobre un fondo de relativa homogeneidad. (Angenot, 2012, p. 32)

Entonces, el metal transgrede lo hegemónico cuestionando sus dogmas, fetiches y tabúes por medio de recursos que traspasan los límites de "lo aceptable" y "lo tolerable", ya que

Las bandas de metal exploran temas como el exceso sexual, el ocultismo, la muerte, la violencia y la mutilación. Se deleitan con mitos que exploran el lado más oscuro de la humanidad y con historias de maldad y degradación humanas. El metal ha probado los límites de la música, el volumen y el sonido en sí. Los fanáticos y las bandas del metal se han lanzado a excesos de todo tipo y, en ocasiones (...), a la violencia extrema (...). Tales temas transgresores están presentes en diversos grados en la música y la cultura metálicas (...). (Hjelm, et al., 2013, p. 10. T. de la A.) ${ }^{48}$

A diferencia de Sánchez Mondaca (2004) que considera que las transgresiones en el metal “(...) implican un rechazo tácito a la sociedad adulta” (p. 55), en el caso de la escena metálica bonaerense la reacción se produce en oposición a la cultura hegemónica. De esta manera, el primer significado central de la semiosfera metálica bonaerense es aquel que se vincula con la transgresión contra-hegemónica.

A continuación se analizarán los modos en que esto aparece en las producciones de Hermética y las maneras en que se materializó en la escena bonaerense, las cuales

\footnotetext{
${ }^{47}$ En la segunda parte analizaré a la escena metálica bonaerense a través de la teoría de los campos culturales de Pierre Bourdieu, por lo que el concepto de hegemonía nuevamente se hará presente. Mientras en esta parte me encargaré de dar cuenta de la construcción de sentidos contra-hegemónicos, en la próxima me detendré en las dinámicas y las disputas a través de las cuales los agentes y las instituciones construyen la escena, la cual no solo se enfrenta a una hegemonía cultural externa sino que también desarrolla internamente determinados centros hegemonizantes.

${ }^{48}$ Los casos más famosos de violencia extrema que se desarrollaron en la escena metálica a nivel global tuvieron lugar en Noruega con la banda de black metal, Mayhem. En 1991 el vocalista de ella, "Dead" se suicidó con varios cortes corporales y un disparo en la cabeza realizado con una escopeta. Fue hallado muerto por el guitarrista del grupo, "Euronymous", quien, antes de dar aviso a la policía, tomó fotos del cadáver. Una de esas imágenes fue utilizada para el arte de tapa del disco que el conjunto editó en 1995 y se tituló Dawn of the Black Hearts. Posteriormente, en 1993, dicho guitarrista fue asesinado por el nuevo cantante de Mayhem, Varg Vikernes, quien fue condenado a 25 años de prisión, no solo por ser autor del crimen sino también por haber incendiado varias iglesias cristianas. Gran parte de la polémica con estos músicos estuvo dada porque todos eran satanistas y Vikernes también defendía ideologías racistas.
} 
algunas veces se trasladaron a eventos de violencia física, cuyo impacto social fue diferente a lo largo del tiempo.

\section{La transgresión en las producciones del metal y de Hermética}

Como ya mencioné, el metal se caracteriza por ser un estilo musical que en diferentes contextos ha sido percibido como polémico, al mismo tiempo que las propias bandas han utilizado esta calificación intencionalmente tanto para construir formas identitarias artísticas como estrategias publicitarias. Ya desde los inicios del estilo, grupos precursores como Black Sabbath y Alice Cooper recurrieron a diversas fuentes para representar imágenes agresivas.

Mientras la primera se inspiró en el ocultismo, la segunda se basó en precursores como The Crazy World of Arthur Brown -un artista británico contracultural de fines de la década del '60 que buscaba generar un "shock visual” (Reynolds, 2017, p. 133) mediante una propuesta teatral que invocaba lo satánico y oscuro- y en la tradición del teatro parisino de fines del siglo XIX llamado Grand Guignol. Este “(...) se hizo popular por sus recreaciones extremadamente realistas y explícitas de asesinatos, violaciones e infanticidios, como así también por su indagación dramática de los estados de locura y psicosis.” (Reynolds, 2017, p. 136) Posteriormente, en la década de los '80 varios conjuntos musicales metálicos utilizaron temáticas y recursos provenientes del cine gore y la pornografía para buscar un impacto similar.

La recepción de ello muchas veces fue mala, por lo que una consecuencia de dichas transgresiones fue la creación en 1985 de la institución, Parent's Music Resource Center (PMRC), por parte de Tipper Gore, la esposa del senador estadounidense, Al Gore. Dicha institución se encargó de controlar y censurar las producciones de diferentes géneros musicales, pero especialmente del metal.

Una de las formas en que se realizó dicha persecución fue por medio de la creación de la etiqueta de clasificación "Parental Advisory: explicit content" (Aviso a los padres: contenido explícito), la cual fue implementada por la Asociación de Industria Magnetofónica de América sobre diferentes álbumes que supuestamente incluían lenguaje y/o contenido ofensivos. A pesar de que esto se inició en la década de los '80, durante el 2017 se pudo observar una etiqueta similar en la plataforma, Spotify.

De la misma manera, diversos músicos de metal fueron demandados, debido a que consideraban que sus canciones habían sido motivantes de algunos suicidios en jóvenes “metaleros". Uno de los ejemplos más relevantes es el del caso que involucró a 
la banda británica, Judas Priest, la cual fue acusada de colocar mensajes subliminales en su disco, Stained Class (1978), que se suponía que habían provocado el pacto suicida de dos adolescentes estadounidenses en 1985. Aunque se realizaron estudios científicos al respecto, finalmente esto no se pudo comprobar, por lo que el grupo musical fue absuelto.

Estas polémicas surgieron principalmente en torno al contenido de las líricas de las bandas metálicas, es decir, a sus elementos extramusicales; y sus principales detractores provenían de sectores políticos conservadores y pertenecientes a corrientes cristianas extremistas que acusaban al metal de satánico ${ }^{49}$.

De esta manera, al tener en cuenta a la recepción del metal, es posible analizar a la construcción de la identidad metálica de acuerdo a los postulados de Goffman (2001) acerca de los modos en que las personas se presentan a los demás. De acuerdo al autor, "La expresividad del individuo (y por lo tanto, su capacidad para producir impresiones) parece involucrar dos tipos radicalmente distintos de actividad significante: la expresión que $d a$ y la expresión que emana de él. (Goffman, 2001, p. 14. Cursivas del original.)

El impacto que produce el metal en la recepción puede ser comparado con el efecto que creó el glam rock y, en particular Alice Cooper: al generar indignación pública, el artista es beneficiado (esto le genera mayor publicidad) y la audiencia siente adrenalina al rebelarse contra aquellas figuras que ocupan un lugar de autoridad similar al del padre y esto le genera una "excitación liberadora" (Reynolds, 2017, p. 138).

Visto lo anterior, y siguiendo los parámetros propuestos por Weinstein (2000) para la cual el corazón del metal está definido de manera no sólo musical, sino también verbal y visual-, a continuación se describirán los principales modos a partir de los cuales se presentan formas de transgresión en las producciones de Hermética.

\section{Plano musical}

El primer plano de las producciones de Hermética que se puede analizar es el que se vincula con lo musical. Debido a que esta tesis no consiste en un análisis musicológico, solamente intenté explorar los modos en que se produce el significado de

\footnotetext{
${ }^{49}$ Fuera del período estudiado y durante la escritura de esta tesis, en el 2018 se produjo la censura de varias bandas metálicas en diversos países de América Latina: El grupo sueco de black metal, Marduk, debió cancelar sus conciertos en Guatemala, Colombia, Panamá y la ciudad mexicana de Monterrey, debido a protestas realizadas por grupos y políticos católicos y evangélicos quienes los acusaban de blasfemos. No obstante, en esa gira sí pudieron presentarse en Argentina. Algo similar sucedió con la agrupación española de heavy metal, Ángeles del Infierno, cuya actuación también fue cancelada en la ciudad colombiana de Ibagué, ya que la administración del local donde se iba a realizar el recital denegó el permiso para ello por considerar que el grupo musical hacía apología a falsos valores.
} 
transgresión en el plano sonoro sirviéndome de algunos elementos técnicos de la disciplina ya mencionada, pero teniendo en cuenta que “(..) las significaciones musicales deben entenderse como construcciones sociales" (Pelinski en Hernández Salgar, 2012, p. 42).

En cuanto al aspecto auditivo, la mayoría de los académicos coinciden en que el metal se define por su potencia (Martínez, 1999; Weinstein, 2000; Walser, 2014; de Val, 2014; Galicia Poblet, 2015). En palabras de Weinstein (2000),

El elemento sonoro esencial en el heavy metal es la potencia, expresada como estridencia pura. La intensidad está destinada a aplastar, barrer al oyente dentro del sonido, y luego otorgarle la sensación de poder que la música proporciona. (...) En los conciertos, el escenario está cargado con pilas de amplificadores, con el fin de que el nivel de decibelios de los instrumentos pueda elevarse al límite. Los estándares sonoros del concierto son replicados en las grabaciones. El tipo de potencia que proporciona el volumen es una inyección de vitalidad juvenil, un poder para resistir la embestida del sonido y para expandir la energía de uno mismo para responder a él con un impulso físico y emocional propio. La sonoridad del heavy metal no es destructiva, irritante o dolorosa (al menos para el fan), sino fortalecedora. No es solo una "pared de sonido", como se quejan los detractores: es un patrón sónico a menudo complicado que se reproduce en grandes volúmenes. (Weinstein, 2000, p. 23. T. de la A.) ${ }^{50}$

Para Fernando Galicia Poblet (2015), las cualidades sonoras del heavy metal se resumen en intensidad, volumen y potencia, y aclara que "No se necesita un volumen, físicamente hablando, excesivo, sino que la sensación de intensidad sea alta (...)” (p. 298). Esta es captada de forma física y temporal por el oyente, quien mentalmente completa el proceso de manera subjetiva, por ejemplo mediante performances corporales tales como el pogo y el headbanging ${ }^{51}$, que pueden ser apreciadas como expresiones de catarsis en términos aristotélicos ${ }^{52}$ (Galicia Poblet, 2015; Walser, 2014).

Entonces, en el metal, "El concepto de potencia, de energía, así como los de intensidad y volumen, forman parte de su idiosincrasia, resultando un pilar básico para poder entenderlo más allá de las diferentes escenas locales" (Galicia Poblet, 2015, p. $300)$.

\footnotetext{
${ }^{50}$ En este punto es necesario hacer la salvedad de que las características de este sonido no solo pueden resultar placenteras para sus aficionados, sino que también han sido utilizadas como instrumento de tortura. Para ampliar este tema, sugiero la lectura del capítulo "Cuando el heavy metal es una tortura. La implementación del género en las cárceles de Guantánamo e Irak" de Ariel Panzini (2018).

${ }^{51}$ Sobre estas prácticas me explayaré más adelante.

52 "La catarsis, constituye el momento final del hecho trágico pues, aquí se produce el momento de recogimiento de la obra por medio de la suscitación de los sentimientos de compasión y temor con arreglo a los cuales, el espectador, es decir el que espera y observa, se identifica con los personajes y expresa con ellos la descarga de aquellas poderosas afecciones." ("Estudio preliminar", en Aristóteles, 2004, p. 27)
} 
Estas características del sonido del metal son las que le otorgan el significado de "poder" al estilo. Esta idea de la música como elemento que empodera es posible encontrarla en la canción "Evitando el ablande" del disco Ácido argentino (1991) de Hermética. Aquí el "yo" lírico describe al metal desde la perspectiva de la primera persona: "junto a su sonido brutal / mi vida / resiste su ruina". Con el adjetivo "brutal" da cuenta de la descripción del sonido del metal.

Siguiendo a Weinstein (2000), al igual que en el rock en general, el instrumento musical esencial del metal es la guitarra eléctrica, cuyo sonido requiere de tecnologías que permiten ejecutar un sonido distorsionado y amplificado. Esto hacía que una de las características de la NWOBHM sea la presencia de los "héroes de guitarra", los cuales se caracterizaban por poseer competencia técnica y por ser admirados desde la distancia por sus seguidores. De acuerdo a la descripción de la autora, esto era diferente en el punk, que proponía la igualdad entre músicos y aficionados.

Como ya mencioné anteriormente, Hermética es una banda cuyas composiciones eran más cercanas al sonido del thrash metal que del heavy metal clásico. Podría decirse que su sonido rescataba gran parte de la tradición de V8 y tenía como influencias foráneas a los thrashers, Metallica (de Estados Unidos), y a los heavys, Motörhead (de Inglaterra) y Vulcain (de Francia).

De acuerdo a Weinstein (2000), el surgimiento del thrash metal se debe en gran parte a la influencia del punk, el hardcore y el crossover, los cuales le otorgaron innovaciones rítmicas y de velocidad. Una de sus principales características era la intención de evocar “(...) nuestros más primitivos instintos de agresión, violencia y sobre todo, diversión” (Rubio, 2011, p. 88. Cursivas del original).

Los músicos thrashers (o "thrasheros", como se los nombra en Argentina) permanentemente se mueven entre el lugar de amateur propuesto por el punk y el experto del heavy metal. Siguiendo esta idea, se observa que Hermética intenta demostrar que no es necesario poseer una gran competencia técnica para poder ser músico de una banda. Esto se expresa en la canción "Ayer deseo, hoy realidad" del disco Victimas del vaciamiento (1994), en los siguientes versos: "Se me cumple hoy / el sueño pendejo de ayer”. Además, en una entrevista que le realicé al guitarrista, Antonio "Tano" Romano, expresó que "Hermética es una banda que demostró que sin ser músicos virtuosos también se puede llegar al corazón de la gente.” (Romano, Tandil, 2016) 
Retomando la descripción del sonido, la guitarra eléctrica en el thrash metal continúa tomando protagonismo al igual que en la NWOBHM. A pesar de que dicho instrumento también aparece en un primer plano en otros géneros musicales, en el metal este instrumento posee gran peso interpretativo, al mismo tiempo que permite generar el sonido distorsionado, elemento que antes del rock era considerado un "ruido", pero este lo desarrolló como una nueva posibilidad sonora (Galicia Poblet, 2015, p. 300). De esta manera,

El heavy metal daría un nuevo giro al uso de la distorsión, aumentándola y empleándola con una significación diferente; haciendo de ella un elemento que, si bien era un recurso musical, también iba a ser mostrada como elemento diferenciador a la vez que de transgresión. Como reflejo de una actitud. (Galicia Poblet, 2015, p. 301)

De hecho, "Los grandes niveles de distorsión, potencia y sustain del género facilitan ese efecto poderoso que tanto se busca para transmitir el mensaje." (Galicia Poblet, 2015, p. 301). En el caso del thrash, al crear el ritmo riff thrash hace que el resto de los instrumentos se acojan a él para generar un todo:

En este sentido, la guitarra rítmica thrash inaugura una forma de tocar basada en la prevalencia de la sexta cuerda, que crea intrincados patrones rítmicos, tocados normalmente con la técnica del alternate picking, el tremolo picking o una combinación de ambos. Desde Annihilator hasta Whiplash, el Thrash Metal basa su sonido en este modelo, que pese a su aparente limitación, parece tener variaciones infinitas. El concepto de riff se complementa con la técnica identificativa del thrash: la rapidísima alternancia cuerda/acorde, en combinación con los llamados power chords (acordes de quinta), todo ello pasado bajo el filtro de la fundamental técnica del palm muting, que a base de puntuales stacattos, convierte la guitarra en un instrumento melódico/percusivo. (Rubio, 2011, p. 89. Cursivas del original)

Otras técnicas usadas en el thrash por la guitarra solista son el shredding, el legato, el tapping, el sweep picking y los "solos de ruido" (mediante el uso abusivo de la barra de tremolo) o dive bombs (Rubio, 2011).

La o las guitarras (algunas veces son dos) son ejecutadas a la par de una batería con una gran cantidad de cuerpos, lo que usualmente incluye un doble bombo (o una doble pedalera cuando solo hay uno). Este instrumento refuerza y amplifica las frecuencias graves y debe ser ejecutado con los dos brazos y ambas piernas a la vez y, a diferencia del rock de principios de los 70, comienza a marcar ritmos mucho más veloces y deliberados que dificultan el acompañamiento corporal mediante formas 
clásicas de baile. De hecho, el sonido resultante produce un "efecto similar al del sonido de las ametralladoras" (Galicia Poblet, 2015, p. 303).

Los ritmos de batería del thrash metal se asemejan al punk “(..) especialmente en el ritmo clásico two beat o tupa-tupa, de alternancia entre la caja y el bombo, que ha sido acertadamente definido como un ritmo acelerado de polka. (Rubio, 2011, p. 89. Cursivas del original). Además de ello, "Son comunes los cambios arbitrarios de tempo (...), mientras que los compases siguen siendo los habituales del rock, 4/4, 3/4, y 2/4, siendo raros tiempos más complejos.” (Rubio, 2011, p. 89)

Con respecto al rol del bajo eléctrico, "El bajista thrash sigue teniendo una función similar al bajista rock tradicional (la de servir de puente entre ritmo y melodía), solo que con la dificultad propia del aumento de velocidad.” (Rubio, 2011, p. 89. Cursivas del original). Además, para poder sonar a la par de las frecuencias altas, el bajo eléctrico demanda de amplificación, cuyo efecto es el aplomo, es decir, el sonido pesado o heavy (Galicia Poblet, 2015, p. 132). La consecuencia de esto es que "Debido a la prominencia del sonido pesado bajo, el heavy metal tiene una dimensión táctil. La música puede ser sentida, no sólo metafóricamente, sino también literalmente, particularmente en el pecho del oyente." (Weinstein, 2000, p. 24. T. de la A.)

En cuanto a la voz del cantante, esta constituye un instrumento más de la banda que se encuentra al mismo nivel de la guitarra. A pesar de la presencia de los famosos solos de guitarra y la posición frontal del cantante, a diferencia del blues, “(...) el heavy metal exige la subordinación de la voz al sonido como un todo" (Weinstein, 2000, p. 26. T. de la A.). De esta manera, “(...) el timbre de la voz y de la guitarra se equiparan en importancia, manteniendo así una tensión doble, no entendida como rivalidad sino como una tensión complementaria.” (Galicia Poblet, 2015, p. 304)

Más allá del contenido de las letras, los tonos vocales del metal se caracterizan por la expresión de emociones que no están vinculadas con el placer o la alegría, sino con el dolor, la rebeldía, la ira y la excitación (Weinstein, 2000, p. 26), las que junto con el sonido instrumental contribuyen a la creación de una sonoridad agresiva. Además, como la voz debe sonar poderosa, se permite la presencia de notas agudas y falsete para enfatizar el poder y la emocionalidad (Weinstein, 2000, p. 26), por lo que puede haber voces rasposas y guturales así como también agudas y agresivas (Rubio, 2011, p. 90).

En el caso de Hermética, la voz del frontman, Claudio O’Connor, se caracterizaba por ser aguda pero a su vez gutural, lo que le permitía una amplia expresión de emociones. Esto contrastaba con las intervenciones vocales de Iorio, cuya 
voz de tonalidad grave y de menor despliegue técnico daba cuenta de emociones más cercanas al enojo y a la protesta. De acuerdo al trabajo etnográfico pude ver que la vocalización es un elemento importante para los aficionados de Hermética, los cuales destacan la voz de O'Connor como una de las mejores del metal argentino. Al mismo tiempo, su modo de cantar es imitado por los vocalistas de la mayor parte de las bandas tributo a dicho grupo.

Entonces la transgresión en el plano musical de las producciones de Hermética aparece en la resignificación artística de lo que suele ser considerado "ruidoso" y en la construcción de una sonoridad agresiva, emoción que culturalmente es vinculada a lo conflictivo y, por ende, causa temor, rechazo y, a veces, censura. Además, a través de los elementos tímbricos, rítmicos, armónicos y de intensidad, en el metal "No se busca, por lo tanto, el preciosismo como forma de llegar al oyente, sino la contundencia para transmitir el mensaje." (Galicia Poblet, 2015, p. 314)

Por su parte, la significación de potencia rompe con la búsqueda de un ambiente armónico o de quietud y, por el contrario, intenta llevar a la audiencia a formas de catarsis. Además, las características musicales del metal lo convierten "En un género que ni pretende ni se adapta a los cánones musicales del baile” (Galicia Poblet, 2015, p. 357). Por su parte, la combinación de habilidad y amateurismo del thrash propone una nueva forma de crear música, similar al punk, que transgrede la idea de la música como fruto exclusivo del aprendizaje académico.

Otra forma de transgresión se presenta en el disco Intérpretes (1990) que, como ya se explicó en apartados anteriores, estaba conformado enteramente por covers. Aquí se incluyó la interpretación metálica de canciones de géneros musicales diferentes, tales como rock y tango. Estas consisten en "versiones raras de lo naturalizado" (Gallo y Semán, 2016, p. 41. Cursivas del original).

En las producciones de Hermética también es posible encontrar un ejemplo de transgresión que se desarrolla en la intersección de los planos sonoro y verbal: en la canción "Vientos de poder" del disco Ácido argentino (1991), antes de comenzar la letra del tema musical, aparece un recitado grabado al revés. Es decir que para poder entender lo que dice es necesario reproducirlo de atrás hacia adelante. Dichas palabras 
corresponden a la decimoséptima sextina ${ }^{53}$ del Martín Fierro del poeta argentino, José Hernández.

Más allá de que la elección de dicha obra literaria da cuenta de un diálogo con la cultura local argentina - de lo cual me ocuparé más adelante-, el formato de grabación a la inversa se relaciona con los juicios a algunas bandas de metal durante los ' 80 y ' 90 , que suponían que si se reproducían sus canciones al revés era posible encontrar mensajes satánicos, tal como sucedió con Judas Priest en 1990. Entonces, al hacerlo adrede se puede ver cómo Hermética juega con dicha creencia y se burla de ella recitando versos cuyo mensaje es la prédica de la fraternidad. Además,

(...) grabar de ese modo la letra implica, como gesto estético, afirmar que, si bien se asume esa tradición literario-poética, no se la seguirá al pie de la letra, no se la aceptará pasivamente: se la asumirá bajo la particularidad del sujeto que la propone como propia. (Pisano, 2016, p. 99. Nota al pie)

Esto, a su vez, consiste en un gesto de transgresión y de rebeldía hacia la tradición literaria hegemónica que propone al Martín Fierro como una obra canónica ${ }^{54}$. Este caso demuestra que en Hermética las formas de transgresión no solo se desarrollan en sus aspectos musicales, sino que se agudizan en los elementos extra-musicales, de los cuales me ocuparé a continuación.

\section{Plano visual}

Como mencioné anteriormente, fueron en mayor parte ciertos rasgos del metal por fuera de lo estrictamente musical los que generaron una recepción polémica. Entre ellos es posible considerar a su aspecto visual, plano en el cual también se desarrollaron modos de transgresión de la hegemonía cultural. Tal como expresa Weinstein (2000),

La potencia sonora del heavy metal es respaldada y mejorada por una amplia gama de artefactos y efectos visuales que muestran su significado inherente. El aspecto visual del heavy metal comprende una amplia gama de elementos que incluyen logos de bandas, portadas de álbumes, fotografías, parches y camisetas; elementos visuales de la actuación en vivo como el vestuario de conciertos, efectos de iluminación, escenarios y coreografía; e ilustraciones de revistas e imágenes de videos musicales. (Weinstein, 2000, p. 27. T. de la A.)

\footnotetext{
${ }^{53}$ Se refiere a los famosos versos que dicen: "Los hermanos sean unidos / porque esa es la ley primera / Tengan unión verdadera / en cualquier tiempo que sea / Porque si entre ellos pelean / los devoran los de afuera."

${ }^{54}$ Sobre este aspecto se discutirá en el capítulo vinculado con el metal y la política.
} 
Todos estos elementos pueden ser analizados en Hermética. En primer lugar, la banda posee un logotipo que la caracteriza y fue diseñado por Ricardo Iorio. En el metal, dicho elemento sirve para identificar a la banda, no solo verbalmente a través del nombre, sino también visualmente por medio de la estilización de la tipografía (Weinstein, 2000). Con este objetivo, se evitan los formatos redondeados, que dan la sensación de suavidad, y los diseños del tipo Helvética, ya que son demasiado neutrales y carecen de adornos. Entonces,

Los requisitos mínimos para un tipo de letra de heavy metal son angularidad y grosor. Los tipos de letra son más elaborados que las letras simples, incorporando una multitud de ángulos oblicuos y extremos bastante cuadrados. Algunos se parecen a las letras rúnicas y teutónicas. Otros tienen una maza amenazante que rompe la armadura o una apariencia de diente de sierra. (Weinstein, 2000, p. 27. T. de la A.)

Hermética posee su propio logotipo (ver figura 3), el cual no solo consiste en la palabra completa sino también en la reducción a la letra hache (ver figura 4), lo que resulta clave para los posteriores cánticos por parte de sus aficionados. En ella las letras son angulosas y la tilde posee forma de rayo y el punto de la "i" es reemplazado por un pentagrama o estrella pitagórica. Ambos refuerzan el significado esotérico del nombre de la banda. Más adelante se verá que Iorio no solo se inspiró en el ocultismo y el hermetismo para bautizar a su conjunto musical, sino también para la escritura de las letras de sus canciones.

Otros elementos visuales importantes son las portadas de los discos. En la época en donde el heavy metal se cristalizó, es decir, a fines de la década del '70, el álbum era el mayor medio para grabar la música. Entonces, el arte de las portadas no solo tiene la función de marketing, sino que también forma parte de la experiencia estética de la cultura del rock, ya que intenta identificar a la banda y proyectar en la audiencia el deseo, la actitud y la emoción a través de la imagen (Weinstein, 2000).

De acuerdo al código propuesto por el metal, visualmente “(...) lo representado debe ser algo ominoso, amenazante y perturbador, sugiriendo el caos, rosando lo grotesco." (Weinstein, 2000, p. 29) De este modo, las formas de transgresión que aparecen visualmente en las portadas de los discos de thrash metal se vinculan con la representación de situaciones de amenaza y caos.

En Hermética estos tópicos no solo aparecen sino que lo hacen de una manera singular, ya que todas las portadas (excepto la de Intérpretes) organizan sus elementos de forma piramidal, por lo que es posible ver posiciones superiores sobre otras 
inferiores. El primer lugar se encuentra ocupado por figuras de diversos victimarios/ opresores y, el segundo, por distintas víctimas/oprimidos. Esto se hace más evidente en las situaciones ilustradas, las cuales dan cuenta de eventos de violencia.

Un primer ejemplo aparece en el primer disco, el cual fue editado en 1989 en formato vinilo y en cassette por Radio Trípoli Discos (discográfica nueva para ese entonces) y distribuido por DBN. Fue titulado con el nombre de la banda, es decir, Hermética (ver figura 5) y su portada fue realizada por Franco Médici, un artista amigo de la difunta esposa de Ricardo Iorio que trabajaba para la revista D'artagnan ${ }^{55}$.

En dicho arte de tapa es posible ver como imagen denotada la ilustración de un carruaje tirado por dos caballos y conducido por una imagen espectral que se asemeja a la figura de Caronte, quien, según la mitología griega, era el barquero del Hades que llevaba a las almas errantes a través del Río Aqueronte. Debajo del carruaje aparecen varios hombres atropellados por el vehículo y otros amarrados a él por el cuello, arrastrados de manera violenta por el suelo en medio de una gran polvareda, cuyos rostros expresan sufrimiento.

Más allá de que el posicionamiento de cada personaje y su caracterización posee una connotación ideológica (de la cual me encargaré en el capítulo referido al metal y la política), aquí la transgresión aparece por medio del retrato de un evento de violencia. Por otra parte, la presencia del conductor fantasmal se vincula con la estética del horror en la que se inspira el metal en general. Además, por su posición en la imagen, se sugiere metafóricamente que las riendas de la vida están en manos de un ser terrorífico y, así, el poder parece adquirir las mismas características.

Luego de Hermética, en 1990 la banda graba un LP de covers titulado Intérpretes (ver figura 6), cuya portada estuvo a cargo de Sergio Assabi y Eric de Haas y consiste en una fotografía de los miembros de la banda de aquel entonces (Ricardo Iorio en bajo y voz, Claudio O’Connor en voz, Antonio “Tano” Romano en guitarra y Antonio "Tony" Scotto en batería), frente a un galpón ferroviario que había sido ocupado por la empresa alimenticia, Sasetru, la que, al igual que otras fábricas, fue cerrada en 1981 como consecuencia de la crisis que se desarrolló a partir del plan económico de José Alfredo Martínez de Hoz durante la dictadura militar.

La selección de una fábrica cerrada como símbolo del desempleo masivo también estuvo presente en la banda de la NWOBHM, Judas Priest, la cual decidió

\footnotetext{
${ }^{55}$ D'Artagnan era una revista argentina de historietas que se publicaba entre 1957 y 2000 por la Editorial Columba de Buenos Aires.
} 
titular a su disco British Steel, editado en 1980, año en el que la compañía que llevaba ese nombre fue privatizada dejando sin trabajo a gran cantidad de obreros: “Originalmente se trataba de una industria privada que por algún tempo fue nacionalizada, pero con las políticas neoliberales de la primer [sic] ministra del Reino Unido Margaret Thatcher, en la década de los años ochenta la empresa sería privatizada nuevamente.” (Domínguez Prieto, 2016, p. 6. Nota al pie)

La transgresión en esta portada se puede visualizar en que no se trata de una fotografía "estándar", sino que está diseñada con efectos en color rojo y negro, los cuales son los que prevalecen en el metal, ya que al contrario de tranquilidad y neutralidad, intentan expresar intensidad, excitación y amenaza (Weinstein, 2000, p. 29).

Dicha combinación de colores también se puede vincular con tonalidades elegidas por bandas de rock angloamericanas, como Pink Floyd, y por los revolucionarios latinoamericanos de izquierda. Por otro lado, en la portada, el paisaje de fondo no se constituye como un espacio agradable, sino que se trata de un lugar abandonado que simboliza el decaimiento económico del país en ese contexto.

En 1991, la banda graba el disco Ácido argentino (ver figura 7), que fue editado en cassette y vinilo por Radio Trípoli Discos y posteriormente lanzado en formato CD por DBN. El diseño de la portada fue realizado por José “Chiche” Ilaluz, un artista que sufría de párkinson. Sin embargo, la idea fue nuevamente de Ricardo Iorio.

A pesar de que esta portada también se encuentra organizada de manera piramidal dando la sensación de victimarios/opresores por sobre víctimas/oprimidos, la disposición en su interior representa caos. Al mismo tiempo, se ilustran diversas situaciones de violencia: aparecen la figura de Tío Sam, símbolo del gobierno de Estados Unidos, con las manos encima del cuello del personaje de la Libertad, en posición de ahorcamiento; varios cuerpos yacentes; dos policías reprimiendo a las Madres de Plaza de Mayo; y dos militares apresando de manera violenta a un joven.

También aparecen ilustraciones de elementos que generan la impresión de caos y destrucción: la presencia de algunas aves negras, símbolos de mal agüero; varias construcciones destruidas y la imagen del ferrocarril tapiada; y un par de manos esposadas, como símbolo del encierro, la detención y/o la esclavitud.

Además, al igual que la figura espectral del disco Hermética, aquí aparecen dos esqueletos ilustrados como si estuvieran en movimiento, los que se pueden relacionar con la tradición artística de la "Danse macabre" del medioevo. Debido al contexto de la 
peste negra, la representación de la danza de la muerte da cuenta de un cambio de sensibilidad ante la caducidad de la vida y de una visión aleccionadora $\mathrm{y}$ democratizante, ya que “(...) la muerte arrastra en su rondalla musical a todos los seres humanos, sean quienes fueren, sin tener en cuenta su edad (juvenes et senes rapio) y sin considerar su condición social, estamento o capacidad económica." (González Zymla, 2014, p. 25. Cursivas del original)

Entonces, podría deducirse que en Hermética la presencia iconográfica de la muerte no solo dialoga con la tradición visual del metal, sino que también da cuenta de una lectura metafórica de su contexto de producción, es decir, de la crisis económica y social producida por el neoliberalismo ${ }^{56}$ en la década del ' 90 . Al mismo tiempo, la idea de la muerte como igualadora da cuenta de un modo de reacción frente a las diferencias sociales y económicas.

El disco Víctimas del vaciamiento (ver Figura 8) fue grabado en agosto y septiembre de 1993 en Estudios del Abasto de Álvaro Villagra. Lo editó Radio Trípoli Discos en formato CD y cassette. La portada en este caso tiene una historia especial, ya que en un primer momento se convocó a la artista plástica, Marina Devesa. Ella realizó un diseño basándose en algunas ideas que Ricardo Iorio había tomado de imágenes de "El Bosco",57.

El dibujo luego fue rechazado debido a que se parecía a la portada de un disco de una banda española. Devesa creó otro dibujo atendiendo a las nuevas ideas de Iorio. Sin embargo, la banda no quedó conforme con esta ilustración, por lo que pidieron a Christian "Tatú" Heredia que volviera a realizar el mismo diseño y resultó ser ese el definitivo. Este joven era un pintor amateur que en varias oportunidades había realizado banderas y telones para la banda.

En Víctimas del vaciamiento aparece nuevamente una imagen denotada compuesta por una multiplicidad de elementos. Una diferencia con Ácido argentino es que está realizada en blanco y negro, mientras la anterior se compone de imágenes con fuertes colores brillantes, muy saturados. Otra divergencia es que, en el resto de las

\footnotetext{
56 Según, David Harvey (s.f.): "El neoliberalismo es, ante todo, una teoría de prácticas político económicas que afirma que la mejor manera de promover el bienestar del ser humano, consiste en no restringir el libre desarrollo de las capacidades y de las libertades empresariales del individuo, dentro de un marco institucional caracterizado por derechos de propiedad privada, fuertes mercados libres y libertad de comercio. El papel del Estado es crear y preservar el marco institucional apropiado para el desarrollo de estas prácticas." (Harvey, s.f., p. 8). En Argentina, dicho modelo económico fue implementado por Carlos Saúl Menem y, posteriormente, por Mauricio Macri.

57 "El Bosco" era el sobrenombre del pintor neerlandés, Hieronymus Bosch. Este vivió entre 1450 y 1516 y sus cuadros representaban, principalmente, a la humanidad condenada por sus pecados.
} 
portadas, el logotipo de Hermética aparecía en el encabezado y, en este caso, se encuentra dentro de los elementos de la ilustración. La similitud se presenta en el ordenamiento piramidal, cuya connotación da cuenta de victimarios/opresores y víctimas/oprimidos.

Aquí la violencia aparece en primer plano, representada con las manos que parecen intentar lastimar el cerebro de un joven con un hueso punzante. Sin embargo dicho elemento se presenta de manera confusa con la representación del jabón "Federal", una conocida marca argentina de panes de jabones, y la espuma alrededor de la cabeza junto con una tabla de lavar la ropa. Esto podría connotar dos interpretaciones: primero, la idea de "lavar la cabeza" (es decir, convencer a alguien de determinadas ideas) o el lavaje de heridas producidas por las manos amenazantes. Sobre las connotaciones ideológicas de dichos elementos me explayaré en el apartado sobre metal y la política.

Además de esto aparecen otros elementos que dan cuenta de caos, como por ejemplo una cantidad de troncos como producto de la deforestación. También se presentan transgresiones a lo que Angenot (2012) denomina fetiches (la Patria, el Ejército, la Ciencia) y tabúes (el sexo, la locura y la perversión), utilizados por la hegemonía discursiva, a través de varias imágenes escatológicas: la presencia de dos perros copulando, la ilustración de un hombre sentado sobre un inodoro en una casa en ruinas, y la exhibición de la masa encefálica en la cabeza del joven, dibujo que dialoga con el cine gore.

También se ve la oposición a lo considerado "aceptable" o "respetable", a través de la presencia de un grupo de jóvenes bebiendo cerveza directamente de la botella, sentados en la vereda o apoyados en las paredes de una esquina de la vía pública, práctica que durante los '90 caracterizaba a los jóvenes de barrios marginales y sobre la cual existía una mirada prejuiciosa.

Si se tiene en cuenta que, "Las portadas del álbum, a menudo reproducidas en camisetas, están diseñadas para transmitir un estado de ánimo o un sentimiento.” (Weinstein, 2000, p. 29. T. de la A., se puede observar que en el arte de tapa de los tres discos analizados se representan sentimientos tales como agresividad (por parte de los victimarios/opresores), dolor y sufrimiento (en el caso de las víctimas/oprimidos).

Por otra parte, "Las imágenes visuales contextualizan la música o al menos proporcionan una pista de su significado, una referencia en términos de la cual apreciarla." (Weinstein, 2000, p. 29. T. de la A.) Sin embargo, a pesar de que la música 
de Hermética tiene un sonido agresivo y las ilustraciones de las tapas se podrían interpretar fácilmente como una apología de la violencia, más adelante con la referencia al plano verbal se podrá ver que la banda se posiciona en el lugar de las víctimas/oprimidos, por lo que en realidad las situaciones ilustradas son hechos que se denuncian.

Además de ocupar un rol importante en los discos, "Los visuales también son una parte integral de la experiencia de un concierto de heavy metal" (Weinstein, 2000, p. 29. T. de la A.), y se presentan en el vestuario utilizado por los músicos y en el diseño escenográfico del show.

De acuerdo a las fotos de Hermética durante sus años de actividad, publicadas en revistas como Madhouse, Jedbangers y Efecto Metal, pude constatar que los músicos utilizaban un look "thrashero", ya que se trataba de vestuario con un estilo más "callejero" que los elementos artísticos y heroicos que caracterizaban a la indumentaria de los músicos de la NWOBHM. Por lo que, de este modo, los músicos y los aficionados se parecían en su apariencia (Weinstein, 2000, p. 49).

Los músicos de Hermética utilizaban borceguíes, pantalones negros de jean y de cuero, y gran cantidad de remeras con logotipos de bandas, tales como Ozzy Osbourne, Metallica, Slayer, Pantera, Danzig, V8, Hermética y, predominantemente, Motörhead; además de camisetas con estampas de festivales como el Monsters of Rock, con el logotipo de la revista Madhouse o de la marca de platillos de batería, Zidjian, y con símbolos del anarquismo.

También usaban camperas de cuero, las cuales eran más características de la década de los '80, por lo que el look metálico "thrashero" podría significar una ruptura con respecto a la moda hegemónica de los '90, cuyos diseños masculinos se inspiraban en estilos musicales que eran masivos en ese entonces, tales como el grunge y el hip hop. Además, los músicos de la banda utilizaban el cabello largo. En el metal este había sido heredado de las bandas hippies y psicodélicas de los '60, pero en el caso del thrash metal se llevaba de forma natural y desprolija para contraponerse a los batidos de cabello que caracterizaban al look del glam metal.

El cabello resulta una cuestión central en Iorio. En su etapa en Hermética, primero lo lucía largo y, repentinamente un día de 1993, apareció rapado, lo que le llamó la atención a sus seguidores de la época. De acuerdo a la biografía de dicha banda publicada en la revista, Efecto Metal del año 2014, las palabras de Iorio fueron: 
Mi pelo fue sinónimo de rebeldía y lo mostré en los ocho discos que grabé. Lo tuve largo cuando todos eran vigilantes y en cualquier esquina te paraban por tenerlo así. Ahora que Diego Torres, JAF y Guillermo Fernández tienen pelo largo, yo me rapo. ¡iAhora que ellos lo tengan largo!! (Iorio citado en Efecto Metal, 2014, p. 34)

Aquí se puede trazar un paralelo con la cultura skinhead, cuyo estilo se caracteriza justamente por la cabeza rapada. Estos grupos juveniles nacieron en Reino Unido en 1969, a partir de la intención de diferenciarse del cabello largo utilizado por los hippies y contraponerse mediante una estética obrera ${ }^{58}$, aunque ideológicamente se identificaban con la apolítica y los ideales anti-sistema. Posteriormente se abrieron dos vertientes, una vinculada al neonazismo y otra, con el antifascismo. En Argentina, en la década de los '90, es decir, en el contexto de producción de Hermética, se hizo visible la presencia de skinheads de ideología de extrema derecha.

La actitud de Iorio de diferenciarse de determinados músicos es similar a la de los skinheads y en las declaraciones citadas se puede leer un tono despectivo con respecto a estilos musicales que estaban de moda en ese momento, como el pop y la balada. Posteriormente, de usar la cabeza totalmente calva, el músico pasó a llevar el peinado conocido como "cresta" o "mohicano". Este corte consiste en rapar ambos lados de la cabeza y dejar el cabello del medio más largo.

El origen de este peinado es incierto, pero se lo comenzó a asociar con la etnia Mohawk o mohicana (proveniente del pueblo Iroqués, que habitaba lo que hoy se conoce como Estados Unidos) a partir de la película Corazones indomables (1939) de John Ford. En la década de los '80 fue popularizado por las culturas del punk rock. Más tarde, fue resignificado con diferentes versiones a partir de nuevos usos: por ejemplo, fue utilizado por el ejército de Estados Unidos durante la Segunda Guerra Mundial y, en su versión más corta, comenzó a identificarse con el estilo de cabello militar.

En el caso de Iorio se puede observar que la "cresta" que lucía en los '90 se fue modificando con el paso del tiempo, ya que en un inicio se asemejaba al estilo punk pero, a partir del 2017, el músico comenzó a peinarla hacia un costado por lo que empezó a parecerse más al corte de cabello de estilo militar, estilo que parece acompañar su posición ideológica vinculada a la ultraderecha.

\footnotetext{
58 John Clarke aclara que “(...) la reacción de los Skinheads contra los Hippies no es únicamente manifestada en la oposición entre sus peinados y sus vestimentas, sino en los maltratos físicos a los Hippies (a veces bajo la apariencia de $<<$ ataques a maricones $>>$ o sus $<<$ invasiones $>>$ en los conciertos gratuitos de Hyde Park)." (Clarke, 2010, p. 320)
} 
En general, el look metálico a nivel global puede ser comparado con los diversos estilos de las subculturas juveniles de Inglaterra en la posguerra, debido a que se constituye como una práctica significante (Hebdige, 2004) en la medida que intenta construir una diferencia mediante la resignificación de elementos cultuales ya existentes -o la operación del bricolage cultural, tal como lo define Clarke (2010) utilizando la terminología de Levi-Strauss-. Para Weinstein (2000) el estilo de la NWOBHM deriva de las culturas motoqueras, hippie y obrera.

En cuanto a las características escenográficas de Hermética, fue posible analizarlas en el video en formato VHS, Hermética en vivo. 1993. Argentina, editado por Radio Tripoli Videos. Tal como plantea Weinstein (2000), los videos musicales permitieron expresar visualmente la sensibilidad del metal, cuya regla principal era que “(...) un elemento fuerte en el video debe ser la secuencia de un concierto o un facsímil realista.” (p. 31. T. de la A.)

Esta búsqueda de realismo chocaba con la teatralidad y la artificialidad que había cultivado primero el glam rock y, luego, la NWOBHM y otros géneros musicales opuestos al metal, como el pop. De esta manera, el realismo presente en el thrash metal y en la corriente fundamentalista se convierte en símbolo de "autenticidad".

Esta postura aparece en Hermética en la decisión de no grabar videoclips, sino directamente un concierto de principio a fin. Allí se pueden ver las performances de los músicos, las que se desarrollan de modo thrasher, es decir, se caracterizan por una fuerte presencia de headbanging, tal como lo realizaban sus seguidores, además de la ejecución exagerada de los instrumentos, acompañada de gestos faciales que denotan esfuerzo físico.

Allí, el escenario se encuentra emplazado a través del esquema italiano, por lo que la banda aparece en escena enfrentada al público. A pesar de que todos los músicos se desplazan (excepto el baterista) y de que se realizan primeros planos al guitarrista durante los solos, el cantante se destaca por sobre el resto. Él parece estar más cerca del público y gracias a la posesión de la voz puede interactuar con la audiencia mayormente que el resto de sus compañeros. Esto también aparece (pero en menor proporción) en el caso de Iorio, quien además de tocar el bajo en algunas canciones también canta y hace coros.

Con respecto a la escenografía se puede ver el predominio de luces de color rojo, las cuales son características del metal y dan la sensación de caos y excitación. Estas en algunos casos se alternan con luces azules y cuando Iorio pasa a cantar desde un costado 
del escenario, una luz lo ilumina desde arriba. También hay fuertes efectos de niebla y viento que permiten que el cantante se muestre como un guerrero. Esto aumenta con la introducción del tema "Sepulcro civil", en el que todos los músicos tararean algo similar a un grito de guerra, al que el público también acompaña.

Por último, se puede observar un gran telón en el fondo del escenario con el logotipo de Hermética en colores blanco y negro. Pero es necesario destacar que las tomas de dicha grabación no solo enfocan al escenario sino que también muestran al público que, a pesar de encontrarse casi a oscuras, es posible notar que se trataba de un teatro de capacidad colmada. Además, otro elemento importante es que aparece el subtitulado de las letras de cada una de las canciones que se ejecutan, por lo que a continuación se verá la importancia que tiene el plano verbal para la banda.

En resumen, es posible decir que la transgresión en el plano visual de Hermética se da principalmente en las portadas de sus discos y en la representación gráfica de eventos de violencia. En cuanto a su performance, se puede observar que todos los músicos lucían atuendo metálico thrasher, lo que más más adelante se podrá ver que resultaba polémico para la época. En cuanto a la composición escenográfica del show, aparecen movimientos, formas de cantar, tipos de iluminación y efectos especiales que acompañan la significación de agresividad y potencia.

\section{Plano verbal}

El plano verbal en Hermética aparece en primer lugar con el nombre de la banda. De acuerdo a una entrevista realizada a Iorio en 1993 para un número especial de su banda editado por la revista Madhouse, explica que el nombre nace antes que agrupación en sí misma y que "Analizando diversos nombres consideré que ese era el que más representaba mi idea, dado que Hermética es una ciencia, que es como paria dentro de todas las religiones, porque todas la condenan como algo oculto que tiene que ver con los espíritus (...)" (Iorio en Madhouse, 1993).

De acuerdo a la biografía del músico escrita por el periodista Ariel Torres (2012), el primer nombre que se le había ocurrido a Iorio era Helvética, el cual había sido inspirado por los acoplados de los camiones semi. Sin embargo, Iorio descartó dicho nombre por estar relacionado con Helvecia. De manera que,

La palabra "hermética", en cambio, por su etimología y por su relación con la alquimia (el adjetivo se aplica también a las especulaciones, escritores y libros atribuidos al 
filósofo egipcio Hermes Trimegisto) y el hecho de querer practicar una música más "cerrada", le pareció más adecuada para bautizar a su nuevo proyecto... su segundo gran proyecto. (Torres, 2012, p. 92)

En otra entrevista, Iorio ratifica el carácter cerrado e "impenetrable" que intentaba crear con la nueva banda, usando un adjetivo y las cualidades propias de la ciencia de la alquimia y la filosofía de Hermes Trismegisto. La búsqueda de cierto elitismo estaba dada por las letras de las canciones, las cuales expresaban "Cosas bastante selectas en sí, cosas que no van a poder enganchar los complacientes." (Iorio citado en Blumetti y Violante, 1993)

Entonces, la denominación Hermética resultó ser para el músico la mejor forma de calificar a su nuevo proyecto con el cual pretendía diferenciarse del resto de la música popular $\mathrm{y}$, al mismo tiempo, evocar a un público selecto. A partir de esta caracterización se pueden desprender los calificativos tales como "elitista", "cerrado" y "auto-marginal". Estos caracteres permiten la comparación con el movimiento literario italiano del Hermetismo, el cual durante la primera mitad del siglo XX desarrollaba una forma de escritura poética oscura que le permitía sortear la censura del fascismo.

Por otra parte, la relación con la filosofía hermética acerca a la banda a la tradición del blues y del rock vinculada con el esoterismo. En algunos trabajos se explica que el blues se identificaba con lo satánico frente al góspel que lo hacía con el cristianismo, lo cual se intensifica con la utilización por parte del primero de los intervalos disonantes de quinta disminuida o de cuarta aumentada, que en la Época Medieval eran denominados "acordes del diablo" o "diabolus in musica" (Salmerón Infante, 2015). Esta misma tradición es recogida por la banda británica, Black Sabbath, la que ya en su nombre da cuenta del contenido esotérico presente en sus producciones.

También es relevante el vínculo del rock con el ocultismo, entre los que se pueden citar la relación de Jim Morrison de The Doors con el chamanismo y la admiración que varios músicos tenían por Aleister Crowley, místico ocultista británico, fundador de la filosofía del Thelema, la cual tuvo gran influencia en la contracultura hippie por su veneración de la libertad sexual y el consumo de drogas. La presencia de Crowley no solo es posible encontrarla en artistas como John Lennon y The Beatles, y Jimmy Page de Led Zepellin, sino también en algunas bandas metálicas tales como Ozzy Osbourne, Iron Maiden, Behemot y Cradle of Filth (Rafanelli, 2015).

La importancia del nombre en Hermética aparece doblemente acentuada si se tiene en cuenta que el primer disco de la banda lleva el mismo nombre. Existen muchos 
casos de bandas que deciden titular sus primeros discos al igual que el conjunto musical. Esto funciona mayormente como un dispositivo de promoción cuando se trata de una banda nueva. El mismo mecanismo de reiteración se puede ver en el tercer disco titulado Víctimas del vaciamiento, que repite el título de una canción del primer disco y posiblemente la intención sea explayar el sentido de dicha frase.

Por su parte, el disco, Ácido argentino, ubica a la producción dentro de un espacio particular mediante el uso del adjetivo gentilicio "argentino". En su biografía, Iorio cuenta que muchos relacionaron al título del disco con una forma de describir a su generación, pero en realidad su idea original era hacer una imagen troquelada que se asemeje a una plancha de ácidos (Iorio en Torres, 2012, p. 115).

Más allá de la explicación del propio autor, el sustantivo ácido puede servir como metáfora e imagen gustativa del contenido general del disco: es decir que las producciones allí no son dulces (adjetivo con el que por lo general se caracteriza a las canciones románticas) sino ácidas, ásperas, agrias, es decir, adjetivos que describen lo contrario a placentero. El gentilicio argentino ubica el contexto del contenido de las producciones.

Además del nombre de la banda y los títulos de los discos, también están las letras de las canciones. A pesar de que en el metal el sonido es más importante que las palabras, las líricas son relevantes por dos motivos: Primero, porque permiten la presencia de la voz humana, la cual no solo es considerada un instrumento musical más, sino que también su importancia radica en ser la forma primaria de comunicar emociones (Weinstein, 2000, p. 125), fundamentales para la expresión de fuerza y potencia, características definitorias del estilo musical.

Y, segundo, porque, tal como afirma Weinstein (2000), la audiencia demuestra su compromiso hacia la banda y el género musical al conocer y recordar las letras de las canciones (Weinstein, 2000, p. 123). Además, "Si la música le da a las letras su vitalidad lingüística, las letras le dan a las canciones su uso social." (Frith, 1989, p. 93. T. de la A.) y "El ritmo se puede ver como un medio para transmitir la letra de una manera rítmica, enviándola a lo profundo de la mente del oyente.” (Lull, 1987b, p. 146. T. de la A.)

En el caso específico de Hermética, anteriormente se pudo observar que el video del show en vivo editado en formato VHS contiene los subtítulos de las letras de las canciones $\mathrm{y}$, además, las primeras ediciones de sus discos en formato vinilo y cassette incluían las líricas. Esto demuestra que ellas resultan importantes para la banda. Por otro 
lado, a partir del trabajo etnográfico pude ver que la mayoría de los aficionados destacan a las canciones de Hermética por sus letras.

Weinstein (2000) explica que la dimensión verbal está compuesta por los nombres de las bandas; los títulos de los álbumes y las canciones; y las letras. Las temáticas recurrentes en ellas son divididas por la autora en dos grupos opuestos: por un lado, los temas dionisíacos y, por el otro, los caóticos. Los primeros se refieren a formas de celebrar la vida, entre las que privilegia a la tríada "sexo, drogas y rock and roll". Los segundos dan cuenta de todo aquello que desafía y transgrede el orden y la hegemonía, por medio de asuntos como la muerte, la destrucción, la violencia y la anomalía.

Como ya mencioné, Hermética fue una banda de thrash metal. Este subestilo se caracterizó por conformar una corriente fundamentalista que se oponía en todos los planos (musical, visual y verbal) al lite o glam metal. Este, a diferencia del thrash, se distinguía por desarrollar temáticas dionisíacas. Por el contrario, el thrash metal se caracteriza por el discurso del caos construido por medio de canciones cuyas letras son más explícitas que alusivas.

Esto lo diferenciaba del heavy metal tradicional cuyas fuentes de temas caóticos eran el misterio y la fantasía. El thrash, en cambio, intentaba mostrar el caos en el mundo real. Por ello sus canciones describían "El aislamiento y la alienación de los individuos, la corrupción de los que están en el poder y los horrores cometidos por las personas entre sí y el medio ambiente.” (Weinstein, 2000, p. 50. T. de la A.)

Estos tópicos están presentes en las canciones de Hermética y la mayoría de ellos hacen referencia a problemáticas que son consecuencia de las políticas económicas y culturales neoliberales del contexto de producción de la banda. Por ejemplo, el aislamiento y la alienación aparecen en la canción "Cuando duerme la ciudad" (1994), en donde se describe de manera realista la situación de un joven vagabundo, abandonado por su familia y la sociedad, que es perseguido por la policía:

La ciudad dormida y él anda aún, / buscando un amigo que no se abra de piernas. / Las patrullas, sé, no lo dejarán, / porque para eso allí están.

El vecindario que le sonrió de niño, / lo denunció por verlo muy despreocupado. / Y al no querer herir a quien lo trajo a vida, /anda por la ciudad dormida, / sin lugar donde parar.

Reformatorios policiales son el sitio / donde condenan al menor no reclamado. / La sociedad lo adopta como hijo de puta, / por eso escapa de la yuta cuando duerme la ciudad. 
Hermética era una banda proveniente de Capital Federal y muchas de sus canciones hacen referencias a elementos de ese espacio geográfico. Posiblemente la situación descrita en la letra haga alusión a una escena típica de dicha ciudad en la década del 90, ya que la presencia de menores en situación de calle aumentó en las metrópolis durante la época de producción de esta canción.

Otro de los temas propios del thrash metal es la denuncia de la corrupción de quienes están en el poder (Weinstein, 2000). Un claro ejemplo de ello aparece en el tema "Olvídalo y volverá por más" (1994), cuya letra describe las acciones de un político corrupto que no cumple con las promesas hechas durante las campañas electorales y, sin embargo, tiene posibilidades de ser votado en la próxima elección:

Politiqueando un doctor de la ley / ganó lugar con sólo prometer. / Carnes asadas convidó al pueblo, / quien dio su voto creyendo / que poseía sensibilidad social, / que cumpliría sin aflojar. / Con sus discursos preelectorales, / con los que tejió su fraude.

En un avión se llevó el dineral, / a donde nadie sabe. / Seguro de que pronto lo olvidarán / y podrá postularse otra vez.

Fue groso el toco que pegó al rajar, / amasijando la capital. / El desvalije está latente, / lo sabe hasta el presidente.

En un avión se llevó el dineral, / a donde nadie sabe, por supuesto. / Seguro de que pronto lo olvidarán / y podrá postularse otra vez, nuevamente.

Olvídalo y volverá por más, / mostrándose confiable en los carteles. / Con prometer a muchos fascinará, / y con su nombre pintarán paredes.

La muerte es ocultar la verdad, / el vacío es dejarse mentir. / En un avión se llevó el dineral, / y volverá por más cuando lo olvides.

Teniendo en cuenta el contexto de producción de la canción, es posible relacionarla con la reelección del presidente Menem en 1995 gracias al Pacto de Olivos de 1994. A pesar de que la canción hace alusión al sistema electoral como un elemento propio de la democracia, se refiere a la contracara de ciertas experiencias democráticas a través de la descripción de los políticos como ladrones y demagogos que, por medio de campañas falsas, seducen a votantes crédulos. La expresión "carnes asadas" no solo alude a un mecanismo de las campañas electorales, sino también a una situación que caracteriza específicamente a los partidos políticos argentinos.

Otra de las temáticas del thrash metal es la referencia a los horrores surgidos por el enfrentamiento entre los hombres. Un ejemplo de ello aparece en la canción "La revancha de América" (1991), en la cual se narran las consecuencias de la colonización de América, las que no solo afectaron a las poblaciones aborígenes, sino también al medio ambiente: 
Pueblos nativos del suelo mío / fueron saqueados y sometidos / por la siniestra garra de la madre perra, / que orgullosa festeja quinientos años/ de haber llegado con sus carabelas / a succionarnos e imponernos fe / estrechos dogmas de su infernal sed. / De los caminos que dan a andar / avergonzado me quiero zafar. / Estos zarpados revientan el planeta/ al ver sus reinos en la nada ahogarse. / Obsérvalos ostentando riquezas/ que formaron en la tierra del sol/ cristianizando, civilizando. / De ese castigo debes zafar, / toma revancha América. / Pueblos nativos del suelo mío/ están viciados y confundidos / por la siniestra garra de la madre perra, / que orgullosa festeja quinientos años/ de haber llegado con sus carabelas / a succionarnos e imponernos fe / estrechos dogmas de su infernal sed. / De ese castigo debes zafar, / toma revancha América.

En esta canción, la descripción de un hecho histórico a través de una óptica indigenista no solo da cuenta de la referencia a una situación local de violencia, sino que además permite realizar una denuncia, lo que también es un carácter específico del thrash metal. Por otra parte, la referencia al festejo realizado por España en 1992 por los quinientos años de la colonización de América da cuenta del contexto en el cual se produjo la canción, perteneciente a un disco editado el año anterior.

Por último, la temática del caos que caracteriza al thrash metal es la destrucción del medioambiente. Es posible encontrar una referencia a ella en el tema "Masa anestesiada" (1989) que contiene los versos: "Porque han traído basura nuclear/ al suelo limpio y rincón final. / Donde no hay fábricas de muerte aun, / y no se comercializó el ataúd. / ¡Oh, no! / No echen / sobre mí su error. / ¡No! / No tapen la luz / con la enorme cruz de su desviación."

En esta canción, Hermética se refiere a la presencia de desechos nucleares en Argentina y problemáticas de la salud como consecuencia de la contaminación ambiental. En la perspectiva de la banda, Argentina ("el rincón final") tenía un "suelo limpio", lo que significa que los daños en el medio ambiente fueron traídos desde fuera del país.

Otra canción que se refiere a los desastres ambientales y que nuevamente menciona a los desechos nucleares es "Otro día para ser" (1994). Aquí la contaminación es vinculada con la tecnología, la cual es promovida por los gobiernos en pos del progreso:

Desnudar el sin razón, que modeló nuestras vidas / parece ser causa perdida. / Nadie apuesta a detener, el motor que contamina/ el aire que a diario respiras, / y que respiraste ayer / y que mañana tal vez, no lo sé.

Por eso hoy, reflexionando en esto, / la madrugada pasó y dejó otro día para ser.

Ser guardianes, o vigías de toda la miel / que guarda en toda colmena el sucio poder. / Predador, ecologista, pobre o gran señor. / Drogadependiente, doctor o paciente. / entreverado en el montón. 
Vender, comprar, comer, cagar, morir, nacer. / Sufrir, gozar, odiar, amar, ser o no ser. Culpable, inocente, malviviente o juez, / o quién, con solo su firma, decreta la ley. Pronucleares informistas, modelan la situación. / Más tecnología por más energía. / Fugas radioactivas del progreso.

Derrames de combustible, exterminio forestal. / El motor contaminante, no se detendrá. / Para ser, hay otro día, en el planeta inferior. / Como cualquier día. / Como todo día, / con o sin mi reflexión.

En ambos casos, la denuncia de la destrucción ambiental no solo implica una visión desencantada acerca de la tecnología sino que se la describe como proveniente del extranjero. Por otra parte, tanto la contaminación ambiental como los tópicos de los jóvenes en situación de calle, el fraude de las campañas electorales y la violencia ejercida durante la colonización de América no solo se vinculan con el thrash metal sino que también se refieren a situaciones del contexto local. Más adelante analizaré cómo el tratamiento de dichos tópicos está ligado con una ideología nacionalista esencialista.

La perspectiva que asume Hermética acerca de las temáticas mencionadas es la de denuncia y el thrash metal le proporciona la posibilidad de realizar esta operación, debido a que su postura retórica es similar a la de la canción de protesta (Weinstein, 2000 , p. 50). De esta manera, la banda no solo denuncia las consecuencias nefastas del contexto neoliberal, sino que también critica las características de dicho sistema.

Parte de ello se representa con la oposición a los consumos masivos propuestos por el modelo neoliberal, la cual aparece en un fragmento de "Masa anestesiada": "La gran masa anestesiada/ se revuelca en egoísmo. / Y si le encontró un sentido, / se ha entregado al escapismo." Esta postura se relaciona con el carácter underground del thrash metal, en el sentido de que rechaza los atractivos masivos (Wenstein, 2000, p. 48), considerados por Hermética como formas "escapistas" de la realidad. Justamente la moda y la masividad eran característicos del glam metal, opuesto al thrash.

Otro de los fetiches cuestionados por Hermética es la Iglesia, la cual no solo es referida como el medio por el cual se produjo la colonización de América -como alude el tema "La revancha de América" con las expresiones "cristianizando, civilizando" y "a succionarnos, a imponernos fe / estrechos dogmas de su infernal sed"- sino que también se la cuestiona mediante el desarrollo de temáticas esotéricas vinculadas al espiritismo.

A través de la biografía de Iorio es posible saber que el músico durante los últimos años de su época en V8 comenzó a interesarse en libros de la Escuela Científica de Basilio, una organización espiritual/religiosa, fundada en Buenos Aires el 1 de 
noviembre de 1917 por dos inmigrantes franceses: Eugenio Portal (1867-1927) y Blanca Aubreton de Lambert (1867-1920). Dicha institución constituye "uno de los grupos espíritas más importantes del campo esotérico argentino del siglo XX” (Bubello, 2017, p. 38), que mediante la reapropiación de terminología propia de la ciencia moderna buscaba diferenciarse de las prácticas esotéricas secretas.

Esta agrupación espiritista también se destacó por ser apoyada por Juan Domingo Perón en 1950, durante un acto de la institución encabezado bajo el lema, “Jesús no es Dios". El gobernante, a partir de 1946 había amparado al catolicismo, pero en dicho evento se hizo evidente su cambio de postura. En él los miembros de Acción Católica reaccionaron con protestas encabezadas con la frase "Jesús es Dios", causando disturbios y la intervención policial. Para Susana Bianchi (1996) este suceso marcó el primer conflicto abierto entre la Iglesia Católica y el Peronismo.

Entonces, el vínculo con la Escuela Científica Basilio le permitió a Iorio introducir temáticas esotéricas en sus canciones, tal como lo propuso con el nombre, Hermética. De esta manera, desde el último disco de su primera banda, V8, hasta su carrera con Almafuerte, es posible encontrar múltiples referencias al espiritismo y al reencarnacionismo. El ejemplo más claro aparece en la canción, "Vida impersonal" (1989):

\footnotetext{
Ya no maltrates a tu animal / pues no lo debes vencer / sino amar y salvar / te lo digo antes de que estés

Ahogado por la pared / que sostienen las últimas sombras / que la congelan de revelación / sostenida por los muertos / que viven en lo externo

Que como nubes vienen y van / alimentando al Ser / testigos de la eternidad / incapaces de comprender / que es hora de amanecer

La tierra se iluminará / cuando liguen a su rollo la vida impersonal / y no existirá otra ley / que la íntima conciencia

No, no esperes de mi nada especial / no busco influenciarte ni convencerte. / Fuera de ti no hay ningún mediador / En el mundo no hallarás más que ilusión

Pues en el mundo no hallarás más que ilusión / Te lo digo hoy

(...) Destronando al cerdo sin paz / generación de serpientes ya reinar no podrá / No habrá velos que te impidan ver / la inmortalidad de tu ser

Fuera de ti no hay mediador / en el mundo no hallarás más que ilusión
}

Otro modo en que aparece el espiritismo es en el consumo grupal de marihuana como una forma de alcanzar la "intuición" o la comunicación con los espíritus, los cuales otorgaban nuevos conocimientos y revelaban las verdades que eran ocultadas por los medios de comunicación. Esto se puede ver en la canción "Soy de la esquina" (1994): 
Cervezas en la esquina del barrio varón. / Rutina sin malicia que guarda razón. / Quién olvidó las horas de su juventud. / Murmurando se queja ante esta actitud. Allí esperan mis amigos en reunión. / Mucho me alegra sentirme parte de vos. Conversando la rueda ya se formó / y las flores se queman buscando un sentido. / Mientras la noche muestra la calle en quietud, / la intuición esquinera encendió mi luz.

Tu risa amiga alejó mi soledad, esos momentos que / viví no he de olvidar. Sé que muchos cavilan, buscando el porqué. / Preferimos la esquina y no mirar tele. / Yo la creo vacía de realidad. / La verdad en la esquina está latiendo.

En este caso, el acto de fumar marihuana es referido mediante las "flores" que se queman, lo cual permite llegar a la intuición y con ella a la verdad. La idea de "rueda" alude al consumo grupal de un cigarrillo que se comparte y pasa de persona a persona, tal como la "pipa de la paz". Esta forma de consumo resulta muy similar al realizado por la cultura rastafari en donde la marihuana es considerada una hierba sagrada que es utilizada para la meditación y la comunicación con el dios, Jah. La temática de las drogas también aparece por medio de referencias a la cocaína con expresiones tales como "polvo inca" y "amargas sales", e incluso el término "drogadependiente".

En la canción "Soy de la esquina" también aparece el consumo de cerveza. Debido a esto, la reunión de amigos aparece como amenazante por ser opuesta a la sociedad respetable y al supuesto orden. Tal como describe Alabarces (2006) en los campos del fútbol, el rock y la cumbia villera,

(...) el consumo se defiende masivamente, porque significa resistir, alternativizar el mundo careta (hipócrita) de los chetos (ampliamente burgueses): es decir, un mundo de "formalidad burguesa" que sin embargo no se piensa en términos políticos ni estrictamente económicos -lo que sería político-, sino vagamente culturales. (Alabarces, 2006, p. 5$)^{59}$

La ilustración de lo que resulta opuesto a lo pulcro, lo ordenado, lo reglamentario y lo moralmente bien visto aparece con mayor claridad en la canción "En las calles de Liniers" (1994) que dialoga fuertemente con la canción "Mañana en el Abasto" (1987) del conjunto de rock, Sumo, ya que en ambas el "yo" lírico describe lo que sucede a su alrededor mientras camina por las calles:

\footnotetext{
59 Gustavo Blázquez (2012) explica que "cheto" y "negro" (lo que antes era "groncho") resultan ser antónimos: "Cheto es una categoría social que con nombres como pijo, fresa, pituco, patrizinha/maurizinho, pelolais, gomas, gomelos, wanabe, puede reconocerse en los mundos ibérico y latinoamericano. Estos términos designan a quienes buscarían representarse, más allá de su capital económico, como parte de las elites sociales/raciales y dueños del «buen gusto». Negro o villero serían antónimos de modo tal que desde la mirada centrada de los normales, chetos y negros representaban dos posiciones distantes y opuestas.” (Blázquez, 2012)
} 
En las mugrientas esquinas de Liniers pierdo los días pues no me toca escapar. / El gran apego a lo ilusorio se refleja en las vidrieras / de un trucho centro comercial.

La idolatría populosa se dibuja en largas filas / para adorar y no pensar. / La piedra muerta del desvío falsamente milagrosa / sigue ocultando la verdad.

Insatisfechos, renegados que se niegan a sí mismos, / faltos de calma y de piedad, / buscan el triángulo en las niñas para alimentar su morbo, / y masturbarse en soledad.

Ellas también gozan mostrándose inocentes, / son harpías, esclavas del televisor, / viven pensando en lo externo, son adictas a la vida / buscan billetes y pasión.

Sólo transmito lo que observo, / no es una invención de mi mente, no. / Esto acontece cuando contemplo el presente / en las calles de Liniers.

Mas cuando el sol, mi fiel testigo, da de lleno en el asfalto / y derrite el alquitrán / los fermentos nauseabundos de la basura estancada / entorpecen mi pensar. En la esquina un policía está peleando con su hembra / pues esta nunca le fue fiel.

Bajo el paso de las vías los mendigos se revuelcan / muy pocos los quieren mirar. Y la imberbe horda humana que desciende de los trenes, / desesperada y alocada / contamina mi cabeza y busco amarlos como sea / para no volver jamás. (...)

La descripción cruda de la realidad es utilizada para transgredir tabúes tales como la pedofilia, la masturbación, la prostitución y la violencia, así como también fetiches como la religión y las fuerzas del orden. La representación detallada de lo escatológico permite comparar a esta canción con la tradición literaria del realismo grotesco, propia de las expresiones de la cultura popular durante el carnaval en la Época Medieval que, mediante la evocación de la degradación, la vulgaridad y la monstruosidad, buscaba diferenciarse de las formas artísticas "nobles" (Bajtín, 2003). Lo mismo se puede decir del tópico del espiritismo, considerado blasfemo por el catolicismo.

En cuanto a los tropos que son utilizados para construir una estética de transgresión, las operaciones retóricas utilizadas son la parresia, la antítesis, la sinécdoque y las imágenes visuales, gustativas y olfativas. En el primer caso, es posible citar el verso que se refiere a España como responsable de la colonización de América: "la siniestra garra de la madre perra", en donde la alusión a tal país como "madre patria" es modificada por el insulto "madre perra".

Por su parte, la antítesis es uno de los recursos más recurrentes y permite dar cuenta de la descripción del antagonismo entre las víctimas y los victimarios. En general, los primeros son referidos como el "indio", "el hombre nativo", "mis hermanos", "los niños y mi juventud", “el joven trabajador", "pobre envejecido", "gil trabajador", "el pueblo" y "el pobre". A los últimos se los referencia como "grises magias conquistantes", "blanco imperio", "inmigrantes", "oscurantistas", "imperio de la 
devastación”, "imperio de la desolación", "madre bestial”, "fugado represor", "la cruz", "la TV", "doctor de la ley", "la yuta" y "control vigilante".

De acuerdo a las formas de narración elegidas por el yo lírico de cada canción, es posible observar que Hermética se posiciona en el lugar de las víctimas, reconociéndose como parte de ellas a través de la primera persona ("Me observo junto a mis hermanos / harto de miserias" ${ }^{60}$ ) o aconsejando y advirtiendo por medio de la segunda persona (como se ve en el título de la canción "Para que no caigas" de 1989).

Por su parte, la tercera persona le permite describir situaciones de manera externa, por lo que aquí los tropos que prevalecen son las imágenes sensoriales. Un claro ejemplo aparece en la canción ya citada "En las calles de Liniers", con la imagen olfativa de la suciedad de la calle: "Mas cuando el sol, mi fiel testigo, da de lleno en el asfalto / y derrite el alquitrán / los fermentos nauseabundos de la basura estancada / entorpecen mi pensar."

Retomando el tropo de la antítesis también es posible citar pares de opuestos como, por ejemplo, el día y la noche, en donde la primera parece dar cuenta de la salvación ("Esquivando patrullas / de la noche enferma / pude amanecer en las llanuras / sostenido en piernas" ${ }^{\prime \prime 1}$ ) y la segunda, del momento en donde sucede todo lo que se quiere ocultar ("La zona duerme en un corte de luz, / el vaciamiento se está efectuando" 62 ) y en donde los victimarios se encuentran al acecho de las víctimas ("Por eso te vi escapando / en las horas sin sol, / de las miradas oscuras / que aprobaron las torturas / del fugado represor"63 ).

Otra antítesis similar es la de luz y oscuridad. Con esta última se hace referencia a los victimarios, sus acciones y al contexto descrito como un país y un continente en derrumbe, como por ejemplo "las grises magias conquistantes" nombrar a los colonizadores de América, o como en el caso en que la víctima clama por su rescate: “¡No! / No echen / sobre mí su error. / ¡No! / No tapen la luz / con la enorme cruz de su desviación", en la canción "Masa anestesiada". También es vinculada con las consecuencias de esta destrucción, es decir, la pobreza, el hambre, la drogadicción, la enfermedad y la contaminación.

\footnotetext{
${ }^{60}$ Fragmento de la canción, "Cráneo candente” (1989)

${ }^{61}$ Ibídem.

62 Fragmento de la canción, "Víctimas del vaciamiento" (1989)

${ }^{63}$ Fragmento de la canción, "Tú eres su seguridad" (1989)

${ }^{64}$ Fragmento de la canción, "Cráneo candente" (1989)
} 
La luz en la mayoría de los casos aparece como una posibilidad de salvación y es vinculada con el conocimiento, es decir, con el descubrimiento de la verdad y de lo que se oculta durante la noche o en la oscuridad. De esta manera, se encuentran referencias tales como "Mi cráneo candente / buscó comprender. / No estaba vacío / mi cráneo candente" ${ }^{\prime 65}$, en donde la sinécdoque del cráneo candente se refiere a la claridad de pensamientos. La metáfora de que "no estaba vacío", se refiere a la idea de las personas que no poseen ideas propias y son consideradas mentalmente "huecas".

La luz también aparece en referencias al espiritismo y al consumo de marihuana como medio para alcanzar el conocimiento: "Mientras la noche muestra la calle en quietud / la intuición esquinera encendió mi luz”. Además, la luz da lugar a la esperanza frente a la oscuridad del contexto. Esto se puede ver en la canción "Yo no lo haré" (1989):

Míralos, / vienen atrás / y nuestro amor ausente está / entorpeciendo su andar...

Acércate, / acompáñame, / busquemos sin mirar atrás, / es la última oportunidad.

Tenemos / este camino / sin más para elegir / que oxidarse o resistir.

Permitir que el miedo los detenga / es dispararles por detrás, /alimentando aun la asfixiante oscuridad

Yo no lo haré, no los entregaré / a la impaciente ansiedad / del vicio o la soledad. Impedir que para el futuro mueran / es encender una vez más / el fuego vivo que este entorno limpiará.

Aquí también se observa otra antítesis representada con la vida y la muerte. La primera aparece como una esperanza del futuro y, la segunda, como algo que sucedió en el pasado a través de la colonización de América, la Conquista del Desierto y la Guerra de Malvinas, pero que también sucede en el presente: "Basta, nada hay que ocultar / muerto estoy aquí / tras el porvenir" ${ }^{\prime 66}$.

Sin embargo, a pesar de ello, Hermética propone diversas formas de salvación y de resistencia. Una de ellas es enfrentar la situación del contexto sin distraerse con entretenimientos escapistas, como se puede ver en el tema "Para que no caigas" (1989):

No juegues a esconderte / pues el miedo a la muerte / tergiversa los valores.

$\mathrm{Y}$ ahogado en escapismos / de un siglo en decadencia / tiembla el planeta con tanta inconciencia.

Tras la cruz se descubrirá la puta enorme / y la eternidad, dará libertad a un nuevo hombre.

Resistirse al sucio poder, es vivir sin temer. / Salirse del molde oficial, ganar o perder, / desaparecer.

\footnotetext{
${ }^{65}$ Ibídem.

${ }^{66}$ Fragmento de la canción, "Sepulcro civil" (1989).
} 
Víctimas de víctimas transcurren sin pensar, / que día a día el desierto va creciendo. / Y el descontento del joven trabajador / será su perdición. (...)

Otra forma de resistir la "decadencia" aparece en la antítesis entre el campo y la ciudad. El primero es descrito de manera bucólica, ya que aparece como el lugar a donde escapar del urbanismo y el segundo es referido como una prisión para las personas en situación de pobreza y en condiciones de explotación laboral que no pueden salir de la metrópolis a buscar otro modo de vida ("Masticando esta siniestra heredad, / prisionero estoy en mi ciudad natal / donando sangre al antojo de un patrón / por un mísero sueldo" $\left.{ }^{, 67}\right)$. Un ejemplo de esta huida ${ }^{68}$ aparece en el tema "Robó un auto" (1991), el cual contiene gran parte de la historia autobiográfica de Iorio:

Robó un auto para trasladarse / hacia las soledades vivientes. / Sentirse, cerca de eso / era su sueño más ardiente.

Aprovechando el apagón / de la ciudad capital, / y renunciando a las amargas sales, / para nunca, para nunca volver.

Jamás se estacionó en su suerte, / por eso no lograron detenerlo / las autoridades camineras, / ni los mecánicos desperfectos.

Sólo el cielo de la pampa lo vio, / como un rayo cruzar el desierto, / y a una simple joven sin planes, / de un pequeño gran infierno arrancar.

Condujeron sus propios destinos / por el sendero que el mundo esquivó/ y pudieron sentirse su estado, / su patrón, su íntimo Dios.

No pudo doblegarlos el invierno / con el azote de sus vientos, / mientras refugio levantaban, / en las vivas paredes de un cerro.

El amor hijos les dio al nacer, / y al Dios vivo agradecieron / el no permanecer prisioneros / del urbano acostumbramiento.

Como ya mencioné, dentro de la antítesis de victimarios/opresores y víctimas/oprimidos, el "yo" lírico se ubica en este último lugar y, en muchas canciones, parece situarse en el lugar de un joven preocupado por sus pares juveniles y por aquellos que le siguen, es decir, los niños.

En la mayoría de las referencias, al joven se lo muestra sufriendo las consecuencias del neoliberalismo. Un ejemplo aparece en la canción "Víctimas del vaciamiento", la que contiene la siguiente estrofa: "Sin ver el futuro / agoniza la imaginación. / Y naufragando en la oscuridad, / los niños y mi juventud”. El presente de la década del '90 le impide al joven creer en un futuro ("Muerto estoy aquí / tras el porvenir"). Partiendo de esta idea, la banda propone la construcción de un futuro mejor

\footnotetext{
${ }^{67}$ Fragmento de la canción, "Gil trabajador" (1991)

${ }^{68}$ Sobre el tema del "viaje" me explayaré en el capítulo dedicado al metal y la política.
} 
para los niños: "Impedir que para el futuro mueran / es encender una vez más / el fuego vivo que este entorno limpiará" 69 .

Por otra parte, aparece una crítica al sistema jubilatorio, ya que se muestra cómo los jóvenes deben perder su juventud y dedicar horas de su vida para asegurar la mantención de su vejez. Esto se puede ver en la canción "Tú eres su seguridad": "Ajeno al tiempo / sé que quisieras seguir, / pero mil voces te ahogan / para que formes la cola / del seguro porvenir".

La juventud también aparece identificada con la representación del "metalerorockero". Esto se encuentra en canciones como "Predicción" ("Hoy niño es / modelado en rockero por Dios) y en "Ayer deseo, hoy realidad" ("Se me cumple / hoy el sueño pendejo $^{70}$ de ayer. / Y fue por rebelde / que al metal pesado me aguanté"). Lo mismo se puede ver en la portada de Victimas del vaciamiento, en donde el personaje que lleva una remera de Hermética es un joven.

Frente a la imagen del joven "anestesiado" (pasivo) por el sistema, la banda propone al metal como una forma de cuestionamiento y de toma de conciencia. Esto aparece en el tema "Cráneo candente ("Mi cráneo candente / buscó comprender. / No estaba vacío / mi cráneo candente") y en "Predicción”, en donde se relata la historia del niño reencarnado que "Es quien dirá / lo que tantos intentan no ver, / lo que muchos quieren tapar, / lo que todo joven busca saber / para poder vivir sin temer".

Esa concepción del metal implica que, de acuerdo a Hermética, no se trata meramente de un estilo de música, sino también de una forma de ver el mundo y de actuar de acuerdo a determinados principios que se comparten con otros. Esto se puede ver en el tema "Vientos de poder" (1991), cuyo título ya da cuenta de la idea de empoderamiento:

Vientos de poder / en el crepúsculo final guían el viaje. / Que más de uno se ha / entregado al polvo inca, / muestran los informes del control vigilante. La cúpula se agita por mostrar decencia / y muchos justicieros se abren de piernas. La estructura emergente se tambalea / en burbujeante orgía de magias negras. El pobre envejecido sigue la procesión / con silencioso instinto de privación. Yo no vendo canciones de amor vendido, / en la que estoy me planto y no me persigo. Si me atrapan las redes de la osamenta, / por pobre de seguro que me harán la boleta. Pero no estoy vencido aún tengo fuerzas / para dar mi mensaje de resistencia. Yo seguiré junto al metal con mi mensaje / vacilaré si tú no estás en este viaje. (...)

Lo mismo se puede observar en la canción "Evitando el ablande" (1991):

\footnotetext{
${ }^{69}$ Fragmento de la canción, "Vida impersonal" (1989).

70 "Pendejo" es un término del lunfardo que significa "púber" ((Gobello y Oliveri, 2010, p. 237).
} 
Con mis amigos en el concierto / de metal duro por sentimiento. / Es fija que me verás si estás presente / brindando aguante con quienes sienten. / Como yo siento latir en la sangre mía. / Salvando mis días, / junto a su sonido brutal, mi vida / resiste su ruina. / Él es reflejo de mi presente, / sin él no hay nada que me contente. / Por eso sigo y seguiré en sus camino, / del cual soy parte y no me rindo. Las voces de discotecas / no tienen cabida en esta movida. / Yo repudio toda esa careta / de mersa coqueta. / No callaré, porque me sobra aguante / y alzo mi voz evitando el ablande del ladrón. / Desenmascarar esas muecas / y sus fingidas historietas / Esto que digo yo lo siento hoy / y sabes bien que no te miento. / No callaré, porque me sobra aguante / y alzo mi voz, evitando el ablande del ladrón.

Aquí se hace referencia al concierto de metal como un momento para compartir entre amigos, pero también se menciona a todo aquello que no pertenece a la cultura de dicho estilo musical, como lo son las discotecas, espacio característico de las prácticas juveniles del contexto de producción de la banda, en el cual circulan géneros musicales de moda y propicios para el baile. La danza no es aceptada en la música metal porque en la tradición moderna de Occidente se vincula con actividad erótica (Weinstein, 2000, p. 130).

De esta manera aparece una nueva antítesis: lo que es metal y lo que no lo es. La discusión acerca de esto no solo forma parte de la audiencia sino también de los músicos (Azevedo, 2007) y se define por establecer los parámetros que miden la autenticidad metálica -concepto que definiré más adelante-. Hermética participa de este debate no solo mencionando qué elementos y géneros musicales no forman parte de la cultura del metal, sino también determina lo que es "falso metal".

En el metal esta expresión se refiere a las bandas de lite o glam metal, las cuales son criticadas por la falta de autenticidad, expresada en el atuendo glamoroso; el desarrollo de canciones con temáticas que el thrash metal consideraba poco "serias", vinculadas con el amor, la lujuria y el hedonismo; y la circulación en medios masivos de comunicación y en públicos no estrictamente metálicos gracias a la producción de baladas. Al contrario de underground, el glam metal era considerado mainstream.

En Argentina, una de las bandas que fue considerada "falso metal" por una gran franja de aficionados es Rata Blanca. Hermética realizó una dedicatoria implícita a su oposición a dicho conjunto en la canción, "Deja de robar" (1989), en la cual se critica a los grupos que pretenden ser mainstream, algo que no es considerado auténtico dentro del metal, ya que por el contrario, quienes pertenecen a su cultura no lo hacen por moda sino por sentimiento: 
Mientras quemo las hojas de mi encarnación, / estoy feliz de no ser parte de tu glamoroso juego.

Ya no engañes con tu vicio de hablar por hablar. / Sé que pretendes hacer moda nuestros sentimientos.

Deja de robar, / gánate tu pan. / ¿O es que nada más / puedes tú hacer?

El metal tiene su historia y la madera también, / pero el plástico que vistes es evidencia que no existes.

En el cemento de las ratas no me encontrarás. / Yo estoy quemando combustible sobre rutas desiertas. Por tu falsedad / no me detendré. / Ni me alcanzarás / con tu estupidez. De quien destruye el cielo eres servidor. / El vaciamiento está en vos.

Los tuyos se enredaron por eso no están / luchando aún por el metal, / por el metal.

En esta canción, Hermética parece considerar que la banda de Giardino busca masividad con la intención de enriquecerse económicamente, algo que no es considerado un "trabajo digno" y que es contrario al producir música por sentimiento, es decir, sin esperar ninguna retribución a cambio. Esta disputa tiene una larga trayectoria en la historia del rock tanto a nivel nacional como internacional, sobre la cual me explayaré en el segundo apartado de esta tesis.

Asimismo, en la canción se demuestra un rechazo a la moda, el cual también se presenta en el tema "Buscando razón" (1994), que menciona estilos musicales que no son metal y son descritos como contrarios a él:

Buscando razón que me impida despreciarte, / nació esta canción / que tal vez pueda alcanzarte.

Mi rechazo hacia tus baladas de amor / me llegó desde pendejo. / Cuando V8 era mala palabra, / se intentaba con vos lavarnos cerebros.

Fuiste azota del jazz-rock, / reggae, pop, new wave, moderno. / Hoy cantas tus amoríos con fanfarrias de rockero.

Yo que nunca compartí tu pose stone, / voy a deschavarte el juego. / Sos veleta de la moda y no me asombra, / que mañana amanezcas metalero. ${ }^{71}$

Al oponerse a la moda y otros estilos musicales, Hermética es leal con lo que considera auténticamente metálico y colabora con su definición al desarrollar una característica propia de este estilo musical: ser culturalmente conservador y resistirse a los cambios (Weinstein, 2000, p. 137). Esto se expresa en los versos: "Sos veleta de la moda y no me asombra / que mañana amanezcas metalero", en donde se demuestra el rechazo hacia los "falsos" metaleros y a los que siguen tendencias musicales de moda.

Más adelante explicaré que el rechazo a estos géneros musicales no solo se debía a que eran considerados como parte de la industria del ocio (por lo que rehuían al

\footnotetext{
${ }^{71}$ A pesar de que la letra de esta canción esté compuesta en segunda persona del singular, no hay datos acerca de una posible dedicatoria para alguien en particular. En la escena, muchos aficionados creen que se refiere a Walter Giardino de Rata Blanca, pero solo es una especulación.
} 
compromiso "serio" demandado por el rock y la corriente fundamentalista del metal) sino que también eran calificados como "femeninos". Todos estos debates forman parte de la discusión acerca de la autenticidad de la música.

Sobre el uso del lenguaje es posible decir que las letras no están escritas tal como lo propone la hegemonía discursiva en Argentina, es decir, en un español formal regido por los patrones de la lengua escrita y la "alta" cultura. Por el contrario, en las canciones aparecen expresiones coloquiales, propias de la oralidad, el lunfardo y el habla popular. Algunos ejemplos son las expresiones, "zafar", "72, "vigilante"73, "abrirse de piernas",74, "aguante",75, "careta"76, "mersa"77, "trucho"78, "cagar"79, "toco"80, "amasijar" $" 11$ " “yuta" 82 " "pendejo" y "pibe" realidades", se utiliza un apócope en la estrofa: “Todo joven que asista / brinda ocasión, / de ordenarle se desvista / pa' la observación."

Entonces, siguiendo los postulados de Angenot, Hermética puede ser ubicada en la tradición del blues y de la música popular latinoamericana que desafía a la hegemonía discursiva mediante la transgresión de fetiches o "intocables", tales como el Gobierno y la Religión o, más específicamente, la Iglesia Católica. Por otra parte, en las canciones se transgreden tópicos tabú tales como la muerte, el abandono, la contaminación nuclear, el fraude, la corrupción y la prostitución, lo cual se realiza por medios de tropos que asemejan a las letras de las canciones con textos poéticos.

Por otra parte, la hegemonía discursiva "No es propiedad de una clase. Pero como instituye preeminencias, legitimidades, intereses y valores, naturalmente favorece a quienes están mejor situados para reconocerse en ella y sacar provecho" (Angenot, 2012, p. 37). De esta manera, se podría decir que Hermética al situarse discursivamente

\footnotetext{
72 Zafar: "Desligarse de responsabilidades. 2. Superar un obstáculo saliendo bien parado. (...) 3. Escaparse o esconderse para evitar un riesgo" (Gobello y Oliveri, 2010, p. 339)

${ }^{73}$ Vigilante: "Delator, soplón" (Gobello y Oliveri, 2010, p. 328). Forma de nombrar a los militares o agentes de policía.

74 Abrirse de gambas (piernas): “Abstenerse de actuar, generalmente para no comprometerse" (Fuente: https://es.wiktionary.org/wiki/abrirse_de_gambas)

75 "Hacer el aguante": "Bancar" (Gobello y Oliveri, p. 2010: 17).

${ }^{76}$ Careta: "Persona que por simulación de poderío económico frecuenta lugares caros. 3. Persona que gusta parecer más de lo que es." (Gobello y Oliveri, 2010, p. 71)

${ }_{77}$ Mersa: "Plebeyo, propio de la plebe" (Gobello y Oliveri, 2010, p. 199)

78 Trucho: "Falso, que imita engañosamente a lo verdadero" (Gobello y Oliveri, 2010, p. 315)

${ }^{79}$ Cagar: "Defraudar, privar a alguien con abuso de confianza o infidelidad de lo que le corresponde" (Gobello y Oliveri, 2010, p. 62)

${ }^{80}$ Toco: "Producto del robo" (Gobello y Oliveri, 2010, p. 308)

${ }^{81}$ Amasijo: "Enredo, engaño que ocasiona dificultades y pleitos" (Gobello y Oliveri, 2010, p. 21)

${ }^{82}$ Yuta o yusta: "Policía, cuerpo encargado de velar por el mantenimiento del orden público y la seguridad de los ciudadanos" (Gobello y Oliveri, 2010, p. 338)

${ }^{83}$ Pibe: "Niño" (Gobello y Oliveri, 2010, p. 241)
} 
en el lugar de las víctimas/oprimidos y denunciar el accionar de los poderosos produce un discurso contra-hegemónico y marginal.

\section{Resignificaciones metálicas}

Tal como mencioné anteriormente, Hermética es la banda que resulta central para la escena metálica bonaerense en tanto semiosfera. Hasta ahora se pudieron observar los modos en que dicho grupo propone diversas formas de transgresión contrahegemónica para la construcción de una identidad metálica. Esta operación constituye una definición tanto de lo propio como de lo ajeno.

A continuación se describirán las maneras en que la escena estudiada resignifica la propuesta de Hermética, generando nuevos modos identitarios que en la actualidad se caracterizan principalmente por su heterogeneidad y por el diálogo (ya sea mediante la semejanza o la diferencia) con otras semiosferas.

\section{Modos de transgresión en la escena}

Las transgresiones a los fetiches y tabúes anteriormente vistas en Hermética son reactualizadas en la escena de diversas maneras. De las que se vinculan con el sexo (y al género) me ocuparé en el capítulo siguiente y las que se refieren a la Patria, en el posterior. La principal forma de oponerse a la hegemonía dentro de la escena es por medio de la transgresión de lo considerado "prolijo", "pulcro", "formal" y, en parte, lo que está de moda, a través de la construcción de expresiones culturales alternativas, operación que resulta similar a la tradición hippie de los ‘ 60 .

De acuerdo a mi trabajo etnográfico puedo postular que la escena metálica bonaerense no se conforma únicamente como una red de eventos e instituciones, sino que más bien lo hace como una red de relaciones sociales. Es decir que la escena emerge mediante la interacción de sus miembros durante eventos especializados en el metal, pero también por fuera, en la vida cotidiana y en entornos digitales. Tal como expresa Weinstein (2016b):

El juego cultural no ocurre en un vacío social. Los músicos de metal, como todos los músicos, están inmersos en una red de relaciones sociales que los incluye a ellos, sus admiradores y mediadores institucionales, como estaciones de radio, programas de televisión y promotores de conciertos, entre la multitud de actores. De hecho, no es posible imaginar ninguna forma cultural existente sin una red de interacción social que la sostenga y la encarne. (Weinstein, 2016b, p. 11. T. de la A.) 
Un ejemplo de ello se da en las conversaciones que presencié o en las que pude interactuar. En este sentido, cuando dos personas a las que les gusta el metal se encuentran casualmente en la calle (situación que, en el área bonaerense, sucede con mayor asiduidad en los pueblos y las ciudades intermedias), existe una gran probabilidad de que el principal tema de conversación que surja de manera espontánea sea el metal. De esta manera, se pueden dar intercambios acerca de bandas extranjeras que visitan al país, próximos recitales en su localidad o charlas sobre sus propias bandas en el caso de los que también son músicos.

Es muy común que los aficionados al metal hagan bromas con símbolos propios del metal, como por ejemplo, la mano cornuta, la palabra "metal" o el color negro que caracteriza a la vestimenta. Esto no solo aparece en las conversaciones mantenidas en forma oral sino también en los intercambios en Facebook y en sus memes (ver Figuras 9, 10, 11 y 12). Los chistes dan cuenta de cómo el metal se entremezcla con la vida cotidiana de sus aficionados, haciendo que ellos resignifiquen los elementos de su entorno de acuerdo a la simbología propia del estilo musical.

Por otra parte, como Hermética resulta ser la banda más conocida por los miembros de la escena, la referencia a sus letras es muy asidua. De esta manera, durante el trabajo de campo realizado en viajes grupales a recitales, pude registrar en conversaciones referencias a la canción "Del camionero" (1991), debido al contacto directo con la ruta y al hecho de cruzarse camiones a lo largo de los viajes. En dicho tema musical el "yo" lírico reflexiona acerca de su actividad como conductor de dicho transporte y describe el paisaje que va visualizando durante el recorrido. Lo mismo sucede con la canción "Convide rutero" (1999) de Almafuerte.

Una de las características de la escena es la oposición al lujo. Esto se observa en la estética de los lugares que se eligen para la realización de recitales o ferias: se trata de lugares que dentro de la escena suelen ser llamados "antros", debido a que se caracterizan por ser espacios con poca luminosidad y escasa, o muchas veces nula, higiene. Se prefieren lugares que aparenten la sensación de abandono, cercana a los significados de muerte y destrucción, pero también contraria a lo considerado "careta", es decir, lo prolijo y pulcro. Esto hace que muchas veces los organizadores de eventos pasen por alto algunas normas de seguridad.

Por otra parte, en la escena bonaerense hay gran cantidad de ciudades que poseen políticas públicas estrictas que no habilitan teatros o bares para la organización de recitales, por lo que muchos productores (especialmente los amateurs) deciden 
realizar sus eventos en clubes barriales y sociedades de fomento, cuya impronta "popular" se alinea con la estética y la ideología "anti-lujo" que critica a la sociedad "respetable" y la cultura hegemónica.

La transgresión propuesta por Hermética también se materializa en los consumos. En la escena bonaerense, una de sus canciones mayormente celebrada es "Soy de la esquina", la que además de cantarle a la amistad lo hace con la cerveza. Efectivamente, pude registrar la ingesta de esta bebida en la totalidad de eventos especializados en metal que constituyeron mi trabajo de campo. La importancia del consumo de cerveza se pudo deducir, por ejemplo, a partir de recitales realizados en plazas al aire libre durante el día, en donde los aficionados al metal llevaban sus propias botellas con dicha bebida.

En otro contexto, pude observar y compartir con ellos el consumo de mate, pero la sola presencia del recital parece animarlos a beber cerveza, en cualquier momento del día. De hecho, vi que algunos desayunaban con esta bebida en encuentros de motos. Por otra parte, el festival Monsters of Rock del 2015 contó con un sector especial para la venta y el consumo de dicha bebida, llamado "Patio Cervecero". La presencia imperante de la cerveza en la escena metálica bonaerense se conecta con el lema que, según Weinstein (2000), caracteriza al metal: "Beber cerveza y levantar el infierno" (Weinstein, 2000, p. 133. T. de la A.).

Otro ejemplo lo observé durante el recital de Black Sabbath y Megadeth en el Estadio Único de La Plata el 6 de octubre de 2013. Allí estaba prohibida la venta de alcohol porque se permitía la entrada de menores de edad ${ }^{84}$, por lo que se vendía cerveza sin alcohol. Una chica de 24 años, indignada por esto, expresó “¡Menos mal que traje faso, si no iba a tener que ver todo el recital de la cara ${ }^{85}$ !" (Referencia en notas de campo personales). Con esto quiso expresar que se alegraba de poder disfrutar del recital bajo los efectos de la marihuana, debido a que no iba a poder hacerlo con el consumo de alcohol.

Como en este caso, el consumo de marihuana es habitual pero no general, lo mismo que la cocaína. Ambas drogas no son consumidas tal como lo propone Hermética, es decir, para conectarse con la intuición espiritual, sino más bien como una forma de aumentar el fervor causado por la música y de socializar con otros agentes de

\footnotetext{
${ }^{84}$ Esta normativa depende de los organizadores y no resulta una generalidad, ya que en muchos eventos que permitían la presencia de menores de edad también se vendía alcohol.

${ }^{85}$ La expresión "de la cara" hace referencia al estado de sobriedad.
} 
la escena. De hecho, sea lo que sea que se consuma (bebidas o drogas) es un elemento que se comparte. Es decir que se da por sentado que quien compra una botella, un vaso de plástico o (en menor medida) un cuerno con cerveza le convidará su contenido a quienes interactúen con él y todos beberán del mismo envase.

De esta manera, el alcohol y las drogas no solo alteran los sentidos de modo que los efectos de la música son potenciados, sino que también su consumo resulta un elemento de integración social. Pero, al igual que en la investigación de Weinstein (2000), el comportamiento en el recital es prácticamente igual entre quien ha consumido y quien no, las diferencias solamente se dan bajo excesos.

La marihuana también se consume de manera social y en general se lo hace abiertamente, mientras que drogas como cocaína o pastillas de diversa índole son consumidas a escondidas en los baños. A pesar de ello, quien posee los narcóticos solo le convida a sus conocidos más cercanos y si estos no aceptan, no resulta ser algo problemático.

Sobre estos consumos pude observar la convivencia de extremos opuestos con casos de drogadicción y de alcoholismo, al mismo tiempo que vi personas transitando tratamientos de rehabilitación. Algunos de ellos simplemente se alejaron de dichos consumos por decisión propia para dedicarse a una vida más saludable y comenzaron a practicar deportes (especialmente, los extremos) o a realizar dietas especiales.

Algunas veces los motivos de estas decisiones son la paternidad y la maternidad y, en otros casos, la conversión a doctrinas pentecostales. Los que no consumen alcohol o drogas continúan participando de los recitales optando por bebidas como gaseosas, mientras que otros prefieren alejarse totalmente de la escena y dejar de interactuar con sus miembros.

Otro consumo importante dentro de la escena es el del asado, pero este no se deriva tanto de Hermética sino más bien de Almafuerte que dedica varias canciones a la temática. En este caso, podría decirse que la influencia está dada por las líricas de Iorio y por su actuación como personaje del "Dios del asado" en la película, Kapanga Todoterreno (2009) de Pablo Parés, Paul Soria y Hernán Sáez, protagonizada por los músicos de Kapanga.

La cocción del asado también dialoga con la idea bucólica del aire libre y, al mismo tiempo, difiere del vegetarianismo y el veganismo, muchas veces vinculados con los aficionados al punk. La carne asada resulta la comida que más se consume en la escena bonaerense, tanto como almuerzo o como cena, muchas veces en previas a 
recitales (ver Figura 13), durante motoencuentros o en reuniones de amigos y en fiestas de cumpleaños. En estos dos últimos casos, se combina el consumo de carne y cerveza (o vino y fernet con gaseosa cola, en menor medida), mientras suena música metal de fondo.

En general, los consumos que se producen dentro de la escena no se restringen a ella pero resultan característicos al punto de que es muy común que se desarrollen en torno a las relaciones sociales de sus agentes. La transgresión no se da a través de lo que se consume sino en los modos en que esto se realiza: en el caso de la cerveza, pude observar que los "metaleros" prefieren aquellas de menor costo antes que las "artesanales", lo que le otorga el carácter de "popular" o "anti-burgués"; al mismo tiempo se prefiere consumirla en recipientes que permitan el uso grupal y no el individual. A pesar de que esto constituye una decisión ideológica, en muchos casos también se desprende de la necesidad de economizar los gastos.

Por su parte, la realización del asado en la mayoría de los casos del trabajo de campo implicó el uso de espacios precarios o que no eran específicos para la cocción. Allí, mediante el uso de parrillas o asadores rudimentarios, rápidamente se improvisaron espacios óptimos para la cocción de la carne. En la mayoría de los casos no había mesa ni sillas, por lo que se debía comer de pie, muchas veces sin cubiertos ni vasos. Estas características son las que constituyen formas de transgresión con respecto al lujo y la cultura "burguesa". En cuanto a las drogas, estas son consumidas de la misma manera que en otros espacios sociales.

La no identificación con la cultura hegemónica permite que en la escena se le otorgue valor a lo que culturalmente es considerado "marginal". Tal como plantea Weinstein (2000), el metal legitimiza el lugar del "paria", de manera que sus aficionados se consideran a sí mismos como "parias orgullosos", lo cual deviene de ser "apreciadores de una gran música" y, al mismo tiempo, rebeldes a la autoridad establecida.

No obstante, en muchas ocasiones, la acentuación de lo "marginal" parece producirse como un mecanismo de automarginación, ya que al aumentar los rasgos que son criticados por las personas externas a la escena se busca generar rechazo en quienes los propios "metaleros" rechazan. Esto da cuenta de una actitud estricta que subraya las diferencias en lugar de dar posibilidades al diálogo o a posturas intermedias.

Aquí la identidad se construye tal como la describe Simon Frith (1996) para la música y los grupos sociales: “(...) sólo consiguen reconocerse a sí mismos como 
grupos (como una organización particular de intereses individuales y sociales, de mismidad y diferencia) por medio de la actividad cultural, por medio del juicio estético.” (p. 187)

En la escena metálica bonaerense los aficionados también pueden ser considerados "parias orgullosos" no solo porque su gusto, al contrario de ser vergonzante, es un elemento que se tiende a ostentar y a exaltar, dándole visibilidad en la vida cotidiana, ya sea por medio de elementos estéticos corporales (remeras, tatuajes, etc.) o simplemente a través de chistes y referencias verbales en la comunicación oral y en la virtual que demuestran el conocimiento acerca del estilo musical. Esto aumenta cuando los músicos y las bandas que se exhiben son más "auténticos" y más "verdaderos". A continuación desarrollaré este aspecto.

\section{Discusiones en torno a la autenticidad}

La noción de autenticidad que es utilizada en la música popular proviene del folklore y de la música erudita. En el primer caso, porque con dicho concepto los folkloristas del siglo XVIII valoraban la experiencia de la comunidad por sobre el individualismo de la sociedad ilustrada y la emocionalidad antes que la racionalidad letrada (Ochoa, 2002). Estos parámetros se desarrollaban en el contraste del tradicionalismo y el modernismo. Por su parte, la música académica consideraba auténtico aquello que buscaba originalidad, valor que provenía del romanticismo.

Posteriormente, el concepto de lo auténtico fue trasladado a varios tipos de músicas populares, las cuales lo desarrollaron como un valor, una medida o un parámetro de clasificación, ya que consistía en “(...) el principal atributo positivo que tienen en cuenta los melómanos para ponderar el valor de una música o de la obra de un artista." (Salerno, 2008, p. 130) De esta manera, la autenticidad difiere de acuerdo a reglas propias de cada género musical y adquiere el rasgo de subjetivo debido a que depende de la percepción de alguien (un músico, un aficionado, un periodista o un productor).

Entonces, la discusión acerca del "falso" y el "verdadero" metal puede ser considerada como un debate en torno a la autenticidad del metal. Esto implica un trabajo de producción de sentido por parte de los agentes de la escena, debido a que “(...) opera como un criterio del juicio en la evaluación que hace el rock de los músicos y la música" (Keightley, 2006, p. 183). 
En consecuencia, el metal es considerado "falso" o "verdadero" de acuerdo a la subjetividad de los aficionados y de ello se desprenden significaciones que son utilizadas para la construcción de identidades. Además, dichas calificaciones poseen una carga de valor que depende de parámetros éticos y morales que generan disputas de poder en el interior de cada escena musical. En el caso estudiado dicha evaluación es realizada y promovida por la línea fundamentalista del thrash metal, caracterizada por ser culturalmente conservadora.

Como ya se vio anteriormente, el "falso" metal se presenta como lo "desviado", por lo que se deduce que dicho estilo musical hereda de la tradición del rock (y del folklore) el rechazo por los cambios y las transformaciones. Parte de esta postura está sujeta a ciertas reglas de comunicación que codifican a las formas culturales en general y que “(...) no son solo prescripciones de la actividad humana que se cristalizan en patrones, sino que son patrones evolutivos que se vuelven implícitamente prescriptivos." (Lull, 1987b, p. 162. T. de la A.) Esto se debe a que "existe una tensión entre las fuerzas de convencionalidad y las fuerzas de resistencia en la producción de la cultura popular" (Lull, 1987a, p. 12. T de la A.).

Pero, además de ser consecuencia de este modo de funcionamiento prescriptivo de la cultura, en el rock "Hay un enorme miedo a la transformación, no por lo que pueda implicar en sí, sino por la manera como puede estar comprometida con el aparato comercial de la industria musical" (Ochoa, 2002). Con esta concepción se trazaron fronteras divisorias dentro de la música popular, especialmente entre el rock y el pop. Algunos artistas no solo hicieron uso de dicha noción para criticar al género musical "opuesto" sino también como una forma de identificación.

En efecto, el glam rock de los '70 -ampliamente calificado como "comercial" por algunos rockeros- utilizaba la frase "Gimme some untruth" (Dame un poco de falsedad) como reacción a la canción de protesta, "Gimme Some Truth" (Dame un poco de verdad), de John Lennon. Esto se debía a que, contrario al realismo que perseguía cierto tipo de rock, buscaba la libertad a través de la fantasía y no de la realidad, por medio de todo aquello que era considerado artificial y antinatural: "Rompiendo con el pietismo de la generación libertaria de cabello largo, el glam celebraba la ilusión y la máscara en vez de la verdad y la sinceridad" (Reynolds, 2017, p. 16). Esta tradición es la que define al glam metal y lo diferencia del realismo que caracteriza al thrash.

La autenticidad también es el fundamento a través del cual el rock intentó constituirse como música "seria", a pesar de sus paradojas. Esto se debe a que dicho 
género musical intentó buscar seriedad para diferenciarse de la "superficialidad" de la música masiva, pero al mismo tiempo rechazaba connotaciones negativas de la seriedad, tales como el elitismo y la intelectualidad (Keightley, 2006).

En suma, la autenticidad es un rasgo intrínseco de la ideología del metal y, por ende, de los miembros de la escena estudiada. Esto se debe a que la comunidad metálica global es una de las más escrupulosas a la hora de asimilar y legitimar intérpretes y discos (Galicia Poblet, 2015, p. 177). Por otra parte, constituye uno de los cuatro mitos que sientan las bases de la comunidad metálica (junto con la igualdad, los guerreros y las groupies $)^{86}$ y son descritos por Rosemary Lucy Hill (2013), quien los toma de nociones que los aficionados consideran que indiscutiblemente caracterizan a la escena, aunque en realidad dependen de su contexto de su uso.

Como se vio anteriormente la oposición hacia el considerado "falso" metal estaba presente en las canciones de Hermética, pero también la pude relevar en el slogan del afiche promocional de la banda del 13 de agosto de 1988 (Ver Figura 14). A partir de entrevistas realizadas a algunos ex integrantes de la banda de ese entonces, pude observar que sus opiniones con respecto a esa frase cambiaron. Por ejemplo, el guitarrista, "Tano" Romano, ante la pregunta acerca de la frase de ese afiche respondió que:

Lo que pasa es que nosotros no hacíamos esos afiches y, bueno, a veces hay gente, viste, que hace cosas de la que nosotros no tenemos nada que ver o ni siquiera estábamos de acuerdo. Porque no existe un "falso" metal o un "verdadero" metal. Metal es metal y a todos nos cuesta lo mismo. Y todo tiene una parte que hay que laburar mucho como para poder hacer música, para poder salir una banda a tocar. Hay veces que esa gente que hace eso no lo ve... al esfuerzo. Uno tiene que dejar un montón de cosas. En esa época que vos me decís, Hermética, el heavy metal todavía era una música muy nueva que nos costaba muchísimo tocar, conseguir lugares para tocar y era todo a pulmón. Vos viste esos afiches y, anterior a eso, salíamos a tocar y hacíamos los volantes a mano. Hacíamos la fotocopia y, a lo mejor si había un amigo que sabía dibujar un poquito mejor, le hacíamos hacer un dibujo para después fotocopiar. Todo tiene un laburo y no creo que haya un falso metal, porque esa gente es como hoy. Hoy también con las redes sociales, Facebook, viste, que hay gente que escribe cosas... porque Facebook da la posibilidad de que uno opine y a lo mejor se siente importante. Y bueno, en ese momento también era así. No hay un falso metal, no, no teníamos nada que ver con eso. Y power metal... Son estilos... Power metal, thrash metal, black metal. Para mí es heavy metal todo. O sea, va todo dentro de lo mismo. Después la gente le empezó a poner esos títulos. Pero para mí donde hay una guitarra distorsionada es heavy metal, sea el estilo que sea. A lo mejor puede ser más duro, menos duro, pero sigue siendo heavy metal. (Romano, Tandil, 2016).

${ }^{86}$ A lo largo de esta primera parte se podrá ver cómo los cuatro mitos operan como principios fundamentales de los significados que forman parte del centro de la escena metálica bonaerense como semiosfera. 
Por su parte, el baterista, "Tony” Scotto, aprovechó la ocasión para criticar a O’Connor, ex cantante de Hermética y actual cantante de Malón, quien hoy en día cambió su look inspirándose en Ozzy Osbourne, por lo que delinea sus ojos con fuerte color negro y tiñó algunos de sus mechones de cabello de color rojo. Es necesario aclarar que Scotto fue expulsado de Hermética por el resto de $\operatorname{los}$ músicos ${ }^{87}$, pero en dicha entrevista explicó que actualmente se había reconciliado con Iorio. Por el contrario, existe una fuerte rivalidad con O'Connor, quien en un video que circula en las redes sociales lo invita a encontrarse cara a cara para pelearse. Con respecto a la idea de "falso metal", Scotto respondió:

Yo: ¿Cuál sería ese falso metal?

S: El falso metal vendría a ser hoy "contra los falsos en el metal”. Los falsos en el metal vendrían a ser hoy los teñidos y los delineados. Son los falsos en el metal. Y en esa época era el falso metal todo lo que no era el metal.

Yo: ¿Tenés alguna banda para nombrar como ejemplo que en ese entonces para vos era falso metal?

S: Y, sí... ¡un montón! Como, qué sé yo... Había unos tipos que hacían glam, qué sé yo, que decían "el metal" y no era metal. Pero yo pienso que en definitiva eran ellos metal también, ¿no? Todos éramos metal. Pero hoy en día yo pienso que la frase "los falsos del metal" serían hoy los teñidos. Como estos idiotas que se tiñen y se pintan los ojos y mandan fruta. Esos serían hoy, ellos.

Yo: ¿Y hay alguno en especial que vos digas que se pinta y se tiñe el pelo?

S: Y, no hace falta que lo diga, no.

Yo: Porque se me ocurre un ex compañero tuyo que ahora en este momento se tiñe el pelo y se pinta...

S: Y, bueno... justamente, justamente. No pasa por ellos sino por la actitud.

En la actualidad, la idea de oponerse al "falso" metal aparece vigente en el fanzine porteño, Metalica, el cual se edita desde el año 1986 de manera autogestiva y con distribución gratuita. En la edición del año 30, número 79, de abril del 2016, en varios apartados de la primera página dedicada a la editorial aparece la afirmación "muerte al falso metal", junto con la frase "no se incluyen tendencias comerciales". Esto

\footnotetext{
${ }^{87}$ Este hecho resulta un punto de polémica. Algunas versiones dicen que Scotto fue expulsado por el resto de sus compañeros porque faltaba a los ensayos y asiduamente estaba alcoholizado. En una situación particular debieron cancelar un show porque él había sido detenido por la policía. La pelea entre el baterista y O'Connor comienza cuando el primero, en una entrevista realizada en 2016, afirma que los músicos de Hermética habían pensado en echar al cantante, aunque esto no se concretó. De esta manera, el segundo grabó dos videos caseros en los que le responde a Scotto con bastante agresividad y le dice que Iorio lo había echado de Hermética porque tenía miedo de que le "robe" a su esposa. Las declaraciones del baterista se pueden ver en el link: https://www.youtube.com/watch? $\mathrm{v}=\mathrm{y} 5 \mathrm{dzWrFXIXE}$; y las de O'Connor en los siguientes: https://www.youtube.com/watch?v=3FmSH5QLpOw ; https://www.youtube.com/watch?v=mCNPVDJ_2uQ
} 
demuestra que la ideología de dicho fanzine es la de promover bandas y editarse de manera underground, lo cual se vincula con la tendencia fundamentalista del thrash y de Hermética.

Por otra parte, la idea de "verdadero" parece mantenerse como un adjetivo que describe al metal en general. Esto se puede observar en el fanzine, Resistiré, de Bahía Blanca, el cual en la edición número 37 del año 20, correspondiente al 2017, en la volanta de la portada aparece la frase "conservando lo verdadero", lo que nuevamente demuestra una ideología fundamentalista y conservadora.

La transgresión de la cultura hegemónica que caracteriza al metal (y al rock en general) se puede ver en una frase que aparece destacada en ambos fanzines y dice "peleando al mundo". De manera que la oposición se generaliza al "mundo". Esto genera una lectura de la propia identidad como "selecta" y, a su vez, "automarginada" de lo que es considerado el "resto del mundo". Al mismo tiempo, existe en la escena una actitud generalizada de "oponerse a" o de "estar en contra de", la cual se nutre de la crítica ideológica y utiliza los parámetros de la autenticidad metálica para evaluar al objeto o agente de oposición.

Jeremy Wallach y Alexandra Levine (2013), en su teoría de la formación de las escenas de la música metal, proponen que una de las generalidades de estas es que “(...) a menudo hacen una demostración de vigilancia de sus fronteras, pero difieren de otras escenas en la intensidad y la función de este patrullaje" (Wallach y Levine, 2013, p. 124). Es decir que las escenas metálicas poseen diferentes formas de legitimar los elementos y los agentes que forman parte de ella, pero en especial se busca definir lo que no pertenece a allí.

Wallach y Levine mencionan la actitud intolerante de los metalheads ${ }^{88}$ hacia los poseurs, es decir, los infiltrados dentro de la escena. En el área bonaerense, los seguidores de música metal se llaman a sí mismos "metaleros" y a los poseurs, "caretas" 89 . A partir de mi trabajo de campo pude relevar algunos códigos comunes dentro de la escena, entre los cuales la vestimenta es uno de los elementos cruciales.

\footnotetext{
${ }^{88}$ Forma de autodenominarse los aficionados de música metal a nivel global.

${ }^{89}$ Distinción similar a la que había en el rock argentino a fines de la década del '70 entre los aficionados que iban a los recitales al sector de la platea y eran considerados "chetos", por los "rockers" (llamados "firestones" y "gronchos" por los otros), a fines de la década del '70. De acuerdo a Pablo Alabarces (1995), este enfrentamiento estaba íntimamente relacionado con la diferente posición social de ambos bloques. (En Alabarces, Pablo. "Qué se puede hacer salvo ver películas". Entre Gatos y Violadores. El rock nacional en la cultura argentina (pp. 72-83). Buenos Aires: Colihue, 1995.)
} 
Tal como propone Hermética en su dimensión visual, el look de los agentes de la escena también se caracteriza por ser transgresor o por buscar la diferencia con respecto a la moda hegemónica. Este se compone por las formas de vestir y con el peinado, los tatuajes, los piercings y otros accesorios de indumentaria. En primer lugar, pude ver que es común entre los miembros de la escena el uso de ropa de color negro y remeras con logotipos de bandas. Es necesario destacar que en las rockerías se puede encontrar muy fácilmente remeras y accesorios con el logotipo de Hermética, tanto como de Metallica y Iron Maiden.

Las remeras son el elemento de indumentaria más característico del metal. Tal como explica Weinstein (2000), desde mediados de la década de los '80 el modelo estándar difundido a nivel global posee mangas cortas, cuello redondo y color negro, con inscripciones, imágenes y logotipos principalmente en el frente y, a veces, también en la espalda. De esta manera, la elección de la remera que se lucirá en un concierto constituye una decisión importante y el hecho de cortarle las mangas es un símbolo de mayor autenticidad (Weinstein, 2000, p. 206), al igual que vestir una remera desteñida, lo que refuerza el carácter de marginal.

En el período de investigación pude observar algunos aficionados tratando de llevar el atuendo metálico tal como se utilizaba en la década de los '80. Por ejemplo, utilizando chalecos de jean con parches con logotipos de bandas; gran cantidad de apliques de tachas en cinturones, camperas y borceguíes; colgantes con cruces invertidas; cadenas colgadas en un costado de los pantalones; cinturones con réplicas de balas $^{90}$; y bandanas atadas en la cabeza. Por el contrario otros simplemente usaban remeras de estilo metálico con pantalones negros, de tela de jean o con estampado de camuflaje militar $^{91}$. Algunos utilizaban borceguíes $^{92}$ y, otros, zapatillas.

\footnotetext{
${ }^{90}$ El origen de estos cinturones es incierto, pero pude relevar el uso de este elemento de indumentaria por parte de Yoko Ono en el videclip de la canción "Love" del disco John Lennon/Plastic Ono Band (1970), en el cual el músico aparece vistiendo una chaqueta de estilo militar. Posiblemente la elección de este look forme parte de una burla y una crítica a los conflictos bélicos. También pude observar una fotografía del bajista de Deep Purple, Roger Glover, en el diseño interior del disco Fireball (1971). En la escena metálica, una de las primeras bandas en hacer uso de los cinturones de balas es Motörhead, pero posteriormente fue un elemento distintivo de las agrupaciones de thrash metal (especialmente aquellas que poseían una ideología anti-bélica) y de black metal. La diferencia con respecto a Yoko Ono es que en ella el cinturón de balas formaba parte de un estilo que buscaba satirizar a la imagen militar, mientras que en la escena metálica formaba parte de una actitud estética amenazante.

${ }^{91}$ De acuerdo a Hebdige (2004), el punk poseía un estilo ofensivo y amenazador y, dentro de su indumentaria, incluía indumentaria terrorista/guerrillera. A pesar de ello, el camuflaje había dejado de restringirse al ámbito militar y comenzó a ser integrado a la moda a partir de la década del ' 70 . Lo cual se puede relacionar con el estilo militar de Yoko Ono, John Lennon y Roger Glover.

92 Según Weinstein (2000), los aficionados de la NWOBHM utilizaban botas del tipo borcegos o borceguíes, los cuales provenían de los uniformes obreros.
} 
Existe una gran diferencia en el look entre los miembros de CABA y el Conurbano Bonaerense con respecto a las ciudades del interior de la provincia. En el caso de los primeros, es posible encontrar aficionados llevando el atuendo metálico en sus vidas cotidianas, mientras que en las ciudades del interior resulta menos común, lo cual se incrementa en pueblos chicos. En una entrevista realizada en un encuentro de motos en Trenque Lauquen a una empleada doméstica de 40 años de edad, junto a sus hijas de 16 y 22, provenientes del pueblo, América, pude ver algunas restricciones en sus decisiones sobre la vestimenta:

Yo: ¿Les es fácil ser metaleras en un pueblo chico? ¿Ser mujeres metaleras?

Madre: A mí me pasa que no. Por mis trabajos...

Hija mayor: No, porque te miran mal.

Madre: Claro, te miran mal, te miran mal. Yo hoy soy yo, en América mañana no soy yo.

Yo: ¿Y allá se pueden vestir como están vestidas ahora o no?

Madre: Sí, podemos, pero te miran así... Te miran mal.

En el momento de la entrevista, la madre llevaba puesto el atuendo metálico: campera de cuero negra, pantalón de cuero negro, borcegos y remera negra. Sus hijas también estaban vestidas de color negro y una de ellas llevaba puesta una remera de Hermética. A través de la entrevista pude ver que el recital y el motoencuentro constituían eventos que les permitía desplegar la identidad que ellas consideraban "auténtica", la cual se representaba en el atuendo. Esto se puede deducir a partir de la afirmación de la entrevistada "hoy soy yo".

Esta idea de que la vestimenta es motivo de miradas discriminatorias también lo encontré en una entrevista realizada en Tandil a una estudiante de diseño gráfico de 20 años proveniente de Laprida. De acuerdo a sus palabras, pude ver que en ciudades intermedias de la provincia (tales como Mar del Plata, Tandil, Olavarría, Bahía Blanca, Junín, Necochea, etc.), la aceptabilidad del look metálico era mayor que en los pueblos de menor cantidad de habitantes:

Ella: Y, mirá, lo que pasa es que allá en Laprida somos muy poquitos, entonces como que si vos te vestís, ponele, con una remera negra, pantalón negro, tachas, cosas así, la gente te mira, o dice "mirá". Entonces yo veo que, ponele, el de Laprida que viene acá, se viste como quiere y como siente, entonces es como que puede expresarse de otra forma. Y cuando vuelve a Laprida, jean y zapatillas, ¿entendes? Es como un prejuicio que tienen las personas... ¡ hasta yo también lo tengo y no me doy cuenta! 
En los ejemplos citados ambas entrevistadas son mujeres, sin embargo las actitudes de discriminación también son vividas por varones. En todos los casos a la vestimenta metálica se la suele vincular con características que atentan contra las "buenas" costumbres impuestas por la cultura hegemónica y los aficionados y las aficionadas son tildados de "grasas". Por su parte, los varones son calificados como "sucios" o "drogadictos", mientras que las mujeres son vistas como "machonas" o "putas" (especialmente en los casos de las "metaleras" que usan indumentaria gótica y proveniente del $\mathrm{BDSM}^{93}$ ).

Sobre el look metálico encontré algunas situaciones particulares. En primer lugar, en las ciudades del interior de la provincia, algunos de los aficionados al metal son trabajadores de zonas rurales, incluso varios son estudiantes de carreras universitarias como Ciencias Veterinarias y Agronomía, o estudiantes de escuelas secundarias agrotécnicas, por lo que es común en ellos el uso de indumentarias típicas de las labores en el campo, tales como la boina vasca, las bombachas de campo y las alpargatas. Muchos de ellos asisten a recitales de metal con ese atuendo, lo que sucede con mayor frecuencia en los conciertos de las bandas de Iorio.

La ruralidad también se presenta en modos de habla vinculadas con la figura del "paisano", con la que también se relaciona a dicho músico. Esta se caracterizaría por el uso de apócopes y de un volumen de voz alto. Además, es necesario destacar que las prendas anteriormente mencionadas provienen de la tradición gauchesca masculina. A pesar de ello, las mujeres de la actualidad (y algunas "metaleras") también hacen uso de ella, en lugar de vestir el atuendo de "chinas", por lo que el look rural actual posee rasgos de masculinidad (Ratier, 2009).

Este vínculo con el mundo rural se produce bajo ciertas tensiones, ya que en este existe una gran tendencia hacia el tradicionalismo y, por ende, al conservadurismo, lo que podría chocar con el metal teniendo en cuenta que se trata de un tipo de música que requiere de cierta tecnología. Sin embargo, este estilo musical también es caracterizado como conservador, por lo que dicho rasgo resultaría una semejanza.

En segundo lugar, es común que en las ciudades de esa magnitud las posibilidades para que se realicen recitales sean menores que en CABA y el conurbano,

\footnotetext{
93 Esta sigla se refiere a prácticas eróticas y sexuales consensuadas, consideradas alternativas, que incluyen Bondage (inmovilización de una persona mediante ataduras), Disciplina, Dominación, Sumisión, Sadismo y Masoquismo. La indumentaria que caracteriza al BDSM está compuesta por prendas de látex, cuero y vinilo, y accesorios como corsé, medias de red, ligas, zapatos de tacón y adornos hechos con cadenas.
} 
por lo que muchas veces las bandas de metal deben compartir escenario con otras de diferentes géneros de rock. Esto sucede por ejemplo en festivales como el "Roca Rock" de Tandil, “Azul rock” de Azul, "Patagones Patagonia Rock” en Carmen de Patagones, "Rock en Baradero" en Baradero y festivales culturales organizados por los alumnos de la Facultad de Bellas Artes en la ciudad de La Plata.

De hecho, también sucede que son pocos los lugares que se dedican especialmente al rock. En los pueblos más pequeños es común que solo haya un lugar especializado a dicho género musical, entonces los aficionados a este tipo de música prefieren concurrir allí a escuchar una banda de cualquier subgénero de rock antes que asistir a una discoteca bailable. De esta manera, es posible encontrar en conciertos de metal asistentes con atuendos típicos de reggae, punk, stone, emo, gótico, skater, rap, entre otros. Incluso, interactué con asistentes que no se identifican como "metaleros" pero que sí escuchan algunas bandas específicas de metal, por lo que asisten a los recitales pero no visten el atuendo metálico.

En cambio, en CABA y en el Conurbano bonaerense es posible ver un gran despliegue de formas de look metálico en la vida cotidiana y durante los recitales, entre las que puedo mencionar casos extremos como el de hombres y mujeres adultos con el cabello largo hasta las rodillas y varones llevando camperas y pantalones cubiertos de tachas, al punto de que otros participantes de la escena los nombran con el apodo de "robocops", en alusión al personaje de la película estadounidense, "RoboCop".

Por último, durante los años que comprende el período de esta investigación, el look metálico es tomado por lo grandes diseñadores, por lo que se pone de moda vestir campera y pantalones de cuero, borceguíes y apliques de tachas. Tal como expresan Ingrid F. Fêo et al. (2015), diseñadores italianos, brasileños, japoneses y dinamarqueses, en las diferentes temporadas del año 2014 deciden inspirarse en la música metal para crear sus colecciones. Esto genera una gran producción de indumentaria basada en el estilo metálico, que no solo se restringe a marcas reconocidas de ropa, sino también a sus imitaciones (de menor costo).

En mi trabajo de campo, pude comprobar que en una gran cantidad de negocios de ropa tanto masculina como femenina se vendían remeras con los logotipos de Led Zepellin, Metallica, Iron Maiden, Black Sabbath, AC/DC y Def Leppard e, incluso, camisetas que poseían frases o palabras sueltas tales como "Love" (amor) cuya tipografía imitaba los logotipos de dichos grupos musicales. De esta manera personas que no son aficionados al metal comenzaron a lucir estas vestimentas, muchas veces sin 
conocer los conjuntos o el estilo musical; mientras que para los "metaleros", se hizo más accesible utilizar dicho atuendo, algo que resulta diferente a los años anteriores en donde el acceso a la indumentaria especializada era algo restringido.

Esta proliferación de vestimenta metálica en personas que no escuchan este estilo de música pone en juego la autenticidad de la identidad metálica en la escena, lo que se vincula con Hermética como banda que propone el fundamentalismo en la diferenciación del "falso" con respecto al "verdadero" metal. Esta idea genera posturas a favor y en contra (Ver Figura 15), al mismo tiempo que nuevas prácticas del estilo de vestimenta. Es por ello que los códigos de autenticidad cobran mayor valor para los miembros de la escena

Por ejemplo, las remeras con logotipos o ilustraciones dedicadas a un grupo en particular requieren que quien la lleve conozca sus canciones, sus discos, sus integrantes y, si es posible, la historia y las últimas noticias de sus músicos. Dentro de la escena está mal visto que alguien lleve una remera sin conocer a la banda de ella. Esta situación tiene más probabilidades con el uso de camisetas que pertenecen a agrupaciones mainstream y son accesibles de conseguir también por fuera de rockerías, como por ejemplo, Iron Maiden y Metallica. A este tipo de portadores se los considera "caretas".

También se cree que es poseur quien no es "metalero" y se viste ocasionalmente con su atuendo solo para asistir a un concierto o con la intención de seducir a algún miembro de la escena. Esto es más visible en ciudades con poca cantidad de habitantes, en donde quienes participan habitualmente de eventos de la escena se conocen entre sí. Weinstein (2000) menciona a estos actores como "guerreros del fin de semana" (p. 129), ya que solo visten el atuendo metálico para asistir a conciertos. En las ciudades del interior de la provincia esto es habitual, sin embargo la autenticidad de los participantes se demuestra de otras formas.

Por un lado, a través del conocimiento y de la información acerca del estilo musical. Esto hace que muchos de los miembros de la escena consideren que el metal no se demuestra exteriormente en la ropa sino que se trata de un sentimiento. Esta idea se puede vincular con la propuesta de Hermética, la cual se hace explícita en la canción "Evitando el ablande":

Con mis amigos en el concierto / de metal duro por sentimiento. / Es fija que me verás si estás presente / brindando aguante con quienes sienten. / Como yo siento latir en la sangre mía. / Salvando mis días, / junto a su sonido brutal, mi vida / resiste su ruina. $(\ldots)$ 
La concepción del metal como un sentimiento justifica que muchos de ellos, durante los días de semana, no vistan con el atuendo metalero debido a requerimientos laborales (la mayoría de los empleos prefieren trabajadores que vistan como lo impone la sociedad "respetable", es decir, la cultura hegemónica), con un signo de madurez (algunos consideran que esa vestimenta estaba relacionada con su juventud) o con la necesidad de vincularse con personas por fuera de la escena, las cuales pueden tener miradas prejuiciosas hacia el atuendo metálico (o rockero en general, ya que en dicho campo también se utilizan remeras con similares características). En una entrevista, pude acceder a la opinión de un "metalero" de 47 años de Carmen de Patagones que aún viste el atuendo metalero en la vida cotidiana:

Él: (...) Lo que pasa es que nosotros estábamos con remeras negras y todo y nos decían, inclusive ahora gente más grande nos dicen, "los chicos". Somos "los chicos" nosotros. Yo: ¿Y vos creés que la vestimenta ayuda a que les digan "los chicos"?

Él: Sí, sí, te catalogan. Porque vos a una edad justamente tenés que estar en camisa y no escuchar ciertas cosas. Y nosotros les decimos... De hecho, podés ser padre de familia, tener un buen laburo, no vestirte así, pero seguir participando. Acá nos matamos de risa que siempre decimos que los pibitos que son los más heavy-metaleros se pusieron de novio y se cortaron el pelo. Podes cortarte el pelo, pero si a vos te gusta, ¿qué te afecta? Podes tener hijos, familia y lo podes seguir. Si en el último recital que estuvo Lethal acá en Viedma fue como... Yo dije "el regreso de los muertos vivos". Pibes que hacía un montón que no veía y te ven a vos y "ah, uh, qué bueno, vos seguís" y vos los ves totalmente cambiados y respondés "sí", y se quedan sorprendidos (risas). Yo estoy más viejo, más canas, pero seguimos.

Sánchez Mondaca (2004) parafrasea a Gallegos (2004) para explicar cómo la participación en la escena thrasher chilena implica un compromiso que comienza en la juventud y continúa en la edad adulta, a lo que califica como "identidad adolescente para adultos” a través de un compromiso “eterno" (Sánchez Mondaca, 2004, p. 57). Lo mismo sucede en la escena metálica bonaerense.

Por otra parte, “(...) en el campo del rock hay diversas formas de ella que permiten, internamente, calificar a los rockeros y distinguirlos de los no-rockeros" (Garriga Zucal y Salerno, 2008, p. 66). Dentro de estas maneras que otorgan autenticidad, describen las que permiten diferenciar a los "iniciados" de los "novatos". Para Garriga Zucal y Salerno (2008), "La pertenencia a un grupo y a otro está determinada por el tipo de participación que tenga la persona en el concierto y no por la cantidad de conciertos a los que haya asistido" (p. 67). 
Por el contrario, en la escena metálica bonaerense sí se valora la acumulación de recitales vistos, lo cual se ostenta no solo exhibiendo las fotografías tomadas en el concierto (con mayor énfasis cuando son junto a un músico metálico famoso), sino también con la colección de los talones de las entradas y con la compra de las remeras pertenecientes al merchandising oficial de la banda vista. Esto se acentúa más cuando los diseños de la prenda son especiales para cada gira de recitales y la única manera de adquirirla es comprándola en el mismo evento.

Otra forma de demostrar autenticidad es durante los conciertos, a través de las prácticas características del estilo musical (headbanging, mano cornuta y $\operatorname{mosh}^{94} \mathrm{o}$ pogo, las cuales describiré más adelante) y del canto de las canciones (especialmente de los covers, en el caso de conciertos de bandas underground).

Las prácticas ajenas al estilo musical dan cuenta de la presencia de sujetos que no pertenecen a la escena. Por ejemplo, en un concierto de la banda Mojón en Tandil en el 2014, un grupo de "metaleros" se burlaba de una pareja de dos mujeres que bailaban con pasos de salsa y cumbia al ritmo de la música ejecutada en ese momento, que era thrash metal. En otras oportunidades, también observé miradas burlescas hacia sujetos que participaban del mosh haciendo pasos de baile de música electrónica.

En ese sentido, pude ver que en la escena bonaerense se mantiene la característica del estilo musical como culturalmente conservador, especialmente porque el público espera que las bandas nuevas se asemejen y respeten las convenciones de las bandas de la "vieja escuela". Estas no solo son aquellas que realizan covers de las bandas pioneras de los subgéneros del metal gestados en los '80, sino también aquellas que construyen su sonido basándose en los instrumentos tradicionales del metal, sin agregar artefactos tecnológicos para proveer un sonido más "moderno".

En la actualidad ya no se produce la disputa entre los seguidores de thrash metal y los del glam metal, de la cual Hermética también formaba parte. Sin embargo, aún persiste el debate acerca de la autenticidad, lo que genera nuevas rivalidades. Una de ellas se produce mediante la tensión entre la audiencia del metal extremo y el "metal argento", ya que los aficionados al primero consideran a los otros como "cabeza de tacho" o "cabeza de termo" por resistirse a conocer bandas por fuera de la trilogía V8,

\footnotetext{
${ }^{94}$ Brevemente diré que se trata de una forma de baile grupal no estructurado en donde los participantes se empujan y dan golpes de puño al ritmo de la música. Más adelante me ocuparé más ampliamente de este concepto.
} 
Hermética y Almafuerte (bandas que resultan fundamentales para los agentes de la escena argentina).

Estas expresiones surgen a partir del criterio de algunos aficionados que consideran que una mente "cerrada" se opone a asimilar nuevas propuestas, por lo que la autenticidad para ellos está vinculada con la evolución. Sin embargo, es posible ver en esas expresiones formas de discriminación clasista, ya que varios de los agentes que las usan como burlas parecen considerar que los "metaleros" provenientes de sectores sociales marginales no son aptos para adquirir nuevos conocimientos (como por ejemplo, producciones de bandas extranjeras en idiomas diferentes al español). Este tipo de críticas genera tensiones que se producen únicamente como enfrentamientos verbales en las redes sociales y burlas mediante memes (Ver figuras 16, 17 y 18), los cuales aumentaron luego del acercamiento explícito de Iorio a la extrema derecha.

Por el contrario, los seguidores de este músico suelen ser muy rígidos en sus elecciones musicales, de manera que el lugar que le otorgan es prácticamente imposible de desplazar por otra personalidad. En segundo y tercer lugar se encuentran Pappo (valorado por su virtuosismo como guitarrista y también por su reconocimiento por fuera de la escena, inclusive a nivel internacional) y Osvaldo Civile (ex guitarrista de la banda de thrash metal, Horcas), pero por debajo del ex líder de Hermética. La figura de Iorio genera un fanatismo tan grande que sus seguidores se caracterizan por imitar su peinado, sus gestos, sus frases y su forma de hablar, lo cual se produce tanto en varones como en mujeres, en adultos como en niños (Ver Figura 19).

Estas oposiciones entre los propios aficionados de la escena metálica bonaerense son similares a las que había en el rock nacional y que estaban dadas de acuerdo a diferentes puntos de vista en torno a la autenticidad: "progresivos" vs. "complacientes"; "eléctricos" vs. "acústicos"; "modernos" vs. "consagrados"; y "duros" vs. "blandos".

A través de la netnografía realizada pude encontrar gran cantidad de grupos y fanpages de Facebook que se dedican a compartir material acerca de Iorio, correspondiente a toda su carrera musical y a sus apariciones en los medios de comunicación. Allí los miembros y seguidores realizan comentarios exaltando y dando su apoyo al músico y, en caso de que exista alguna opinión en contra de él, se producen enfrentamientos verbales con cierta agresividad.

El ejemplo más claro se encuentra en el grupo "Iorio lo más grande del heavy nacional", el cual fue creado y es administrado por aficionados. Hasta diciembre del 2017 contaba con 18160 miembros y suma nuevos constantemente. Es necesario 
destacar que, de acuerdo a las publicaciones y algunos comentarios realizados, se pudo deducir que muchos de ellos tenían un vínculo personal con el músico. Esta relación hacía que muchas veces se lo justifique y defienda sin importar cuál sea la acción o la declaración que haya hecho el artista. Sobre esto me explayaré más adelante en el capítulo vinculado al metal y la política.

\section{El metal y la violencia}

El objetivo de expresar rebeldía, transgresión y oposición a la cultura hegemónica y a formas culturales de las cuales el metal pretendía diferenciarse muchas veces llevó a formas concretas de violencia. Tal como expresa Maximiliano Sánchez Mondaca (2007), “Thrash significa Azote, es a partir de la propia etimología y traducción literal de la palabra que el movimiento nace con la idea de ser algo violento, o que al menos denote cierto grado de violencia.” (p. 89)

A nivel global, en la década de los '90, algunos músicos de black metal cometieron asesinatos, suicidios y quemas de iglesias, materializando en la realidad las prédicas anticristianas que desarrollaban en sus producciones artísticas. Por otra parte, el 8 de diciembre de 2004, Dimebag Darrell, guitarrista de la banda estadounidense de groove metal, Pantera, fue asesinado de dos disparos mientras se encontraba sobre el escenario dando un show con la banda, Damageplan.

En Argentina, los sucesos de violencia en la escena metálica también tuvieron lugar con la banda, Riff, cuyo público se encargaba de destrozar los locales y teatros en donde se presentaban. Fue por ello que el año 1983 decidieron realizar un recital bajo el título "Riff termina el año sin cadenas" para intentar calmar los incidentes de violencia por parte de sus aficionados. Esto generó todo lo contrario, por lo que la banda decidió pausar su actividad de manera momentánea por ya no poder controlar el caos que generaban sus seguidores.

Aunque Riff fue la banda que durante los '80 estaba plenamente vinculada a los sucesos de violencia, existe un antecedente en la presentación de Billy Bond y La Pesada del Rock and Roll durante un festival realizado el 20 de octubre de 1972 en el Luna Park, junto con Color Humano, Pescado Rabioso, Aquellarre, Pappo's Blues (bandas cuyos seguidores eran principalmente los "firestones") y Litto Nebbia.

Allí, Bond, el cantante de La Pesada, incitó al público que ocupaba las ubicaciones populares a pasarse a las que estaban vacías en la platea con la frase “¡Rompan todo!”. De esta manera, la audiencia comenzó a derribar los enrejados que 
dividían ambos sectores para poder cambiarse de lugar. Esto generó grandes disturbios que conllevó la represión policial.

Sobre este evento, los medios de esa época publicaron titulares tales como "El rock infernal: hordas de hippies arrasaron el Luna Park" (Así, 24 de octubre 1972) y “Escándalo en el Luna Park" (La Razón, 21 de octubre de 1972). En esta última se narraban los sucesos acontecidos destacando la violencia de la audiencia mediante expresiones tales como "grupos de desarrapados", jóvenes con atuendos "posiblemente 'de guerra"”, “jóvenes desorbitados", "revoltosos", "vocingleros", "grupos de exaltados", mientras que al accionar policial solo se lo nombró como "represión de los agentes del orden".

En el libro, Cuando éramos reyes. Memorias del heavy argentino de los ' $80 \mathrm{~s}$ (2015), Rubén Cañizares recopila una gran cantidad de anécdotas y testimonios de músicos, aficionados y mediadores de la escena metálica porteña de esa década. Allí el autor afirma que "Los '80s sin violencia no son los '80s" (Cañizares, 2015, p. 64) y, a través de las palabras de los diferentes entrevistados, es posible reconstruir el panorama de aquella época en donde las brigadas metálicas no solo se enfrentaban físicamente con la policía sino también entre ellas, debido a que seguían a distintas bandas generando una especie de competencia. Algo similar sucedía con los "papperos" y los punks, quienes eran considerados "chetos" por los primeros.

Por ejemplo, durante mi trabajo de campo, gran cantidad de aficionados que forman parte de la escena desde los ' 80 recuerdan los accidentes y disturbios que hubo la primera vez que la banda estadounidense, Quiet Riot, visitó Argentina en 1985. Frank Henstein, ex bajista y cantante de la banda, Dr. Jekyll, expresa que durante esos años, en la escena metálica,

Había demasiado quilombo. Armar un show era saber que podía pasar cualquier cosa. Estuve en el mítico recital de Quiet Riot en el Luna Park, donde no sé porque [sic] se armó todo el bolonqui. Se cayó una columna, todo era muy confuso. Para colmo el escenario era chiquito y muy bajo, casi al ras del suelo, el sonido era horrible y el público tenía poca paciencia, por lo que se armó el descontrol con butacas volando, humo y peleas por doquier. El heavy se creía capaz de generar toda clase de disturbios, se sentía un ser todopoderoso, era un bardo total”. (Cañizares, 2015, p. 286)

En el documental Sucio y desprolijo, los entrevistados también se refieren acerca de la violencia que caracterizaba a la escena porteña tanto en los 80 como en los 90. Lo mismo se puede observar a partir de la netnografía realizada en la fanpage de Facebook 
“Fan Rev Rebelion Rock”, la cual es administrada por Luis “Alakrán” Ferrofino, ex locutor del programa radial especializado en metal, "Rebelión" y del fanzine "Rebelión Rock”. La página en Facebook es una extensión de los medios anteriores y en ella se publican anécdotas desde el punto de vista de "Alakrán", las cuales son enriquecidas con comentarios de diferentes participantes de la escena que demuestran conocerse entre sí de manera offline.

Entonces, a través de algunas publicaciones de dicha página fue posible reconstruir que durante los 90 existían frecuentes enfrentamientos violentos entre los "metaleros" y los skinheads porteños. Sin embargo dichas peleas no surgían como una rivalidad tal como la que sucedía con las "brigadas metálicas" sino que tenían un trasfondo ideológico que considero apropiado desarrollar en el apartado acerca del metal y la política.

Las prácticas violentas de los "metaleros" porteños de la década de los '80 hicieron que algunos investigadores los diferencien del resto de los rockeros de la época (Jelin, 1985; Garriga Zucal y Salerno, 2008) y los caractericen como agresivos. Durante mi trabajo de campo pude ver que esta vieja caracterización se modificó a través de algunos comentarios y decisiones tomadas por los miembros de la escena. Posiblemente estas transformaciones se debieron a la madurez de los aficionados y a la consolidación de la democracia y la evolución a un contexto más pacífico que el de entonces.

Un ejemplo de ello pude notarlo en una conversación entre dos parientes durante una reunión familiar. Ambos eran varones, pero uno de ellos tenía 28 años de edad y el otro 50. El más grande le preguntó al otro: "Me comentaron que el otro día a la salida del recital de Tren Loco se cagaron a palos, ¿es verdad?". El más joven respondió: "Sí, me dijeron. Yo ya me había ido. Uno terminó en el hospital.”. A lo que el otro respondió: "Son unos boludos. Esas cosas ya no tienen que pasar. En mi época te cagaban a palos por cualquier cosa y después nadie conseguía lugar para poder tocar" (Conversación transcripta de notas de campo personales).

Algo similar pude observar en la ciudad de Tandil durante la clausura de un local en un festival de bandas de diferentes ciudades de la provincia:

A mitad de la noche, cuando todavía faltaba que dos grupos suban al escenario, llegaron los bomberos a inspeccionar el lugar y, como no estaba en regla, lo clausuraron inmediatamente sin permitir que el concierto se siga desarrollando. De esta manera, todos fuimos expulsados del lugar. La gente salió de manera pacífica, con excepción de un solo varón que estaba alcoholizado y comenzó a agredir verbalmente al personal de seguridad para que le devuelva el dinero de la entrada. Cuando estaba a punto de 
empujarlo, vino un joven a frenarlo, gritando “ ¡No se peleen! ¡No se peleen! En el metal no tiene que haber violencia", por lo que finalmente la pelea no se concretó. (Fragmento de notas de campo personales)

La relevancia de ambos ejemplos se debe a que en los dos casos los aficionados se manifiestan en contra de la violencia, opinión que fue mayoritaria durante los intercambios que tuve durante la observación participante. Por el contrario, los aficionados de la escena bonaerense tienden a considerar que el metal es una forma lícita de canalizar el enojo y descargar la impotencia originada por diversas situaciones de la vida cotidiana sin llegar a la violencia en la práctica real, tal como expresa un joven de 19 años durante una entrevista etnográfica:

A mí lo que me gusta del metal es lo que se construyó al lado, que es que sea la expresión más violenta que puede haber. Vos podés estar hablando de algo personal emocional tuyo y tratar a... Ponele, si estás enojado, sentir ira... Bueno, ahí le metés distorsión. Que no tiene que ser controversia política ni nada. Podés estar enojado con la situación de tu familia o de tu vida y... ¡distorsión!

Asimismo, prácticamente no presencié enfrentamientos físicos entre los miembros de la escena. Por el contrario, vi gran cantidad de saludos amistosos y gestos afectuosos ligados a la camaradería masculina.

El headbanging, la mano cornuta y el pogo

Durante mi trabajo de campo, las expresiones propias de la autenticidad y las performances violentas se hicieron presentes en mayor medida durante los recitales. Sobre estos eventos, Weinstein (2000) explica que los shows en vivo son centrales en el metal y que, "En su conjunto, un concierto de heavy metal abarca una densa y amplia variedad de acciones comunicativas" (p. 213. T. de la A.), las cuales se consuman de tres formas: como un entretenimiento placentero y excitante; con el orgullo de presentarse como una comunidad idealizada; como momento en donde la banda y la audiencia se vinculan de manera directa.

El recital se desarrolla como una experiencia multisensorial, lo que permite que el disfrute sea más elevado (Weinstein, 2000). Los componentes del concierto que producen impacto emocional son el sonido amplificado, el cual aumenta los niveles de adrenalina; la emocionalidad expresada por el cantante tanto con su voz como con su gestualidad; los efectos visuales de la escenografía, que buscan ampliar los niveles de 
excitación; y la presencia de una fuerte actividad kinésica en donde el cuerpo se mueve al ritmo de la música pero sin desarrollar un baile de manera convencional.

Las performances realizadas por el público durante el recital representan formas de autenticidad y, en el metal, existen prácticas que son propias de sus músicos y sus audiencias que, de manera similar a otros géneros musicales, constituyen formas de catarsis generadas por la potencia y la intensidad que caracterizan al metal (Galicia Poblet, 2015). Las más distintivas son el headbanging, la mano cornuta y el pogo.

La primera también es referida en la escena bonaerense como la acción de "revolear los pelos", ya que consiste en el movimiento frenético de la cabeza -y con ella, el cabello- al compás de la música, algunas veces verticalmente hacia abajo y hacia arriba y, otras, de manera circular o transversal. De esta manera, "Headbanger es, literalmente, alguien que sacude o golpea la cabeza." (Christe, 2005, p. 50). Esta práctica es más común en aficionados con cabello largo. De hecho, algunos entrevistados expresaron que este look les permitía disfrutar más de dicha forma de baile (Ver Figura 20).

La segunda consiste en doblar hacia adentro los dedos pulgar, corazón y anular y dejar extendidos el índice y el meñique, de manera que la mano asemeja tener dos cuernos. Este gesto supuestamente fue creado por Ronnie James Dio (cantante de Black Sabbath, Rainbow y Dio) para saludar al público, quien lo extrajo del malocchio, una costumbre utilizada por su abuela italiana con la intención de curar el mal de ojo (Christe, 2005). Si bien dicho origen es incierto, constituye una práctica muy extendida dentro de la comunidad metálica global (Ver Figura 21).

Ambas performances son ampliamente realizadas por quienes no participan del pogo, a lo que también se le suman prácticas como alzar el puño y golpear al aire; mover un pie, golpearse las piernas o el torso con las palmas de las manos al compás de la música; y simular la ejecución de una guitarra o una batería invisible ${ }^{95}$.

En tercer lugar, otra práctica característica del metal es el pogo o mosh-pit, cuya participación -al igual que en el rock chabón- es un medidor de autenticidad. En el estilo musical aquí analizado, esta práctica se caracteriza por desarrollarse de manera más agresiva que en otros subgéneros del rock, pero, en todos los casos, se define por su carácter grupal.

\footnotetext{
${ }^{95}$ El gesto de tocar una guitarra invisible es denominado de manera anglófona, "air guitar". Esta es una práctica extendida en la audiencia metálica a nivel global, al punto de que existen campeonatos al respecto.
} 
Sergio Pujol (2007a) explica que el pogo es inventado por Sid Vicious, bajista y vocalista de Sex Pistols, quien comienza a saltar sobre el escenario e inmediatamente es imitado por el público. De esta forma nace este tipo de baile cuyo componente esencial es la diversión:

\begin{abstract}
¿Por qué se salta en un recital de punk? ¿Por qué se saltará en próximos recitales, aun fuera de la influencia directa del estilo? Hay en esto una necesidad de descarga y de identidad en el riesgo, allí donde la música baja del escenario convertida en juego. Es un juego brusco, sin duda, y a veces peligroso. Pero no es más que un juego (Pujol, 2007a, p. 130).
\end{abstract}

En el metal, el mosh-pit se desarrolla en forma de círculos como algunos bailes folklóricos europeos, pero se le agregan saltos y empujones amigables, mientras los sujetos se desplazan de manera similar a los autos chocadores (Weinstein, 2000). Por su parte, el slam dancing es la forma más tardía del mosh, la cual proviene del hardcore e incluye golpes de puño, patadas y volteretas. De manera que el contacto entre los participantes es más violento.

En Estados Unidos, una de las primeras bandas que presenció estos bailes en sus conciertos fue la thrashera, Megadeth (Christe, 2007, p. 182), por lo que se dice que esta práctica se extendió gracias a dicho subestilo del metal. Luego se comenzó a multiplicar en conciertos al aire libre (open-air), por lo que surgieron diferentes maneras de realizarse.

Algunas formas posmodernas que son propias de la audiencia de los conciertos de metal a partir de la década del '90 son el stage diving (cuando suben al escenario por el frente y luego se arrojan al público), el wall of death (o "pared de la muerte": cuando se agrupan en dos líneas enfrentadas y al ritmo de la música corren hacia la línea contraria embistiendo con el cuerpo al resto de los aficionados a su paso, de la misma manera que en las batallas de la Antigüedad) y el crowd surfing (cuando algunos son trasladados en manos de otros sobre las cabezas de los demás, como si estuvieran surfeando sobre un mar de personas -Ver Figura 22-) (Hoffstadt y Nagenborg, 2010).

Estas prácticas parecen haber surgido en recitales masivos. No obstante, en mi trabajo de campo pude observar que también son realizadas en conciertos underground, en espacios mucho más pequeños que los grandes festivales en estadios de fútbol, como por ejemplo, pubs, bares, teatros, centros culturales y plazas públicas.

Por otra parte, al pogo no solo pude registrarlo en la mayor parte de los conciertos etnografiados, sino que también lo observé en una discoteca porteña dedicada 
al metal, la música electrónica y la cultura gótica y dark, en donde los asistentes masculinos realizaban mosh al ritmo de la música proyectada en videoclips en grandes pantallas, mientras algunas mujeres realizaban un espectáculo de pooldance sobre una tarima.

A pesar de que consiste en una práctica cuyos movimientos son agresivos y posee ciertos riesgos físicos, el mosh-pit no tiene como objetivo la violencia ni la destrucción mutua. Es por ello que puede ser analizado como performance en términos de Schechner (2011) ya que se trata de secuencias de conducta manipuladas con un significado determinado; es decir "conductas restauradas" que "(...) se desarrollan en una espiral de retroalimentación con las acciones de los individuos cuando son representados" (Schechner, 2011, p. 38). Los golpes entre los "pogueros", que en otra ocasión podrían ser utilizados en un enfrentamiento, en dicha práctica son resignificados.

La idea de que el pogo se desarrolla bajo ciertos códigos hace que tenga un "efecto comunicativo", ya que algunos de sus rasgos "(...) funcionan como señales que definen el rol de los participantes y en general la estructura del baile" (Citro, 2008, p. 11). Una de estas reglas consiste en que los golpes propiciados durante la performance no consistan en un enfrentamiento personal real. De este modo, a pesar de que estos movimientos corporales están vinculados con expresiones de enojo, constituyen "formas de interacción con el propósito de representar la ira de una manera controlada" (Hoffstadt y Nagenborg, 2012, p. 41).

De cierta manera, el pogo puede caracterizarse como una actividad conformada por un exceso de movimiento pero que se desarrolla mediante la ideología del autocontrol $^{96}$ (Kahn-Harris, 2007), por lo que se produce mediante la tensión entre la violencia y el orden. Esto se debe a que los participantes, a pesar de golpearse, tienden a ser cuidadosos entre sí. Es decir que son conscientes de que están participando de un mosh-pit y no de un motín (Berger, 1999, p. 72).

A través de la netnografía realizada en la plataforma YouTube, pude observar que en el recital de Malón realizado en Malvinas Argentinas en diciembre del 2011, el cantante, O’Connor frenó a sus compañeros dos veces durante varios minutos para poder pedirle al público que pare de empujar hacia adelante, advirtiendo que se iban a

\footnotetext{
${ }^{96}$ Según Kahn-Harris (2007) otra forma de autocontrol aparece en la evitación del mosh, lo que se da en miembros de la audiencia demasiado adultos, cansados o aburridos como para ingresar al pogo, a lo que también agrego el no animarse a participar del pogo, el preferir no exponerse a lesiones físicas y la necesidad de ver a la banda y prestar atención a los detalles del show.
} 
lastimar ya que se habían corrido las vallas de protección. Por su parte, el guitarrista, “Tano" Romano, hacía señas para que la gente se desplazara hacia atrás.

En este caso, la actividad se presentó como controlada por los músicos y no por los participantes de la audiencia ${ }^{97}$. La netnografía me permitió acceder a las opiniones de algunos asistentes (Ver Figura 23). Posiblemente la precaución por parte de los artistas se relacione con su propia experiencia en Hermética, con la muerte de José Damián (descrita en capítulos previos) y con los efectos de la tragedia de Cromañón sucedida en 2004, la cual tuvo fuertes repercusiones en el campo del rock argentino.

De manera contraria al desarrollo pacífico y "amistoso", una pelea real podía suceder si se le propinaban golpes a quien se había caído y no se lo ayudaba a levantarse. Esto es considerado por los "pogueros" como una actitud de "mala leche" y podía llegar a suceder si se "metía" al pogo, alguien que estuviera alcoholizado o bajo los efectos de drogas, lo que se puede observar en el siguiente fragmento de una entrevista realizada a un aficionado y músico metálico de 27 años:

Yo: ¿Qué es hacer pogo para vos?

Él: Para mí hacer pogo es la forma de descargar. Es como... la música te lleva a tratar de expresar de alguna manera lo que le genera a uno. $Y$ en este caso el pogo hace eso. Hay distintos tipos de pogo, depende para qué banda, ¿no es cierto? Si estamos escuchando $\mathrm{AC} / \mathrm{DC}$, el pogo es de una manera, si estás escuchando Cannibal Corpse es de otra, obviamente.

Yo: ¿Y en todos los recitales donde vos vas, siempre haces pogo?

Él: Ahora no, en este momento no. Antes por ahí capaz que sí. Pero no, no pueden ser todos.

Yo: ¿Por qué?

Él: Porque alguna banda me llega menos que otra. O por ahí una banda que me gusta muchísimo, que es la primera vez que veo, hago un poco de pogo pero también la miro porque quiero verla y no sé si tengo otra oportunidad de verla en la vida.

Yo: ¿Por qué decís que antes hacías pogo y ahora no?

Él: Porque también por lo general al pogo lo empezamos a hacer entre grupo de amigos siendo acá en la ciudad, que es chica. Pero si yo voy a ver una banda que por ahí no es muy poguera lo que genera, la música en sí no es muy poguera... Si no me transmite algo bien o no me llega tanto como otras bandas, capaz que no hago pogo. Miro y escucho nomás.

Yo: ¿Cómo sería una banda poguera?

Él: Que la música me genere las ganas de hacer pogo. Para mí es una, para otros será otra banda, o tema.

Yo: ¿Cómo es hacer pogo? ¿Qué hacés?

Él: Y, depende qué pogo, pero hay algunos que saltas, otros que es empujarse y otros que nosotros siempre le dijimos "el piñerío", pero ahora ya me enteré que es hacer el

\footnotetext{
${ }^{97}$ Es necesario destacar que a esto lo pude advertir en videos capturados por aficionados. Este show fue grabado y posteriormente vendido como DVD por la banda bajo el título "El regreso más esperado" (2012). Sin embargo, allí se editaron las imágenes y no es posible ver dichos baches en el show. Un video que muestra este evento puede verse en el siguiente link: https://www.youtube.com/watch?v=KOzzRzmyHTg
} 
mosh. Pero nosotros le decimos el piñerío, es así. Acá en Argentina es el piñerío. A nivel global será mosh, o no sé cómo sea, pero acá estamos en Argentina y es el piñerío. Que acá en la ciudad en un momento éramos siempre los mismos y un par de gente como que no les gustaba, nos miraban raro. Y ahora hay un momento que ya no hacen eso y cuando hay ese pogo es porque lo hacemos nosotros.

Yo: ¿Cómo sería el piñerío?

F: Y, el piñerío no sé (risas), el que lo ve de afuera ve un par de diez pibes o cinco pegándose, pero pegándose sin mala leche. O sea, no es ir y pegar y verlo ahí y meterle una trompada, tirarlo al piso y empezar a pegarle. Si una persona se cae, lo levantas y si le tenés que pegar de vuelta, le pegas y lo levantas.

Yo: ¿Y en ningún momento se confunden las piñas, la intención?

Él: Sí, cuando se mete alguien que no entiende cómo es, sí. Me pasó. Que se metió una persona que no era del palo. O sea, si bien era metalero no era como por decirlo de un pogo más violento, se metió pero de manera mala leche, con mala intención y bueno, hubo que pegarle para que entienda.

Yo: ¿Cómo te diste cuenta de que era con mala intención?

Él: Porque en una me caí y, en vez de ayudarme a levantarme, me tiró de vuelta al piso. Entonces cuando me levanté, lo primero que hice fue pegarle y no se pudo meter más, porque no lo dejó nadie.

Yo: O sea que hay ciertos códigos en el pogo.

Él: Exactamente. Así como ir a ver una banda a otra ciudad, que me pasó también. Un pogo violento de otra ciudad pasa lo mismo. O sea, no hay... puede haber mala leche si la persona, la que aparenta ser mala leche esté borracha o drogada, pero si no, no. Si te caes, te levanta la gente, no te sigue pegando ni nada. A no ser que sean pungas, y te quieran robar (risas).

Yo: ¿Cómo lo ves del lado del escenario? Porque eso que me comentas es del lado de abajo del escenario. ¿Desde arriba cómo sería?

Él: Y del lado de arriba, en mi caso es... cómo te puedo explicar... El pogo tiene que estar... Es como si... si el pogo no está, para lo que hacemos nosotros, es como si, no sé, le faltara una cuerda a una guitarra. O sea, se puede tocar, porque el guitarrista podrá dibujarla, lo que sea, pero no es lo mismo. No sé, como un tema que es para dos guitarras y la otra guitarra no esté y haya un guitarrista solo, pero algo le falta. Suena, todo, pero algo le falta. Entonces para mí tiene que estar. Porque es como que lo que uno hace, en este caso lo que nosotros hacemos, es tratar de generar que le guste y que lo que hacemos nosotros es para hacer pogo. Y verlo así abajo cuando lo hacen, está buenísimo. O sea, me genera más ganas de seguir tocando, de no bajarme nunca.

Yo: ¿Cómo construís una música poguera?

Él: Y, ipero es mi perspectiva! Puede ser que todo va en base a lo que es guitarra y batería. La rítmica de lo que es la guitarra con la batería. O sea, lo que marca el nivel de violencia o lo que sería poguero, es más la batería que la guitarra, pero las dos cosas tienen que ir para el pogo.

De acuerdo al caso citado y a otra gran cantidad de músicos metálicos entrevistados, para ellos es importante la presencia del pogo, ya que denota que la gente lo está pasando bien y su música es aprobada por el público. En algunos casos, expresaban explícitamente en el micrófono el deseo de que la gente haga mosh-pit.

Un ejemplo sucedió durante el concierto de la banda estadounidense de thrash metal, Testament, en CABA en 2015, en donde Chuck Billy, el frontman, durante el tema "Into de pit" (1988), pidió al público que se separe en dos para realizar wall of 
death, mientras la música dejó de sonar. Cuando el cantante dio la señal, esta comenzó de nuevo y los aficionados que quisieron participar embistieron a los de la fila contraria.

Al indagar acerca de la violencia, los entrevistados explicaron que el pogo funciona como una forma de descargarse de los enojos y el agobio de la rutina laboral. Es decir, que funciona como un modo de "expresión de emociones socialmente censurables" (Rivera-Segarra et al., 2015, p. 109). También les permite seguir el ritmo de la música ejecutada en vivo y "hacerle el aguante" a la banda, es decir, demostrarle que les gusta su producción.

Al igual que expresaron los entrevistados, a través de mi trabajo etnográfico pude notar que la mayor parte de los pogos de los conciertos a los que asistí se desarrollaron de manera pacífica y las peleas aparecían en casos aislados con sujetos que habían consumido alcohol o drogas en exceso.

Es posible decir que dicha práctica resulta relativamente peligrosa, debido a que observé casos de lesiones de cierta gravedad ${ }^{98}$. Sin embargo quienes participan del pogo disfrutan el poder mantenerse en pie en medio del frenesí agresivo de este baile. Cuando las lesiones son rápidamente tratables, los participantes vuelven a ingresar a pesar de haberse lastimado.

Retomando la idea de baile codificado, de acuerdo al entrevistado citado, una de las principales reglas es ayudar a levantarse al "poguero" que se haya caído. Weinstein (2000) considera que el hecho de que el público no deje caer a otro aficionado al suelo es un signo de solidaridad dentro de la audiencia del estilo musical (p. 230). Otros modos de ayuda aparecen cuando alguno de los participantes necesita frenar para atar los cordones de su calzado y el resto forma una ronda en torno a él para protegerlo hasta que finalmente logre acomodarse.

En algunas entrevistas me aproximé a la misma perspectiva, ya que en todos los casos los aficionados explicaron que si alguien se caía en medio del pogo se sobreentendía que alguien lo iba a levantar. Tal como propone Jonathan Gruzelier (2013)

Esta capacidad para que los moshers se cuiden unos a otros es un aspecto noble del moshing que permite que se convierta en una práctica que no se desintegre en violencia sin sentido. Aunque esta práctica es una regla no escrita de la subcultura, es evidente en

\footnotetext{
98 Por ejemplo, heridas sangrantes, desgarros musculares, fisuras óseas en las extremidades e, incluso, desmayos.
} 
los sentimientos de los moshers de todo el mundo. (Gruzelier, 2013, p. 65. T. de la A. Cursivas propias)

De hecho, el autor destaca que en su propia etnografía realizada en recitales de bandas de metal contemporáneo en Estados Unidos observó gran cantidad de casos en que los participantes del mosh pit, luego de finalizar la música, se abrazaban y estrechaban sus manos, al igual que los deportistas luego de una competencia. Lo mismo pude constatar en mi trabajo de campo en casos en donde algunos desconocidos se saludaban, agradecían y felicitaban luego de hacer pogo.

Otra similitud con las prácticas deportivas se pudo observar en la preparación previa de los moshers: muchos de ellos se vestían con ropa y calzado deportivo para poder moverse con mayor comodidad $\mathrm{y}$, en este último caso, rodeaban con cinta adhesiva sus zapatillas para no perderlas en medio de la multitud. Algunos también utilizaban protectores bucales iguales a los que se usan en el boxeo. Además, muchos de ellos buscaban a alguien que no ingrese en el pogo (en la mayor de los casos, mujeres) para dejarles sus pertenencias de valor y no correr el riesgo de perderlas en el mosh.

Algunos autores consideran que esta presencia del respeto por el otro en el desarrollo del pogo hacen que el contacto físico construya formas de colectividad (Alabarces, 2006) y el carácter grupal visibilice la autopercepción de la escena como una comunidad basada en el sentimiento de "amor fraternal" (Weinstein, 2000). De la misma manera, Rivera-Segarra et al. (2015) observan que en la escena puertorriqueña el mosh funciona como un espacio de recreación terapéutica debido a que posee un factor de universalidad. Es decir,

(...) quienes entran al mosh mantienen una relación de igualdad dado a la ruptura de ciertas convenciones sociales a la vez que comparten un código no escrito que solo quienes pertenecen a la comunidad conocen. Estos aspectos nos llevan a resaltar la importancia de la cohesión grupal (Rivera-Segarra et al., 2015, p. 116).

Por el contrario, al igual que Hill (2013), en mi trabajo de campo pude observar que en general la igualdad formaba parte de un mito propio de la escena y dentro del pogo se presentan varias desigualdades. Una de ellas se produce entre los varones y las mujeres -sobre lo que me explayaré en el próximo capítulo- y, otra, aparece en la 
división que se realiza en algunos recitales masivos en el campo "VIP" 99 " y el campo "trasero", en la cual entran en juego factores económicos y percepciones de clase social.

Por ejemplo, en el festival, Monsters of Rock del 2015 en CABA, los sectores mencionado estaban separados por vallas (Ver Figura 24) y un gran número de personal de seguridad para impedir que la gente pasara de un lado a otro. Esto se debía a que el “campo VIP” se situaba más cerca del escenario y para acceder a él había que pagar una entrada más costosa.

Durante el desarrollo del concierto, el público del "campo trasero", les gritaba "chetos" y "caretas" a las personas del campo delantero y, a través de cánticos, se jactaba de tener más "aguante". Esta expresión funcionaba como un medidor ya que dicho sector de la audiencia consideraba que allí la gente "hacía más pogo" que la de adelante. Esta riña continuó de manera online en el grupo "Monsters of Rock Argentina" de Facebook.

Las expresiones mencionadas dan cuenta de los modos que se utilizan dentro de la escena para nombrar a personas de clase social alta o de mayor poder adquisitivo, lo que se deducía a partir de la posibilidad de adquirir entradas para el sector "VIP", las cuales eran más costosas. Sin embargo, a través de algunas entrevistas, varios aficionados de clase trabajadora me explicaron que accedían a esos tickets utilizando ahorros, pidiendo dinero prestado o utilizando tarjetas de crédito para la compra.

La cantidad de audiencia también marcaba diferencias en el desarrollo del pogo, ya que en los conciertos de bandas underground quienes participaban de la práctica eran pocos (algunas veces no llegaban a veinte) y allí los golpes eran más directos. Cuando los asistentes eran cientos, el desarrollo era más confuso y caótico y, muchas veces, más riesgoso. Sin embargo, en audiencias de miles de personas, la fracción que ingresaba al mosh-pit se separaba del resto en el espacio de un círculo. Pero, en estos casos, en cualquier sector de la multitud el movimiento era constante e involuntario, ya que los empujones del público producían una especie de marea humana.

Además de ello, en los pogos observados (y algunos de los cuales a los que ingresé como participante) se desarrollaban de manera similar a la descripción que realizó Silvia Citro (2008) de la audiencia de Bersuit Vergarabat: Por un lado, el público se dividía en uno o varios centros en los cuales se realizaba pogo y varios sectores periféricos en los que la gente lo evitaba. A esto puedo sumar las diferencias entre

\footnotetext{
99 Esta sigla se refiere a la expresión "Very important person" (Persona muy importante) y posee rasgos elitistas.
} 
quienes se encontraban próximos al escenario (muchas veces aplastados por el resto de la multitud contra las vallas de seguridad), los que estaban en el medio y aquellos que se posicionaban más alejados.

Por otra parte, también observé "pogo abierto", el cual "se desarrolla espacialmente en todo el sector central del público y tiene un carácter generalizado ya que participan casi todos los jóvenes que allí se ubican, incluso suelen participar algunas mujeres" (Citro, 2008, p. 9) y "pogo cerrado", en el cual solo ingresan amigos y conocidos.

En estos casos no solo incidía la cantidad de audiencia sino también el lugar en donde se realizaba el concierto, ya que en los lugares más pequeños los "pogueros" solían cuidarse de no dañar el sitio de manera involuntaria (tirar y romper amplificadores de sonido, mesas, sillas, vasos, etc.) y, cuando se trataba de participantes provenientes de otras ciudades, solían acercarse físicamente a aquellos que conocían de antemano.

Entonces, el headbanging, la mano cornuta y el mosh-pit no solo constituyen performances características de la escena metálica global sino que, en el caso bonaerense, también son valoradas como formas de autenticidad que legitiman a los "verdaderos metaleros", que son quienes supuestamente saben qué hacer durante un recital y se animan a realizarlo.

Esto último se debe a que dichas prácticas pueden ser descritas como transgresoras. Primero, porque no constituyen modos hegemónicos y tradicionales de baile y, segundo, debido a que por fuera de la escena pueden ser leídos como formas de violencia y alteraciones del orden. Quien se atreve hacerlo ostenta tener coraje, rasgo que es valorado como un parámetro de masculinidad.

\section{El metal, la discriminación y la integración}

Debido a la intensidad de sus rasgos, el metal se caracteriza por poseer una relación conflictiva con el exterior de sus escenas. Por un lado, porque genera rechazo en quienes no adhieren a sus estéticas e ideologías y, por el otro, debido a que juega con las características que son criticadas para generar un propio lenguaje que legitima lo que es auténticamente metálico y aparta lo que no pertenece al metal. Esta operación de diferenciación hace que surjan formas de discriminación hacia y desde el exterior de la escena, a la vez que integración de aquello que cumple con los parámetros morales de la autenticidad metálica. 
En la escena metálica bonaerense, durante las décadas de los '80 y '90, los principales detractores estaban constituidos por las fuerzas policiales, con las cuales los "metaleros" se enfrentaban constantemente. De hecho, a través de los archivos de 1996 de la Dirección de Inteligencia de la Policía de la Provincia de Buenos Aires, es posible ver que los aficionados al metal eran perseguidos y sospechados por esos agentes.

En dicho documento, aparece una descripción de grupos juveniles que la Secretaría de Seguridad y Protección a la Comunidad consideraba que desde la década de los "80 habían tenido participación en "desórdenes y alteraciones del orden público". Entre ellos son mencionados los "heavy" ("metaleros") y los "poder negro"100 (Ver Figuras 25 y 26), descritos de una manera superficial, fragmentaria y generalizante.

También existen videos grabados por el Servicio de Inteligencia en los cuales se incluyen a bandas metálicas (Provéndola, 2015) y ejemplos concretos de abusos policiales, como el caso de gatillo fácil que produjo el asesinato de Javier Jorge "Colo" Rojas, guitarrista de la banda de death metal, Exterminio, en 1994.

Al tener en cuenta a la discriminación que se daba hacia el metal, es posible decir que no estaba dada solo por parte de la policía, sino también de quienes no participaban de la escena. Un ejemplo de ellos pude deducirlo a partir de la entrevista realizada a un "metalero" de 47 años que vive en Carmen de Patagones que conocía al autor de la "masacre de Carmen de Patagones"

Esta sucedió el 28 de septiembre de 2004 en la escuela No 202, "Islas Malvinas", en donde Rafael "Junior" Solich, de 15 años, disparó a sus compañeros con el arma reglamentaria de su padre policía, asesinando a tres e hiriendo a cinco adolescentes. En los medios de comunicación de esa época se remarcaba que el asesino era fanático de Marilyn Manson, cantante de metal industrial ${ }^{101}$. A continuación se puede ver un fragmento de la entrevista acerca de este asunto:

\footnotetext{
${ }^{100}$ Se trataba de un grupo de "metaleros" y punks anarquistas, trotskistas y antifascistas, proveniente del Conurbano Bonaerense que, además de componerse por músicos y aficionados y poseer una ideología explícita bien definida, participaba de enfrentamientos físicos con los skinheads porteños, los cuales se hacían llamar "poder blanco", debido a que defendían la supremacía de la raza blanca. Es por eso que "poder negro" surge como un modo de identificarse con los valores opuestos.

${ }^{101}$ Un ejemplo de estos artículos fue redactado por Infobae, el 29 de septiembre de 2004, y titulado "El joven asesino era fanático de la "música satánica"'. Se puede acceder a él a través del siguiente link: https://www.infobae.com/2004/09/29/142542-el-joven-asesino-era-fanatico-la-musica-satanica/ Con la misma lógica se escribieron artículos acerca de "El Manso", un joven de 15 años que fue acusado de asesinar a su hermanastra y su sobrino el 31 de mayo de 2009 en Manuel Alberti, partido de Pilar. Al igual que con "Junior", de él también se destacaban sus gustos musicales como factores que habían incidido en su accionar: http://www.lacapitalmdp.com/noticias/La-Ciudad/2009/06/19/112772.htm
} 
Yo: Te hago una pregunta: cuando vinieron a vivir a acá, ¿ya había pasado o fue contemporáneo lo que pasó en la escuela? ¿Cómo vivieron eso?

Él: Fue después. Bueno, los conocíamos a los pibes. (...) Bueno, está este "Junior" que dicen y Dante, que es el amigo. A los dos los conocíamos. Lo que pasa que por ahí es raro. Porque yo he hablado por ahí con los chicos antes y los pibes nos decían "en la escuela nos marginan, nos putean, nos insultan, nos cargan porque nos vestimos de negro". Y los pibes eran pibes muy leídos. Vos te ponías a hablar con ellos y no parecían pibitos. La tenían muy clara. Y acá era como "ah, los mataron". Y bueno, cada uno reacciona como... Yo por ahí en el caso de ellos agarraba y los "mataba" a trompadas, les metía una trompada o por ahí los puteaba y no les daba bola. Viste, cada uno reacciona... Pero sí, eran muy castigados los dos.

Yo: ¿Y acá cómo se vivió eso?

Él: Fue bastante. Aparte después se le tira todo lo negativo a lo otro. Por ejemplo, el pibito este, uno de los que... era un hijo de puta. Porque el padre es uno de estos que va, se come todo, no le importa, pasa todo por encima. Los hijos son reflejo de los padres. O sea, el padre ese viene acá, se lleva el mundo por delante, digamos, le chupa un huevo de todos. Y el hijo era igual.

Yo: O sea, vos te referís al padre de una de las victimas.

Él: Después te lo venden como que los nenes eran unos santos. ¡Eran salvajes con los otros! Vos no necesitas ser agresivo con otro. Podes ser agresivo sin tocarlo. Y eran agresivos. Y son pibes tranqui... y qué sé yo, cada uno reacciona con lo que puede. (risas)

Yo: ¿Creés que la sociedad de Patagones se parece más a los chicos que le hacían bulling a estos otros dos?

Él: Sí, sí, totalmente. Nosotros lo vivimos acá al principio cuando teníamos el local. Hasta la gente... bueno, ahora nos conoce todo el mundo y hay buena onda con todos. ¡Pero de todo decían de nosotros! O sea, "hacíamos magia negra, éramos satánicos, drogadictos, vendíamos droga". ¡Lo peor que te puedas imaginar! Que cuando nosotros venían los pibes, le tirábamos la mejor onda. Pero bueno, no podíamos andar explicando. Y pibes que venían "no, mi viejo no me deja escuchar esto y me reta". Pero después te contaban historias como "mi viejo caga a trompadas a mi vieja" y después vos a los padres los escuchas a hablar... que te hablan desde un lado así. Pibes que no los escucharon nunca nadie. ¡Si acá una vez alguien del municipio me dijo "a ustedes tendrían que darles un sueldo como taller de contención psicológica para los pibes"! Nosotros a los pibes les decíamos "Vos escucha esto. No te dejes... Vos estás contento, no importa lo que te digan los otros, lo que cree el otro. Vos tenés que estudiar, no dejes de estudiar". Viste, uno le tira la mejor. Y por el otro lado, el padre pensaba que vos... no sé, que te desayunabas con fetos humanos, como dije una vez en la radio (risas). ¡Se pensaban que era...! Como que te ven con una idea y después que te conocen, rompes con eso.

Yo: O sea que con el tiempo después se modificó. ¿Ahora aceptan más a una persona vestida de negro?

Él: Sí, sí, sí. En eso ahí nosotros hicimos muchísimo, por eso nos reconoce la gente. Sacarle el velo ese de maldad, de oscuro, toda la parte... en la cabeza de uno. ¡Que generalmente el que piensa eso es porque son oscuros ellos! (risas) Entonces te lo tiran a vos. Siempre es más fácil echarle la culpa al otro que hacerse cargo uno.

Yo: Otra pregunta: los medios de comunicación remarcaban que él era fanático de Marilyn Manson y que a su vez leía mucho sobre Hitler. ¿Vos has visto en algún momento alguna relación? ¿Metaleros nazistas o relacionados con el nazismo?

Él: No, no. Y si lo pueden hacer, es más por pose, o por chocar que otra cosa.

Yo: ¿Pero acá no han ocurrido hechos así de violencia racista?

Él: No, no. Hay muchas cargadas en la escuela, viste. Porque bueno, acá tenés al $90 \%$ sigue a la manada por música, vestimenta, todo. Vos te salís de eso y todos te atacan a vos: "el raro", "el esto", se te ríen en la cara. Ahora por ahí no tanto, pero era así. Bueno nos pasaba a nosotros cuando éramos chicos allá también [en la ciudad de Buenos 
Aires]. Yo cuando iba a la secundaria, maestras que me decían “¿Por qué escuchas a estos drogadictos? ¿Por qué te dejas el pelo largo?”. Lo mismo te puede contar mi vieja: todos los fines de semana nos llevaban en cana. Íbamos a un recital, todos los fines de semana. Y la misma policía me paraba a mí y me dice -porque yo tengo título secundario, familia- y te escuchan hablar y "Pero vos tenés título, hablas bien, ¿por qué te juntas con estos negros?" y le digo "Compartimos gusto musical, ¿qué me importa?". Pero te escuchaban hablar y "Fíjate, vos no te vistas así, tenés que tener estudios". Viste, siempre esa de... No podían concebir que vos podías tener estudios, tener una familia, querer a tu familia y escuchar metal. Como que eran incompatibles. Y nosotros decíamos “i¿por qué?!" (risas).

Tal como mencionaba el entrevistado, las personas que no pertenecen a la escena pueden tener una mirada prejuiciosa y discriminatoria hacia sus miembros, al mismo que tiempo que muchos de estos la tienen sobre el resto. Lo mismo se puede apreciar en dos fragmentos anteriores en entrevistas a mujeres provenientes de América y Laprida (localidades que, de acuerdo al censo del 2010, tienen entre 8000 y 12000 habitantes), a lo que puedo sumar mi propia memoria biográfica personal en donde la vestimenta metálica provocaba que algunas personas decidieran no vincularse conmigo por no estar de acuerdo con mi apariencia.

De todas formas, es necesario señalar que a pesar de ser asiduamente atacados o discriminados, los "metaleros" de la escena también actuaron de la misma manera con aquellos considerados su alteridad y el caso de la masacre de Carmen de Patagones constituye uno de los extremos más trágicos a los que llegó el mecanismo de la diferenciación.

Esta interacción conflictiva con la alteridad se debe a que la identidad “(...) sólo puede construirse a través de la relación con el Otro, la relación con lo que él no es, con lo que justamente le falta, con lo que se ha denominado su afuera constitutivo" (Hall, 1996, p. 18. Cursivas del original). Teniendo en cuenta a la escena metálica bonaerense como semiosfera, se puede decir que dentro de su espacio cerrado se construye la identidad metálica, mientras que por fuera se encuentran el resto de las identidades que constituyen las alteridades de las que el metal busca diferenciarse.

El carácter grupal que adquieren estas formas de identificación permite hablar de identidad social, la cual es "aquella parte del autoconcepto de un individuo que deriva del conocimiento de su pertenencia a un grupo (o grupos) social junto con el significado valorativo y emocional asociado a dicha pertenencia." (Tajfel, 1984, p. 292)

Es así que gran cantidad de aficionados al metal se sienten parte de dicha escena o grupo social. Y en ese sentido, la afiliación a este estilo musical es una forma de gusto estético conformado por ciertas preferencias que “(...) son la afirmación práctica de una 
diferencia inevitable. No es por casualidad que, cuando tienen que justificarse, se afirmen de manera enteramente negativa, por medio del rechazo de otros gustos (...)" (Bourdieu, 1998, p. 53).

La escena metálica bonaerense se caracteriza por componerse de manera heterogénea a pesar de que el metal funciona como elemento de cohesión. Tal como plantea Weinstein (2000), el punto en común entre sus participantes es apreciar una "gran" música o el estilo musical que ellos consideran "más auténtico". Pero también el elemento compartido es la crítica a aquellas identidades externas consideradas “opuestas", entre las cuales las más destacadas son las que propone la cultura hegemónica.

Tajfel y Turner (1984) explican que “(...) la mera conciencia de la presencia de un grupo externo es suficiente para provocar respuestas competitivas o discriminatorias entre los grupos por parte del grupo interno" (Tajfel y Turner, 2004, p. 281. T. de la A.). Esto se debe a que la diferenciación se realiza por medio de calificaciones positivas o negativas, entre las cuales aparece la idea de prejuicio.

Este consiste en “(...) un juicio previo no comprobado, de carácter favorable o desfavorable, acerca de un individuo o de un grupo, tendente a la acción en un sentido congruente." (Kineberg citado en Tajfel, 1984, p. 159). Además de ello, "El hombre con prejuicios está comprometido emocionalmente en el mantenimiento de la diferenciación entre su propio grupo y los «otros»." (Tajfel, 1984, p. 162) Dicha emocionalidad parece ser aumentada si se considera que la música posee una fuerza emotiva especial sobre las audiencias (DeNora, 2004).

A todo esto se le suma la disputa por la autenticidad y, en ese caso, es necesario mencionar que “(...) en el contexto de las luchas simbólicas por la clasificación 'legítima' del mundo social, las identidades dominantes tienden a exagerar la excelencia de sus propias cualidades y costumbres y a denigrar las ajenas." (Giménez Montiel, 2002a: 93) De esta manera, el centro de significado de la semiosfera coincide con la corriente fundamentalista, la cual tiende a ubicarse como dominante con respecto a la diversidad que en realidad compone a la escena.

Entre los principales agentes externos que son valorados de manera negativa por la escena metálica están los cumbieros, los "chetos" (también llamados "caretas") y, en menor medida, los "rolingas". Parte de estas oposiciones provienen de la tradición del rock, el cual criticaba a la cumbia y a la música electrónica por desarrollar letras que no 
poseen un compromiso social profundo, sino que se dedican a exaltar la diversión y la conquista amorosa (Garriga Zucal, 2008).

Es necesario aclarar que existen diversas formas de rivalidad e incluso, ciertas zonas grises. Por ejemplo, los seguidores de Iorio son los que más discriminan a la cumbia (especialmente, la cumbia villera, que posee un contenido social más explícito). Gran parte de ellos provienen del mismo estrato social que los cumbieros. Ambos públicos se asemejan en considerarse a sí mismos "negros", lo que fue posible constatar en conversaciones durante los trabajos de campo y en un cántico que es frecuente en los recitales de Iorio, Almafuerte, Malón y tributos a Hermética, cuya letra dice: "Baila la hinchada, baila. Baila de corazón. Somos los negros, somos los grasas, pero conchetos no".

Esta denominación proviene de la idea de que "Ser negro en Argentina no depende, necesariamente, del color de la piel, de los rasgos fisonómicos, aunque los incluye sin reducirlos, en una construcción en la que también operan definiciones de clase y cualidades morales." (Martín, 2011, p. 240) Esto genera un discurso dominante que conjuga elementos morales, clasistas y fisonómico-raciales, mediante el cual ser "blanco" posee valores positivos y se vincula con el imaginario racial europeo, mientras que ser "negro" posee atributos negativos y es ligado a la fisonomía andina, mestiza e indígena.

Esta resignificación de la negritud en la escena metálica bonaerense choca con la valorización del carácter étnico blanco y el fuerte etnocentrismo que se percibía en el metal estadounidense y anglosajón de los '70 y 80 (Weinstein, 2000), por lo que se puede observar la agencia de los aficionados a partir de la construcción de su propia identidad metálica a través de la hibridación del metal con elementos culturales locales.

La supuesta diferenciación entre las audiencias del metal y de la cumbia se da en un punto de vista opuesto hacia la cultura del trabajo, lo que constituye una perspectiva ética. Por un lado, en la escena metálica se valora el esfuerzo que implica el trabajo como una manera "digna" de "ganarse el pan" y se repudia al robo. No obstante, dicha concepción da cuenta de una contradicción interna de la escena, ya que se trata de un modo de adaptación al sistema que supuestamente se critica mediante la transgresión contra-hegemónica.

De manera contraria al metal, en las líricas de la cumbia villera este acto suele ser legitimado. Por lo que es muy común que los "metaleros" generalicen y simplifiquen la caracterización vinculando a los cumbieros con la delincuencia, 
acusándolos de hacer apología al robo tal como lo han hecho los medios de comunicación ${ }^{102}$. En ese sentido, los "metaleros" apelan a una moralidad mediante la cual se pueden autorreconocer como "negros", pero con el "alma" blanca.

Un claro ejemplo de esto se da en las declaraciones de Iorio -quien desde los inicios de su carrera se caracteriza a sí mismo como un "laburante" que proviene "del barrio"- durante una entrevista en el programa "Mundo Casella" del conductor Beto Casella, en el año 2011, en donde critica duramente a los cumbieros y se burla de ellos imitando sus modos de habla. Sus palabras fueron:

Entonces sepan ustedes los "cumbia", los giles: La yuta, la yuta -gilo, gato, mulo- la yuta existe por ustedes, soretes, no por nosotros. ¡Mulo, mulo, gato, gil! Si no saben ni hablar, brutos. ¡Vayan a estudiar! Hay que estudiar, negro. (Iorio en Mundo Casella, 2011)

Con las palabras "mulo", "gato" y "gil" imitó la forma de hablar de los villeros, a quienes trató de "brutos" por no hacerlo de acuerdo al lenguaje utilizado por la cultura hegemónica que, de acuerdo a su criterio, demostraba que no habían asistido a la escuela. Esto también resulta paradójico, ya que en gran cantidad de líricas de su autoría se puede ver el uso de vocabulario propio del lunfardo y diversos argentinismos, a la vez que dicha crítica choca con la ideología contra-hegemónica que caracteriza al metal.

Por otra parte, los condenó como "delincuentes" al considerar que la policía (la "yuta") era consecuencia de su existencia y no de los "metaleros". Además, exaltó el estudio al igual que se mencionó anteriormente con el trabajo, como formas contrarias a la "vagancia", la cual es directamente vinculada con la actividad delictiva.

En su biografía el músico explica que escribió la canción "Gil trabajador" a partir de la mirada burlesca que otro "metalero" le dirigió mientras él trabajaba cargando ristras de ajos. A partir de ello dedujo que “"Gil trabajador” es el código de la nación: el que labura es un gil. Tenés que ser chorro o policía para vivir bien" (Iorio en Torres, 2012, p. 117), con lo cual no estaba de acuerdo.

De esta manera se deduce que en la escena metálica bonaerense se valora el esfuerzo personal como forma de lograr bienestar y se crítica el enriquecimiento ilícito. Sin embargo, en mis etnografías pude interactuar con aficionados que habían estado convictos por delitos tales como robo y venta de drogas.

\footnotetext{
${ }^{102}$ En su estudio acerca de la cumbia villera, Eloísa Martín (2011) analiza cómo la exaltación del robo no constituye una "apología del delito", sino una alternativa frente a la explotación laboral y una forma de relativizar al trabajo "como la principal práctica legítima para obtener sustento" (Martín, 2011, p. 220).
} 
La misma paradoja se puede observar a partir de la participación de Hermética en el recital organizado por Alejandro Taranto y Norberto "Ruso" Verea el 17 de agosto de 1993 en la Penitenciaría "Lisandro Olmos" de Buenos Aires. Allí la banda dio un show junto a otros grupos de rock y el setlist elegido estaba compuesto por canciones que trataban acerca de un hecho delictivo, como "Robó un auto", o de metáforas sobre el escape, como "Ideando la fuga" (de V8). De hecho, el primer tema citado es valorado por los aficionados, quienes pasan por alto la presencia del hurto cometido por el protagonista de la letra, posiblemente porque el relato concluye con la formación de una familia, valor moral propio de la escena.

Dentro de ella, los "metaleros" que se identifican con la proveniencia villera, suburbana o marginal son los que más discriminan a los considerados "chetos" o "caretas", expresiones con las que se refieren a personas que pertenecen a clases altas, educadas o que consumen productos culturales masivos y a la moda. Por lo que muchas veces se da una convivencia más cercana de los "metaleros" con los "villeros"103.

En efecto, en algunas ciudades pequeñas de la provincia de Buenos Aires, al haber escasos locales de actividad nocturna de esparcimiento, los "metaleros" optan por asistir a "bailantas"104, a pesar de no gustarles el estilo musical que se escucha en esos espacios (que suele ser cumbia y diversos ritmos latinos, como salsa y reggaetón). Estos son locales bailables que suelen ser calificados como "villeros" por los "metaleros" y por diversos sectores sociales dominantes. En otros casos, los aficionados al metal prefieren estos lugares porque allí les permiten ingresar con el atuendo metálico, lo que no sucede en discotecas propias de sectores sociales medios y adinerados.

Esta flexibilidad suele ser condenada por los integrantes de la escena más fundamentalistas y consideran que, antes que asistir a un boliche o una bailanta, es preferible reunirse con amigos a escuchar música. Sin embargo, la sociabilidad se

\footnotetext{
${ }^{103}$ Esta denominación también es usada en ciudades en las que no hay villas de emergencia pero se utiliza para nombrar a los habitantes de barrios periféricos o "barrios mancha" (Gravano, 1996). En todos los casos, constituye un adjetivo utilizado por la cultura hegemónica de manera estigmatizante.

${ }^{104}$ Según Eloisa Martín (2011), "'Bailanta' define, para una lectura casi exclusivamente no nativa (de los medios, de algunos analistas y del sentido común dominante), a un conjunto de géneros musicales y a los espacios adonde es ejecutada y bailada, así como adjetiva la estética, los productos y las personas que adhieren al mismo. Esta misma mirada la caracteriza como grotesca, humorística, picarezca, vulgar, chabacana y poco creativa. Una lectura más afín a la nativa, particularmente presente al interior de esta sección específica del mercado, define lo que otros llaman 'bailanta' como 'música tropical', que incluye, junto con la cumbia, ritmos heterogéneos y no necesariamente 'tropicales' como el cuarteto cordobés y el chamamé." (Martín, 2011: 213). Es interesante señalar, que los músicos y aficionados de la "cumbia" son estigmatizados socialmente, pero en los festejos de clase media y alta se bailan las canciones de esos géneros musicales.
} 
reduce a participantes de la escena, los que en general suelen ser pocos $\mathrm{y}$, muchos menos, en ciudades y pueblos pequeños.

La actitud rígida de los "metaleros" fundamentalistas es posible compararla con la caracterización que hace Tajfel (1984) acerca de la identidad social insegura, la cual intensifica las distinciones, busca modos de conservación y toma precauciones para mantener un estatus de superior (Tajfel, 1984: 317) cuando se percibe como amenazado por otro grupo. Para esos aficionados, el metal es un estilo musical mejor que el resto y se encuentra acechado cuando las innovaciones y los cambios intentan modificar el estatus original (el de la "vieja escuela), defendido ampliamente como un requerimiento de autenticidad.

Por otra parte, la mirada prejuiciosa hacia los cumbieros no solo forma parte de la escena metálica: esta perspectiva también proviene de la cultura hegemónica en donde dicho público lleva los estigmas de "negros" y "chorros". Es así que el prejuicio de la audiencia metálica se construye de manera contradictoria a los ideales de transgresión, ya que dicha apreciación se encuentra reforzada por la visión hegemónica que genera un "mito social” (Tajfel, 1984).

Además de ello, en el interior de la escena también existen diferencias entre "chetos" y "villeros", al mismo tiempo que se produce la convivencia entre ambas partes. Muchas veces, los "villeros" son identificados como "cabezas de termo", que se resisten a conocer bandas por fuera de las propias creaciones de Iorio.

Por su parte, los "chetos" suelen ser señalados por poseer instrumentos y vestimenta de mejor calidad, o por poder acceder a la compra de entradas a conciertos de más valor. Es necesario aclarar que esta división no deriva de un reflejo de la clase social real de pertenencia, sino que más bien se trata de la percepción que tienen los integrantes de la escena de sus pares. La mirada clasista cree que quienes pueden adquirir objetos económicamente más caros pertenecen a sectores sociales adinerados, sin embargo, tal como expliqué anteriormente los modos y los objetivos de estas compras más costosas no se vinculan con la proveniencia social.

En Argentina, en general, se vinculó a la escena metálica con la clase trabajadora (Vila, 1985; Alabarces, 1995; Svampa, 2000; Torreiro, 2016; Panzini, 2018), pero a partir de mi trabajo etnográfico pude constatar que los miembros de la escena bonaerense pertenecen a diferentes franjas sociales, a pesar de que gran parte de sus agentes identifican al metal con la clase obrera. 
Weinstein (2000) explica que el metal en Estados Unidos e Inglaterra no es exclusivo de la clase trabajadora, pero la cultura de esta lo permea. Esto resulta diferente a la caracterización que hace Sánchez Mondaca (2004) de los thrashers chilenos, a quienes calificó como perteneciente a clases medias y altas con niveles educativos elevados, lo cual les permitía adquirir indumentaria e instrumentos musicales directamente de Europa y Estados Unidos y romper la barrera idiomática con las producciones musicales de dichos países. En Argentina esto no fue así, ya que el acercamiento al thrash metal se produjo de manera subterránea y marginal.

Entonces, se puede deducir que, tal como propone Hermética en sus canciones, el metal provee diversas formas de empoderamiento a quienes son víctimas en diferentes situaciones. Esto permite la identificación con dicho estilo musical en personas de diversos sectores sociales. Si bien es cierto que la mayor parte de los participantes de la escena identifican al metal con la clase trabajadora (lo cual se incrementa a partir de las canciones de gran cantidad de bandas dedicadas a dicho sector social ${ }^{105}$ ), las situaciones de marginalidad presentes en las producciones de la escena metálica bonaerense no poseen una relación homológica con la proveniencia social de sus aficionados.

Además de sufrir y producir discriminación, los miembros de la escena proponen diferentes modos de integración de personas que consideran que son discriminadas socialmente, lo cual parece inspirarse en la idea de la canción "Yo no lo haré”, en cuya letra aparecen los versos “acércate, acompáñame”. En estos casos la ética que parece acompañar al discurso de la autenticidad (en la demanda de los aficionados hacia los músicos) también se extiende a la moralidad de los participantes de la escena durante la vida cotidiana.

Un ejemplo de estas formas de integración aparece en un breve documental titulado "Juntos por la inclusión" "106 realizado por dos músicos de la banda azuleña de metal, I.R.A. Allí se relata la historia de Leito, un joven que posee síndrome de down y es integrado al conjunto, acompañando a los músicos sobre el escenario haciendo movimientos tales como el headbanging y la mano cornuta.

En el video también aparecen algunos mediadores de la escena bonaerense brindando su mensaje de apoyo al muchacho y promoviendo la inclusión de personas

\footnotetext{
105 Panzini (2018) ejemplifica dicha afirmación con las bandas, Tren Loco, Serpentor, Nepal, Lethal, Horcas, Almafuerte, Malón y Hermética.

106 Para poder ver el documental hay que acceder al siguiente link: https://www.youtube.com/watch?v=oJU6ZTr6UGw
} 
con síndrome de down, expresando que "todos somos iguales". A partir de mi trabajo etnográfico pude observar que en varios recitales de I.R.A. también asistían gran cantidad de personas con la misma discapacidad. A pesar de que el objetivo de dicho documental es la inclusión, esta acción no abarca a otros marginales y minorías.

Otro ejemplo lo encontré en el proyecto "Una silla para Walter", que posee una fanpage de Facebook nombrada con el mismo título (Ver Figura 27), en la cual se promocionaban los eventos que realizaba un grupo de amigos para recaudar fondos para comprar una silla de ruedas para un viejo integrante de las brigadas metálicas, Walter "Muletas", quien posee una atrofia muscular que no le permite caminar normalmente. Entre los eventos que se realizaron, se pueden mencionar peleas de boxeo y recitales en el bar metálico de CABA, Cuarto Apóstol (Ver figura 28).

También se pueden citar la gran cantidad de recitales organizados en la provincia de Buenos Aires a beneficio de casos particulares de enfermos con pocos recursos para sus tratamientos o como el caso conocido de Iorio que a lo largo de su carrera se dedicó a colaborar económicamente con varios comedores escolares. Un caso particular es el del Frente Heavy Metal que se fundó en 2017 como una agrupación organizada para colaborar con diferentes causas sociales. En su fanpage de Facebook describen su actividad:

El día martes 6 de Junio nos hemos reunido en asamblea para crear y darle vida al "Frente Heavy metal" que se encargara de buscar problemáticas sociales como trata de personas, comedores infantiles, pueblos originarios, etc... La idea es interiorizarse en dichas problemáticas e identificar cual es la necesidad real de cada una de ellas y ver cómo podemos ayudar a resolverlas. Inicialmente, nuestra herramienta más fuerte, es la organización de recitales y/o eventos para recaudar fondos a fin de resolver dichas problemáticas. Es importante el apoyo y la presencia de los integrantes del frente en los eventos, marchas y cuestiones organizadas por el frente o por las diferentes entidades a ayudar. Para esto hemos decidido hacer una bandera con el nombre del frente y un logo, los colores serán el negro y el blanco. (Frente Heavy Metal, actualización de estado de Facebook del 10 de agosto de $2017^{107}$ )

Más adelante me referiré a la actividad política de dicha agrupación. Pero con respecto a actividades solidarias puedo mencionar la organización de varios festivales titulados "Se trata de no + trata" (Ver figura 29), con los cuales se buscó apoyar la causa de las madres de las víctimas de la trata de personas. También organizaron recitales en los cuales no solo se cobraba una entrada, sino también se pedía la donación de

\footnotetext{
107 Recuperado de: https://www.facebook.com/notes/frente-heavy-metal/frente-heavy-metalfhm/256137848225138/
} 
alimentos no perecederos, los cuales eran recolectados para diferentes instituciones benéficas, especialmente comedores escolares.

\section{Algunas consideraciones}

De acuerdo a lo analizado hasta ahora, la escena metálica bonaerense se conforma como una semiosfera, debido a que dentro de ella se producen ciertos significados que son compartidos por sus miembros otorgándoles unidad pero sin quitarles la diversidad que los constituye. Dichos sentidos se conforman a partir de la traducción de significados externos a un "lenguaje" interno que es conocido, compartido y discutido por los agentes de la escena.

Estos códigos conforman el centro de la semiosfera y se caracterizan por construir un modo de identidad que es legitimada como "auténticamente" metálica, desarrollado a través de la corriente fundamentalista proveniente del thrash metal y representado en las producciones de Hermética.

Dichos significados centrales definen lo "metálico", pero no lo conforman como una construcción homogénea. Por el contrario, la semiosfera metálica bonaerense se encuentra en permanente diálogo con las semiosferas externas que, además de otorgarle diversidad, contribuyen a la negociación y disputas que se dan entre sus miembros en la lucha por la legitimidad y la construcción de sus propias identidades en tensión con las identidades sociales que circulan dentro de ella.

Los significados centrales construyen los parámetros de dicha autenticidad, la cual no solo proporciona valoraciones estéticas y éticas sino que también consiste en un metadiscurso acerca de la escena y sus agentes. A pesar de que el mecanismo principal en la producción de identidades es la diferenciación, se observa que en la escena bonaerense lo "auténticamente metálico" emerge a través de la paradoja, ya que por un lado se busca distanciar de la cultura hegemónica y otras alteridades pero, al mismo tiempo, se apega indirectamente a dicho sistema al utilizar sus parámetros en la selección y exclusión de elementos y agentes.

Por ejemplo, en la escena metálica bonaerense se resignifica estéticamente la violencia como una manera de transgredir lo "aceptable" y lo "tolerable", pero al mismo tiempo se rechaza el enfrentamiento físico real de sus participantes en el contexto del concierto. También se incluyen e integran ciertos marginales (personas discapacitadas o con capacidades diferentes) y oprimidos (los pobres, los trabajadores, los pueblos 
originarios), pero se discrimina a otros (los cumbieros, los ladrones y, más adelante se verá, el colectivo LGTBIQ).

Asimismo, el pogo -una de las prácticas corporales características de la audiencia de la escena estudiada-, a pesar de que constituye una transgresión del orden por medio de la expresión corporal de emociones censurables a través del baile como medio lícito, no llega al punto de constituir un modo de "desorden" o "descontrol", ya que dentro de sus códigos están el autocontrol, la moderación y el respeto por el otro.

Entonces, la transgresión contra-hegemónica que propone el centro de la semiosfera metálica bonaerense se podría resumir en: la búsqueda de potencia sonora y la resignificación de lo "ruidoso" frente a la concepción de la música como armoniosa y académica; la valoración de lo "antro", "sucio", “desprolijo" y del habla popular, en oposición al lujo y los buenos modales de la cultura burguesa; la relación con lo "esotérico" en detrimento del cristianismo; la estética realista para diferenciarse de lo "fantasioso" y "artificial" con que identifican a la cultura masiva; la ejecución de performances estéticamente agresivas que se oponen a la idea tradicional de la danza; y la denuncia de las consecuencias nefastas de las políticas gubernamentales como una crítica al sistema político.

El significado de poder que se representa en la autenticidad metálica de la escena bonaerense se construye como una propuesta de empoderamiento para aquellos marginales con quienes los "metaleros" moralmente se identifican. Sin embargo, dichos parámetros éticos excluyen a los que son vistos como una alteridad con quien rivalizar $\mathrm{y}$, en muchos casos, contra quien pelear: la policía, las personas vinculadas con la moda y la cultura masiva, los "chetos", los cumbieros y los poseur.

Estos actores forman parte del "afuera" de la escena en tanto semiosfera y se produce con ellos una relación conflictiva, debido a que existe discriminación mutua, la cual no es negociada sino aumentada a través de la automarginación y la exaltación y celebración de las diferencias por parte de los "metaleros" mediante cierto "orgullo" metálico.

Los principales valores morales que se cultivan en la escena metálica bonaerense son la honestidad (como forma de autenticidad y de realismo) y la solidaridad. Sin embargo, esta solo constituye un ideal que refuerza la autopercepción de la escena como una comunidad y la autovaloración positiva de sí misma, ya que en realidad dicha ética es puesta en duda por gran cantidad de sus agentes y solo se ve reflejada en los actos de beneficencia y en ciertos códigos del mosh-pit. En el capítulo siguiente se analizará la 
perspectiva de género que toma la escena metálica bonaerense, ya que considero que muchas de las decisiones de inclusión y de exclusión se sostienen mediante moralidades propias del sistema patriarcal. 


\section{Metal, sexualidad y perspectivas de género}

En el capítulo anterior expliqué que al estudiar a la escena metálica bonaerense como semiosfera es posible observar los significados que se producen dentro de ella, los cuales tienden, en general, a la construcción de un modo de identidad metálica vinculada con la tendencia fundamentalista. A pesar de que el metal funciona como elemento aglutinante, la escena se caracteriza por ser heterogénea.

Esto significa que sus agentes no solo se identifican a sí mismos como "metaleros" o aficionados al metal, sino que también poseen diversas identidades como resultado de su interacción con otros espacios (o semiosferas) sociales y culturales. Dentro de estas identidades se encuentra la identidad de género. Sobre ella, Judith Butler (2007) explica que el género es una construcción cultural performativa que no es resultado del sexo biológico. Por el contrario, es

(...) el medio discursivo/cultural a través del cual la $<<$ naturaleza sexuada $>>$ o un $<<$ sexo natural $>>$ se forma y establece como $<<$ prediscursivo $>>$, anterior a la cultura, una superficie políticamente neutral sobre la cual actúa la cultura. (Butler, 2007, p. 56. Cursivas del original.)

De esta manera, la identidad de género también es performativa y subjetiva, a pesar de que "masculino" y "femenino" sean géneros "inteligibles", ya que "(...) instauran y mantienen relaciones de coherencia y continuidad entre sexo, género, práctica sexual y deseo" (Butler, 2007, p. 42) y dan cuenta de la normatividad y el binarismo dominante que se instaura mediante la heterosexualidad.

Es necesario hacer la salvedad de que,

La identidad de género se construye mediante los procesos simbólicos que en una cultura dan forma al género. (...) Esta identidad es históricamente construida de acuerdo con lo que la cultura considera "femenino" o "masculino"; evidentemente estos criterios se han ido transformando. (...) En cambio, la identidad sexual (la estructuración psíquica de una persona como heterosexual u homosexual) no cambia: históricamente ha habido personas homo y heterosexuales, pues dicha identidad es resultado del posicionamiento imaginario ante la castración simbólica y de la resolución personal del drama edípico. (Lamas, 2013, p. 350. Cursivas del original)

A continuación analizaré las formas en que la identidad de género y la sexualidad dialogan con la construcción de la identidad metálica en la escena bonaerense. Para ello partiré de la propuesta de Tia DeNora (2012), quien considera que 
la música posee un rol constitutivo en la construcción del género, "no como 'reflejo de' sino como recurso para poner en ejecución el imaginario de género en (y mediante) el modo como fue apropiada esa música" (p. 202).

Por otra parte, en el capítulo anterior fue posible ver que la autenticidad forma parte esencial de la construcción de la identidad metálica y, por ende, de la corriente fundamentalista que ocupa el lugar central de la semiosfera. Es por ello que a continuación se verá cómo la autenticidad opera mediante parámetros vinculados a moralidades y valoraciones provenientes del sistema patriarcal.

\section{El género y la sexualidad en las producciones de Hermética}

Tal como se realizó en el primer capítulo, en este también se considera a Hermética como la banda que representa a la corriente fundamentalista de la escena metálica bonaerense. Por este motivo, a continuación se analizarán las perspectivas del género y de la sexualidad que son plasmadas en sus producciones.

\section{Plano musical}

Como ya mencioné reiteradamente, el estilo musical elegido por Hermética es el thrash metal. De acuerdo a Weinstein (2016), este tipo de música ofrece una magnificación de la masculinidad por medio de la presencia de voces agresivas y de tonos más bajos, características que son intensificadas con el uso de la batería de doble bombo. Es decir, que el thrash metal aumenta lo que tradicionalmente había sido codificado como masculino: los sonidos bajos (Weinstein, 2000) y el rock (más específicamente, el estilo "cock rock") como terreno de sexualidad masculina (Frith y McRobbie, 1991), los cuales contrastaban con géneros musicales ligados generalmente a las mujeres, como el pop.

De por sí, las características sonoras del metal podrían ser consideradas como masculinas, debido a que la búsqueda de potencia e intensidad contribuyen a la representación estética de la agresividad y la violencia simbólica forma parte de los modos mediante los cuales la virilidad hace ejercicio de la dominación social masculina (Bourdieu, 1998).

Es necesario destacar que Hermética también incluye una canción con ritmo de chacarera a su repertorio propio, la cual es una danza propia del Folklore argentino, género musical que se construyó a través de la figura del gaucho, un arquetipo nacional masculino (Archetti, 2007; Chindemi y Vila, 2017) que posee rasgos contrarios a la 
domesticidad (femenina). Esto se debe a que, en su figura mítica, era descrito "libre como el viento", ya que

Lógicamente, elegir como arquetipo nacional a un solitario jinete, sin casa y sin familia, que vive únicamente para atravesar la llanura a galope tendido (...), esto resulta mucho más atractivo que hacerlo de un pequeño chacarero o un humilde pastor de rebaños. (Garavaglia, 2003, p. 146)

Esta descripción del gaucho como varón libre que recorre el espacio se puede comparar a la de los motoqueros. Por otra parte, la masculinidad también caracteriza a los géneros musicales de las canciones versionadas por la banda en el disco Intérpretes: metal, rock (Frith y McRobbie, 1991) y tango (Archetti, 2016).

\section{Plano visual}

De acuerdo al análisis del capítulo anterior, la dimensión visual de las producciones de Hermética se compone por sus logotipos, las portadas de sus discos, sus afiches y su atuendo en fotografías, videos y sobre el escenario. Al tener en cuenta el arte de las tapas de su discografía, es posible observar la vasta presencia de personajes masculinos: en Hermética aparecen próceres de la Historia argentina (Bartolomé Mitre, San Martín y Juan Manuel de Rosas) y personalidades arquetípicamente masculinas como un sacerdote y la imagen de un hombre nativo. Por su parte, la única mujer que aparece allí se la ve cargando un bebé en sus brazos, es decir, representada como una madre, rol tradicional asignado a las mujeres.

En Ácido argentino aparecen personajes varoniles como soldados y policías, además de un indígena, algunos manifestantes y dos hombres que parecen “evangelistas”. También se puede ver al personaje arquetípico de Estados Unidos, Tío Sam, quien se encuentra en la parte superior de la ilustración en una posición violentamente dominante sobre la Libertad, personificada como una mujer. Aquí las figuras femeninas se reducen a ella y a la imagen de algunas Madres de Plaza de Mayo (nuevamente, mujeres identificadas con la maternidad).

Tanto en esta portada como en la anterior aparecen figuras que no dan cuenta de ninguna forma de género: la representación fantasmal del primer disco y el par de esqueletos en este último. Estos casos que no se ajustan al binario "varón" y "mujer" están constituidos por imágenes de la muerte, la cual se opone a la valoración del sexo biológico como "creador" de vida. 
En cuanto a Víctimas del vaciamiento, la mujer es únicamente representada como enfermera (en un afiche con la imagen icónica que pide silencio y en la ilustración de una mujer cumpliendo su función junto a la puerta del hospital), es decir, desarrollando el rol de "cuidado de personas", tradicionalmente caracterizado como femenino. Por el contrario, las figuras varoniles ocupan la mayor parte del cuadro y se presentan con imágenes de un colimba, un niño corriendo, los miembros de Hermética, un hombre sentado sobre un inodoro, algunos pacientes esperando fuera del hospital y un joven fanático de Hermética, como figura central de la portada.

Si se tiene en cuenta que, de acuerdo a lo mencionado en el capítulo anterior dicha banda parece posicionarse en el lugar de los oprimidos, es posible decir que esa posición es ocupada en su mayoría por figuras varoniles, tales como los hombres nativos, los ex combatientes, los manifestantes, el colimba, los jóvenes "metaleros" y los próceres, San Martín y Juan Manuel de Rosas. Las mujeres incluidas también aparecen en un lugar de opresión y en todos los casos, excepto en la personificación de la Libertad, son madres o enfermeras, es decir, cumpliendo roles domésticos tradicionalmente asignados a las mujeres (Fernández, 1993).

En cambio, en el disco Intérpretes, la portada se compone por la fotografía de los miembros de la banda, quienes lucen un atuendo totalmente metálico (cabello largo, camperas de cuero, remeras con logotipos de bandas metálicas y poses desafiantes y relajadas), el cual corresponde a un estilo masculino y se revela como amenazante (Weinstein, 2000). En este sentido, es posible rescatar la caracterización de Leonor Arfuch (2002) que, en una línea similar a Goffman (2001) y a Butler (2009), considera que

La identificación lo es siempre en virtud de cierta mirada en el Otro, por lo cual, frente a cada imitación de una imagen modélica, cabría formularse una pregunta del para quién se está actuando ese rol, qué mirada es considerada cuando el sujeto se identifica él mismo con una imagen. Esa divergencia entre el modo en que cada uno se ve a sí mismo y el punto desde el cual es mirado/deseado actuar (...), señala la doble refracción a tener en cuenta en todo análisis cultural sobre estos fenómenos. (p. 64. Cursivas del original)

De esta manera, la imagen que intentan construir los músicos de Hermética busca el mismo efecto que el nombre de la banda: generar rechazo con su actitud amenazante y, al mismo tiempo, adhesión en aquellos que se sienten parte de la escena metálica y constituyen un público "selecto". Esto mismo forma parte de la actitud 
"transgresora" del metal: se busca generar polémica en aquellos ámbitos que la escena mantiene por fuera como "ajenos" y, algunas veces, "contrarios" o "rivales".

El uso de camperas negras de cuero en las escenas metálicas globales se incorporó desde los '70 con la New Wave of British Heavy Metal. Dicha prenda representaba masculinidad y rebeldía y había sido impuesta en la moda a partir del actor, Marlon Brando, en la película, "The Wild One" ("El salvaje"), el cual inspiró la iconografía motociclista (Weinstein, 2000).

Por otra parte, en la fotografía de este disco y en el concierto grabado en formato VHS todos los integrantes llevaban el cabello largo y desarreglado. Este estilo de peinado deriva de la cultura hippie y es considerada como la característica más distintiva del metal, ya que no puede ser ocultada (Weinstein, 2000) y, por ende, se convierte en un medidor de autenticidad. No obstante, esto resulta diferente en aquellos aficionados adultos que lo utilizan corto o rapado debido a la caída de cabello como consecuencia de la edad.

La cabellera larga también proviene de la tradición rockera argentina. A fines de la década de los 60 , muchos jóvenes varones decidían no cortarse el cabello y comenzar a ser "pelilargos". De acuerdo a Valeria Manzano (2011), "Para ellos, el pelo fue un medio para construir lazos fraternales y comunicar una actitud anticonvencional cimentada, también, en un gusto común por el rock” (Manzano, 2011, p. 34). Su idea era oponerse a la imagen de sus padres, del oficinista y del servicio militar. Esto hizo que sufrieran grandes persecuciones policiales y debieran organizar "melenazos" para poder ingresar en masa a la escuela con cabello largo y lograr no ser expulsados.

Sin embargo, como ya mencioné, en un momento Iorio decidió cortarse el pelo y esto vuelve a ser una característica masculina, ya que lo hizo para oponerse a Diego Torres, JAF y Guillermo Fernández, músicos que en esa misma época también llevaban la cabellera larga y pertenecían a géneros musicales descalificados como "femeninos" por los "metaleros". Además, en ese mismo período los músicos de cumbia -principal género musical criticado por los aficionados al metal- también comenzaron a utilizar el mismo peinado, lo que posiblemente haya contribuido a la decisión tomada por Iorio.

\section{Plano verbal}

En las canciones de Hermética también predominan las figuras varoniles, por ejemplo las canciones "Del colimba" y "Del camionero" están dedicadas a actividades propiamente masculinas. También se hace referencia a varones pertenecientes a los 
pueblos originarios mediante expresiones como "hombre nativo" y "malón", y a los "gauchos". Por otro lado aparecen referentes masculinos para dar cuenta de las alteridades ("policía" y "ladrón"), de los polos opuestos entre los que se mueven sus críticas ("Jesús" y "diablo") y de los referentes o modelos a seguir ("como mi padre hizo ayer"). Al mismo tiempo que aparece varias veces el impersonal "hombre".

Las referencias a las mujeres son pocas y aparecen ocupando lugares tradicionales y de opresión violenta. Para el primer caso es posible citar la canción "Robó un auto", en la cual "una simple joven sin planes" es rescatada por el varón de "un gran infierno". Es decir, la mujer no solo es ubicada en el plano doméstico tradicional sino que además ocupa el lugar de debilidad. Por su parte, el hombre es quien circula fuera de la casa y tiene el poder de "salvarla". Esta letra, que posee el formato de un relato, finaliza con el nacimiento de un hijo como "final feliz", es decir, con la concreción de una forma patriarcal.

Para el segundo caso se pueden citar algunos fragmentos de la canción "En las calles de Liniers" en donde aparece una descripción machista de la mujer:

Insatisfechos, renegados que se niegan a sí mismos, / faltos de calma y de piedad, / buscan el triángulo en las niñas / para alimentar su morbo/ y masturbarse en soledad.

Ellas también gozan mostrándose inocentes, / son arpías, esclavas del televisor. / Viven pensando en lo externo, son adictas a la vida / buscan billetes y pasión.

(...) En la esquina un policía está peleando con su hembra / pues esta nunca le fue fiel.

En primer lugar se describe una situación de pedofilia. La vagina es mencionada con la sinécdoque "triángulo" y aparece como objeto de búsqueda de placer y de morbo por parte del varón. En segundo lugar se realiza una descripción de las mujeres en donde el pronombre "ellas" puede referirse tanto a las mujeres en general como a las niñas mencionadas en la estrofa anterior.

El "yo" lírico describe a la mujer como alguien que aparenta ser inocente y no lo es, en realidad es una "arpía", es decir, una "mujer muy malvada" o una "persona codiciosa que con arte o maña consigue lo que quiere"108. Este deseo, de acuerdo a la canción, es la apariencia exterior. Esta es promocionada por los medios de comunicación, a los que les cree ingenuamente, lo que resulta contrario a la identidad de Hermética que en varias canciones denuncia las mentiras que se transmiten por la

\footnotetext{
${ }^{108}$ Definiciones de la Real Academia Española.
} 
televisión. De esta manera, los varones "metaleros" son caracterizados como “inteligentes" por ser desconfiados.

La mujer además busca "billetes y pasión", lo que la describe como materialista y, al mismo tiempo, se muestra como una censura del deseo sexual femenino. Por otra parte, la expresión "adictas a la vida" podría leerse de dos maneras: la "vida" como una metáfora de las posesiones materiales y los vicios, o como la condena velada de que las mujeres no tienen derecho a disfrutar de la vida. En tercer lugar, la mujer es nombrada con el sustantivo "hembra", denominación que refuerza la perspectiva machista, y es condenada por haber sido infiel.

Estas descripciones son similares a las que se realizan en el tango de las "milonguitas", mujeres que escapan de la pobreza, del mandato de la maternidad y el destino de ama de casa, para ir en busca de lujos y placeres otorgados por la vida en el cabaret. Archetti (2016) explica que "Muchos tangos retratan la pura sensualidad de la mujer y su interés egoísta por la seguridad material, de un modo tan destructivo como la ciega pasión.” (p. 208)

A pesar de que en toda la canción el "yo" lírico describe de manera negativa el entorno constituido por las calles del barrio porteño de Liniers, en su mayor parte se refiere a sus personajes de manera impersonal. Siguiendo la idea del capítulo anterior, se puede ver que se produce una transgresión con respecto al tabú del sexo en el hecho de mencionarlo explícitamente en una canción, sin embargo la sexualidad que se describe continúa los patrones de la heteronormatividad y la moralidad del patriarcado a través de la censura de la sexualidad femenina. La desviación solo aparece con la presencia de la pedofilia.

De esta manera, de los varones únicamente se condena la pedofilia, pero en el caso de las mujeres la crítica es más puntual y toma un punto de vista patriarcal, que podría ser comparado con la perspectiva de los compadritos del tango:

La figura del compadrito difiere, en gran medida, de la del hombre que busca la felicidad a través del amor romántico. Le preocupa mucho la lealtad de las mujeres, pero en un contexto donde los hombres esperan obediencia y sumisión por parte de ellas. Es un personaje de los suburbios, no del centro de la ciudad; no es un hombre del cabaret y la mayor parte del tiempo vaga por un territorio local habitado por otros hombres como él. (Archetti, 2016, p. 215)

Desde esta perspectiva se critica a la mujer que disfruta de la sexualidad y se la condena como "prostituta", ya que de ella se espera la obediencia y la sumisión. Sin 
embargo, la práctica sexual parece ser un deber y una expresión de virilidad en el caso del varón, lo cual se puede comprobar en la letra de la canción "Moraleja", cuyo estribillo expresa: “Conocé la moraleja: / el que no coge, se deja; / el que no coge, se deja / el que no coge, se deja; / ¡la puta que lo parió!”.

Estas formas de concebir la sexualidad se alejan del ideal hippie que proponía la libertad sexual. En la propuesta de Hermética, banda que representa la corriente fundamentalista del thrash metal, parecen predominar las interacciones sexuales heteronormativas y monogámicas, al mismo tiempo que se revaloriza a la familia, institución tradicional ligada al conservadurismo y a la moral cristiana.

Por otra parte, en Hermética la única presencia de amor romántico aparece en el caso ya citado de la canción "Robó un auto", el cual es producto de una relación heterosexual y su consecuencia es el nacimiento de una familia. En otras canciones se puede ver que se propone como únicos formatos de amor "verdadero" o "auténtico" a los que se dan entre familiares y entre amigos, calificados como modos de "amor fraterno".

La familia aparece como modelo de vínculo social legítimo, a la vez que los amigos y las personas consideradas "pares" son nombrados como "hermanos". Un ejemplo de ello se puede encontrar en el fragmento del Martín Fierro que se recita y se graba al revés como introducción del tema "Vientos de poder":

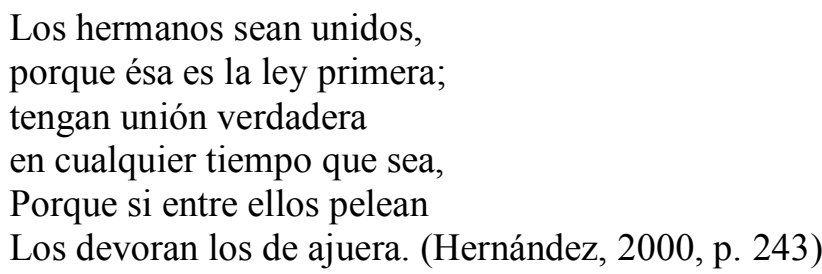

El valor fundamental del amor fraternal es la lealtad. Un ejemplo de esta forma de moralidad aparece en la canción citada anteriormente que condena a las mujeres por infidelidad. También se pueden encontrar ejemplos referidos a la amistad y a los vínculos filiales, como por ejemplo "buscando un amigo que no se abra de piernas"109. Hermética se muestra como leal con expresiones como "Yo no lo haré", "no te fallaré" y “mil amigos con el corazón / esperan esta canción”. El tema musical que resume este

\footnotetext{
109 “Abrirse de piernas" o "abrirse de gambas" es una expresión que se refiere a "Eludir; desentenderse de un problema o pedido; excusarse" (Fuente: Todo Tango, http://www.todotango.com/comunidad/lunfardo/termino.aspx?p=abrirse+de+gambas )
} 
pensamiento se titula “Traición” (1994), acción que resulta contraria a valores morales como la honestidad y la confianza:

Me jugué por un amigo que al final / me abrió una herida. / Y estoy dejando un rastro al desangrar / decidido a no callar.

Cosas malas tiene la vida / pero ninguna peor que la traición. / Unos callan, otros olvidan, / y yo lo canto recordándotelo.

Confié y me cagaron por amistad / pero aún sigo. / Saber perder es bueno para empezar / a hacerse vivo. (...)

El amor romántico es considerado por Hermética como algo falso e inauténtico, que es propuesto por los géneros musicales que se oponen al suyo: el glam metal, el rock Stone (o "rolinga") y el pop, a quienes califica con expresiones como "glamoroso", "plástico", "careta de mersa coqueta" y "veleta de la moda", las cuales describen de manera despectiva a los géneros musicales promocionados comercialmente para el público femenino. Por el contrario, afirma "yo no vendo canciones de amor vendido" y propone su "mensaje de resistencia": el metal. De hecho, en una entrevista realizada a Iorio en 1994, el músico expresa:

Con respecto a Hermética, no creo que pueda ser un grupo para que lo vaya a ver la tía, o la novia, o la ahijada. Porque la música de Hermética, es algo que no se baila, que no habla de amor, que no entra en la televisión, que no es popular. Entonces, los que siempre van a ir a los conciertos son los heavies, que son para quienes realmente queremos actuar. (Iorio, 1994b, p. 6)

Esta crítica del amor romántico es diferente de la que realizó el feminismo en las décadas del '60 y el '70, inspirado en la obra de Simone de Beauvoir, El Segundo Sexo (1945). Allí se creía que el romanticismo era un "instrumento de manipulación emocional" del "macho" (Millet, 1975) y que la "adoración" de la mujer por parte del hombre era una "farsa" (Firestone, 1976). Hermética también encuentra falsedad en el romanticismo, pero esto se debe a que dicho concepto es ligado a la feminidad. En general, para la música la autenticidad ha sido caracterizada como masculina ${ }^{110}$.

La actitud "anti-femenina" es heredada de la tradición angloamericana del "cock rock". Algunos autores consideran que "en este esquema binario, en el que el rock era metonímico para la autenticidad, y el pop para el artificio, el rock auténtico se convirtió

\footnotetext{
${ }^{110}$ De acuerdo a Diego Fischerman (2004), gran parte de la música popular "se cristalizó alrededor de la figura de Beethoven" (Fischerman, 2004, p. 26), cuyas creaciones fueron consideradas "música absoluta" y paradigma de autenticidad. Por su parte, DeNora (2012) caracteriza a la música de Beethoven como "masculina".
} 
en masculino y el pop artificial en femenino" (Mäkelä citado en Galicia Poblet, 2015, p. 177) o, como expresa Fernan de Val (2014)

El pop, desde la perspectiva rock, se suele entender con una música para mujeres, o para chicas adolescentes, mientras que el rock es una música para hombres y adultos. Ejemplo de ello es que el rock se suele describir en términos masculinizados: fuerte, vigoroso, potente... mientras que muchos de los adjetivos que se utilizan para designar al pop (o denigrar a ciertos grupos de rock) tienen que ver con características que culturalmente se asocian con lo femenino: suave, bello, débil, blando... (de Val, 2014, p. 92)

Esta oposición se puede observar en gran parte del rock a nivel global. Según Valeria Manzano (2011), en Argentina, a principios de la década del 70, “Tocar 'como nenas' era tan insultante como 'tocar para nenas': se suponía que el rock vinculaba a una fraternidad de varones.” (Manzano, 2011, p. 39) Para los rockeros de esta época lo "femenino" fue "(...) muchas veces degradado como sinónimo de superficialidad y objetivación." (Manzano, 2011, p. 55) De hecho, el rock a nivel global había restringido todo aquello que estaba relacionado con las mujeres para preservar su autenticidad (Hill, 2013) y la feminidad era vinculada con la música mainstream y la masculinidad, con el underground (Kahn-Harris, 2007).

Hermética se posiciona en un lugar masculino con el cual describe a su entorno local: “cervezas en la esquina del barrio varón", "siempre ansié cantar / el canto macho nativo de mi nación", "un guerrero de poder / tendrá el sur americano". Por su parte, las alteridades de estos espacios físicos son descritas de manera femenina: "la siniestra garra de la madre perra" (España) y "el nido de la madre bestial” (Inglaterra). De esta manera se puede ver cómo el "yo" lírico recurre a la feminidad como una manera de insultar a sus oponentes.

Efectivamente, aquellos estilos musicales considerados "falsos" y "caretas" son vinculados por Hermética con lo femenino, entre los que se menciona al new wave, que aparece explícitamente en la canción, "Buscando razón”. En Argentina, en la década de los '80 una de las principales bandas de rock que desarrollaban un estilo "moderno", pop o new wave era Virus, la cual icónicamente jugaba con la ambigüedad sexual y la androginia, además de que Federico Moura, su cantante, expresaba su homosexualidad abiertamente. Dicho grupo fue criticado por gran parte del rock, incluido el metal, debido a que desafiaba los estándares tradicionales heteronormativos. 
En la misma línea se puede mencionar la rivalidad con la cumbia, ya que al tratarse de un género musical bailable los "metaleros" lo vincularon con el erotismo y la conquista sexual, tópicos que no eran propios de la música "seria". Por otra parte, el posterior antagonismo con la cumbia villera surgió como contraposición de diferentes tipos de moralidades: ambos se constituían como alternativas a la masculinidad hegemónica, pero en el caso de los "metaleros" se defendía la "ética del trabajo" y se consideraba que los cumbieros se identificaban con la "ética del delito". De manera que los parámetros morales que miden dicha autenticidad están apegados a estándares hegemónicos.

\section{La construcción de la masculinidad metálica}

Diversos autores dan cuenta de cómo la masculinidad funciona como base de la construcción cultural del metal, primero porque socialmente ha sido ocupado mayormente por participantes varones (Weinstein, 2000) y, luego, porque tanto la sonoridad como las performances asociadas al metal constituyen “(..) la personificación de trazos masculinos" (Janotti Jr, 2013, p. 76. T. de la A. Cursivas propias).

Es posible que el predomino de lo masculino sea consecuencia de que las escenas metálicas globales estén conformadas mayoritariamente por varones, sin embargo, la masculinidad que caracteriza a la escena se desprende de la resignificación de elementos culturales tradicionalmente codificados como "masculinos", los que tanto hombres como mujeres utilizan para construir sus identidades metálicas.

Debido a que la escena estudiada se conforma de manera heterogénea, es necesario analizar cuáles son los modos de masculinidad que se practican dentro de ella. De acuerdo a R. W. Connell (1997), la masculinidad

(...) es al mismo tiempo la posición en las relaciones de género, las prácticas por las cuales los hombres y mujeres se comprometen con esa posición de género, y los efectos de estas prácticas en la experiencia corporal, en la personalidad y en la cultura. (Connell, 1997, p. 35)

Además, existen múltiples masculinidades y una masculinidad hegemónica que

(...) se puede definir como la configuración de práctica genérica que encarna la respuesta corrientemente aceptada al problema de la legitimidad del patriarcado, la que 
garantiza (o se toma para garantizar) la posición dominante de los hombres y la subordinación de las mujeres. (Connell, 1997, p. 39)

Por otra parte, "La definición hegemónica de la virilidad es un hombre en el poder, un hombre con poder, y un hombre de poder." (Kimmel, 1997, p. 51. Cursivas del original) A pesar de que el metal se construye como una propuesta de empoderamiento, existe una tensión entre las masculinidades que se practican en la escena con la que se establece como hegemónica. Tal como Gustavo Blázquez (2008) describe para el caso de los bailes de cuarteto, en el metal también "(...) las diferentes masculinidades se articulan en relación con diferentes organizaciones de clase, género, raza, edad, etc., dando lugar a un entramado complejo donde diversos modos de advenir varón compiten por hacerse hegemónicos”. (Blázquez, 2008)

Entonces el metal dialoga de diversas maneras con la masculinidad hegemónica, plasmando algunas de sus características y transgrediendo otras por medio de la construcción de formas alternativas de masculinidad. Si se tiene en cuenta que "los roqueros hicieron del oficinista su contrafigura" (Manzano, 2011, p. 30), es posible considerar que esta misma dirección toma el metal, por lo que se puede ver la búsqueda de referentes culturales masculinos contrarios a la prolijidad y la "buena" educación, como por ejemplo, el gaucho.

En este sentido, en la escena son resignificados elementos culturales de formaciones sociales que históricamente fueron consideradas "bárbaras": los pueblos originarios y ancestrales, como por ejemplo los aborígenes de Sudamérica y los vikingos. Es así que muchos "metaleros" comparan el uso del cabello largo y desarreglado con las características estéticas de nativos sudamericanos, o llevan grandes barbas y peinados con "cola de caballo" y trenzas tal como los utilizaban los vikingos. Incluso, algunas bandas de folk metal de escena bonaerense también agregan el uso de polleras escocesas y maquillaje de guerra, como las porteñas, Cernunnos y Vorgrum.

De hecho, en una entrevista realizada durante la etnografía, una aficionada de 33 años, describió a los "metaleros" como "cavernícolas", concepto que se refiere a los estereotipos con los cuales se representan culturalmente a los humanos prehistóricos y son caracterizados mediante la agresividad, la baja inteligencia y una fuerte tendencia a la homosociabilidad.

Esta relación con algunos pueblos ancestrales también se puede vincular con las innumerables referencias que hay en el metal a las batallas y a la épica como fuente 
temática para desarrollar canciones con sonoridad agresiva. De hecho, el metal se caracteriza por describir a la vida de manera épica con la metáfora de la lucha, en donde los metaleros deben "pelear" por ser quienes son y enfrentarse a quienes no les permiten serlo, tal como se pudo apreciar en los ejemplos de los fanzines del capítulo anterior.

Como fue dicho anteriormente, en las producciones de Hermética aparecen varias referencias verbales y visuales a los pueblos originarios, esto parece marcar una tendencia indigenista sobre la cual me explayaré en el siguiente capítulo. Pero aquí puedo adelantar que en general se tomó la figura del aborigen como varón guerrero, especialmente en las portadas de los discos de algunas bandas de thrash metal de la escena bonaerense, como No Guerra (2016) y Rotas Cadenas (2013) (Ver Figuras 30 y 31).

En este último caso se destaca la presencia del varón con cuerpo atlético, rasgo que también se presenta en el ser antropomórfico de las portadas de los discos Justicia o resistencia (1996) y Nuevo Orden Mundial (2015) de Malón (ver Figuras 32 y 33). Aquí se liga la virilidad con la imaginería del terror, por medio de la representación de seres que poseen, al mismo tiempo, rasgos animales y humanos con atuendos aborígenes masculinos. Estos no solo exaltan la virilidad sino que, por medio del antropomorfismo, se refieren a leyendas de los pueblos originarios y a religiones precristianas y precolombinas, ligadas al mundo de la mitología, tal cual sucede con la música metal de diferentes partes del mundo (Weinstein, 2000, p. 120).

Es necesario aclarar que, no solo en la escena bonaerense sino también en el metal a nivel global, existe la tendencia a homenajear y hacer referencia a guerreros ancestrales, pero se critica y se condena la actividad militar contemporánea ${ }^{111}$. La descripción de enfrentamientos bélicos muchas veces se realiza a modo de denuncia. En la escena bonaerense, tanto los militares como la policía constituyen las alteridades a las cuales los "metaleros" se enfrentan. Sin embargo, hay una gran franja de participantes que homenajea a los ex combatientes de la Guerra de Malvinas, pero sobre ello me detendré en el próximo capítulo.

De todas formas, en todos los ejemplos citados es posible ver cómo se reproduce el denominado "mito del guerrero" a través del cual la prensa especializada construyó la virilidad metálica (Hill, 2013). Este les otorgó cierta ventaja a los varones para ingresar

111 Aquí la excepción aparece con Iorio que, con Almafuerte, dedicó una canción a Mohamed Alí Seineldín. En el próximo capítulo se analizará cómo esto resulta paradójico si se tiene en cuenta que el mismo grupo también posee un tema musical que critica a la dictadura militar. Por otra parte, Iorio con su banda solista comienza a mostrarse con algunos elementos de la indumentaria propia del atuendo militar. 
al metal, debido a que el guerrero es un estereotipo al que pueden acercarse fácilmente, mientras que resulta menos accesible para las mujeres, aunque esto no constituye una barrera para que puedan participar, ya que muchas de ellas juegan estética y verbalmente con el concepto de la "guerrera".

Retomando la temática del antropomorfismo, es posible encontrar como referente de masculinidad, más específicamente en el metal extremo, a la figura del "macho cabrío" como símbolo de Satanás, o de Baphomet, también como imagen satánica de acuerdo a algunas corrientes ocultistas. Varias bandas de la escena bonaerense utilizan este símbolo en portadas de discos y elementos escenográficos, así como también gran cantidad de "metaleros" y "metaleras" poseen tatuajes con representaciones de estos personajes. Esta relación con el esoterismo se puede vincular con la tradición de Hermética y del metal en general.

Por su parte, en Almafuerte también se pueden encontrar como modelos de masculinidad el guapo tanguero y el gaucho, prototipo del Folklore y de la vida rural. Con respecto al primero, aparece la idea de amistad entre varones, cuyas virtudes son el coraje, la fortaleza, la lealtad y el compañerismo, las cuales también son atribuidas al "macho-guapo-tanguero" (Gasparri, 2011) o "compadrito" (Carretero, 1999), habitante de los suburbios porteños. En cuanto al segundo, se ve que Almafuerte le otorga una valoración positiva a un personaje masculino que desde los discursos dominantes fue caracterizado como "inferior, antihigiénico, cruel, bárbaro, perezoso"112. (Plesch, 2013, p. 340)

Otro referente de masculinidad tomado por la escena metálica bonaerense es el del motoquero, el cual es descrito por Paul Willis (2014):

El estilo de los chicos de motos fue masculino en formas más desarrolladas que simplemente violentas. Su apariencia era agresivamente masculina. El engranaje del motor de motocicleta se veía duro, con su cuero, tachas y tela vaquera, y al asociarse con la motocicleta, se hizo cargo de parte de la cualidad intimidante de la máquina. El cabello era largo, en un estilo grasiento y recogido, y se basaba en las connotaciones de la imagen original de Elvis Presley. Las botas pesadas eran una reminiscencia de la fábrica, así como las armas temibles en una situación de lucha sin restricciones.

\footnotetext{
112 De acuerdo a Melanie Plesch (2013) la perspectiva negativa del gaucho se fijó mediante una construcción discursiva de la sociedad hegemónica de los siglos XVIII y XIX a través de la cual se buscó "controlar y representar un segmento de la población campesina y crear un modelo específico de identidad argentina" (Plesch, 2013, p. 338). En la historiografía se encuentra una visión romántica del gaucho como "jinete de las pampas", la cual es revisada por historiadores como Juan Carlos Garavaglia, Jorge Gelman, Samuel Amaral y Carlos Mayo, quienes dan cuenta de los modos de control y explotación por parte del gobierno y los terratenientes sobre una clase de trabajadores rurales itinerantes y una población campesina de pequeños agricultores y pastores (AA.VV., 1987).
} 
Tatuajes en las manos, los brazos y el tórax eran extremadamente comunes; las argollas de oro en los lóbulos de las orejas perforadas no son poco comunes. (Willis, 2014, p. 27. T. de la A.)

Además de ello, el vehículo también se presenta como una extensión fálica, al igual que la guitarra en el caso de los músicos. En la escena bonaerense existen muchos "metaleros" que también se identifican como motoqueros y, como ya describí, en las ciudades del interior existen gran cantidad de motoencuentros que se presentan como lugares propicios para el desarrollo de festivales en donde participan bandas de metal. Allí no solo se desarrollan conciertos sino otras actividades típicas, como juegos de destrezas o caravanas.

La mayoría de estos están acompañados por grandes ingestas de alcohol y prácticas lúdicas vinculadas a la resistencia física y la velocidad (como las acrobacias sobre las motos), las cuales pueden ser codificadas como masculinas a pesar de que en ellas también participen mujeres, pero en menor medida. En los motoencuentros observé que algunas de ellas, también ocupan lugares como concursantes en certámenes de belleza de mujeres "moteras" y como bailarinas en show de strippers. Ambos son valorados como espacios de exhibición del cuerpo femenino pero no de agencia y participación de la mujer.

Otros modos de masculinidad también se pueden observar en gestos y actitudes corporales, las cuales se pueden ver tanto en fotografías tomadas por las bandas, así como también por los miembros de las audiencias durante los recitales. Un gesto común en ellos es el de cruzar los brazos, el cual posee el significado de hostilidad, rechazo y agresividad, a lo que podemos sumar la actitud evaluativa sobre el "otro" (Pease y Pease, 2006). Además suelen pararse con las piernas semi abiertas, lo cual

(...) se trata básicamente de un gesto masculino y sería el equivalente a una exhibición de la entrepierna pero de pie. La persona que exhibe la entrepierna apoya con firmeza ambos pies en el suelo, dejando con ello claro que no tiene ninguna intención de irse. Los hombres lo utilizan como una señal de dominio porque destaca los genitales y proporciona aspecto de macho. (Pease, 2006, p. 230)

A pesar de que las piernas separadas darían cuenta de un rasgo característico del varón, es posible leerlo culturalmente como un símbolo de masculinidad que también es utilizado por mujeres "metaleras". Lo mismo sucede con las gestualidades que se pueden ver en las fotografías que se toman tanto músicos como aficionados, en las 
cuales suelen realizar expresiones faciales con expresiones agresivas, intimidatorias o de enojo, algunas de las cuales

(...) evocan representaciones de villanos de películas de terror y parecen diseñadas para sorprender y atemorizar al espectador, aunque, por supuesto, los fanáticos del metal no tendrán miedo. La gente real a la que estas imágenes pretenden impactar es un grupo anónimo fuera de la comunidad de hard rock y metal que puede incluir figuras de autoridad como padres, maestros, empleadores, policía, la iglesia o el gobierno (...) (Hill, 2013, p. 122. T. de la A.)

Esta costumbre gestual parece prevalecer en la corriente fundamentalista y comienza a diluirse en subestilos como el emocore ${ }^{113}$.

Uno de los modos en que la escena metálica bonaerense se opone a lo aristocrático y a la "buena" educación se produce por medio de gestualidades, prácticas y modos del habla que culturalmente suelen ser calificados como "groseros". Por ejemplo, observé a varios "metaleros" que, estando en grupo, desarrollaban con mayor énfasis este tipo de masculinidad, a través de prácticas como descuidar la higiene propia $^{114}$ o del lugar en el que se encontraban y arrojar vasos al suelo, escupir, eructar de manera exagerada y orinar en cualquier lugar público. Además, muchos se sentían identificados con la canción "Sucio y desprolijo""115 (1972) de Pappo's Blues.

De hecho, en uno de los viajes en mi trabajo de campo, pude observar a un varón de unos 25 años que no quiso esperar a que el colectivo frene para hacer sus necesidades y pidió al chofer que abra la puerta. De manera que, mientras el vehículo continuaba andando a gran velocidad, él orinaba hacia la ruta, parado en la plataforma de subida al micro. Aquí el individuo no solo se oponía a la moralidad y al recato propios de la intimidad que propone culturalmente el uso del baño, sino que también desplegaba resistencia física para no caer. Esta actitud puede ser codificada como libertad

\footnotetext{
${ }^{113}$ El emocore es la forma abreviada de "emotive hardcore", el cual surgió en la década de los '90 y llegó a ser mainstream a partir del 2000. Musicalmente es cercano al pop punk y sus letras hablan acerca de temáticas emocionales e introspectivas, muchas veces desarrollando reflexiones acerca del suicidio y la depresión. Estéticamente sus aficionados se caracterizan por utilizar ropa muy ajustada y el cabello con un gran flequillo que tapa la mitad del rostro, a la vez que sus fotografías muestran gestos de tristeza.

114 Esta observación en la escena metálica bonaerense es similar a la realizada por Blázquez (2014) en la provincia de Córdoba, que en su trabajo de campo en los bailes de cuarteto describió la presencia de los "heavys" como parte del grupo de los "harrys", caracterizados por una apariencia personal sucia y desaliñada. De acuerdo a la perspectiva de algunos cuarteteros: "Los heavys son sucios, con pelo largo, medio hippie (jipi) y eran asociados a el [sic] consumo de drogas, son fumancheros (fuman marihuana) o papeleros (toman cocaína) y les gusta el rock.” (p. 103. Cursivas del original)

${ }^{115}$ La letra de esta canción toma la perspectiva de un rockero que decide llevar un atuendo "sucio y desprolijo". De cierta manera, se describe el look hippie de ese entonces, pero los "metaleros" no lo relacionan con dicho grupo cultural, sino que lo trasladan al universo metálico. Esto se puede observar en el uso que se hace de ese título en el documental sobre el metal argentino denominado de la misma forma.
} 
masculina, por vincularse con la agresividad y por el rechazo de los límites y la exposición de sus genitales.

La masculinidad exaltada mediante lo "grosero" puede parecer contradictoria si se tiene en cuenta que dentro de la escena también se encuentran habilitados gestos como el llorar de emoción durante los conciertos, ya que, de acuerdo a una concepción machista, el llanto es vinculado con la feminidad.

Sin embargo, a través de mi trabajo de campo pude ver muchos casos de varones que lloraban durante los conciertos, tanto de bandas del underground de la provincia como con grupos internacionales; no solo con temas musicales lentos del tipo "baladas metaleras", sino también con canciones que sonaban agresivas pero en la mayoría de los casos contenían letras emotivas. Se puede deducir, entonces, que dentro de la escena se considera como "auténtica" la expresión sin filtro de las emociones más viscerales, las cuales son valoradas por ser honestas y no artificiales.

Por otro lado, los gestos groseros pueden resultar incompatibles con la idea de lo "culto" que muchas veces intentan exaltar los "metaleros", sobre todo aquellos que eligen bandas europeas, más ligadas a composiciones orquestales o fusionadas con la música clásica; o, por parte de aquellos que forman parte de los nuevos círculos intelectuales de la escena. Sin embargo, observé que estos eligen mezclar el lenguaje formal de la academia y del discurso escrito con expresiones informales propias de la oralidad, el lenguaje coloquial y el lunfardo. Aunque es probable que esta decisión intente ser una contraposición al intelectual burgués, que también se puede leer como una forma de masculinidad anti-hegemónica.

Otros modos "groseros" de sociabilidad son los chistes, los cuales tienden a ser críticas despectivas hacia un "otro" considerado inferior, por lo que son comunes los chistes machistas, discriminatorios y, entre ellos, homofóbicos. Estos resultan moneda corriente entre los miembros de la escena y en general "puto" aparece como una forma recurrente de insultar a otro (inclusive, las mujeres a los varones, o los "metaleros" anarquistas y de tendencia de izquierda a los de derecha), casi siempre por no "bancársela" en el pogo, no animarse a utilizar el atuendo metálico, preferir estilos de metal nuevos como el emocore, o preocuparse por el aseo personal y la higiene.

En la escena, la homosexualidad es ligada a la debilidad y a la feminidad (KahnHarris, 2007) y, en el caso de la escena bonaerense esto se refuerza contextualmente, ya que el Estado argentino configuró la ciudadanía bajo un modelo masculino, blanco, católico, "natural" y herosexual, frente a lo femenino (que incluía tanto a las mujeres 
como a los homosexuales), cuya moralidad condenaba a quienes llevaban una "mala vida" (las prostitutas y los homosexuales) (Simonetto, 2016).

En efecto, en mi trabajo de campo, observé que ante un chiste homofóbico los aficionados varones solían retrucarlo acusando al otro de ser el varón pasivo de la relación sexual y aclarando que ellos cumplían el rol activo, como una manera de defender su virilidad y heterosexualidad. En este sentido, las interacciones sexuales entre miembros del mismo género eran mal vistas u observadas con extrañeza dentro de la escena y solían ser ridiculizadas, por lo que los miembros de la comunidad LGTBIQ permanecían invisibilizados ${ }^{116}$.

En efecto, en algunas entrevistas realizadas, los participantes expresaron que desconocían la existencia de miembros que no sean heterosexuales y que, en caso de que hubiera, posiblemente no lo expresen abiertamente por temor a recibir burlas. En este sentido, reconocieron ser un público "cerrado", "estructurado" y "chapado a la antigua". Solo encontré dos ejemplos por fuera de la heterosexualidad: primero, una chica que se reconocía a sí misma como queer y no conocía ningún otro caso excepto el propio; y luego uno de los líderes de los movimientos LGTBIQ y anti-fascista marplatense, responsable del pub en donde se llevaron a cabo algunas Ferias del Libro Heavy en Mar del Plata.

En algunas conversaciones mantenidas con él en mis etnografías logré saber que era fanático de Rob Halford, cantante de la banda de la NWOBHM, Judas Priest, conocido por ser el primer músico metálico gay en dar a conocer su sexualidad abiertamente. De esta manera, los "metaleros" de la escena marplatense respetan a

\footnotetext{
${ }^{116}$ Esto parece modificarse en el año 2019 con el surgimiento del colectivo "Unión Transfeminista en el Under" (UTFU) que se constituye como un grupo de mujeres, lesbianas, travestis y trans, autoconvocados y autogestionados, que tiene como objetivo visibilizar, cuestionar y erradicar la violencia y los "macro" y "micro" machismos dentro de la escena, ya que consideran que como miembros nunca fueron completamente bienvenidos. De esta manera es su fanpage de Facebook (https://www.facebook.com/SomosUTFU/) y en su blog (https://somosutfu.wordpress.com/) se encargan de publicar escraches a músicos y productores de la escena underground del Área Metropolitana Bonaerense a través de fotografías y los testimonios de las propias víctimas. Otra de sus actividades consistió en el llamado "UTFU Fest", el cual se realizó el 8 de marzo de 2019 en consonancia con el Paro Internacional de Mujeres. De esta manera, los y las integrantes del colectivo, se organizaron para asistir juntos a la marcha en CABA y, al finalizar, se congregaron en dicho festival, en el que participaron feriantes y bandas de metal, punk y hardcore. Para dicho evento, la organización daba la dirección por mensaje privado a través de Facebook y, a su vez, se reservaba el derecho de admisión y permanencia. En la fanpage, la fotografia de portada posee la frase "Some heads are gonna roll" ("Algunas cabezas van a rodar"), al igual que el título de una canción de laagrupación de la NWOBHM, Judas Priest. Por su parte, la foto de perfil consiste en un logotipo con el símbolo feminista modificado: en lugar de tratarse de un puño cerrado dentro del signo de "femenino", la mano aparece con el gesto de la mano cornuta y las uñas pintadas de negro. Además, el color violeta del símbolo tradicional, es reemplazado por verde, negro y blanco.
} 
ambos referentes e interactúan con aficionados de otros estilos musicales tales como el glam rock y la música electrónica al asistir a las actividades nocturnas de dicho pub, en una convivencia pacífica. No obstante, dicho espacio fue víctima de violencia por parte de una agrupación neonazi, sobre la cual me referiré en el próximo capítulo.

También es posible ver algunas formas de interacción lésbica en videoclips de algunas bandas de la escena, como por ejemplo el del tema musical "Deseo" del disco El tiempo es tan pequeño (2004), de la banda O'Connor, perteneciente al ex cantante Hermética. Allí el artista aparece junto a tres mujeres que por su parte interactúan sexualmente. Sin embargo, en este caso el lesbianismo aparece como objeto de heteroerotismo y la figura del músico rodeado de mujeres refuerza el mito de la "groupie" (Hill, 2013). Al igual que en el metal extremo, en la escena metálica bonaerense las mujeres lesbianas y bisexuales tienen una visibilidad mayor que los varones gays, ya que son utilizadas icónicamente por algunas bandas (Kahn-Harris, 2007).

Es así que, con respecto a la sexualidad en la escena bonaerense, se puede decir que predomina la heterosexualidad. Tal como explica Pujol (2013), en los '80, “Un estilo como el heavy metal acentuaba su identidad heterosexual constantemente, retomando muy a su manera, ciertos temas populares: el barrio, las minas, los coches..." (Pujol, 2013, p. 250). Estos tópicos continúan siendo recurrentes en las producciones de las bandas metálicas bonaerenses y, además, se materializaron durante en "Monsters of Rock" del 2015 a través de la exposición de autos y motocicletas del tipo "choppers", como las tradicionales Harley-Davidson (Ver Figuras 34 y 35).

La heterosexualidad no solo forma parte de las líricas, sino también de las interacciones que mantienen los miembros de la escena. Fue muy común ver parejas de "metaleros" y "metaleras" y de "metaleros" con mujeres que no les gusta el metal, pero prácticamente no observé casos de "metaleras" que estén en pareja con varones que no pertenezcan a la escena. En estos casos, era muy probable que dejaran de participar de los eventos propios de ella. De hecho, los miembros de la escena suelen tener dificultades para conseguir pareja sexual debido a que son pocos y relacionarse con alguien por fuera les dificulta la dedicación plena al metal (Kahn-Harris, 2007).

Con las parejas heterosexuales aparecían ciertos códigos en donde el varón era quien se destacaba por sobre la mujer. Por ejemplo, el trato que recibía la mujer solía ser correspondiente al respeto que se le tuviera a su pareja. En muchos casos, algunos varones se mantenían distantes con la mujer que era pareja de su amigo por respeto a él, 
pero se acercaban simpáticamente (a menudo a través de las redes sociales virtuales) a la mujer de quien se llevaban mal, solo para molestarlo a él.

Es muy visible cómo se demuestra físicamente la idea de la mujer como una "posesión" y un "trofeo" y del varón como un "protector": por ejemplo, en muchos recitales de gran cantidad de asistentes fue posible ver a varones parados detrás de sus parejas abrazándolas por la cintura, no solo dando cuenta de que eran "suyas" y apoyando sus genitales sobre ellas de manera dominante, sino también para "cuidarlas" de la posibilidad de que algún varón del público les toque las nalgas. Esto resulta paradójico ya que muchas veces estas parejas se sitúan cerca del pogo y el peligro es más probable que venga del frente con la posibilidad de que algún mosher caiga encima de la mujer.

Respecto de la identidad de género, a pesar de que los "metaleros" suelen criticar al varón oficinista y burgués, muchos de ellos pertenecen a dicho sector y en su gran mayoría se dedican a trabajos vinculados con la programación de sistemas informáticos. Sobre esto pude ver dos situaciones: por un lado, aficionados que asistían con atuendo semi formal o uniformes laborales a recitales de bandas de metal extremo, posiblemente porque el horario del concierto no les permitía ir a su casa a cambiarse la ropa de trabajo; y por el otro, oficinistas que para continuar identificándose como "metaleros" en la vida diaria, poseían gran cantidad de tatuajes o llevaban el pelo largo atado con una "cola" o un rodete.

De hecho, a lo largo de mi trabajo de campo y contribuyendo a él mi memoria biográfica, pude observar que muchos aficionados modificaron su atuendo de acuerdo al empleo, especialmente aquellos que tenían más de 27 de años de edad. Gran cantidad de ellos cortaron su cabello y comenzaron a utilizar prendas de la moda hegemónica y a vestir remeras metálicas ocasionalmente para los recitales. Esto se daba con más frecuencia en las ciudades del interior de la provincia que en CABA o en localidades de gran cantidad de habitantes, como Mar del Plata.

En su estudio sobre las canciones y los videoclips del metal, Walser (2014) propuso cuatro estrategias por medio de las cuales se desarrolla el género y el poder en el metal: la misoginia, la "exscription" o la ausencia total de mujeres, la androginia y el romance. Estos últimos dos era posible encontrarlos en el glam metal de la década de los '80, sin embargo en la actualidad prácticamente no aparecen. Solo puedo mencionar la presencia de canciones románticas en bandas como Rata Blanca, las cuales son cuestionadas por algunos "metaleros" de la escena, por considerarlas "falso metal". 
Aunque muchos recurren a ellas cuando intentan ser "románticos" con sus parejas heterosexuales.

En la actualidad, dos estrategias que se pueden encontrar son la misoginia y la "excription". Para el primer caso se pudieron ver las descripciones machistas que Hermética hacía de las mujeres. Esta perspectiva es llevada al extremo por algunas bandas, entre las que es posible mencionar al grupo de death metal, Eternal Grave, cuyas letras describen abusos sexuales aberrantes, femicidios, pedofilia, necrofilia, zoofilia y canibalismo utilizando la retórica propia del cine gore, es decir, la descripción descarnada y explícita. El "yo" lírico de estas letras usa la primera persona y muestra la perspectiva sádica de quien comete estos crímenes, el cual se deduce que es un varón por medio de referencias a la genitalidad masculina. Las portadas de sus discos también recrean dichas acciones (Ver Figura 36).

En entrevistas realizadas a algunas mujeres pude observar que hay opiniones ambivalentes acerca de las bandas que desarrollan temáticas con una perspectiva misógina y sexista. Por un lado, una comerciante de 27 años no reconoce que se trate de representaciones de violencia hacia la mujer, sino que son una forma más de las recreación de agresiones que caracterizan al metal; por su parte, una bibliotecaria y periodista de 44 años, al preguntarle sobre esto, dice que no le agrada pero que "hace la vista gorda". Por el contrario, una docente de 36 años, expresa que:

Me parece basura, realmente, creo que no tiene nada que ver con la música... Hay bandas y estilos como el grindcore que se alejan totalmente de lo musical, que lo importante está en las letras y en que suene lo más violento y sucio posible. Es "a ver quién la tiene más grande", quién transgrede más... Es basura, vacío de contenido, cosa de enfermos. La mujer como objeto es una cosa horrible, pero a veces ellas eligen ese lugar (esto es muy relativo, no siempre eligen... Es más complejo el tema). Y, bueno, es cuestión de libre albedrío, ponele. Que hagan lo que quieran, yo no consumo eso ni pierdo mi tiempo limitado de vida en prestarle la menor atención.

Como ya mencioné, Eternal Grave es una banda valorada tanto por varones como por mujeres. Muchos destacan su calidad musical y al contenido de sus letras lo aprecian como discursos humorísticos que llevan al extremo la transgresión, sin tomar conciencia de la violencia que se describe. De cierta manera, estos participantes toman al metal como un "género fantástico", es decir que en él "(..) las necesidades y los deseos sociales reales se abordan y se resuelven temporalmente de manera irreal." (Walser, 2014, p. 134). 
En contraste, algunos actos de misoginia real fueron denunciados. Un caso difundido es el de la banda de deathcore, Anomalía, que en el 2017 decidió desvincular de la banda a su cantante, quien fue acusado de practicar diversas formas de violencia de género a su ex novia, incluso de haber intentado asesinarla. Este fue denunciado en el blog del colectivo, "Ya no nos callamos más"117, cuya función es visibilizar situaciones de violencia machista y proporcionar asesoramiento y orientación psicológica y legal. Sobre dicha publicación ${ }^{118}$ se produjeron gran cantidad de intercambios, en los cuales no solo se brindaba apoyo a la víctima y nuevos testimonios, sino también se escribían amenazas por parte de quienes defendían al acusado.

A través de la netnografía pude arribar a una publicación del portal web, "Rock and Ball", titulada "Impunidad total: Un cantante denunciado por violencia se autoincrimina en una canción"119. En la nota periodística se relata que dicho cantante, tras ser denunciado, compone una canción dedicada a su ex pareja, titulada "Q.E.P.D.", en la que reafirma sus hechos de violencia. Esta es publicada en la plataforma YouTube $^{120}$, en donde aparecen 110 comentarios, entre los que se pueden ver personas que insultan al compositor y condenan su violencia, y otras que lo defienden, se sienten identificadas con la letra y/o destacan la música por sobre el contenido lírico.

Con respecto a estos tópicos, existen varias bandas a nivel internacional que desarrollan temáticas similares en sus canciones y parte de ellas se vinculan con la estética del BDSM, cuya moda fue inculcada por Rob Halford, quien resignificó el uso de la indumentaria de dichas prácticas eróticas, realizadas con cuero, tachas y cadenas y la incorporó a la cultura del metal.

Esta relación del género musical con las prácticas eróticas BDSM se puede ver en espectáculos realizados en la escena bonaerense como el "Circo del Horror" y el "XXX Extreme Blood Show", cuyas bandas sonoras son canciones del estilo metal alternativo. Dichos shows se basan en la tradición del teatro, Gran Guignol, e incluyen representaciones terroríficas del sexo, la pornografía y la mutilación, y prácticas extremas como el faquirismo y la suspensión corporal aérea por medio de piercings.

\footnotetext{
117 Este blog es similar al de UTFU pero, en este último caso, se concentran en casos de la escena metálica underground del Área Metropolitana Bonaerense.

118 Esta publicación y sus comentarios pueden ser vistos en el siguiente link: https://yanonoscallamosmas.wordpress.com/2017/12/07/ramiro-arias-cantante-de-anomalia-misoginogolpeador-violento-yanonoscallamosmas/comment-page-2/\#comments

119 Dicha nota periodística puede leerse en el siguiente link: https://rockandball.com.ar/archivo/impunidad-total-ramiro-arias-148934/

${ }_{120} \mathrm{La}$ canción "Q.E.P.D" aparece con el detalle de la letra en el siguiente link: https://www.youtube.com/watch?v=m801MsShMY8
} 
Con respecto a la "exscription" o a la idea utópica de un mundo con ausencia de mujeres pude observar que esto no se da en ningún evento especializado, es decir, recitales y ferias. Allí, a pesar de que las asistentes mujeres suelan ser pocas, en la mayoría de los casos se encuentran ocupando el rol de mediadoras además de aficionadas.

Sin embargo, al considerar que la escena no solo emerge en dichos eventos sino también en la vida cotidiana, pude ver que algunos "metaleros" se caracterizaban por preferir las reuniones homosociales y por mostrarse incómodos ante la presencia de mujeres, a las que solían prejuzgar como "poseurs" o, en caso de que tengan vasto conocimiento sobre el metal, intentaban disminuirlas y ponerlas a prueba con cuestionarios difíciles y profundos.

En muchas ocasiones de mi trabajo de campo sucedió que fui la única mujer presente. La consecuencia de esto fue que en reiteradas veces el trato hacia mí era en un tono casi acusatorio, dando cuenta de que no debía estar allí. Esto se modificaba con aquellos varones con quienes poseía un trato de confianza y, de algún modo, se habían "acostumbrado" a mi presencia. Sin embargo, las diferencias permanecían cuando me pedían disculpas por haber eructado o expresado un chiste o comentario grosero frente a mí, a quien consideraban una "dama". De esta manera, mientras que los "buenos" modales eran adjudicados a la mujer, las groserías eran vinculadas con lo masculino y se utilizaban para reforzar la virilidad.

Otras formas de desigualdad de género que viví en la escena se producían cuando las decisiones acerca de la actividad las debía tomar un varón sin darme lugar a expresar mi opinión o sin tenerla en cuenta. Lo mismo sucedía con los lugares de liderazgo en organizaciones grupales (académicas y musicales) en las que participé: las mujeres solo podíamos ocupar un lugar secundario.

Entonces, a pesar de que en la escena metálica bonaerense se trata de transgredir la masculinidad vinculada con el orden, la buena conducta y la burguesía, se mantienen los rasgos morales del patriarcado. En este sentido, "Aunque algunos de estos discursos representan desafíos o transformaciones de la ideología hegemónica, algunos reproducen de manera bastante directa las estrategias hegemónicas de control y represión de las mujeres que penetran en la cultura occidental.” (Walser, 2014, p. 118. T de la A.) 


\section{Ecos de patriarcado}

Walser (2014) afirma que "El heavy metal es, inevitablemente, un discurso moldeado por el patriarcado." (p. 109. T. de la A.), debido a que ha circulado principalmente por sociedades capitalistas occidentales, de las que ha tomado muchos rasgos culturales. En la escena metálica bonaerense es posible encontrar la estructura patriarcal en diversas formas, las cuales se vinculan con el ideal de la familia tradicional y con el carácter conservador del metal.

El primero aparece en las producciones de Hermética y es ampliamente difundido en la escena a través de su formato tradicional, es decir, mediante la familia heteronormativa, conformada por un varón y una mujer, en la cual el padre es el encargado de proveer el sostén económico, mientras la mujer se dedica a desarrollar su rol como madre y ama de casa.

Este ideal es apreciado por la mayor parte de los miembros de la escena, a pesar de que no sea frecuente en la práctica. Por el contrario, pude ver muchos casos de parejas separadas que tienen hijos como fruto de relaciones durante la juventud, familias ensambladas y gran cantidad de aficionados que prefieren no tener una pareja estable. A pesar de ello, la monogamia es valorada ampliamente por los agentes de la escena.

El valor de la familia aparece plasmado en la crianza de los hijos, por lo que existen muchos aficionados de la escena bonaerense que intentan inculcar en ellos el gusto por el metal así como también su cultura y sus valores, tanto a los varones como a las mujeres. De esta manera observé gran cantidad de bebés y niños vestidos con remeras que poseen logotipos de bandas de metal, lo que se hacía más visible durante los recitales y los eventos especializados. De hecho, algunas familias metálicas decidieron poner a sus hijos nombres relacionados con el metal, especialmente con títulos de canciones y nombres de músicos y bandas.

Al mismo tiempo, a través de varias entrevistas pude ver que muchos "metaleros" habían conocido al metal por medio de familiares como padres, tíos, hermanos y padrinos. Esto resulta más común en jóvenes menores de 30 años de edad. Lo que se diferencia de la caracterización que hace Walser (2014) del metal de la década de los '80, más específicamente del glam metal, debido a que este continuaba la tradición del rock and roll de la "rebelión edípica", es decir, el enfrentamiento a la tradición patriarcal dominante, similar a las contraculturas y su oposición a la cultura parental y al mundo adulto. 
La familia también se presenta mediante el concepto de la escena como una "hermandad", lo cual es una característica que también circula a nivel global. Esta idea que tienen los miembros de la escena, se traduce como el deseo de comunidad que, a pesar de encontrarse dispersa geográficamente, se mantienen unida mediante la cooperación y sostenida por el amor por la música (Weinstein, 2000).

A través de la netnografía pude encontrar gran cantidad de grupos de Facebook con nombres tales como "Hermandad metalera" o "Unión metalera argentina". No obstante, la concepción de "hermandad" solo constituye un ideal de la escena que se mantiene mediante el "mito de la igualdad" (Hill, 2013).

En segundo lugar, el sistema patriarcal también se presenta en el rasgo culturalmente conservador del metal, el cual valora las relaciones interpersonales, trasciende generaciones y tanto las audiencias como los productores y medios tienden a valorar los músicos de la "vieja escuela" y a las "bandas de culto", siendo reticentes con las tendencias nuevas.

Por ejemplo, en la editorial del número 79 del año 30 del fanzine, Metalica, aparece el slogan "No se incluyen nuevas tendencias comerciales". Además, el editor, expresa allí:

\footnotetext{
Y si me preguntan ¿que siento luego de tantos años al frente de este proyecto tan personal?, la respuesta es que todo sigue igual en mi interior, me siguen gustando absolutamente las MISMAS bandas con las que me formé, me refiero al Hard Rock y Heavy Metal que brilló principalmente en los años '70 y '80. El Metal se ha expandido explotando en mil vertientes y eso está muy bien, está claro que aquí NO existen reglas y cada cual escucha $-\mathrm{y}$ eventualmente toca- lo que le viene en ganas, pero a mi mucha diversidad no me atrae y si en algún momento la trato o escucho, es sólo para darle difusión a través de las páginas de METALICA ZINE, nada más. (de la Torre, 2016. Destacados del original)
}

Lo mismo pude corroborar en algunas conversaciones mantenidas durante el trabajo de campo, en las cuales los miembros más antiguos de la escena (de entre $40 \mathrm{y}$ 60 años de edad) mostraban su preferencia por las primeras bandas de metal e, incluso, algunos consideraban que el metal había sido arruinado con el nacimiento de estilos nuevos como el ñu metal. Estos subestilos más contemporáneos son consumidos principalmente por miembros menores de 30 años de edad, quienes a pesar de ello también reconocen a las bandas más antiguas como las genuinas.

La ideología de estos "metaleros" más "antiguos" puede ser considerada como una búsqueda de legitimidad, ya que la diversificación del estilo musical, si bien lo 
enriquece, también amenaza con descender su autenticidad, rasgo que forma parte de su idiosincrasia (Galicia Poblet, 2015, p. 547).

Los músicos de las primeras generaciones del metal durante el período estudiado transitan edades adultas. Al contrario que rebeldía, el respeto hacia ellos hace que los agentes de la escena le otorguen a la adultez poder y autoridad. Estos miembros son mencionados por los aficionados como "padres" y, en la escena bonaerense, Iorio es nombrado como "patriarca" por una gran cantidad de miembros de la audiencia.

Este lugar de padre fundador también es otorgado por los miembros del GIIHMA, quienes publicaron diversos artículos periodísticos y de opinión con títulos tales como "Vivir sin los padres: dilema del metal criollo" (Scaricaciotolli, 2017), "Heavy metal nacional: cómo matar al padre" (Pisano, 2017) y "Iorio: el auto-parricida metalero" (GIIHMA, 2017). Allí los investigadores proponen la idea de la muerte simbólica de Iorio, el padre, a través del cambio de rumbo de su producción artística y de sus expresiones ideológicas, además de la ruptura que produce la nueva generación de bandas metaleras con respecto a su tradición.

\section{¿Y las mujeres? (Análisis en tercera y primera persona)}

Diversos autores de diferentes partes del mundo dieron cuenta de que, a nivel global, las mujeres son una minoría dentro de las diferentes escenas del metal (Weinstein, 2000; Kahn-Harris, 2007). Fue por esto que varias autoras comenzaron a investigar la situación específica de ellas dentro del estilo musical, tales como Rosemary Lucy Hill $(2013,2016)$ y su estudio del fandom femenino en el hard rock y el metal y Laina Dawes (2012) cuyo trabajo se centra en la presencia de mujeres negras dentro de la escena.

De hecho, en el rock argentino, la escasa presencia femenina dentro de él se debía a que

(...) el acceso de las mujeres a los recitales se mostró acotado. Estos encuentros fueron asociados con modelos de conducta que tendieron a estar más legitimados y permitidos entre los varones. La cultura de la noche, el deambuleo nocturno en grupo por la ciudad o la imagen asociada al consumo frecuente de drogas y alcohol entre los roqueros tendieron a ser prácticas más aceptadas para los varones que para las mujeres. Incluso, el gusto por este género musical y el deseo de hacer del rock un medio y un estilo de vida tendió a ser considerado cosa de hombres. Estas concepciones delinearon un extendido sentido común que definió el rock como un estilo de vida y una cultura musical machista. (Sánchez Trolliet, 2017, p. 87) 
En la escena metálica bonaerense, las mujeres también somos minoría y la mayoría de nosotras no ingresa sola, sino que lo hace junto a una pareja, un grupo de amigos (Kahn-Harris, 2007) o de familiares. Por lo que una característica es que aquí las mujeres no tenemos la misma autonomía que los varones. De todas formas, pude observar casos de mujeres que asistían solas a recitales, pero varias veces oí cómo se comentaba su presencia con extrañeza por parte de varones, algo que no sucedía con los varones que también asistían solos.

A partir de algunas entrevistas realizadas tanto en su formato cara a cara como a través de chat en Facebook, en tanto método netnográfico, pregunté a varias mujeres si concurrían solas o en grupo a los recitales y la mayoría contestó que lo hacía acompañada, ya que preferían compartir el momento con otro. No obstante, no tenían inconvenientes en ir solas, ya que algunas veces la conexión entre la música y la persona generaba sentimientos individuales. Solamente en dos casos respondieron que preferían asistir acompañadas debido a que la mayoría de los conciertos son por la noche y consideraban que las calles eran peligrosas para transitarlas en soledad.

La minoría femenina no solo la pude observar y componer en la audiencia, sino también en aquellas que desarrollaban papeles mediadores (productoras, periodistas, managers, fotógrafas e investigadoras) o cumplían el rol de músicas. A esto lo pude constatar a través del análisis cuantitativo de los datos registrados en la página web "Enciclopedia Metallum. The Metal Archives""121. Allí observé que en la escena metálica bonaerense las bandas que poseen integrantes mujeres solo son el $10 \%$ del total $\mathrm{y}$, de ellas, sólo 3 bandas estaban compuestas totalmente por músicas ${ }^{122}$.

121 "Enciclopedia Metallum. The Metal Archives"121 es una base de datos que registra de manera colaborativa (de forma similar a Wikipedia) la biografía de bandas de música metal de todo el mundo, además de poseer el espacio para un foro de debate y una sección de noticias. En este sitio solo se aceptan agrupaciones estrictamente de metal, lo que de acuerdo a su propia caracterización, da cuenta de una perspectiva fundamentalista, ya que se excluyen estilos como el glam rock y el industrial. Además, no es posible agregar conjuntos que no hayan publicado ningún disco. A pesar de la rigidez de estas reglas para el registro de material, no se garantiza la información que allí aparece. Por ejemplo, pude ver que figuran como "activos" grupos que ya no existen y viceversa.

Sin embargo, esta base de datos permite estudiar algunos aspectos generales. Por ejemplo, al realizar una búsqueda aplicando el filtro por país, es posible arribar a un listado de bandas de Argentina y, a partir de allí, desglosar las que son procedentes de la provincia de Buenos Aires y de CABA que estuvieron activas durante el período de esta investigación, es decir, del 2011 al 2017. Por otra parte, al ser una página web colaborativa, es relevante la agencia de los participantes de la escena, ya que al agregar una agrupación a dicho sitio, dan cuenta de la necesidad de visibilidad, ya sea con el objetivo de promoción -en el caso de los conjuntos actuales- o de formar parte de la historia global del metal -en caso de bandas que se encuentran inactivas-.

${ }^{122}$ En "Enciclopedia Metallum. The Metal Archives" solo figuraban las bandas Psicosis (death metal), Indisposed (thrash metal) y Las Brujas (heavy metal). Sin embargo a través de mi trabajo etnográfico 
Del total de las bandas bonaerenses de metal que tienen al menos una integrante mujer, la mayoría cumple el rol de vocalista (tanto principal como en coros) siendo el $52 \%$ del total. En segundo lugar, el instrumento más ejecutado es el bajo (un 16\%) y, luego, la batería (12\%). Con respecto a los estilos de dichas bandas, los tres más difundidos son heavy metal en primer lugar con un 15\%; en segundo lugar, death metal y power metal con 14\% cada uno; y en tercer puesto, thrash metal y gothic metal con 12 $\%$ cada uno (Ver Gráficos 1 y 2).

Estos datos derribarían algunos mitos: que solos los varones tienen fuerza física para tocar metal en la batería; y que las mujeres solo cumplen el rol de vocalista en estilos que les permiten exaltar su feminidad (como por ejemplo, el gothic metal) y se mantienen alejadas del metal extremo. También se ve la apropiación por parte de la mujer de instrumentos musicales que habían sido codificados como masculinos, como es el caso de la guitarra eléctrica (Onkey en Sánchez Trolliet, 2017) o la batería (Pujol, 2013).

Esto resulta similar a lo descrito por DeNora (2012) para el caso de las mujeres de Viena del año 1796 que, en lugar de ejecutar instrumentos de viento o el chelo, solo tocaban el piano, debido a que los movimientos corporales que demandaba la ejecución de los primeros rompía con las normas aristocráticas del decoro femenino. De manera que se consideraba que los instrumentos musicales que implicaban movimientos bruscos eran propios de los músicos varones.

Las bandas metálicas bonaerenses que fueron relevadas y estaban integradas totalmente por mujeres no poseen la misma búsqueda que las músicas argentinas de los '80, quienes intentaron buscar "nuevas formas de identidad femenina a través del rock" (Sánchez Trolliet, 2017, p. 92). Solo observé referencias al propio género en los casos de la agrupación de thrash metal, Indisposed -nombre que, traducido al español ,significa "indispuesta", adjetivo con que se describe el estado de la mujer durante sus días menstruales- y en el caso del conjunto de heavy metal, Las Brujas -que en el 2013 reeditaron sus canciones compuestas entre 1987 y 1993, en el disco, La reencarnación; en donde el "yo" lírico de las canciones toma una identidad amenazante a partir de las perspectiva de la "bruja" y la "loca"-.

Pero al analizar el plano visual, tanto estas bandas como Psicosis y Filosa, a pesar de que publican fotos en las cuales se ve a las integrantes luciendo el atuendo también encontré grupos tales como Dirty Women (tributo femenino a Black Sabbath) y Filosa (heavy metal). 
metálico, se observa que este se ajusta a la moda femenina, en el sentido de que su indumentaria posee características distintas a la que utilizan los varones. También se diferencian de ellos porque aparecen maquilladas y peinadas tal como lo propone la moda hegemónica y el erotismo heteronormativo. Estas características, que son codificadas como femeninas, se conjugan con poses y gestos vinculados a la masculinidad como el beber cerveza del envase, el cual rompe los "buenos modales" asociados a la feminidad.

Es necesario destacar que en la escena metálica bonaerense los diseños de ropa mantienen la división binaria del "femenino" y el "masculino". A pesar de que el período estudiado se diferencia de las épocas anteriores a través de la inclusión de la mujer mediante la confección de ropa metálica femenina, se pueden observar algunas desigualdades.

Por ejemplo, la supuesta inclusión se dio a través del ingreso en el mercado de leggins y remeras ajustadas con escotes más pronunciados que poseían estampas de iconogafía metálica. Sin embargo, sus talles se adecuaban a modelos de belleza hegemónicos (se dirigían a mujeres flacas) y a patrones de erotismo femenino heteronormativos. Además, las remeras "metálicas" de diseño "femenino" no poseían el logotipo de cualquier banda, sino de las que más comerciales, tales como Metallica y Guns 'N Roses, por lo que se siguió vinculando a la mujer con la idea de la música masiva y menos "auténtica".

De esta manera, muchas mujeres decidieron comprar remeras "unisex" (utilizadas mayormente por varones) y realizarles recortes que les permitieran otorgarle "feminidad" a la prenda. Esto se debe a que solo estos modelos poseen logotipos de bandas underground y poco populares, o existen en talles más grandes como el "Extra Large" (XL). En otros casos, algunas aficionadas comenzaron a realizar su propia indumentaria e, incluso, crearon emprendimientos, tales como la marca tandilense, "Freya, ropa sin talle" y la porteña, "Xtreme Rags Indumentaria”, que producen diseños personalizados.

A través de la netnografía realizada en Facebook encontré dos formas opuestas referidas a la mujer dentro del metal: por un lado, la fanpage "Las Metaleras Argentinas Son Hermosas", creada en el 2013, en la cual algunos administradores anónimos publican fotos de participantes femeninas de la escena. La descripción de la página dice que 
Esto es un pequeño homenaje a todas esas hermosas y exóticas mujeres argentinas que son metaleras de alma y corazón, Esto no es un concurso solo es un reconocimiento sincero a esas damas de negro que derrochan sensualidad y aguante en el movimiento. (Descripción de la fanpage de Facebook ${ }^{123}$ )

De esta manera, la mayor cantidad de fotografías publicadas son de metaleras realizando poses de modelaje o en formato selfie, las cuales dan cuenta de una hipersexualización ya que se intenta destacar partes del cuerpo femenino (el busto, las nalgas, los ojos y la boca) ligadas al erotismo heteronormativo. Quienes comentan estas fotos son en su mayoría varones, los cuales escriben palabras tales como "hermosa" y "diosa", e incluso realizan comentarios groseros, referidos a la masturbación masculina.

En el otro extremo encontré el grupo denominado "Mujeres Del Metal Argentina!! [Unidas, Somos Más]", el cual es administrado por una mujer y en la descripción del mismo expresa:

Bienvenidas chicas y tambien chicos! Este grupo lo hize para unir a las mujeres del metal! Difuciones [sic] de bandas! Fechas! Demos! Busqueda de musicos [sic] mujeres! No se permite putiadas ni peleas de puterio! Esto es para las mujeres para conocernos entre todas! Cada mujer que toque en una banda ddifundanla asi nos podemos apoyar entre si! Y seamos mas! Gracias por todoo!!.! [sic] (Descripción textual en Facebook: https://www.facebook.com/groups/1835847483306995/about/)

De esta manera, una gran cantidad de mujeres promocionan la actividad de sus bandas, así como también sus trabajos, como por ejemplo la fotografía y el diseño de indumentaria. Sin embargo se trata de un grupo pequeño compuesto por 655 miembros. La diferencia entre ambos es que la primera fanpage, a pesar de que se dedica exclusivamente a las mujeres, las "cosifica" u "objetifica" mediante parámetros heteronormativos, mientras que el otro intenta recuperar la agencia femenina y la sororidad.

Con respecto a los medios de comunicación especializados, la mayoría tiende a destacar a las músicas mujeres con adjetivos calificativos vinculados a la belleza, algo que no sucede con los varones, a quienes se los describe como "maestros", exaltando sus habilidades técnicas, o como "bestias", una metáfora de las características agresivas de la sonoridad y la retórica del metal. Por el contrario, otros medios intentaron destacar la agencia de las mujeres, como una forma de contrarrestar el peso de la descripción de la apariencia física.

\footnotetext{
${ }^{123}$ Recuperado de: https://www.facebook.com/pg/razaloable/about/?ref=page_internal
} 
Sobre esta línea, es posible citar un antecedente publicado en la revista Metal, la que en el año 1990 editó un "informe especial” sobre las mujeres metálicas argentinas con el título "Las damas del heavy", en las cuales se nombraba a algunas mujeres que cumplían diferentes roles: "músicas y cantantes", "las bandas", "detrás de escena" y "la radio". Dicha nota periodística comienza de la siguiente manera:

\begin{abstract}
El heavy es un género eminentemente masculino y Argentina un país de raíz machista. Sin embargo, cuando se empieza a pasar revista a las filas femeninas del metal nacional uno no puede menos que asombrarse. Porque "ellas" ni son tan pocas ni tan secundarias. Hay músicas, cantantes, periodistas, mánagers, etc.

Todas y cada una de ellas tienen ambiciones, proyectos y expectativas y toman su profesión tan en serio como cualquier representante del mal llamado "sexo fuerte".

Invariablemente, no están en esto por el glamour ni por el brillo que supone pertenecer al medio del espectáculo y en mayor o menor medida todas conocieron las [sic] discriminación sexual. Sin embargo, no arrugaron y como el mejor, pisaron a fondo el acelerador de sus vidas buscando la meta que ya muchas alcanzaron: hacer lo que sienten. (Revista Metal, 1990)
\end{abstract}

Esta misma postura adopta un artículo publicado en Cultura Metálica 3, el cual resume lo charlado en una mesa redonda que tuvo lugar en la tercera Feria del Libro Heavy de CABA, en el 2015, la cual intentaba dar cuenta del rol de la mujer en el metal. Para ello fuimos invitadas a dialogar Myriam Onchimiuk, periodista y webmaster; Carine Alfie, guitarrista invitada de la banda solista de Iorio; y quien escribe esta tesis. Las preguntas en dicho debate estuvieron enfocadas en nuestra experiencia como mujeres dentro de la escena y en las dificultades que esto suponía.

Esta intención de visibilización de la mujer dentro del metal argentino también fue llevada adelante por los realizadores del documental Sucio y desprolijo (2015), en el cual incluyen una sección especial en donde entrevistan a algunas aficionadas mujeres y músicas reconocidas dentro de la escena. También se puede mencionar el aporte del GIIHMA que en su segundo curso de extensión universitaria en 2016 dedicó una clase al análisis de letras de diferentes bandas argentinas de metal para dar cuenta del tratamiento que se hacía de la mujer, además de desarrollar una historia de las músicas mujeres que habían sido parte del metal argentino. Dicho análisis fue realizado por dos docentes que se autorreconocían como feministas.

De esta manera, a partir de la Feria del Libro Heavy se instaura el debate acerca de la problemática de la mujer dentro del metal argentino. En Cultura Metálica 4 aparece un artículo escrito por Noelia Adamo y Paula Naamin Tellis (2017), el cual se basa en la exposición de dichas autoras en la cuarta edición del evento en CABA en 
2016. Allí proponen que "(...) hoy es momento de problematizar los estereotipos de género dentro del heavy metal y de cuestionarnos por qué la presencia de mujeres es minoría" (p. 58). Estas iniciativa de visibilización y problematización parecen estar en sintonía con los reclamos de la protesta, "Ni Una Menos", iniciados en Argentina en el 2015.

Una de las maneras con que estas autoras reflexionan sobre la perspectiva de género es mediante la reivindicación del canto gutural en las mujeres como una forma de grito, opuesto al estereotipo de la mujer sumisa y callada: “(...) creemos que la mujer que se dedica al growl trasciende todos los roles femeninos esperados por la sociedad y fundamentalmente, los estereotipos que hay dentro del mismo metal." (Adamo y Tellis, 2017, p. 58. Cursivas del original). Las autoras finalizan dicho artículo con un llamado al empoderamiento y la sororidad:

\begin{abstract}
Porque aunque la sociedad siga escuchando como "masculinas" a las mujeres que rugimos, nosotras decimos que NO, que lo hacemos porque nos enojamos en tanto humanas. Y es por ello que exclamamos este ;Grito o muerte! como un doble llamamiento: El primero, destinado a ser vistas como artistas, músicas, cantantes, gritadoras y no solo como chicas de póster/videoclip o groupies. El segundo está destinado a oKupar [sic] y crear lugares protagónicos compartiendo y no compitiendo entre nosotras para, de esta forma, afirmarnos, fortalecernos y asegurarnos nuestra perpetuación como generadoras activas dentro de la sociedad en general y dentro de la cultura heavy metal en particular. (Adamo y Tellis, 2017, p. 60. Cursivas del original)
\end{abstract}

La perspectiva de Adamo y Tellis (2017) asume una postura feminista en tanto que rescata la labor de las mujeres que accedieron a espacios tradicionalmente dominados por los varones (como las músicas y las cantantes). Sin embargo, parece renegar del mito de la groupie y de la participación de la mujer como parte de la iconografía metálica (que suele ser sexista y heteronormativa), sobre los cuales se tiene un juicio negativo que también deriva de una perspectiva patriarcal conservadora (como ya mencioné, la mujer sexualmente activa y de atuendo "erótico" era relacionada con la prostitución y, por ende, con la "mala vida").

En el mismo sentido, Groupie es un concepto a través del cual la prensa especializada en rock y metal durante las décadas del '70 y '80 denominó a las aficionadas que mantenían relaciones sexuales con algunos músicos considerados "rockstars". Hill (2013) explica que dicha denominación constituye un mito, debido a que ha estigmatizado a las aficionadas, a la vez que ha impactado en sus modos de actuar dentro de la escena, los cuales se verán más adelante. 
Asimismo, la mayor parte de los ejemplos citados, a pesar de intentar otorgarle visibilidad a la mujer por medio de la exaltación de roles específicos (tales como el de música, cantante, periodista, productora, etc.), relegaron a las aficionadas a un lugar pasivo ya que no se consideró su agencia como oyente. Por lo que parecen permanecer parámetros patriarcales en la consideración de la mujer únicamente a través de espacios protagónicos.

De cierta manera, estas posturas reafirman la perspectiva masculinista con la que se juzga la "autenticidad" de las "metaleras". Tal como pude comprobar en el trabajo de campo, bajo esta mirada se pretende que las aficionadas "demuestren" la "veracidad" de su gusto musical y su "capacidad" para dar cuenta de ello, por lo que muchas veces han comenzado a realizar actividades como mediadoras a partir de la propia necesidad (consciente e inconsciente) de exhibir su autenticidad como "metaleras".

Con respecto al canto gutural, puedo agregar mi experiencia autoetnográfica. En primer lugar, participé como cantante invitada de una banda de death metal desarrollando la técnica growl de manera amateur, en varias oportunidades en distintas ciudades bonaerenses. Tal como escribí al inicio de esta tesis, algunos varones me expresaban su sorpresa por poder alcanzar esta técnica vocal muy contrastante con mi tono de voz suave al hablar. Según ellos, yo podía cantar “como varón”. Por su parte, muchas mujeres se acercaron a abrazarme y a expresarme su gratitud por el hecho de que una mujer lograba ocupar un lugar mayormente dominado por varones.

En algunos casos pude ver varones que se mostraron prejuiciosos al canto gutural femenino mostrándose más exigentes con la habilidad técnica. También fue posible observar cómo se dejaba de mencionar el nombre de la cantante invitada porque a esto se lo consideraba una actitud "comercial", ya que de acuerdo a esta perspectiva "que haya una mina, vende". Por el contrario, observé que las mujeres mostraban su aprobación mayormente cuando se trataba de músicas ejecutando un instrumento o desarrollando canto gutural.

En general, observé que la sororidad no suele ser una característica de las "metaleras". Existen algunos grupos de mujeres que fomentan la amistad femenina y otros cuyas participantes se autorreconocen como "feministas" (de hecho, vi algunas mujeres que, en sus chalecos con parches con logotipos de bandas de metal extremo, también incluían algunos con simbología del feminismo), pero en las entrevistas realizadas y en mi trabajo de campo pude observar que el hecho de que las participantes mujeres sean pocas hace que existan actitudes de celos y competencia, sobre todo 
porque la mayoría de ellas son heterosexuales y mantienen relaciones de pareja con algunos miembros de la escena.

Esto se hace mayormente visible en la relación entre las aficionadas y los músicos. Algunas entrevistadas expresaron que veían una situación injusta, ya que muchos músicos famosos permitían que ingresen a los camarines aficionadas mujeres pero no a varones. Por otra parte, a través de mi memoria autobiográfica pude constatar que algunos músicos metálicos consagrados demostraban intenciones sexuales a las aficionadas que solo se acercaban a pedir un autógrafo o una foto. En mi propia experiencia, este hecho determinó una decisión metodológica que fue asistir acompañada a una gran cantidad de entrevistas con varones desconocidos o realizar algunas en lugares públicos. Incluso, en ocasiones debí explicar con claridad el objetivo de la entrevista para que no sea interpretado como una excusa de acercamiento sexual.

Por otra parte, varias entrevistadas expresaron que las mujeres que se aproximaban a los músicos en realidad solo lo hacían con un fin sexual, a las que criticaban, ya que "por culpa de ellas", los músicos "engañaban” a sus novias o esposas. De hecho, algunas reconocían que muchas bandas compuestas totalmente por varones no permitían el ingreso de una música mujer porque esto generaba una situación de celos con sus propias parejas.

Las posturas de estas aficionadas se pueden ver como "conservadoras", ya que describen al varón como alguien que no puede controlar sus instintos sexuales, mientras que las mujeres son las culpables de esto. Además, en estas opiniones se ve la permanencia del "mito de la groupie", el cual

(...) tiene un impacto en las formas en que las fans entienden su propio fanatismo. Esto tiene que ser negociado para que las implicaciones del deseo sexual excesivo y el fanatismo frívolo no se "adhieran" a ellas. Para algunas mujeres esto significaba minimizar sus deseos apasionados e intentar construir su sexualidad como una que no fuera promiscua ni llamara la atención de su serio compromiso con la música. (...) El poder del mito de la groupie significa que las fans todavía sienten que deben negociar la negatividad del estereotipo y posicionarse como fanáticas serias o auténticas. Al reclamar, o con el objetivo de reclamar, la posición del "fan real", se salen del rol de fan que la ideología del género les prescribe (o al menos imaginan que son capaces de hacerlo). No se ven a sí mismas como groupies y rechazan el posicionamiento de su sexualidad como fácilmente legible (que como mujer fanática se siente naturalmente atraída por los músicos de sus bandas favoritas, y que esta atracción sexual excede su compromiso intelectual con la música) dentro del mundo heterosexual. Están decididas a no tener una posición sexual o musical "simplemente" debido a su género. Esta negociación y reposicionamiento de su estatus como mujeres y fans, sin embargo, no es una maniobra segura o sencilla. Para algunos, esto requiere la supresión de cualquier deseo por los músicos y otros miembros de la comunidad que puedan tener, lo que 
significa que no pueden expresarse libremente. (Hill, 2013, p. 163. T. de la A. Cursivas propias.)

Entonces, este mito no solo genera dudas acerca de la autenticidad de las "metaleras" sino que se impone como una creencia dominante acerca de los modos en que se pueden relacionar sexualmente los miembros heterosexuales de la escena. Dentro de ella, tanto los varones como las mujeres aficionados al metal valoran de manera positiva los ideales de la pareja monogámica heteronormativa y de la familia tradicional. Por otra parte, algunos músicos hacen eco de este mito al intentar posicionarse como "rockstars" y pretender un rol dominante sobre las aficionadas.

Al igual que expresan Leigh Krenske y Jim McKay (2000) en su propia etnografía, en mi trabajo de campo noté que el lugar más propicio para la sociabilidad femenina dentro de la escena metálica bonaerense es el baño (toilette) de mujeres de los recitales o de los encuentros de motos. Este se desarrolla como un lugar favorable, ya que en la sala de recitales es más probable que las mujeres se encuentren dentro de grupos donde también hay varones.

Por otra parte, el baño público permite que se desarrollen conversaciones de las que no se quiere hacer partícipes a los varones. De hecho, en algunas ocasiones de la etnografía, varias mujeres utilizaron la excusa de acompañarme a dicho sitio para contarme problemas íntimos que no querían que se enteren sus novios o amigos varones. Sin embargo, mayormente observé que las mujeres tienden a mostrarse integradas a grupos de varones y muy pocas veces sociabilizan de manera homosocial.

En cuanto al atuendo utilizado por las mujeres, pude ver aquellas que decidían exhibir feminidad y otras que preferían utilizar el look metálico casi de la misma manera que los varones. Para el primer caso, puedo citar el ejemplo de una "metalera" de 31 años, Ingeniera en Sistemas, a quien le pregunté por sus elecciones relacionadas con la vestimenta:

Para conciertos uso todas aquellas prendas que no puedo utilizar en mi vida cotidiana. Esto incluye ropa de cuero, corsets, medias rotas, cinturones de cadenas o de tachas, capas de pollera, mucho maquillaje, accesorios de pelo con tachas, extensiones de pelo, a veces ropa interior como portaligas, medias con liga, corpiños con y sin tachas. Siempre conservando la parte femenina y sutil aunque el look parezca rudo. Esto es importante para mí, porque es el momento en el cual puedo lucir representando lo que siento, mi alter ego, incluso creo que cambia algo en mi actitud en esos momentos en relación a sentir una mayor seguridad conmigo misma. Durante la vida cotidiana me visto como una persona normal, trabajo en una oficina así que trato de mantener la misma estética femenina mencionada anteriormente, con la diferencia de que la ropa 
diaria es de colores. Esto empezó a ser así hace 2 años, cuando me di cuenta de que podría estar bueno experimentar con colores más que blanco, negro y jean. Generalmente uso muchos vestidos y polleras, durante el verano y el invierno, en donde uso más ropa oscura. Es ropa más cómoda que la de recitales, también llama menos la atención y no me gusta ser el centro de atención de las miradas por la calle.

A pesar de que dicha ropa parece "liberar" a la aficionada entrevistada, se observa cierta autocensura que solo le permite utilizar dicho look durante los recitales, en los cuales construye una identidad alternativa a la cotidiana, en donde cualidades como la comodidad y la exhibición aparecen como polos opuestos.

Esta decisión acerca de la combinación de indumentaria culturalmente codificada como femenina con el atuendo metálico proviene de las tradiciones del glam, power, black metal, sinfónico y gótico. En el caso del glam metal, las mujeres que formaban parte de los videoclips y portadas de discos eran modelos que representaban a la femme fatale hipersexualizada.

Posteriormente el power metal y el sinfónico crearon los personajes de la heroína romántica (Weinstein, 2016b) y la princesa, representado principalmente a través de los vestidos de estilo decimonónico utilizados por sus vocalistas ${ }^{124}$. Por su parte, el black y el gothic metal utiliza la imagen de la mujer como bruja o vampiresa (Castillo Bernal, 2007), también hipersexualizada, que combina elementos del BDSM.

Sin embargo, en la corriente fundamentalista de la escena metálica bonaerense, se ve cierto rechazo por estos modelos femeninos. Más bien, se prefiere a la mujer que utiliza el atuendo metálico clásico. De hecho, pude observar un caso de una pareja heterosexual, en la que el hombre y la mujer vestían exactamente igual e incluso llevaban la cabellera del mismo largo, al punto de que si uno los miraba de espaldas no podía reconocer a uno y a otro. Pero a pesar de ello, mayormente se produce una diferenciación: las mujeres deciden utilizar mucho maquillaje en su rostro (especialmente en los ojos y la boca), mientras que gran cantidad de varones utilizan diferentes tipos de barbas.

Por otra parte, la mayoría de las "metaleras" de la escena poseen el cabello muy largo, el cual es utilizado para realizar headbanging en gran parte de los casos. A pesar de que algunas tiñen su cabello con colores fantasía como el azul, el violeta o el blanco, las coloraciones que predominan son el rojo y, sobre todo, el negro azabache. Algunas de ellas, rapan uno o ambos costados de su cabeza, de manera que pueden realizarse

\footnotetext{
${ }^{124}$ De hecho, tal como explica Weinstein (2016b), muchas bandas utilizan la técnica denominada "la bella y la bestia", en donde una mujer realiza canto lírico mientras un varón desarrolla las voces guturales.
} 
peinados simulando una cresta, tal como la que utilizaban los punks. Esto es frecuente en las seguidoras de Iorio.

Otros modos en que las mujeres deciden hacer uso de características culturalmente codificadas como masculinas se dan a través de la gestualidad y el vocabulario grosero, el consumo de grandes cantidades de alcohol, el contacto físico rudo y la participación en el pogo (sobre lo cual me explayaré a continuación). Estas mujeres tienen más facilidad para ingresar a grupos de varones, mientras que estos, en general, prefieren como pareja sexual a aquellas "metaleras" que se exhiben mayormente femeninas.

\section{El pogo como expresión de masculinidad y de inequidad de género}

Como mencioné anteriormente, el pogo se construye como una performance que despliega violencia mediante ciertos códigos que garantizan el desarrollo pacífico del mismo. Allí, acciones como golpes de puño, empujones y patadas constituyen prácticas agresivas que no se utilizan con el fin de enfrentarse físicamente sino que componen una forma de baile. Sin embargo, es posible considerar a dicha violencia como un modo de expresar e, incluso, exaltar la masculinidad.

Como expliqué anteriormente, muchos moshers (participantes del mosh-pit) se preparan de manera especial para participar del pogo (se despojan de los bienes que no quieren perder o romper, se sujetan el calzado, se colocan protectores bucales, etc.) y al finalizar se saludan entre sí, como si hubieran participado de una práctica deportiva.

Además de ello, ostentan los golpes recibidos o la rotura de algunas de sus prendas como una forma de demostrar orgullo de haberse desplegado con destreza dentro del mosh-pit y de haber podido "aguantar". En este sentido, el pogo se vincula con la estética del aguante del fútbol, en donde las cicatrices y las marcas corporales son testimonio de "(...) una masculinidad legítima de los luchadores” (Alabarces, 2006, p. 4).

Entonces, el espacio del pogo o mosh-pit, a pesar de mostrarse como un espacio en donde se desarrolla violencia con códigos de nobleza e inclusión, se trata de una práctica que posee significados vinculados con lo masculino y que tiende a ser homosocial (Krenske y McKay, 2000; Gruzelier, 2013; Riches et al., 2014). Por eso, cuando ingresan mujeres se produce una ruptura con respecto a esa dinámica. Esto hace que el lugar de varones y mujeres dentro del pogo no sea el mismo. 
Por un lado, los varones tienden a ocupar los lugares centrales de dicha práctica, mientras que las mujeres que se suman lo hacen en posiciones periféricas (Krenske y McCay, 2000). En mi trabajo de campo pude constatar que muchas de ellas deseaban participar al igual que los varones, pero tenían miedo de estar en el centro, por lo que solo lo hacían dando empujones y patadas desde los costados. Muchas entrevistadas dijeron que solo ingresaban a los pogos que se animaban y algunas anhelaban que más mujeres lo hagan para poder estar en condiciones de igualdad, ya que no era lo mismo recibir el golpe de un varón que de una mujer.

En otros casos, observé mujeres que participaban del mosh-pit a la par de los varones. Sobre estos casos pude conversar con algunos de los que habían compartido con ellas dicho espacio y se mostraban sorprendidos de que ellas se hayan animado a participar e incluso bromeaban de manera denigrante con sus características físicas: las comparaban con varones por su contextura física o decían que algunas les habían "pegado un tetazo" (golpe realizado con los pechos).

Por su parte, las que no participaban del pogo preferían evitarlo y se mostraban incómodas si en algún descuido eran empujadas, por lo que preferían mantenerse alejadas. Algunas de ellas eran utilizadas como "percheros" (Gruzelier, 2013, p. 70) o guardarropas, ya que muchos varones les dejaban sus abrigos y sus pertenencias de valor. De hecho, muchas veces tuve que ocupar dicho lugar y cuando me negaba a hacerlo porque decidía participar del pogo, varios varones se mostraban sorprendidos y frustrados, ya que daban por sentado que podían dejarme al cuidado de sus objetos personales.

Al utilizar la "moshografía” propuesta por Gabrielle Riches, Brett Lashua y Karl Spraklen (2014) como metodología en mi trabajo de campo, la mayoría de las veces que ingresé al pogo pude notar cómo los varones me esquivaban para no golpearme o, en algunos casos, me pedían disculpas por haberse caído sobre mí o haberme pisado como consecuencia del empujón de otro. En este sentido, algunos varones se mostraban demasiado protectores con las mujeres (algo que también fue expresado por una de mis entrevistadas).

En una sola oportunidad de las "moshografías" realizadas en mi trabajo de campo, un varón me golpeó fuertemente con el codo de manera intencional. Producto de ello apareció un hematoma en mi brazo. Luego de unas semanas tuve la oportunidad de cruzármelo nuevamente en la vida cotidiana y pude contarle acerca de la marca que me 
había quedado producto de su golpe. Entre risas, él me explicó que esa había sido su manera de integrarme dentro del pogo.

Es necesario destacar que estas diferencias dentro del mosh-pit se ven con mayor claridad en recitales con pocos asistentes, en los que apenas llegan a las 50 personas. En los recitales en donde el público está integrado por miles de asistentes, es realmente difícil poder participar, ya que las mareas de personas empujando, hacen que la presión entre los cuerpos sea mayor y muchas veces resulta dificultoso mantener los pies apoyados en el suelo.

En estos casos multitudinarios, al igual que algunos pocos varones, muchas mujeres optan por subirse a los hombros de alguno de ellos para poder resistir entre la multitud o para lograr ver el escenario. Otras opciones son ubicarse en dos posiciones opuestas: una, contra las vallas de seguridad, soportando la presión corporal del resto de la audiencia que empuja hacia el escenario; y otra, en sectores más alejados de este, en los cuales la comodidad y la seguridad física son mayores pero la lejanía hace que se pierdan detalles visuales del espectáculo.

Si utilizo mi memoria autobiográfica puedo mencionar otros golpes más graves sufridos dentro de pogos, los cuales produjeron sangrado de nariz, torcedura de muñeca y hematomas en los pies, al mismo tiempo que sufrí caídas al suelo y sobre la gente, a la par que fui aplastada por otros participantes de los pogos (algunos de ellos de contextura física mucho mayor a la mía) tanto al estar en la periferia como en el sector de la valla, cerca del escenario. A pesar de los dolores causados, estas anécdotas parecían empoderarme.

Con respecto al crowd surfing pude observarlo en pocos recitales. Una característica es que requiere de gran cantidad de asistentes que puedan sostener a la persona mientras se desplaza de mano en mano. Un caso especial en donde note esta práctica fue durante el concierto de la banda estadounidense de death metal, Obituary, en CABA en el 2017. Allí una gran cantidad de mujeres participaron de ello y observé que, al mismo tiempo que muchos varones las sostenían y cuidaban para que no se caigan, algunos aprovechaban para manosearlas. A esto puedo agregar que, en muchos casos que observé recitales desde el sector de la valla, algunos varones utilizaron el vaivén del pogo para tocarme las nalgas a mí o a otras mujeres que estaban en el mismo lugar.

Entonces, es posible afirmar que, de acuerdo a la etnografía realizada, la práctica del pogo en la escena metálica bonaerense permite a las mujeres empoderarse, ya que se 
incorporan al ethos masculino, participan de sus valores, alteran sus lazos homosociales y transgreden los estereotipos patriarcales de la feminidad como pasiva, delicada y "recatada".

\section{Algunas consideraciones}

Tal como se pudo observar en el análisis de este capítulo, tanto los varones como las mujeres de la escena construyen la identidad metálica por medio de elementos que tradicionalmente fueron codificados como masculinos, los cuales parecen constituir el centro de significado de la escena en tanto semiosfera. Mientras que lo que es tradicionalmente "femenino" en la cultura, parece pertenecer a una semiosfera externa, con la cual se dialoga de varias formas.

De esta manera, se exaltan diversos modos de masculinidad, los cuales se muestran como alternativos a la masculinidad hegemónica, ya que se basan en modelos masculinos que sugieren la idea de "poder" a través de figuras "amenazantes" (bárbaros, guerreros, monstruos, motoqueros), "marginales" (guapos y gauchos) y se contraponen a los que se consideran dominantes (el burgués y las autoridades). Lo mismo sucede con las mujeres que representan personajes como la bruja y la vampiresa, y con aquellas que al rol de la "princesa" le agregan elementos vinculados con el estilo "prostibulario" o del BDSM, los cuales se oponen a la feminidad hegemónica decorosa.

La masculinidad que forma parte del centro de significados de la escena metálica bonaerense en tanto semiosfera se desprende de la búsqueda de autenticidad por parte de los aficionados al metal. A través de ella, se construyen las alteridades del metal a las cuales se les asignan rasgos "femeninos" (como el pop y la música masiva) o vinculados a otros tipos de masculinidades (por ejemplo la cumbia, que supuestamente exalta masculinidades "delictivas", o géneros musicales bailables, que se cree que no son "serios" por centrarse en la conquista sexual).

De esta manera, la autenticidad opera otorgando valores morales positivos a los rasgos culturales "metálicos" y negativos a los que forman parte de identidades "contrarias" y/o "externas", por lo que la masculinidad es valorada como éticamente buena. Sin embargo, a pesar del predominio y la exaltación de ella, la mayoría de los

participantes de la escena se identifican como varones y mujeres, por lo que la identidad de género dentro de ella se construye mediante la binariedad heteronormativa.

En el caso de las mujeres se puede observar que no se identifican a sí mismas como masculinas, sino que construyen modos novedosos de identidad al interactuar con 
elementos culturales masculinos otorgándoles algunos rasgos de feminidad. En este sentido, no solo rompen con el rol doméstico y el ámbito privado asignados tradicionalmente a la mujer, sino que también producen un quiebre con respecto a la identidad femenina hegemónica. A su vez, esto constituye una ruptura con los códigos de la propia escena, ya que dentro de ella la visión predominante acerca de la mujer y lo femenino se ajusta a parámetros patriarcales.

Esto sucede tanto en el caso de las mujeres que desarrollan papeles de instrumentistas, vocalistas y mediadoras, como el de aficionadas. En el primer caso su rol activo es más visible, ya que se trata de lugares de actividad y liderazgo que tradicionalmente se identificaban con el varón. Por su parte, la agencia de las aficionadas (papel que también ocupan las anteriormente mencionadas) resulta innovadora ya que construyen modos de identificación femenina que desafían tanto la feminidad como la masculinidad.

En este sentido, las mujeres "metaleras" se identifican con un tipo de poder culturalmente entendido como masculino y son capaces de acceder a él, debido a que “(...) es canalizado a través de un medio, la música, el cual es intangible y difícil de vigilar." (Walser, 2014, p. 132. T. de la A.) Podría decirse que este es el ejemplo más claro de cómo la música funciona como dispositivo habilitante para la construcción de identidades (DeNora, 2013). Tal como explica Janotti Jr. (2013), "Ser mujer en el universo del metal es hacer emerger lo femenino, pero una feminidad que se encarna en medio de la distorsión y la autenticidad que la intensidad sonora del heavy metal evoca" (Janotti Jr., 2013, p. 79. T. de la A.), lo cual se produce mediante articulaciones complejas y, a veces, contradictorias (Janotti Jr., 2013, p. 87).

El empoderamiento femenino dentro de la escena bonaerense del metal no se realiza de manera consciente, sino que son aquellas "metaleras" feministas las que dan cuenta de ello. En general, la mayoría de las participantes mujeres sostienen el "mito de la igualdad", en donde prevalece la idea de "hermandad", y no reparan en las diferencias de género. En este sentido, permanece la dominación masculina, ya que “(...) la visión androcéntrica se impone como neutra y no siente la necesidad de enunciarse en unos discursos capaces de legitimarla." (Bourdieu, 2000, p. 22)

En efecto, a pesar de su voluntad contrahegemónica, la escena metálica bonaerense se caracteriza por ser conservadora y desarrollar una moralidad que se ajusta a parámetros del sistema patriarcal, por ejemplo, mediante el valor del amor "fraternal" propio de las relaciones de amistad y de la familia. Esto hace que predomine la 
heteronormatividad, la cual impacta principalmente en las "metaleras" a través del "mito de la groupie". Por medio de este no solo se rechaza a la mujer sexualmente activa sino que también algunos varones lo utilizan para ubicarse en una posición dominante. A continuación se analizarán los modos en que se transgrede el sistema hegemónico mediante el vínculo del metal y diversas ideologías políticas. 


\section{EI metal y la política}

Anteriormente, se explicó que la escena metálica bonaerense se construye mediante la interacción de sus participantes, es decir, por medio de sus relaciones sociales. Es por ello que, cuando se habla de identidad metálica, no solo se hace referencia al trabajo subjetivo de manera individual, sino también a la conformación de una identidad colectiva. Lo mismo sucede con Hermética que propone un "nosotros" metálico (Gendler y Prado, 2016).

La idea de la escena como grupo o colectividad se encuentra en consonancia con la idea de comunidad. Nelson Varas-Díaz y Niall Scott (2016) consideran que los individuos que disfrutan el metal probablemente aprecian tanto la música como su cultura en términos de comunidad, a través de la cual no solo se producen experiencias y significaciones compartidas, sino también el sentimiento de unión. No obstante, aclaran que

\footnotetext{
Más allá de ser una mera asociación de personas, la complejidad involucra procesos que implican explorar la expansión y los límites de la comunidad metálica e incluso lidiar con paradojas donde, si bien la música es posible que sea compartida, valores tales como los políticos, los artísticos y los éticos pueden ser extremadamente diversos. A pesar de ello, todos estos se mantienen unidos bajo la bandera del "metal". (Varas-Díaz y Scott, 2016, p. vii)
}

En esta misma línea es posible decir que la identidad metálica que se construye en la escena bonaerense en tanto semiosfera se compone de manera heterogénea pero el centro de significados permite la articulación de sus miembros bajo una experiencia comunal en común. Es así que la construcción de las identidades individuales y sociales se produce de formas complejas y, algunas veces, contradictorias y ambiguas.

En este punto resulta productivo tomar la comparación que hace Kahn-Harris (2007) de la escena metálica como una "comunidad imaginada" en términos de Benedict Anderson (1983). De esta manera, una escena musical en tanto semiosfera puede ser comparada con una "nación" debido a que es "imaginada" -sus miembros mentalmente poseen la idea de comunión-, "finita" -tiene fronteras- y se percibe como una "comunidad" -se concibe una idea de fraternidad y compañerismo plasmada en el "mito de la igualdad"-.

A la vez que la escena metálica bonaerense se asemeja a la idea de nación, es justamente la multiplicidad ideológica con respecto a dicho concepto uno de los 
elementos que generan mayor heterogeneidad entre sus participantes. Al comienzo de este apartado, se partió del postulado de Gendler y Prado (2016) que consideran que la construcción del "nosotros" metálico por parte de las bandas hegemónicas se encuentra asociado a la problemática de la argentinidad. Efectivamente, en las producciones de Hermética se ve que esta preocupación parece ser inaugural de la corriente fundamentalista que constituye el centro de la escena.

Por otra parte, es necesario mencionar que la argentinidad, según Luis García Fanlo (2010), se encuentra estructurada como un régimen de verdad que indica los modos de ser argentino como un efecto de poder cuyo objetivo es hacer que los argentinos sean "gobernables" y adaptados a las condiciones sociales del orden capitalista argentino. Al tratarse de un efecto de verdad, la argentinidad que se disputa en la escena metálica bonaerense está ligada a la idea de "autenticidad" que indica cuál es el "verdadero" metal.

El vínculo entre el metal y el contexto local argentino puede ser analizado como un modo de "hibridación" tal como la describe Motti Regev (2012) para el caso del poprock. De acuerdo al autor, el concepto se refiere a las prácticas creativas de los músicos de varios países que unen y fusionan el pop-rock con la música tradicional y otros elementos etno-nacionales (p. 100).

Esta característica de la escena metálica bonaerense no resulta diferente a las demás escenas metálicas de Latinoamérica, ya que

La integración continua de la cultura local en el metal en América Latina sirve como un ejemplo de cómo estas comunidades no están construidas sobre el aislamiento. Sus fronteras son porosas y en constante interacción con el contexto cultural en el que están incrustadas. (Varas-Díaz et al., 2016, p. 105)

De esta manera, el metal funciona como dispositivo habilitante para que los participantes de la escena metálica bonaerense reflexionen acerca de su contexto local (cuyo principal referente es la Argentina) y se identifiquen con diversas ideologías en torno a la problemática de la nación y la argentinidad. Por otra parte, la música permite a los aficionados realizar juicios de valor acerca de diversos asuntos, entre ellos su contexto sociopolítico:

Se puede decir que la música es política cuando sus letras o melodías evocan o reflejan un juicio político por parte del oyente. La política de una pieza musical se comunica por medio de su tiempo, su intérprete y su audiencia. Por lo tanto, la definición más 
completa de música política tomaría en cuenta su contexto específico: la función comunicativa de una obra particular en un entorno particular en un lugar determinado en un momento determinado. (Dunaway, 1992, p. 37. T. de la A. Cursivas del original)

Debido a que la semiosfera del metal se halla en contacto con las diversas semiosferas ideológicas es necesario analizar las tensiones y los diálogos que surgen de dichas relaciones. A continuación, se hará referencia a los antecedentes con respecto a la relación entre el metal y la política. Luego, se analizará la propuesta de Hermética y las ideologías políticas que aparecen en sus producciones a partir de su preocupación por las problemáticas propias del contexto argentino $\mathrm{y}$ latinoamericano $\mathrm{y}$, posteriormente, se verá de qué manera los participantes de la escena han resignificado dicho mensaje realizando un interjuego entre la identidad metálica y la identidad argentina.

\section{La relación entre el metal y las ideologías políticas: antecedentes}

\section{Las críticas}

Como ya fue mencionado, lo que caracteriza al metal es la expresión de potencia (Weinstein, 2000; Walser, 2014). A nivel global, las múltiples formas con las que el metal buscó representar poder y masculinidad han generado malestar tanto en instituciones políticas como religiosas, por lo que es posible afirmar que la relación del estilo musical con el exterior de su escena ha sido compleja y conflictiva desde sus inicios, no solo porque hubo lecturas prejuiciosas y distorsionadas acerca de sus composiciones y su retórica agresiva, sino porque también hubo casos en que algunos de sus participantes efectivamente fueron parte de la materialización de la violencia.

De acuerdo a Weinstein (2000), el metal fue criticado tanto por ideologías progresistas como conservadoras. Para el primer caso, en Estados Unidos, el periodismo especializado en rock consideraba al metal como un tipo de música poco sofisticada. Pero su principal desacuerdo residía sobre el contenido de las letras, a las que acusaba de hedonistas, sexistas y pesimistas. Esto se debía a que

El subtexto de la crítica progresista es que las letras deben ser serias y deben relacionarse con preocupaciones sociopolíticas, no con meros placeres personales. Por supuesto, el heavy metal también aduce tales preocupaciones, pero no de la manera radical o reformista que favorecen a los críticos. Por lo tanto, ellos ignoran sus mensajes. (Weinstein, 2000, p. 241). 
En el plano nacional, esto mismo sucedió con el rock argentino. Pablo Vila (1987) explica que

Para la juventud socializada en la militancia, las propuestas del rock nacional aparecían cargadas de individualismo, carentes de contenido social y sus valores eran sumamente desleídos. Su caracterización de los rockeros era desdeñosa y peyorativa. Para ellos, los rockeros eran parte del sistema (...) (p. 27).

De cierta manera, "El pacifismo del rockero, con su prédica romántica de la no violencia, exasperaba al militante de armas llevar" (Pujol, 2013, p. 26). Esto se debía a que los intelectuales y periodistas de izquierda consideraban a la postura del rock como una forma de "rebelión individual" ligada al "ámbito de la sensibilidad" (Manzano, 2011). Por lo que esta crítica “(...) estuvo también anclada en términos de género, ya que se entendía jerárquicamente lo sensible/femenino frente a lo ideológico/masculino" (Manzano, 2011, p. 47).

Por otra parte, la visión que tenía el militante de los rockeros como parte del sistema provenía de la perspectiva de algunos intelectuales de izquierda que consideraban al movimiento hippie latinoamericano como una "mala copia" del desarrollado en los países centrales: "Estos intelectuales veían a los 'hippies' locales como emuladores y -más serio aún- como desmovilizadores en términos políticos." (Manzano, 2011, p. 47)

En todos estos casos, las críticas provenían de perspectivas que pretendían que la música desarrolle tópicos "serios". Por lo cual, en el caso de la militancia política de izquierda, la concepción de "seriedad" estaba vinculada con la adultez y el compromiso político-ideológico. Por su parte, la crítica realizada por la prensa especializada en rock juzgaba a la seriedad del metal a partir de los parámetros de la "autenticidad" rockera.

Con respecto a la crítica al metal realizada por sectores conservadores, Weinstein (2000) manifiesta que, a nivel global, esta provenía de la oposición de aquellos al rock and roll de los años ' 50 , el cual era considerado inmoral y propulsor del mestizaje entre jóvenes blancos y negros. Tal como ya se explicó, estas críticas provenían de los "pánicos morales" mediante los cuales se atacaba y perseguía a los jóvenes entre las décadas del '50 y el '70. En Estados Unidos, el principal detractor estaba encarnado por la asociación, Parents Music Resource Center (PMRC) que, como ya se mencionó, se encargó de censurar las letras de las canciones de distintas bandas, 
condenándolas por incitar al suicidio y la agresión, a la perversión sexual y al satanismo.

En Argentina, las críticas realizadas por los sectores de derecha al rock argentino fueron, en primer lugar, desde una postura homofóbica, ya que "Varones adultos y jóvenes vieron en los roqueros (...) una 'amenaza homosexual', temiendo que pusieran en peligro la continuidad generacional del 'hombre argentino' y la transmisión del poder patriarcal." (Manzano, 2011, p. 37). De hecho, los hippies fueron efectivamente perseguidos por organizaciones nacionalistas, católicas y ultraderechistas, como por ejemplo "La barra de la Nueva Pompeya", la Federación Argentina de Entidades Democráticas Anticomunistas (FAEDA) con el Movimiento Nacional de las Juventudes y el Consejo Nacional del Movimiento Acción Patriótica (Provéndola, 2015).

Estas persecuciones iban desde escraches públicos hasta la violencia física. Las críticas se centraban en la inmoralidad, la corrupción del valor de la familia cristiana y en la acusación de tráfico y consumo de drogas e, inclusive, de prostitución, es decir, ocupaciones propias de la "mala vida". Esta oposición radicaba en que los hippies rechazaban ideales que consideraban propios del mundo adulto, tales como el catolicismo, el nacionalismo y el anticomunismo (Provéndola, 2015, p. 61).

Más tarde, el rock fue censurado durante la dictadura militar de entre los años 1976 y 1983. Primero, porque se ubicaba en la zona opuesta al sistema educativo del Proceso, cuyo objetivo era “(...) educar 'con los valores de la moral cristiana, la tradición nacional y la dignidad del ser argentino'." (Pujol, 2013, p. 53) También porque "(...) chocaba con el auge nacionalista a partir de su origen norteamericano y británico (...)" (Provéndola, 2015, p. 55), tal como sucedió con la detención de la banda británica, Génesis, y el boicot a la cantautora, Joan Báez, en sus visitas a Argentina en 1977 y 1981, respectivamente.

Esta postura se acentuó durante la Guerra de Malvinas, años en los cuales se comenzó a usar la expresión "rock nacional", la cual resulta paradójica, debido a que

(...) si antes del 82 se había dicho rock nacional para no repetir tanto rock argentino, a partir de los meses de la guerra la expresión ya no pudo desprenderse de la caudalosa irrupción de la música joven en las radios. Las palabras cristalizaron y el rock dejó de ser contracultural (imposible ser nacional y contracultural a la vez), lo que no necesariamente significó la postergación de todos sus ideales. Curiosamente, para muchos rockeros era ignominioso asociar el rock a lo nacional. Y para los viejos nacionalistas, el rock nunca sería nacional, por más que pusiera la mejor de las voluntades. Sin embargo así quedaron las palabras. (Pujol, 2013, p. 233) 


\title{
¿Qué ideología?
}

Al igual que a nivel global, el metal en Argentina surgió a partir del rock. De acuerdo a Vila (1989) este no poseía una ideología fija, sino que

\begin{abstract}
A excepción de algunos asuntos permanentes (la lucha contra el establishment, el pacifismo, la ecología, etc.), la ideología cambia no solo con el tiempo, sino también entre las diferentes ramas del movimiento. La autenticidad es la palabra clave que une a un cantante con la ideología. (Vila, 1989, p. 6. T. de la A. Cursivas propias)
\end{abstract}

Entonces, a lo largo del tiempo, es posible ver que la ideología del rock no solo surge a partir de la búsqueda de autenticidad, sino también de su relación directa con el contexto sociopolítico, haciendo que justamente lo "auténtico" varíe de acuerdo a las condiciones de producción en determinados momentos históricos, aunque el ideal contra-hegemónico pareció permanecer.

De esta manera, Vila describe el desarrollo del rock argentino de acuerdo a su contexto histórico en determinados períodos: 1) los orígenes (mediados de los '60 y década del (70); 2) la dictadura; y 3) el retorno de la Democracia. A ellos es posible sumarle la 4) década de los '90. A continuación describiré cada período:

1) En este período la ideología del rock argentino era muy similar a la del rock angloamericano, ya que representaba los cuestionamientos de los jóvenes de esa época, cuyas denuncias se dirigían contra “(...) la inconsistencia entre los valores afirmados por la sociedad adulta y su práctica social" (Vila, 1989, p. 10). En consecuencia, surge en el rock argentino el término "careta" para dar cuenta de la hipocresía que se criticaba.

A mediados de la década del 60, la idea de revolución del rock no se direccionaba al accionar político sino que tomaba un carácter existencial, ya que "El objetivo no era lograr el poder político de una nación sino el poder creativo de una generación.” (Provéndola, 2015, p. 56) Entonces, en las primeras composiciones del rock argentino, como por ejemplo "La balsa" de Los Gatos o "Rebelde" de los Beatniks, las letras funcionaban como una declaración ética que proponían una moralidad alternativa (Provéndola, 2015, p. 56).

A principios de la década del '70, el rock, al igual que la música comercial y las prácticas políticas de izquierda, era una de las opciones que poseían los jóvenes de dicha época para expresarse e integrarse. De manera que, en este período,

(...) la ideología del rock (...) mezclaba los problemas nacionales con los internacionales de formas extrañas: el compromiso con los jóvenes de la clase 
trabajadora y la lucha contra el régimen militar, con el ocio, el cuerpo, el placer, etc., reflejando las dificultades de ser joven bajo una dictadura. En la interacción de las interpelaciones, el rock nacional intentó representar y atraer a los jóvenes de los estratos medios y bajos que no son ni "estúpidos consumidores" ni "militantes". (Vila, 1989, p. 12. T. de la A. Cursivas del original)

En ese contexto aparece la denominada "música progresiva nacional", la que constituyó un punto de intersección entre el activismo político y la sociabilidad rockera, en donde "(...) algunos crearon una narrativa de vida caracterizada por una transición entre 'rebelión' y 'revolución' en la cual el rock tenía un lugar preponderante.” (Manzano, 2011, p. 48)

También se produce la división entre la "juventud comprometida" y la "juventud escapista" (Vila, 1989) y, tal como mencioné anteriormente, para los jóvenes sociabilizados en la militancia, el rock formaba parte del segundo grupo, debido a que no poseía contenido social o sus valores se encontraban diluidos (Vila, 1989). Es así que surgen posiciones opuestas: militancia vs. introspección y acción política vs. cambio interno (Vila, 1989).

2) De 1976 a 1983, el rock facilitó la integración de los jóvenes a un "nosotros" al mismo tiempo que estos constituían el grupo etario más perseguido por la dictadura. A pesar de ello, en este contexto, "El rock habitaba con certeza el territorio de oposición al régimen aunque lo hiciera de una manera un tanto autista" (Pujol, 2013, p. 168), debido a que estos jóvenes no se declaraban de manera explícita tal como lo hacían los jóvenes militantes.

Por su parte, el "movimiento" del rock de fines de los '70 y principios de los '80, no pretendía impactar de manera directa en el plano político, pero "llegó a tener una fuerte presencia contestataria" (Jelin, 1985, p. 31). Parte de ello se materializó en los recitales de rock, los cuales “(...) configuran un claro ejemplo de resignificación de la política en períodos de cierre de los espacios tradicionales de acción de la misma." (Vila, 1985, p. 86) Entonces, al abrir nuevos sitios para las relaciones sociales cotidianas, poseía una "fuerza democratizante" (Jelin, 1985).

Sin embargo, dicho rasgo no parecía caracterizar a los "metaleros" de esa época (llamados “metálicos"), los cuales se distinguían por violentar directamente al "enemigo", es decir, el sistema y lo que simbólicamente lo representaba: “(...) las instalaciones del club, los coches estacionados afuera, una persona bien vestida que pasa por los aledaños (...)" (Vila, 1985, p. 120) y los "chetos", entre los que incluían a los hippies. Estos hechos fueron vistos como atentados contra el ideal democrático y 
equiparados con la persecución de los ultraderechistas contra los hippies, a quienes ellos también violentaban.

A pesar de ello, la agresividad de estos jóvenes no provenía de una ideología que estuviera a favor de la dictadura. Por el contrario, gran cantidad de enfrentamientos violentos estaban dados con la policía. Los aficionados del Área Metropolitana Bonaerense se agrupaban bajo el nombre de "brigadas metálicas", las cuales tenían la función de auto-protegerse de los abusos policiales y poder movilizarse hasta los conciertos sin sufrir detenciones. Pero entre ellas también había rivalidad que desencadenaba hechos de violencia. Estas situaciones no solo se desarrollaron durante la dictadura sino también en los años posteriores.

La violencia de los "metálicos" en dicha época, entonces, formaba parte de la ideología con la que juzgaban la autenticidad del rock y de los jóvenes, la cual se encontraba influida por la agresividad del contexto sociopolítico. Estas disputas de legitimidad estaban dadas de manera enfrentada en los tres actores que constituían el rock argentino:

Salvo los "punk", todos se autodenominan "rockeros". Sin embargo los "heavy" llaman "hippies" a los cultores del "rock nacional", negando además que hagan verdadero rock, ya que identifican su música con la canción y la balada. Critican su "blandura" frente al sistema (según ellos, los "hippies" "piden", en tanto que los "heavys" "exigen"). La paz no existe, sostienen los "metálicos", existe la guerra y a la violencia hay que responderle con la misma moneda. Su actitud violenta es una prefiguración, un "aviso" al sistema de lo que le espera como resultado de su propia violencia disimulada. (Vila, 1985, p. 141)

3) Con el regreso a la democracia aparecen otras posibilidades para la construcción identitaria de la juventud a partir de nuevos interpeladores como los partidos políticos, los sindicatos y los derechos humanos, por lo que el rock dejó de ser el principal apoyo para la identidad juvenil y su idea de "movimiento" comenzó a disminuir (Vila, 1989). A pesar de ello, “(...) los partidos políticos despiertan desconfianza, más que por los valores que sustentan, por actuar en un ámbito, el de la lucha por el poder, en donde todo, hasta los valores, puede ser negociados." (Vila, 1985: 140)

De esta manera se produjo la fragmentación y la superposición de nuevas identidades juveniles: los "divertidos" (Los Abuelos de la Nada, Los Twist, etc.), los "underground" (Sumo, Patricio Rey y sus redonditos de ricota, etc.) y los "modernos" 
(Virus, Soda Stereo, etc.). Estos se desarrollaban a la par de los anteriores "rockeros", "punks" y “metálicos" y su disputa por la "autenticidad" adquirió nuevas perspectivas.

4) Los jóvenes rockeros argentinos de la década del '90 continuaban desconfiando de la política partidaria y se caracterizaban por la despolitización activa (Lunardelli, 2002), al desistir de participar en las organizaciones e ideologías políticas ya existentes. Esto fue visto como "antipolítico", ya que directamente "Rechazan la organización política como expresión colectiva y, en consecuencia, rechazan nada más ni nada menos que la base del credo democrático." (Lunardelli, 2002, p. 29)

Por el contrario, el rock constituía para ellos su "verdadera conciencia de clase", al que lo entendían “(...) como un género cultural, es decir, no sólo como música sino como postura ante la sociedad, ideología, universo simbólico, protesta social implícita o explícita." (Lunardelli, 2002, p. 29) Esto se debía, en parte, a que el rock (también llamado "rock chabón") comenzó a incorporar la experiencia de las clases suburbanas, la simbología del Che Guevara, el apoyo a la causa de las Madres de Plaza de Mayo y el discurso nacionalista como forma de protesta frente al neoliberalismo, lo que resulta diferente a la tradición rockera anterior:

En el rock nacional las clases media habían combinado el espíritu liberal del rock con el progresismo argentino que se reconocía enfrentado al nacionalismo, al que consideraba autoritario. El "rack chabón", en cambio, reivindicaba los valores patrióticos a través de performances en que aparecían las banderas argentinas, en que se reivindicaban los de sujetos prototípicos de la nación y se recuperaban ritmos folclóricos nacionales como la zamba y la baguala. (Semán, 2006, p. 69. Cursivas del original)

En sus trabajos junto con Vila y Benedetti, Semán incluye dentro del "rock chabón" a bandas de metal, tales como Hermética y Almafuerte (Semán y Vila, 1999; Semán, Vila y Benedetti, 2011). Estos autores indican que el nacionalismo que caracteriza a este tipo de rock no se reduce a una categoría de ideología política, sino que se trata de formas de sensibilidad de ciertos sectores populares. Por lo que argumentan que

(...) los jóvenes de clase media, a quienes les gusta el rock de los años 80, piensan que el rock chabón de los ' 90 pertenece al nacionalismo de derecha. Lo importante es que, tanto la idealización positiva, que imagina a los seguidores del rock chabón como revolucionarios, como la negativa, que los imagina como "fascistas", superponen una lectura etnocéntrica de lo social y lo político en la descripción del mundo de los sectores populares. (Semán, Vila y Benedetti, 2011, p. 278. T. de la A. Cursivas del original) 
Asimismo, es necesario considerar que la heterogeneidad que caracteriza la composición interna de las escenas rockeras y metálicas de Argentina también permite la presencia de aficionados que adhieren a dicho nacionalismo bajo una lectura realizada desde posturas de derecha. Con todo esto es posible decir que la ideología del rock argentino no es fija ni homogénea, sino que fue variando a lo largo del tiempo de acuerdo a las circunstancias históricas y se diversificó a la par que surgieron diferentes ramas en su interior. A pesar de ello, es posible afirmar que lo que parece permanecer es el rechazo a aquello que es considerado "el sistema".

A nivel global, el metal ha sido caracterizado de una manera similar: según Weinstein (2000), la política se acercó al metal a partir del thrash, pero solo a través de la presencia de juicios políticos y no de programas de acción colectiva. En ese sentido, los "metaleros" preferían sobrellevar las dificultades por medio de esfuerzos personales, ya que descreían en la posibilidad de resolver los conflictos con reformas o revoluciones políticas, actitud que es similar a la del existencialismo filosófico (Weinstein, 2000). Por otra parte, ser políticamente correcto era algo extraño para la audiencia del metal ya que lo que importaba era la demostración de rebeldía (Weinstein, 2000, p. 242).

Para el caso del metal extremo, Kahn-Harris (2007) explica que dentro de la escena virtualmente nada es político, ya que el uso de este concepto es restringido al uso en la esfera pública, es decir, al exterior de la escena. De manera que esto demuestra una perspectiva idealista, en donde la música es autónoma con respecto a las fuerzas sociales.

Este argumento sirvió para que muchos músicos de metal extremo justificaran el uso lúdico de expresiones racistas y fascistas (Kahn-Harris, 2007, p. 154), actitud que fue definida por Kahn-Harris como "reflexividad anti-reflexiva" y consiste en la utilización de simbologías y temáticas propias de algunas expresiones políticas de forma provocativa, pero sin demostrar ser partidarios de dichas ideologías. Esto permite a los miembros mantener la ilusión de la escena como un ambiente seguro e inmune a las complejidades del mundo (Kahn-Harris, 2007, p. 157).

En ese sentido, el rechazo de la política gubernamental y de los procesos políticos organizados por el Estado ha generado que muchas veces el metal sea caracterizado como "apolítico". Sin embargo, dentro de la escena existen múltiples formas con las que sus actores se expresan políticamente, muchas veces a través de ideologías no solo variadas, sino también incompatibles. 
De cierta manera, "El heavy metal rechaza la política en el sentido gubernamental del término, pero también en el sentido de evitar conflictos que pueden dañar la unidad de lo que significa ser metal, un ser que trasciende las perspectivas e identidades políticas." (Scott, 2013, p. 241. T. de la A.) Aquí el punto en común entre los miembros no solo es la lucha por la autenticidad -construida mediante el rechazo del status quo y la cultura de masas (Scott, 2013)- , sino también el mantenimiento del "mito de la igualdad".

Scott (2013) considera que el uso de un discurso político o politizado sirvió como forma de marketing a determinados músicos y bandas, aunque algunas audiencias tomaron dichas producciones como bandera política para su accionar. Por ejemplo, los casos más conocidos se produjeron con el Black Metal Nacional Socialista, surgido en Noruega con grupos que por medio de sus composiciones desarrollaron un neonacionalismo pagano, anticristiano y antisemita. Esto también fue llevado a la acción a través de la quema de iglesias, asesinatos y suicidios, por parte de los músicos de Bathory, Mayhem, Satyricon, Gorgoroth y Darkthrone.

En contraposición, surgió la corriente del Black Metal Rojo y Anarquista, el cual poseía una ideología antifascista. Esta circuló principalmente de manera underground y dentro de ella, se encontraba una banda argentina: Profecium, la cual editó en 1997 un disco titulado Socialismo satánico. Este conjunto musical, al igual que Sartán, estaba formado por algunos integrantes del grupo autodenominado "Poder negro", el cual, como ya se mencionó, era perseguido por los Servicios de Vigilancia de la Policía Federal.

El antifascismo en el metal argentino llevó a diversos sucesos de violencia en la década de los '90. A través de la netnografía realizada a la fanpage de Facebook "Fan Rev Rebelion Rock", pude observar relatos en los que se narraban enfrentamientos entre metaleros y punks anarquistas contra los skinheads neonazis porteños en Parque Rivadavia de la ciudad de Buenos Aires. En ese contexto, los editores del fanzine, Metálica, organizaron un festival antifascista denominado “Anti Cessar Fuentes Tour", en el cual se acusa de fascista al reconocido periodista especializado, agregando una doble S a su nombre de pila. "SS" aludía a Schutzstaffel, la organización militar y policial al servicio del nazismo.

Dentro de las bandas que participaban en este festival se encontraba Sartán, un grupo de black metal integrado por músicos que, como ya se dijo, también participaban de las actividades políticas de "Poder negro". En un artículo escrito para el diario, La 
Nación del 6 de mayo de 1996, Alejandra Rey entrevista a varios anarquistas y uno de ellos explica que los "Poder negro" son un grupo organizado de chicos que "(..) dicen que quieren llegar a la anarquía a través del trotskismo." La periodista agrega que "El joven sin nombre explica que Poder Negro tiene entre sus filas a punks y heavys." (Rey, 1996)

También es posible mencionar otros ejemplos de bandas y músicos que se proclaman explícitamente o desarrollan formas de activismo político: en el plano global, System of a Down, un conjunto estadounidense de descendencia armenia que se pronunció en contra del genocidio armenio; y para el caso argentino, el grupo Tren Loco, que en el 2003 participó de la grabación del programa televisivo "Aló presidente" del venezolano, Hugo Chávez.

Entonces, este uso ambiguo de la política también es posible encontrarlo en las producciones de Hermética y en el desarrollo de la escena metálica bonaerense en general. A continuación se analizarán las producciones de dicha banda como discursos polisémicos, en tanto que es posible encontrar en ellos una multiplicidad de ideologías, las cuales permiten diversas lecturas que repercuten de diferentes maneras en las instituciones y los participantes de la escena en el período estudiado (2011-2017).

\section{La diversidad ideológica de Hermética}

\section{Indigenismo}

Una de las perspectivas que toma Hermética es la del indigenismo, la que, al igual que el Indigenismo literario, se desarrolla cuando "un autor externo al referente denuncia la desigualdad de los indígenas" (Nicolás Alba, 2016, p. 54) con respecto a sus victimarios, pero sin dar cuenta de las diferencias en el interior de las propias comunidades nativas; y utilizando lenguajes y lógicas discursivas que no pertenecen al mundo aborigen. Como ya mencioné, en dicho conjunto musical las canciones están compuestas en idioma español y el estilo elegido es el thrash metal, el cual tiene su origen en el contexto del capitalismo y la globalización.

Un antecedente de esta postura indigenista es posible encontrarlo en la tradición de la revista, Expreso imaginario, editada entre 1976 y 1983 por Jorge Pistocchi, quien tenía una relación cercana con Iorio. Dicha publicación se caracterizaba porque "En la agenda de la revista, el de las culturas aborígenes era un tema casi tan relevante como el del rock y sus creadores" (Pujol, 2013, p. 131), por lo que se editaban notas acerca de los mapuches, los indios del Amazonas y los pieles rojas de los Estados Unidos. 
En ese contexto -el de la dictadura militar-, Expreso Imaginario fue un importante medio de comunicación entre los jóvenes (Vila, 1985), por lo que es posible deducir que los músicos de Hermética fueron parte de esta generación. Además del rock y la temática aborigen, en la revista se publicaba acerca de la ecología, la antimateria y el I Ching (Provéndola, 2015), los cuales fueron tópicos desarrollados por Hermética en sus canciones.

Entonces, en dicha banda es posible encontrar formas de defensa de los pueblos aborígenes en el plano verbal y visual. Para el primer caso se pueden mencionar canciones como "Cráneo candente", "La revancha de América" y "Moraleja". La primera desarrolla el relato de un joven que después de haber sido perseguido por la policía durante la madrugada, despierta en un campo y el efecto del sol le hace reflexionar acerca de la Conquista al desierto y el destierro de los pueblos originarios, situación que compara con la guerra de Malvinas y con la forma en que la economía imperialista de su contexto (la década de los '90) produce miseria y quita derechos.

Por otra parte, la canción posee una visión de lo indígena que puede ser considerada populista y romántica, ya que describe lo aborigen como aquello que es puro y auténticamente latinoamericano (Martín-Barbero, 1991). A esto se lo observa en la estrofa que expresa: "Miles de inmigrantes / conforman la ciudad. / Han mutado al indio / quitando su lugar. / Sembraron la muerte / por toda la extensión / de esta tierra infecta / sin sentido y sin razón.”

En el caso de la segunda canción, se habla acerca de los aborígenes desde su contexto de producción, es decir, los años '90. Allí, frente a los festejos de los 500 años de la colonización de América, el "yo" lírico incita a los pueblos originarios a tomar revancha, los cuales se encuentran "viciados y confundidos" como consecuencia del saqueo, el sometimiento, la esclavización y la profanación, llevados adelante por los colonizadores. En ambos ejemplos, la contraposición del nativo con la del inmigrante da cuenta de la oposición de la banda a lo extranjero lo que, a su vez, constituye una de las principales premisas de las ideologías nacionalistas.

En el tercer caso (que, a diferencia de las anteriores, no posee ritmo metálico sino de chacarera), además de mencionarse algunos pueblos originarios y el lugar que ocupaban, el "yo" lírico se identifica de manera confusa con el fin de los malones: "Pampas del Ranquel, sierras del Comechingón. / Sepan que, quien canta lleva en la sangre / la historia final del malón.”. En las otras dos canciones se describe al indígena 
de manera externa, en tercera persona, pero la cercanía aparece con el hecho de habitar el mismo territorio: "Pueblos nativos del suelo mío".

En el plano visual aparecen ilustraciones de personajes representados como aborígenes tanto en el disco Hermética como en Ácido argentino, aunque ambos casos resultan diferentes. En el primero, aparece ocupando un lugar de opresión y, en el segundo, bajo la forma de un guerrero, es decir, una figura empoderada. Esta última representación se puede relacionar con la canción, "La revancha de América", que también forma parte de este disco.

La postura indigenista también compuso una performance durante un show en vivo de dicho grupo, más exactamente el que se desarrolló en Stadium en agosto de 1993. De acuerdo a la crónica publicada en el número especial dedicado a Hermética de la revista Efecto Metal de julio de 2014:

(...) luego del tema "La Revancha de América", Iorio exhibió una banda multicolor que pertenecía a las comunidades indígenas. Hizo subir al escenario a un grupo de indios vestidos con plumas y vinchas. Estos indios realizaron como un ritual homenaje a la tierra, quemando granos de diversas plantas, bailando y tocando el charango, quenas y bombos. Al finalizar les pusieron a los integrantes de Hermética unas vinchas con plumas, declarándolos nuevos indios. ¡iEspectacular!!” (Efecto Metal, 2014, p. 60)

En la cita se puede ver que el narrador había sido parte del público de dicho espectáculo, pero sin embargo demuestra no haber comprendido bien de qué se trataba la performance de los nativos. Además de este relato, en la página siguiente de la publicación gráfica, aparece una fotografía del guitarrista, "Tano" Romano tocando la guitarra eléctrica y portando una vincha con plumas.

De acuerdo a la biografía de Iorio, es posible saber que la defensa de los pueblos originarios también formó parte del accionar de los integrantes de Hermética por fuera de su actividad musical. De hecho, esto llevó a que se genere una rivalidad con la banda argentina de ñu metal, A.N.I.M.A.L., que era contemporánea y también desarrollaba temáticas indigenistas (De hecho, el nombre de la agrupación es el acrónimo de la frase “Acosados nuestros indios murieron al luchar"). Según Iorio, la diferencia consistía en que dicha agrupación solo cantaba en defensa de los aborígenes, mientras que él se había acercado personalmente a ellos para colaborar con su lucha. (Torres, 2012, p. 97)

En la canción "La revancha de América" se puede ver que Hermética extiende su referente a Latinoamérica. Lo mismo sucede en el tema "Predicción", cuyos versos dicen "un guerrero de poder, tendrá el sur americano" y en "Sepulcro civil", en donde se 
expresa una opinión: "Conformada y aburrida / es la enferma sociedad latina. / Que usa las reglas de la creencia oficial / para esconder su hipocresía”. Entonces, además del indigenismo se puede ver la adhesión de la banda al latinoamericanismo, a pesar de que su principal referente fue la Argentina, como se verá a continuación.

\section{Nacionalismos}

Las reiteradas referencias a lo local pueden ser analizadas en tanto formas ideológicas que representan varios modos de nacionalismos. Esto se debe a que, como ya se mencionó, las producciones de Hermética se presentan como discursos altamente polisémicos. Al mismo tiempo, no intentan dar cuenta de una perspectiva política en particular, sino que su función es la de denuncia de situaciones particulares, las que en su conjunto pueden ser leídas de acuerdo a ideologías políticas que, en algunos casos, son opuestas. Esto da como resultado la producción de un discurso contradictorio que por momentos parece vincularse con el nacionalismo popular y, en otros, con el de derecha.

La primera forma en que Hermética decide dar cuenta de su contexto local es mediante el uso del idioma español. Las letras del grupo fueron compuestas en su totalidad en esta lengua, incluso los covers grabados en el disco Intérpretes también son en español, excepto el tema "No class" del conjunto inglés, Motörhead. Sobre la grabación de esta canción aparece una anécdota en el documental, La H (2011). Allí Tony Scotto, el ex baterista de la banda, se burla de la mala pronunciación del inglés del vocalista, Claudio O'Connor.

A pesar de haber decidido elegir al español como idioma propio de la banda, hubo un intento de que Hermética grabara un disco en inglés. Esta idea fue de Radio Trípoli quien pensaba realizar un intercambio con el sello Roadrunner para que los discos de dicho grupo sean escuchados en el exterior. De esta manera se intentó traducir algunas canciones del conjunto al inglés, pero al poco tiempo se dieron cuenta de que no iba a tener resultado, ya que O'Connor no dominaba el idioma y los temas musicales estaban traducidos solo en fonética.

En su biografía, Iorio reconoció haberse opuesto a este intento, no solo porque lo consideraba una pérdida de dinero, sino porque para él "La onda es ser reconocido en el país de uno" (Iorio en Torres, 2012, p. 108), postura que puede ser considerada como nacionalista. 
También es posible encontrar referencias a lo local en el plano musical y aquí el principal ejemplo es la idea de incorporar una canción con ritmo de chacarera (aunque no se trata de una chacarera propiamente dicha). Además se pueden mencionar las canciones que se versionaron en el disco Intérpretes, entre las cuales se destaca el cover de ritmo metálico del tango, Cambalache, de Enrique Santos Discépolo. Tanto la chacarera (un ritmo de Folklore) como el tango forman parte de los géneros musicales más representativos de Argentina. El resto de las canciones, con excepción de la de Motörhead, pertenecen a grupos musicales de rock argentino: Patricio Rey y sus redonditos de ricota, Manal y V8.

Con respecto al Folklore, se puede trazar otra referencia mediante la relación de Iorio con el folklorista, José Larralde, la cual comenzó a partir de Hermética, más concretamente en 1992, en el contexto del festival realizado por SADAIC y Radio Nacional en Córdoba. Como consecuencia de este vínculo, el folklorista se presentó en uno de los recitales de Hermética en Stadium en 1994. En esa oportunidad, dicho músico solo se limitó a subir al escenario a saludar al público. Ese mismo año, la banda realizó un cover de su tema, "De los pagos del tiempo", en un concierto en el Estadio Obras, el cual posteriormente fue grabado por Iorio con Almafuerte.

Otra forma de dar cuenta de una perspectiva localista es mencionando temáticas propias del contexto argentino de la década de los ' 80 y principios de los '90, como por ejemplo el servicio militar obligatorio y la guerra de Malvinas, sobre lo cual no solo hay referencias en letras como "Cráneo candente" y "Del colimba", sino también en la portada de Víctimas del vaciamiento, en donde aparecen las figuras del colimba, las ilustraciones referidas a las propagandas electorales (características del período democrático) y una ilustración del Banco Central de la República Argentina con la leyenda "Bank off Amer", que posiblemente se refiera a las políticas económicas propias del gobierno de Menem.

Más referencias se pueden encontrar en la portada de Ácido argentino, en donde aparece la figura de Tío Sam ahorcando a la de la Libertad, lo que sirve como metáfora de la dependencia económica con los Estados Unidos. También se pueden ver a las Madres de Plaza de Mayo reprimidas por policías, un par de militares deteniendo a un hombre, algunos hombres en situación de calle y la figura de un ferrocarril tapiado y cerrado con un candado. Todas estas imágenes permiten ilustrar el contexto argentino entre las décadas de los ' 80 y los '90. 
Pero Hermética no solo se refirió a su contexto local contemporáneo, sino también a ciertos procesos y personajes de la Historia argentina. El principal ejemplo aparece en la portada del disco Hermética, en la cual, de acuerdo a lo que indica Iorio en su biografía: "En el dibujo aparecen Bartolomé Mitre, el obispo de Buenos Aires y un milico, y abajo, muriéndose, San Martín, Juan Manuel de Rosas y la gente que luchó por el país. O sea, algo así como: matemos a los indios para poder traer extranjeros." (Iorio en Torres, 2012: 109) Los personajes históricos que en esta portada ocupan el lugar de "víctimas" forman parte de la línea ideológica "San Martín-Rosas" defendida, principalmente, por Perón y el peronismo de derecha.

También aparecen referencias a la cultura de Argentina con menciones de la gastronomía ("El tormento del vino artificial / y su atmósfera parrillera"), la mitología ("por la suerte y las apariciones de la luz mala ${ }^{125,)}$ y prototipos culturales ("como ayer gauchos al desierto") del país, además de la estrofa del poema del Martín Fierro en el inicio de la canción "Vientos de poder".

Esta obra de José Hernández formaba parte de la literatura gauchesca y del canon literario argentino impuesto por la hegemonía cultural y la élite nacional. Los intelectuales argentinos de principios del siglo XX consideraban que la figura del gaucho, a diferencia de la caracterización barbárica realizada por Sarmiento, poseía el carácter de raza "hercúlea", "épica" y "civilizadora" que se oponía a los "gringos" (inmigrantes europeos) y representaba la verdadera nacionalidad argentina (Garavaglia, 2003).

De esta manera, el Martín Fierro fue valorado como la obra más representativa de la literatura argentina. No obstante, dicho reconocimiento fue tardío y se produjo al mismo tiempo que la derecha nacionalista argentina comenzaba a tomar forma. En ese contexto, el poeta militarista, Leopoldo Lugones, rescató la figura del gaucho viril dispuesto a morir por su jefe, para mostrarlo como contracara del inmigrante (Echeverría, 2009).

Como se explicó anteriormente, Hermética utiliza un fragmento de dicha obra pero lo realiza de una manera original: a través de la lectura al revés. Es posible que ella sirva como referencia a la cultura local. Pero, además, el modo de nacionalismo que desarrolla la banda es similar al que se propone desde la literatura gauchesca al oponerse a lo extranjero. La diferencia con esta tradición es que, como ya se describió,

\footnotetext{
${ }^{125}$ La "luz mala" es un mito de la cultura argentina y uruguaya que surge a partir de las apariciones nocturnas de una luz que sobrevuela el suelo de los campos.
} 
la agrupación parece revalorizar el carácter del gaucho como "bárbaro" mediante la concepción del "paria orgulloso".

Con respecto a las referencias geográficas de la Argentina, se encuentran menciones de lugares específicos del país ("Solo el cielo de la pampa lo vio"; "A las montañas del noroeste argentino...”; “En el terreno del Atlántico a los Andes, del verde Chaco a los hielos fueguinos") y de la ciudad de Buenos Aires y el conurbano bonaerense ("río poluído"; "caminando por los barrios del oeste"; "De Pachecho a la Paternal, de Dock Sud a 3 de Febrero").

Aquí es posible ver cómo Hermética marca un claro contraste entre la capital y el interior del país -tópico propio del nacionalismo-, en donde la primera es descrita mediante la urbanización y, el segundo, mediante la ruralidad y el viaje, sobre los que es posible citar las canciones "Robó un auto" y "Del camionero". Además, el viaje por el interior formó parte de la actividad de la banda, lo cual se encuentra además plasmado en la letra de "Ayer sueño, hoy realidad":

Salir de gira / para llevarte en vivo el concierto. / Exalta mi vida, / cumplir con lo que fue mi deseo.

Cuando ya lejos de la ciudad central / los horizontes me ven. / Rutas saldar, para llegar / y mostrar que soy quien quise ser.

La idea de giras y tours no solo forma parte de la tradición propia del metal "Como los trovadores medievales, ellos viajan hacia su audiencia" (Weinstein, 2000, p. 84)-, sino también de un rasgo que caracterizaba al rock argentino, el cual poseía una "suerte de utopía rural" (Díaz, 2005) a través de la cual se construía un proyecto de huida de la urbanización. Esta postura estaba representada por León Gieco, quien a partir de la época de la dictadura empezó a desconfiar de la ciudad y a interiorizarse por lo provinciano (Pujol, 2013, p. 244).

En mi anterior trabajo sobre el metal pesado argento de Almafuerte (Calvo, 2012, 2014) analicé cómo esta operación permitía describir el contraste entre el campo y la ciudad y dar cuenta de referencias geográficas de Argentina, tal como lo hace el Folklore para valorizar lo tradicional (Díaz, 2009). Por lo que se ve que en Iorio, luego de Hermética, continúa siendo una temática recurrente. Al igual que en la tradición del rock y el metal, en las producciones de Iorio el viaje le permite al espíritu rockero alcanzar la ansiada libertad (Bernal y Caballero, 2016). 
Como ya mencioné, en las producciones de Hermética se destaca la defensa de ciertos oprimidos en el contexto argentino y latinoamericano. En primer lugar, se ve que abundan las denuncias acerca de la desigualdad, la injusticia, la pobreza y el desempleo consecuentes de las políticas neoliberales de fines de los ' 80 y los '90. Por ejemplo, la estrofa del tema "Cráneo candente" dice: "Me observo junto a mis hermanos / harto de miserias / y despojados de todo derecho / por el blanco imperio". Esta intenta dar cuenta de las injusticias que sufre el pueblo como consecuencia de dicho régimen políticoeconómico.

Al tomar como referencia la portada del disco Ácido argentino, es posible encontrar una pluralidad de imágenes que dan cuenta de lo que Ernesto Laclau (2005) denomina "demandas del pueblo" y caracterizan al "populismo" y al nacionalismo popular. En dicho arte de tapa aparece la protesta propiamente dicha a través de la recreación de "La manifestación" de Berni y de la figura principal de la obra "La libertad guiando al pueblo", la cual representa a la Revolución Francesa. También aparecen representaciones de la olla popular y de la movilización de las Madres de Plaza de Mayo.

Todas ellas pueden ser consideradas "demandas del pueblo", las cuales son democráticas debido a que "(a) (...) son formuladas al sistema por alguien que ha sido excluido del mismo -es decir, que hay una dimensión igualitaria implícita en ellas; (b) que su propia emergencia presupone cierto tipo de exclusión o privación [...]." (Laclau, 2005, p. 158)

El tópico de la igualdad aparece también en el tema "Masa anestesiada" que, en una de sus estrofas, expresa "La gran masa anestesiada / se revuelca en egoísmo. / Y si le encontró un sentido, / se ha entregado al escapismo". Aquí se critica al individualismo que caracteriza a la masa popular de los '90 como producto de los entretenimientos de moda de índole "pasatista", propios de la cultura de masas y del neoliberalismo. Estos valores son contrarios al amor fraternal y a la forma de autenticidad que predica Hermética, ya que juzga como "escapistas" a los consumos culturales que no están comprometidos con una causa ideológica "seria" y se vinculan con la sociedad de masas.

La idea de la "masa anestesiada" también aparece en el tema "Gil trabajador" en los versos que dicen "El tormento del vino artificial / y su atmósfera parrillera / anestesian la conciencia común". De este fragmento se puede entender que Hermética 
propone la idea de la masa popular como engañada y sin posibilidad de tener conciencia a causa de sus consumos.

Lo mismo se observa en "Desde el oeste", en donde el yo lírico parece apartarse de la masa popular en los versos que dicen "Elementales del montón, / intoxicados de pasión, / sienten miedo al verme / lejos de su niebla”. Otra crítica aparece en la caracterización ya mencionada acerca de la sociedad latinoamericana como "conformada y aburrida" que aparece en el tema "Sepulcro civil".

Entonces tanto la idea de conformismo como la del adjetivo "anestesiada" parecen criticar la inmovilidad de las masas populares, por lo que se deduce que en Hermética se valoriza la idea de movilización popular. Pero, paradojicamente, se propone al metal como una forma que se diferencia de la masa popular a la cual se critica, lo que supone cierto elitismo, característica de los nacionalismos de derecha que se oponen al populismo anteriormente mencionado. Por otra parte, dicha banda no propone la acción política, sino que el modo de resistir las injusticias es conservar la dureza de la identidad metálica, tal como se propone en "Evitando el ablande".

En ese mismo sentido, las referencias a los trabajadores que aparecen en las letras no suponen un modo marxista de conciencia de clase o un programa de acción colectiva, sino que simplemente se denuncian las injusticias de los obreros de su contexto de producción. El tema que se dedica a esta temática es "Gil trabajador", cuyas estrofas expresan:

Masticando esta siniestra heredad, / prisionero estoy en mi ciudad natal, / donando sangre al antojo de un patrón / por un mísero sueldo.

Con el cual no logro esquivar / el trago amargo de este mal momento. / Mientras el mundo, policía y ladrón/ me bautizan sonriendo: gil trabajador.

Como ya se mencionó, los antecesores de los aficionados al metal eran los "firestones", seguidores del rock pesado (blues y heavy metal) o rock "prole" (Pujol, 2013), los cuales eran miembros o hijos de la clase obrera (Alabarces, 1995) Esta caracterización continúa siendo parte del imaginario colectivo que los "metaleros" tienen de la escena y de sí mismos. Efectivamente, en una entrevista realizada en la época de Hermética, Iorio expresa:

En este país, se produce un fenómeno especial con el heavy metal. Al menos, pasa con mi grupo: lo escuchan los pobres. En otros países es distinto, son generalmente los ricos quienes tienen acceso al heavy metal. Siempre trato de remarcar eso, porque 
sinceramente, no quiero a la gente de la oficina, ni de carreras universitarias, ni a las chicas que se desviven por rendir un parcial de medicina para que después la madre diga en la carnicería. "la nena ya tiene la placa". Con mis letras y con mi música, trato de remarcar que no me copa eso. Yo apuesto más por el negrito que dice: "jaguante vieja!", que nadie lo quiere. Porque a los intelectuales, que manejan radios y revistas, succionando el beneficio del heavy metal, no les copa el "aguante vieja", el ser de verdad. Pero ese "aguante vieja", es el que se va a juntar con una negrita y van a tener una prefabricada en Moreno y con su esfuerzo, con su pequeño trabajo, van a seguir cambiando el mecanismo. Mientras que los "abortivos" de carreras universitarias, terminan desechos en la nada. Por supuesto, a ellos no les cabe que tenga las uñas sucias o que hoy no me haya bañado. Ellos quisieran que Hermética fuera un gupo de trajecito, siempre arregladitos... Pero no, detesto eso. (Iorio en RNS Magazine, 1994: 6)

En el caso del metal de Estados Unidos y el Reino Unido, su audiencia nunca perteneció exclusivamente a la clase obrera, ya que además de trabajadores blue-collar, había jóvenes universitarios y pertenecientes a familias de clase media. Sin embargo, "la cultura obrera impregnaba a la subcultura del heavy metal" (Weinstein, 2000, p. 114. T. de la A.).

A pesar de que parecen valorarse las demandas del pueblo como una forma democrática de protesta social, en Hermética se puede encontrar desconfianza hacia dicho sistema político. Esto aparece con claridad en la letra del tema "Olvídalo y volverá por más", en donde se representa el descreimiento hacia los representantes políticos:

Politiqueando un doctor de la ley / ganó lugar con sólo prometer. / Carnes asadas convidó al pueblo, / quien dió su voto creyendo.

Que poseía sensibilidad social, / que cumpliría sin aflojar. / Con sus discursos preelectorales, / con los que tejió su fraude.

En un avión se llevó el dineral, / a donde nadie sabe. / Seguro de que pronto lo olvidarán, / y podrá postularse otra vez.

Fue groso el toco que pegó al rajar, / amasijando la capital. / El desvalije está latente, lo sabe hasta el presidente.

(...) Olvídalo y volverá por más, / mostrándose confiable en los carteles. / Con prometer a muchos fascinará, / y con su nombre pintarán paredes.

La muerte es ocultar la verdad, / el vacío es dejarse mentir. / En un avión se llevó el dineral, / y volverá por más cuando lo olvides.

En consonancia con este cuestionamiento al régimen democrático, se pueden mencionar algunas fotografías ${ }^{126}$ de archivo de la banda realizadas por Andrés Violante, su fotógrafo oficial, en donde se ve al cantante, O'Connor, usando una remera con un símbolo anarquista, ideología que es muy característica del mundo del punk rock, pero

\footnotetext{
${ }^{126}$ Estas fotografías aparecen en el número especial de la revista Efecto Metal, dedicado a Hermética, de julio de 2014, más específicamente en las páginas 18 y 19.
} 
que también dialoga con el contexto de la escena metálica de Capital Federal y el Conurbano en la década del '90.

Otra referencia indirecta al anarquismo se ve en el tema "Robó un auto", en los versos que dicen "Condujeron sus propios destinos / por el sendero que el mundo esquivó/ y pudieron sentirse su estado, / su patrón, su íntimo Dios.” Estos resultan similares al eslogan que utilizaban las anarquistas argentinas de fines del siglo XIX y principios del XX que decía "Ni dios, ni patrón, ni marido" (Molyneaux, 2002).

Además de las críticas realizadas a su propio contexto de producción, Hermética realiza su posicionamiento con respecto a las políticas de su pasado, lo que aparece con mayor claridad en la portada del disco homónimo. Como ya se dijo, con los personajes de dicho arte de tapa Iorio exhalta a quienes considera que lucharon por el país y critica la idea de matar a los aborígenes para traer pobladores extranjeros.

Tanto en esta declaración como en varias canciones de Hermética, es posible ver una forma de nacionalismo esencialista. De acuerdo a Clifford Geertz (2003), los nacionalismos americanos tenían dos tendencias: una, epocalista, y la otra, esencialista. En la primera predominaba la atracción por los avances técnicos del Occidente, la urbanización, el dinamismo y la contemporaneidad. Por el contrario, la segunda buscaba continuidad y coherencia en la tradición para la construcción de una identidad nacional esencial que, al parecer inmutable en el tiempo, se oponía al dinamismo y el cambio histórico. Esta última tendencia es la que se puede ver en Hermética.

Algunos ejemplos aparecen en versos como "Miles de inmigrantes / conforman la ciudad. / Han mutado al indio / quitando su lugar" de "Cráneo candente", los cuales ya se han mencionado por poseer una perspectiva indigenista. Lo mismo sucede en "Sepulcro civil", en la estrofa que dice "Sin futuro, sin piedad, / sin conciencia fraternal, / han mutado la raíz / aniquilando el país, tu país, mi país".

Entonces se puede deducir que la idea de mutación se refiere al mestizaje que se produce con la llegada de extranjeros europeos, los cuales, de acuerdo a esta perspectiva, corrompen la pureza de la tradición de los nativos. Como ya mencioné parcialmente, esta oposición a los inmigrantes forma parte de una creencia típica de los sectores nacionalistas de derecha de principios del siglo XX. Esta misma postura tenía Juan Manuel de Rosas, uno de los personajes históricos que aparece representado en la portada de Hermética. Sobre la crítica a Mitre que también se puede leer allí, Iorio explica: 
Mi filiación política son los tres tomos de "La Historia de la Confederación" de Saldías. Cuando en la escuela me enseñaban que Mitre era un patriota, yo respondía con los argumentos de Saldías, que fue un alumno de Mitre y a quien en su momento tildaron de traidor a la Patria y quemaron sus Obras. Ahora cualquiera puede comprarlas y ver las cosas desde otra óptica. Esa es mi política: la verdad. ¿Estar en algún partido?, no, no me interesa quién esté al mando mientras sea el pueblo quién elija. Lo que sí me interesaría es que venga algún gobierno y diga: "Tanta tierra para tanta gente", en lugar de reducirlos a los monoblocks del Fonavi en Lugano, Piedra Buena o Ciudadela, porque en un país que tiene una superficie de $3 \mathrm{~km} 2$ por habitante y reduce a la gente pobre a vivir en palomares, lo que está fomentando es la corrupción, perversión, drogadicción, prostitución y el odio, más el resentimiento social. Mis letras giran en torno a eso. (Iorio en Revista Metal, 1992)

Entonces, Iorio afirma que su postura es la misma que Adolfo Saldías, un intelectual representante del liberal-positivismo que junto con Ernesto Quesada puede ser considerado uno de los iniciadores de la relectura de la Historia y del período denominado "época de Rosas” (Echeverría, 1997).

En el metal es común que las bandas utilicen personajes y acontecimientos históricos, especialmente para homenajearlos (Poleto dos Santos, 2013), pero en el caso de Hermética se utilizan como una invitación a la relectura de la historia, en consonancia con la idea que aparece en aquellas letras que proponen la búsqueda de verdades que ocultan los poderosos.

Además de ello, en las producciones de dicha banda es posible ver que se exaltan las figuras tanto de Rosas como de San Martín, por lo que podría decirse que del primero se adopta la perspectiva en contra de los ideales unitarios (que se corresponden con un tipo de nacionalismo epocalista) y, del segundo, se lo valora en tanto libertador de América. Sin embargo, la presencia de Rosas como autoritario parece chocar con la perspectiva de Hermética en contra de los abusos policiales y militares. Tanto en las portadas de los discos Hermética y Ácido argentino, estos agentes aparecen representados como como represores, al igual que sucede en las canciones.

Un ejemplo se observa en la canción "Sepulcro civil”, en los versos que dicen "Demorados contra el paredón, / controlados por el represor, / sometidos al circo de la tonta identidad, / para esconder el basurero nuclear", en donde se describe el padecimiento de los jóvenes frente al sistema policial. Lo mismo se puede ver en "Tú eres su seguridad", en la estrofa que dice "Por eso te vi escapando / en las horas sin sol, / de las miradas oscuras / que aprobaron las torturas del fugado represor".

Por otra parte, la canción "Del colimba" relata el pesar de los conscriptos del servicio militar obligatorio: 
Sirviendo a quienes eligieron aquí estar / mis metaleros sueños deben demorarse. / Estoy forzado a la militar instrucción, / y cantando trato de aguantar.

En un cuartel, / en un cuartel.

Fue por sorteo y no por propia voluntad / que me han rapado y separado de mis pares. /

Ser vigilante pareciera ser mejor. / Yo cantando trato de aguantar.

En la canción también se denuncia el abuso policial por parte de los superiores a los "colimbas". Al ver esta injusticia el "yo" lírico reflexiona: "ser vigilante pareciera ser mejor". En los últimos discos de la banda grabados en vivo del concierto realizado en el estadio Obras Sanitarias el 12 de noviembre de 1994, es posible ver una modificación en la letra. Esta es cantada por Iorio y a continuación de la frase anteriormente citada, agrega la aclaración “¡Pero no lo es!” (En “Del colimba”, 1995). Esta expresión posiblemente permitió reforzar la postura de la banda ante el caso de Omar Carrasco, asesinado en 1994 en el servicio militar de Zapala, Neuquén. Debido a este hecho, el 31 de agosto de ese año se suspendió la ley $N^{0} 3948$ que establecía el servicio militar obligatorio.

La oposición a la actividad militar también aparece en la canción "Desterrando a los oscurantistas", en la cual se describe: "Bendicen armas para la destrucción / usando en vano el nombre de Dios. / Guerra/ pre-fabricaron. / Muerte, / siguen sembrando. / Contra, / el amor fraterno. / Odio / ha generado". Además, en la portada de Ácido argentino los militares aparecen deteniendo a un hombre de manera violenta.

Entonces, la pluralidad ideológica de Hermética podría resumirse en una serie de sujetos que resultan antagónicos a la nación: los responsables de la colonización de América (España) y de la Guerra de Malvinas (Inglaterra y el gobierno argentino de facto), el imperialismo estadounidense propiciado por las políticas neoliberales y la Iglesia Católica, todos considerados como extranjeros y extraños dentro de la "verdadera" ("auténtica") identidad argentina y latinoamericana. Además, el sistema contra el cual hay que luchar está representado con la burguesía, la cultura de masas y la corrupción.

\section{Los nacionalismos de Ricardo Iorio}

Luego de la separación de Hermética, sus músicos formaron dos nuevas bandas: Malón y Almafuerte. Ambas continuaron desarrollando las temáticas que se habían iniciado con Hermética. A pesar de que para la escena este grupo es central, la figura de Iorio pasa ocupar el lugar principal dentro de la construcción de la identidad metálica 
bonaerense. Es por ello que considero necesario reconstruir sus fluctuaciones ideológicas para entender las maneras en que la audiencia no solo las recibió sino también resignificó.

Debido a que la principal preocupación en las creaciones de Iorio no solo parece ser la definición del metal sino también la referencia al contexto local de Argentina es posible encontrar gran cantidad de expresiones nacionalistas (tanto mediáticas como dentro de sus producciones), al mismo tiempo que la prensa lo acusa con dicho calificativo y el propio músico lo utiliza para identificarse.

Los modos en que se construye dicho nacionalismo no se desarrollaron de manera fija. Por el contrario, a lo largo de su carrera es posible ver que la ideología del músico y de sus creaciones ha ido variando con el tiempo. Para poder analizar el nacionalismo en Iorio, primeramente es necesario tener en cuenta que se puede ver en él una identificación con la nación Argentina, de manera que su ideología puede ser leída en términos de identidad. Tal como argumentan las dos premisas de Frith (1996) acerca de este concepto:

(...) primero, que la identidad es móvil, un proceso y no una cosa, un devenir y no un ser; segundo, que la mejor manera de entender nuestra experiencia de la música — de la composición musical y de la escucha musical - es verla como una experiencia de este yo en construcción. La música, como la identidad, es a la vez una interpretación y una historia, describe lo social en lo individual y lo individual en lo social, la mente en el cuerpo y el cuerpo en la mente; la identidad, como la música, es una cuestión de ética y estética. (Frith, 1996, p. 14. Cursivas del original)

Entonces la identidad "política" de Iorio se desarrolla de manera dinámica y temporaria (Hall, 1996), en constante reconstitución, implicada en una temporalidad social (Butler, 2009). Y, efectivamente, se puede observar una relación estrecha entre las expresiones ideológicas y su contexto sociopolítico de producción, en donde las primeras pueden ser consideradas como "lecturas" e "interpretaciones" subjetivas del segundo. Es decir, no se produce una reacción homológica o de "reflejo", sino que la música es utilizada por Iorio como un instrumento para la construcción de su identidad e ideología.

Para poder dar cuenta de las formas en que se presenta el nacionalismo en Iorio me referiré a cada una de sus bandas, las cuales desarrollan su actividad en diferentes momentos históricos con contexto sociopolíticos diferentes: 
V8: la dictadura y el regreso de la democracia

La primera banda del músico fue conformada en 1978 cuando él era un adolescente de 16 años de edad y duró hasta sus 25 . La misma se desarrolló en el contexto de la dictadura hasta 5 años después del regreso de la democracia. En esa época, Iorio formaba parte de los rockeros "metálicos" que se identificaban con la clase obrera, lo cual aparece representado en la canción "Muy cansado estoy" (1983). Además, poseía una postura muy fuerte contra el hippismo al que consideraba "careta" no solo por considerarlo como propio de las clases medias, sino también por calificarlo como "hipócrita".

Posiblemente uno de los sucesos que contribuyeron a su preocupación por "lo nacional" fue la Guerra de Malvinas sobre la cual cantó en el tema "Deseando destruir y matar”. Aquí se puede ver una perspectiva crítica hacia los gestores de la guerra (el gobierno de facto e Inglaterra) y en defensa de los combatientes. Sin embargo, la canción no expresa a dichos referentes de manera explícita, sino que se puede ver una letra con temática apocalíptica pero de retórica metafórica.

Más tarde, con la canción "El visitante" (1999) de Almafuerte se comprende que el apoyo de Iorio a los ex combatientes proviene, por un lado de una perspectiva nacionalista y, por el otro, de considerar a la guerra un engaño del gobierno de facto del cual las principales víctimas fueron los veteranos; además de empatizar con ellos por también haber sido parte de los jóvenes de esa generación que debieron combatir en dicho conflicto bélico.

\section{Hermética: entre los '80 y los '90}

Como describe de manera central esta tesis, Hermética constituye la banda principal dentro de la carrera de Iorio ya que no solo constituye el punto de unión de la audiencia metálica bonaerense sino también la que inaugura la preocupación por las temáticas vinculadas a lo local y lo nacional.

El contexto de desarrollo de esta banda es el país en democracia gobernado, en primer lugar, por Raúl Alfonsin y, luego, por Carlos Saúl Menem; en donde el primero se encargó de la recuperación democrática $\mathrm{y}$, el segundo, de palear la crisis hiperinflacionaria desarrollada durante el mandato del anterior a través del neoliberalismo. En ambos gobiernos la pobreza y la desocupación fueron las principales consecuencias. 
De todas formas, el contexto democrático permite que la banda pueda desarrollar líricas más explícitas, en donde la crítica social posee como referentes directos a Latinoamérica y principalmente a la Argentina. Tal como se vio en el apartado anterior, la reflexión sobre esos tópicos permitió el desarrollo de diferentes ideologías dentro de las cuales el nacionalismo era una de las principales.

Al considerar sus relaciones con el Folklore se observa que Iorio elige músicos vinculados al nacionalismo popular -como Larralde- o ideologías de izquierda. Este caso aparece con el cover del tema "Si se calla en cantor" de Horacio Guarany, el cual fue compuesto por el músico en la década de 1970 cuando estaba afiliado al partido comunista y dicha canción de protesta buscaba pronunciarse en contra de la censura que él mismo había sufrido.

Por otra parte, durante estos años, Iorio se continúa identificando con las clases trabajadoras, es decir, las más perjudicadas por el neoliberalismo, y se muestra crítico con aquellos actores que cree que "transan" con dicho sistema y con la cultura de masas. Además, debido a que las políticas de dicho contexto favorecían el ingreso al país de entretenimientos provenientes del extranjero (principalmente, Estados Unidos) y permitían ciertas formas de imperialismo cultural, Iorio se mostró reaccionario a través del desarrollo del localismo y el nacionalismo en sus creaciones.

\section{Almafuerte: entre 1995 y 2016}

Esta banda surge durante la segunda presidencia de Menem, en la cual se continúa desarrollando un gobierno neoliberal con una fuerte presencia del Fondo Monetario Internacional (FMI). Por lo que la impronta surgida en Hermética se mantiene vigente y es reforzada por su contexto de producción. Sin embargo, los años que duró la carrera de la agrupación musical fueron testigos de varios gobiernos de diferentes tipos. Pero, a pesar de ello, el nacionalismo permaneció como marca identitaria, más allá de las circunstancias contextuales del país.

A la par de Almafuerte, se desarrollaba Malón, la otra banda surgida a partir de la disolución de Hermética. En aquella también continúa la preocupación por otorgar rasgos locales a sus producciones por medio de la crítica social de su contexto. Solo por citar algunos ejemplos, en Malón es posible encontrar letras de canciones como "Revolución nacional"; otras de temática indigenista como "Grito de Pilagá"; y "30 mil plegarias", una canción dedicada a los desaparecidos de la dictadura. Al mismo tiempo, en el plano visual, persiste la temática aborigen junto con el uso de la imagen del escudo 
nacional argentino, y en la actividad del grupo se puede mencionar su participación en diversos eventos en defensa de los Derechos Humanos.

Por su parte, Iorio con Almafuerte se dedicó con énfasis a fusionar el metal con la cultura argentina mediante la creación del estilo "metal pesado argento", el cual se caracteriza por la utilización de algunos símbolos patrios y de géneros musicales como el tango y el Folklore; la creación de letras que tratan temáticas propiamente argentinas; y la realización de recitales para celebrar fechas patrias tales como las del 25 de mayo, el 9 de julio y el 1 de mayo por el día del trabajador.

En mi trabajo anterior (2012), propuse que las producciones de Almafuerte poseían una dimensión ideológica subyacente que se constituía como un "nacionalismo argentino de tendencia esencialista" (Calvo, 2014, p. 135). Sin embargo, solo se trata de una ideología predominante, ya que no es la que representa la totalidad de los discursos de la banda, debido a que pude detectar algunas contradicciones y expresiones confusas, en el sentido de que al mismo tiempo que se defiende a los pueblos originarios, los pobres, los trabajadores y las Madres de Plaza de Mayo, y se homenajea a folkloristas como José Larralde y Rubén Patagonia, también se celebran personajes antidemocráticos y fascistas y se critica a los militantes de izquierda.

Sobre este hecho paradójico, Semán, Vila y Benedetti (2011) consideran que "La aparente contradicción se supera si entendemos que tanto su apoyo a las Madres como su nacionalismo surgen de una matriz en la que el 'hogar' y la 'madre' son sagrados, y por lo tanto Madres y la nación son sus metáforas.” (Semán et al., 2011: 278), es decir que aquí predominarían valores del sistema patriarcal. Por otra parte, dichos ejes temáticos son recurrentes en el nacionalismo neocontestatario que caracteriza al rock chabón.

En efecto, una referencia a dicha asociación aparece con la intervención de los antiguos músicos de Hermética en los festejos de 1997 por los 20 años de existencia de la asociación. Allí Malón fue parte del festival de rock realizado en el estadio de Ferro y Iorio realizó un homenaje audiovisual citando una estrofa del Martín Fierro, más específicamente la misma que se incluyó en el tema "Vientos de poder".

Esta identificación del rock con las Madres de Plaza de Mayo puede ser leída como propia de una "izquierda romántica" (D’Addario citado en Provéndola, 2015, p. 172) que encuentra un punto en común en la actitud antipolicial y antimilitar. Otra similitud es la causa por los derechos humanos, un movimiento social que defiende la vida, lo que “(...) tiene amplios contactos con la ideología rockera” (Vila, 1985, p. 140). 
Por el contrario, en Almafuerte también aparecen algunas de las expresiones que podrían estar vinculadas al nacionalismo de derecha, las cuales parecen resguardarse mediante la temática del juego y el recurso de lo lúdico (Calvo, 2012), el que según Kahn-Harris (2007) es utilizado por los músicos que eligen la práctica de la "reflexividad anti-reflexiva" y manipulan su discurso para servirse de la polisemia y así mostrarse ingenuos frente a sus expresiones xenófobas y homofóbicas.

Este procedimiento fue utilizado por Iorio en Almafuerte para incluir algunas expresiones fascistas, las cuales parecen incrementarse en las declaraciones que realizó en varias entrevistas en diferentes oportunidades $y$ en distintos medios de comunicación, tanto en los especializados en metal y rock, como en los de interés general.

Con respecto al fascismo en dicha banda, es posible mencionar en primer lugar a la canción "Cumpliendo mi destino" del disco Piedra libre (2001). Allí se critica a Ernesto "Che" Guevara a través de los versos "Prefiero a José Larralde, / que al Che Guevara", comparación que solo haya sustento en las declaraciones del propio Iorio que afirma "Si yo no agarro un arma, yo agarro un instrumento" (Iorio para Pagina 12, en Torres, p. 210).

Esta crítica se puede vincular con los fundamentos ideológicos opuestos que poseían los jóvenes rockeros y los militantes en la década del ' 70 . De esta manera se puede entender que para el músico citado es mejor "defender” el país con la música y no mediante la lucha armada. De todas formas, más adelante, en la canción "Toro y Pampa" del disco homónimo (2006), aparece una clara crítica a la militancia de izquierda: "Hijos del brazo nunca torcido / de donde nace esa intención / tan tonta de andar / cheguevariando". En ambos casos, la postura de Iorio se muestra como anticomunista.

Retomando la canción "Cumpliendo mi destino" es posible encontrar una alusión a Mohamed Alí Seineldín, un militar golpista católico y ultranacionalista, que en ese momento estaba en prisión por haber participado de los alzamientos "carapintada" que intentaron derrocar el régimen democrático. Según el biógrafo de Iorio,

La alusión a Mohamed Alí Seineldín en "Cumpliendo mi destino", está en una frase atribuida a este militar que encabezó dos alzamientos entre 1988 y 1990, y que combatió en Malvinas en 1982: "Es más fácil encontrar un caballo verde que un judío honesto". (Torres, 2012, p. 218) 
La frase de Seineldín tenía un claro contenido antisemita, lo cual es un tópico fundamental dentro del nacionalismo (Lvovich, 2003). En la versión de Almafuerte, las frase es modificada: "Guardo de un hombre grande, / guerrero nacional que hoy tienen preso. / Puede haber caballo verde / más no uno de ellos honesto. / Y en ésta, mi canción, lo manifiesto." (Destacado propio) La inclusión de ella puede considerarse provocadora si se tiene en cuenta que, en el año 2000, Iorio fue denunciado por Víctor Ramos, entonces presidente de la INADI, por unas declaraciones realizadas durante una entrevista para la revista, Rolling Stone, que violaban la Ley Antidiscriminatoria 23592. Las palabras del músico fueron:

Yo creo que debe haber pocas personas que no sean judías que sepan tanto del judaísmo como yo. Y si hay algo que yo valorizo (sic) de mi Nación es el libre culto. El libre culto hace bien al orden social. Lo que pasa es que nos falta tiempo de desarrollo. Somos una sociedad que se independizó de España hace apenas doscientos años. Pero para nada estoy en contra de nadie. Estoy a favor de todos. Que prefiero a los pecadores antes que a los santos, sí. Pero es bueno que haya diversidad religiosa $-\mathrm{y}$ enseguida remarcó una frase de respuesta, y allí está lo que encendió la mecha-: Eso sí: si vos no sos judío, no me vengas a cantar el Hava Naguila en la fiesta judía. Y si vos sos judío, no me vengas a cantar el Himno, (...). Cada lechón en su teta es el modo de mamar. Lo que no me gusta es que a mi país traigan guerras intestinas de otros lares. Y eso se evita siendo argentino. Ojalá los políticos se dieran cuenta." (Iorio en Torres, 2007, p. 207)

En las declaraciones citadas se observa confusión entre nacionalidad, religiosidad y origen étnico. La resolución de este caso fue que Iorio fuera sobreseído. Por ello, posteriormente declaró en Página 12:

Yo pienso en función de la música y por eso me sentía satisfecho de que podía llegar a un medio como Rolling Stone, que es tan selectivo y tan concheto para la música. Y me encuentro que el día que salgo en la revista, después de una super-sesión de fotos y de siete veces que me hicieron la nota, con que (en el editorial) me generalizaban con el fascismo... Si yo no agarro un arma, yo agarro un instrumento. Nunca hice manifestaciones con respecto a eso, siempre hablo de otro tipo de cosas. A muchos les pega mal que uno se identifique como nacionalista. Yo considero que nacionalismo es conocer la nación, sentirse orgulloso del lugar donde uno encarnó y darse cuenta de que el objetivo de haber nacido acá es conocer, querer, difundir y proteger este lugar. No agarrar una bandera o ir a poner bombas, o a ir a la manifestación de Hebe de Bonafini, o ponerme una remera del Che Guevara. Eso no es nacionalismo." (Iorio para Pagina 12, en Torres, 2007, p. 210)

Las palabras de Iorio permiten deducir que las expresiones anticomunistas de sus canciones se realizan mediante la "reflexividad anti-reflexiva", haciendo que su discurso, a pesar de ser nacionalista, se desarrolle de manera fluctuante y no homogénea. Por otra parte, la crítica a Hebe de Bonafini, una de las Madres de Plaza de 
Mayo, parece contradictoria si se tiene en cuenta el apoyo que demostró Hermética y Iorio a dicha asociación.

Por su parte, la defensa del nacionalismo en la canción mencionada aparece como algo "no consiente" sino ligado al "sentimiento patriótico". Es por esto que la construcción ideológica se desarrolla de una manera difusa y poco concreta. Además, al defender a un militar golpista se presenta como contradictoria si se tiene en cuenta que Almafuerte también posee canciones tales como "Los delirios del defacto" (1996), la cual muestra una postura en contra de la dictadura.

A pesar de ello, el homenaje a Seineldin da cuenta de los primeros acercamientos explícitos de Iorio con la ultraderecha y con la línea nacionalista, "San Martín, Rosas, Perón”. Luego de cumplir dos condenas, el segundo alegato de Seineldín realizado el 7 de agosto de 1991 fue conocido como "El Nuevo Orden Mundial" en el cual afirmaba algunas teorías conspirativas mediante las cuales acusaba a Menem de ser servidor de las maquinaciones imperialistas del gobierno norteamericano. Dicho militar, además, soñaba con la instauración de una segunda República.

Por otra parte, las críticas realizadas en las producciones de Almafuerte que parecen poseer una perspectiva nacionalista se entremezclan con la retórica y la temática de lo lúdico, y con lo humorístico en el caso de los shows en vivo. De esta manera, pareciera que su postura política no tuviera un compromiso concreto, activo y "serio".

Con respecto a la causa judicial por sus declaraciones antisemitas, puedo afirmar que, al tomar como referencia mi memoria autobiográfica como método autoetnográfico y por medio de algunas entrevistas realizadas a varios "almafuerteros", en gran cantidad de recitales de Almafuerte, Iorio realizó chistes burlándose no solo de los judíos sino también de los homosexuales. Sin embargo, durante los años de Almafuerte, nunca se declaró de manera explícita como derechista o anticomunista.

Por el contrario, en las producciones de Almafuerte se pueden ver expresiones confusas y contradictorias. Las líneas nacionalistas que aparecen en la banda van desde el nativismo hasta el federalismo. Incluso se homenajean personajes como Juan Domingo Perón y Eva Duarte, aunque en su biografía se explica que Iorio no se autodefine como peronista:

Mi afinidad con Perón proviene más de las personas que escuchan mis canciones. Canté canciones dedicadas a Perón para dejar constancia en mi carrera de que yo no fui quién 
negó al gran benefactor de la nación. Y no hablo del Perón del 73, a quien recuerdo como un anciano manipulado, sino del anterior, del que me hablaron mis padres y mis abuelos. (Iorio en Torres, 2012, p. 118)

Posiblemente la no identificación con el peronismo se relacione con su contexto de producción: durante esos años, el primero estaba vinculado con el Partido Justicialista y, posteriormente, con el Frente Para la Victoria (Kirchnerismo). Por otra parte, el interés centrado en la figura de Perón es similar al del peronismo de derecha a partir de 1973, que se oponía a la "patria socialista" propuesta por el peronismo de izquierda.

Tal como explica Juan Luis Besoky (2016), en las publicaciones de los primeros "Solían ser frecuentes las referencias a la 'lealtad' y la 'ortodoxia' frente a la ‘infiltración' y el 'disfraz de peronistas' atribuido a la izquierda.” (Besoky, 2016, p. 204) De cierta forma, la postura del peronismo ortodoxo es comparable a la del fundamentalismo metálico en el sentido de que define y defiende al que considera como "verdadero" peronismo.

Sorpresivamente, en mayo del 2016, Almafuerte anuncia que durante ese año el conjunto no daría más conciertos y que se tomarían un tiempo de descanso. Esto es publicado en el Facebook oficial de la agrupación que era administrado por su manager, Marcelo Caputo, pero pronto dicha fanpage dejó de existir. En la etnografía que realicé en un concierto de la banda solista de Iorio en La Plata el 12 de noviembre de 2016, en el intervalo del show se pudo ver un anuncio que decía que Almafuerte no se había separado y que volvería al ruedo muy pronto.

Sin embargo, en varias entrevistas realizadas en el 2017 en programas radiales de Bahía Blanca y de Mendoza, Iorio ratificó que Almafuerte se había separado y que el principal problema había surgido con Caputo, quien había acordado una presentación de la banda en un show organizado por la Subsecretaría de Juventud de La Nación, conducida en ese entonces por La Cámpora, en septiembre del 2015. De acuerdo a lo relatado por la revista Rolling Stone (julio de 2016), Iorio se enteró el día anterior que el concierto tenía un trasfondo político, por lo que decidió cancelar su presentación. En dicha nota se explica:

(...) el 9 de mayo, en una entrevista para Radio El Sol, Iorio confirmó la versión: "Tuve una agarrada muy grande porque pareciera que los que están acompañándome a mí durante tantos años no advirtieran cuál es el sentido de mi fundamento. ¿Cómo me vas a mandar a tocar en La Noche de Los Lápices para Milagro Sala dos meses antes de que 
vengan las elecciones? Me pareció una reverenda patada, una manera de probarme hasta dónde los puedo aguantar", dijo. (Mancusi en Rolling Stone, 2016)

Pero al año siguiente en una entrevista realizada por la FM 96.3 de San Rafael, Mendoza, Iorio argumentó que el principal motivo de la disolución fue por cuestiones políticas y su total rechazo hacia el Kirchnerismo. En ese momento, muchos seguidores del músico creyeron que este apartamiento se debía a la negación característica del metal a la política partidaria. Sin embargo, más adelante, se vio que en realidad era por el choque con una ideología bien formada, la cual se vio con más claridad en las entrevistas radiales y, principalmente, televisivas.

A partir de sus apariciones en el programa televisivo "Mundo Casella", conducido por el periodista, "Beto" Casella", del 2010, 2011 y 2012, Iorio comenzó a convertirse en un personaje "mediático", es decir, conocido por mayor cantidad de gente que por estrictamente su público musical. Allí el músico comenzó a hablar más abiertamente de sus opiniones acerca de temáticas más generales y no solo las relativas a la música. Sin embargo, a la par de sus declaraciones, el cantante no dejó de utilizar el tono humorístico en sus discursos, por lo que gran parte del público creyó que algunas de sus afirmaciones eran parte del montaje de un "personaje".

Al realizar un análisis netnográfico de los videos de estas apariciones televisivas, incluidas las entrevistas del 2015 en el programa de televisión, "El ángel de la medianoche", conducido por Baby Echecopar (conocido por sus posturas clasistas, discriminatorias y misóginas), es posible ver cómo la opinión del músico se va modificando: fue posible detectar casos puntuales en donde una opinión parece contradecirse luego de algunos años, lo que va en aumento al tener en cuenta las producciones y las entrevistas anteriores a la época de Almafuerte.

Iorio solista: desde el 2017

En realidad, la carrera solista de Iorio comenzó de manera paralela a Almafuerte por medio de la grabación de tres discos de rock y metal y uno de tango. El primero fue Peso argento en 1997 realizado junto a Flavio Cianciarulo, en el cual no solo se incluyen temas compuestos por ambos músicos sino también covers de Hermética, Los Fabulosos Cadillacs y Hugo Giménez Agüero (referente del folklore patagónico). Además aparecen músicos invitados como el folklorista, Rubén Patagonia, y León Gieco. 
Luego, en 2005, grabó Ayer deseo, hoy realidad, un disco de covers del rock argentino con canciones de bandas como Color Humano, Almendra, El Reloj, Pappo's Blues, Roque Narvaja, Miguel Abuelo, entre otras. Es necesario mencionar que muchas de ellas habían sido criticadas por el músico durante los años de V8 y Hermética por medio del discurso de la autenticidad.

En 2014 fue grabado el disco Tangos y Milongas, dedicado enteramente a dichos géneros musicales, los cuales son considerados por Iorio como típicamente argentinos. De esta manera, la elección musical puede ser considerada nacionalista. En dicha producción se realizaron covers de músicos tales como Enrique Maciel, Héctor Pedro Blomberg, Enrique Santos Discépolo, Juan Miguel Rodríguez, Joaquín Mora y Héctor Marcó, entre otros.

Por último, grabó Atesorando en los cielos en 2015 en el cual, además de temas de su propia autoría, se realizaron covers de las bandas Budgie, Black Sabbath, Roxette, V8, Hermética y el músico, Mariano Mores. Las canciones que originalmente estaban compuestas en inglés, fueron interpretadas en español, lo que constituye una característica vinculada al nacionalismo ideológico.

Finalmente, en 2016, luego del intervalo de Almafuerte, Iorio presenta su banda solista compuesta por los hermanos Walter (batería) y Rubén Martínez (guitarra rítmica); Alejo (guitarra líder) y Facundo L. León (bajo); y Joana Gieco (teclados), hija del rockero y folklorista, León. Además de dicha formación, es asidua la presencia de Carina Alfie como guitarrista invitada. Dicha agrupación cuenta con su propio logotipo realizado con los mismos colores de la bandera argentina y presenta a su estilo musical como "metal pesado argentino" (diferente al "metal pesado argento" de Almafuerte).

El contexto de producción de esta nueva agrupación está dado por la presidencia de Mauricio Macri del partido político, Cambiemos, el cual asume en diciembre del 2015 a partir de la iniciativa de generar un "cambio" con respecto al gobierno anterior, basando sus argumentos y su campaña electoral en las acusaciones contra diversos funcionarios kirchneristas.

Ideológicamente dicho gobierno ha sido caracterizado como conservador y de derecha, lo que habilitó fuertes medidas represivas contra manifestaciones populares, entre las que se pueden mencionar las realizadas por los pueblos mapuches. Al mismo tiempo, se retoman políticas neoliberales, las cuales no solo se ven en la marcada presencia del FMI en la economía argentina, sino también en la composición 
gubernamental empresarial. Además, se produce una fuerte intervención del gobierno sobre los medios de comunicación.

Por otra parte, en 2015, como ya se mencionó, se gesta el movimiento "Ni una Menos", por lo que se comienza a desarrollar un fuerte activismo feminista en Argentina, el cual se encuentra en consonancia con la actividad mundial y la cuarta ola del feminismo. Además, se presenta una intensa polarización ideológica en la población y la opinión pública argentina, debido al accionar represivo del Estado y las consecuencias de las políticas económicas que generan inflación y aumento del índice de pobreza y desocupación.

Es en estos años que la transformación ideológica de Iorio llega a uno de sus puntos más polémicos, más específicamente en una entrevista realizada por César Fuentes Rodríguez el 10 de julio de 2017 para el programa de radio "Tiempos violentos", emitido por la FM Rock \& Pop y especializado en la música metal.

Allí, el músico expresa que esa era, para él, la "época de definirse”, porque ya no se consideraba un joven, sino un "hombre grande". Y, dentro de esas definiciones, se identifica como "ultranacionalista", "anti-montoneros", "anti-comunista", "anti-progre", "anti-neomarxistas". Y, como ejemplo que lo define, cita al libro de los escritores ultraconservadores y de la extrema derecha, Nicolás Márquez y Agustín Laje, que se titula El libro negro de la nueva izquierda. Ideología de género o subversión cultural (2016), el cual no solo critica duramente a las luchas feministas sino también al colectivo LGTIBQ ${ }^{127}$. De cierta manera, la idea de "definirse" en la historia de Iorio se puede interpretar como la acción de expresar de manera clara aquello que solo había sido demostrado de manera parcial y confusa.

El hecho de que la ideología de Iorio termina por definirse como consecuencia de su edad se puede ver en la declaración que dice:

\begin{abstract}
Estoy en desacuerdo con aquellos que dicen "un mundo sin fronteras, loco. No a la guerra". Yo creo diferente ahora que soy un hombre: Sí a la guerra, sí a armarse, sí a no pedirle piedad a un gorrita cumbia villera que venga a manosearte tu familia. Ama, ama, ¡a matar, negro! ¿A quién? Y morirán inocentes también. "Paredón y después" se llama esto. (Iorio, 2017 en "Tiempos violentos")
\end{abstract}

\footnotetext{
${ }^{127}$ En el año 2018, por fuera del período de esta investigación, en el marco del debate por la legalización del aborto, Iorio se manifestó en contra de dicha lucha, criticando de manera agresiva y misógina a las mujeres. Al mismo tiempo, muchos de sus seguidores expresaron de manera explícita su apoyo a Bandera Vecinal y Proyecto Segunda República, los cuales se autodefinían por medio de la postura "pro-vida" que rechazaba dicho proyecto de ley. A través de las redes sociales, dichos actores realizaron publicaciones e hicieron circular memes que criticaban al feminismo y a las mujeres por medio de discursos misóginos y discriminatorios.
} 
Esta postura es totalmente opuesta a la ideología anti-bélica que se puede leer en las producciones de Hermética. En esa entrevista el cantante además afirmó que

(...) eso de que este puñado de indemnizados, por desaparecidos, por destruir nuestra nación son superiores, no, loco. Están errados. Por eso mi look es un look botonazo. Porque prefiero a José Larralde que al Che Guevara. Prefiero a Aldo Rico que a Victoria Donda. (Iorio, 2017 en "Tiempos violentos")

Es necesario aclarar que Victoria Donda es la nieta recuperada número 78 gracias a la agrupación HIJOS y las Abuelas de Plaza de Mayo. Había sido apropiada por el ex prefecto Juan Antonio Azic y en el 2006 recuperó su verdadera identidad. Desde antes de esto, comenzó a ser activista por los derechos humanos. Luego, en 2007 fue elegida diputada nacional por la provincia de Buenos Aires, por el Frente para la Victoria. Además de ello posee una postura explícitamente feminista. Por lo que la figura de Aldo Rico es ideológicamente opuesta a la política mencionada.

El otro punto polémico en la carrera de Iorio transcurre a partir de una publicación en Facebook realizada por la Secretaría de Prensa de Bandera Vecinal el 18 de agosto de 2017, en donde aparecen varias fotos del músico en un café de la ciudad bonaerense de Luján, estrechando la mano y abrazando a Alejandro Biondini.

Este había formado parte de la Juventud Peronista y apoyado al peronismo de derecha. En 1990 se apartó del Partido Justicialista y creó el Partido Nacionalista de los Trabajadores (PNT) al que posteriormente quiso denominar "Partido NacionalSocialista de los Trabajadores" y adoptar la cruz esvástica como símbolo oficial. Mientras Biondini negó que esto intentara acercarse al nazismo, la Justicia Argentina no permitió esto debido a las similitudes con el partido alemán.

De esta manera, el nombre elegido fue Partido Nuevo Triunfo, el cual tomó como símbolo el número 7 (muy importante para los seguidores de Hitler) y una esvástica modificada, al mismo tiempo que adoptó estandartes y saludos propios del nazismo. Nuevamente la Justicia Electoral impidió el desarrollo de esta agrupación, ya que consideraba que trataba de emular un régimen que promovía el odio y la discriminación.

Tal como explica Dilton Cândido Santos Maynard (2013), dicho partido se caracterizaba por hacer apología del régimen autoritario al mismo tiempo que criticaba la democracia y defendía valores morales cristianos y el mayor accionar militar y 
policial contra el aborto y la homosexualidad, a la que acusaba de responsable de la drogadicción. Después de diversas estrategias por parte de Biondini para lograr reconocimiento oficial, en 2009 este fue negado definitivamente por la Corte Suprema, por lo que el PNT se disuelve.

En 1999 Biondini creó el portal de Internet "Ciudad Libertad de Opinión”, el cual se convirtió en "(...) el sitio web sudamericano de extrema derecha más conocido" (Santos Maynard, 2013). A pesar de ello y de la cercanía estética del Partido Nuevo Triunfo, el líder político nunca reconoció su adhesión al nazismo. Por el contrario, evadió dicha implicación expresando ser seguidor del peronismo de derecha y defensor del revisionismo histórico y de la línea "San Martín, Rosas, Perón”, negando ser antisemita ya que, según él, en realidad estaba en contra del sionismo y no del judaísmo. Estas operaciones discursivas son similares a las que Kahn-Harris denominó "reflexividad anti-reflexiva" en la escena metálica.

Finalmente, en 2014 logró crear el partido Bandera Vecinal a partir de la fusión de Gente en Acción y Alternativa Social, el cual adquierió personería jurídica. Ante esto, la DAIA intentó impugnar dicha determinación judicial pero le fue negada. De esta manera, en agosto de 2017, Biondini logró presentarse en las elecciones primarias como candidato a diputado nacional por la provincia de Buenos Aires, en las cuales obtuvo más de 28000 votos.

En octubre de ese año serían las elecciones generales, por lo que durante ese año Bandera Vecinal se encontraba en una fuerte actividad de campaña electoral. De esta manera, las fotografías entre Iorio y Biondini no escapaban de dicho contexto. Las imágenes mencionadas estaban acompañadas por la siguiente descripción:

El jueves 17 de agosto por la tarde, tuvo lugar en la Ciudad de Luján el encuentro entre los dos referentes emblemáticos del Patriotismo: Alejandro Biondini y Ricardo Iorio. El líder de Bandera Vecinal fue invitado por el gran cantautor y máxima figura del metal argentino a compartir una charla, que finalmente se extendió a lo largo de varias horas, durante la cual ambos intercambiaron y coincidieron en apreciaciones sobre la actualidad política, social y cultural, así como respecto de las perspectivas y desafíos que deberá afrontar nuestro país. Biondini le agradeció a Iorio su hospitalidad y lo felicitó por la extraordinaria e incansable labor que viene desarrollando en pos de la afirmación de los valores autóctonos y el nacionalismo cultural, especialmente como un ejemplo y arquetipo para las nuevas generaciones.

En dichas palabras, ambos personajes son valorados como "patriotas". Una consecuencia directa de dichas fotografías -además de las reacciones generadas en la propia escena metálica que más adelante se verán- fue la suspensión de la presentación 
de la banda solista de Iorio en el festival B.A.Rock por parte de la organización, presionada ante la amenaza de un escrache público al músico. Dicha noticia fue comunicada por la fanpage oficial del evento el 8 de octubre de 2017:

Debido a reclamos expresados por organismos no gubernamentales, otros a través de redes sociales, al respecto de la presentación de la banda Iorio en el festival B.A.ROCK, la producción del mismo ha creído que en esas circunstancias no parece indicada su actuación, tanto para resguardo del propio artista como del público en general. (Actualización de estado en Facebook, 8 de octubre de 2017 ${ }^{128}$ )

Es por esto que el cantante fue nuevamente entrevistado por Beto Casella en el programa "Bien levantado" emitido por FM Radio Pop, el 16 de octubre de 2017. Allí Iorio afirmó haber sido censurado y afirmó que quienes pidieron que se lo aparte de la cartelera del B.A.Rock fueron Juan Cabandié Alfonsin (dirigente político de La Cámpora y nieto restituido por las Abuelas de Plaza de Mayo, número 77), las Madres de Plaza de Mayo y la DAIA.

En dicho reportaje el músico demostró haberse equivocado y calificó a sus imágenes junto a Biondini como "una piedra de tropiezo". Además explicó que se fotografió con él tal como lo hace con cualquiera que se le acerca y dio a entender que el estar de acuerdo con algunas de sus ideas motivó la decisión de saludarlo. Sin embargo, aclaró que no estaba afiliado a Bandera Vecinal: "Yo no pertenezco a la 'partidocracia', yo soy un libre pensador. No adhiero a ningún partido político. Apoyo proyectos y necesito conocer a la gente que apoya la identidad nacional (...)" (Iorio en "Bien levantado", 16 de octubre de 2017).

Nuevamente se puede ver cómo Iorio se muestra ambivalente en sus expresiones políticas. En este caso, por ejemplo, reniega de su decisión de haberse fotografiado junto a un político vinculado al filonazismo, pero sin embargo a lo largo de las entrevistas realizadas en "Mundo Casella" se refirió de manera discriminatoria a los cumbieros, aclaró estar en contra del sionismo y nombró de forma peyorativa a los chinos y a los peruanos. A la par, intentó disimular la xenofobia de sus dichos aludiendo a su amistad con personas de nacionalidad paraguaya, exhaltando a los bolivianos por ser "trabajadores" y negando haber hablado mal de la comunidad judía.

También se puede citar el ejemplo del 15 de agosto de 2016 en donde el periodista, Adrián Salbuchi, en un programa televisivo de la cadena TLV1, comenta que

\footnotetext{
${ }^{128}$ Recuperado de: https://www.facebook.com/barockar/posts/comunicadodebido-a-reclamos-expresadospor-organismos-no-gubernamentales-otros-a/345686519175984/
} 
en una conversación con Iorio, el músico le informó que había decidido cambiar la letra de la canción "La revancha de América" de Hermética, porque estaba siendo utilizada por la Resistencia Ancestral Mapuche (RAM) como acompañamiento de su reclamo político.

Ante esto, según el periodista, la nueva letra contendría la frase "Nuestros enemigos han generado falsos nativos que se han aliado con los siervos de la bestia disfrazados de mapuches". Esta decisión continúa la línea de la declaración realizada en el reportaje realizado por Baby Echecopar en 2015, en donde afirma que los mapuches son un grupo financiado por una ONG que tiene su sede en Bristol, Inglaterra.

Dicho presupuesto proviene de la teoría de la existencia de una conspiración judía para ocupar la Patagonia mediante el "Plan andinia" (Boholavsky, 2009), la cual se reactualizó en Argentina entre los años 2015 y 2016 a partir del accionar de la RAM y la represión que sufrió esta comunidad por parte de la gendarmería nacional, teniendo como resultado la desaparición y muerte del artesano anarquista, Santiago Maldonado, y el asesinato del joven mapuche, Rafael Nahuel.

Luego de dichas declaraciones, en el reportaje realizado por Beto Casella en 2017, Iorio afirmó que "A los mapuches los queremos. ¡Si son argentinos, hermano!” (Iorio, 2017), por lo que nuevamente su postura se ve como confusa y contradictoria. En contraposición a ello, se pueden ver definiciones más claras en su canal de YouTube, "Iorio Channel”, creado el 9 de mayo de 2016 y auspiciado por la Asociación Sindical de Motociclistas, Mensajeros y Servicios (ASiMM), y en las publicaciones de la fanpage de la nueva banda solista del cantante, la cual debuta el 20 de agosto de 2016.

En dicho canal de YouTube se puede ver que todos los videos publicados finalizan con las imágenes de las banderas de la Confederación Argentina y de la República Argentina -que incluye al Sol de Mayo o Sol Incaico-; de Perón y Evita; y de las islas Malvinas coloreadas con la bandera de Argentina y la inscripción “Argentinas!!”. Luego de dichas ilustraciones, aparece el logotipo de la AsiMM, agrupación que colabora con Iorio para cargar el material en dicha plataforma virtual.

Estas imágenes están acompañadas musicalmente por la introducción de la canción homónima de la banda Almafuerte, en la cual el cantante inicia con la frase “Con lo que digo voy”. Para Juan Ignacio Pisano (2016)

Ese sintagma, esa unidad mínima del discurso, encierra un elemento central de la lírica de Iorio: en el decir, en la palabra, se expone el núcleo ético de este autor como 
exposición del sujeto frente al mundo. Esa palabra escrita para ser cantada se presenta como arma y como escudo, como apertura y repliegue. (Pisano, 2016, p. 93)

En este caso, la frase es extraída de la canción ya que solo se reproduce este fragmento. Además, deja de ser solo palabras, ya que se la acompaña visualmente con las imágenes ya mencionadas, las cuales parecen reivindicar ideológicamente al rosismo, al peronismo y la soberanía de Argentina sobre las islas Malvinas, lo que se condice con la defensa y homenaje que ha realizado el músico a los ex combatientes.

Uno de los componentes importantes de los videos que aparecen en el canal está constituido por las apariciones de Iorio frente a cámara, en donde no solo cobra relevancia lo que dice, sino también la imagen que construye. En cuanto a la vestimenta, se puede decir que el músico trata de mezclar el estilo metálico/rockero con sus improntas ideológicas. De esta manera, además de mostrarse con su característico peinado de cresta, utiliza remeras negras o de la banda de punk rock, Jauría, y un colgante con una cruz cristiana con el formato de las que caracterizan a la agrupación, Black Sabbath.

Además de esto, se lo puede ver llevando abrigos tales como una campera con estampado de camuflaje; un tapado estilo militar (similar a la chaqueta que utiliza en los shows en vivo de su banda solista); un chaleco con el escudo de la CGT; y un chaleco con imágenes bordadas del suri o ñandú, tal como lo representaba la comunidad originaria de los Kilmes. Estos looks tienen como antecedentes la vestimenta que Iorio solía utilizar en los recitales de Almafuerte: en un primer momento, usaba un mameluco similar al de los obreros metalúrgicos y posteriormente lo cambió por uno igual al que utilizaban los militares de la Fuerza Área durante la guerra de Malvinas.

En cuanto a las imágenes de fondo, se puede observar que la mayoría de los videos son grabados en el campo, al aire libre (posiblemente, en la casa del músico), excepto un caso en el que Iorio dice haber improvisado una fachada para el video, en la cual se puede ver una mesa cubierta con un mantel que posee una guarda con la cruz andina y, sobre ella, un busto de Juan Manuel de Rosas, cuadros de San Martín y de Rosas, y un portarretrato familiar. Además, acompañan esto dos guitarras criollas, una bandera argentina y un cuadro con dibujos pertenecientes a alguna comunidad aborigen.

Con respecto a los videos que aparecen en el canal, se puede observar un claro apoyo del músico al Proyecto Segunda República (PSR), un movimiento político ultranacionalista, liderado por el periodista ya mencionado, Adrian Salbuchi, quien fue 
acusado de antisemita y, al mismo tiempo, fue elogiado por teóricos de la conspiración antisemita y líderes políticos fascistas. Esto se ve en los videos que muestran fragmentos de algunos programas transmitidos por TLV1, un canal televisivo alternativo de tendencia ultranacionalista, creado por el Juan Manuel Soaje Pinto, también acusado de fascista.

El apoyo al proyecto político se hizo más visible el 13 de mayo de 2017 en el recital de la banda solista del músico en Temperley, en el cual algunos integrantes del PSR repartieron volantes con información sobre dicho movimiento político. En el grupo de Facebook, IORIO_oficial, uno de los integrantes de dicha agrupación publicó una fotografía en donde se veía a algunos de los miembros del PSR vistiendo remeras con su logotipo, junto una leyenda que decía

Gracias a Ricardo, Julia y su equipo, por dejarnos repartir volantes. Gracias a los seguidores de Ricardo por el respeto. Los que quieren ponerse la Patria al hombro y emprender esta lucha contra los enemigos de la Humanidad, están más que invitados a unirse a la manada. Los esperamos!!! [sic] (Publicación de Facebook en el grupo IORIO_Oficial. 4 de mayo de 2017)

Dicha descripción de la alteridad como "enemiga" resulta similar a la línea metálica fundamentalista de los fanzines que proponen "pelear contra el mundo".

Uno de los videos de TLV1 que aparecen en Iorio Channel está constituido por un fragmento del programa del PSR, conducido por el propio Salbuchi, que explica que dicho proyecto se declara americanista y nacionalista, ya que su intención es luchar por recuperar el continentalismo para poder enfrentar a los "caballos de Troya", es decir, los enemigos externos de la nación, constituidos por "el dinero, la usura, los gerentes generales y CEOS, los narcotraficantes, subdirigentes políticos, jueces, legisladores y comunicadores", los cuales son "enemigos de los pueblos trabajadores" (Salbuchi en Iorio Channel, "\#Bicentenario", 8 de julio de 2016).

También aparecen fragmentos de una entrevista realizada por Soaje Pinto al profesor de historia, Héctor Maccione, académico del Instituto Nacional de Investigaciones Históricas Eva Perón, quien anteriormente había sido delegado del partido político derechista, Nueva Fuerza, y había demostrado su apoyo a Francisco Franco, el dictador español. En los fragmentos de la entrevista mencionada, Maccione destaca el origen militar de Perón, propone al peronismo como la "tercera posición" entre la izquierda y la derecha, y explica que la diferencia entre Movimiento Nacional 
Justicialista y el Partido Justicialista es que el segundo es carente de la doctrina peronista, por lo que lo califica como una "cáscara vacía".

Lo videos de Maccione aparecen presentados con expresiones tales como el hashtag \#ConElCantoNoMeAlcanza. Lo mismo sucede con los videos titulados "La educación progre [Premiando la mediocridad]" (un corto que, a través de la parodia, critica ideas tales como la tolerancia, la multiculturalidad y la igualdad de género) y "El ángel de Matías [En memoria de Gerónimo Venegas]".

Este último es un recitado del payador gauchesco, Pampa Cruz, que homenajea al sindicalista de la Unión de Trabajadores Rurales y Estibadores, "Momo" Venegas, quien ideológicamente seguía al peronismo de derecha. Además, se había enfrentado a Cristina Kirchner en el conflicto con el campo en el 2008, apartándose de la CGT y defendiendo a los grandes productores rurales. Más tarde se constituyó en el primer sindicalista en generar una alianza con el macrismo.

La frase "Con el canto no me alcanza" aparece como presentación de videos que, en todos los casos, contienen un fuerte y explícito contenido ideológico y político. A través de ella, Iorio le otorga un nuevo significado a sus producciones, ya que de esta manera da cuenta de que, entonces, su intención había sido demostrar su ideología a través de sus producciones y realizar creaciones artísticas ya no le resulta suficiente para expresarse.

Por último, además de apoyar al PSR, se puede observar en Iorio Channel que el músico también lo hace con la CGT. Esto se ve a través de las entrevistas radiales y en los videos en los que interactúa con Federico Addisini, un pensador perteneciente al revisionismo histórico, que es miembro del Instituto de Investigaciones Históricas Juan Manuel de Rosas, Director de Cultura de la Fundación Rucci de la CGT y autor del libro San Martín, Rosas, Perón. Un Homenaje a Fermín Chávez (2008). Además, fue Addisi quien entrevistó a Iorio en el marco de la charla "Nacionalismo Cultural: Cultura Popular vs. Cultura de Masas”, realizada en el Salón Felipe Vallese de la CGT en abril de 2016.

La conexión con dicho historiador revisionista se puede trazar a partir de las declaraciones del músico en la entrevista televisiva realizada por Beto Casella en 2011, en donde Iorio afirma reinvindicar la línea San Martín, Rosas, Perón. De acuerdo a Michael Goebel (2003), esta parece haber sido reafirmada en su libro Los vendepatria (1958) por el propio Perón, quien agrega su figura a la histórica línea San Martín-Rosas 
que se oponía a la de Mayo-Caseros, propuesta por el General Pedro Eugenio Aramburu, quien derrocó a Perón a través de un gobierno de facto en 1955.

Con todo esto, se puede decir que la ideología política de Iorio se caracteriza por ser dinámica, ya que el músico dice y algunas veces también se “desdice”. Empero, es posible afirmar que se trata de una ideología nacionalista, aunque no se encasilla en una única vertiente. En la mayoría de los casos, el cantante huye de los calificativos y prefiere construir su identidad mediante el apoyo a determinadas personas y agrupaciones. A pesar de que fue notoria su afirmación política de manera explícita a partir de 2017, aún continúa utilizando el procedimiento de la "reflexividad antireflexiva".

No obstante, Iorio en gran cantidad de oportunidades ha dado cuenta de formas ideológicas ligadas a la derecha. Pero, tal como expresa Echeverría (2017)

Es necesario entender que las derechas fueron - y son - colectivos amplios, diversos y dinámicos que están siempre construyendo y reconstruyendo su identidad en una relación dialógica conflictiva con su entorno y con otras fuerzas políticas e ideológicas. Por lo tanto, no se puede dar un sentido absoluto al concepto, sino considerarlo en su relatividad histórica e interpretarlo como actitudes de fondo, como intenciones, y una cosmovisión compartida. (Echeverría, 2017)

A continuación analizaré cómo repercutieron en la escena los puntos polémicos de la carrera del músico mencionado.

\section{La fractura ideológica de la escena metálica bonaerense}

Una de mis principales observaciones en esta investigación es el claro quiebre en la escena metálica bonaerense a partir de la entrevista que le realizó César Fuentes a Iorio en 2017 y de las fotografías de este con Biondini. Como ya mencioné, el estilo musical que constituye dicha escena se caracteriza por demostrar predominantemente una ideología apolítica, en donde la música se presenta de una manera ideal en la cual no se "mezcla" con lo político, al menos de manera explícita.

Sin embargo, dicho presupuesto parece romperse ante la necesidad de Iorio por definirse políticamente. Como consecuencia, los participantes de la escena adquirieron la misma actitud y comenzaron a expresar de manera más explícita su ideología política y el vínculo de esta con la música que les gusta, por lo que fue posible ver franjas que apoyaron al músico incondicionalmente y otras que hicieron todo lo posible para alejarse de su identificación. 
Pero, previamente a esto, pude observar casos de músicos, aficionados y mediadores que ya habían dado cuenta de su ideología política. Los ejemplos más evidentes aparecen con los conjuntos de las corrientes opuestas: el Black Metal Rojo y Anarquista (entre los que se encuentran Bolchevikes y, el ya mencionado, Profecium; los cuales se caracterizan como antifascistas) y el Black Metal Nacional Socialista.

A través de la netnografía realizada en la página "Enciclopedia Metallum. The metal archives”, encontré varias bandas pertenecientes a esta línea: VII Batallón de la muerte, Argenfaust, Uriburu, Aesir, Eaglenest y Pagancult. La mayoría de estas editaron sus discos a través de los sellos discográficos, Argenreich Records y Winter Solace Productions, especializados en dicho subestilo musical.

Las bandas mencionadas se autoidentifican como fascistas, nacional-socialistas o por reivindicar la supremacía blanca. Algunas, en sus nombres y en sus letras, hacen referencia a la cultura nórdica (como Aesir, concepto que refiere al panteón de dioses nórdicos) y a la Historia argentina (por ejemplo Uriburu, nombre que homenajea al dictador argentino, José Félix Uriburu, primer presidente de facto de la Argentina contemporánea y de clara tendencia filofascista).

También relevé bandas que parecen haber estado interesadas en seguir la corriente nacionalista de Hermética y en sus creaciones dieron cuenta de ello: por ejemplo, el grupo porteño, Güemes, cuyo nombre se refiere al General Martín Miguel de Güemes, militar salteño que colaboró con la independencia del Virreinato del Río de La Plata. Este grupo editó un disco en 2017 titulado Güemes y los infernales, nombre que llevaba la División Infernal de Gauchos de Línea, un ejército gaucho creado por Güemes. Dicho nombre no solo hace referencia a un elemento de la Historia argentina, sino también al carácter esotérico del metal mediante el adjetivo "infernales".

Otra banda que se puede mencionar es Rotas Cadenas de Tres Arroyos, la que en la foto de perfil de su fanpage de Facebook tiene una imagen de su propia creación. Se trata de un escudo argentino modificado (Ver figura 37). Sobre ello tuve la oportunidad de dialogar con tres de sus integrantes en una entrevista:

Yo: Vi que en Facebook tienen una imagen de perfil que es un escudo argentino modificado

1: Lo hice yo.

Yo: Contame, cómo lo imaginaste, qué significa, por qué lo eligieron...

2: Tiene la bandera de Artigas, ¿no?

1: Y... tiene muchas cosas. Va conmigo. Mi ideología política, digamos, es...

Yo: ¿Y es la ideología de la banda también? 
2: Obviamente...

3: Sí, también.

Yo: ¿Cuál sería su ideología política?

1: Por ejemplo en el escudo, es como el escudo argentino, pero las manos están con otro saludo. Saludo más amistoso. Las manos son más oscuras, no blancas. Está el Chaltén de fondo. Hay un cóndor, abajo la bandera de Artigas, que es como la de Entre Ríos, que simboliza el federalismo, Artigas. Para mí, el prócer más grande de Argentina es Artigas...

2: Es uruguayo

1: Ni San Martín... Ah, es de la Banda Oriental. La uva, hay dos banderines: un banderín negro y uno rojo. El rojo significa el socialismo con la actividad y el negro simboliza la libertad.

Yo: Y luego vi que está el escudo nativo, ¿no? ¿De qué comunidad?

Todos: Está el cultrún ${ }^{129}$.

Yo: ¿Y ese qué significa para ustedes?

2: Es un instrumento.

1: Para dar cuenta que también esas comunidades antiguas son el origen, digamos... un problema grande de Argentina es la falta de identidad nacional. Nos identifican desde la escuela como que somos descendientes de los inmigrantes y la mayoría del país el origen racial es autóctono, y eso se oculta. Es para demostrar también que somos un país polinacional, muchas naciones lo componen.

"Rotas cadenas", además, es un fragmento del himno nacional argentino, por lo que se observa cómo dicha banda resignifica dos símbolos patrios (el escudo y el himno). De manera similar se puede citar a la agrupación porteña de death and roll, Avernal, que en su disco Réquiem para los rebeldes/Necrología Parte 1 (2011) dedica canciones a los militares argentinos, Juan Lavalle y Manuel Dorrego. Tanto en estos casos, como con Güemes y Uriburu es posible ver cómo se utiliza la figura de algunos referentes de la Historia argentina, no solo para dar cuenta de la proveniencia local de los conjuntos, sino también para demostrar su acercamiento a ciertas ideologías políticas.

Otro ejemplo acerca de la ideología nacionalista en la escena lo encontré a través de la netnografía realizada en YouTube. Allí aparece un video del recital de la banda británica, Iron Maiden, en el estadio Vélez Sarsfield en el 2001, en el cual la audiencia comenzó a abuchear y a cantar “¡El que no salta es un inglés!”-cántico surgido en las manifestaciones populares durante la Guerra de Malvinas y posteriormente trasladado al rock- luego de que el cantante, Bruce Dickinson, flamee una bandera de Gran Bretaña durante el tema, “The Trooper", en cuya letra se describe la Guerra de Crimea de 1854 a través de la perspectiva de un soldado británico ${ }^{130}$.

\footnotetext{
${ }^{129}$ El cultrún es un instrumento musical de percusión característico de la comunidad mapuche. Sobre él se suele pintar la imagen del Meli Witran Mapu ("tierra de los cuatro lugares"), la cual define la cosmovisión de dicho pueblo aborigen y representa a la tierra y sus cuatro puntos cardinales.

${ }^{130}$ Dicho suceso se puede ver en el siguiente link: https://www.youtube.com/watch?v=UNFqwbq 7LQ
} 
Más tarde, en el año 2016 en su visita nuevamente a Buenos Aires, Steve Harris, bajista y líder de dicha banda utilizó una remera de la selección argentina de fútbol durante uno de los temas musicales. Posteriormente, Dickinson introdujo el tema "Bloodbrothers" ("Hermanos de sangre") diciendo que siendo inglés se consideraba "amigo" de Argentina y no le gustaban las "estupideces", refriéndose al enfrentamiento entre países. La canción que seguía acentuaba el carácter de "hermandad" no solo entre "metaleros" sino también entre sus naciones de origen. Ambos sucesos resultan importantes ya que Iron Maiden es uno de los conjuntos metálicos extranjeros que en Argentina poseen más convocatoria.

Al utilizar mi memoria autoetnográfica puedo decir que el cántico mencionado era muy escuchado en el público en los conciertos de Almafuerte. Sin embargo, a través de la netnografía pude observar que, durante su presentación en el festival Pepsi Music del año 2007 en el Estadio Obras Sanitarias, Iorio reprendió a la audiencia diciéndoles:

¿Qué están diciendo, loco? ¿Cantan "el que no salta es un inglés" y después van a ver a Motörhead o Iron Maiden? ¡Tenés la remera de Iron Maiden, pelotudo! ¿Qué están diciendo? ¿Son pelotudos? Allá hay gente tan buena como acá. Lo que pasa es que no nos dejan conocerla. Si las naciones dejasen conocerse a toda la gente buena de cada país no sería este infierno en el que vivimos. (Iorio en Pepsi Music, 2007) ${ }^{131}$

Otro modo en que la audiencia metálica dialoga con el nacionalismo propuesto por Iorio es a través de la asistencia a conciertos de José Larralde por parte de aficionados al metal. De acuerdo a Pablo Vila (1997), la adhesión de estos a las producciones del folklorista provienen de una identificación no tanto musical sino más bien con respecto a su posición en contra de los grandes circuitos comerciales y del sistema neoliberal de los '90, postura que es valorada como moralmente buena de acuerdo a la autenticidad metálica.

No obstante, la música que produce Larralde constituye un género musical representativo de la Argentina y que Iorio valora como autóctono. Lo mismo sucede con el vínculo artístico entre Iorio y el acordeonista misionero, Chango Spasiuk. Ambos se presentaron juntos en el Festival Nuestro, realizado en Tecnópolis en 2017. Allí el folklorista presentó al músico metálico como el "Yupanqui urbano" (comparándolo con Atahualpa).

También se puede observar la presencia de nacionalismo en las banderas argentinas que suelen llevar algunos aficionados a recitales de Malón, Almafuerte y

\footnotetext{
${ }^{131}$ Esto se puede observar en el siguiente link: https://www.youtube.com/watch?v=C9afD-vu5KM
} 
Iorio. Muchas veces, dicho símbolo patrio es utilizado de la misma manera que se lo hace en el "rock chabón" (Salerno y Silba, 2005). Es decir que sobre el paño se pinta el nombre de la zona, el barrio o la localidad a la que pertenecen los portadores de la bandera y a veces se incluyen nombres de algunas bandas, los cuales suelen ser los de Hermética y V8 (Ver Figura 38)

Además del nacionalismo, se observa en la escena bonaerense una fuerte presencia de indigenismo, el cual parece caracterizarse como una tradición dentro del metal argentino. En dicha escena, hay gran cantidad de conjuntos que poseen nombres de comunidades originarias o que utilizan la lengua de dichos pueblos para titular a sus canciones, al mismo tiempo que dedican canciones a esta temática o usan representaciones icónicas de los aborígenes. Entre estas bandas se pueden mencionar Malón ${ }^{132}$, Yanaconas ${ }^{133}$, Almafuerte, Tren Loco, Devastación, El Dragón, Raza Truncka, Mun Ra, L6b6t6my y No Guerra.

Pero la postura indigenista no solo se localiza en las producciones de las agrupaciones, sino también en la organización de eventos. Un ejemplo es el del festival que se realizó el 29 de julio de 2016 en Tandil y que tuvo como figuras principales a Rubén Patagonia, un músico folklórico y actor argentino de origen tehuelche que además es activista por la causa de los pueblos originarios patagónicos, junto a Claudio "Tano" Marciello, ex guitarrista de Almafuerte. A pesar de que Patagonia es un folklorista, la producción del evento decidió que las bandas soportes sean en su totalidad rockeras y metálicas. De hecho, el cantante abrió su presentación diciendo que su intención era romper las barreras entre el rock y "esta música" (refiriéndose a la propia).

Esta conjunción también se podía observar en el público, en donde no solo se veían adultos (algunos de ellos con atuendo rural), sino también a jóvenes que lucían vestimenta metálica y rockera. A pesar de ello, se pudo ver que la audiencia caracterizada de manera diferente al atuendo folklórico, también cantaba y alentaba las canciones de Patagonia, las que posiblemente conocieran gracias al acercamiento

\footnotetext{
132 Según Mandrini (1987; 1993) los malones eran ataques indígenas frente a los '(...) abusos o agresiones de los cristianos' (1993, p.31), y también una empresa económica de saqueo de ganado para su posterior comercialización.

${ }^{133}$ Yanaconas era una forma de servidumbre en la sociedad incaica (Basadre, 1989, p. 193).
} 
musical de Iorio a dicho $\operatorname{artista~}^{134}$. Al mismo tiempo que algunos temas del repertorio pertenecían al disco Peso argento (1997).

Sin embargo, en un momento se hizo evidente que posiblemente la audiencia que no era aficionada al folklore haya asistido principalmente por estar interesada en la actuación del "Tano" Marciello, ya que además de ser ovacionado, en un momento un joven del público le pidió que toque la guitarra eléctrica y no solo la criolla, algo que no sucedió en toda la noche. Además, varios le reclamaron que ejecute algunos temas instrumentales de Almafuerte.

En dicho concierto pude ver que muchos "metaleros" y rockeros mostraban aprobación frente a los dichos de Patagonia sobre la lucha de los pueblos originarios, pero también observé la importancia que tenía para ellos el estilo musical, ya que las canciones más aplaudidas eran aquellas que habían conocido a través de Iorio y Almafuerte.

Otra línea ideológica que se mantiene en la escena metálica bonaerense desde la década de los '80 y que también se desarrolló en Hermética corresponde a la defensa de los Derechos Humanos y la oposición a la dictadura. Una muestra de ello está en el “Festival Nunca Más", organizado y autogestionado totalmente por bandas metálicas, anualmente todos los 24 de marzo, día de la memoria por la verdad y la justicia. Allí participan conjuntos de diferentes estilos de metal y en el año 2017 se realizó el evento por décima vez.

Con respecto a la política partidaria, dentro de los participantes de mi trabajo de campo realizado en la escena metálica bonaerense, encontré "metaleros" que eran militantes de partidos y agrupaciones de ideologías diferentes e incompatibles tales como el Frente de Izquierda, La Cámpora, Bandera Vecinal y organizaciones anarquistas.

Además, observé varios seguidores de Almafuerte y Iorio que también lo eran de la banda de rock, La Renga, la que no solo homenajea al Che Guevara sino que también expresó abiertamente su apoyo al Kirchnerismo. Mientras que otros realizaban comentarios nacionalistas en apoyo a los ex combatientes de Malvinas. Asimismo, algunos que adhieren a ideologías de izquierda se identifican con la figura del militante,

\footnotetext{
${ }^{134}$ La banda Almafuerte grabó el tema "Rubén Patagonia" en el disco Del entorno (1996) y a partir de ello se produjo una relación de amistad entre los músicos metaleros y el folklorista, el cual no solo fue convocado a participar en diversos shows de Almafuerte sino que también participó interpretando el tema "Cacique Yatel" de Hugo Giménez Agüero, en el disco Peso argento (1997). Además, en 1998 Patagonia grabó el disco Cutral-Có, el cual fue producido por el líder de Almafuerte.
} 
Darío Santillán, que al momento de su asesinato el 26 de junio de 2002 llevaba puesta una remera con el logotipo de Hermética.

Pero además de estos ejemplos que funcionan como antecedente, encontré una fractura visible a partir del accionar polémico de Iorio, el cual generó posturas a favor y en contra, las cuales no solo consistieron en simples opiniones sino también en publicaciones y hechos concretos, sobre todo de aquellos que se oponían a la ideología política a la que parecía alinearse Iorio.

Los ejemplos más concretos de las posturas en contra aparecen en el ambiente académico o intelectual de la escena metálica. Entre ellas se pueden mencionar el posteo colectivo del GIIHMA el 13 de julio de 2017 en su fanpage de Facebook y varios ensayos publicados por el EIESHM. En el primer caso, los integrantes de dicho grupo académico expresaron que

Como grupo de investigación que asume sus propias especificidades, hemos dejado de lado la actuación pública de los artistas que hacen e hicieron la historia del heavy metal argentino. Incluso hemos defendido, tanto en nuestros textos como en medios de comunicación, la importancia de Ricardo Iorio para la historia de la música argentina frente a aquellos que lo definían únicamente a través de sus apariciones televisivas. (...)No obstante, la reciente entrevista que Iorio brindó a "Tiempos Violentos", el programa de César Fuentes Rodríguez que se emite por Rock \& Pop, nos convoca a romper, por primera vez, el silencio en relación a ese más allá de la obra e intervenir con algunas breves reflexiones. Para decirlo sin ambages: repudiamos los dichos de Iorio respecto del pasado de nuestro país ya que sostenemos que no hubo guerra y no adherimos a la teoría de los dos demonios; así como también nos oponemos a su postura política en relación al presente, que justifica el fascismo al optar por figuras políticas que alguna vez se pintaron la cara para atentar contra un gobierno democrático desde un cuartel. (GIIHMA, Actualización de estado de Facebook, 2017 julio $13^{135}$ )

Uno de los miembros de este grupo publicó un artículo periodístico el 16 de septiembre de 2017 en la revista digital autogestiva, Nan, en donde se posiciona como "metalero" y da cuenta de los sentimientos causados por la foto de Iorio con Biondini al compararla con las producciones del músico:

Todas esas ideas imbuidas de un sincero amor a "lo local" que, nadie niega, regalaron una serie de himnos a una juventud (la nuestra) sumida en la noche del neoliberalismo. Por eso duele este gesto - porque después de todo no es más que eso, un gestogrosero de fotografiarse con un ser que, por principios, se encuentra parado en las antípodas de todos nuestros "himnos". Por eso, esta "nueva" veta nacionalista causa tanto escozor. (...) Porque representa todo lo que el metal no representa. Porque es

\footnotetext{
135 Recuperado de; https://www.facebook.com/giihmargentino/posts/como-grupo-deinvestigaci\%C3\%B3n-que-asume-sus-propias-especificidades-hemos-dejado-d/673467266182248/
} 
incompatible con lo escrito y popularizado (con aristas, con particularidades) durante los últimos 30 años. (Minore, 2017)

En este caso, el autor demuestra el dolor que le produce la decisión tomada por uno de sus ídolos, al mismo tiempo que considera que el metal no se vincula con las ideologías políticas de derecha. Sobre este sentimiento Germán Palkowski (2017) del EIESHM expresa:

\footnotetext{
Sincerémonos: no es novedad. La foto con el neonazi Biondini reconfirma intuiciones que apenas queríamos ya soslayar o preferíamos dejar en suspenso. "Para adentro", como quien dice.

Otra vez debate; otra vez pronunciamientos; otra vez justificaciones, cuando no una búsqueda frenética de atenuantes: que la falopa, que está quemado, que es una jugada de prensa.

Ahora bien, ¿y si resulta que el tipo finalmente dejó ese coqueteo histérico con un ideario nacionalista-conservador? ¿Si resulta que esta vez sí, definitivamente, Ricardo Iorio ha elegido definirse sin ambages y ubicarse de manera incontestable en ese cuadrante del mapa político-ideológico argentino?

Se advierte entre queridos y respetados amigos y compañeros, metaleros los más, un grito angustioso ante la ratificación de que Papá no es lo que hubiéramos querido que fuese. (...)

$\mathrm{Y}$ en ese punto surge, de esta parte, cierto disenso. Cierta animosidad por señalar la herida; exponerla, escarbarla.

Por si fuera necesario aclarar: quien esto escribe no se considera ajeno a los sentimientos que despierta la definitiva asunción de ese ideario por parte de Ricardo; quien suscribe se considera a sí mismo una persona de izquierda y es sincero admirador de las mejores tradiciones de lucha de los pueblos.

(...) ahora parece que Ricardo, finalmente, se definió. Decidió blanquear. (Palkowski, 2017)
}

La idea de "blanqueo" político, también aparece en un artículo de Marcelo Morandini (2017), perteneciente al mismo equipo de investigación. En él también se refiere a la fotografía ya mencionada: "Definitivamente la foto en cuestión representa la liquidación final de una historia. Es el final de un enigma, si se quiere, la puesta en blanco de una situación. Ya nadie podrá decir que no sabía. Es el vaciamiento que se completa." (Morandini, 2017)

En estas citas, se puede ver que el retrato referido constituyó un hecho doloroso debido a que la ideología política de Biondini resulta contraria a la que se puede leer en Hermética. Pero, por otra parte, se ve que estos autores dan cuenta de que dentro de la escena había dudas acerca de la postura política de Iorio, la cual era calificada como "enigma", por lo que el hecho de tomarse una foto con un filonazi da cuenta para ellos de un "blanqueo", expresión de lunfardo que significa "Legalizar una situación ilegal, clandestina o solo fundada en la costumbre" (Gobello y Oliveri, 2010, p. 44). 
Esta misma postura de confusión y decepción la pude notar en un seguidor de Hermética y Almafuerte, joyero y estudiante universitario de 37 años de edad, hijo de judíos, a quien entrevisté el año anterior a los puntos polémicos de Iorio. Allí, él expresó:

Y la convocatoria y lo que generó Ricardo es impresionante. Porque el tipo convoca. Y por ahí con el tiempo se volvió más... Tiene muchísima bajada de línea y no comparto un montón de... Por ahí, hay cosas que las dice... Se creó un personaje también, que por ahí tiene que mantenerlo y que le cuesta por ahí reflexionar a veces. Y es un tipo que por ahí en sus declaraciones o estás $100 \%$ de acuerdo o estás $100 \%$ en contra. Nunca manejó grises. Y por ahí hay declaraciones que duelen o que no son... Qué sé yo... Yo como descendiente de judíos, que el tipo salga a decir que si sos judío no podes cantar el himno nacional o declaraciones así, muy xenófobas... Muy facho por momentos... Es raro porque, en realidad, cuando era Hermética era otra cosa, no sé. Es como una especie de peronista de la vieja guardia, porque el tipo es recontra re peronista, pero se quedó ahí. Y tira por ahí a veces mucha... Que en parte es porque tiene un personaje y en parte también a veces se le escapa un poco. A veces se le va de las manos el personaje. Es entendible y no, porque tampoco... Qué sé yo, el tipo es Iorio. (...) Pero una cosa es en la música y otra en las declaraciones personales, en realidad.

(...)Yo en realidad, lo pienso ahora, siempre pienso: ¿era tan facho antes como lo es ahora? ¿No me di cuenta? O el tipo cambió o yo no me daba cuenta. Porque nos sentábamos a tomar cerveza después de un show con el tipo este y era fantástico. Y era escucharlo, anécdotas... El tipo se sentaba y era un padre, todo anécdotas. Y te contaba anécdotas y anécdotas, jte daba consejos! El tipo se cansaba de darte consejos: "No, pibe... ustedes estudien, sí, laburen pero lo importante es el estudio". El tipo te bajaba como una línea piola. Después con los años no sé si el discurso fue el mismo, no sé. En realidad eso es como un debate. Me gustaría tener la habilidad del tipo de ver si antes era facho o se puso facho, porque en realidad fue como una desilusión ver al tipo así, que tenés toda una idea... Lo escuchas hablar... Criminaliza un poco también lo que es... Asociar la cumbia con cierta gente de cierto estrato social, como muy básico, iy no podés! Qué sé yo, es como muy general. Como decir "todos los metaleros son drogadictos, toman merca". Sí, seguramente tomarán merca, toman, ipero no todos toman merca! (...) Se volvió... con el tiempo no sé si se volvió más viejo y más boludo o siempre le pasó.

Entonces, al igual que expresaron los investigadores citados anteriormente, en el 2016 el entrevistado ya demostraba haber sentido cierta confusión acerca de los dichos de Iorio, algo que en su caso se presentaba como una desilusión más marcada por su condición de descendiente de judíos.

Muchos medios de comunicación contribuyeron a esta confusión al evadir la temática o al contrarrestarla con información sobre la actividad benéfica del cantante. Por ejemplo, el 14 de septiembre de 2017, después de que Iorio criticara a los Mapuches, uno de los editores de la revista Efecto metal, publicó en su perfil de Facebook algunas fotos para informar que el músico había recibido en camarines a "16 jóvenes QOM, del Barrio Nocaayí, Juan José Castelli, Chaco impenetrable” (Efecto 
metal, Actualzación de estado de Facebook, 2017 septiembre $14^{136}$ ). Por su parte, Mario Mintz y Federico Addisi, pidieron al cantante que cuente en una entrevista del $2017^{137}$ las causas por las cuales el gobernador de Chaco lo echó de la provincia, las cuales tenían que ver con la colaboración solidaria que tenía Iorio con sus amigos "metaleros" de la comunidad Qom.

Lo mismo sucedió en la entrevista en "Mundo Casella" del 2013, en la cual el conductor destacaba que Iorio había financiado la totalidad de una cirugía reparadora de una niña accidentada y que era padrino de muchos niños. Esta defensa del músico a través de su actividad benéfica también la noté en dos músicos amigos de Iorio, a quienes entrevisté en 2016. Allí cuando les pregunté qué pensaban acerca de que acusen al cantante de fascista, uno de ellos respondió:

Ricardo es anti todo. Ponele facho... A ver, si vamos a ponernos a explicar cómo es Ricardo estamos hasta las bolas, porque necesitamos otra camarita de esa. Él es una persona muy nacionalista en cuanto a nacionalismo acá, Argentina, y que tiene sus convicciones. Pero lo que es importante es que es una persona que yo lo he visto dar la vida y no salen en ningún lado esas cosas, de las cosas que él ayuda, cómo te ayuda. Pero no a nosotros, a gente que realmente vos decis "este tipo tiene un corazón enorme". Y que bajo esa coraza que se hace él de malo, es un tipo super sensible, super bueno. Con los chicos vos tenes que ver lo que es. Él es el padrino del nene. Y te das cuenta con los chicos si una persona es buena o no, porque los chicos lo aman. Lo aman porque lo ven que es un loco lindo. Y a veces cuando él se quiere hacer odiar, lo hace a propósito. El artista dice. No importa si lo que dice o no es mentira, sino lo que causa en la otra persona, lo que te causa a vos. Es eso. Y él juega con todo eso, juega con la ironía, juega con que no sabes si está hablando en serio, si esto, lo otro. Entonces a vos que te genera eso, que hace que pienses un poquito. La gente, ¿sabes lo que quiere? Que le digas lo que tiene que pensar. Él te hace pensar. Porque vos decís "iputa!", es tanto torbellino de cosas que te muestra, que por ahí no son comunes...

Además de reinvindicar a Iorio a través de su buena interacción con los niños, los músicos indicaron que el cantante utilizaba la ironía, recurso que generaba una interpretación confusa en sus amigos.

Retomando la postura de los medios de comunicación, se puede decir que, en general, las revistas y portales hegemónicos especializados en metal directamente no se ocuparon de los puntos polémicos de Iorio. Algo diferente a lo que sucedió en los medios especializados en rock, entre los que se puede mencionar a la revista "Soy rock", la cual publicó dos artículos ${ }^{138}$ informando sobre cada hecho mencionado.

\footnotetext{
${ }^{136}$ Recuperado de: https://www.facebook.com/efectometalrevista/posts/1708155135863591

137 Este reportaje se puede escuchar en el siguiente link: https://www.youtube.com/watch?v=BAlXgdrwEnA

${ }^{138}$ Ver Mileo, 2017a y Mileo, $2017 \mathrm{~b}$.
} 
Por su parte, en la entrevista realizada en el programa "Tiempos Violentos", el periodista Fuentes Rodríguez parecía estar de acuerdo con el músico, ya que expresó que "La idea es hablar con alguien que no es políticamente correcto y eso trae un soplo de aire fresco a la situación. Por lo menos se puede debatir con alguien que piensa distinto. Con Ricardo efectivamente se puede ver otro lado de las cosas" (Fuentes Rodríguez, 9 de julio de $2017^{139}$ ).

Por el contrario, en el fanzine Enterrado vivo número 4, de noviembre de 2017, editado en San Justo, la editorial titulada "Ya no sos igual, ya no sos igual, sos el vigilante del heavy metal" ${ }^{\text {"140 }}$, critica directamente a Iorio y da cuenta de la misma desilusión que expresaron los aficionados anteriormente citados:

Durante el mes de agosto fueron de público conocimiento las fotos de la reunión entre Ricardo Iorio y Alejandro Biondini (para todos los que esperaban que la $\mathrm{H}$ se junte, ahí tienen, esa es una verdadera reunión!). Uno es un viejo de ideas fachas, declaraciones reaccionarias y propagador de nacionalismo berreta y rancio. $\mathrm{Y}$ el otro es el candidato de Bandera Vecinal. No hace falta dar mayores explicaciones de el [sic] contexto, circunstancias y protagonistas, si a alguno le falta un dato relevante, informensé [sic]. Encima el 17 de Agosto se reunieron, si resucita San Martín los caga a cachetazos. Y los escupe (?)

El tiempo pasa, nos vamos volviendo fachos, pareciera ser ley para algunos. Lo primero que pensé es "Y bueno, faltaba la foto nomás", porque seamos sinceros, a ésta altura ¿alguien se puede sorprender realmente? Iorio hace más de 15 años que viene derrapando, y derechizándose cada vez más en sus letras, sus declaraciones, la ropa, y toda pelotudez que haga. La falopa ya no cuenta como excusa, que digan "el chabón está re quemado". Me hago cargo de que yo también trataba de justificar con la limadura de cerebro de éste tipo las declaraciones de mierda que venía haciendo. Una mezcla de bronca y dolor, y pena. No por lo que es, sino pena por lo que supo ser, por todo lo que construyó para un movimiento tan genuino como el Heavy Metal nacional. ¿Todo lo anterior queda manchado, y hasta con un manto de duda?.. porque pienso que al final que onda, ¿era todo grupo? (como decía Julio de Grazia en la maravillosa película "Plata Dulce") ¿Era todo chamuyo? ¿Cómo puede cambiar tanto una persona? ¿Cambió o siempre fue así?

Esta catarsis no tiene sentido. No lo tiene porque no voy a dejar de escuchar a V8 y Hermética, de hecho hace 2 días puse Luchando Por El Metal, lo escuché entero. Sigue siendo una gloria. Me dio una nostalgia que no me había dado nunca, es un disco que me sé de memoria y cada tanto lo escucho, pero nunca lo había sentido tan lejos- Tan de otra época, tan de algo que ya no existe.

Otra razón por la que ésta catarsis no tiene sentido, es que no sé hasta que punto no se vuelve un acto de egoísmo pretender que una persona no cambie. ¿Pero tan radical tenía que ser el cambio? Algunos andan agitando de "siempre fue el mismo facho, ya en Hermética era una mierda", que V8 les chupa un huevo y bla bla bla, bueno, no pienso ni a palos lo mismo. Y ni en pedo voy a entrar en la pelotudez de hacerme la que yo no anduve con remeras de ninguna de sus bandas ni escucho sus discos ni siento las buenas letras que solía escribir, aunque esté haciendo todo lo contrario a lo que solía cantar.

\footnotetext{
${ }^{139}$ Recuperado de: https://www.youtube.com/watch?v=oVMMJ0Yg_EY

${ }^{140}$ Esta frase se basa en los versos de la canción "Ya no sos igual" (1994) de la banda argentina de punk, 2 minutos, que dicen: "Ya no sos igual. / Ya no sos igual / Sos un vigilante de la Federal".
} 
Acá el problema es que no hay nadie que convoque como convoca éste tipo, y que en éstas épocas de botas y fajina reemplazadas por zapatos importados y camisas celestes, éste tipo esparciendo toda su mierda derechista, xenófoba, reaccionaria y berreta, hace que las cosas solamente empeoren. (...)

En éste pasquín me hago cargo de todo lo que escribo y pienso. Bien o mal, equivocada o no, me hago cargo de que tengo pensamientos de izquierda pero con los pies en el sur de América, con preocupaciones que atañen a ésta tierra. Como todo fanzine, tiene ganas de expresarse, está todo plasmado acá, es solamente leer. Y estoy convencida de que no es tiempo para ambiguos. ¿Son de derecha? Haganse cargo, vieja. Miren que es lindo hacerse cargo de lo que uno opina eh, no es para tener miedo che, vamos. ¡Salgan al sol, idiotas! ${ }^{141}$ (...) (Editorial Enterrado Vivo Fanzine, 2017. Cursivas propias)

En esta editorial, la autora denota ser aficionada a las producciones de Iorio y se ve en una encrucijada ante la actitud del músico, ya que a pesar de no estar de acuerdo con él sabe que no le dejarán de gustar sus canciones. A través de la netnografía realizada en diferentes grupos de Facebook, teniendo en cuenta las publicaciones de algunos miembros de la escena y los comentarios realizados sobre ella, pude observar que la misma problemática surgía en gran cantidad de aficionados. Muchos demostraban haber tenido la intención de separar al artista de su obra, pero la fotografía con Biondini les impedía que no se "mezclen".

En todos los casos se puede observar que la afiliación musical de estos aficionados es producto del interjuego entre lo ideológico y lo sentimental. Es decir, que su gusto no solo se define por la adhesión consciente e intelectual a ciertas ideologías expresadas en las producciones metálicas, sino también por lo emotivo, ligado a lo visceral y lo irracional. Este último aspecto es necesario para que la música ejerza su "fuerza semiótica" sobre sus oyentes (DeNora, 2004). Sin embargo, esto no representa la alienación de la audiencia. Por el contrario, con las polémicas anteriormente descritas se observa con claridad la agencia de los aficionados quienes, mayormente, deciden resolver la encrucijada separando al artista (y su ideología) de su obra.

En Facebook también encontré las fanpages "Anti-Iorio" y "Metaleros antiIorio", las cuales tuvieron una permanencia fluctuante en el tiempo, debido a que los seguidores de Iorio más acérrimos denunciaban constantemente ambas páginas para evitar que publiquen memes y comentarios criticando al músico. Pero la crítica traspasó las redes sociales, lo cual se pudo observar en un escrache realizado en Isidro Casanova, en donde aparecieron algunos carteles que decían "Fuera Iorio facho. Amigo de la yuta.

\footnotetext{
${ }^{141}$ La frase “¡Salgan al sol, idiotas!” pertenece a un verso de la canción "Salgan al sol” (1971) de Billy Bond y la Pesada del Rock and Roll.
} 
El metal no se mancha ${ }^{142 "}$ (Ver Figura 39) pegados sobre los afiches que promocionaban la presentación de la banda solista del músico el 15 de septiembre de 2017.

De manera similar a los casos ya citados en que los aficionados se pronunciaban como partidarios de ideologías de izquierda, muchos "metaleros" se agruparon y comenzaron a militar en causas antifascistas. Un ejemplo de ellos es la "Resistencia Heavy Punk", integrada por conjuntos de punk y de metal de diferentes zonas del Área Metropolitana Bonaerense. Esta "Asociación de hermandad y solidaridad de Bandas Heavy's y Punk's (y sub-géneros) de distintas zonas" (Resistencia Heavy Punk. Descripción en fanpage $^{143}$ ) realizó recitales y grabó un compilado para pedir la liberación de Facundo Jones Huala, referente de la RAM. Además, posteriormente a la fotografía polémica de Iorio, hicieron circular algunos flyer en donde convocaban a realizar un boicot al músico.

Por otro lado también se pueden mencionar a los "metaleros" que, junto con el movimiento LGTBIQ y algunos seguidores de punk de ideología anarquista, conformaron el colectivo “Acción antifascista Mar del Plata”. Esta agrupación surgió como consecuencia de una serie de hechos de violencia llevados a cabo entre el 2013 y el 2016 por una agrupación neonazi marplatense, entre los que se puede mencionar el ataque físico a algunos gays, la agresión verbal a mujeres feministas y el destrozo del pub perteneciente a uno de los referentes del colectivo LGTBIQ marplatense y activista de la Asociación Marplatense por los Derechos a la Igualdad (AMADI).

A pesar de que muchos aficionados marplatenses etnografiados se autodefinieron como anti-fascistas, otros no lo hicieron. En un caso porque prefirieron continuar con la ideología apolítica y, en el otro, porque sus ideas eran cercanas a las del grupo neonazi. De hecho, de acuerdo a la netnografía realizada pude observar que en una de las fotografías publicadas por algunos de los medios de comunicación que escribían acerca del accionar y la condena al grupo racista, uno de los miembros vestía una remera de la agrupación de thrash metal, Megadeth (aunque esta banda no tiene una ideología de derecha). Por otra parte, en una de mis etnografías, interactué con un miembro de la escena metálica marplatense que no quiso opinar acerca de lo sucedido

\footnotetext{
${ }^{142}$ Esta expresión fue tomada de la frase "La pelota no se mancha" dicha por el jugador de fútbol, Diego Armando Maradona en 2001 en su despedida de dicho deporte. Con ella quería explicar que dicha actividad no debería "ensuciarse" con conflictos a su alrededor, devenidos de los casos de doping positivo (como en el suyo), la violencia, etc.

${ }^{143}$ Recuperado de https://www.facebook.com/pg/ResistenciaHeavyPunk/about/?ref=page_internal
} 
debido a que él tenía amigos en ambos bandos, es decir, el de las víctimas y de los victimarios.

Más allá del colectivo "Acción Antifascista Mar del Plata”, miembros de la escena metálica bonaerense por fuera de dicha ciudad también mostraron su apoyo. Entre ellos se encuentran los miembros del GIIHMA, quienes dedicaron su primer libro de ensayos al responsable del pub afectado; y los organizadores de la Feria del Libro Heavy y Gustavo Zabala, guitarrista de la banda, Tren Loco, quienes dedicaron posteos de Facebook con la consigna "Basta de Nazis en Mar del Plata". De la misma manera procedió el conjunto brasileño de hardcore punk, Ratos de Porão.

Con respecto a las posturas a favor de Iorio, pude relevar una infinidad de comentarios y publicaciones de Facebook en donde se lo defendía al músico mediante argumentos que apelaban al desconocimiento de la verdadera persona de Iorio por parte de quienes lo criticaban. De esta manera, se desarrollaron gran cantidad de intercambios agresivos entre ambas partes, en donde la mayoría de los insultos tenían connotaciones homofóbicas, de uno y de otro lado.

Quienes lo defendían parecían considerarlo "intocable” y, en muchos casos, usaban frases del músico para agredir a sus críticos, como por ejemplo "Vayan a estudiar". De esta manera, querían demostrar que quienes estaban en contra de Iorio lo hacían porque no sabían cómo era él en realidad o porque no habían estudiado lo suficiente como para entender qué era el fascismo.

Por otra parte, otros demostraban estar de acuerdo con la ideología nazi y fascista y acusaban a los críticos de Iorio de "zurdos" y "policías del pensamiento", que se contradecían en su prédica pacifista y de igualdad al no permitir que haya ideas contrarias a la suya, sin asumir la discriminación que conlleva la ideología de derecha. Con esta línea de pensamiento se produjo la defensa del artista al momento de ser suspendido de la grilla del festival B.A.Rock del 2017 por la organización del festival.

Los seguidores de Iorio consideraron a este acto como una censura. Fue por eso que en el grupo IORIO_oficial gran cantidad de aficionados a dicho músico publicaron fotos propias o de personas y elementos particulares con carteles e inscripciones que exponían la frase "Todo aquello que despierte conciencia será prohibido. Aguante Iorio", la cual es de autoría del cantante.

Estas fotografías se caracterizaron por tener imágenes de los aficionados en sus propios lugares de trabajo, con remeras, tatuajes o discos de Iorio y sus bandas, posando junto al músico y, en muchos casos, con niños llevando remeras o peinados que 
homenajeaban al músico. Como dentro del grupo hay miembros de diferentes lugares del país, una recurrencia en dichos posteos fue indicar la ciudad desde donde se realizaba dicha publicación, por lo que pude observar que hubo gran cantidad de participación de la escena bonaerense.

Debido a que en dicho grupo no solo se demostraba el apoyo mediante la consigna anteriormente mencionada, sino que en algunos comentarios también se veía que algunos seguidores intentaban realizar un boicot grupal al B.A.Rock, los managers de Iorio publicaron un comunicado en Facebook para pedirles que no lo lleven a cabo. En sus palabras, también calificaban como "censura" al hecho de no permitir que el músico forme parte del festival:

De parte de esta producción y a pedido de RICARDO queremos agradecer profundamente todo el apoyo de los fans, periodistas, musicos, publico en general, ya que los mensajes han llegado de diversos lugares del país, como así tambien desde el extranjero. En esta página seguiremos subiendo las fotos que solidariamente nos envían en su totalidad. Lamentablemente hemos visto publicaciones que convocan al escrache público hacia las personas organizadoras del festival, al respecto queremos aclarar: "La producción de BAROCK y la totalidad de sus integrantes, hasta último momento intentaron que IORIO y su banda realice el show pactado para el dia domingo 15 . Tristemente y como lo manifestaran en su comunicado, fueron presionados por organismos no gubernamentales desde hace más de un mes, bajo amenazas de escraches y manifestaciones. Por temor a ello creyeron conveniente en resguardo del artista y fans en general la decisión hoy públicamente conocida. Por tal motivo pedimos a todos los metaleros de corazon, que se abstengan de realizar las acciones que tanto repudiamos, la intolerancia, la discriminación, y la soberbia no es parte de nuestra acción, son las accioness de esas organizaciones, una vez más puestas en evidencia. Seamos solidarios con todas las personas que nada tienen que ver y trabajan en la música, stage, técnicos, bandas. No convocamos a ninguna manifestación, ni escrache, LA MEJOR MANERA DE COMBATIR LA CENSURA ES DIFUNDIENDO LA OBRA DEL ARTISTA. Gracias y AGUANTE EL METAL PESADO ARGENTINO ! (Iorio. Actualización de estado de Facebook, 2017 octubre $10^{144}$ )

Además del apoyo por parte de la audiencia, la banda solista del "Tano" Marciello y el grupo, Horcas, decidieron suspender su participación en el festival para demostrar solidaridad con Iorio y por mostrarse en contra de la censura. A esto lo comunicaron a través de publicaciones realizadas en Facebook, sobre la cual hubo gran cantidad de comentarios de apoyo a la decisión de estos artistas ${ }^{145}$.

\footnotetext{
144 Recuperado: https://www.facebook.com/IORIO.oficial/posts/comunicado-importante-dia-martes-10de-octubrede-parte-de-esta-producci\%C3\%B3n-y-a-pe/779063192277240/

$145 \mathrm{La}$ actualización de estado de Horcas se puede ver en el siguiente link: https://www.facebook.com/HorcasWeb/posts/1879773862051715?_xts_[0]=68.ARBAwG6Y6aEGNv_ aMO5ZJJG8up6I6SxItKWQ4mfoA22jJq689KMuvA7b0wH9UjTVDrdJ0NttJdnVpnLcr0x-

Lx_lobFUI8_rYrvtRPFgvmsXxmI5fiCprctwH9P35aF1Vc7BDLwFR10gcNiZGH7EkO17ZpbO10mnYIw 69u3pgxu9FWctF3GncP4ZoXv0EjAHNkhXmeMvtvjnqx4wlp13672_RvfwhFCXPUPYwBL_Kt3N09B
} 
Pero en ambos casos no se demostró tanto una aprobación debido a la ideología política, sino que más bien fue realizado como un gesto de "hermandad metalera", es decir, como una defensa del género musical. Esto permitiría que la escena se siga viendo a sí misma como apolítica a cambio de mantener la supuesta unidad de sus miembros y el "mito de la igualdad".

En una línea similar se expresaron otros que no se mostraron bajo ninguna línea política específica, sino que prefirieron mantener una postura apolítica $\mathrm{y}$, de alguna manera, hacer del metal su bandera política. Bajo esta impronta se conformó el Frente Heavy Metal, el cual intenta no identificarse con ningún partido político, únicamente con el metal, pero su actividad tiene acciones concretas como la lucha contra la trata de personas y la defensa de los pueblos originarios, lo que se concreta a través de la realización de recitales y festivales benéficos. Otro ejemplo de activismo político de dicha agrupación se puede ver en la fanpage de Facebook, en donde publicaron una fotografía de sus miembros junto a la comunidad mapuche solicitando la aparición con vida de Santiago Maldonado ${ }^{146}$, causa que también apoyó la Resistencia Heavy Punk.

De esta manera se puede ver que la escena bonaerense del metal se caracteriza por ser un espacio en el que conviven una pluralidad de ideologías, aunque algunas veces esto no se da de manera pacífica como se observa en los intercambios agresivos que se producen en las redes sociales y en los hechos de violencia causados por un grupo neonazi en Mar del Plata.

Por otra parte, la definición ideológica de Iorio generó la de gran cantidad de actores de la escena. A pesar de la existencia de cierta intolerancia, discriminación y homofobia en algunos de sus miembros, muchos de ellos no se identifican como fascistas y, en gran cantidad de casos se autocalifican como partidarios de las ideas de izquierda. En estos casos la discriminación es utilizada para identificar la alteridad de la que se buscan diferenciar para construir su propia identidad metálica.

\section{Algunas consideraciones}

KgsOzng_dIGEflgvf6eEBYKYooBIAhlfGiLdZDaraCOfRsw4sztYX2OSaPpQxHvsYb6hTSYYm5b8TC

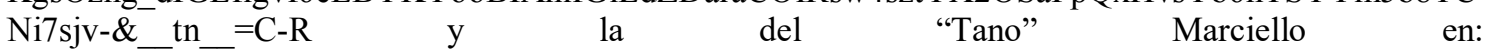
https://www.facebook.com/permalink.php?story_fbid=354718228314618\&id=100013293310611\&_xts $[0]=68$. ARCpi66W2HW9ocs3F6wf7WxddTf-KqznWxSQaogk35U7jbnVwjJGJ5h7X-

KGQxGXNO9KLWCfngImBynW3uSg1g76CMvAMY-QL84H151KcqJLwIj7DJRHapYSEvzm6ooOEpyEVWXyDuDZ1YMWFJSWbGoE_NHZGtZCfvhO4O8ON vKaIUP2cxhSuQ\& tn $=\mathrm{C}-\mathrm{R}$

${ }^{146}$ Dicha fotografía se puede ver en el siguiente link:

https://www.facebook.com/FrenteHM/photos/a.256252531547003/257092338129689/?type=3\&theater 
A partir del análisis anteriormente presentado es posible ver que la identidad política constituye uno de los puntos más dinámicos y heterogéneos de la escena metálica bonaerense. Si se considera a Hermética como la banda que representa la centralidad de la semiosfera, se puede decir que los principales significados estarían dados por la acción de reflexionar mediante la música acerca del contexto sociopolítico como un asunto "serio" y "auténtico".

Al mismo tiempo y a diferencia de Almafuerte, dicho grupo mantiene una postura apolítica por no adherir explícitamente a ninguna ideología política, a la par que se expresa políticamente en contra del sistema y de la cultura de masas, tal como lo ha hecho la tradición del rock. La apoliticidad parece permitir la convivencia de ideologías incompatibles entre los participantes de la escena, la cual es alterada a partir de la identificación de Iorio con la extrema derecha.

Entonces, podría decirse que las ideologías políticas específicas parecen formar parte de semiosferas externas a la escena metálica bonaerense, la cual dialoga con algunos de sus supuestos a través de la traducción a significados propios desarrollados mediante la experiencia musical (tanto desde su producción, como de su difusión y su consumo) cuya consigna principal es mantener la aparente apoliticidad y la consecuente unidad de la comunidad metálica.

Sin embargo, es posible observar que la preocupación por el contexto local argentino posee límites difusos con la ideología nacionalista, aunque gran cantidad de aficionados (principalmente aquellos que parecen adherir a ideologías de izquierda) decide no asumirlo. Mientras que, en otros casos, la problemática de la argentinidad que atañe a la escena, el conservadurismo que caracteriza a la autenticidad metálica y ciertas operaciones discriminatorias como mecanismo para la creación de la propia identidad parecen habilitar la presencia de nacionalismos de derecha y de vertientes ideológicas intolerantes, aunque muchas veces la responsabilidad sobre esto se oculta mediante el mecanismo de la "reflexividad anti-reflexiva".

En suma, Hermética propone como centro de significados la reflexión política apolítica del contexto argentino a través de producciones altamente polisémicas, las que son resignificadas por los aficionados de la escena que utilizan a la música como dispositivo para generar sus propias identificaciones políticas en diálogo con sus respectivos contextos. Posiblemente, el discurso en defensa de lo marginal y lo popular permita la recepción positiva por parte de agentes con ideologías anarquistas y de 
izquierda; y, al mismo tiempo, la discursividad nacionalista y la ética propia del sistema patriarcal dé lugar al vínculo con ideas políticas de derecha.

Por su parte, Iorio constituye la figura central de la escena, primero, porque pareció instalar la reflexión política apolítica musical dentro de la escena a través de sus bandas y, segundo, porque a partir del 2017 es tomado como modelo para generar nuevas identidades tanto por la similitud como por la diferencia.

Hasta ahora, se estudió a la escena metálica bonaerense bajo el marco teórico de la semiosfera. En el próximo apartado analizaré de qué manera se desarrolla la escena metálica bonaerense en tanto campo cultural en donde la heterogeneidad característica se desarrolla por medio de posiciones dispares y la disputa de sus actores. 


\section{Parte II: Reconstrucción de la escena metálica bonaerense como campo cultural: Hermética como centro de disputas}

Como ya fue explicado, al estudiar a la escena metálica bonaerense como un campo cultural es posible encontrar una serie de disputas relacionadas no solo con el capital cultural, sino también con el social y el simbólico. Es decir que además de disputarse el metal en tanto producto de una industria musical específica, también hay una lucha por el acceso a las formas de interacción social de la escena y el reconocimiento y el prestigio dentro de ella.

Por otra parte, debido a que la escena metálica bonaerense logra concretarse mediante rasgos particulares que le otorgan relativa autonomía con respecto a otros géneros y comunidades musicales, sus participantes logran tal grado de reflexividad que dentro de ella se comienza a formar una especie de campo intelectual o "del saber", que debate diversas cuestiones en torno al metal y la propia escena. La característica de todas estas disputas es que contienen a Hermética como centro, ya sea en tanto objeto de admiración o como modelo de acción y producción para sus agentes.

Es por ello que la mejor forma de organizar el análisis de estas disputas es hacerlo, primero, mediante el carácter espacial; segundo, a través de lo temporal; y luego, con respecto a lo intelectual; para, finalmente, arribar a los modos mediante los cuales se produce la consagración de Hermética. Mi hipótesis es que todas estas disputas -excepto las que se producen entre lo local ${ }^{147}$ y lo global- tienen como centro de consagración a CABA, en tanto capital del país. A continuación daré cuenta de ello.

\footnotetext{
147 En este caso se utiliza el adjetivo "local" con referencia a la escala nacional y "global" a la internacional. En el primero, se elige dicha conceptualización para evitar que sea emparentada con la ideología nacionalista.
} 


\section{Tensiones espaciales en la escena metálica bonaerense}

\section{Entre lo local y lo global}

El metal, al igual que el rock, se caracteriza por ser un estilo musical global. Incluso, ha sido calificado como un producto de la globalización (Wallach et al., 2011, p. 16) Como consecuencia, puede ser considerado como transcultural, ya que "(...) no es una música ligada a una cultura en particular, que las personas de otras culturas disfrutan como personas externas; más bien, el metal es la música de un grupo de personas que trasciende otras fronteras culturales y nacionales preexistentes." (Weinstein, 2011b, p. 46)

Sin embargo, dicha transculturalidad no es sinónimo de igualdad. Por el contrario, es posible ver que, al igual que sucede con el rock, las metrópolis consagratorias son europeas y norteamericanas. En este sentido, el rock (y, dentro de él, el metal) “(...) como fenómeno cultural se origina en los Estados Unidos y el Reino Unido, y sus artistas canónicos, así como los más exitosos comercialmente también son de esos países.” (Regev, 2013, p. 50. T. de la A.)

Este carácter global puede ser analizado bajo la noción de "cosmopolitización estética" de Motti Regev (2013), la cual

(...) refiere a la formación en curso, en la modernidad tardía, de la cultura mundial como una entidad interconectada complejamente, en cuyas agrupaciones sociales de todos los tipos alrededor del mundo comparten cada vez más amplios campos comunes en sus perspectivas estéticas, formas expresivas y prácticas culturales. Cosmopolitismo estético refiere, entonces, a la cultura mundial singular ya existente, el estado de asuntos alcanzado siguiendo lo anterior. (Regev, 2013, p. 3. T. de la A. Destacado del original)

Mediante este proceso, los artistas y los mediadores del arte se posicionan frente a dos campos de la producción cultural: "el campo global de la forma de arte en cuestión (...), y el campo de la cultura nacional en la que se encuentran.” (Regev, 2013, p. 13. T. de la A.). No obstante, en el metal es posible observar una escala múltiple, ya que

Las escenas son reproducidas globalmente, regionalmente, nacionalmente $\mathrm{y}$ localmente. Esto superficialmente aparece como una serie de muñecas rusas: la escena global, la escena europea, la escena sueca, la escena de Gotemburgo. Pero la situación es más complicada que esto. Por una cosa, no todas las escenas en todos los niveles replican discursiva e institucionalmente a la otra. (Kahn-Harris, 2007, p. 99. T. de la A.) 
Esta disposición espacial de las escenas puede vincularse con la idea de Bennett y Peterson (2004) de las escenas translocales, las cuales son escenas locales diseminadas que se comunican en torno a un estilo de música particular.

En el caso de la escena metálica bonaerense, esta se encuentra interconectada por medio de vínculos translocales tanto con lo global, como con lo local (nacional, regional y local propiamente dicho). En esta sección me ocuparé del primer movimiento, el cual se produce primeramente a partir de lo idiomático. Tal como plantea Weinstein (2011b), en la década de 1970 el inglés fue el lenguaje global del metal, por lo que las bandas que fueron reconocidas internacionalmente cantaban en dicho idioma.

En Argentina, como se mencionó en capítulos anteriores, en las décadas del '70 y del '80 se escuchaban bandas que componían sus letras tanto en inglés como en español, lo que se vio reflejado en las primeros grupos de metal que visitaron el país: los estadounidenses, Quiet Riot, y los españoles, Barón Rojo.

En la actualidad, a nivel global, gran cantidad de conjuntos de metal cantan en sus lenguas de origen, aunque otra gran parte decide continuar el desarrollo del inglés para poder ser difundidos de manera internacional. De hecho, la mayoría de las bandas utilizan este idioma para poder hablar a su audiencia durante los shows en vivo fuera de sus propios países.

Esto sucede en Argentina en los recitales de bandas extranjeras. En mi trabajo de campo pude observar allí una tensión: A pesar de que muchos miembros de la audiencia parecían comprender lo que expresaban los artistas en el micrófono, otra gran cantidad no lo hacía, pero a pesar de ello ovacionaba al igual que el resto. Esto mismo sucedía con las canciones: observé gran cantidad de aficionados que cantaban las canciones por memoria fonética y otros que tarareaban las melodías instrumentales de la guitarra o la batería.

De hecho, los aficionados argentinos crearon un fenómeno particular con la banda estadounidense, Megadeth. En el concierto de dicho grupo en el Estadio de Obras Sanitarias de la ciudad de Buenos Aires en 1994, el público comenzó a cantar la frase “iMegadeth, Megadeth, aguante Megadeth!” sobre una parte instrumental de la canción “Symphony of destruction" (1992). Este cántico no solo traspasó los límites temporales (aún es cantado en la actualidad) sino también las fronteras geográficas: de acuerdo a la 
netnografía realizada en YouTube ${ }^{148}$ observé que dicha frase es cantada en otros países durante los recitales en vivo del grupo, a pesar de que el concepto "aguante" forme parte del lunfardo argentino.

A diferencia de los aficionados chilenos al thrash metal que necesitaron romper la barrera idiomática para vincularse con el estilo musical - “(...) lo que sólo era posible si se tenía la educación adecuada o si se provenía de familias que tuviesen alguna vínculo con el extranjero (...)" (Sánchez Mondaca, 2006, p. 67)-, en Argentina esto no impidió que aficionados de distintas proveniencias sociales pudieran consumir y producir metal en todas sus variantes.

De hecho, es posible ver que la gran mayoría de los participantes de la escena bonaerense no pronuncian con la fonética inglesa los nombres de estilos como el thrash o el death o los nombres de bandas, discos y canciones, a pesar de que muchos de ellos sí poseen conocimientos del inglés. Inclusive, la denominación "metal” generalmente es pronunciada de acuerdo a la fonética del español [me 'tal], lo que no solo sucede con los seguidores del "metal pesado argento" de Almafuerte sino también con los aficionados al metal extremo.

Igualmente, se utiliza el inglés para nombrar festivales, los que usualmente se titulan con un sustantivo (muchas veces en español) acompañado de la palabra inglesa "fest". Y, al igual que en otros géneros musicales, también se realizan covers de canciones cuya letra está compuesta en inglés. En esos casos, los intérpretes que no tienen conocimiento del idioma piden ayuda para poder pronunciar correctamente o directamente copian la fonética del tema musical original.

En otros casos, los propios conjuntos deciden componer sus canciones en inglés, algunas veces por considerar a dicha fonética más acorde a la sonoridad del metal. Esto le permitió a muchas poder grabar sus discos con sellos discográficos extranjeros de distribución internacional. Un caso destacable del período estudiado es el de la banda porteña de heavy metal clásico, Helker, que en 2013 graba el álbum En algún lugar del círculo (y su versión en inglés, Somewhere in the circle) con AFM Records -sello alemán especializado en metal-, el cual es producido por Matt Sinner, bajista de la agrupación alemana de power metal, Primal Fear.

\footnotetext{
${ }^{148}$ El video fue creado por un aficionado que recopila imágenes de conciertos y de entrevistas a Dave Mustaine, líder de Megadeth, quien explica el fenómeno global del cántico argentino y el significado de la expresión "aguante". Dicho material está disponible en el siguiente link: https://www.youtube.com/watch?v=lgOsh_s223U
} 
También es posible mencionar el caso de la banda porteña de death metal, Vibrion, la cual se había formado en 1989 y luego de un impasse entre 1998 y 2001, retomó su actividad con uno de sus integrantes radicado en Bélgica. De esta manera, el grupo regresó con doble nacionalidad, por lo que le resultó más accesible realizar giras y grabar sus producciones fuera de Argentina. Es así que en el 2016 grabaron el disco Bacterya bajo el sello español, Xtreem Music. ${ }^{149}$

Otros grupos de la escena bonaerense (y, más específicamente, porteña), como por ejemplo, Rata Blanca, A.N.I.M.A.L., Malón y Horcas, lograron grabar con sellos multinacionales, tales como Sony Music, Warner Music, Universal Music y EMI Music, pero la diferencia con Helker es que, en el caso de este grupo, se trató de una discográfica centrada en el metal, mientras que las otras se dedican a diversos géneros musicales. Estas posibilidades permitieron que dichas agrupaciones sean mayormente difundidas y reconocidas, de manera que se convirtieron en representativas del metal de Argentina, no solo hacia el exterior sino también hacia el interior.

El objetivo de difundir su propia obra en el extranjero parece encontrarse en el polo opuesto de aquellos aficionados que solo eligen a las bandas de su propio país como parte de una ideología nacionalista y anti-colonialista. Por ejemplo, es posible citar a la fanpage de Facebook, "Metal Argentino (lo nuestro en idioma original)"150, cuya descripción expresa que "Difundir lo nuestro es crecer", por lo que allí solo circula información acerca de bandas argentinas que componen sus canciones en español.

Sin embargo, observé que hoy en día los participantes de la escena poseen un mayor acercamiento a las producciones de bandas que no componen sus temas en español gracias a Internet, el cual les permite acceder a las traducciones de las letras de las canciones. De hecho, en YouTube es posible encontrar gran cantidad de videos subtitulados, tanto videoclips oficiales como videos realizados por aficionados. Por lo que no es estrictamente necesario conocer el idioma de los grupos musicales para poder adentrarse en el significado de sus canciones.

A pesar de ello, el uso extendido del inglés en la escena da cuenta del carácter translocal del metal, el cual, a pesar de difundirse de una manera descentrada (Kahn-

\footnotetext{
149 Agradezco a Hernán Mazón del portal "Metal-Daze" por su aporte a la recolección de información acerca de los sellos discográficos con los que editaron sus discos las bandas metaleras argentinas; al igual que los datos aportados por Exequiel Núñez y César Fuentes Rodríguez.

${ }^{150}$ Dicha fanpage se puede ver en el siguiente link: https://www.facebook.com/pg/Metal-Argentino-lonuestro-en-idioma-original-114621378589382/about/?ref=page_internal
} 
Harris, 2007; Mayer y Timberlake, 2014) no escapa de la globalización y del imperio idiomático de la lengua mencionada.

Pero también es necesario destacar que las diferencias lingüísticas permiten que muchos aficionados le den mayor importancia a la música que a las líricas. Esto resulta fundamental con los grupos que expresan un contenido ideológico contrario al que poseen algunos aficionados: por ejemplo, muchas agrupaciones extranjeras de black metal de temática satánica son consumidas por "metaleros" cristianos, al mismo tiempo que algunas "metaleras" feministas no dejan de escuchar bandas que poseen letras machistas y misóginas.

En la mayor parte de estos casos, los aficionados obvian las líricas y le prestan atención al resultado total de las canciones, en donde la voz es considerada un instrumento musical más y de ella se valoriza la sonoridad. Por otra parte, esto es más frecuente con aquellas bandas que utilizan la técnica del growl que muchas veces hace que sea muy difícil (e incluso imposible) entender con claridad el contenido de lo que se canta.

Esto resulta diferente en el caso de Hermética: la mayoría de los aficionados que fueron entrevistados destacaron el contenido de las letras de la banda y calificaron a Iorio como un poeta. Por el contrario, quienes no adhieren a dicho grupo argumentan distanciarse de ella debido a su baja calidad musical y prefieren agrupaciones extranjeras o argentinas que se asemejan a estas. Entonces, la decisión del grupo musical de producir sus canciones en español fue fundamental para su circulación dentro de la escena no solo argentina, sino también latinoamericana.

Con respecto a esto, pude observar que la banda es valorada no solo en Argentina, sino también en países en los que nunca se presentó en vivo, tales como Colombia, Ecuador y Perú. En el primer caso, a través de la netnografía en Facebook encontré una fanpage denominada "La H NO murió - Colombia", cuya descripción explicita "Esta es una reunión de los Hermetiqueros Colombianos. Aguante la H, no murió!!!",151.

Por su parte, en 2015 y 2016 se realizó el festival "Hermética. Ecuador evitando el ablande" en la ciudad ecuatoriana de Quito, en el cual participaron bandas de dicho país realizando un tributo al grupo musical argentino. A partir del festival del primer

\footnotetext{
151 Dicha fanpage se puede encontrar en el siguiente link: https://www.facebook.com/pg/LaHNoMurioColombia/about/?ref=page_internal
} 
año se grabó un $\mathrm{CD}$ que recopilaba covers de dicha agrupación realizados por los conjuntos ecuatorianos que participaron del mencionado show.

Dentro del evento se encontraba la banda Herkraniu, cuyo logotipo es prácticamente una emulación del que utilizaba el conjunto argentino. Lo mismo sucede con el grupo, Madrágora, de Perú, que además de ser un tributo a Hermética, también diseñó su logotipo basándose en la caligrafía del grupo argentino. Se puede deducir que probablemente el vínculo de estos aficionados ecuatorianos, colombianos y peruanos con Hermética provenga de la ideología latinoamericanista que desarrollaba la agrupación en sus canciones.

La netnografía de Facebook también me permitió arribar a la fanpage, "U.S.A. Metal En Español $\backslash \mathrm{m} /{ }^{\prime \prime 152}$. De acuerdo a la información proporcionada, sus ciudades de origen son Nueva York y Nueva Jersey. En la descripción se explica que “(...) es un movimiento que intenta hacer que este género crezca y sea conocido en Estados Unidos" y que sus intereses son "Dar a conocer las bandas de metal en español, así como las actividades de ellas por U.S.A. Engrandecer este género en los U.S.A." ${ }^{153}$ De esta manera, en ella se difunden los conciertos de agrupaciones metálicas en idioma español que se presentan en Estados Unidos, entre las que se encuentran algunas argentinas como Horcas y Malón.

Además, esta fanpage es complementada con el blog, "USA Metal en español" 154 , en el cual aparecen reseñas de los recitales de las bandas hispanas y de sus nuevos discos, realizadas por el poeta costarriqueño, Mayron Blanco. La descripción indica que

Este blog es enfocado a el [sic] metal en nuestro idioma. "El Metal en español" Nos encontramos en USA" y queremos crear un movimiento de metaleros hispanos para en el futuro trabajar en conseguir que las bandas en nuestro idioma puedan llegar a estas tierras a entregar su arte. (Descripción textual del blog ${ }^{155}$ )

No obstante, además del vínculo idiomático, la escena metálica bonaerense también se relaciona con el campo global a través del flujo de bandas y shows en vivo, tanto de argentinos en otros países, como de extranjeros en Argentina. Para el primer

\footnotetext{
${ }^{152}$ En el nombre de dicha fanpage aparece el símbolo " $\mathrm{Im} /$ ", el cual es utilizado globalmente como una manera gráfica de representar a la mano cornuta. Posiblemente, el mismo se originó a través de plataformas anteriores a Facebook y a la aplicación, WhatsApp, en las cuales aún no existían emoticones o emojis que representaran icónicamente dicho gesto característico del metal.

${ }^{153}$ Recuperada de: $\mathrm{https}: / / \mathrm{www}$. facebook.com/pg/UsaMetalEnEspanol/about/?ref=page_internal

${ }^{154}$ La dirección de esta página es: https://usametalenespanol.blogspot.com/?m=0

${ }^{155}$ Recuperado de: https://www.blogger.com/profile/16051705016519807971
} 
caso es posible encontrar dicho movimiento desde los orígenes a través de la figura de Pappo y su contacto con músicos ingleses, como Lemmy Kilmister de Motörhead.

Por su parte, Rata Blanca es una banda que asiduamente se presenta en Estados Unidos, España, Japón y países americanos como México, Costa Rica, Colombia, Chile y Perú. Además ha alcanzado el título de una de las mejores agrupaciones del rock en español, lo que la introduce en el campo global y le otorga reconocimiento a nivel internacional.

Otro conjunto que también ha realizado shows fuera de Argentina es Malón, el que a partir de su regreso en el 2011, se presentó tanto en Colombia como en Estados Unidos. Posiblemente esto se relacione con la gran cantidad de seguidores que posee el grupo por fuera de su propio país, lo cual se puede observar a través de la netnografía de Facebook anteriormente descrita.

Otros grupos que también se han presentado fuera de Argentina en países como Japón y Estados Unidos son Horcas y Tren Loco, sin embargo no fueron integrados al circuito del campo global. Esto se debe a que solo un número reducido de bandas de Sudamérica y América Central se han vuelto mundialmente populares y la mayoría de los países de estas regiones carecen de capital en la escena global, por lo que son relativamente invisibles en términos globales ${ }^{156}$ (Kahn-Harris, 2007, p. 116).

Un caso particular dentro del período estudiado es el de la agrupación, De La Tierra, conformada por el vocalista argentino, Andrés Giménez (de A.N.I.M.A.L.); el guitarrista brasileño, Andreas Kisser (de Sepultura); el baterista mexicano, Alex González (de Maná); y el bajista argentino, Flavio Cianciarulo (de Los Fabulosos Cadillacs), que en 2017 es reemplazado por el puertorriqueño, Harold Hopkins (de Puya). Este conjunto plurinacional de groove metal con impronta latinoamericanista, compuesto por músicos que provienen de diversos géneros musicales, grabó dos discos: De La Tierra (2014) y De La Tierra II (2016), bajo la firma, Roadrunner Records, discográfica multinacional especializada en metal.

Por otra parte, a partir del 2016 se comenzó a realizar en CABA el "Wacken Metal Battle", un certamen en el cual se selecciona una banda para presentarse en el festival más importante del campo global del metal: el Wacken Open Air, realizado en

\footnotetext{
${ }^{156}$ Esto mismo se podía observar en las primeras publicaciones académicas de los estudios metálicos. Por otra parte, a través de mi trabajo etnográfico, pude dialogar con aficionados e investigadores provenientes de Venezuela, Chile, Brasil, México y Puerto Rico, quienes confirmaron que las bandas argentinas mencionadas no son muy reconocidas por fuera de nuestro país. En la mayoría de los casos, la que estos interlocutores conocían con seguridad era Rata Blanca.
} 
Alemania. El conjunto seleccionado en el concurso participa en dicho festival en un escenario secundario y, a su vez, compite con los grupos de otros 40 países que también realizaron sus propios certámenes. El conjunto ganador se acerca a la posibilidad de grabar con sellos discográficos internacionales, entre otros premios.

A pesar de que en dicho certamen participan bandas de toda la Argentina, la escena bonaerense (y dentro de ella, la porteña) posee relevancia debido a que el evento es organizado por el programa radial porteño, Vorterix Metal, y se realiza en teatros de CABA que tienen gran prestigio dentro de la escena metálica, como el Teatro Vorterix y The Roxy Live. Además, las agrupaciones ganadoras también son originarias del Área Metropolitana Bonaerense: Lepergod y Against, de CABA, y Malicious Culebra, de Berazategui.

Asimismo, dicho concurso da cuenta de un claro policentrismo y su carácter competitivo representa literalmente las luchas por la legitimación: mientras que para gran cantidad de músicos de países de escenas metálicas periféricas (como la argentina) persiste el rasgo marginal en el hecho de que el logro es presentarse en un escenario de menor importancia; las figuras principales continúan siendo las consagradas en el campo global, las cuales son promovidas por los sellos discográficos y los medios de comunicación que hegemonizan la escena metálica global.

En el movimiento inverso (es decir, de lo global hacia lo local) es posible ver gran cantidad de agrupaciones extranjeras presentarse en Argentina y aquí la escena bonaerense vuelve a tomar partido, debido a que la mayoría de estos conciertos se realizan en CABA. Los conjuntos que poseen públicos masivos se presentan en estadios de fútbol o en parques al aire libre (Ver Figura 40), ya sea como artistas principales con bandas teloneras argentinas (las que son principalmente las que hegemonizan la escena), o dentro de festivales tales como el "Monsters of Rock" y el "Maximus Festival".

Por su parte, los grupos que no alcanzan una audiencia de miles de asistentes se presentan en teatros de CABA como los ya mencionados Teatro Vorterix y The Roxy Live, y también Luna Park, Groove, Teatro Flores, Uniclub, Speed King y Museo Rock. Además de estos espacios porteños, en siguiente lugar se encuentra el Estadio Único de la ciudad de La Plata. En el período que contempla mi investigación pude registrar la visita a ciudades del interior, como Mar del Plata, Tandil y Bahía Blanca, por parte de bandas extranjeras como los brasileños, Ratos de Porão y, el estadounidense, Tim "Ripper" Owens, los cuales son reconocidos a nivel global. 
De esta manera, pude observar que las bandas extranjeras que visitan Argentina (o, mayormente, la escena metálica bonaerense) no solo pertenecen al mainstream metálico, tales como Iron Maiden y Metallica, sino que también se trata de grupos underground que circulan globalmente y pertenecen en su mayoría a diferentes estilos de metal extremo.

Entonces, la escena bonaerense se presenta como apta para el desarrollo de eventos internacionales, debido a que no solo dispone de espacios físicos para ello (tanto teatros y estadios de fútbol, como la presencia de aeropuertos que permiten el acceso de artistas de países remotos) sino que también cuenta con una audiencia disponible para asistir a dichos shows. En primer lugar, porque la mayor parte de los participantes de la escena se concentran en el Área Metropolitana Bonaerense (CABA y el conurbano) $\mathrm{y}$, en segundo término, porque para poder asistir los aficionados del interior bonaerense deben recorrer menor distancias que los que provienen de otras provincias.

Sin embargo, los aficionados de las ciudades del interior de la provincia de Buenos Aires requieren de esfuerzos extras a comparación de los porteños: no solo deben costear sus viajes a la capital (ya sea en colectivo, de forma individual, o por medio de tours grupales en combis y minibuses), sino que también muchas veces arriesgan sus puestos de trabajo, pidiendo permisos especiales para faltar, salir antes o llegar tarde y, de esta manera, poder asistir a los recitales.

Esto se debe a que el horario de estos conciertos no suele coincidir con los que corresponden a los transportes ni con la cantidad de horas de viaje, además de que muchas veces se realizan durante días laborables. En efecto, a través de mi trabajo de campo pude vivir las complicaciones de traslado: en varios casos debí contratar transportes particulares para dirigirme a ciudades que no disponían de colectivos de larga distancia entre una y otra y, de cierta manera, poseían poca o nula interconexión.

Por su parte, en el Área Metropolitana Bonaerene también observé que al finalizar los recitales la frecuencia de los colectivos y trenes era reducida e, incluso, en CABA los subtes cesaban su actividad en dicho horario (alrededor de las 23:30). Es por estos motivos que dentro de la escena los viajes grupales se han popularizado y conservan cierta impronta de lo grupal que caracterizaba a las "brigadas metálicas" de $\operatorname{los}$ ' 80 .

A pesar de dichas complicaciones, los aficionados se mostraban dispuestos para asistir a esos recitales. A través de conversaciones mantenidas durante la etnografía, 
pude conocer que estos esfuerzos eran justificados por los propios aficionados, quienes creían que tal vez esa era la única oportunidad que tenían en sus vidas para poder ver a determinada banda en vivo. Al mismo tiempo, observé que, en dichos intercambios, un tema de conversación recurrente era la especulación acerca de las posibilidades de que algunos conjuntos específicos hagan giras por Latinoamérica, lo que aumentaba las chances de que se presenten en Argentina.

Estos aficionados conocieron a agrupaciones extranjeras de metal a través de formatos "clásicos": recomendaciones de amigos y familiares, intercambio de discos y cassettes y medios de comunicación especializados (revistas, documentales y programas de radio y televisión). Pero la mayoría, en la actualidad, consume bandas tanto argentinas como extranjeras a través de Internet, por medio de estaciones virtuales de radio de diferentes países; sitios de videos, como YouTube y Vimeo; redes sociales, como Facebook e Instagram; y plataformas de reproducción de música, como Spotify, Deezer, MySpace, Bandcamp, Soundcloud, Mixcloud y ReverbNation, muchas de las cuales también poseen el formato de aplicaciones para sistemas Android, aptos para escuchar a través de smartphones.

En este último caso -es decir, el de las plataformas digitales de reproducción de música vía streaming-, a pesar de que algunas veces es necesario pagar o suscribirse para poder oír las canciones, resulta más accesible que la adquisición de discos en formato físico, los cuales muchas veces no llegaban al país y, en caso de conseguirlos, muchos debían adquirir copias piratas de los originales. De hecho, en la actualidad, además de los sitios web mencionados, hay gran cantidad de posibilidades de descargar canciones y álbumes completos de forma pirata a través de Internet, los cuales no solo son escuchados por medio de computadoras y reproductores MP3y MP4, sino también en teléfonos celulares.

Las producciones de agrupaciones extranjeras no solo son consumidas por los participantes de la escena bonaerense, sino que también son versionadas por gran cantidad de conjuntos underground semiprofesionales. En los recitales observados, las canciones elegidas para interpretar no solo consistían en hits de grupos reconocidos como Metallica o Iron Maiden, sino también de temas musicales de bandas globales underground, muchas de ellas inexistentes (por ejemplo, Death). Estos covers eran realizados para cautivar al público y captar su atención para presentar temas propios.

El interés por agrupaciones extranjeras hace que muchos miembros de la escena bonaerense se interioricen por la cultura de dichos países. El ejemplo más claro aparece 
a través de los grupos de viking y folk metal, provenientes de países como Noruega, Suecia y Finlandia, los cuales desarrollan temáticas propias de las mitologías celtas y nórdicas. Es así que muchos "metaleros" de la escena bonaerense también participan activamente de las ferias de recreación medieval y utilizan adornos y tatuajes con simbología tradicional de dichas culturas, como por ejemplo, el Mjolnir, martillo del dios vikingo, Thor.

Este último puede ser considerado un ejemplo del "cosmopolitismo estético", el cual es exhibido “(...) cuando los individuos, como miembros de una cultura nacional o étnica, tienen un gusto por los productos culturales o las obras de arte que inequívocamente 'pertenecen' a una nación o etnia diferente a la suya" (Regev, 2013, p. $8)$.

\section{Vínculos inter-provinciales}

Gran cantidad de bandas de la escena metálica bonaerense logran presentarse en festivales en otras provincias. De hecho, para los participantes de la escena, fue Hermética la agrupación que inició dicho intercambio dentro de este campo cultural, ya que se trató de uno de los grupos pioneros de metal en recorrer el país realizando giras de conciertos en ciudades de diferentes provincias.

En el período estudiado en esta tesis, uno de los principales festivales que tuvieron alcance nacional fueron los "campamentos metaleros" con impronta indigenista titulados con nombres en diferentes lenguas aborígenes: "Ruca Hue" en Bariloche, Río Negro, en 2014; "Huarpe Cuyum" en el Valle de Zonda de San Juan en 2015; "Pacha Huasi" en Belén (Catamarca) en 2016 y "Pacha Huasi Famayfil" también en esta ciudad en $2017^{157}$. El objetivo de estos acampes era reivindicar tanto al federalismo como a los pueblos originarios que habitaron en los territorios en donde transcurría dicho evento. Este integró a grupos y aficionados metálicos de distintas provincias, aunque las bandas principales -es decir, las que cerraban la grilla- solían ser de CABA.

Otro festival que también intenta integrar a las bandas de diferentes puntos del país es el "Criminal Metal Camp", realizado en la provincia de Córdoba desde el año 2015. La diferencia con respecto a los eventos anteriormente mencionados es que se

\footnotetext{
${ }^{157}$ La edición del año 2018 también fue nombrada "Pacha Huasi Covun-có" y se realizó en la ciudad de Mariano Moreno en la provincia de Neuquén. En esta oportunidad, la novedad consistió en el agregado de exposiciones y debates en el marco de la Feria del Libro Heavy al evento, que anteriormente solo había consistido en un recital de bandas.
} 
dedican exclusivamente a agrupaciones de metal extremo y también incluyen en su convocatoria a conjuntos sudamericanos. Este evento parece inspirarse tanto en el "Wacken Open Air" de Alemania -el cual también posee el formato de festival con campamento, similar al de Woodstock de 1969 en Estados Unidos- como en el local, "Cosquín Rock".

Este último consiste en un festival de rock que se realiza durante varios días en la provincia de Córdoba desde el 2001 y, de acuerdo al periodista, Gabriel Martínez (2015), es uno de los más importantes de Latinoamérica junto con "Rock in Rio" de Brasil y "Rock al Parque" de Colombia. El "Cosquín Rock" se caracteriza por poseer una variada grilla que es organizada en varios escenarios y días especiales para cada estilo de rock, de manera que es posible encontrar divisiones específicas para el metal, el reggae, el punk, etc.

En el caso del metal, a pesar de que allí se presentan grupos de reconocimiento nacional e internacional (debido a que también participan bandas extranjeras que circulan a nivel global), la mayoría de ellos provienen de CABA. Es por eso que tanto los "campamentos metaleros" indigenistas como el "Criminal metal camp" intentan federalizar la escena del metal argentino saliendo físicamente del área bonaerense y otorgando la oportunidad de tocar a las agrupaciones sin que tengan que pagar algún costo económico para ello.

En el lugar opuesto se encuentra el festival "Metal para Todos", organizado desde 2007 a 2017 por 4G Producciones, al mando de Carlos Tórtola ${ }^{158}$. Los primeros años se llevó a cabo en predios tales como el Estadio Malvinas Argentinas y, a partir de 2012, en el Teatro Vorterix (Scarrone, 2016). Este evento se caracterizaba por integrar a los grupos underground de distintos puntos del país al circuito de bandas de músicos consagrados en la escena metálica argentina.

De manera similar al certamente Wacken Metal Battle, a pesar de que el festival se constituía como una oportunidad de reconocimiento para los conjuntos poco conocidos, permanecían algunas diferencias: las agrupaciones underground usualmente debían pagar para participar y tenían menos tiempo sobre el escenario, mientras que las consagradas generalmente cerraban los shows y eran mayormente promocionadas. De manera que las primeras continuaban ocupando un lugar secundario y periférico.

\footnotetext{
${ }^{158}$ Era un productor reconocido dentro de la escena metálica argentina que falleció el 9 de enero de 2017.
} 
De hecho, frente a estas diferencias, mediante la netnografía en Facebook vi que varias bandas y músicos realizaron publicaciones y comentarios en tono de protesta contra el cobro a los grupos para que puedan presentarse en el festival. Al mismo tiempo, otros músicos expresaban su alegría a través de la red social cuando lograban ingresar a la grilla del evento sin haber tenido que pagar o rendir una determinada cantidad de entradas, régimen económico que suele caracterizar a las escenas tanto del rock como del metal y sobre lo cual me explayaré más adelante.

Además de estos festivales, también pude encontrar otros de menor envergadura realizados en provincias tales como Salta, Jujuy, San Juan y Buenos Aires, en los cuales participaban bandas de diferentes puntos del país. En el caso de la escena bonaerense, la mayoría de dichos eventos fueron realizados en el Área Metropolitana Bonaerense bajo una impronta underground.

En este sentido, pude ver que los grupos que hegemonizan la escena metálica bonaerense también lo hacen a nivel nacional. De manera que, al igual que sucedía con Hermética, grupos tales como Malón, Almafuerte y Horcas realizan giras por distintas provincias del país, pero el movimiento inverso (es decir, de los grupos provincianos hacia la capital) se hace mayormente de manera underground.

De acuerdo a las entrevistas realizadas, este intercambio no implica necesariamente el reconocimiento a nivel nacional, por lo que cuando algunas bandas semi-profesionales son reseñadas por revistas, portales de Internet o fanzines de otras provincias, es tomado por sorpresa. Por ejemplo, los músicos de un conjunto de thrash metal de la ciudad bonaerense de Tres Arroyos se sorprendían de que su disco estuviera en manos de un aficionado catamarqueño:

Una cosa es lo que pasó en Catamarca en el "Pacha Huasi" el último día, ya no teníamos más plata y salimos a vender discos para comer, ¿viste? Y pasó que a un pibe le digo: "Eh, loco, te vendo el CD de mi banda". Y me mira y me dice: "No, te lo compré en el 'Metal para Todos"”. ¡En Catamarca estaba el chabón!

En general, las agrupaciones que logran ser reconocidas a nivel nacional son aquellas que pudieron grabar con sellos discográficos porteños, lo que aumenta las posibilidades de distribución y la calidad de producción. Un caso que se puede citar es el de Aonikenk, conjunto originario de Neuquén que desde 1998 fue apadrinado por Iorio por su impronta indigenista y en 2014 grabó el disco "Sentir metalero" con el sello porteño, Icarus Music. 


\section{Intercambios entre las ciudades (y la puja entre la capital y "el interior")}

Como ya mencioné en capítulos anteriores, dentro de la escena metálica bonaerense existe una gran circulación tanto de bandas y músicos como de aficionados. De esta manera, una característica de esta escena es el movimiento espacial mediante el viaje, lo cual sucede en tres direcciones: primero, entre las propias ciudades del interior; luego, por parte de los metaleros porteños hacia esos lugares; y finalmente, a la inversa. A pesar de ello, CABA constituye la meca a la cual aspiran llegar tanto músicos como mediadores para ser consagrados, al mismo tiempo que resulta ser el centro de las instituciones que son la base de la escena.

Estas diferencias se materializan en la descripción de la escena porteña como "saturada" (González en Caballero y Bernal, 2016, p. 49), mientras que en las ciudades del interior hay menor cantidad de bandas y suelen pasar varias semanas e, inclusive, meses entre cada recital. Estas diferencias se pueden visualizar en la cantidad de conjuntos musicales. De acuerdo al análisis cuantitativo de Javier Alfredo Rodríguez (2017) basado en los datos de Enciclopedia Metallum - Metal Archives:

Con más de 3.000.000 de habitantes repartidos en sus escasos $203,3 \mathrm{~km}^{2}$ de superficie, sus 421 bandas la ponen en una situación de clara preeminencia y hegemonía frente al resto del país. No hace falta ser un especialista para observar que se repite claramente aquí lo que ya conocemos: se trata de la principal metrópolis económica, política y comercial del país, y considerando los hechos específicos de nuestra historia nacional, su hegemonía cultural la ponen en un lugar de vanguardia en los términos de la aparición y difusión de cualquier fenómeno cultural urbano, y en ese sentido el heavy metal no escapa a esa particularidad. (Rodríguez, 2017, p. 34)

Efectivamente, el análisis de la misma página web extendido a CABA y a la provincia de Buenos Aires demuestra que en el Área Metropolitana Bonaerense se concentran la mayor cantidad de agrupaciones, mientras que el resto se encuentran dispersas en pequeñas cantidades en el resto el territorio de la provincia (Ver Mapa 1).

Pero además de los grupos musicales se encuentran los mediadores de la escena, cuya presencia es relevante debido a que "Las escenas de la música metal dependen de instituciones para su supervivencia" (Wallach y Levine, 2013, p. 121). Estas están constituidas por las disquerías, rockerías, salas de ensayo, estaciones de radio y, especialmente, espacios para el desarrollo de recitales.

De todas las instituciones mencionadas, en la escena metálica bonaerense las estaciones de radio son las que resultan más accesibles y con mayores posibilidades de 
desarrollo, ya que muchas son beneficiadas con la extensión de su transmisión vía Internet, lo que permite la llegada a mayor cantidad de audiencia en un rango más extenso que el de la propia ciudad. Además, dicho medio de comunicación se encuentra disponible tanto en la capital como en los pequeños pueblos del interior.

En la vereda opuesta está la televisión, ya que el único programa televisivo relevado en la escena fue "MTL" transmitido por el canal CMTV entre 2011 y 2015. Este era conducido por Walter Meza del grupo, Horcas. A pesar de que se podía ver por televisión abierta en cualquier localidad de la escena, era producido en CABA. En la misma línea que algunas emisoras como Vorterix y Rock and Pop, con "MTL" se puede observar el movimiento de la capital hacia el interior, pero no en sentido inverso.

Por el contrario, las rockerías y principalmente las disquerías son lugares en vías de extinción en la provincia, pero que se mantienen en pie en CABA. En consecuencia, se produce la circulación desigual de discos, indumentaria y accesorios típicos de metal y otros estilos musicales. Lo mismo sucede con las casas que venden instrumentos musicales.

En general, cuando estas instituciones se ubican en ciudades del interior, compran mercadería en la capital. Esto hace que, en muchos casos, los aficionados prefieran adquirir discos, ropa, accesorios e instrumentos musicales a través de Internet, ya que les permite encontrar objetos que son difíciles de conseguir o están a menor costo sin necesidad de viajar a CABA o de depender del stock que hay en sus ciudades, las cuales se abastecen de aquellos elementos que van a vender con seguridad. Es por esto que en las rockerías abunda mayormente material de las bandas más comerciales de metal.

Entre el 2011 y el 2017 surgió un nuevo formato de reunión: las ferias. Estas aparecieron como una manera alternativa de comercio y de sociabilidad, y se asemejan a las ferias de discos y fanzines de la década de los '80. Algunas de ellas son montadas a la entrada de los recitales, tomando como referencia los puestos de merchandising de los conciertos de bandas de circulación global. Otras prescinden del concierto y el objetivo simplemente es difundir la cultura metálica. Un ejemplo de ellas son las Ferias del Libro Heavy, realizadas en CABA, Mar del Plata y Tandil a partir del 2013.

Por su parte, los espacios para la realización de conciertos constituyen la institución escénica más celebrada (Weinstein, 2000; Wallach y Levine, 2013). A pesar de ello, en la escena bonaerense este espacio es castigado por las políticas públicas de 
los diferentes municipios. En la mayor parte de las ciudades observadas o referenciadas por sus agentes en las entrevistas hay pocos lugares disponibles para realizar recitales.

De esta manera, las bandas deben buscar espacios alternativos como por ejemplo, plazas, clubes barriales y sociedades de fomento (Ver Figura 41). En algunos casos, estas alternativas son ofrecidas por la Unión de Músicos Independientes (UMI), aunque son pocos los músicos que se asocian a dicha institución. Es necesario destacar que solo las agrupaciones amateurs deben enfrentarse a la escasez de "lugares para tocar", ya que para las agrupaciones profesionales locales $\mathrm{y}$, especialmente, las extranjeras, los productores disponen de teatros y estadios con mejores condiciones de producción y de infraestructura.

Uno de los factores que incidió en la dureza de las políticas públicas fue la tragedia del local porteño, República Cromañón en 2004, durante un recital de la banda de "rock chabón", Callejeros. Dicho accidente dejó un saldo de 194 muertos y 700 heridos, e implicó un punto de inflexión en la actividad musical a través de la intervención del estado mediante diversas medidas de seguridad, el achicamiento del circuito de locales para conciertos y la limitación del desarrollo de la música independiente (Corti, 2009, p. 1).

A pesar de que mi trabajo de campo fue realizado 7 años después, pude ver cómo las políticas públicas muchas veces imponían un control rígido sobre los locales dedicados al rock, mientras que no existía tanta dureza con aquellos lugares que organizaban eventos para otros géneros musicales. Estas diferencias generaban un malestar amplio en la escena bonaerense del rock, lo que también traía consecuencias en el campo metálico. De hecho, en mis etnografías pude presenciar las clausuras transitorias e, inclusive, el cierre definitivo de algunos espacios para la realización de conciertos.

Un productor independiente tandilense se expresó sobre este asunto en una entrevista en la cual le pregunté acerca de las consecuencias de la tragedia de Cromañon:

Hoy en día creo que hay más controles. Y la gente a veces se cuida un poco de esas cosas. Yo no sé qué decir... hoy creo que del lado de la producción, yo pienso que la producción tuvo la culpa de ese accidente, porque la producción sabe todo. Desde el día uno, hasta el día cero, que terminó el show, vos sabés todo lo que está sucediendo, todo. $\mathrm{Si}$ vos pichuleas en la seguridad, sabés que si hay un quilombo muy grande, vas a tener un problema porque pichuleaste en la seguridad. A veces, yo también... hemos hecho, todo productor que venga y te diga "no, yo nunca hice nada", es mentira. Todos hemos achicado gastos, todos hemos pasado por alto algo, porque la exigencia te ha llevado. 
Entonces hoy en día creo que todos los que somos más o menos coherentes en ese aspecto sabemos lo que va a suceder, qué es lo que tenés. Pero vos se lo exigís a la persona que corresponda, ¿entendes? Si yo contrato a una seguridad y pasa algo, yo contraté a la seguridad, el responsable es la seguridad, ¿entendés? Porque por algo yo pongo toda mi confianza en tu productora de seguridad, para que vos cuides y no pase esto. Entonces la productora sabía lo que pasa en ese momento: la seguridad era muy floja en los cacheos, ¿entendes? (...) Yo creo que hoy en día los lugares están más capacitados para eso. Nadie quiere comerse un garrón en este momento. Ni tampoco una persona va a querer que pase eso. Ningún productor en la puta vida va a querer que alguien se le muera en un recital. (...) Hoy generalmente en nuestros "recis" hacemos un seguro de espectador, ¿viste? Que eso te cubre. A partir de todo esto se hizo eso. Entonces, el seguro de espectador te cubre cualquier cosa que le pasa a la persona. (Productor independiente tandilense, 2015)

Sin embargo, este productor se encarga mayormente de recitales de bandas profesionales, lo que resulta diferente en el caso de los productores amateurs que muchas veces no tienen las posibilidades de acceder a estos detalles. Pero, tal como se expresó en la primera parte de esta tesis, es muy visible la intensidad con la que el público se cuida entre sí para que el desarrollo de los conciertos se produzca de manera pacífica.

A partir de las dificultades que se presentan ante las instituciones propias de la escena, se conforma una red de agentes (en su mayoría amateurs) que se movilizan para que puedan realizarse eventos especializados y facilitan la producción, la circulación y el consumo del estilo musical. Al igual que el resto de las escenas musicales del Área Metropolitana Bonaerense, "Junto a una oferta musical clásica (basada en grandes grupos, recitales, discografía, promoción radial y televisiva) se despliega una escena que en un nivel menos visible es como un movimiento hormiga intenso y continuo." (Gallo y Semán, 2016, p. 19)

Esto se debe a que, además de los mediadores -productores, editores, periodistas, managers- y músicos consagrados, existe otra gran cantidad de agentes que mantienen activa a la escena metálica bonaerense y le otorgan continuidad, pero se movilizan en un nivel que se podría denominar underground, debido a que se trata mayormente de amateurs, muchas veces músicos o aficionados que comienzan a hacerse cargo de la producción. La importancia de la agencia de dichos seguidores es expresada por el gestor cultural, Gito Minore (2014):

El heavy metal argentino es un fenómeno autogestivo e independiente, que no necesita pagar grandes campañas publicitarias para difundirse. Todo lo contrario. Se reproduce entre los mismos seguidores, los mismos fieles, miembros irremplazables de la movida, que llevan y traen la información con todos los dispositivos disponibles, desde los más rústicos a los más sofisticados. 
Básicamente, de ese modo se movió siempre este género, sin más grandes necesidades que seguir generando y disfrutando la música que nos gusta. (p. 9)

Dentro de esta red de agentes, la amistad aparece como uno de los valores fundamentales para la producción, la cual trasciende el interés puramente económico. Tal como expresan Gallo y Semán (2016),

Los proyectos estéticos y comerciales que encarnan cada una de las organizaciones implican un trabajo en redes que no está reducido ni a lo técnico ni a lo virtual. Lo virtual y otras condiciones permiten redes que, antes que nada, después de todo, están definidas por una moralidad, un valor afectivo que tienen mínimos de cumplimiento. En ellas, el término "amigo" significa varias cosas al mismo tiempo: que no se trata simplemente de una cooperación técnica o comercial, que hay una familiaridad precedente o por construir, que hay una afinidad que tiene que ver con el ser artistas y con serlo de una determinada manera. (...) Esto no implica de ninguna manera vínculos de lealtad a prueba de cualquier conflicto ni pactos de sangre, sino una dimensión de empatía que une a la cooperación interesada el horizonte cualitativamente definidor de la complicidad en un proyecto difícil: vivir del arte. Darse impulso recíprocamente en caminos que son cuesta arriba tanto en lo económico como en la labor de darse un lugar en un universo de intervenciones estéticas saturadas en el que, sin embargo, hay que marcar una diferencia. (p. 55)

Al igual que en el indie platense, en la escena metálica bonaerense la idea de amistad resulta “(...) capital social clave para esta arena musical” (Boix, 2016, p. 112). Esto se debe a que "Fotógrafos, diseñadores (gráficos, de ropa, de objetos), escenógrafos, ilustradores, videastas, djs y vjs, dibujantes, participantes de colectivos culturales diversos, periodistas gráficos o de radio, colaboran por bajas o nulas remuneraciones monetarias con la producción de esta escena.” (Boix, 2016, p. 112. Cursivas del original)

Efectivamente, la escena metálica bonaerense está compuesta por miembros que no solo se reducen a músicos, mánagers, productores, periodistas o públicos, sino que también se constituye por artesanos, diseñadores, tatuadores, peluqueros, maquilladores, mecánicos, dibujantes, herreros, pintores, escritores, performers, etc., que colaboran de diversas formas y en diferente medida con el desarrollo del campo aquí estudiado.

Dicha variedad se hace visible en las ferias metaleras y en las Ferias del Libro Heavy, eventos en donde dichos agentes no solo pueden exponer sus creaciones sino también comercializarlas, aunque muchas veces el objetivo de ellos es principalmente la visibilización y la promoción de sus trabajos. Esta multiplicidad de tareas en torno a la relación de amistad hace que sea pertinente, 
(...) pensar al grupo de amigos en los términos de un mundo del arte de Howard Becker (2008); una red de personas cuya actividad cooperativa, organizada a través de un conocimiento conjunto de hacer cosas, produce trabajos que un grupo dado define "artísticos". (Boix, 2016, p. 111)

De esta manera, la amistad actúa como un "vínculo cooperativo" (Becker, 2008, p. 43) que, en el caso del metal, se produce a través del valor de la solidaridad (Weinstein, 2000). A esto lo pude observar en una entrevista realizada a un productor amateur de la ciudad de Mar del Plata:

Empecé lo de la producción por el tema de autogestionar nuestros propios recitales cuando comencé con la banda que tengo. Viendo también y aprendiendo, primeramente por el hecho de tener muchos amigos músicos más grandes que yo. Y siempre me gustó estar en ese ámbito, porque noté mucho compañerismo, amistad y un mundo muy especial... La música, el arte en sí, muy nómade. Yo siempre fui muy nómade, de estar de lugar en lugar, pero nunca escapando, sino buscando lograr cosas y funcionabilidad sobre todo, ¿no? Así que lo de la producción se dio principalmente como algo que se inició como músico. Primero observando como público, después como músico y hoy en día viendo que sea entre amigos. Entre colegas nos unimos y hacemos de esto, de lo imposible, lo concreto, lo real. Hoy podemos dar fe de que entre amigos podemos hacer esto posible. (Productor amateur marplatense, 2016)

La amistad, además, en la escena analizada puede describirse como un vínculo que implica el conocimiento personal del otro, es decir, la comunicación "cara a cara". En algunos casos, especialmente los que se producen entre habitantes de diferentes ciudades, la interacción comienza de manera virtual a través de las redes sociales de Internet y el viaje a un recital resulta ser el movilizador para el encuentro de manera personal.

Este conocimiento cara a cara es el que permite el flujo de bandas en el interior de la provincia y la amistad resulta ser el valor que asegura estos intercambios: cuando hay una buena relación entre los músicos de diferentes conjuntos o entre ellos y los productores existen mayores posibilidades de volver a ser convocados para recitales en otras ciudades.

De esta manera, la escena metálica bonaerense se caracteriza porque sus participantes mantienen vínculos amistosos no solo con agentes de sus propias ciudades, sino también con los de otras. Esto permite que se realicen festivales con bandas provenientes de distintas zonas. Por ejemplo, en una entrevista realizada a uno de los productores amateurs del festival "Zona de aguante" realizado en Tandil en 2015, cuando le pregunté acerca del nombre del evento me respondió: 
El aguante significa, en la movida de las bandas y de la música en vivo, significa estar, participar, ser testigo presente de un evento donde bandas o una banda organiza un festival... Y se juega mucho en esas cosas, porque son músicos que no viven de la música. Son jefes de familia, trabajan, mantienen una casa y tienen un gasto en ensayo, en instrumentos, en tantas cosas, que después lo vuelcan, lo ponen en un escenario en vivo, montando un show en donde tienen que alquilar el lugar, rendir entradas, pagar SADAIC. Y creo que debemos de estar nosotros como un estilo de vida que elegimos vivir y oír un estilo de música. Creo que debemos aportar nuestra presencia física. Yo lo comencé a entender desde hace cinco años. Yo iba a recitales, viste, pero era una persona que se quedaba oculta en un rincón, o sea no se mostraba. Pasaron situaciones que me volcaron la cabeza hacia otro punto y comencé a entender lo que significa seguir de pie, yendo al frente, siguiendo un espíritu combativo. Se me despertaron motivaciones extra que me permitieron estar al frente de una banda, apasionadamente mostrándome, y ver que con el tiempo se generó un cambio porque es una forma... La gente viene y te lo dice "loco, cómo nos inspirás, cómo nos inspirás a estar acá. Me inspirás a manifestarme a mí de una manera que yo antes no lo hacía". Entonces te mirás al espejo y decís "loco, algo bueno está pasando", ¿esto es el aguante? ¿Será la motivación? Creo que el aguante es eso me parece, la motivación hacia una persona que por alguna razón te presta atención, porque vos... Se palpa en vos el aguante, se palpa, nace un respeto hacia vos, entonces esas personas se interesan en conocerte, en llegar a vos. Y por ahí, sin querer, conociendo a esa persona vos, en una charla en donde uno se muestra como es, podés llegar a contagiarle un grado de voluntad que por ahí no lo tiene hasta ese momento y encontrás en un punto... "Pucha, loco, cómo me motiva este chabón para ir para adelante". Estar acá en un recital, mostrarme apasionadamente con las bandas. Creo que me parece que eso es el aguante, ¿no? Contagiarnos mutuamente, tratar de inspirarnos, motivarnos cada uno: músico-público, público-músico o público y público. Me parece que es eso. Conocernos desde un lugar que generalmente son los recitales y siempre lo serán y contagiarnos esa motivación, ¿no? Me parece donde uno despierta al otro de un momento y le genera un antes y un después, ¿no? Me parece que en mi caso eso es el aguante, ¿no? Como te digo, te lo repito nuevamente, una cosa de contagiarse inspiración, respeto, voluntad, la cosa es siempre ir para adelante. Y bueno, y en la zona desde hace tiempo que comencé a ir a recitales, desde Tandil, Tres Arroyos, alguna que otra vez en Azul, en Benito Juarez, Ayacucho, fui conociendo gente, mucha gente, y siempre hubo un respeto entre ellos y yo, y yo y ellos, y se fue dando esa cosa de que por alguna razón, "che, loco, tengo una banda en Mar del Plata para que te puedas presentar. Comunicate con ellos, tal vez querés ir a tocar a Mar del Plata". Y se han comunicado, y han sido esos idas y vuelta que las bandas suelen hacer, yo te lo hago y venís a mi ciudad. Y se fue encendiendo una llama que se había perdido en realidad, los idas y vuelta. Conocernos entre público tandilense con público marplatense, o público de Benito Juarez, o público de Azul, y fue naciendo un espíritu que bueno, yo como siempre estoy vigente y voy a recitales, veo que está muy encendida esa fogata. Entonces desde ese lugar me nació el título "Zona de Aguante", porque es una zona: Azul, Olavarría, Tandil como el centro de la provincia, Ayacucho, Benito Juarez, Bahía Blanca, Tres Arroyos, Balcarce. Entonces en esta ciudad he conocido a distintas personas. (Productor amateur marplatense, 2015)

Esta forma de relacionarse se liga con el valor de la amistad en tanto "hermandad", tal como mencioné en la primera parte de esta tesis. Mediante este vínculo la escena se conforma como una comunidad a pesar de que sus participantes se encuentren dispersos geográficamente y se promueve un ideal o "mito" de la igualdad. 
Sin embargo, tal como he mencionado, los vínculos cara a cara son fundamentales para dichos agentes, por lo que es necesario para ellos acortar las distancias físicas. Esto se puede observar en la gran cantidad de grupos de Facebook que fueron creados para poder contactarse con aficionados de la propia ciudad y de la región y coordinar encuentros ya sea simplemente para asistir a recitales, como para formar bandas y organizar eventos. A través de la netnografía pude relevar los siguientes: "metal-tandil 'mosh, pogo y eslam"”; "Heavy Metal Junin"; “Ayacucho Underground"; "HIJOS DEL METAL , BALCARCE"; "Metaleros de Olavarria y la Zona"; "NecoMetal"; "Metaleros del atlantico" y "sociedad de metaleros suipacha, mercedes y chivilcoy".

Estos grupos dan cuenta de que la red social, Facebook: “(...) raramente aparece para crear escenas puramente virtuales; más bien se ha esforzado por colonizar las zonas liminales entre escenas musicales virtuales, locales y translocales" (Bennett y Rogers, 2016, p. 154). De hecho, en la escena metálica boanerense dicha red también es utilizada como un portal de información, una guía de eventos y una plataforma de conocimiento comunal que permite coordinar y aumentar las formas locales de participación (Bennett y Rogers, 2016).

Por otra parte, en la denominación "zona de aguante" del festival citado, si se toma al concepto de "aguante" como forma de resistir al sistema dominante (Blanco y Scaricaciottoli, 2014), se puede ver en dicha frase cierta "exaltación localista" (Pasolini, 2013) que es comparable al "orgullo del paria", ya que propone la supervivencia frente a las dificultades que conllevan no ser el "centro" sino el "interior" y la "periferia".

Al mismo tiempo, los aficionados del Conurbano bonaerense también realizan una exaltación de sus zonas de proveniencia, entre las que el oeste parece ser la privilegiada por los músicos de metal. Esto se puede ver especialmente a través de las producciones de Iorio que, tanto en Hermética (con la canción "Desde el oeste") como en Almafuerte (por medio del tema, "Donde está mi corazón”), homenajea a dicha zona. De cierta forma, para el imaginario metálico del Área Metropolitana Bonaerense, la zona oeste del Gran Buenos Aires es la "cuna" del "rock pesado" y del metal, al mismo tiempo que dicha ubicación geográfica otorga cierto carácter de marginalidad.

Frente a esto, la escena bonaerense no adquiere un carácter “provinciano". Por el contrario, las escenas de las diferentes localidades se autoidentifican como "locales" y “zonales", mientras que la escena porteña (al igual que en otras expresiones culturales) parece verse a sí misma como "argentina” -por medio de la operación de la sinécdoque-, 
cuyas referencias a la argentinidad están dadas por elementos culturales rioplatenses y por referentes impuestos por la cultura hegemónica, tales como el tango y la figura del gaucho.

Con respecto a la amistad, en su trabajo sobre el indie platense, Boix (2016) explica que en dicho campo esa categoría “(...) no responde a una amistad personal o emocional, sino a una proximidad estética y ética que no implica necesariamente la intimidad (aunque ésta pueda manifestarse)" (p. 113). Por el contrario, en la escena metálica bonaerense el vínculo amistoso cobra una dimensión diferente, ya que sí tiene en cuenta lo emocional, debido a que, como analicé en la primera parte, la amistad resulta ser uno de los significados morales fundamentales para los agentes de la escena, ligado a la ética de la autenticidad metálica.

No se trata simplemente de desarrollar la confianza como un elemento clave de la red (Becker, 2008, p. 109). La lealtad cobra una profundidad especial, ya que los participantes de la escena no solo la involucran en sus acciones hacia el desarrollo de dicho campo, sino también en el resto de los ámbitos de sus vidas. De manera que la moralidad que caracteriza a la autenticidad metálica es traspolada a la cotidianeidad y, de esa manera, el metal se convierte en una "filosofía de vida".

La concepción profunda de la amistad hace que además de posibilitar el desarrollo de la escena, también genere trabas. En primer lugar, porque dicho vínculo resulta ser un criterio de selección por parte de los mediadores (productores y periodistas), tal como se puede observar en el siguiente fragmento de la entrevista realizada a un productor amateur marplatense en 2016:

Productor: (...) siempre tratamos de encontrar el camino acorde a la amistad. Uno llama a grupos que conoce, no gente que convoca y de repente no tenes ese feeling, esa química que se necesita para sentirse bien, ¿no? Entonces yo creo que si uno confía y apuesta a la amistad, de la misma forma va a ser el reflejo que te van a devolver a vos, ¿no? Entonces con ese sentimiento y esa convicción es que sí, estoy produciendo eventos, sino de otra forma no lo haría.

Yo: O sea que uno de los criterios para que vos selecciones las bandas que participan en tus eventos es la amistad.

P: Sí, sobre todas las cosas (...).

Entonces, cuando la amistad resulta ser un criterio de selección, muchas veces también puede ser de exclusión para aquellas bandas que no poseen un vínculo amistoso con los productores. Por otra parte, la amistad entre músicos (y aficionados) resulta necesaria para poder acceder a aquellos eventos que deben realizarse de manera 
clandestina cuando las políticas públicas no lo permiten. En otros casos, este contacto interpersonal permite que algunos aficionados asciendan de nivel. Por ejemplo, esto se pudo apreciar en aquellos amigos de Iorio que provienen de ciudades del interior y, a través del vínculo con el músico, generan un intercambio profesional que les permite acceder a los circuitos nacionales.

De cierta manera, dicha amistad forma parte del capital social necesario para la actividad musical dentro de la escena, ya que este es

(...) el conjunto de recursos actuales o potenciales que están vinculados a la posesión de una red sostenible de relaciones más o menos institucionalizadas de conocimiento mutuo e interreconocimiento; $\mathrm{o}$, en otras palabras, el hecho de pertenecer a un grupo como un conjunto de agentes que no solo están dotados de propiedades comunes (que pueden ser percibidas por el observador, por otros o por ellos mismos) sino que también están unidos por enlaces permanentes y útiles. (Bourdieu, 2006, p. 31. T. de la A.)

La amistad no solo se convierte en capital social para los músicos sino también para algunos miembros de la audiencia, los cuales se benefician a través de la invitación a reuniones y la integración a grupos de amigos. En ciertos casos, este tipo de relaciones también conlleva el abuso por parte de algunos aficionados que, al ser cercanos a los organizadores o a las bandas que se presentan en el concierto, intentan ingresar sin pagar entrada. En una entrevista etnográfica, un productor independiente de la ciudad de Tandil me explicó lo siguiente:

Yo: ¿Qué perspectiva tenés acerca del público metalero de Tandil?

Productor: Que no van a los recitales, eso veo. Porque mirá, yo no entiendo mucho... La otra vez que vino el cantante de Slayer, creo que era...

Yo: Ripper Owens.

P: Ese, Ripper Owens. Y había 130 personas. ¿A vos te parece? (...) ¿A dónde estabas, hermano? ¿En tu casa? Te lo pusieron un poco más en la puerta de tu casa, jte tocaba timbre para ir! Pero no, llegaba a tocar en Buenos Aires, "no, me voy a Buenos Aires a ver a Ripper Owens, eh. Me gasté una luca en el viaje y la comida y el chupi y la entrada que me salió 500 mangos". Y, ah, ahí sos re pro. Pero venir a verlo acá, a la vuelta de tu casa y pagar 250 pesos, 300 pesos, no lo pagas. Sos un pija bárbaro.

Yo: ¿Y por qué creés que pasa eso, que no van?

P: Porque, ¿sabés lo que pasa hoy en día? La gente pretende lo siguiente: pretende que le pagues el remis ida y vuelta a la casa, pretende escabiar gratis adentro del lugar y que lo dejes entrar gratis. Eso es lo que pretende el público de Tandil hoy en día, y no se concientiza en todo lo demás. De que hay una movida, de que la persona que trajo, a ese artista que a vos te gusta está cortando clavos y esperando a que vos pagues la entrada para poder zafar.

Esta poca predisposición para pagar entradas muchas veces genera que los productores independientes no apuesten a organizar grandes recitales en ciudades 
pequeñas, por lo que se continúa manteniendo la centralidad de CABA, en la cual la gran cantidad de habitantes y, por ende, de público metálico, aseguran la organización de un concierto sin pérdidas económicas.

Por otro lado, la amistad también implica la existencia de enemistad. Es decir que, dentro de la escena, no todos los participantes tienen un vínculo amistoso entre sí, sino que también existen diferencias entre algunos de ellos que hacen que existan múltiples grupos, muchas veces rivales entre sí, lo que dificulta el desarrollo óptimo de la escena. En ese sentido, se plantean diferencias intergrupales dentro de la propia comunidad metálica. Tal como plantea Tajfel (1984)

\begin{abstract}
Las relaciones intergrupales competitivas o con espíritu de cooperación, hostiles o amistosas, están determinadas en gran medida por la lógica de las situaciones dentro de las cuales surgen. Una vez dado esto por sentado, también es cierto que estas situaciones tienen sus efectos en los motivos y actitudes de millones de individuos, que estos motivos y actitudes a su vez determinan la conducta, y que esta conducta determina a su vez en parte las subsiguientes relaciones intergrupales. (Tajfel, 1984, p. 157)
\end{abstract}

En el caso de la escena metálica bonaerense la lógica que predomina está ligada a la ética de la autenticidad, por lo que las relaciones interpersonales se encuentran determinadas por dichos parámetros. Por otra parte, muy raramente los aficionados se mueven de manera individual dentro de la escena. Por lo general suelen formar parte de un grupo de amigos o conocidos, al menos transitoriamente durante los eventos especializados. Esto hace que los vínculos interpersonales algunas veces dialoguen con el carácter intergrupal, lo cual se acentúa con mayor énfasis en el caso de las bandas entre sí.

Gallo y Semán (2016) explican que "Como no hay armonía eterna y como los proyectos se agotan, se terminan o dispersan; concluida la amistad, los conflictos, reclamos y estallidos que puedan presentarse deben ser procesados para no bloquear definitivamente las iniciativas artísticas." (p. 56). Esto se puede observar en la gran cantidad de agrupaciones que se separan, inclusive, la propia Hermética.

Su historia, además, resulta un reflejo de cómo la amistad se fija como un valor fundamental: al separarse el conjunto se conformaron Malón y Almafuerte y la escena se dividió movilizada por la fidelidad hacia uno u otro bando. A pesar de que solo el círculo íntimo conoció la versión oficial de la disolución, se generaron una gran cantidad de historias en torno al hecho, no solo para defender una posición sino también para defenestrar a la otra. 
La enemistad entonces genera algunas trabas, como explica el productor marplatense anteriormente citado:

(...) muy distinta es la escena de Capital, cuando hay cuatro millones de personas alrededor, ¿sí? Como el hecho de decir, bueno, en Mar del Plata a veces las bandas te hacen cuatro eventos el mismo día y van veinte personas a cada recital. Cuando hay cuatro bandas y van veinte personas, ¿cómo puede ser? Y no solo la banda de afuera brilla, sino que le cuesta a todos y todos se opacan también. Es como una competencia que se ha generado y que la escena, si no está con los cimientos tan firmes... ¿Sabes cuál es el problema? Que la mayoría de la gente no es público, son todos músicos. Entonces son todos celosos del otro. Eso genera ese clima tenso que después las amistades terminan enroscadas en quilombos y dicen "no, no puedo ir a ver a la banda de Alfredo porque qué me va a decir Roberto". ¿Entendes? Y yo soy amigo de los dos pero no quiero quedar mal con ninguno. Entonces preferí no ir a ninguno de los dos. Y están perdiendo fluidez y a vos te están privando de disfrutar lo que a vos te gusta. Si el problema es de ellos, no es tuyo, por qué te tienen que generar. Si la música tiene cuña, si ellos tienen problemas, que se lo arreglen entre ellos y si no, mala suerte. Pero bueno, eso es lo que veo de la movida en general. Estamos ahí... de a ratos en terapia intermedia, de a ratos en sala común, después entramos en un coma... o sea, estamos en una situación que, te repito: en el under, se sigue resistiendo, más allá de todos estos inconvenientes. (Productor amateur marplatense, 2016)

Tal como planteó el entrevistado, en mi trabajo de campo observé que la enemistad muchas veces generó fracturas fuertes que se visibilizaron en recitales con muy poca cantidad de asistentes. De hecho, en ciudades pequeñas fue evidente que a determinadas bandas las iban a ver sus propios amigos, los cuales jamás iban a ver al grupo de músicos con lo que no tenían una buena relación. Cuando sí asistían, en las conversaciones daban cuenta del esfuerzo que había implicado ir y, a su vez, dicha concurrencia muchas veces significaba ir a observar el recital desde una perspectiva evaluativa, dispuesta a criticar a sus "rivales" hasta en el más mínimo "pifie".

Por otra parte, tal como plantea el productor citado, pude ver que en los últimos años una gran cantidad de aficionados de la escena comenzaron a tocar un instrumento musical y a formar sus propias bandas. La expresión de "ahora son todos músicos" no solo la escuché en conversaciones durante mis etnografías en ciudades del interior, sino también en CABA. De esta manera, si existía una enemistad anterior, el hecho de convertirse en músico hacía que la conflictividad del vínculo se hiciera más visible.

Otra similitud con el indie platense es que en la escena metálica bonaerense la amistad y la enemistad muestran que “(...) entre sus participantes, se despliegan lazos que tienden a disolver las diferencias clásicas entre los 'músicos' y los 'públicos' (...) resultando una escena musical y estética co-constituida” (Boix, 2016, p. 113). Esto se 
reafirma con la transformación de los aficionados devenidos en músicos y en mediadores especializados de la escena.

Entonces, tal como se puede ver en las palabras del productor marplatense, la enemistad genera competencia, la cual se incrementa cuando el objetivo no solo es promocionarse, sino también ser reconocido. $\mathrm{Y}$ en este proceso entran en juego los mediadores especializados: por un lado, las instituciones de producción (sellos discográficos y productores de recitales) y, por el otro, las de difusión (medios de comunicación, tanto los especializados al metal como los dedicados al entretenimiento en general).

Con respecto a las instituciones vinculadas con la producción, tanto los principales sellos discográficos de la escena como las productoras más grandes se encuentran en CABA. Estas se caracterizan por ser independientes con respecto al mercado cultural hegemónico. Según Boix:

La industria de la música en cada país se divide en majors (las grandes empresas globales) y las llamadas indies o minors (independientes), que van desde las micro empresas de subsistencia y las PyMEs hasta las grandes empresas nacionales, usualmente pertenecientes a conglomerados mediáticos (Yúdice, 2008). Así, las majorlabels son Universal, Sony-BMG, EMI y Warner Music, multinacionales que se han diversificado hacia otros campos del "entretenimiento". (2016, p. 122. Nota al pie. Cursivas del original)

Entonces, las instituciones de producción propias de la escena metálica bonaerense no forman parte de ninguna multinacional y en general se encuentran enfrentadas a la hegemonía de los productores de música masiva. La definición "independiente" incluye a "músicos que aún no han editado placas ni tienen relación con productoras y/o discográficas, músicos que han editado de forma casera, músicos que producen y/o distribuyen a partir de sellos pequeños y medianos (...), etc.” (Boix, 2016, p. 123). A pesar del carácter alternativo,

(...) esta "forma de hacer" tampoco garantiza una diferencia estilística respecto a aquellas obras creadas desde el centro de la industria (una alternatividad estética) o una actitud contraria al sistema imperante (una alternatividad ideológica): No obstante, la autogestión al permitir una mayor libertad de acción propicia una posición divergente e inclusive una diversidad sonora. (Lamacchia, 2015: 31. Cursivas del original)

A través de la netnografía realizada en la página web "The Metal Archives: Home - Encyclopaedia Metallum", mediante la búsqueda avanzada de sellos 
discográficos activos ${ }^{159}$ de la Argentina, observé que allí figuran un total de 34 sellos en la escena bonaerense, de los cuales 29 están ubicados en CABA. El resto se encuentran en Hurlingham, Villa Adelina, La Plata, El Talar y San Miguel (ver Mapa 2) ${ }^{160}$.

Por otra parte, es posible mencionar a varias bandas y músicos profesionales representativos a nivel nacional de origen porteño que crearon sus propios sellos discográficos, como por ejemplo Dejesú (de Ricardo Iorio), Ian (de Mario Ian) y Yugular Records (de Tren Loco). A pesar de ello, también existe una gran cantidad de grupos de la provincia que en una escala mucho menor graban sus demos de forma casera y suelen repartirlos personalmente sin ninguna retribución económica o, en otros casos, suben sus canciones a plataformas digitales de reproducción gratuita. Esto se debe a que "Hacerse conocido es la llave para poder tocar" (Corti, 2007, p. 69).

Aunque existe gran circulación en Internet, los sellos discográficos permiten la producción de calidad, la difusión asegurada del material grabado y la convocatoria a participar de recitales con agrupaciones reconocidas tanto a nivel nacional como internacional. En este sentido, aunque en la actualidad la industria discográfica haya cambiado (Gallo y Semán, 2016), en la escena metálica bonaerense los sellos siguen demostrando un pasaje de nivel.

Esto genera posiciones ambivalentes, debido a que algunos valoran que determinados grupos salgan del "under" y, otros, los tildan de "caretas" por haberlo hecho. Como ya se mencionó, uno de los ejemplos de bandas criticadas por estos motivos es Rata Blanca. También es posible mencionar a aquellos grupos que utilizaron las nuevas tecnologías no solo como forma de marketing sino también para interactuar de manera innovadora con su público.

Algunos ejemplos están constituidos por la banda porteña de ñu metal, Carajo que en 2016 creó una aplicación propia para celulares; y Metallica -la agrupación más mainstream de la escena metálica global- que en 2014 se presentó en La Plata en dos recitales que formaban parte del tour interactivo, "Metallica by request" ("Metallica a pedido"), en el cual la audiencia podía elegir las canciones del setlist al momento de adquirir la entrada vía Internet por medio de una votación. Además, el último tema de la

\footnotetext{
${ }^{159}$ Es necesario tener en cuenta este detalle, debido a que en dicha página web también figuran gran cantidad de discográficas especializadas porteñas que en su descripción no especificaron su ubicación, sino que directamente indicaron que eran de Argentina. Esto hizo que quedaran fuera del rastreo. Sin embargo, los resultados obtenidos permiten ver un panorama general.

${ }^{160}$ Este predominio también es visible a nivel nacional, ya que además de los 34 mencionados, solamente hay 7 por fuera de la provincia de Buenos Aires que se ubican en las ciudades de Rosario, Córdoba, Tucumán, Santa Cruz, San Salvador de Jujuy, Entre Ríos y Neuquén.
} 
lista de cada día fue elegido en vivo por aquellos miembros del público que votaban a través de sus smartphones. En pantallas gigantes que estaban a los costados del escenario se iba mostrando el progreso de los resultados minuto a minuto.

En este sentido, es posible observar que a pesar de que la independencia es el mecanismo de gestión de toda la escena metálica bonaerense, existe una lucha por la intensificación de esta característica. De esta manera, al igual que en otros géneros del rock, ser independiente es parte de la moral económica de la escena, debido a que

(...) aparece contrapuesto a lo mainstream, anglicismo usado para referir a los gustos y preferencias mayoritarias, asociadas a los grandes medios masivos. Por lo general, esta distinción implica un contraste moral, donde lo independiente es siempre creativo, puro $\mathrm{y}$ democrático frente a lo pretendidamente estandarizado, corrompido y oligárquico. (Boix, 2016, p. 123. Cursivas del original)

Esta moralidad forma parte de la ética de la autenticidad que no solo identifica al metal sino también al rock en general. De esta manera, se rechaza a la cultura de masas (Keightley, 2006) y al rótulo de "comercial” (Vila, 1989; Salerno, 2008), aunque las producciones rockeras y metálicas también sean una mercancía, tal como se convierte indefectiblemente la música a partir de ser grabada (Attali, 1995). Esta característica se constituye como una paradoja (Alabarces, 1995; Keightley, 2006).

Frente a esto se propone la idea de "Do it yourself" (DIY: "hazlo tú mismo") que tiene como objetivo evitar la mediación entre el artista y el público, la cual era ligada a la alienación con que caracterizaban a la sociedad de masas (Keightley, 2006). Con ese mecanismo se lograba mayor "realismo", es decir, más "autenticidad" y la "apariencia de libertad" (Keightley, 2006, p. 185). Entonces, de cierta forma, ser "auténtico" se convierte en sinónimo de ser "independiente" y underground, lo cual es valorado de manera positiva.

Esta moralidad hace que muchas veces las bandas mantengan “(..) su independencia hasta sus últimas consecuencias, aunque su no ingreso a la industria conlleve a una escasa o nula difusión en los medios masivos" (Corti, 2007, p. 67). Por el contrario, en la escena son valoradas aquellas agrupaciones que lograron masificarse sin haber "transado" con las multinacionales, dentro de las cuales Hermética es una de las más destacadas por los propios integrantes del campo metálico ${ }^{161}$. Aunque, desde mi punto de vista, aquí la apoyatura estuvo dada por parte de los medios de comunicación.

161 Tanto Hermética como Patricio Rey y sus redonditos de ricota son dos de las bandas más representativas del rock argentino que lograron tener convocatoria masiva a través del desarrollo 
Un ejemplo de la defensa ideológica de la independencia aparece en la fanpage de Facebook, "Metal que no se vende". Su descripción explica que el objetivo es "Difundir el Heavy Metal de descarga libre, promocionar a las bandas o solistas que eligen la distribución gratuita de su material a través de internet"162, para lo cual brindan el link de su blog, en el cual es posible ver que la ubicación de sus autores es Buenos Aires, quienes aclaran que se trata de un "blog de descargas legales"163. Los conjuntos que aparecen allí son en su mayoría del underground y pertenecen a distintos puntos del país. Visualmente, en ambos sitios web es posible encontrar tanto iconografía propia del metal, así como también simbología argentina, tales como la bandera del país.

La defensa de la independencia también fue observada en la tercera Feria del Libro Heavy de Mar del Plata del 2016. De acuerdo a algunos de sus organizadores, "La gestión del evento fue totalmente under" (Berta et al., 2016, p. 99). Esto se debía a que: "Hay que amar mucho lo que se hace para poder entregar tantas energías sin esperar nada a cambio. Es algo que el metalero entiende y que abraza como bandera.” (Berta et al., 2016, p. 99)

Además de las discográficas, otra de las instituciones de la escena son las productoras, las cuales poseen la misma ideología que los sellos: mantener la independencia. Sin embargo, aquí también sucede que se pueden ver varios niveles: En CABA se encuentran varias productoras que aglutinan tanto el trabajo de producción de recitales, como la edición discográfica y los medios de comunicación. Dentro del período estudiado, las más destacadas son Vorterix, 4G Producciones, MTM e Ícarus Music, las cuales se especializaban en metal no solo nacional sino también internacional.

En un nivel por debajo de estas productoras, se encuentran aquellos aficionados que se convirtieron en productores amateurs y trabajan de manera semi-profesional,

alternativo, lo que les otorgó legitimidad dentro del público rockero. Al mismo tiempo, esta elección económica tenía motivos éticos que permitía que artistas tan diferentes como Iorio, Skay Beilinson y José Larralde tengan vínculos en común. Esto se puede ver en una entrevista realizada al primero en 1994, cuando se le preguntó qué opinión tenia acerca de Los Redondos, respondió: "Muy buena. Me parece que, al igual que yo, consiguieron lo que siempre quisieron sin desviarse de su rumbo. Aparte, son una banda de Rock \& Roll argentina, no son un grupo de Los Ángeles o Inglaterra. Y son grandes. Yo no creo en las casualidades, sino en las causalidades, por eso me alegra que Skay y Poly siempre vengan a verme... Lo mismo pasa con Larralde, que cuando va a Sadaic, todos le tienen miedo y con el único que habla es conmigo (Iorio, RNS, 1994b)

${ }^{162}$ Dicha fanpage se encuentra disponible en el siguiente link: https://www.facebook.com/Metal-que-nose-vende-192947687349/

163 Dicho blog se encuentra disponible en Internet en el siguiente link: https://metalquenosevende.blogspot.com/?fbclid=IwAR2qX36GkXqVuCo-

v42jbBxGZMCWIdXOzhLUzoqfqxQ2s_7ZYGc7wku5BxU 
muchas veces obteniendo nulas ganancias, ya que su único objetivo es facilitar la organización de eventos especializados por lo que todo aquello que se comercializa allí es utilizado para la cobertura de la totalidad de los gastos.

Entre estos modos de producción existen varias diferencias: las grandes productoras porteñas especializadas en metal pueden acceder a locales con una infraestructura de mayor calidad y capacidad, al igual que al backline requerido por las bandas. Al mismo tiempo, la ubicación geográfica les asegura tanto un mínimo de asistentes como el contacto directo con las agrupaciones de la misma procedencia. Por el contrario, la mayoría de los productores amateurs se ubican en el Conurbano Bonaerense y en ciudades del interior de la provincia, en donde las condiciones con respecto a CABA son menos beneficiadas.

Por ejemplo, pude comprobar esto a través de la netnografía realizada en Facebook acerca de los recitales de Almafuerte. Primeramente, tuve en cuenta que los productores entrevistados expresaron que la banda de Iorio resultaba ser la más difícil de contratar para que se presente en las ciudades del interior, debido a que su valor de cobro era más alto y poseía más requerimientos, ya que era la única agrupación de la escena que con seguridad convocaba miles de asistentes. A diferencia de ella, el resto de los grupos reconocidos podía contar con una audiencia de cientos de participantes y los que pertenecían al circuito underground, con suerte llegaban a verlas 50 personas.

De acuerdo a estos entrevistados, Almafuerte (y luego, Iorio) era contratada por productores comerciales, debido a que

\begin{abstract}
Almafuerte está en otra escala, como el Indio [Solari]. Después, los músicos del Indio tocan para 250 personas sin el Indio, y con el Indio tocan para 250000. A Almafuerte le pasa eso. Cuando Almafuerte toca para 1500 personas, (...) Horcas, Tren loco, Jericó, no sé, todas las bandas tocan para 200 personas. (...) Almafuerte tiene una mística que te repito: se baja Ricardo y queda el Tano [Marciello] solo y se esfuma la gente. Y queda solo el Tano con 100 personas. 100 personas quedan... Es muy loco también eso. (Productor amateur marplatense, 2016)
\end{abstract}

Entonces, partir de la netnografía realizada en la fanpage llamada "Almafuerte", creada por aficionados a esta banda (“almafuerteros") ${ }^{164}$, más específicamente en la sección "Eventos"165, pude registrar los lugares de la escena bonaerense en los que se

\footnotetext{
${ }^{164}$ El link de dicha fanpage es el siguiente: https://www.facebook.com/Almafuerteros/

${ }^{165}$ El link de dicha sección es el siguiente: https://www.facebook.com/pg/Almafuerteros/events/
} 
realizaron recitales entre el 2011 y el $2016^{166}$ : CABA, Morón, Temperley, Zárate, José C. Paz, Virrey del Pino, Haedo, Florencio Varela, Moreno, San Justo, Floresta, Ramos Mejía, La Plata, Luján, Baradero, Tandil, Mar del Plata, Bahía Blanca y Tornquist.

Esta información resulta relevante porque la cantidad de conciertos realizados en las distintas ciudades mencionadas permite deducir que ellas se conforman como lugares propicios para el desarrollo de este tipo de eventos. Este carácter se presenta con varias condiciones en ellas: poseen estadios y sitios para la realización de recitales de un gran número de asistentes, además de un amplio público metálico que asiste a los conciertos; o se conforman como espacios de concentración zonal de aficionados de diversas ciudades vecinas.

Entonces, pude calcular que entre los años 2011 y 2016 Almafuerte se presentó en conciertos 69 veces. De ellos, la mayor cantidad de veces fue en CABA con 21 recitales. Luego, las ciudades en las que más veces se presentó son La Plata (8 recitales), Mar del Plata (6 recitales) y Tornquist (5 recitales). Sin embargo, hay una gran diferencia entre el Conurbano y el interior. En el primer caso, sumé un total de 32 conciertos y, en el segundo, 17 (ver Mapa 3).

Esto se debe a que, como ya mencioné, al haber menor cantidad de habitantes también se reduce el número de aficionados al metal y, consecuentemente, de asistentes a los conciertos. Por lo que los productores apuestan a organizar eventos en sitios que les aseguran un mínimo de asistencia. En caso contrario, la estrategia es convocar a bandas de diferentes ciudades para que sean acompañadas por sus grupos de amigos y aficionados provenientes del mismo lugar.

Otra particularidad de Almafuerte y Iorio es que, a pesar de promover la ideología de la independencia, poseen algunos rasgos propios de los conjuntos musicales comerciales: por ejemplo, para sus recitales tienen una serie de sponsors entre los que se puede mencionar a las empresas Paladini, Vía Bariloche y Amargo Obrero. Además poseen gran cantidad de estrategias de marketing que se observan principalmente en Internet, más específicamente, en Facebook.

Por su parte, Rata Blanca es otra de las bandas cuyo manejo dentro de la escena es más comercial que en otros casos. Además de ser una de las más convocantes (debido a que no solo es consumida por público metálico), posee algunos requerimientos que son propios de los músicos de conjuntos comerciales: la característica más visible es su

\footnotetext{
${ }^{166}$ No hay que olvidar que Almafuerte se disolvió en el año 2016 y a partir de allí Iorio dio comienzo a su banda solista.
} 
desarrollo como rockstars, debido a que los músicos no solo se alojan en hoteles lujosos sino que también suelen dirigirse a los locales del concierto en autos de alta gama. Estas características hacen que también sean duramente criticados por los participantes de la escena, muchos de los cuales los tildan de "falso metal".

A diferencia de Almafuerte y Rata Blanca que cobran altos valores para dar un concierto, la mayoría de las bandas underground de la escena deben pagar para poder tocar, una práctica comercial considerada injusta y que consiste en "garantizar la venta de determinada cantidad de entradas para poder hacer uso del espacio físico de los boliches, como una deformación del tradicional alquiler de sala de décadas anteriores." (Corti, 2007, p. 70) De esta manera, los productores se aseguran la asistencia de público.

Este régimen sucede mayormente con los grupos que se presentan como "teloneros" de bandas consagradas tanto nacionales como internacionales. Aquí aparecen varias diferencias: los grupos underground no reciben el mismo trato que el conjunto principal, no solo porque las condiciones de producción son peores (los instrumentos musicales y el equipamiento de sonido suele ser de menor calidad y, en gran cantidad de casos, no hay contacto entre los músicos principales y los grupos "soporte"), sino también porque generalmente el público asiste en el horario que tocará la agrupación principal, por lo que los "teloneros" se presentan frente a un público pequeño o a asistentes que les prestan escasa atención y se mantienen alejados del escenario.

Cuando estas bandas underground reciben una remuneración, generalmente suele ser pequeña o el pago se produce a través de consumiciones gratuitas de bebidas (usualmente, cerveza). A pesar de ello, se mantienen activas. De todas formas, la moral económica suele ser ambivalente: algunos se muestran desinteresados por las ganancias y aceptan la necesidad de "pagar para tocar" y otros se oponen a esto rotundamente e, incluso, dejan de seguir a aquellos grupos que se muestran más comerciales.

Algunos periodistas especializados (de medios tanto radiales como gráficos) dan cuenta de las controversias que genera la dimensión comercial de la escena. Como mencioné en el párrafo anterior, las agrupaciones pequeñas suelen tener que aportar grandes esfuerzos económicos para poder mostrar su actividad:

Si bien todos decimos "la hermandad del heavy metal", está bien; pero hay ciertos puntos en los que no somos muy hermanos que digamos, sobre todo cuando hay dinero de por medio. Es duro decirlo pero muchos de los grupos que vienen a nuestro 
programa hablan de esto. Pelearla de abajo, sin retribución económica alguna, es muy difícil, y ellos también lo hacen por amor sino estarían tocando cumbia o algo que les diera plata. Hay que unirse tanto los medios, como el público, las propias bandas, para poder seguir subsistiendo, que es la idea. (González, en Caballero y Bernal, 2016, p. 49)

Además de argumentar acerca del funcionamiento económico de la escena metálica, en las palabras del periodista citado es posible ver que la oposición del metal a la cumbia también se da porque los "metaleros" la consideran un género musical comercial. Continuando con la idea de pasaje de nivel, cuando los grupos logran consagrarse son criticados:

Es difícil en este país que una banda crezca porque cuando eso pasa se le recrimina al toque. Pasó con Rata Blanca o con Almafuerte que llegó a hacer estadios, por ejemplo en All Boys o puede hacer un Malvinas cuando quiere. A su vez van llegando a lugares grandes como Vorterix. Eso lleva a la típica frase "se vendió". (Pogonza en Caballero y Bernal, 2016, p. 50)

Ya en el rock nacional estaba instalada esta discusión en torno a la autenticidad con respecto al carácter comercial de las bandas. De esta manera, se encontraban las que habían "zafado" o "escapado" del sistema y las que habían "transado" con él (Vila, 1989). A pesar de las consideraciones económicas, el reconocimiento que se presenta “(...) implica más que la dedicación absoluta, la consagración mediática o el éxito estelar: el 'hacer lo que se quiere'," (Gallo y Semán, 2016: 32) Para el caso del metal es visible cómo dicha ética parece tensionar con el "mito de la igualdad" y la idea de "hermandad" metálica.

De todas formas, la existencia de los grupos del underground mantiene viva a la escena, debido a que, al igual que en el rock en general, las bandas de aficionados son el alma de las escenas del metal (Wallach y Levine, 2013, p. 123). Esto se debe a que "Las escenas de la música metal son popularizadas por 'amateurs' musicales" (Wallach y Levine, 2013, p. 123. T. de la A. Cursivas propias): esto significa que es necesario que exista una gran cantidad de músicos semi-profesionales que integren agrupaciones solo por hobby, sin aspirar a que la ganancia de su conjunto musical sea su salario, y que el objetivo sea componer temas musicales propios y realizar covers de hits populares. De cierta forma, la actividad de los grupos musicales permite la reunión de aficionados y, por ende, la sociabilidad.

Otra de las instituciones que posibilitan el reconocimiento de un conjunto metálico son los medios de comunicación, los cuales pueden ser enumerados en: 
aquellos que son especializados en rock, los que se dedican específicamente al metal y los fanzines. En los primeros es posible ver a las bandas que son reconocidas a nivel nacional y que, de cierta forma, se mueven en un nivel más profesional y comercial. Dentro de ellos se pueden mencionar revistas como la Rolling Stone y a los suplementos gráficos, "Sí!" (del diario Clarín), "No" (de Página 12) y "No sé” (de Diario Registrado), entre otros.

En segundo lugar, los medios especializados en metal más reconocidos de la escena son aquellos que circulan a nivel nacional: las revistas, Jedbangers y Efecto Metal; los programas radiales, “Tiempos Violentos” en FM Rock \& Pop (conducido por el periodista más reconocido de la escena, César Fuentes Rodríguez) y Vorterix Metal, en FM Vorterix (cuyo conductor es Javier “Knario" Compiano). Todos estos medios se ubican en CABA y funcionan como difusores $\mathrm{y}$, al mismo tiempo, selectores de músicos, bandas y agentes de la escena. En efecto, estos mediadores fueron los que promovieron la actividad de Hermética y su lugar como conjunto metálico emblemático de la Argentina.

Por último, se encuentran los fanzines que, a diferencia de los anteriores, dan cuenta de la ideología de la independencia comercial de forma sustancial, ya que la condición principal del fanzine es ser hecho de manera autogestiva. Algunos de ellos se realizan manualmente, sus tiradas están constituidas por fotocopias y las ediciones no suelen ser tan prolijas, lo que busca intensificar el carácter artesanal. En cuanto al contenido, se constituye por entrevistas y reseñas de bandas del underground y de fanzines de otras provincias y países, y también por artículos de opinión acerca de temas de interés general, vinculados a la escena metálica o a asuntos sociopolíticos. También se caracterizan por poseer ilustraciones, al contrario de las revistas especializadas que se destacan por publicar fotografías de gran calidad.

Además de ello, la característica más importante es que son de tirada gratuita o, muy pocas veces, se entregan a cambio de una colaboración opcional. Algunos editores de estos fanzines hacen distribución de su material en eventos tales como la Feria Metalera de Temperley, las Ferias del Libro Heavy en diferentes ciudades, los recitales y reuniones tales como "Las plazas por asalto"167 de Mar del Plata. En otros casos, los

\footnotetext{
${ }^{167}$ El "asalto al cielo" es una expresión que utilizó Karl Marx en la carta que le escribió al doctor Ludwig Kugelmann para explicar el fracaso de la iniciativa revolucionaria de la Comuna de París de 1871. La frase se refiere a la toma revolucionaria del poder, por lo que la denominación "Las plazas por asalto" se puede ver cierta vinculación con la ideología socialista.
} 
envían por correo a quien lo solicite a cambio del pago de una mínima cantidad de estampillas, ganancia que permite costear su impresión.

Estos medios de comunicación se caracterizan por defender el nivel underground como una de las ideas morales fundamentales. Esto se puede observar en el slogan del fanzine Metálica: "No se incluyen tendencias comerciales. Acceso denegado a estrellitas del rock". Tal como ya se explicó, esto se debe a que existe la creencia dentro de la escena de que quienes ingresan a un nivel más comercial cambian su actitud y comienzan a actuar con soberbia y vanidad, valores que son condenados y vinculados a la figura del rockstar característico del glam metal y al pop, de los cuales el metal busca diferenciarse.

\section{Algunas consideraciones}

A partir de lo analizado anteriormente es posible observar que la escena metálica bonaerense se conforma como un espacio heterogéneo en el cual se presentan una serie de desigualdades que corresponden a la presencia de diferentes niveles de interacción relacionados con lo geográfico.

En primer lugar, la escena se caracteriza por ser translocal ya que interactúa con la escena global y la local al mismo tiempo. Sin embargo, el ingreso al circuito internacional otorga mayor reconocimiento y los parámetros de dicho acceso están dados por sellos discográficos multinacionales y medios de comunicación provenientes de Europa y Norteamérica que hegemonizan la escena metálica global.

A su vez, la escena local Argentina contiene a las escenas locales más pequeñas conformadas por las ciudades del interior y por la escena capitalina. De esta manera, se pudo observar que los participantes de la escena metálica bonaerense (recorte conceptual que incluye a CABA y a la provincia de Buenos Aires de manera interrelacionada) admiten dos identidades: primero, la escena porteña se identifica a sí misma como "argentina" y, luego, las escenas locales resaltan el adjetivo "local" como forma de situarse en y de identificarse con el interior y la periferia.

En este último caso se observa la exaltación de la ubicación geográfica marginal por parte de los aficionados, lo cual es similar a la autenticidad que proporciona la identidad del "paria orgulloso". Por otro lado, ubica analíticamente a dichos agentes en la "doble periferia" (Castelnuovo y Guinzburg, 1979), ya que CABA constituiría el centro de las escenas bonaerense y argentina pero, a su vez, Argentina forma parte de la periferia con respecto a la circulación global del metal. 
En ambas posiciones, es necesario aclarar que "La periferia no reproduce el centro en forma mimética y posee elementos que la distinguen en su particularidad" (Pasolini, 2013, p. 190), al mismo tiempo que “(...) las capitales juegan el rol del lugar donde parecerían 'suceder las verdaderas cosas': centros de producción, polos de atracción, nudos de difusión y espacios a conquistar.” (Pasolini, 2013, p. 188). La aspiración de "veracidad" y "autenticidad" hace que CABA sea centro de legitimación.

Por su parte, la consagración otorgada por dicha ciudad también se refleja con la posibilidad de acceder a través de ella al circuito nacional y también al internacional, en varios casos. Los agentes que ingresan a este nivel se posicionan como referentes y son valorados por el resto de los aficionados. Al mismo tiempo, la ética metálica se muestra atenta a las formas en que se produjo este pasaje de nivel, ya que critica a los artistas que "transaron" con las multinacionales. La autenticidad metálica se opone rotundamente a la cultura de masas.

En segundo lugar, la escena metálica bonaerense al estar dispersa geográficamente requiere de diversos medios que permitan que sus miembros estén comunicados entre sí y sea posible la interacción translocal. Aquí la interacción cara a cara es fundamental. Esto se refleja en la importancia de observar a una banda en vivo; en la valoración del concierto y las ferias como formas de reunión; y en la creación de fanpages y grupos de Facebook que promueven el encuentro de manera personal con aficionados de las mismas o cercanas zonas geográficas (lo que a su vez, demuestra que el intercambio online no reemplaza el contacto offline). Además de ello, los viajes son esenciales para la conexión entre sus aficionados, por lo que las complicaciones vinculadas con el traslado inciden directamente en el desarrollo de la escena.

Al igual que sucede con otros géneros, en la actualidad, la producción musical se caracteriza por una fuerte presencia de la comunicación humana, lo que posibilita la movilidad social y la sostenibilidad de la práctica sin que las inversiones y la experticia sean factores decisivos. Sin embargo, esto no significa que se haya democratizado, ya que se mantienen algunas desigualdades y estratificaciones (Bennett y Rogers, 2016).

La comunicación permite el pasaje de nivel de los miembros, los cuales desarrollan su actividad en dos estratos que intentan profundizar en diferente medida la independencia comercial como una manera de oponerse moralmente a las multinacionales: primero, se encuentran las bandas, músicos y mediadores que buscan diferenciarse de la música popular masiva, generalmente identificada con el pop y los géneros musicales de última tendencia (como el reggaetón); y, luego, una serie de 
agentes que en un nivel inferior tratan de distinguirse del anterior que es el que hegemoniza la escena. En esta capa el objetivo es mantenerse en el underground y defenderlo. Por lo general, los participantes del primer nivel se ubican geográficamente en CABA y, a partir de allí, se proyectan hacia el interior y el exterior de la provincia, y al exterior del país.

Por otra parte, la defensa de la independencia comercial y del underground también se convierte en una forma ideológica propia de la escena, ya que identifica con dichas características a la autenticidad. En el metal, un grupo “(...) cuanto más se aleja de las listas de éxito y del mainstream, más auténtico se va a considerar." (Galicia Poblet, 2015, p. 178) y, por ende, será más “verdadero", de acuerdo a la vigilancia que realiza la escena hacia lo que es considerado como "falso metal".

Al mismo tiempo, la comunicación es importante porque permite establecer vínculos amistosos, capital social clave para el desarrollo artístico de los músicos dentro de la escena. Dicha forma de interacción no solo constituye una herramienta de producción, sino que también es uno de los principales valores morales de la escena, junto con el de la solidaridad. No obstante, las desigualdades descritas parecen atentar contra el "mito de la igualdad" y ponen en cuestión dentro de los participantes de la escena la real existencia de la "hermandad" metálica, mientras que dicha ética es la que regula las relaciones sociales. A continuación se analizarán los modos en que dichas desigualdades se presentan en el plano temporal. 


\section{Tensiones temporales en la escena metálica bonaerense}

\section{La continuidad generacional}

Las escenas metálicas en general se caracterizan por poseer una "brecha generacional” que le permita tener coherencia a través del tiempo, “(...) es decir, una generación más antigua envejeciendo y miembros más jóvenes entrando a la escena" (Wallach y Levine, 2013: 126. T. de la A.). En la escena bonaerense, efectivamente se produce la permanencia de los aficionados más antiguos al mismo tiempo que van ingresando miembros más jóvenes, lo cual no solo sucede en las audiencias sino también en los sectores de producción (músicos y mediadores).

En primer lugar, la variedad de generaciones se observó en el público de los recitales. En algunos de ellos pude ver padres con sus hijos (en muchos casos, niños), vestidos con remeras metálicas. Esto sucedía con más frecuencia en los conciertos de bandas extranjeras realizados en estadios y parques al aire libre y en los shows de los grupos argentinos más reconocidos de la escena, los cuales permitían el ingreso de menores de edad. Esto es importante ya que, considerando que los conciertos son el evento más celebrado por todas las escenas metálicas, es necesario que los espacios para organizar recitales sean aptos para todo público (Wallach y Levine, 2013, p. 121) y esto favorezca la incorporación de miembros más jóvenes a la escena.

Sin embargo, esto no sucede de igual manera en toda la provincia. En algunos lugares, como por ejemplo, en la ciudad de Mar del Plata y José C. Paz, se organizan recitales matinée, especiales para asistentes menores de edad. A pesar de estas excepciones, gran parte de los conciertos comienzan después de la medianoche y la restricción por edad depende de las políticas públicas de cada municipio. Algunas veces, a pesar de las normativas, los adolescentes menores de edad igualmente logran ingresar a esos locales.

En ciudades donde no existen tantos controles es posible ver más cantidad de público joven. Por ejemplo, en la ciudad de Necochea pude observar un importante número de aficionados al metal de entre 15 y 20 años. En el resto de la provincia, la audiencia conformada por adolescentes fue más visible en recitales y festivales vespertinos. Por el contrario, en la mayoría de los recitales a los que asistí en mis etnografías era notablemente mayor la cantidad de público adulto, el que en muchos casos aparentaba tener más de 50 años de edad. 
Debido a que la escena metálica bonaerense no solo está integrada por aficionados jóvenes sino también por una fuerte presencia de participantes adultos, es posible definirla como multigeneracional, tal como Andy Bennett y Paul Hodkinson (2012) caracterizan a las escenas de la música popular que se conformaron a fines del siglo XX y, en ese entonces, eran catalogadas como culturas "juveniles".

Para estos autores, la persistencia de los aficionados que en dicho momento eran jóvenes y hoy en día siguen participando durante su adultez, no significa un rechazo de los compromisos propios de esta etapa, tales como la familia y el trabajo, sino que de acuerdo a sus investigaciones, la afición convive con las responsabilidades de la vida cotidiana. Por el contrario,

(...) es posible ver cómo una continuación en los patrones de gusto entre los individuos envejecidos es un símbolo de la transformación de los estilos de vida de los consumidores en modos de empoderamiento cultural a través de los cuales continúan construyendo y articulando identidades y reclamando distinción en la vida cotidiana contemporánea. (Bennett y Hodkinson, 2012, p. 11)

Por su parte, las nuevas generaciones de jóvenes "metaleros" también constituyen un sector del público al que algunos conjuntos intentan dirigirse para integrar a la escena. Un ejemplo observado se desarrolló en el festival Monsters of Rock del 2015 en el cual se presentó la banda Heavysaurios ${ }^{168}$, la cual realiza canciones de música heavy $\mathrm{y}$ power metal pero con letras de temática infantil $\mathrm{y}$, en sus presentaciones, los músicos aparecen disfrazados de dinosaurios caricaturizados con look metálico. En dicho festival, los Heavysaurios tocaban en un escenario aparte y durante el día; esto contrastaba con el show de strippers -comúnmente llamado “espectáculo para adultos"-, que se realizaba durante la noche en el otro extremo del predio.

Lo mismo pude apreciar en las Ferias del Libro Heavy de Mar del Plata y Tandil del 2016, las cuales poseían espacios de recreación dedicados especialmente para niños, en los cuales se les enseñaba a realizar muñecos artesanales con forma de dragón:

(...) una de las características de la Feria de Mar del Plata es el sector "Metaleritos", donde Silvia Beatriz Ontiveros, Eugenia Luro y Jorgelina Barraza, desarrollaron el "Taller de Dragones". Espacio que es un éxito y donde las futuras huestes del metal se divierten mientras sus padres presencian las ponencias. (Berta et al., 2016, p. 103)

\footnotetext{
${ }^{168}$ Esta banda es la versión argentina del grupo finlandés, Hevisaurus, bajo licencia exclusiva de "Sony Music Finland a Fa Sostenido SA".
} 
Tanto los dinosaurios como los dragones forman parte de las figuras monstruosas que el metal toma de la literatura y el cine para construir modos de transgresión en sus producciones. Además, al formar parte de la narrativa infantil y juvenil y de los dibujos animados, funcionan como elemento conductor entre los niños y el metal.

Otro ejemplo se desarrolla con la figura de Iorio. Tanto en los recitales de Almafuerte como de su agrupación solista, en los que hice trabajo de campo, pude observar una fuerte presencia de niños y adolescentes, los cuales concurrían con sus padres. Esto mismo observé en conciertos de Malón y Rata Blanca, pero el caso de Iorio resulta particular porque el merchandising de la banda suele incluir remeras de talles pequeños con su logotipo y frases del músico, como por ejemplo, "Las cosas se aprenden de pibe".

La presencia de niños también se pudo relevar en un recital de Malón en mayo de 2016 en Bahía Blanca, en el cual O’Connor, el cantante, frenó el recital para alertar sobre la presencia de varios niños que habían sido descuidados de sus padres durante el show. Ante esto, ofreció un espacio al costado del escenario para que las criaturas queden al cuidado de los asistentes de la banda ${ }^{169}$.

La presencia de niños y adolescentes en los recitales resulta relevante ya que, la mayoría de los aficionados entrevistados de entre 15 y 19 años conocieron el estilo musical a través de un familiar mayor a ellos (padres, hermanos, tíos y primos) que les recomendaron determinadas bandas. Por el contrario, los "metaleros" de más de 20 años lo hicieron principalmente por parte de amigos o a través de algún medio de comunicación.

Pero, además del público, la variedad generacional también es posible observarla en la producción, ya sea desde los roles de los mediadores que gestionan los eventos y los discos, hasta los propios músicos y sus bandas. En todos los casos la característica principal es que los agentes más antiguos se han constituido en los consagrados de la escena. Es decir que, a pesar de que existen agrupaciones de músicos jóvenes, las más reconocidas son aquellas cuyos miembros tienen más de 25 o 30 años de edad.

\footnotetext{
${ }^{169}$ Sobre esto, el diario Líder de Trenque Lauquen publicó un artículo titulado, “'Malón' frenó un recital en Bahía Blanca para proteger a hijos descuidados por algunos espectadores". Dicha publicación se encuentra disponible de manera digital en el siguiente link: http://diariolider.medios.com.ar/noticia/56/malon-freno-un-recital-en-bahia-blanca-para-proteger-a-hijosdescuidados-por-alg
} 
Efectivamente, los músicos, productores y periodistas que hoy en día son los más reconocidos de la escena metálica bonaerense (Ricardo Iorio, Claudio O'Connor, Walter Giardino, César Fuentes Rodríguez, entre otros) comenzaron su actividad en la década de los '80. Entonces, la valoración de estos por parte del público no solo es consecuencia de la calidad de sus producciones sino también de la experiencia acumulada a partir de la persistencia en la escena a lo largo de los años.

Esto sucede, primero, porque para los aficionados al metal la llegada a la adultez significa la adquisición de saberes (no solo relativos a lo técnico de la propia actividad, sino también con respecto a las vivencias personales), elemento muy apreciado por los "metaleros". Por otra parte, estos agentes también son valorados por haber formado parte del "mito del origen" de la escena, de manera que se considera que esta fue creada gracias a la labor de ellos.

De hecho, una de las manera en que se produce la brecha generacional necesaria para el desarrollo de las escenas metálicas es por medio de la celebración de las bandas pioneras de las escena a través de sus instituciones (Wallach y Levine, 2013). Por medio de la etnografía, observé que en la escena bonaerense dichos grupos son Riff, V8 y, en mayor medida, Hermética.

Estas bandas son homenajeadas mediante las instituciones y también por los propios agentes de la escena. En el caso particular de Riff, existen varios monumentos en homenaje a "Pappo", su líder, en diversas ciudades de la provincia, como Tandil, Luján, Necochea y CABA. Pero además, las tres agrupaciones son reconocidas por medio de covers, recitales tributo, remeras, tatuajes, murales y la utilización de los títulos y las letras de sus canciones para nombrar reuniones y publicaciones escritas.

Además de esto, en mi trabajo de campo pude notar que gran cantidad de bandas nuevas son valoradas porque se asemejan y respetan las convenciones de los grupos musicales de la "vieja escuela" 170 , es decir que poseen un sonido similar a los orígenes del estilo musical, sin hibridaciones con otros géneros musicales ni la intervención de nuevas tecnologías digitales $\mathrm{y}$, por lo tanto, es valorada por los miembros más fundamentalistas de la escena, es decir, el sector ortodoxo del campo, en términos bourdianos.

\footnotetext{
${ }^{170}$ Según Simon Reynolds (2012), "La expresión old skool [vieja escuela] viene del hip hop, pero se ha difundido en la cultura pop para sintetizar las nociones de orígenes y raíces. Es un término usado por los epígonos, los patriotas de la escena que creen que el presente es menos distinguido que el ilustre pasado." (p. 256. Destacado del original)
} 
De hecho, a partir de esta caracterización, en los años que implicaron mi investigación uno de los subestilos más difundidos en la escena fue el stoner ${ }^{171}$, el cual pareció aumentar su popularidad a partir de la reunión de Black Sabbath en 2012 con todos sus miembros originales (excepto el baterista) y la posterior visita a Argentina en 2013.

Entonces, es posible afirmar que en la escena metálica bonaerense además de multigeneracional puede ser caracterizada como transgeneracional. Asimismo, mantiene la característica del metal como culturalmente conservador, ya que

\begin{abstract}
Sus estándares y su música, sus estilos e intérpretes, trascienden a varias "generaciones" de audiencias adolescentes. Los sellos discográficos y los promotores de conciertos no tuvieron que preocuparse por las nuevas tendencias: las viejas bandas continúan vendiendo sus catálogos de álbumes y tickets de sus conciertos actuales sin necesidad de mucha promoción. Cashmore afirma que el heavy metal es "un dinosaurio de la cultura juvenil, sobreviviendo a sus contemporáneos y perdurando aparentemente sin cambios en la década de 1980", Los cambios son, de hecho, resistidos por el público, una realidad que demuestra el poder residual de la audiencia sobre la constitución de la música. (Weinstein, 2000, p. 137)
\end{abstract}

Este rasgo conservador es observado por Pablo Espíndola y Germán Morales (2013) en los aficionados argentinos al metal, debido a las discusiones y rivalidades que se producen a partir de la persistencia de la idea del "falso metal", consecuentes de la nostalgia con que se valoran los inicios de la escena y se idolatra a los músicos de las primeras épocas.

Además, como se mencionó en el apartado anterior, el conservadurismo es uno de los significados centrales ligados a la autenticidad, la que de acuerdo a la enumeración de Keightley (2006) corresponde con el tipo "romántico", ya que privilegia la tradición y la continuidad. A esta característica es posible analizarla desde dos ópticas: En primer lugar, dicho conservadurismo es similar al "tradicionalismo" que se oponía a la Modernidad, una postura fundamentalista que consideraba a la tradición como lo "verdadero". En este sentido,

(...) la Tradición es definida como inmovilismo, ignorancia, prejuicio, superstición, reproducción de los sistemas de valores, de las lenguas, mentalidades y actitudes de pasado remoto. Este universo que estaría regulado por reglas y prácticas inalterables no habría estado regido por la razón, sino que los sentimientos, y los prejuicios, lo irracional, la magia. La tradición sería como la pre-historia de los pueblos y sociedades. (Cancino, 2003)

\footnotetext{
${ }^{171}$ Este subestilo musical se encuentra musicalmente influenciado por el rock psicodélico, el desert rock y el doom metal.
} 
De acuerdo a esta descripción es posible comparar al tradicionalismo con la valorización por parte de la escena de los pueblos originarios y las culturas bárbaras. Pero, al mismo tiempo, la escena también se identifica con la Modernidad ya que, al contrario de la Posmodernidad, "Los artistas y escritores modernos innovaban, alteraban los modelos o los sustituían por otros, pero teniendo siempre referentes de legitimidad." (García Canclini, 2012, p. 299. Cursivas del original). En la escena estudiada estos estarían compuestos por las bandas y los aficionados pioneros que entre el 2011 y 2017 son adultos.

En segundo lugar, la postura ideológica conservadora que valora la autenticidad en aquellas producciones en donde el metal aparece casi inmutable y más similar al considerado "original” parece posicionarse como una negación de la genealogía tal como la describe Foucault (1992):

(...) es percibir los accidentes, las desviaciones ínfimas -o al contrario los retornos completos-, los errores, los fallos de apreciación, los malos cálculos que han producido aquello que existe y es válido para nosotros; es descubrir que en la raíz de lo que conocemos y de lo que somos no están en absoluto la verdad ni el ser, sino la exterioridad del accidente (...) (p. 13)

Para el autor, la genealogía no conduce al origen como lugar en donde hallar la verdad ni para buscar formas de continuidad. Por el contrario, permite ver los cambios. En la escena metálica esto funciona de manera contraria, ya que se considera "verdadero" y "auténtico" aquello que está ligado con el "mito de origen" y preserva su supuesta "pureza". No obstante, la genealogía es un movimiento hacia el pasado, el que sí se presenta en la escena por medio del uso de lo "retro". A continuación haré referencia a ello.

\section{La "retromanía"}

Es posible vincular el carácter culturalmente conservador de la escena metálica bonaerense con la idea de lo "retro" y la "retromanía" que propone Simon Reynolds (2012). Según el autor, lo "retro" se presenta de cuatro maneras en que la cultura se relaciona con su pasado:

(1) Lo retro siempre alude al pasado relativamente inmediato, a cosas de las que se tiene una memoria viva.

(2) Lo retro implica un elemento de recuerdo exacto (...) 
(3) Por lo general, lo retro también incluye los artefactos de la cultura popular. (...)

(4) Una última característica de la sensibilidad retro es que no tiende a idealizar ni a sentimentalizar el pasado, sino que busca que el pasado la divierta y la fascine. (...) (Reynolds, 2012, p. 27)

A continuación se analizarán diferentes maneras en que la escena metálica bonaerense se relaciona con el tiempo pasado.

\section{Reuniones de bandas, homenajes y bandas tributo}

Uno de los modos en que se presenta lo "retro" se produce a través de la reunión de las agrupaciones que fueron exitosas en la década del ' 90 . En el período estudiado en esta investigación, el principal ejemplo es el de Malón, agrupación que volvió conformarse en 2011 luego de la reunión temporal del 2001. Ese año se presentaron por primera vez como teloneros de Megadeth, pero un mes después realizaron un show como conjunto principal en el Microestadio Malvinas Argentinas de CABA. La grabación de este concierto fue editada posteriormente en formato DVD bajo el título $E l$ regreso más esperado (2012), cuyas imágenes intentan dar cuenta de la cantidad de público que asistió a dicho show.

Otro ejemplo relevante es el de la banda, A.N.I.M.A.L., la cual volvió en el 2015 luego de 10 años de inactividad y realizó varias giras por Argentina y algunos países de América Latina. De la misma manera, algunos músicos del underground se reunieron con aquellos con quienes compartieron sus primeras agrupaciones, como por ejemplo, los thrasheros, Scarface, de Tandil.

Además de las reuniones de los grupos musicales es posible mencionar aquellos conciertos en que algunos músicos invitaron a sus ex compañeros con la intención de homenajear algún disco en particular. Algunos ejemplos son el del recital en Malvinas Argentinas en 2013, en el cual Rata Blanca celebró sus 25 años de carrera junto a los miembros de su primera formación, además de los que componían la banda de manera estable en ese momento; y el concierto por los 30 años del disco El fin de los inicuos de V8 en 2016, organizado por su baterista original, Adrián Cenci.

También es posible citar el concierto realizado por Alberto "Beto" Zamarbide, ex vocalista de V8 y Logos, en CABA por el $30^{\circ}$ aniversario del disco, Luchando por el metal. Allí se incorporaron varios músicos invitados pero el caso más singular es el de Iorio, único ex integrante de V8 que aparece como músico "sorpresa" y canta a dúo con Zamarbide algunos temas de dicho disco. 
Esta participación fue sorpresiva para los participantes de la escena metálica argentina, ya que en gran cantidad de entrevistas el líder fundador de V8, Hermética y Almafuerte había expresado su negación a reunirse con los ex compañeros de sus antiguas agrupaciones, debido a los malos términos en que había concluido dichas relaciones. A pesar de esto, otra reunión que tuvo Iorio con su pasado se produjo al incorporar al plantel de su banda solista a Walter Martínez, uno de los primeros bateristas de Almafuerte.

Otro caso relevante para esta investigación es el de los recitales homenaje por los 25 años del disco Ácido argentino en 2017. Este fue realizado por los músicos de Malón, pero en los flyers promocionales en lugar de aparecer el nombre de esta banda, solo se podía ver el de los músicos, como una manera de desvincular a aquella agrupación con Hermética.

Ante esto, la audiencia se demostró dividida. Por un lado, estaban aquellos que celebraron la posibilidad de disfrutar las canciones de Hermética en vivo, ya que musicalmente sonaba muy similar al grupo original. Mientras que, del otro lado, se encontraban aquellos que criticaron fuertemente este homenaje considerándolo una actitud netamente comercial. Este suceso ocurrió al mismo tiempo que la ya comentada fotografía de Iorio con Biondini, por lo que en las redes sociales pude observar críticas a todos los antiguos músicos de Hermética, quienes eran calificados como "ídolos caídos", tal como propone la canción "Memoria de siglos" de dicha agrupación.

Las reuniones de bandas suelen producirse bajo un acuerdo que beneficia mutuamente a los músicos y a la audiencia:

El público entrado en años obtiene fiabilidad (saben cómo será la música) y una oportunidad de revivir su juventud. La banda se regodea en su propia leyenda y vuelve a conectarse con sus fans. También ganan más dinero del que ganaban como futuras leyendas en ascenso (las entradas pueden cobrarse mucho más caras sin ahuyentar al público, que ya no está formado por estudiantes universitarios y vagos sino por profesionales de mediana edad) y pueden salir de gira con muchas más comodidades que en aquella época cuando se subían a una destartalada camioneta. (Reynolds, 2012, p. 66)

Efectivamente, de acuerdo a las conversaciones mantenidas en mi trabajo de campo, en el concierto homenaje a Luchando por el metal había una gran cantidad de aficionados de la época de V8. Mientras que en las giras de Ácido argentino, muchos jóvenes aprovecharon la ocasión como una posibilidad de acercarse a sentir algo similar a lo que se vivía cuando Hermética estaba activa y ellos no habían podido verla debido a 
la corta edad que tenían en ese entonces. De hecho, algunos de los nuevos aficionados aún no habían nacido en esa época.

Además de las reuniones de las bandas y los recitales homenajeando el aniversario de determinados discos, otro modo en que se presenta lo "retro" son las bandas tributo. Un ejemplo que resulta controvertido para los miembros de la escena metálica bonaerense es el que se desprende a partir de la agrupación de thrash metal, Horcas.

Dicho grupo se conformó, al igual que Hermética, a partir de la disolución de V8 bajo el liderazgo del guitarrista, Osvaldo Civile. Cuando este falleció en 1999 de un disparo en el pecho por causas no esclarecidas, el resto de los miembros decidió continuar la banda como un homenaje a su líder cambiando de formación constantemente hasta la actualidad. A pesar de esta continuidad, fueron demandados por el uso indebido del nombre original del conjunto ${ }^{172}$.

A la par de esto, en 2013 comenzó su actividad el conjunto, Reinará Tempestad, conformado por los músicos que fueron parte del primer disco de Horcas, Reinará la tempestad (1990). Esta agrupación, a pesar de homenajear a Civile y a dicho disco, no se considera a sí misma una banda tributo ya que afirman ser los compositores originales de las canciones de la primera época de Horcas ${ }^{173}$.

Al igual que sucedió con Malón y Almafuerte luego de la separación de Hermética, esta situación generó divisiones entre los aficionados: por un lado, se encuentran aquellos que apoyan a la banda denominada Horcas a pesar de haber continuado sin Civile y, por el otro, están quienes consideran al uso del nombre de la agrupación como una actitud comercial y, al mismo tiempo, creen que el verdadero homenaje al histórico guitarrista es el que realiza el conjunto, Reinará Tempestad.

Esto es posible observarlo en las declaraciones de un aficionado entrevistado de la ciudad de Tres Arroyos cuando le pregunté por qué elegía como referente a Hermética y no a Horcas:

\footnotetext{
${ }^{172}$ Sobre la denuncia penal hay dos versiones: por un lado, se encuentra la del cantante, Walter Meza quien confirma la realización de un juicio por parte de Teresa Salto, amiga cercana de la familia de Civile; por otra parte, Salto desmiente dichas palabras explicando que solo existe una denuncia penal realizada por ella en la cual reclama el uso indebido de la marca "Horcas" (que supuestamente es de su propiedad) por parte de la banda.

${ }_{173}$ Para más referencias ver la entrevista realizada a Hugo Benítez, primer cantante de Horcas, para el portal, Metal Daze en el siguiente link: http://webzine.metal-daze.com/entrevistamos-a-hugo-benitez-dereinara-tempestad/
} 
Pasa que vos decís Horcas, ¡y a nosotros nos encanta! Éste lo tiene tatuado [refiriéndose a un compañero de banda]. Pero vos decís "Horcas" y te dicen "¿Eh?" y tenes que andar explicando que Horcas es tal, "me gusta Hugo Benítez, no me gusta el otro". Entonces, bah... (Músico de Tres Arroyos, 2016)

Lo mismo observé en uno de mis trabajos de campo en el que algunos aficionados conversaban sobre sus intenciones de ir a algunos recitales y uno de ellos expresó que tenía ganas de ver a Horcas en vivo ya que hacía mucho tiempo que no tenía la oportunidad de hacerlo. Ante esto, otro joven respondió "Pero, ¿qué Horcas querés ver?", dando cuenta de que quería saber si se refería al conjunto liderado por Walter Meza o al que tenía como vocalista a Hugo Benítez.

Retomando a la idea de las bandas tributo como uno de los modos en que se presenta la "retromanía" en la escena metálica bonaerense, es posible observar que el conjunto que más se homenajea es Hermética. Para esta investigación pude relevar las siguientes bandas tributo: Víctimas, de Quilmes; Ácido Argentino, de Moreno; Predicción, de La Plata; Cráneo Candente, de San Nicolás de los Arroyos; Lucha Extrema, de Balcarce; Trágico Siglo, de Coronel Suárez; y Scottus, formada por "Tony” Scotto, primer baterista de Hermética ${ }^{174}$.

Estos grupos no solo realizan shows en los que ejecutan las canciones de la banda original tratando de imitarla (lo cual se hace más visible en los vocalistas que copian el estilo de $\mathrm{O}^{\prime}$ Connor), sino que también eligen nombres basados en títulos de canciones y discos de Hermética (Ácido argentino, "Predicción” y “Cráneo candente”), confeccionan sus logotipos imitando la tipografía que utilizaba la agrupación original y suelen identificarse con los colores de la bandera argentina, en concordancia con la impronta nacionalista que definía a aquella.

Todas estas bandas también se caracterizan por formar parte del circuito underground. De hecho, además de los conjuntos ya mencionados, en mi trabajo de campo también pude ver una gran cantidad de recitales en homenaje a conjuntos reconocidos, en donde los grupos en vez de ejecutar las canciones de su propia autoría, solo realizan covers del conjunto homenajeado. Como he mencionado, en la escena bonaerense las agrupaciones más celebradas son Riff, V8 y Hermética.

En efecto, una de mis etnografías fue realizada en un recital denominado "Homenaje a Hermética” en 2016 en José C. Paz. Allí participaron cuatro agrupaciones

\footnotetext{
${ }^{174}$ Fabián Spataro, otro ex baterista de Hermética, también tiene su propia banda solista pero esta no dialoga con su antiguo grupo tan fuertemente como lo hace el de "Tony" Scotto.
} 
del underground que desarrollaron en su totalidad covers de dicho grupo. Lo más notable fue que el local estaba colmado de asistentes, los que tanto cerca del escenario como en los sectores más alejados se mostraban enfervorizados al ritmo de la música: además de la presencia de pogo y headbanging, se podía apreciar que la mayoría cantaba las letras a la par de las bandas. De cierta manera, era muy visible el frenesí con el que disfrutaban el concierto, como si en realidad estuviera tocando la agrupación original.

Cuando entrevisté a uno de los organizadores del festival acerca de los motivos por los que habían elegido a Hermética como grupo a homenajear, demostró que se debía a que era un conjunto que aseguraba la asistencia de un público numeroso: "Hermética sabemos lo que significa acá en Argentina. Es una banda emblemática, así que no hay más que decir lo que significa Hermética. La misma fecha lo demuestra. La gente que viene a la fecha, la concurrencia que tuvo es por Hermética." (Productor amateur del Conurbano bonaerense, 2016)

Esta estrategia forma parte de lo que James Lull (1987a) describe como "tradición de imitación" dentro de los patrones de control que actúan como fuerzas de convencionalidad dentro de la música popular. De esta forma, muchos artistas nuevos tratan de imitar tanto los sonidos como los contenidos líricos de aquellos grupos que fueron exitosos, al mismo tiempo que algunas bandas realizan el mismo movimiento sobre aquellas propias producciones que sirvieron como "gancho" para atraer al público y también al mercado.

\section{Dispositivos de memoria}

En la escena metálica bonaerense es posible encontrar una variedad de formas en las que se intenta conservar su historia, las cuales surgen a través de la intersección entre los modos individuales de preservar la memoria personal y las maneras en que dichos recuerdos se socializan y comienzan a conformar una red de memoria colectiva $^{175}$ de los participantes de la escena.

En ese entramado formado por las memorias individuales se hallan algunos artefactos subjetivos de la memoria emotiva como los talones de las entradas a los

\footnotetext{
${ }^{175}$ Esta característica de la escena resulta particular ya que la memoria colectiva ha sido objeto de estudio principalmente en aquellos trabajos que intentaron abordar procesos históricos "traumáticos". Por ejemplo, en Argentina uno de los ejes paradigmáticos se presenta con la dictadura y el informe "Nunca más", a partir del cual la memoria colectiva se presentaría como una forma contraria al "olvido" y se vincularía a la lucha por los derechos humanos mediante la prédica de la "verdad" y la "justicia" (da Silva Catela, 2005; Jelin, 2012).
} 
recitales, los posters, folletos y grabaciones caseras (que, en los años que comprende esta investigación, se constituyen en formato visual y audiovisual a través de la grabación de videos y la toma de fotografías con smartphones), los cuales le permiten a los aficionados recordar conciertos que fueron importantes para ellos (Bennett y Rogers, 2016). Esto es posible gracias a que "La música es tradicionalmente considerada como la banda de sonido de la propia vida: la canción favorita como conmemoración, un disparador proustiano que nos deja a la deriva en el recuerdo dichoso" (Reynolds, 2016, p. 135).

En la escena aquí estudiada gran cantidad de aficionados (especialmente los que tienen más de 25 años) son coleccionistas de los elementos anteriormente mencionados, así como también de artefactos decorativos (tanto de hogar como del propio cuerpo) y discos. Este último caso es llamativo ya que muchas veces las canciones suelen ser reproducidas desde alguna plataforma digital y los discos (y cassettes) en formato físico solo son utilizados para la colección.

En efecto, de acuerdo a la etnografía realizada, los aficionados más antiguos parecen exaltar las complicaciones que debían sortear en el pasado para acceder a elementos necesarios para la construcción de su identidad metálica (discos, cassettes, remeras y revistas), mientras que desestiman las facilidades que existen en la actualidad para que los miembros más jóvenes ingresen a la escena. Los esfuerzos que debían hacerse en épocas anteriores son relatados con orgullo, al mismo tiempo que se critica la presencia de Internet, mediante el cual, hoy en día "cualquiera puede ser metalero". De esta manera, la dificultad y la antigüedad dan cuenta de rasgos con los que se mide la autenticidad metálica.

Esto se puede observar en palabras de Hugo García, editor de la revista, Jedbangers en una mesa debate sobre los medios de comunicación especializados en metal en la Feria del Libro Heavy de Buenos Aires del 2015:

El contacto virtual está bueno para gente que vive lejos, acorta distancia realmente. (...) pero también genera vagancia, y tiende a despersonalizar. Viste cuando escuchás esas historias de músicos viejos que se toman un ferry para conseguir un disco o Iorio caminando por el barrio para encontrar la sala de El Reloj; hoy se perdió un poco, no sé si echarle la culpa a las redes sociales, pero al hacer todo más fácil pierde un poco de valor. Antes conseguías un cassette y era el único del mes. Hoy en un día podés bajar miles de discos. (García en Caballero y Bernal, 2016: 47)

Pero la escena se caracteriza porque en la actualidad los elementos de colección no quedan relegados a la intimidad, sino que se comparten a través de las redes sociales 
de Internet, de manera que pasan al plano público y se convierten en piezas del gran entramado que constituye la memoria colectiva de los agentes de la escena.

Aquí lo que abunda son las fotografías y las filmaciones personales de la década de los '80 y '90. Por ejemplo, es posible mencionar las fanpages, “Archivo Hermetica”, "Graffitis Pesados",176, “Cemento (1985-2005)", "La historia del Metal Extremo en Argentina"177 y "Fanz Rev Rebelion Rock". A través del relevamiento netnográfico, también encontré algunos grupos dedicados a homenajear programas de radio ("Yo escuchaba Cuero Pesado"178), revistas ("EPOPEYA y MADHOUSE"179) y espacios para recitales ("Yo fui a Halley - 80s/90s"

Otra fanpage de Facebook relevante para la escena metálica bonaerense y argentina es "Canal Cero Joaquin Amat", cuyo administrador es el amigo personal de Iorio que documentó a través de filmaciones la actividad de V8, Hermética, Almafuerte y la banda solista del músico, al igual que el registro audiovisual de reuniones de artistas del underground y del rock argentino de los '80 y de lugares emblemáticos como la galería porteña, Bond Street. Además del sitio en Facebook, Joaquín Amat posee un canal de YouTube en donde comparte su videoteca, también denominado "Canal cero".

Además de estas páginas que parecen organizarse con la intención explícita de generar un archivo en torno a una temática especial, también es posible encontrar fotografías antiguas e inéditas de las bandas que ya no existen (especialmente, V8, Hermética y Almafuerte) en las fanpages que las homenajean.

Al mismo tiempo, en todos estos sitios (tanto grupos como páginas de Facebook) los participantes intercambian comentarios, muchos de los cuales constituyen anécdotas personales y experiencias subjetivas en relación a la información compartida. También

\footnotetext{
${ }^{176} \mathrm{La}$ información de la fanpage explica que es una "Pagina creada para archivar y compartir graffitis/pintadas/murales relacionados con el Metal Argentino" (Recuperado de: https://www.facebook.com/pg/Graffitis-Pesados-130990620285499/about/?ref=page_internal)

${ }^{177}$ La descripción de la fanpage es la siguiente: "El metal extremo en Argentina tiene más de 25 años de historia y en este espacio lo rescatamos a través de entrevistas, fotos y videos". (Recuperado de: https://www.facebook.com/pg/deathmetalargentino/about/?ref=page_internal)

${ }^{178}$ La descripción del grupo dice: "A principios de los 80 (83-84) hubo un programa de FM que marcó un antes y después en la difusión del Heavy Metal en la Argentina. Se llamaba Cuero Pesado y podían escucharse desde clásicos como Iron Maiden, Judas Priest o Black Sabbath hasta bandas nuevas para ese momento como Metallica, Mercyful Fate, Exciter y Anthrax Este es un breve homenaje al programa y a su conductor, Daniel Aguilar" (Recuperado de: https://www.facebook.com/groups/75515218642/about/)

${ }^{179}$ Según su descripción: "Dos revistas dedicadas al Metal que florecieron en los '90s. Las dos formaron parte de la Editorial Llamoso que fundó César Fuentes Rodríguez y hasta tuvieron públicos muy diferenciados. Pero marcaron una época." (Recuperado de: https://www.facebook.com/groups/44903627703/about/)

${ }_{180} \mathrm{El}$ objetivo del grupo es contactar a "Gente que paso por Halley Discoteque en la década de los 80s y 90s". (Recuperado de: https://www.facebook.com/groups/27309419423/about/)
} 
es común que algunos aficionados al metal en sus propios perfiles de Facebook relaten alguna anécdota o recuerdo como descripción de los temas musicales que suelen compartir en sus propios perfiles.

Esta necesidad de generar un relato subjetivo acerca de la historia de la escena metálica tanto bonaerense como argentina se ve reflejada en la edición de los libros Cuando éramos reyes. Memorias del heavy argentino de los '80s (2015) de Rubén Cañizares, Historias de metal marplatense (2016) de Pablo Antonio D'Amore y El homenaje $H$ (2016) de Soledad Bianculli. En todos ellos aparecen testimonios de los propios autores y en los libros de Cañizares y Bianculli se incluyen relatos por parte de algunos aficionados que vivieron la actividad que se desarrolló en la escena en las décadas de los ' 80 y '90.

El caso particular del homenaje realizado por la autora anteriormente mencionada es relevante ya que se trata de una recopilación de material publicado en revistas especializadas intentando reconstruir la historia de Hermética. Pero, además de ello, aparece la opinión de sus propios seguidores y fotografías de material de colección de los aficionados, por lo que da cuenta de un panorama más amplio que aquellas publicaciones que solo narran la actividad de los músicos.

Estos relatos suelen formar parte de ediciones especiales lanzadas por las revistas dedicadas al metal. Aquí uno de los editores más difundidos es Andrés Violante, quien fue fotógrafo oficial de Hermética y en la actualidad forma parte del equipo editorial de la revista, Efecto metal. Es por ello que se encargó de publicar una selección de su archivo fotográfico en el libro, Hermética, las fotos (2015).

Como ya mencioné, Hermética es una de las bandas más celebradas por la escena metálica bonaerense, lo que es notable en las ediciones homenaje publicadas por las revistas especializadas. En el período estudiado es posible encontrar la "revi-póster", Hermética, a 20 años del Obras 1994 (2014) y Hermética. iiSigue Vivo!!! (2014) de Efecto Metal, en las que se incluyen fotos inéditas; además de la edición especial de la revista, Jedbangers, en 2014 que incluye un artículo especial por el $20^{\circ}$ aniversario del disco Víctimas del vaciamiento.

Entonces, además de la información que es compartida vía web, también es posible encontrar formas de documentación gráfica y audiovisual. En este último caso se encuentran los documentales, La H (2011) de Nicanor Loreti; El blues de los plomos (2013), de Paulo Soria y Gabriel Patrono; Relámpago en la oscuridad (2014), de Germán Fernández y Pablo Montllau; Sueños de rock (2014), de Alexis Jorquera; 
Antena metálica (2015), de Fernando Díaz; Sucio y desprolijo (2015) de Lucas Lot Calabró y Paula Álvarez; Cemento, el documental (2017), de Lisandro Carcavallo; y Alguien más en quien confiar (2017), de Matías Lojo y Gabriel Patrono. Todos ellos se caracterizan por intentar reconstruir la historia y la actividad pasada de la escena y de bandas, músicos y agentes específicos.

\section{El uso de la historia y la idea de inmortalidad}

Como ya he mencionado, en Hermética la historia constituye una de las principales fuentes en las que la banda se basa para la construcción de una perspectiva con respecto al contexto local. De hecho, no solo se utiliza la temática propia de dicho campo discursivo, sino que se propone la acción de revisar la historia, es decir, el movimiento de revisitar el pasado. Esto resulta diferente de aquellos conjuntos de metal que utilizan como fuente de temáticas de transgresión a la literatura de ciencia ficción (Weinstein, 2000), la cual recrea visiones tanto utópicas como distópicas del futuro.

Según Ivison Poleto dos Santos (2013) el metal a nivel global ha utilizado a la historia como fuente de inspiración, mediante tres formas: primero, a través del homenaje a grandes héroes y personajes históricos (especialmente jefes guerreros); segundo, por medio de la representación de grandes períodos y eventos de la historia, como por ejemplo el Medioevo y la Segunda Guerra Mundial; y tercero, la referencia a pueblos de la Antigüedad para nombrar bandas, discos y canciones.

Aquí, los temas escogidos deben cumplir con el requisito de representar fuerza, también requerida musicalmente, por lo que son comunes las referencias a conflictos bélicos. Además, la inclusión de descripciones de guerras, no solo es utilizada para exaltar a los héroes sino también para plantear una perspectiva pacifista (Folgueira Lombardero, 2010-2011), de manera que las canciones metálicas desarrollan el rol de discursos históricos alternativos y formas renovadas de divulgación histórica (Boffa, 2005; Folgueira Lombardero, 2010-2011).

En la escena metálica bonaerense, esta referencia a la historia se puede observar en los nombres de las bandas que se basan en personajes históricos (Por ejemplo, las ya citadas, Uriburu y Güemes) o que utilizan referencias a ellos y a acontecimientos históricos para la construcción temática y visual de sus producciones (especialmente los grupos de impronta indigenista). De cierta manera, en la escena estudiada es más probable que iconográficamente los conjuntos musicales utilicen versiones de guerreros ancestrales (entre los cuales, los indígenas son los predilectos) que imágenes de robots. 
Como ya se mencionó en el primer apartado, uno de los modos en que Hermética utiliza la historia es a través de la invitación a revisarla. Desde su origen, el nacionalismo tuvo una estrecha vinculación con el revisionismo histórico, de modo tal que la escritura de la historia se entremezcló con la política para volverse un componente esencial del discurso nacionalista en su disputa con la llamada Historia oficial o liberal.

Aunque Iorio ha mencionado explícitamente referenciarse en Saldías, un escritor positivista que buscó instalar al rosismo como problema histórico, su ideología esgrimida en sus declaraciones públicas y en su obra poético musical se vincula mayormente con el revisionismo histórico de derecha. Este surgió en los años veinte del siglo pasado y construyó un modo de identidad argentina enraizado en las tradiciones federales del interior y de los caudillos, perspectiva que alcanzó una fuerte presencia en los imaginarios sociales y políticos.

Para Goebel (2013), lo novedoso en el revisionismo no era tanto la evaluación positiva de Rosas sino el carácter sistemático de crear un panteón alternativo como eje central de un ferviente nacionalismo antiliberal y, por ende, antimitrista. Por su parte, Halperín Donghi (2005), consideraba que el revisionismo era una visión decadentista de la Historia que se basó en postular a Rosas como la figura heroica nacional opuesta a los intereses oligárquicos y a la dominación colonial de Gran Bretaña.

Lo cierto es que el revisionismo se construye a través de ideologías, narrativas, mitos y símbolos que constituyen la materia prima a partir de la cual los nacionalismos argentinos interpretaron (e interpretan) la identidad del país y los rasgos fundamentales de su estado-nación. De acuerdo a Cattaruzza (2003), la gran tarea que se adjudicaba el Revisionismo era cambiar la versión dominante de la Historia por otra nueva, no sólo más "verdadera" sino también más adecuada a los intereses nacionales hasta convertirse en la Nueva Historia oficial y en el discurso histórico de la sociedad. Por otro lado, los revisionistas buscaban una utilización plenamente política para dotar a la Historia de una función social como discurso científico del pasado que permeara a las masas.

Este modo en que la escena metálica bonaerense utiliza al revisionismo para cuestionar al pasado se asemeja a la crítica que hace el posmodernismo de la idea de progreso que caracterizaba a las sociedades modernas occidentales. Empero, a pesar de desarrollarse en el contexto de la globalización y de que dicho proceso suela ser vinculado con la posmodernidad, la escena metálica bonaerense responde más bien a parámetros propios de la modernidad cásica occidental (Beck, 1998). 
Esto se debe a que la operación revisionista demuestra confianza principalmente en el estado-nación, una institución propiamente moderna $\mathrm{y}$, al mismo tiempo, en la escena metálica bonaerense se desconfía de características posmodernas, tales como la masividad, la sociedad de la comunicación y la diversidad o "liberación de las diferencias" (Vattimo, 1994), las cuales se considera que pueden atentar contra la auténtica esencia metálica. Esta última postura es similar a la que persigue el nacionalismo con el objetivo de construir una identidad nacional pura.

Por otra parte, la utilización que hace la escena de la historia como una forma de regresar al pasado no significa la negación del futuro, tal como sucedía con el punk rock que

(...) se oponía al progreso. Musicalmente, rechazaba la idea setentista de progresión y madurez que dio origen al rock progresivo y a otros sofisticados sonidos de los años setenta. Decidido a retrasar el reloj para volver al pasado adolescente del rock, al rock'n'roll de los años cincuenta y al garaje de los sesenta, el punk rock también rechazaba la idea de progreso en un sentido filosófico más amplio. Impulsado por un apetito apocalíptico de colapso y destrucción, tenía una visión literalmente desesperanzada de las cosas. (Reynolds, 2012, p. 263)

Los aficionados más fundamentalistas de la escena metálica bonaerense también rechazan la idea de progreso representada en las bandas de estilos más nuevos (ñu metal, metalcore y metal industrial) que no solo utilizan herramientas de las TIC's ${ }^{181}$ para la producción de su sonido sino que, en algunos casos, también generan híbridos con música electrónica, es decir, música hecha con máquinas y no con los instrumentos musicales tradicionales. En este punto, chocan dos formas de autenticidad rockera opuestas: por un lado, la "romántica", que privilegia la ocultación de la tecnología musical; y, por el otro, la "moderna", que prefiere el progreso y la experimentación, por lo que celebra la tecnología (Keightley, 2006).

También es usual que muchas agrupaciones de la escena estudiada compongan las letras de sus canciones con temáticas apocalípticas y que utilicen iconografías tales como el personaje de la Parca y las calaveras. Sin embargo, a pesar de que dichos símbolos estén vinculados con la "muerte" y, por ende, con la ausencia de futuro, son utilizados con el objetivo de representar transgresión, igualdad (tal como lo hace la Danse macabre) y como una advertencia para la preservación de la vida.

\footnotetext{
${ }^{181}$ Sigla que se refiere a las Tecnologías de la Información y la Comunicación.
} 
Al contrario del punk, en la escena metálica bonaerense es posible observar la idea recurrente de la inmortalidad. Esto se puede observar en los cánticos y nombres de fanpages de Facebook que expresan frases tales como "La hache no murió", "V8 no murió", "Civile no murió", "Pappo no murió" y frases en murales, tatuajes y estampados de remeras que dicen "Larga vida al metal", "V8 vive" y "Hermética vive". El deseo de perpetuidad de las bandas también parece indicar la intención de otorgarle continuidad a las propias identidades metálicas tanto individuales como grupales.

Esta concepción de inmortalidad, además, está ligada a la idea del "aguante" como forma de resistencia ante las adversidades (Salerno y Silba, 2006). Ejemplos de ello aparecen en el título del fanzine de Bahía Blanca, Resistiré; en el nombre de la banda, Inmortales; y en el título del disco de la agrupación porteña, Renacer, Espíritu inmortal (2013). Al mismo tiempo, con Hermética y Iorio se la puede vincular con la idea de reencarnacionismo y con la vida después de la muerte y la comunicación con los espíritus.

La aspiración de inmortalidad se ve afectada ante la muerte real de algunos miembros de la escena. Un ejemplo de ellos lo pude observar en un concierto en José C. Paz en el cual una banda colgó en el micrófono la fotografía de un miembro de la escena bonaerense recientemente fallecido para dedicarle su performance (Ver Figura 42). Asimismo, a través de la netnografía en Facebook y YouTube, pude observar comentarios de condolencia y fuerte pesar ante las pérdidas de varios músicos tanto internacionales como argentinos, tales como el baterista, Nick Menza, de Megadeth; Juan "Locomotora" Espósito, baterista de El Reloj y Lovorne; y Guillermo Sánchez, bajista de Rata Blanca.

Uno de los casos más relevantes fue el del bajista, Lemmy Kilmister de Motörhead, uno de los grupos icónicos de la NWOBHM, quien falleció el 28 de diciembre de 2015 a los 70 años de edad. A través de la netnografía en Facebook pude ver que ese día la reacción de muchos fue el descreimiento ya que en dicha fecha se suelen hacer bromas por el "día de los inocentes". Esto se debía a que la imagen del músico era la de haber sobrevivido a pesar de llevar una vida de constantes excesos. El hecho además tuvo mayor impacto debido a que, ese mismo año, Motörhead se había presentado en el festival "Monsters of Rock" en CABA, lo que para muchos aficionados de la escena efectivamente había constituido la última oportunidad de haberlo visto en vivo. 
El 9 de enero de 2016 se realizó el funeral del músico en su bar favorito en Hollywood, al cual asistieron músicos reconocidos de rock y metal de la escena global, tales como Dave Grohl (Foo Fighters), Slash (Guns N' Roses), Robert Trujillo, Lars Ulrich (Metallica), Rob Halford (Judas Priest) y Scott Ian (Anthrax).

Dicha ceremonia fue transmitida vía streaming por YouTube, la cual fue seguida en directo por cerca de 221 mil usuarios de diversas partes del mundo. Ese mismo día en Tandil etnografié un festival metálico que se realizaba en el mismo horario de transmisión del velatorio, por lo que algunos aficionados y músicos dedicaron explícitamente sus performances en memoria de Lemmy. Asimismo, varios no asistieron al concierto para quedarse en sus casas a ver el velatorio.

\section{Algunas consideraciones}

A partir de lo analizado anteriormente, es posible observar la preponderancia del pasado sobre el presente y el futuro de la escena. Esto sucede debido a que los antiguos miembros continúan permaneciendo y porque se difunde la idea de respeto y veneración del pasado, tanto del que constituye la propia historia de la escena como del que forma parte de la historia del contexto local argentino.

Entonces, a pesar de que existen diversos mecanismos mediante los cuales se intenta integrar a nuevas generaciones de aficionados, parece predominar la celebración y consagración de los pioneros, pertenecientes a los años fundantes, considerados la “época dorada". De esta manera, estos miembros son elevados a un estatus de autoridad y de estrellato al que aspiran llegar los nuevos participantes, al mismo tiempo que monopolizan una pretendida ortodoxia, propia de los sectores fundamentalistas:

Aquello que, dentro de un estado determinado de la relación de fuerzas, monopolizan (de manera más o menos completa) el capital específico, que es el fundamento del poder o de la autoridad específica característica de un campo, se inclinan hacia estrategias de conservación -las que, dentro de los campos de producción de bienes culturales, tienden a defender la ortodoxia-, mientras que los que disponen de menos capital (que suelen ser también los recién llegados, es decir, por lo general, los más jóvenes) se inclinan a utilizar estrategias de subversión: las de la herejía. (Bourdieu, 2002, p. 121)

La escena metálica bonaerense puede ser caracterizada como culturalmente conservadora, tanto por esta celebración de los pioneros, como por la valoración del pasado. Lo "retro" es generado a partir de la subjetividad de los participantes, los cuales mediante la nostalgia y diversos artefactos de memoria permiten construir socialmente la memoria colectiva de la escena y una especie de archivo virtual. En efecto, "La 
memoria tiene entonces un papel altamente significativo, como mecanismo cultural para fortalecer el sentido de pertenencia a grupos o comunidades." (Jelin, 2012, p. 44)

Además, ideológicamente la valoración del pasado aparece a partir del uso de los relatos históricos como fuente de temáticas para la producción de discos y canciones. Esto, a su vez, se vincula con la idea de inmortalidad, la que no solo se liga con el ideal de "aguante" que se predica en la escena, sino que también resulta un mecanismo que permite la perpetuación y la continuidad del propio estilo musical a lo largo del tiempo.

Debido a que la escena se construye en torno a un estilo musical surgido en el contexto de la globalización podría ser considerada como una producción de la posmodernidad. Sin embargo, el carácter conservador y el uso del revisionismo histórico, vinculado de manera estrecha con la idea de estado-nación, acerca a la escena a características propias de la modernidad clásica occidental.

Al mismo tiempo, se ve una actitud anti-modernista que prefiere rescatar la "tradición" en lugar del cambio y el progreso, a la vez que lo "retro" permite realizar una genealogía con la intención de encontrar lo "verdadero" en el "mito de origen", negando la dinámica histórica con sus cambios y desviaciones. En ese sentido, la autenticidad metálica se asemeja a la que Keightley (2006) calificó como "romántica" para el caso del rock, ya que privilegia la continuidad y se opone a los cambios tecnológicos.

Por otra parte, el uso de la memoria en la escena permite la conservación de la propia historia y de cierta "ortodoxia" frente a las posibles modificaciones que presupone la lógica de la evolución. Parte de esta actitud es constitutiva de la ideología de la autenticidad heredada de la tradición del rock que se opone a las transformaciones por temor a que los cambios se vinculen con la cultura de masas (Ochoa, 2002). En el capítulo siguiente analizaré las tensiones surgidas en el naciente campo "intelectual" de la escena estudiada. 


\section{Un nuevo campo intelectual en la escena metálica bonaerense}

\section{La Feria del Libro Heavy y su impronta intelectual}

Como ya mencioné en la primera parte de esta tesis, el metal a nivel global se caracteriza por hacer uso de la literatura, la historia y otras artes como fuente de temáticas y retóricas para la construcción de una estética de transgresión. Este vínculo permitió que sus aficionados entablen una relación cercana con la literatura y la cultura del libro.

En efecto, en mi trabajo de campo pude observar que muchos aficionados se acercaron al metal a través de textos literarios (por ejemplo, fanáticos de J.R.R. Tolkien se interesaron por bandas como Blind Guardian, la cual construye canciones con asuntos propios de la narrativa de dicho autor) y otros que, en el camino inverso, se convirtieron en sujetos lectores a partir del interés que le despertaban las referencias literarias en las letras de algunas canciones de metal.

Esta relación fue la que motivó la creación de las Ferias del Libro Heavy, por parte del escritor, Gito Minore y la editora y emprendedora, María Inés Martínez. La primera de estas ferias se realizó el 19 de octubre de 2013 en el Centro Cultural La Imaginería, en el barrio porteño de Boedo, bajo la impronta de que "el heavy metal es una cultura letrada" (Minore, 2014, p. 7).

En palabras de Minore, el objetivo de la feria es “(...) generar un espacio de circulación y socialización de todo nuestro trabajo tanto intelectual como material, referido al heavy metal argentino (...)” (2015, p. 9), “(...) un movimiento de intercambio tanto de saberes como de productos (...)” (2014, p. 12), además de “(...) un espacio de difusión y legitimación de todo este esfuerzo musical, artístico e intelectual, que desde los años 70 iniciaron los padres fundadores de nuestro género y hoy humildemente tomamos la posta todos los que nos sumamos (...).” (2015, p. 9)

De esta manera, a partir del 2013, la Feria del Libro Heavy se comenzó a desarrollar anualmente en CABA y comenzó a expandirse a otras ciudades del interior, por lo que también se llevó a cabo en Mar del Plata en 2014, 2015, 2016 y 2017, y en Tandil en 2016, junto con organizadores provenientes de dichos lugares ${ }^{182}$. Lo que

\footnotetext{
${ }^{182}$ Posteriormente a mi trabajo de campo y al período estudiado en esta tesis, la feria se desarrolló en 2018 en las ciudades bonaerenses de Ayacucho y Monte Grande, y en Zapala (Neuquén), en el marco del campamento metalero, Pacha Huasi.
} 
efectivamente significó que la Feria se desarrolló como una "movida colectiva" (Minore, 2017, p. 7).

Una de las características comunes en esas tres ciudades fue que los lugares en donde se desarrollaron las Ferias eran espacios "alternativos": centros culturales autogestivos, bares y clubes barriales. A pesar de ello, el evento fue declarado de interés cultural por los municipios de ambas ciudades del interior y, en CABA, los agentes del evento accedieron a espacios que pueden ser considerados propios de la hegemonía cultural: la Biblioteca Nacional, la Feria del Libro de Buenos Aires y medios de comunicación de alcance nacional como La Nación, InfoBAE, Página 12, Télam y Crónica TV.

De acuerdo a Minore, la intención del evento no era limitarse al debate literario (Minore, 2014), por lo que se utilizó la denominación “feria” para poder “(...) incluir las más diversas maneras en que la imaginería metalera se venía manifestando, ya sean artesanías, manualidades y todo tipo de elaboraciones." (Minore, 2015, p. 7). De esta manera, también expusieron (y, en algunos casos, comercializaron) sus obras artesanos, fotógrafos, editores, dibujantes, actores, performers y músicos. A pesar de esta variedad de rubros, el título de la Feria tiene al sustantivo "libro" como centro (Ver Figura 43).

De hecho, esta preponderancia de la cultura en torno a este tipo de publicación escrita hace que dicha reunión se distinga de la Feria del Libro Punk y sus Derivadxs que se organiza en CABA desde el 2012. A diferencia de esta, los organizadores de la Feria del Libro Heavy publican las charlas que se llevaron a cabo en el formato de una colección de libros titulados, Cultura Metálica. Ponencias, debates y exposiciones de la Feria del Libro Heavy de Buenos Aires (2014, 2015, 2016, 2017 y 2018).

De esta manera, la primera Feria fue modelo para el resto de ellas, en donde además de haber puestos para feriantes (constituidos por artesanos, editores de revistas y fanzines, vendedores de discos, ilustradores y fotógrafos) y una exposición de fotografías de aquellos especializados en captar las imágenes de recitales de metal realizados en $\mathrm{CABA}$, también contaba con un espacio especial en donde a través de un micrófono varios periodistas, escritores, y académicos exponían trabajos que reflexionaban acerca del metal y debatían sobre él.

Entonces, la originalidad de la Feria del Libro Heavy fue la creación de un espacio de exposición que daba cuenta de cierto trabajo de reflexión intelectual acerca del metal, es decir, el desarrollo de una especie de metadiscurso sobre el estilo musical, 
no solo relacionado con el contexto inmediato de la Argentina, sino también mediante sus expresiones internacionales.

Fue a partir del nacimiento de este evento que una gran cantidad de universitarios, docentes y periodistas comenzaron a elaborar trabajos con el formato similar a las ponencias que se presentan en los congresos académicos, por lo que la feria constituyó un espacio alternativo al circuito intelectual tradicional pero que, en alguna medida, se desarrollaba con parámetros similares ${ }^{183}$.

El ejercicio reflexivo acerca del metal permite analizar a la Feria del Libro Heavy como un evento que permitió el surgimiento de una nueva actividad intelectual, un campo del saber propio de la escena metálica bonaerense, el cual no solo está integrado por estudiosos del ámbito universitario (los que, al mismo tiempo, contribuyen con el campo académico de los estudios metálicos) sino también por una diversidad de agentes que comienzan a desarrollar la función social del intelectual Gramsci, 2018).

De acuerdo a Edward Said (1996), "En la actualidad, todo aquel que trabaja en cualquiera de los campos relacionados tanto con la producción como con la distribución de conocimiento es un intelectual en el sentido de Gramsci." ${ }^{184}$ (1996, p. 28), por lo que es posible considerar como intelectuales a quienes exponen sus ponencias en la Feria del Libro Heavy. Por otra parte, muchas de las exposiciones y los coloquios que se desarrollan en la Feria dan cuenta de una perspectiva crítica hacia el metal y su cultura. Entonces, es posible considerar a estos agentes como intelectuales en términos de Said:

\begin{abstract}
Básicamente, el intelectual en el sentido que yo le doy a esta palabra no es ni un pacificador ni un fabricante de consenso, sino más bien alguien que ha apostado con todo su ser en favor del sentido crítico, y que por lo tanto se niega a aceptar fórmulas fáciles, o clisés estereotipados, o las confirmaciones tranquilizadoras o acomodaticias de lo que tiene que decir el poderoso o convencional, así como lo que éstos hacen. No se trata sólo de negarse pasivamente, sino de la actitud positiva de querer afirmar eso mismo en público. (Said, 1996, p. 39)
\end{abstract}

\footnotetext{
${ }^{183}$ Esta característica es comparable con el interés académico que Eduardo Archetti (2016) describe hacia el tango: "El impacto musical y literario del tango en la sociedad argentina fue enorme. La rápida aceptación y expansión de las composiciones y orquestas, y luego de las letras y cantores, crearon un universo para las "interpretaciones" nacionales, "lecturas" y distintas clases de análisis: ensayos panegíricos, enciclopedias y textos cuasi-históricos, autobiografías, academias populares de tango y lunfardo - la jerga porteña utilizada en cantidad de tangos- y numerosas biografías de músicos, autores y cantores. Recientemente, el tango se transformó en asunto "académico", con importantes aportes de sociólogos, críticos literarios e historiadores, a quienes los expertos tradicionales perciben como extraños o ajenos (...)" (Archetti, 2016, p. 201).

${ }^{184}$ Gramsci considera que todos los hombres poseen facultades intelectuales pero solo algunos de ellos cumplen la función social del intelectual.
} 
El más claro ejemplo del disenso y la discusión en torno al metal y la presencia de una perspectiva crítica se materializa a partir de las mesas-debate desarrolladas en estas Ferias, en las cuales diversos investigadores, docentes, periodistas, gestores culturales y músicos dialogaron en torno a temáticas como la figura de Iorio en los estudios académicos, el rol de los medios alternativos, la presencia de la mujer en el metal, y la intolerancia y la discriminación en la escena. Algunas veces estas charlas tuvieron fervientes polémicas.

Al mismo tiempo, al tener en cuenta que entre los aficionados al metal es valorado el conocimiento acerca del estilo musical como una forma de autenticidad (Weinstein, 2000; Galicia Poblet, 2015), es posible ver que esta característica se intensifica al presentarse un espacio para dar cuenta de dicho capital simbólico en público y hacer de él un ejercicio intelectual.

\section{El vínculo con Boedo}

Una de las consecuencias de la primera Feria del Libro Heavy fue la creación del Grupo de Investigación Interdisciplinaria sobre Heavy Metal Argentino (GIIHMA), el cual lleva la misma impronta que la feria: sus miembros consideran que el metal constituye un género musical marginal que, al poseer estas características, es difícilmente aceptado por la academia ${ }^{185}$. Es por ello que buscan modos alternativos de investigación académica.

Entonces, tanto la Feria como el GIIHMA se presentan como instituciones escénicas que se caracterizan por su lucha contra una hegemonía cultural y académica a través del trabajo interno, como docentes y alumnos en la Universidad de Buenos Aires, y externo, con la constitución de una editorial autogestiva y la organización de la propia Feria. Este perfil puede compararse con la impronta que poseía el grupo Boedo, una agrupación de artistas de la vanguardia argentina de 1920 creada en el mismo barrio en que se originó la feria mencionada: Boedo.

Este grupo artístico se caracterizaba por vincularse con los sectores populares y la ideología de izquierda, al mismo tiempo que representaba "(...) el mundo social de los pobres, los carenciados, los marginados, excluidos" (Vitagliano, 2012, p. 9).

\footnotetext{
${ }^{185}$ Sobre este punto debatí con algunos de ellos en la mesa-debate, "La recepción de Iorio en la academia" del año 2013. Allí planteé mi desacuerdo ya que mi propuesta del metal como objeto de estudio fue aceptada para mi tesis de Maestría por la Facultad de Lenguas de la Universidad Nacional de Córdoba y para mi tesis de Doctorado por la Facultad de Periodismo y Comunicación Social de la Universidad Nacional de La Plata, a la vez que fue aprobada por CONICET para otorgarme una beca doctoral.
} 
Algunos miembros del grupo Boedo eran los escritores, Elías Castelnuevo y Álvaro Yunque, y el músico, Cátulo Castillo.

Tradicionalmente, la historiografía opuso este grupo al de Florida, que se desarrolló en la misma época, el cual se conformaba en torno a la revista literaria, Martín Fierro; estaba integrado por escritores como Jorge Luis Borges y Leopoldo Marechal; y se caracterizaba porque sus miembros pertenecían a la élite económica y social de Argentina, a la "alta cultura" y apoyaban a los movimientos europeos de vanguardia, tales como el surrealismo, el dadaísmo y el ultraísmo.

Minore compara al metal con el grupo Boedo como dos temas que, en su opinión, parecen no ser aceptados dentro del ámbito académico por la defensa que hacen de lo marginal:

Esto le valió a Boedo ser tratado de forma despectiva y no ser leído como "literatura seria" y digna de ser analizada en las universidades sino hasta hace muy poco. Ellos traían en las páginas de sus libros, a los monstruos, a los ciudadanos de segunda, a los males del siglo que "la vereda de enfrente" no quería mirar. (...) Estos autores son los llamados "malditos", a los que siempre, tanto ayer como hoy, tratan de correr, de ningunear, porque son zurdos, son "grasas" o, como en el caso nuestro, son metaleros. (Minore, 2014, p. 23)

El surgimiento de este campo intelectual reciente puede ser comparado con el nacimiento del campo intelectual argentino de principios del siglo $\mathrm{XX}$, el que, según Carlos Altamirano y Beatriz Sarlo (1997) se gestó a partir de "la constitución de ideologías de artista" (1997, p. 167, Cursivas del original), las cuales estuvieron vinculadas con la reflexión acerca del nacionalismo. En dicha época, estos escritores comenzaron a poseer un nuevo lugar de legitimidad en la estructura social del país, ya que ellos eran los encargados de “(...) decir la verdad de los orígenes, fundar la tradición, espiritualizar el país.” (Altamirano y Sarlo, 1997, p. 188) Esta postura nacionalista es similar a la que caracteriza a la línea fundamentalista de la escena metálica bonaerense, la cual se debate en la Feria del Libro Heavy.

Otro punto de comparación entre dicho evento metálico y el campo intelectual argentino del 1900 aparece en que, en dicha época, la Facultad de Filosofía y Letras de la Universidad de Buenos Aires contribuyó al desarrollo de nuevas formas de sociabilidad intelectual (Altamirano y Sarlo, 1997). En el caso actual, la mayoría de los miembros del GIIHMA (grupo surgido de la feria mencionada) provienen de dicha institución pero se muestran críticos con ella a partir de la construcción de un discurso antiacademicista y una identidad intelectual "marginal", alternativa a la que se 
construye hegemónicamente. No obstante, en el transcurso de los años, también se integraron a las exposiciones de la Feria académicos provenientes de otras instituciones y diversos campos disciplinares que se mostraron diferentes a la identidad ensayísticoliteraria y política que asume el grupo citado.

La Feria del Libro Heavy también se asemeja con el grupo de Boedo a través de la editorial independiente que gestionan sus organizadores, la cual se denomina "Clara Beter", al igual que el seudónimo del escritor del grupo Boedo, César Tiempo. A través de dichos editores se producen los libros Cultura metálica.

Entonces tanto la Feria del Libro Heavy como el GIIHMA intentan replicar algunas características del grupo Boedo al considerar al metal como un estilo musical marginal. De acuerdo a la perspectiva de ambas instituciones metálicas, este tipo de música no solo se encuentra excluido de los parámetros convencionales del mercado, sino que también en Argentina posee una fuerte cercanía con los sectores populares.

\section{Metal y Literatura}

La referencia al grupo Boedo como modelo ideológico y de acción también se observa en la fuerte presencia de la literatura en la impronta creativa de la Feria. En efecto, gran cantidad de exposiciones tuvieron como eje de análisis la relación entre el metal y algún autor u obra literarios en particular, al mismo tiempo que varios escritores daban cuenta de cómo incluían al metal dentro de sus creaciones literarias, especialmente vinculadas con la narrativa de terror y la poesía oscura y grotesca.

Además de ello, las performances que se desarrollaban en el evento también se basaban en obras de la literatura. Por ejemplo, es posible mencionar los números artísticos de terror del performer, Vampire Destroy, basados en el capítulo, "La virgen de hierro" del relato, La condesa sangrienta (1966), de Alejandra Pizarnik y en el cuento, "El horror de Dunwich" (1928) de H.P. Lovecraft (Ver figura 44). Todos estos textos se asemejan en la descripción de situaciones de horror y violencia. Entonces, este dialogo que realiza el metal con la literatura permite a la Feria calificar a este estilo musical como una "cultura letrada".

\section{Celebrar o reflexionar}

El surgimiento de un nuevo modo de reflexión intelectual acerca del metal fue ampliamente aceptado por los miembros de la escena metálica bonaerense, lo que permitió que el evento se continúe desarrollando con vasta convocatoria y aumenten las 
propuestas de exposiciones año a año. Sin embargo una gran cantidad de agentes de la escena demuestran no interesarles dicho tipo de intervención e, inclusive, algunos expresan estar en contra del evento y de los estudios acerca del metal.

Sobre estos modos de recepción pude ver el desinterés en aquellos que, a pesar de asistir a la feria, no se acercaban a escuchar a los expositores y preferían permanecer en la vereda, fuera del local, utilizando a la Feria solamente como una excusa para reunirse con otros miembros de la escena. Esto se intensificó en las versiones marplatense y tandilense que, luego del debate intelectual, se desarrollaban conciertos de bandas de metal. Por lo que, en muchos casos, el público llegaba directamente en el horario del recital.

Otros directamente no asistían a la Feria ya que consideraban que se trataba de una práctica aburrida y "careta", misma calificación que le daban al trabajo de investigación aquellos que se negaron a ser entrevistados como parte de mi etnografía. En mi trabajo de campo etnográfico y netnográfico pude observar que estos participantes consideran que el metal es algo que se siente y se vive, pero no se estudia. Por lo que sus modos predilectos de celebración del estilo musical son la escucha (individual y social) y la participación de recitales, mediante actividades que según ellos no implican el uso del intelecto, sino que lo ligan a lo pasional y lo práctico.

Al contrario de estos agentes, otros demostraban interés por las exposiciones desarrolladas en las Ferias y consideraban a estos eventos como oportunidades para adquirir nuevos saberes acerca del estilo musical que apreciaban. Esto se puede observar en las palabras de uno de los organizadores de la versión marplatense que, aparte de ello, en la vida cotidiana se desarrolla como vendedor viajante:

\footnotetext{
A mí me costó entender que la base de la Feria del Libro Heavy es dar a conocer el mundo de tachas, cuero, pelo largo y sonidos furiosos a través de un evento académico que quienes lo llevan a cabo están muy ligados con la literatura y desde ese lugar hacen un análisis, un estudio muy profundo demostrando a nuestra sociedad lo que somos, con fundamentos y hechos bien explicados, que al metalero ortodoxo por ahí le cuesta entender y asimilar, pero es muy satisfactorio y beneficioso poder ver esta cultura del heavy metal de forma académica, y creo que así como en su momento no se supo entender el heavy en los años 80 y hoy por hoy tiene cabida en esta sociedad, la Feria quizá no se entienda por todos hoy, pero pasado el tiempo va a dejar un rastro en la historia. (Julio en Berta et al., 2016, p. 109)
}

La calificación de "ortodoxo" utilizada por el actor anteriormente citado puede ser comparada con la idea de "fundamentalismo" que predomina en el centro de la escena metálica. En la descripción de dicho aficionado, la “ortodoxia” parece oponerse 
a la reflexión intelectual; primero, porque posiblemente al tratarse de algo "novedoso" significa la presencia de cambios, los cuales son resistidos por la escena; y segundo, porque la autopercepción que tiene esta de sí misma como "popular" parece oponerse a la imagen del intelectual "educado" y ligado a instituciones hegemónicas, como lo son las universidades y las escuelas.

\section{La canonización de Iorio}

Continuando la idea de la formación de un campo del saber, es posible dar cuenta de este en términos de Bourdieu (2002), ya que mediante el ejercicio reflexivo y metadiscursivo se contribuye a la definición de lo que es auténticamente metal y, en este sentido, se legitiman y se consagran determinadas obras y bandas, mediante la posición de autoridad que el campo cultural le otorga.

Entonces, en cierta medida, este campo naciente de intelectuales de la escena contribuye a la conformación de un canon, concepto que está ligado de manera estrecha al de hegemonía, ya que esta "(...) debe describirse formalmente como un 'canon de reglas' y de imposiciones legitimadoras y, socialmente, como un instrumento de control social, como una vasta sinergia de poderes, restricciones y medios de exclusión ligados a arbitrarios formales y temáticos." (Angenot, 2012, p. 32)

De acuerdo a Harold Bloom (1994),

El canon, una palabra religiosa en su origen, se ha convertido en una elección entre textos que compiten para sobrevivir, ya se interprete esa elección como realizada por grupos sociales dominantes, instituciones educativas, tradiciones críticas o, como hago yo, por autores de aparición posterior que se sienten elegidos por figuras anteriores concretas. (p. 30)

De esta manera, “Todos los cánones, incluyendo los contracánones tan de moda hoy en día, son elitistas" (Bloom, 1994, p. 47). Esto implica que se basan en un proceso de selección y de exclusión a partir de otorgarle determinado valor estético a una obra. El trabajo de Bloom se centraba en el campo de la literatura, mientras que en la música, "El canon se manifiesta en la vida musical: programaciones de concierto, libros de divulgación, audiciones radiales, antologías, listas de grabaciones más vendidas (...)” (Corrado, 2004, p. 23). En dicho campo,

Los espacios institucionales son decisivos en la conformación y perpetuación de las normas y los valores que presiden el canon. En primer lugar, el espacio académico lo establece y lo preserva a través de los repertorios de obras analizadas, de las selecciones, cortes y filtros en los programas de historia y/o de análisis, de los modelos 
compositivos que instaura -con sus reglas y exclusiones-, de los programas recurrentes en las cátedras de instrumento. En estas últimas se consagran no sólo repertorios, sino tradiciones interpretativas también canónicas.

Los espacios físicos contribuyen igualmente a este proceso: compositores y obras que migran, por ejemplo, del off al Colón, o incluso en el interior mismo de los circuitos alternativos, también ellos organizados valorativamente, conquistan lugares de prestigio en sí mismo legitimantes. Lo son igualmente los sistemas de premios, becas, recompensas: en ellos, a través de la selección de jurados, de los géneros, a través de la historia de lo anteriormente premiado cristaliza una idea de excelencia que actúa sobre la producción subsiguiente. (Corrado, 2004, p. 24. Cursivas del original)

A pesar de que el metal en Argentina no forma parte de los repertorios canónicos de la musicología, se puede plantear un paralelo con el naciente campo intelectual detectado en la escena metálica bonaerense: en el ejercicio de sus agentes, en sus investigaciones, ponencias y publicaciones aparece la actividad de selección de ciertos nombres que adquieren mayor jerarquía y legitimidad dentro del campo cultural.

Además de los actores, los espacios también son canonizantes y como he mencionado en apartados anteriores, los locales y teatros de CABA son los que otorgan prestigio. Lo mismo sucede con las discográficas que seleccionan a determinadas bandas para producir. También se puede mencionar la actividad de los medios de comunicación. Tal como afirma Hugo García, editor de la revista, Jedbangers, "Tal vez suene medio elitista pero también nuestro rol es jerarquizar un poco la información o la actividad artística" (García en Caballero y Bernal, 2016, p. 48). Nuevamente, una de las agrupaciones que fue seleccionada primordialmente por los medios especializados es Hermética.

Por otra parte, Bourdieu explica que

Existe el efecto de campo cuando ya no se puede comprender una obra (y el valor, es decir, la creencia, que se le otorga) sin conocer la historia de su campo de producción: con lo cual los exégetas, comentadores, intérpretes, historiadores, semiólogos y demás filólogos justifican su existencia como únicos capaces de explicar la obra y el reconocimiento del valor que se le atribuye. (Bourdieu; 2002, p. 123. Cursivas del original)

Entonces el nuevo campo del saber que se desarrolla dentro de la escena metálica bonaerense no solo contribuiría a la selección de un repertorio propio de ella generado inicialmente por las discográficas y los medios de comunicación-, sino que reforzaría dicha valoración a través de la reflexión y la comprensión del metal.

Sin embargo, es necesario aclarar que tal como expresa Frith (2014), "Los géneros musicales populares se forman $-\mathrm{y}$ deben ser entendidos- en el interior de un 
proceso comercial/cultural; no son el resultado de análisis académicos distanciados o de historias musicológicas formalistas." (p. 167) De esta manera, la conformación de un canon particular de la escena es resultado de la interacción entre las tres instituciones mencionadas: el mercado, los medios de comunicación y el círculo intelectual.

Dentro de este canon, la figura de Iorio parece ser preponderante. Sus bandas (V8, Hermética, Almafuerte y Iorio) no solo poseen el grado de "consagradas", sino que se convirtieron en referentes de la escena metálica argentina tanto para el afuera como para el interior de la misma. Esto es reafirmado constantemente por los medios de comunicación, pero a partir del surgimiento de un nuevo campo intelectual, la figura del músico es revalorizada y vuelta a jerarquizar.

En este proceso de canonización, Iorio no es tan valorado como músico sino más bien como lector y poeta. Un ejemplo de dicha valoración se puede ver en el discurso de Emiliano Scaricaciottoli (2014) en la mesa debate de la primera Feria del Libro Heavy, "La recepción de Iorio en la academia":

(...) en realidad Iorio representa muchísimo más que su persona. Me parece que tendríamos que hablar de un antes y después de él en el heavy metal argentino (...) también representa una literatura, una historia literaria, de un movimiento crítico y detrás del tipo hay una biblioteca. Esa biblioteca habla muchísimo del heavy metal argentino, no sólo como movimiento musical o performático de cuatro o cinco tipos que se ponen a distorsionar sus guitarras arriba de un escenario, sino también marca un antes y un después en el rock argentino, me parece que es mucho más amplio que el heavy metal, su figura representa un quiebre, un antes y un después de cómo componer, en cómo dialogar con la coyuntura de lo que representaba en su momento V8, volviendo de la dictadura militar, con lo que representó Hermética, poniendo como eje el menemismo y Almafuerte continuando la discusión con ese segundo menemismo y posteriormente con la crisis del 2001, me parece que Iorio marca un antes y un después no sólo con su propia serie, que es el heavy metal sino al mismo tiempo también con el rock argentino. Es una figura que merece ser estudiada y analizada más allá del periodismo y del biografismo. (Scaricaciottoli en Minore, 2014, p. 26)

Al afirmar que "detrás" de Iorio existe una biblioteca, Scaricaciottoli se refiere al músico en tanto lector. A través de diversas entrevistas y en su biografía es posible conocer el acercamiento de Iorio a la lectura de libros de diversos géneros discursivos: tanto de relatos historiográficos, como literatura argentina y obras del ámbito del esoterismo, el espiritualismo y la religión. Además, en sus canciones es posible encontrar gran cantidad de relaciones intertextuales con sus lecturas previas, entre las cuales la más representativa es la que se produce con Pedro Bonifacio Palacios, al cual homenajea con el nombre de la banda, Almafuerte. 
Pero además de lector, Iorio es valorado como poeta por gran cantidad de aficionados que utilizan a las letras de sus canciones como poesía. A esto es posible verlo en palabras del investigador del GIIHMA, Juan Ignacio Pisano (2018), que compara a la frase “¡Maten a Borges!” -que circulaba en la década del 60 y representaba la intención de deconstruir a la figura canónica del escritor argentino- con la idea de "parricidio" que propone dicho grupo en 2018 como un modo de deconstruir a la figura de Iorio:

El metal tiene su Borges: una figura cuya obra merece ser deconstruida y valorada, y cuya vida él mismo se ha encargado de teñir de oscuridad. Ricardo Iorio es el nombre de ese emblema y, así, como emblema, se afirma en la estética de su más reciente formación cuyo nombre, carente de alegorías, es Iorio, lleva como logo el escudo nacional y demuestra, en esa imaginería, una obstinada intención por mantenerse Atesorando en los cielos, al parecer, la imagen de una figura institucionalizada. (Pisano, 2018, p. 153. Cursivas del original)

No solo es posible ver la canonización de Iorio a través de las opiniones de estos intelectuales, sino también en la preponderancia de su obra de los análisis en los nacientes estudios metálicos de Argentina y, particularmente, de la escena metálica bonaerense.

\section{Algunas consideraciones}

A partir de lo analizado anteriormente, es posible afirmar que además de las clásicas instituciones y mediadores que conformaban a la escena (espacios para recitales, productores, medios de comunicación, discográficas, rockerías, disquerías y locales de venta de instrumentos musicales, entre otros), la Feria del Libro Heavy instauró un nuevo espacio y modos novedosos de comprensión de la escena.

$\mathrm{Al}$ abrir paso al ejercicio reflexivo, permitió el surgimiento de un nuevo campo del saber dentro de la escena, conformado por nuevos intelectuales que no solo se encargaron de intentar comprender las implicaciones del metal como fenómeno cultural, sino que también contribuyeron a la conformación de un canon de músicos y bandas, dentro del cual la figura de Iorio parece ser la predilecta, ya que además de ser seleccionado en tanto músico, también se lo revaloriza como lector y poeta.

Por otra parte, tanto en el desarrollo intelectual de la Feria como en los caracteres de los artistas elegidos (especialmente, Iorio), parece predominar la relación de la literatura y el metal. A pesar de que también se le presta atención a vínculos con otras artes como el cine, la pintura y el teatro, parece preponderar la relación con las 
obras literarias. Una de las consecuencias de esto es que el evento se denomine "feria del libro" y se centre la atención en este formato de publicación escrita. Esto produce cierta paradoja ya que a pesar de intentar otorgarle a la Feria el carácter de popular mediante la consideración del metal como marginal, también se acerca a la noción de lo "culto" propia de la alta cultura, en el sentido de que el evento se enmarca en torno a la cultura letrada del libro.

La Feria del Libro Heavy colabora con el nacimiento de un campo intelectual compuesto por el GIIHMA y por otra gran cantidad de periodistas, académicos y artistas que poseen diversas ideologías y provienen de variados campos disciplinares de las humanidades y las ciencias sociales y de diferentes instituciones educativas y culturales. No obstante, la propia Feria junto con el grupo de investigación mencionado intenta oponerse a cierta hegemonía cultural que, en su criterio, está representada por las investigaciones académicas convencionales y el sistema científico tradicional.

Frente a ello, proponen nuevas formas de investigación alternativas que luchan por el reconocimiento, lo cual se realiza tomando como modelo la misma impronta del grupo de Boedo y su rescate de lo marginal. A pesar de ello, este nuevo espacio intelectual contribuye con la conformación de un canon propio de la escena $\mathrm{y}$, como consecuencia, colabora con la hegemonización de determinadas obras en el interior del campo metálico bonaerense. 


\section{Consideraciones finales}

A través de la presente investigación se estudió a la escena metálica bonaerense entre los años 2011 y 2017 de manera holística -es decir, considerando tanto a sus actores como a sus instituciones y su infraestructura- y desde adentro -indagando reflexivamente a través de la participación dentro de ella-. Se partió de la idea de una conformación diversa que revestía cierta unidad por medio de la circulación de determinados códigos compartidos.

La concepción del objeto de estudio como una escena musical otorgó operatividad a través del recorte temporal y espacial. No obstante, se tuvieron en cuenta parámetros propios de la escena: el período tomó como años de referencia a dos hechos relevantes para sus agentes (el regreso de Malón en 2011 y el vuelco explícito de Iorio a la extrema derecha en 2017) y la frontera territorial no respetó los límites geopolíticos y cartográficos, sino que se ajustó al modo de funcionamiento espacial interno y bajo el gentilicio "bonaerense" se incluyó a la actividad desarrollada tanto en la provincia de Buenos Aires como en CABA.

De esta manera, a través de la investigación se observó que la escena más bien se desarrolla como una red de agentes aficionados y no aficionados que colaboran con la producción, el desarrollo, la difusión, el consumo y la resignificación y recreación del metal.

Por lo tanto, se concluye que es posible plantear a la escena metálica bonaerense como una semiosfera debido a que se construye como una entidad diversa. Una de sus principales características es la heterogeneidad, debido a que no solo se compone por varones sino también por mujeres; tanto por jóvenes, como también por adultos y niños. Al mismo tiempo, los participantes provienen de diversos sectores sociales, habitan en ciudades de diferentes rangos y poseen numerosas ocupaciones, a la vez que se identifican con ideologías políticas variadas e, incluso, contrarias, contradictorias e incompatibles.

A pesar de ello, es posible encontrar ciertos significados que parecen unificar dicha diversidad, los cuales constituyen las estructuras nucleares de la semiosfera. Estos sentidos aparecen plasmados en las producciones y en la actividad de la banda Hermética, la cual no solo representa a la corriente fundamentalista de la escena sino que también encarna ciertos valores tanto estéticos como éticos considerados 
"auténticos" que funcionan como modélicos y unificadores, a pesar de que los participantes de la escena los resignifican de maneras subjetivas.

Dichos significados se construyen de forma paradójica ya que la escena intenta situarse en contra de la hegemonía pero, a su vez, se apega a parámetros de dicho sistema para seleccionar y excluir a aquello que queda por fuera de lo auténticamente metálico. De esta manera la autenticidad queda definida a través de características como el realismo; el conservadurismo; la masculinidad contra-hegemónica, el patriarcado y la heteronormatividad; la auto-marginalidad del "paria orgulloso"; y la lectura y la reflexión política apolítica acerca del contexto argentino a través de la preocupación por "lo nacional".

Por su parte, en la periferia se encuentran aquellas expresiones que conforman la escena pero que no son compartidas por la totalidad de sus miembros y que tienen un fuerte vínculo con semiosferas externas a la escena. En dicho sector interno están la mayoría de subestilos del metal que dialogan con otras culturas y otros géneros musicales, como la cultura medieval y la música electrónica. De esta manera, la semiosfera metálica bonaerense permanece en diálogo con las estructuras externas pero selecciona qué aspectos ingresan, al mismo tiempo que los traduce al propio lenguaje metálico.

Las estructuras nucleares de la semiosfera funcionan como metalenguaje que describe al metal y a lo que deriva de y pertenece a él, por lo que Hermética ocupa un lugar importante al respecto a través de la definición de la identidad metálica argentina. No obstante, que dicho grupo ocupe el centro no significa que la totalidad de los participantes de la escena sean seguidores de ella.

A pesar de ello, es una agrupación ampliamente respetada y los significados centrales anteriormente puntualizados algunas veces son explícitamente valorados por los miembros de la escena y, otras, resignificados de manera inconsciente. Parte de ello se debe a que dichos sentidos también son compartidos por diversas bandas, músicos, géneros musicales, culturas e ideologías no estrictamente metálicos y/o "thrasheros", lo que demuestra la porosidad que constituye a la semiosfera

Por otra parte, es posible analizar a la escena bonaerense de la música metal como campo cultural debido a que sus agentes se encuentran en una lucha permanente no tanto por la posesión del capital cultural propio de la escena (el metal), sino más bien por el reconocimiento y la legitimación de este. La causa de esto son las diversas posiciones de jerarquía en las cuales se encuentran dichos participantes. 
Con respecto a lo espacial, las principales tensiones se producen entre la escena metálica bonaerense -como un recorte micro de la escena argentina- y la hegemonía que supone el circuito global del metal, el cual se desarrolla de manera descentrada pero sus instituciones pertenecen principalmente a las metrópolis europeas y estadounidense. Al mismo tiempo, la misma lucha se produce entre las instituciones de CABA y las del interior de la provincia, ya que la capital porteña funciona como meca de la consagración. Es así que en la escena se distingue un campo con múltiples centros en donde las localidades del interior ocupan el lugar de "doble periferia".

En cuanto a lo temporal, es visible el predominio del pasado. Aquí los agentes que hegemonizan la escena son aquellos que estuvieron presentes en su origen. Al mismo tiempo, al prevalecer el ideal de lo "retro", se produce un fuerte movimiento hacia el pretérito, en el cual se consagran aquellas bandas e instituciones de los comienzos. Esta característica no solo otorga a la escena el rasgo de "conservadora", sino que también permite la preservación del estilo musical. De esta manera prima la ortodoxia representada por los agentes "fundamentalistas", vinculada a una autenticidad "romántica" que se resiste a los cambios.

Por otra parte, a partir de la creación de las Ferias del Libro Heavy comienza a surgir un nuevo campo intelectual dentro de la escena, el cual funciona como una institución más dentro de las que permiten la consagración de determinados músicos y obras y le otorgan a la escena cierto grado de autonomía con respecto a otros géneros musicales. Este campo naciente intenta oponerse a la hegemonía cultural propia de la academia tradicional, pero al generar un canon alternativo, colabora con la construcción de una hegemonía interna a la escena.

Además de ello, es posible decir que, a pesar de que Iorio se posiciona como centro del canon de la escena metálica bonaerense, construido por el mercado, los medios de comunicación y los intelectuales, se observa que Hermética es la banda que logra consagrarse, además, por elección de la audiencia. Este conjunto parece hegemonizar la escena no solo porque es constantemente elegida por las instituciones (especialmente los medios de comunicación y los intelectuales), sino porque también es la que reúne a sectores opuestos de la audiencia.

En suma, la escena bonarense de la música metal se conforma principalmente como una red de personas, sentidos e instituciones en la cual se identifica el carácter relacional de su funcionamiento, no solo basado en la interacción social y el diálogo, 
sino también en la presencia de intersubjetividad y el intercambio de capital cultural, social y simbólico.

A pesar de que la línea fundamentalista y ortodoxa parece ser la que mantiene la unidad y los actores intentan demarcar las fronteras de manera constante, la escena se constituye como un espacio semi abierto que puede ser caracterizado como transcultural, translocal y transgeneracional.

Por su parte, la afición musical de los participantes se concreta tanto de manera individual como colectiva y se encuentra motivada por el interjuego entre lo ideológico y lo emocional. De esta manera, ser aficionado no solo implica la escucha musical sino también la acción, la cual está motivada por un compromiso con la conservación y la perpetuación de la música metal y con la cultura y la comunidad que surge a partir de ella.

En el caso de la escena estudiada, dicha afiliación no consiste en un trabajo de subjetividad temporal, sino que en la mayoría de los casos persiste en el tiempo y traspasa los ámbitos y eventos puramente metálicos. En efecto, dicha identificación se convierte en un modo de ser en la vida cotidiana que se traduce en un conjunto de valores y moralidades que provienen de la escena y se transforman en maneras de ver el mundo. Al mismo tiempo, dicha ética metálica es utilizada como parámetro para interpretar la vida y la sociedad, juzgar a objetos y personas, y construir la propia identidad.

De acuerdo a lo analizado, el metal aparece como un estilo musical que permite la acción y la interacción social mediante la construcción de una infraestructura de eventos, instituciones y formas de identificación especializados, en los cuales se destaca el trabajo comunitario y la agencia de sus participantes desde las escalas más pequeñas y amateurs hasta las más profesionales.

Además de ello, el metal constituye un medio de comunicación propicio para la transmisión de mensajes emotivos e ideológicos, cuyo principal significado es el de poder y potencia, de los cuales la audiencia se apropia generando diversas formas de agencia, ya sea mediante la construcción de identidades individuales como a través del compromiso de actividades grupales. En la mayor parte de los casos, la identidad metálica parece surgir a partir del empoderamiento de algunos marginales $\mathrm{y}$, al ser legitimada, se convierte en "orgullo del paria".

Las formas de comunicación que se desarrollan en el interior de la escena son diversas y deben sortear las dificultades y las tensiones provenientes del contexto 
geográfico, temporal y sociopolítico. Esto se debe a que en ella conviven numerosas características y, a veces, opuestas, tales como la urbanización y la ruralidad, la comunicación virtual y interacción cara a cara, la autogestión y las multinacionales. Dichos rasgos surgen frente a los avances tecnológicos, la globalización y la cultura de masas.

La identidad metálica auténtica a la que aspira el centro de la escena es, al mismo tiempo, preservada y resistida por sus agentes, y permite discutir con las categorías de subcultura y contracultura. En el primer caso, porque dicha categoría se refiere a culturas juveniles pertenecientes a la clase obrera y, a pesar de la identificación con lo marginal y lo popular, la relación que hay en la escena entre metal y clase social no es homológica. Por el contrario, la proveniencia social de sus miembros es variada y desigual.

En segundo lugar, tampoco se puede analizar a la escena bajo la noción de contracultura, debido a que esta se caracterizaba por ser una expresión juvenil que confrontaba con la cultura parental y hegemónica y, en la escena metálica bonaerense, la moralidad que se legitimiza a través de la autenticidad metálica responde a parámetros propios del sistema patriarcal y de la Modernidad clásica occidental (más específicamente, a la figura del estado-nación), es decir, del mundo adulto. Al mismo tiempo, la escena se conforma como transgeneracional y los miembros que alcanzaron una posición de poder y autoridad no son los jóvenes novatos, sino los más antiguos y maduros.

Para concluir, el presente estudio no pretendió agotar el análisis pero sí llegar a los detalles más finos posibles. De él, surgieron nuevas preguntas de investigación y nuevas pieles, a través del proceso de deconstrucción personal constante que significó ocupar el lugar de investigadora y "metalera" al mismo tiempo. Por otra parte, la gran diversidad de materialidades y soportes del corpus analizado intentó dar cuenta de la polifonía que caracteriza a la escena y de la presencia imperante del diálogo como naturaleza del objeto y metodología de investigación.

Asimismo, se pudo observar cómo la música se constituye como un vehículo para la interacción social y la formación de cultura, dando cuenta de que el estudio de la misma excede lo estrictamente musical. Para ello, la Comunicación y los estudios culturales, en tanto campos disciplinares que privilegian el diálogo, resultan operativos al respecto. 
Considero que en futuras investigaciones sería productivo indagar las escenas locales de las diferentes provincias argentinas, ya que en ellas es posible hallar particularidades vinculadas con sus propios contextos. Al mismo tiempo, sería interesante analizar las producciones y apropiaciones de otras bandas por fuera del canon representado con Iorio. De esta manera se podría abordar la diversidad que caracteriza al la escena metálica argentina con mayor amplitud. 


\section{Anexo gráfico}

\section{Figuras}

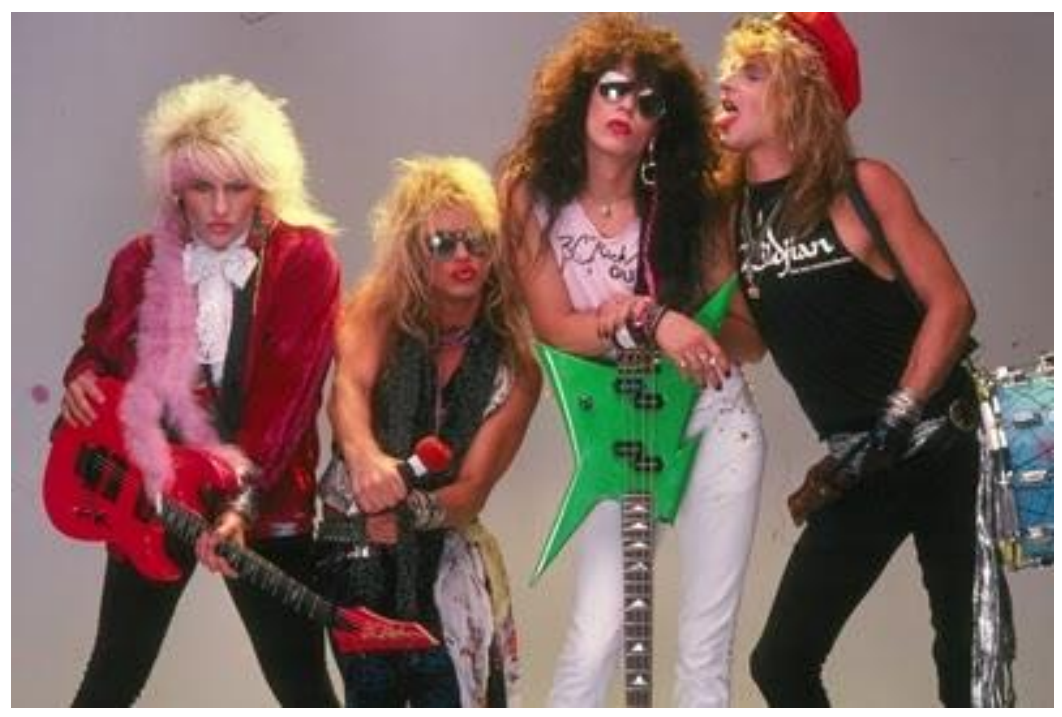

Figura 1: Banda estadounidense de glam metal, Poison ${ }^{186}$. En los atuendos de los músicos predomina un estilo andrógino que combina, colores vivos, prendas masculinas con accesorios, maquillajes y gestualidades femeninos.

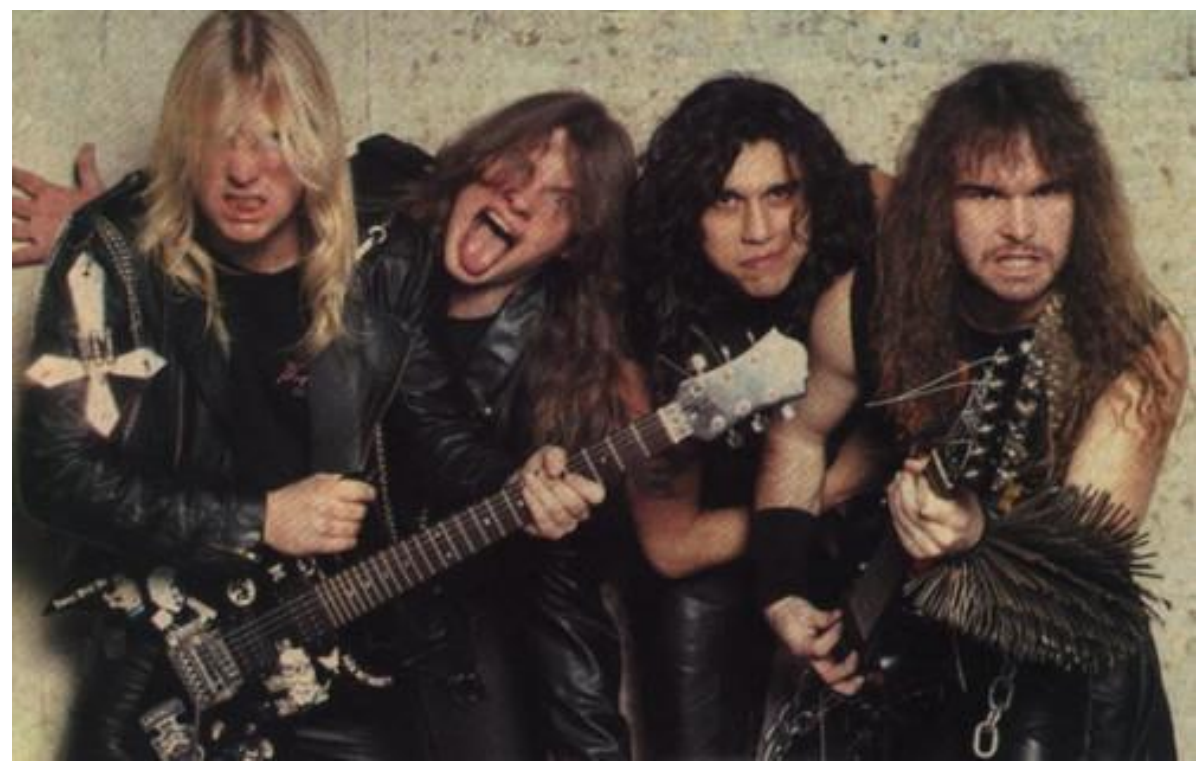

Figura 2: Banda estadounidense de thrash metal, Slayer $^{187}$. Su look se compone de vestuario color negro y gestualidades y accesorios que otorgan el carácter de amenazante.

\footnotetext{
${ }^{186}$ Recuperada de: http://www.theglamnationnetwork.com/uploads/1/3/1/2/13123626/8210803_orig.jpg (Octubre 10, 2017)

${ }^{187}$ Recuperada de: http://www.listal.com/viewimage/2256375 (Octubre 10, 2017)
} 


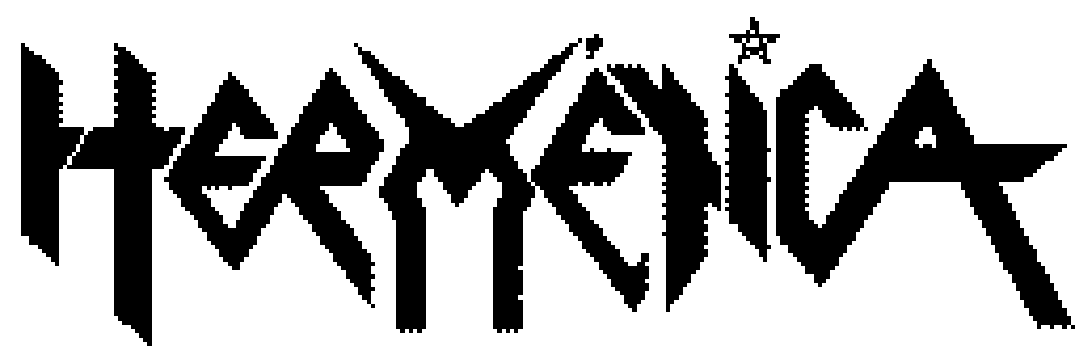

Figura 3: Logotipo de Hermética.

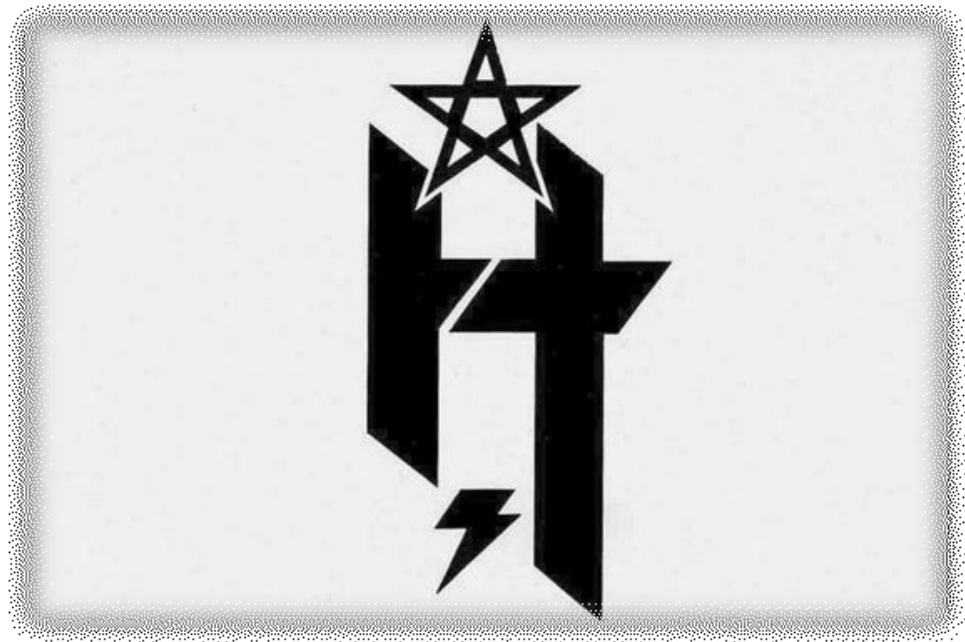

Figura 4: Logotipo reducido con la inicial, "hache".

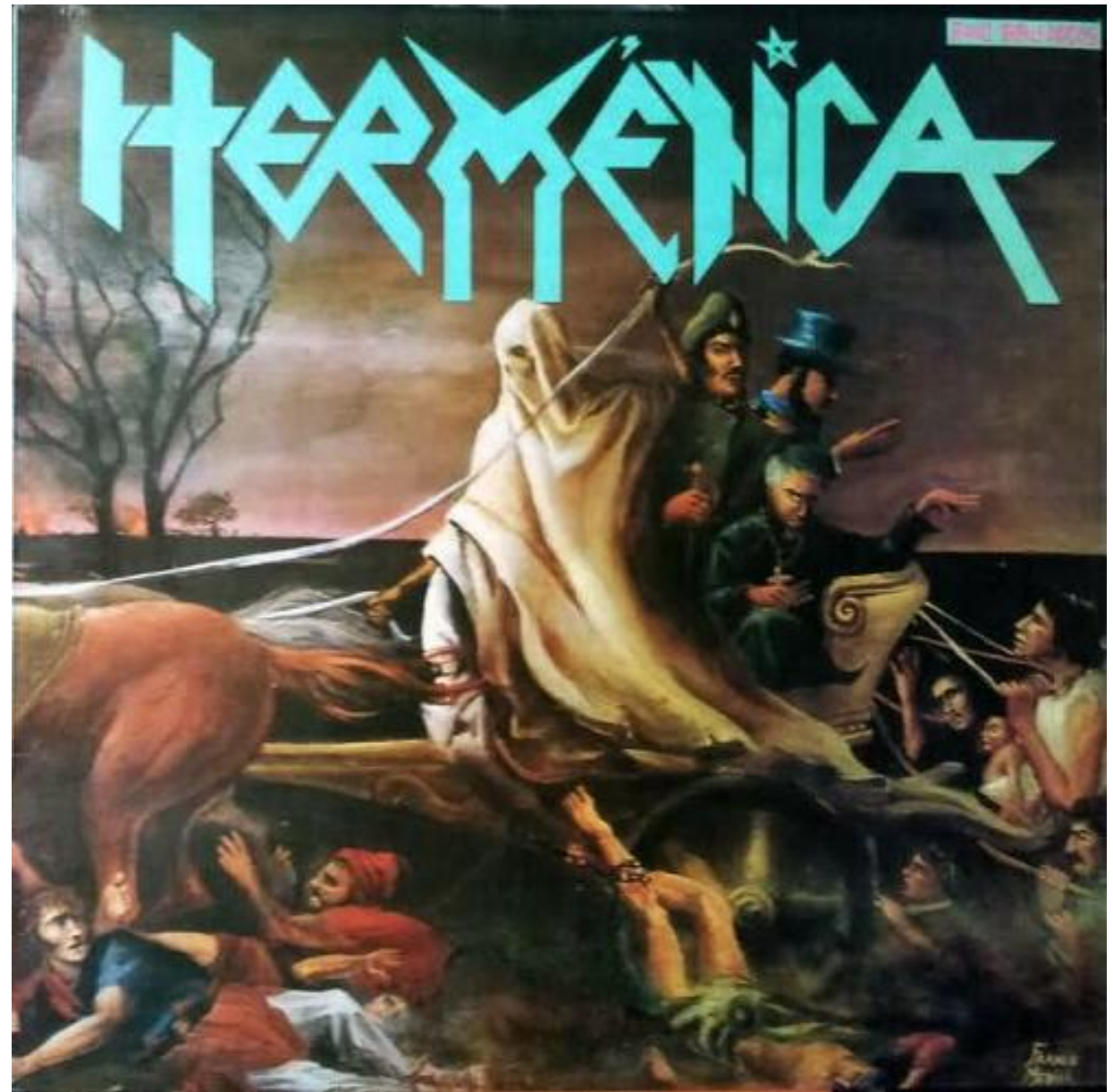

Figura 5:

Portada frontal del disco "Hermética" de 1989. 


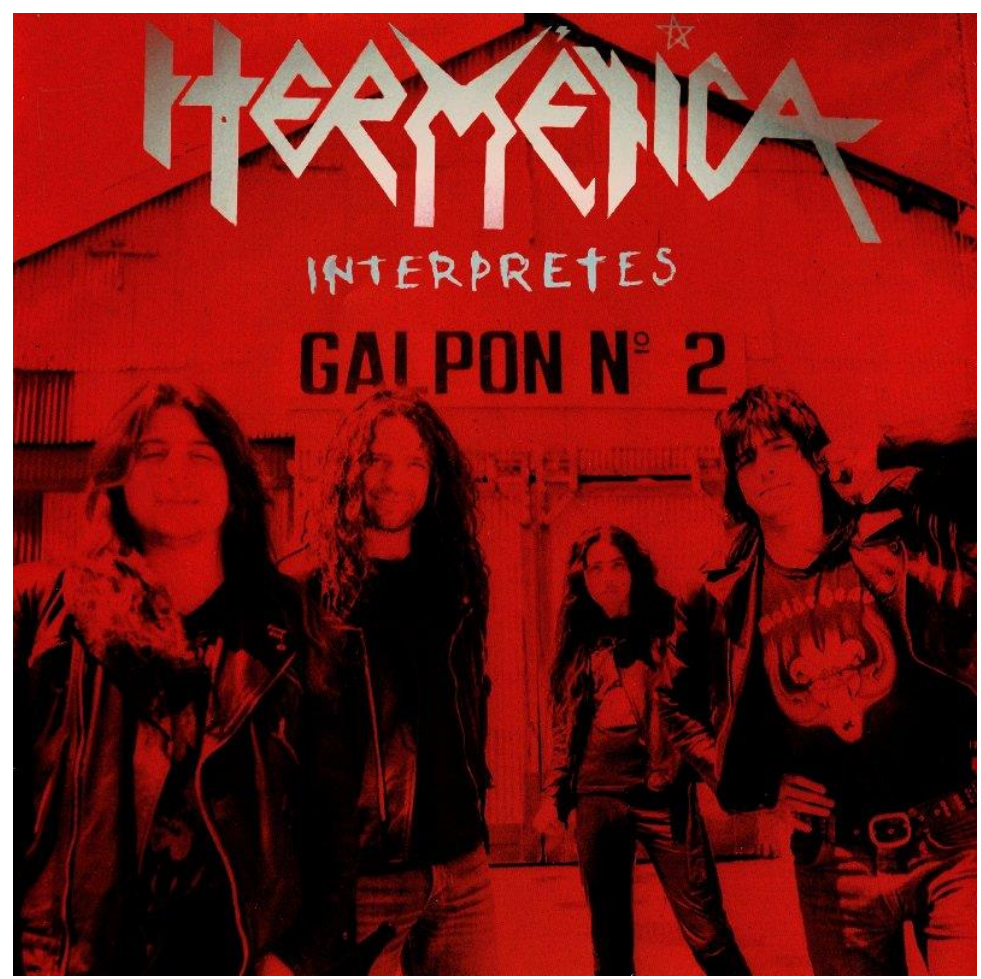

Figura 6: Portada frontal del LP "Intérpretes" de 1990.

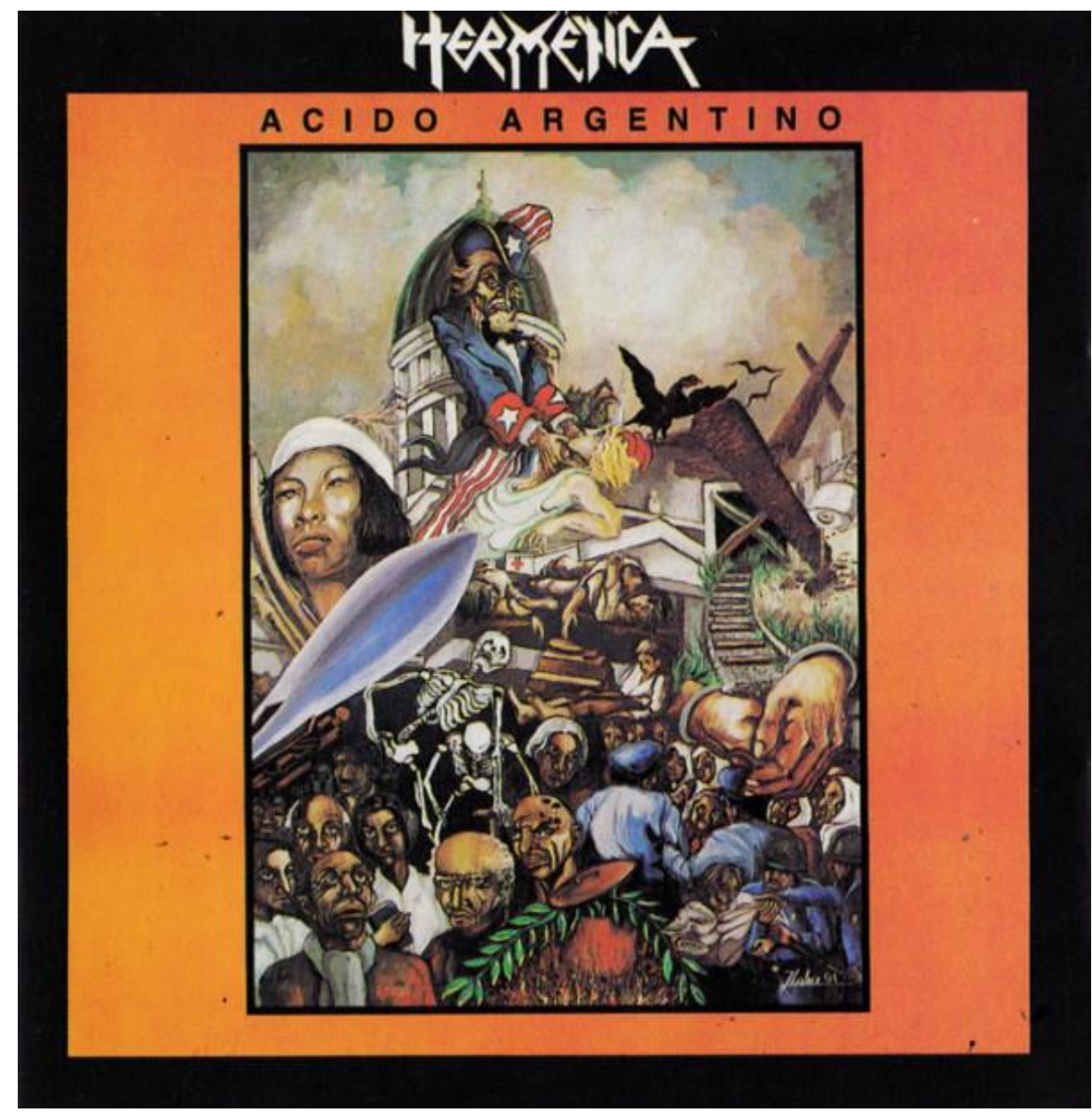

Figura 7: portada frontal del disco "Ácido argentino" de 1991. 


\section{VICTIMAS DEL VACIAMIENTO}

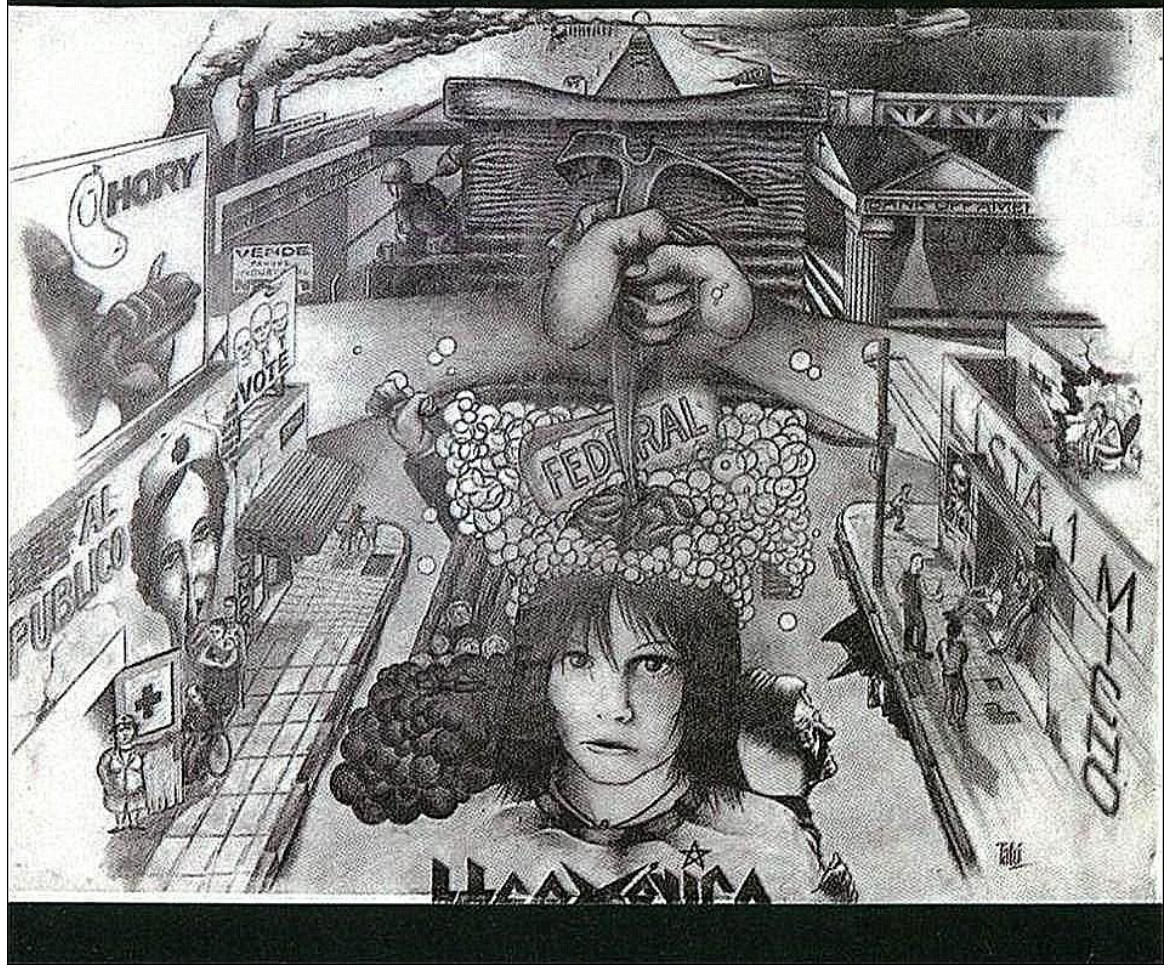

\section{PEBRONA WOBCAR LAVANDO BOPA}

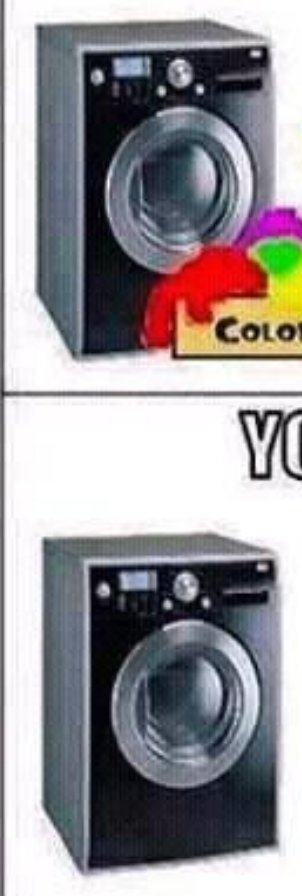

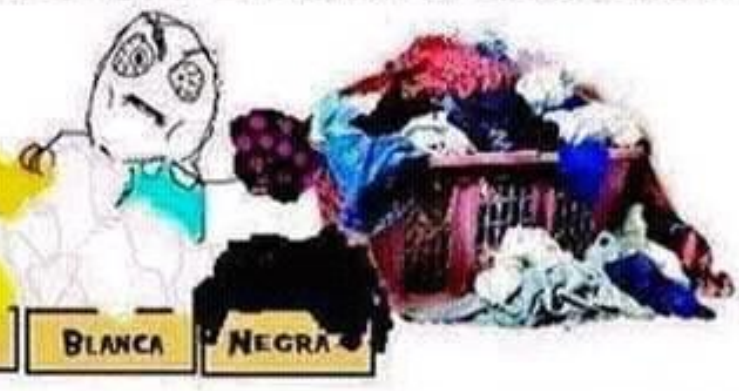

YOLACANDO BOPA

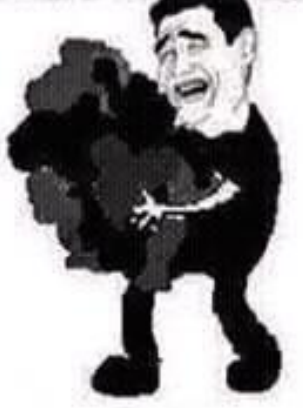

Figura 8:

Portada frontal del disco

"Víctimas del vaciamiento" de 1993.
Figura 9: Meme extraído de

Facebook en donde se bromea con el color que caracteriza a la ropa que utilizan los fans de metal 

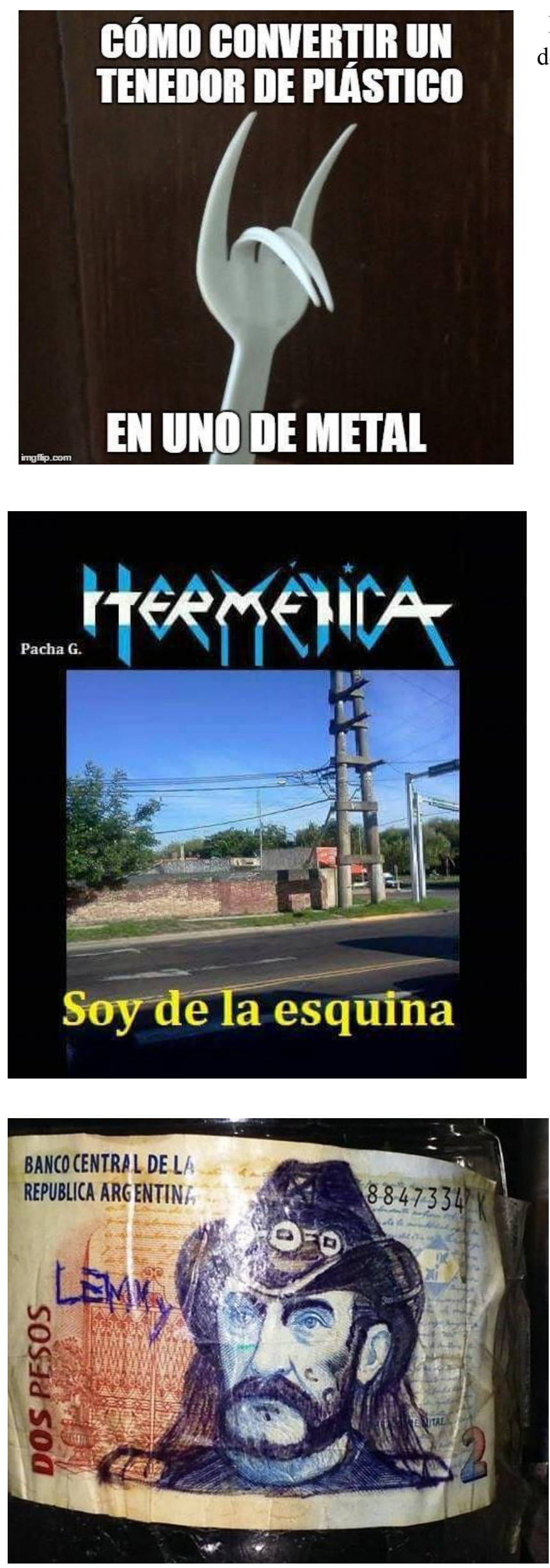

Figura 10: Meme extraído de Facebook en donde un tenedor deformado resulta similar a la mano cornuta.

Figura 11: meme extraído de Facebook en donde la sombra generada por unos postes de luz posee la forma de una letra "hache". Como se encuentra en una esquina, se bromea con la canción de Hermética titulada "Soy de la esquina".

Figura 12: Fotografía de billete de dos pesos argentinos, en donde el retrato que originalmente representa a Bartolomé Mitre es modificado y caracterizado como Lemmy Kilmister, líder de la banda de heavy metal británica, Motörhead. 


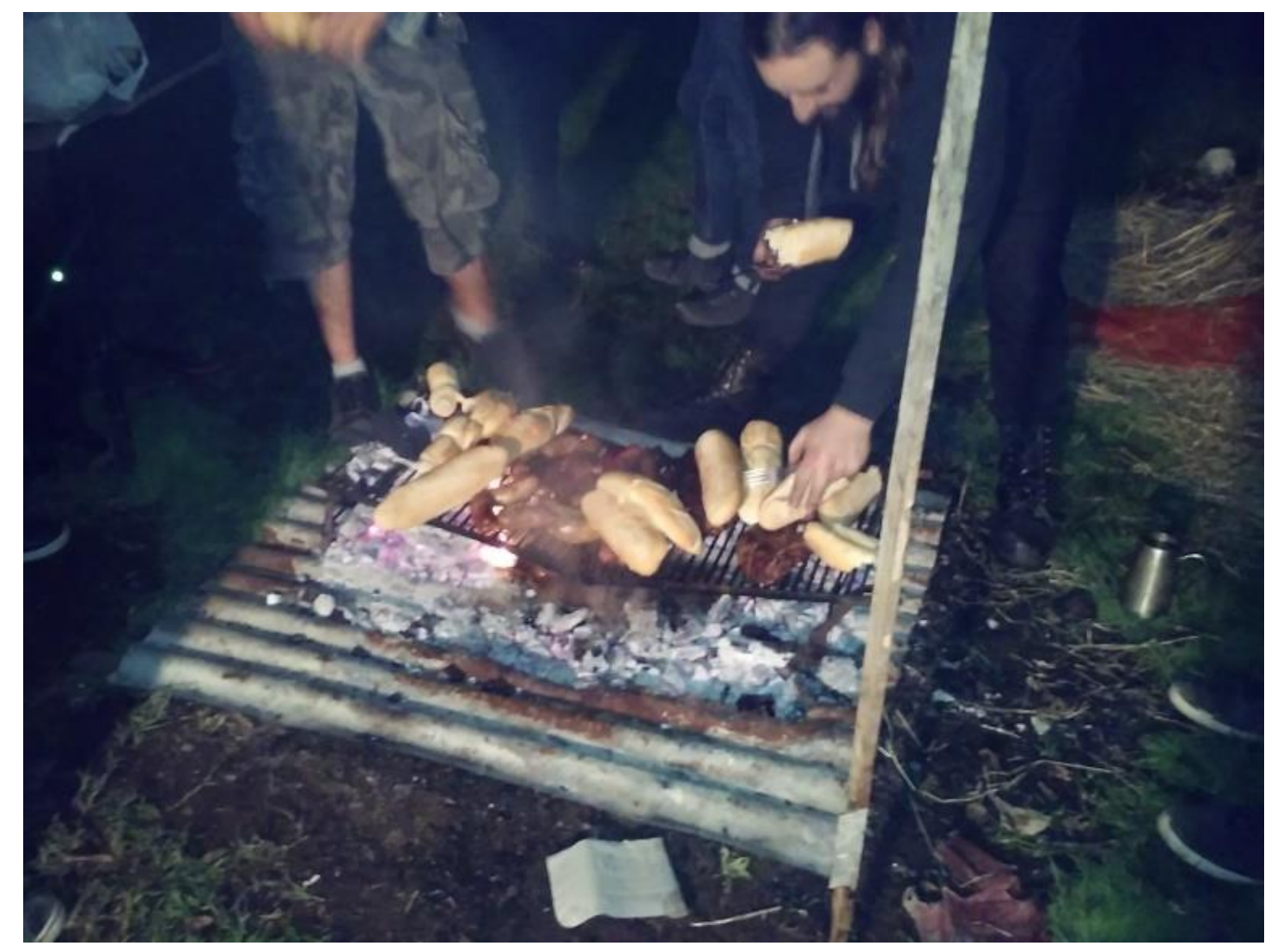

Figura 13: Fotografía tomada durante el trabajo de campo en un asado durante una previa a un recital en un galpón en Necochea, en 2016. Allí se ve la improvisación de una parrilla de forma rudimentaria.

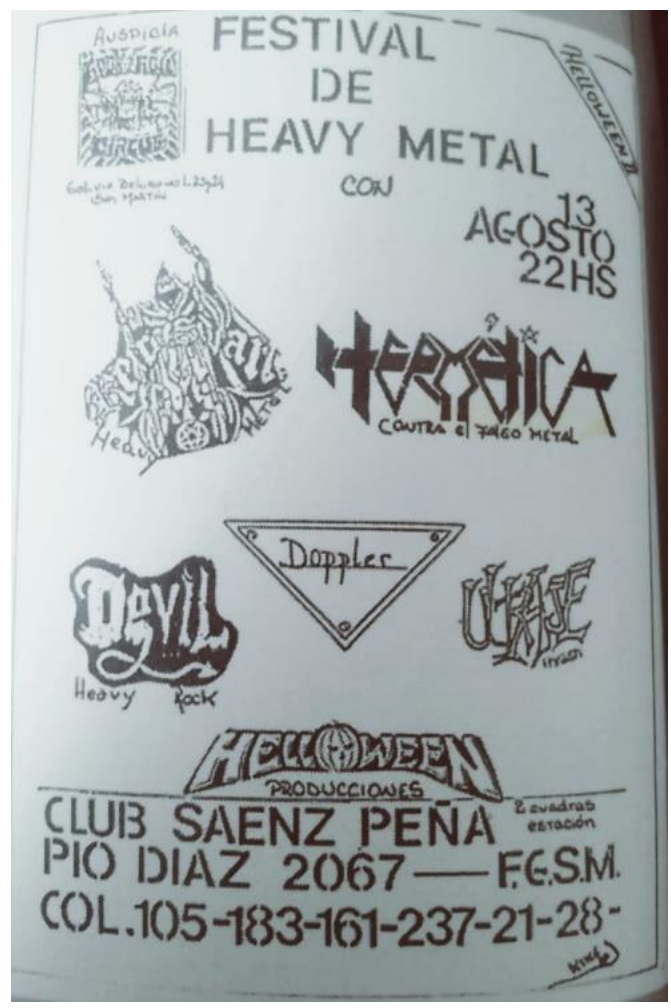

Figura 14: Afiche de 1989 en donde se promociona un festival en el cual participa Hermética y la banda lleva el slogan "contra el falso metal". 


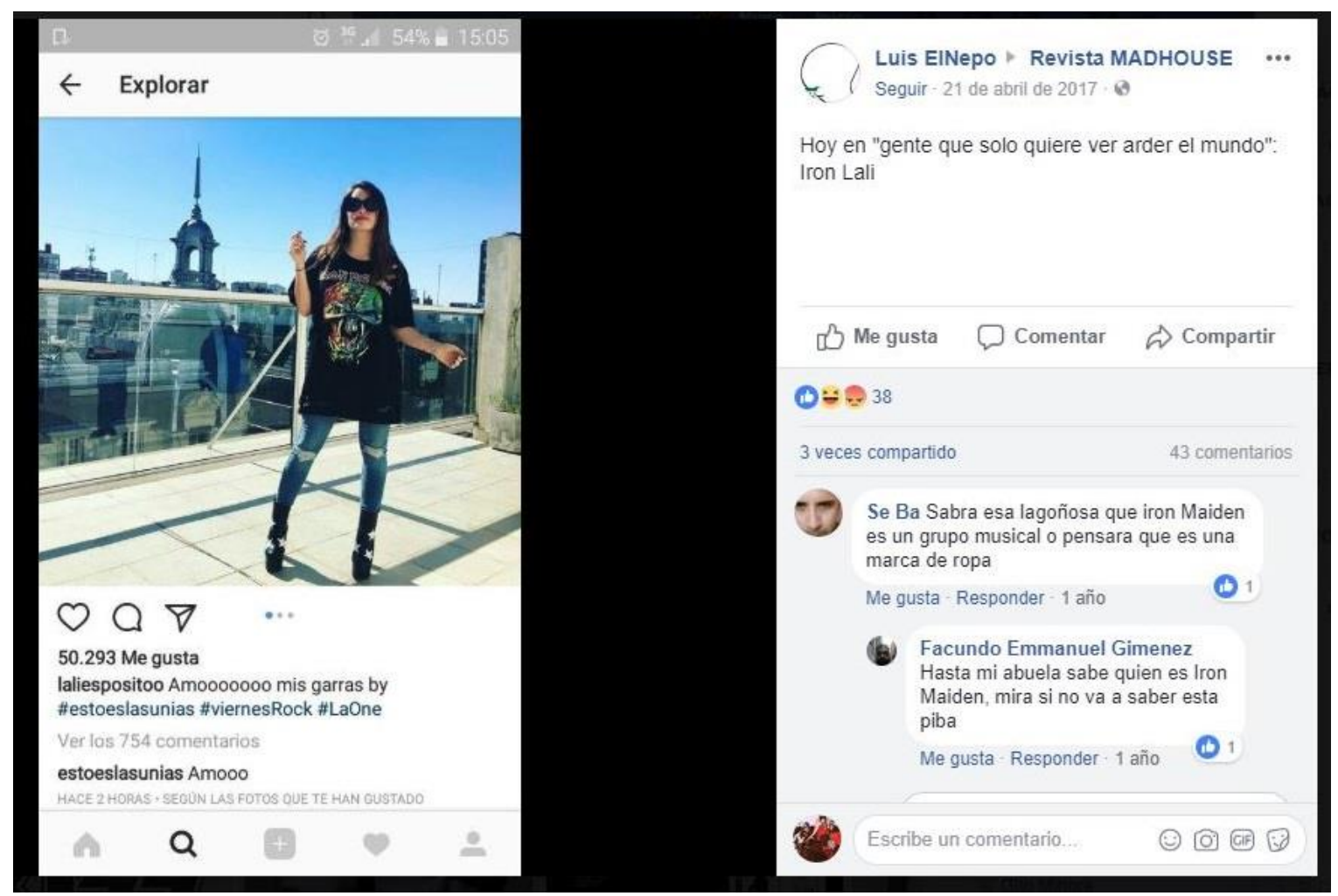

Figura 15: Captura de pantalla del grupo Madhouse de Facebook, en donde un integrante comparte una publicación de la cantante argentina de pop, Lali Espósito, luciendo una remera de Iron Maiden. En los años que comprende esta investigación, también se pudo ver el repudio a

fotografías en donde artistas pop internacionales, como Justien Bieber, o influencers, por ejemplo Kim Kardashian, vestían remeras de bandas de metal.

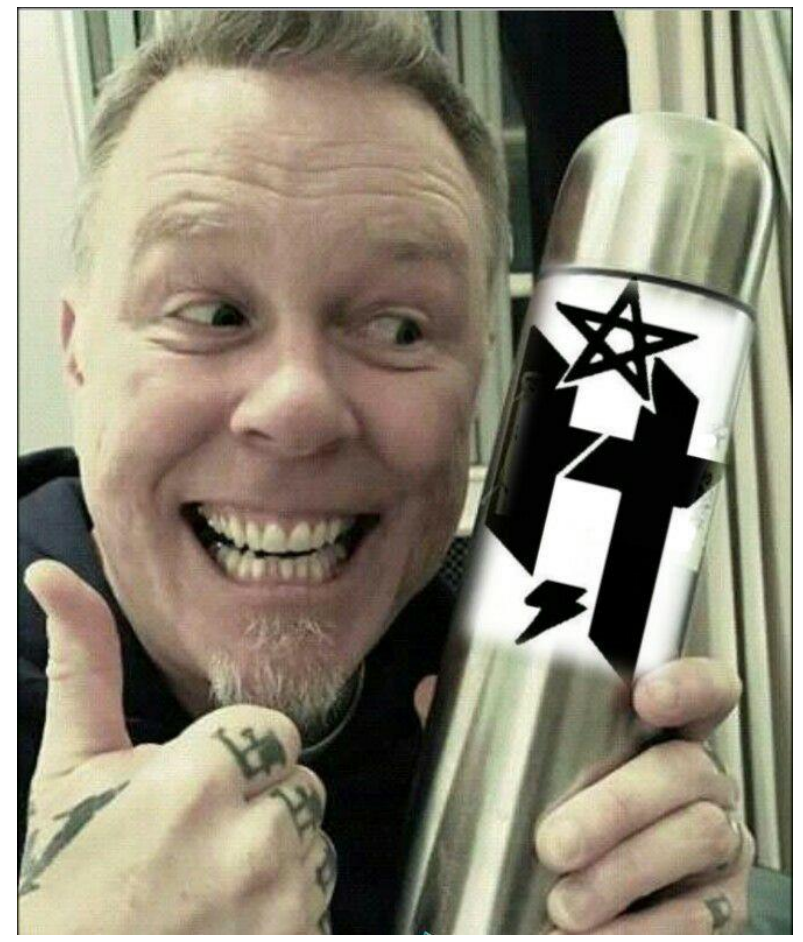

Figura 16: Fotografía intervenida, extraída de Facebook, en donde el autor coloca el

logotipo de Hermética sobre la imagen real de un termo, portado por el líder de la banda de thrash estadounidense, Metallica, James Hetfield. Este músico se encuentra casado con la argentina,

Francesca Tomasini, por lo que existen varias imágenes suyas mostrando su gusto por el mate. El chiste aparece en la idea de "termo", en alusión a la cerrazón que le adjudican los metaleros extremos a los seguidores de Hermética y Iorio. 


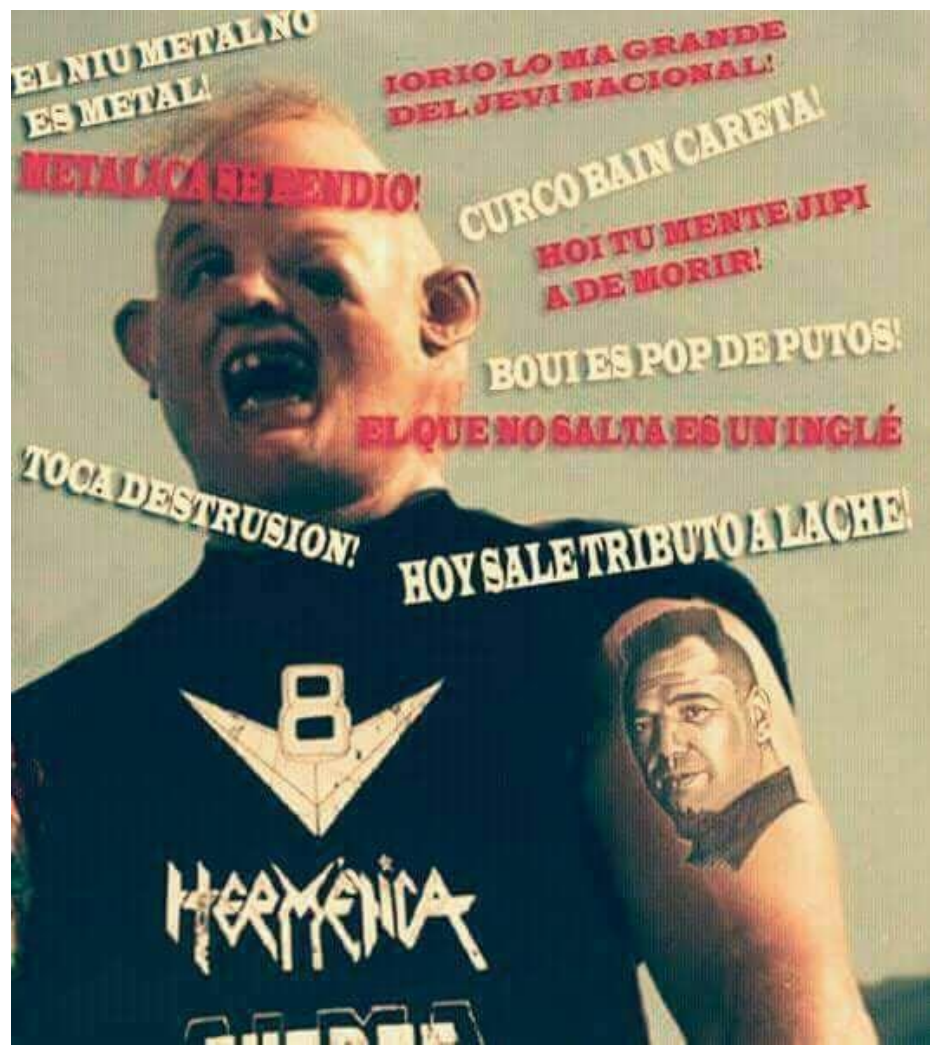

Figura 17: Meme extraído de

Facebook, en donde se representa a los "metaleros" que no intentan conocer bandas nuevas por preferir continuar escuchando siempre las mismas, dentro de ellas, Hermética.

Figura 18: Meme extraído de Facebook en donde se utiliza al personaje, Sloth Fratelli, de la película "Los Goonies", para representar a los seguidores de Iorio.

A su alrededor aparecen frases y opiniones que caracterizan a dichas personas. Las faltas ortográficas son

puestas adrede para representar modos de habla de estos aficionados, los cuales se corresponden con caracterizaciones del habla popular y marginal. 


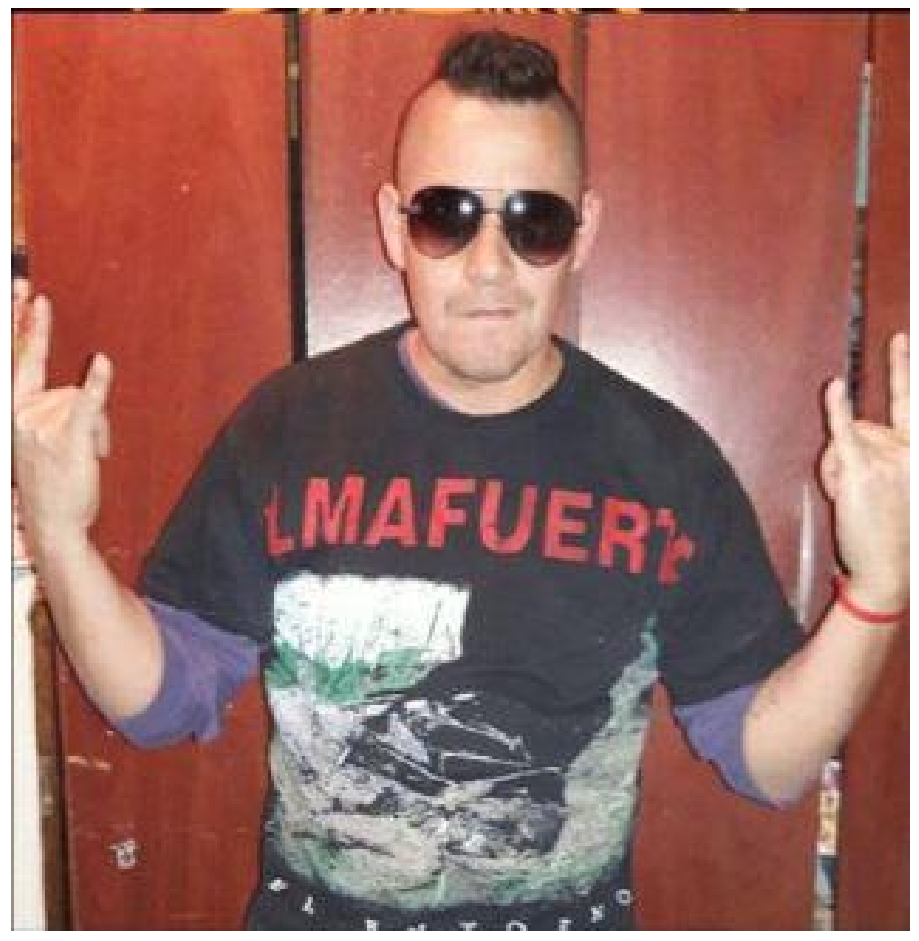

Figura 19: Fotografía extraída del grupo Iorio_Oficial de Facebook en donde se ve a un aficionado del músico con el mismo estilo de peinado.

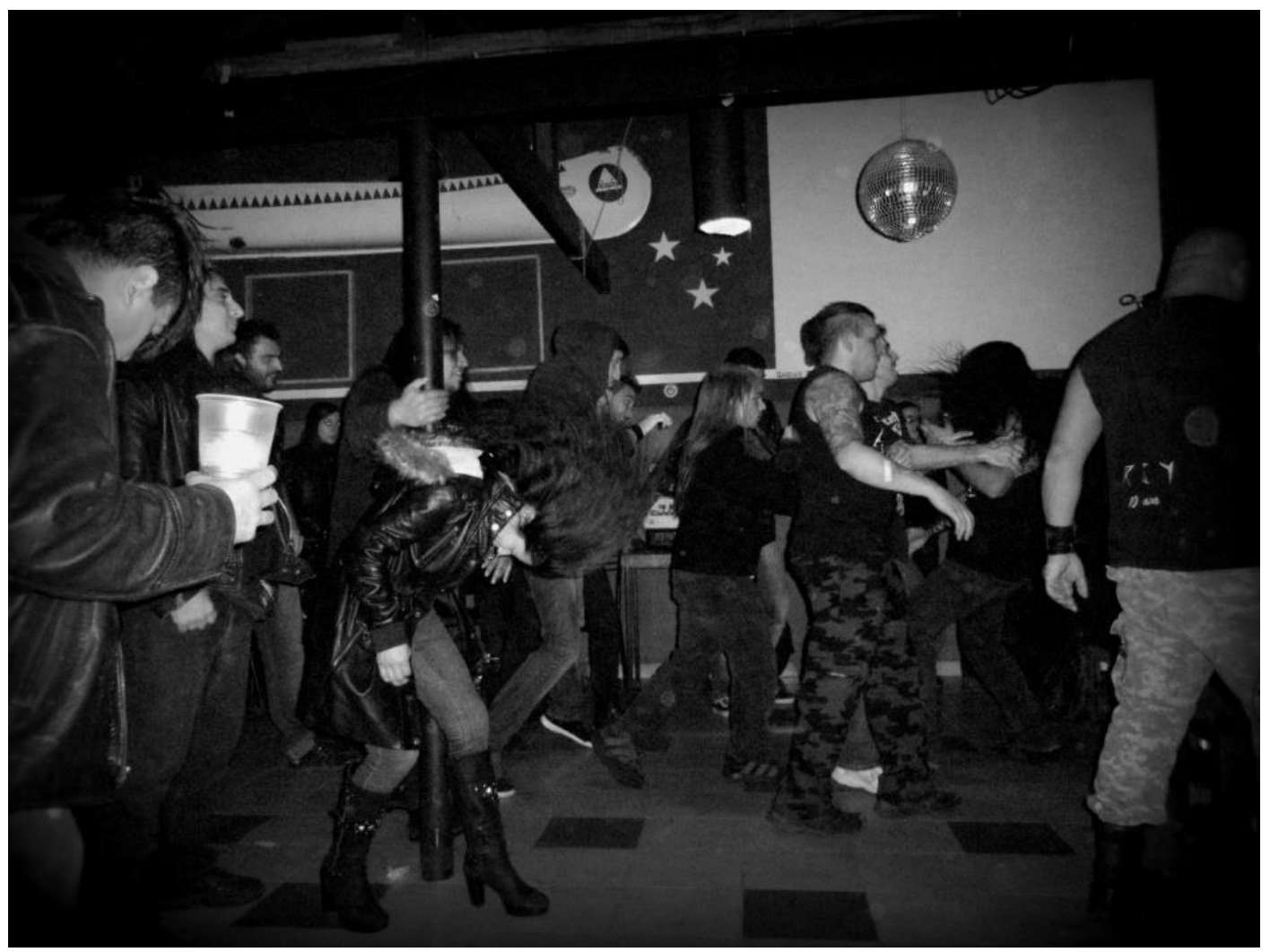

Figura 20: Fotografía tomada en trabajo de campo e intervenida con filtro en blanco y negro para fanpage de una banda bonaerense. En la imagen se ve el desarrollo de pogo durante un recital de varios conjuntos metálicos en un pub de Miramar en el 2015. En el fondo se ve un grupo de varones haciendo pogo y, en el frente, una mujer haciendo headbanging. 


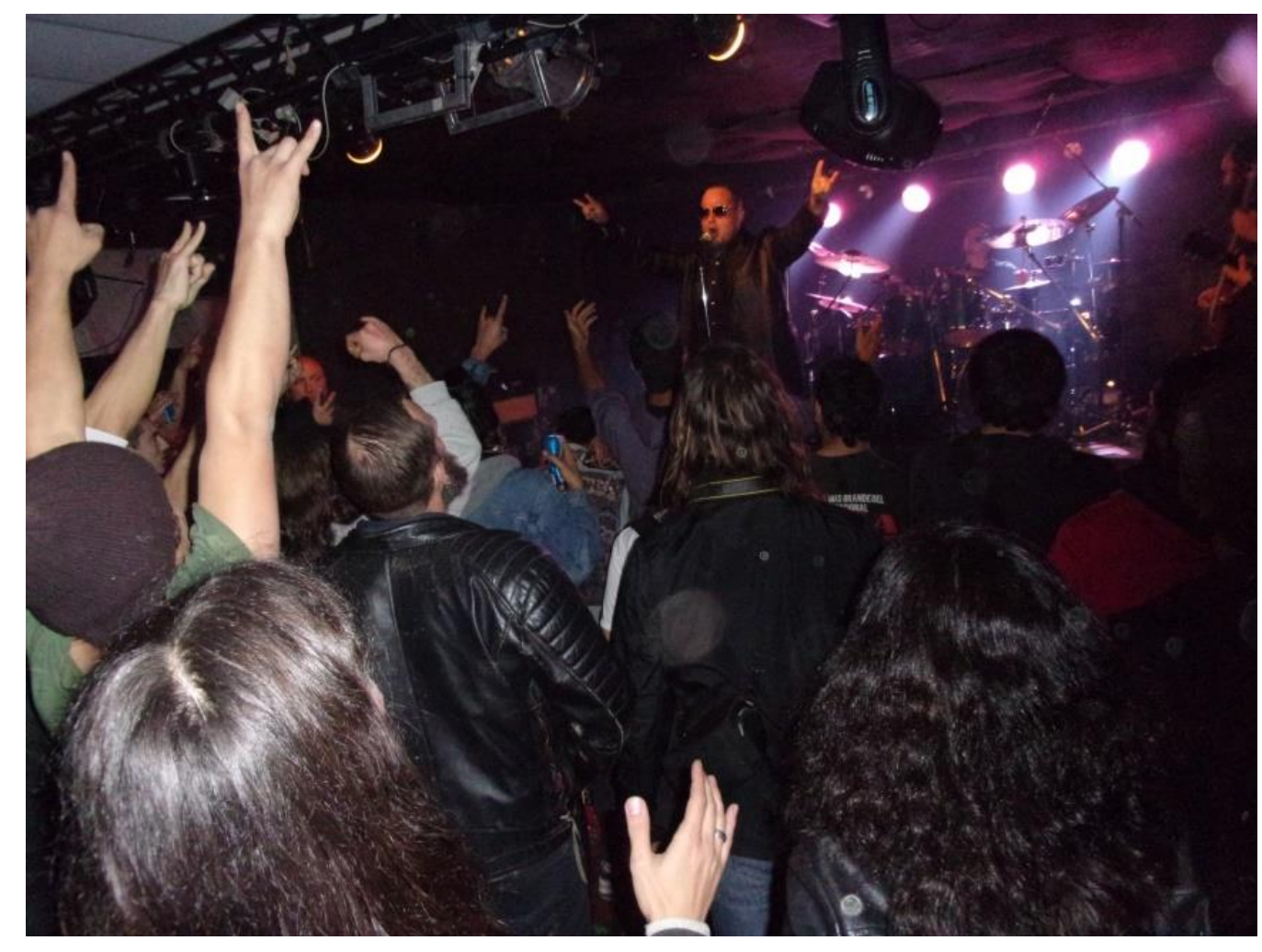

Figura 21: Fotografía tomada en etnografía del concierto de Tim Ripper Owens en Tandil en el 2016. Aquí se ve al cantante haciendo el gesto de la mano cornuta y algunos miembros de la audiencia respondiendo de la misma manera.
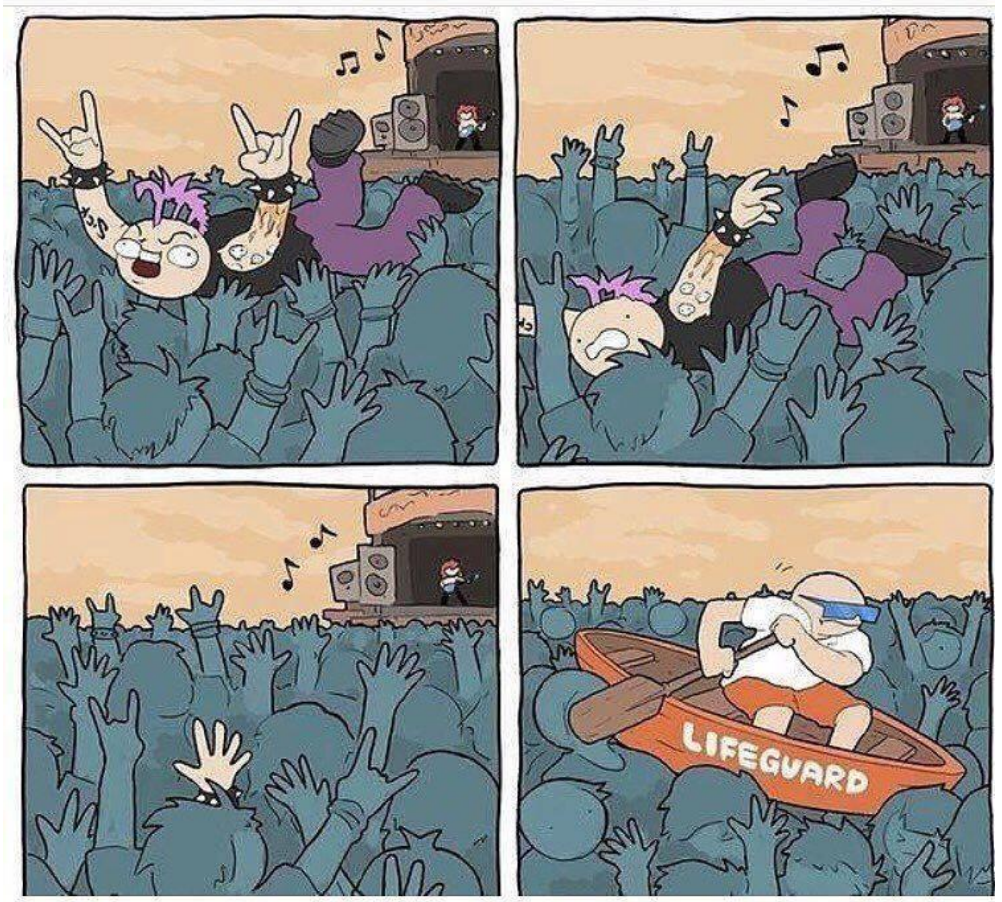

Figura 22: Meme extraído de Facebook que bromea con la práctica del crowd surfing. 
A Alalala192 Hace 5 años

q recital por dios! yo era uno de los seguridad de chaleco limon feo q estaba en el vallado dsd q empezo el recital... eramos 2 y me acuerdo q depronto veo y estaba el vallado todo doblado gracias a dios algunos de prensa nos dieron una mano hasta q se corrio la voz y vino mas seguridad. dsd antes el vallado estaba flojo avisamos y nadie nos dio pelota... la verdad yo lo vivi dsd el escenario y el vallado y pudo haber sido una trajedia... al otro dia no podia moverme de la fuerza $q$ hice jaja

Mostrar menos

I. 1 \%

kacikek Hace 6 años

primero $\mathrm{m}$ calenté cuando corto el tema por la mitad, pero dsps al entender LO q pasaba, ENTENDI y ME PARECIÓ PERFECTO LOCO! ESTUVIERON BIEN en PARARLO! Dsps pasan cosas terribles en otros recitales y nos lamentamos! APLAUSOS PARA LOS MUSICOS!!!

16. RESPONDER

Figura 23: Captura de pantalla de algunos comentarios realizados al video grabado por una aficionada y subido a la plataforma, YouTube, en el que se puede observar el momento en donde Malón debe frenar el recital en el Estadio Malvinas Argentinas en 2011.

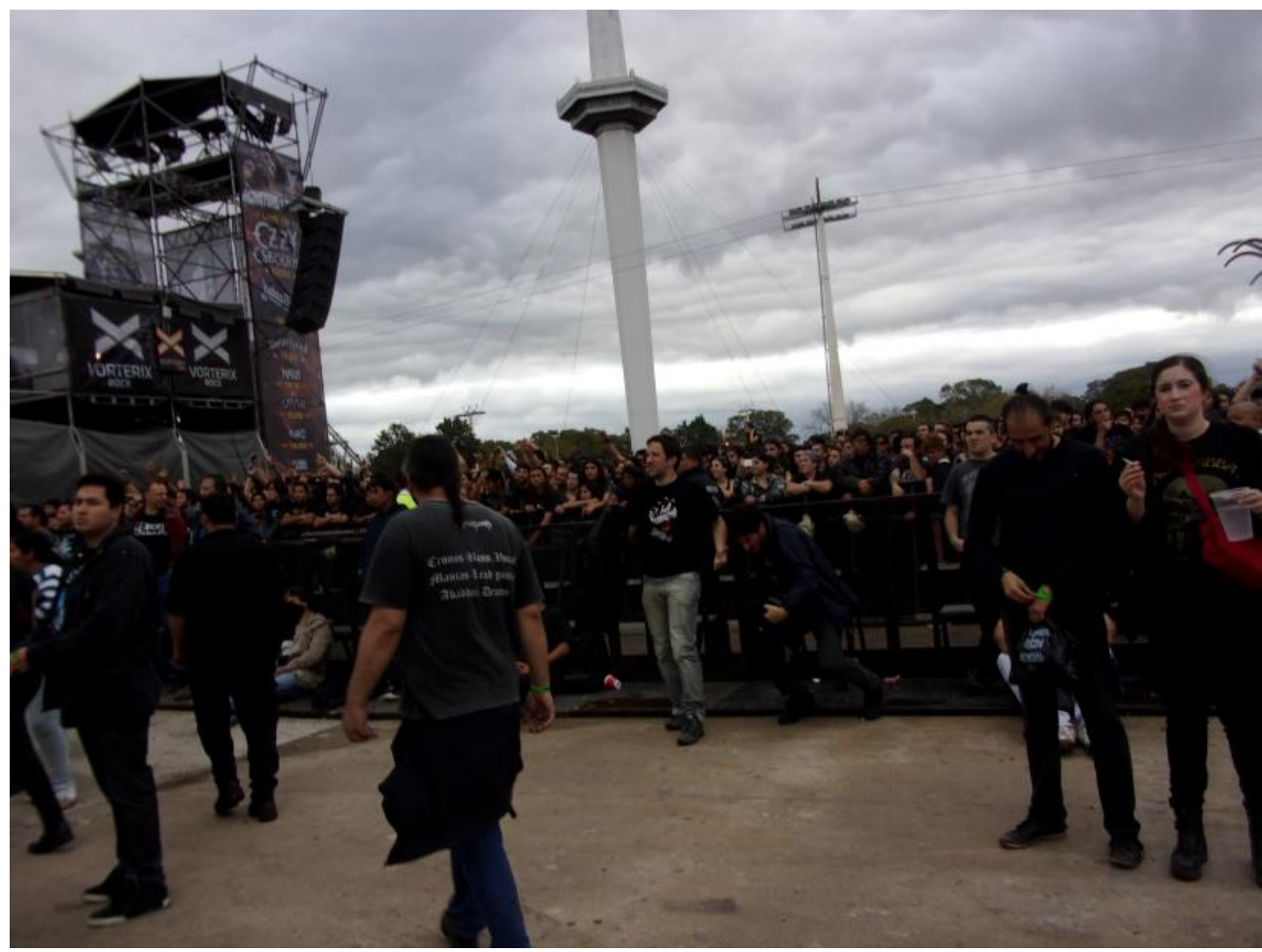

Figura 24: Fotografía tomada en etnografía del festival "Monsters of Rock" del 2015 desde el sector del "campo vip". Se puede ver la valla que divide a este del "campo trasero". 

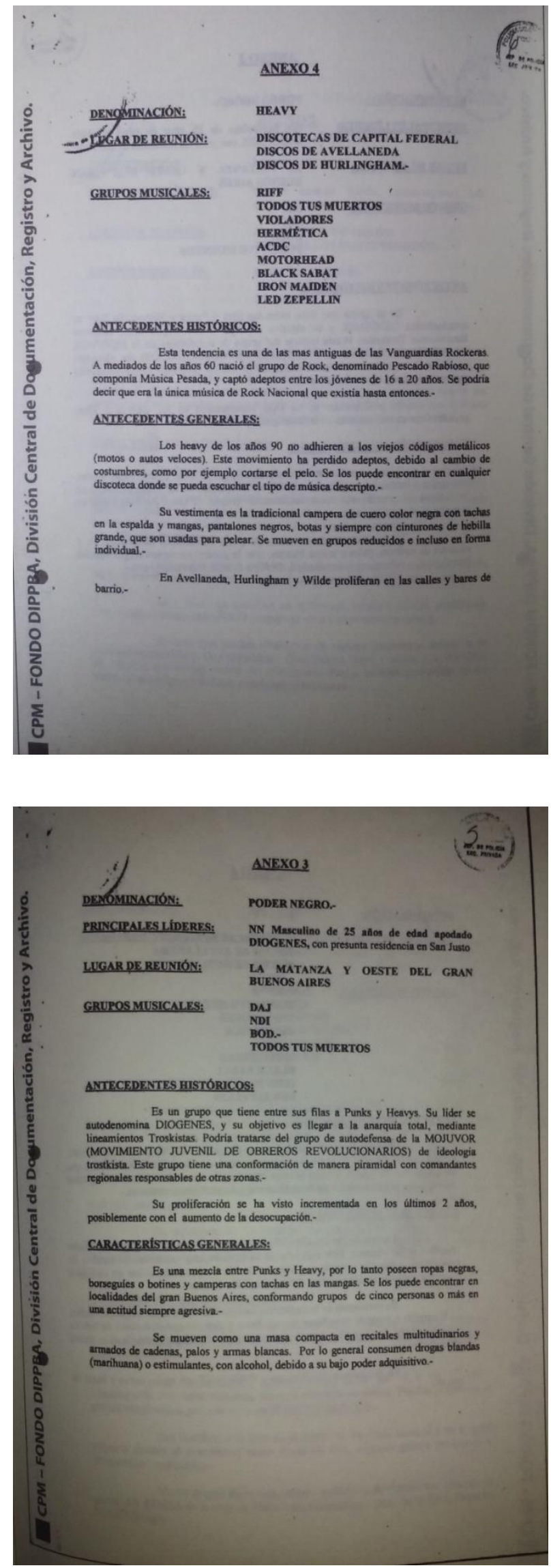

Figura 25: Copia del informe de Inteligencia sobre los "heavy".

Figura 26: Copia del informe de Inteligencia sobre los "poder negro". 


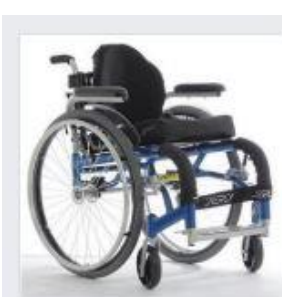

Una Silla para

Walter

@unasillaparawalter

Inicio

Información

Fotos

Eventos

Videos

Publicaciones

Comunidad

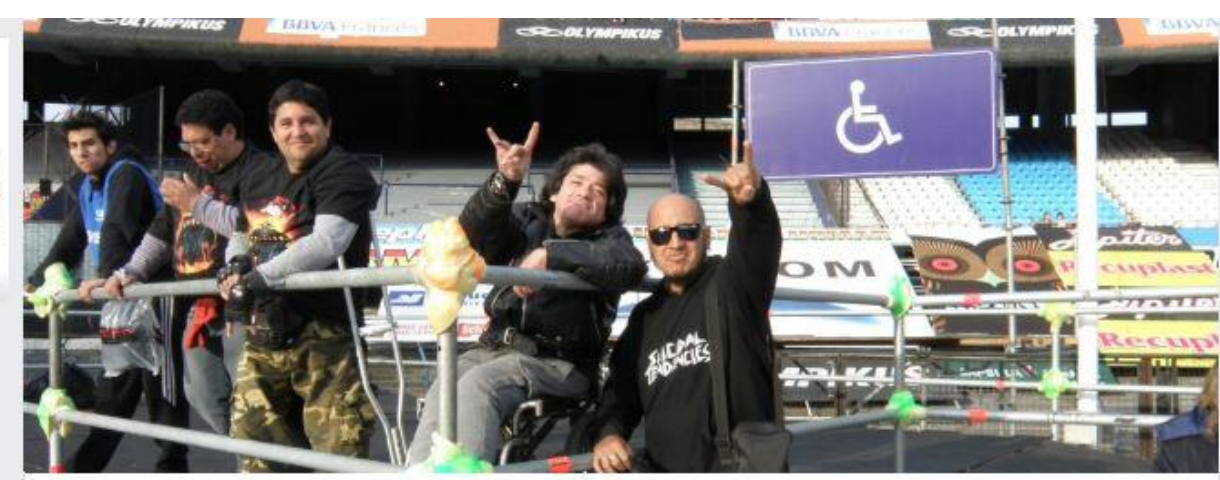

\begin{tabular}{l|l|l|l|} 
He gusta & Si Siguiendo & $\rightarrow$ Compartir & $\ldots$ \\
\hline
\end{tabular}

$\odot$ Enviar mensaje

Información

INFORMACIÓN DE CONTACTO

HISTORIA

\begin{tabular}{l} 
Qunasillaparawalter \\
http-/wwwwidea.me/proyecto/39848/una-silla-para- \\
walter \\
MÁS INFORMACIÓN \\
\hline Descripción \\
Somos un grupo de amigos que nos juntamos para ayudar a \\
Wäter a comprar la alla de vuedas especifica que necosita. \\
hacen fatta 35.000 pesos \\
a Comunidad
\end{tabular}

ä Comunidad

Figura 27: Captura de pantalla de la fanpage de Facebook, "Una silla para Walter".

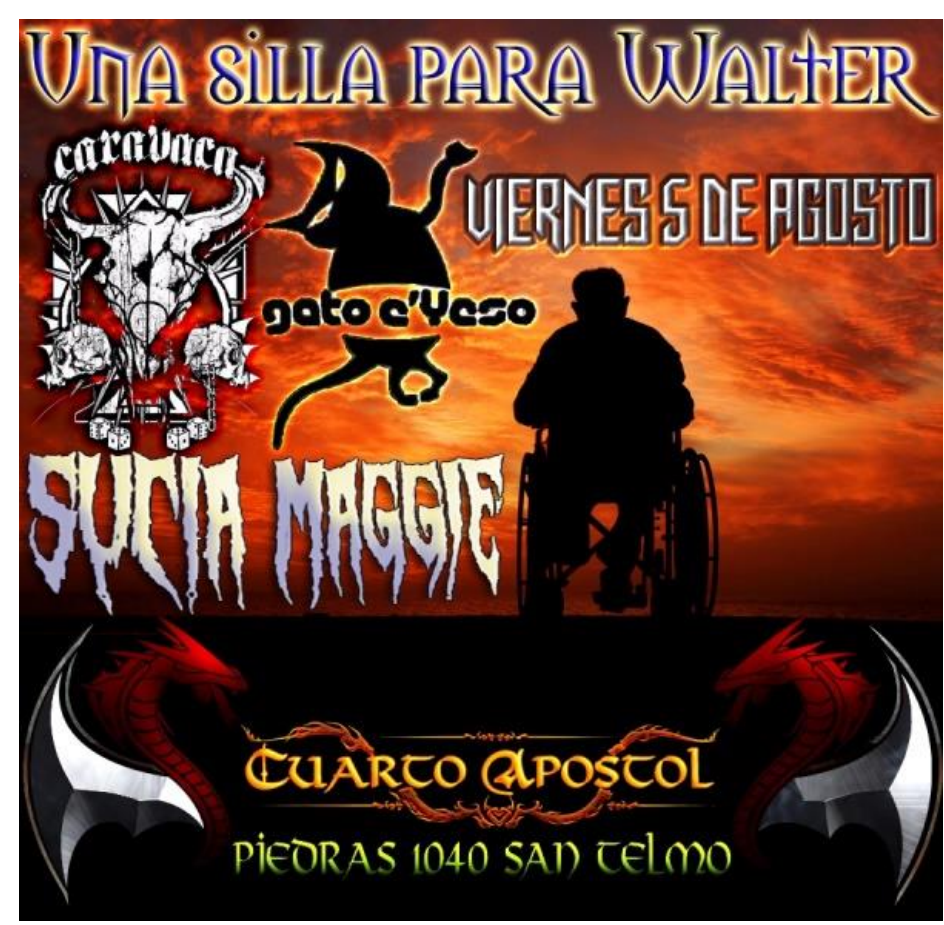

Figura 28: Flyer de uno de los recitales a beneficio de Walter "Muletas". 


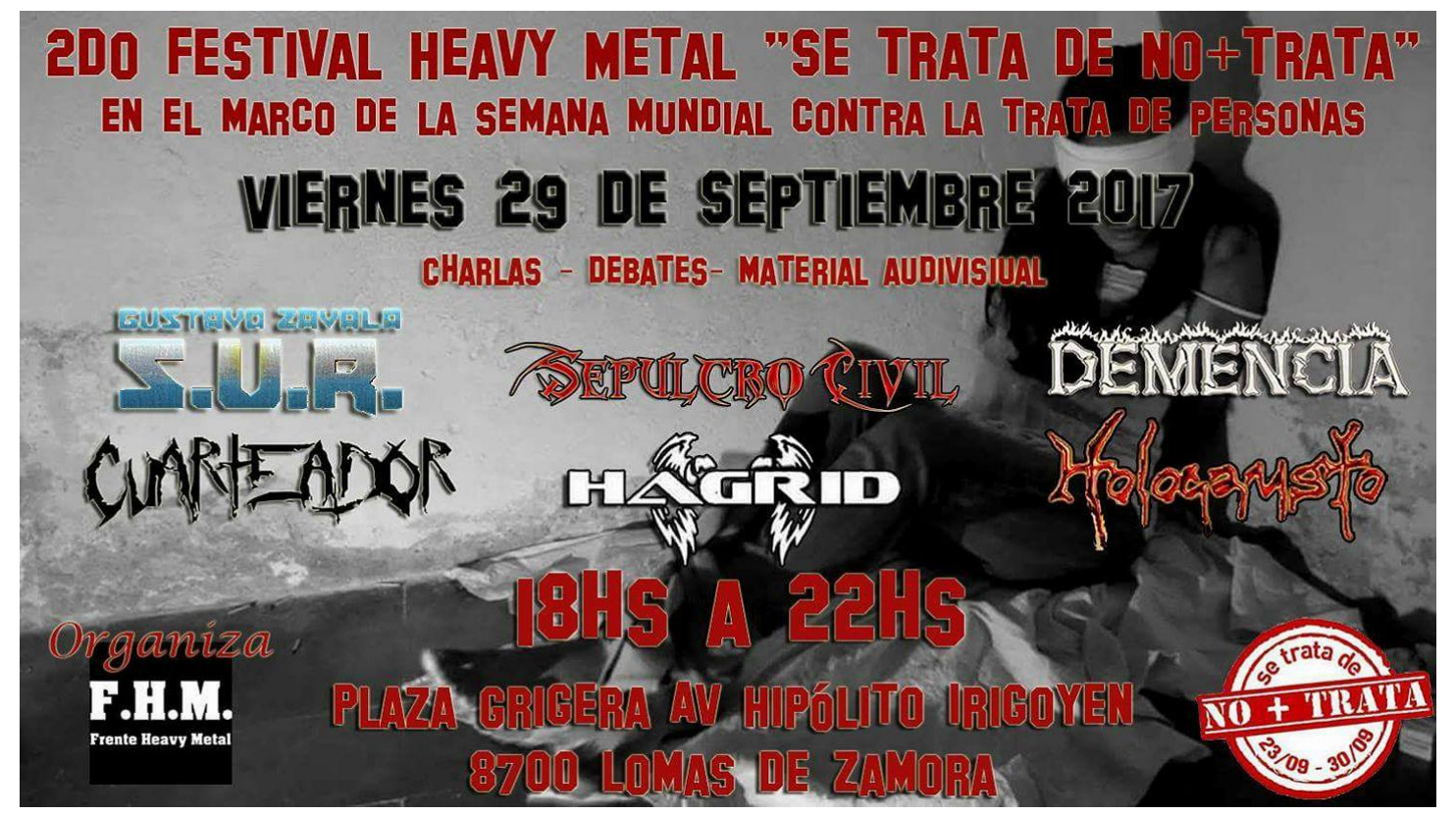

Figura 29: Flyer extraído de Facebook del segundo festival "Se trata de no +trata" organizado por el Frente Heavy Metal

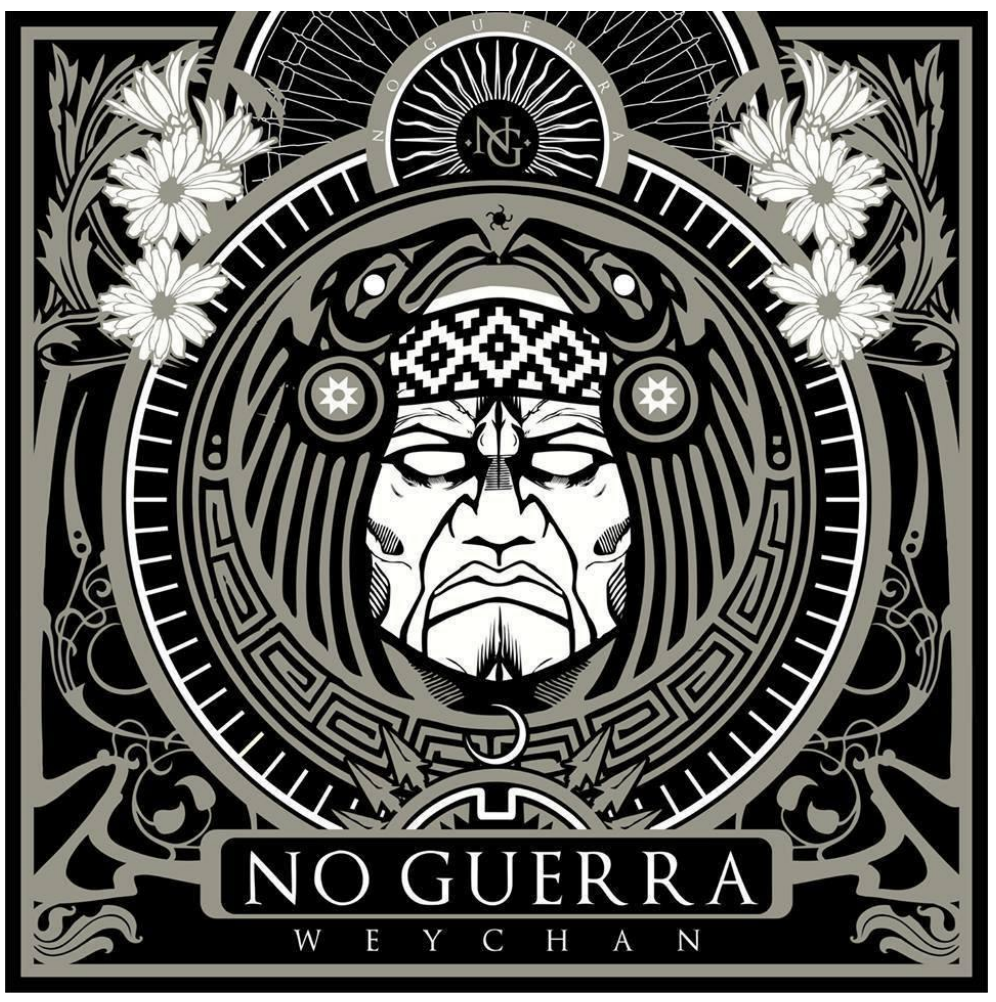

Figura 30: Portada del disco Weichan del año 2016 de la banda No Guerra de la zona sur del Gran Buenos Aires. Allí aparece representado el rostro de un nativo con rasgos y símbolos característicos de su etnia y se le agregan elementos decorativos. 


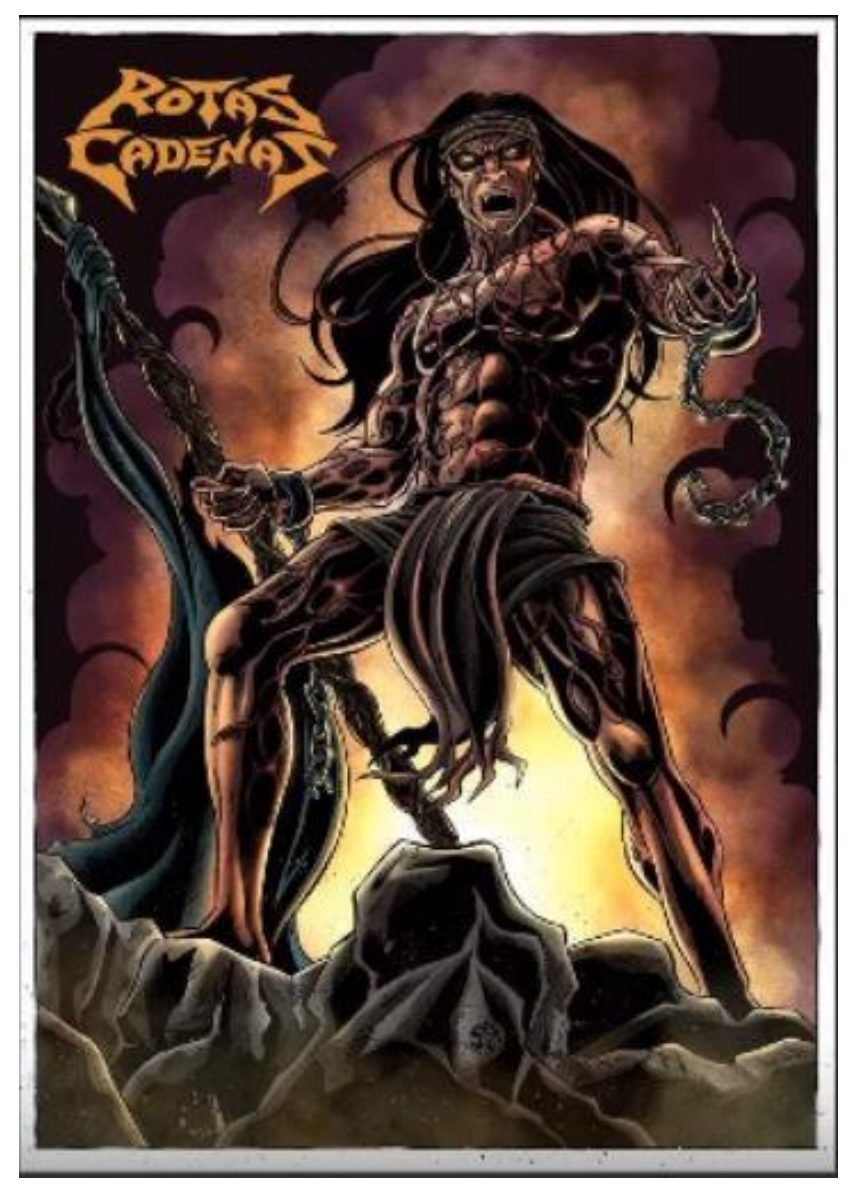

Figura 31: portada del demo de la banda de thrash metal de Tres Arroyos,

Rotas Cadenas. En ella se ve la recreación de un aborigen de cuerpo atlético y rostro monstruoso.

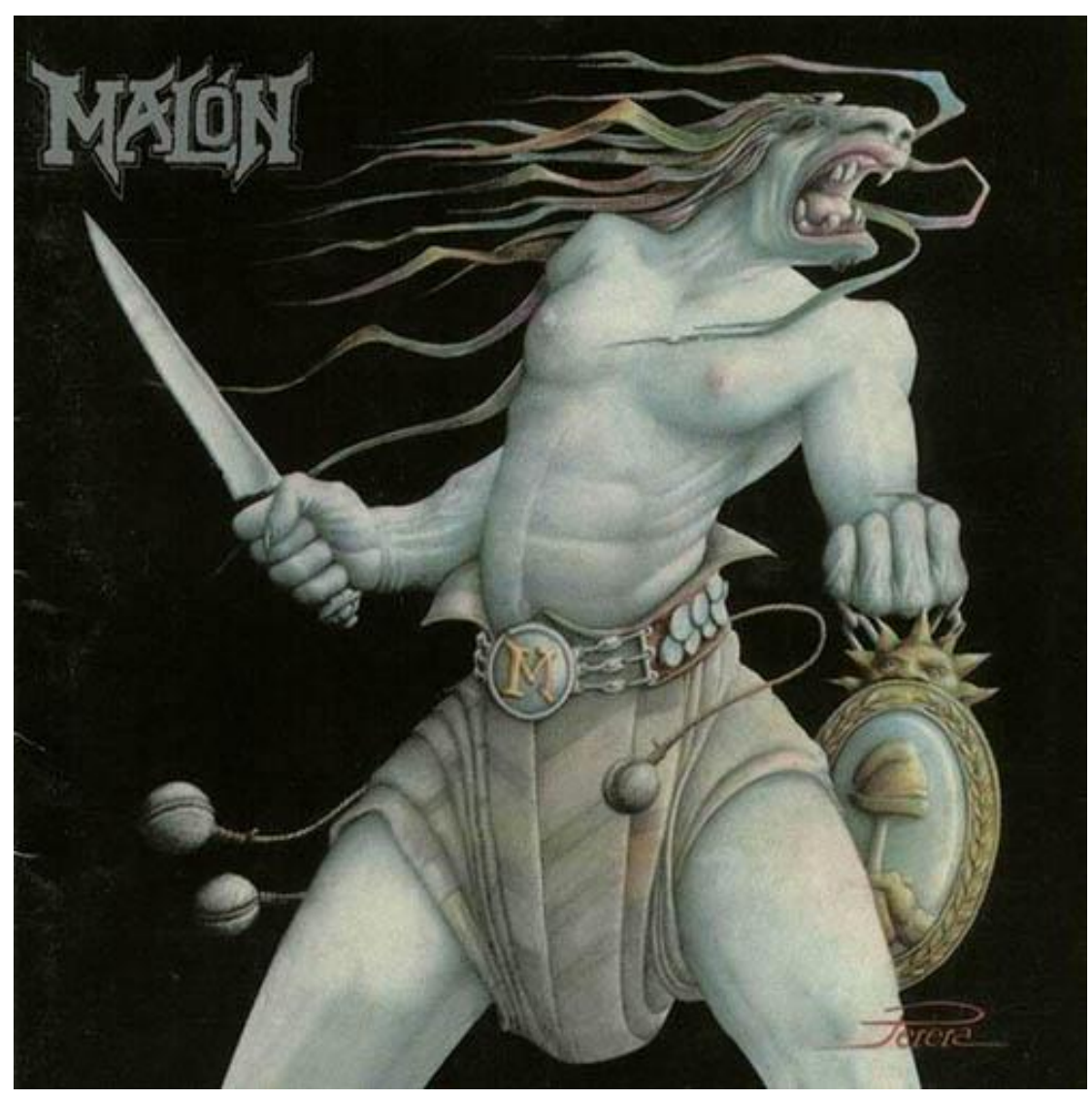

Figura 32: portada del disco Justicia o Resistencia del año 1996 de Malón. Allí se ve una figura antropomórfica cuyo cuerpo parece humano y viste atuendo propio de los nativos patagónicos y su cabeza asemeja a la de un caballo. 


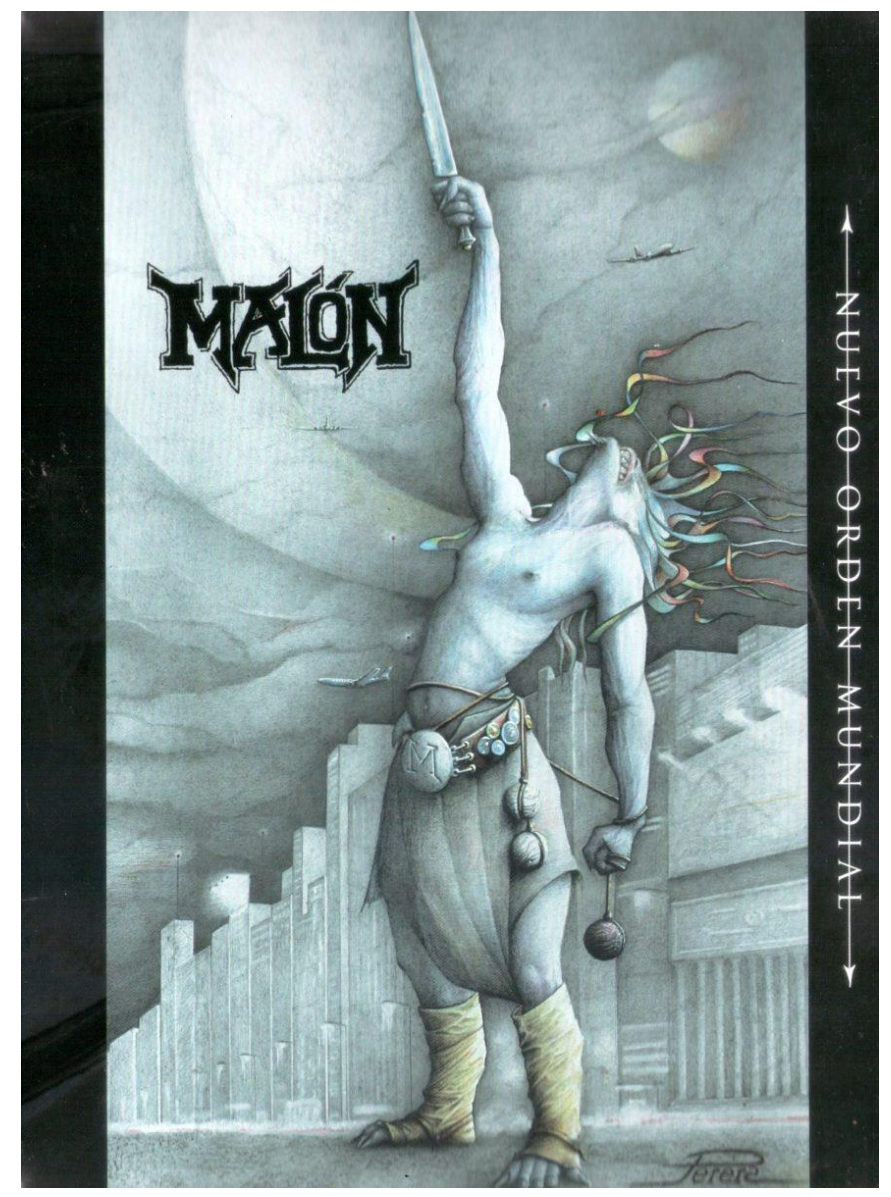

Figura 33: portada del disco Nuevo Orden Mundial del 2015 de la banda Malón. Aparece el mismo personaje antropomórfico pero con el fondo de una ciudad con edificios.

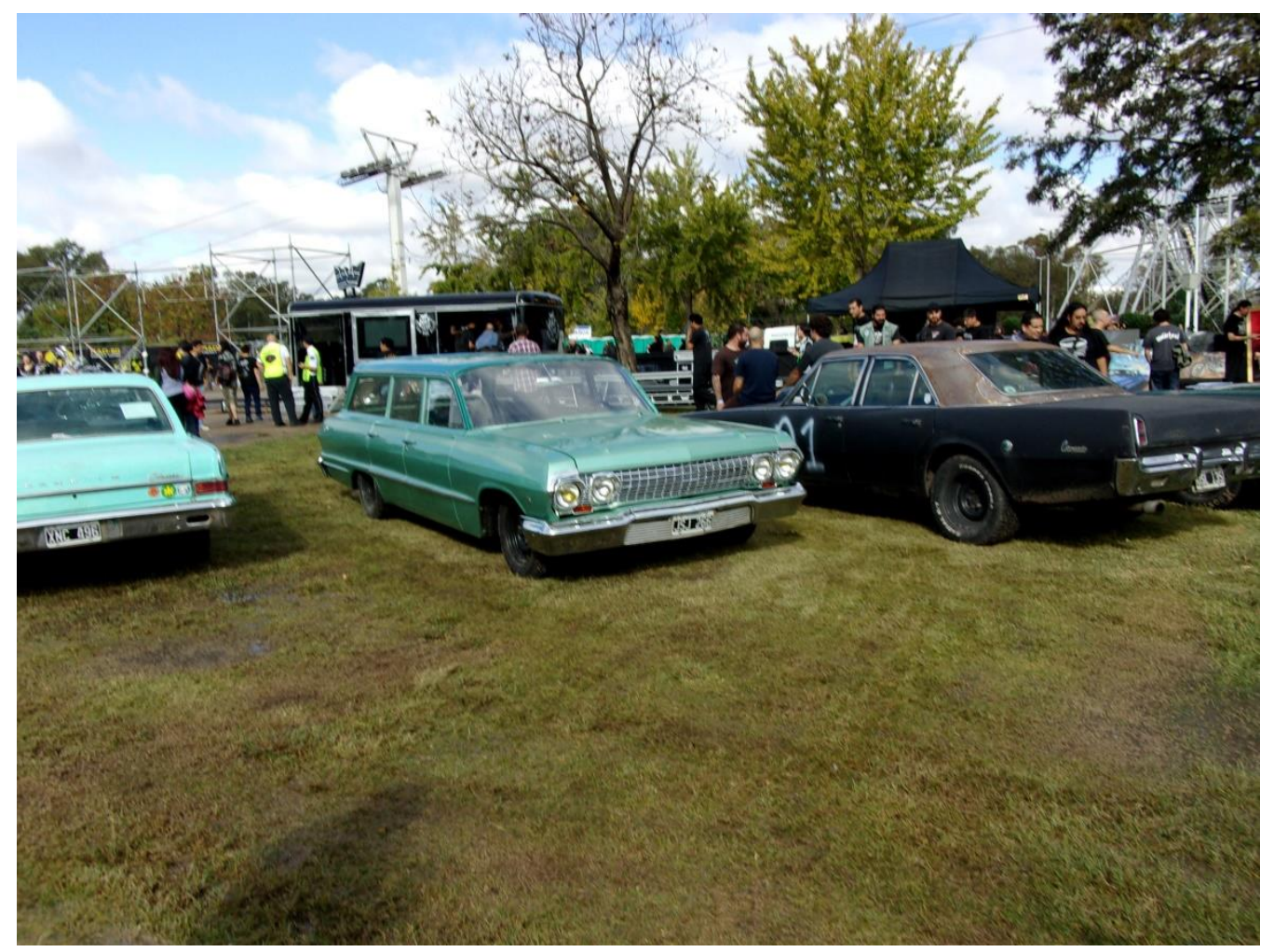




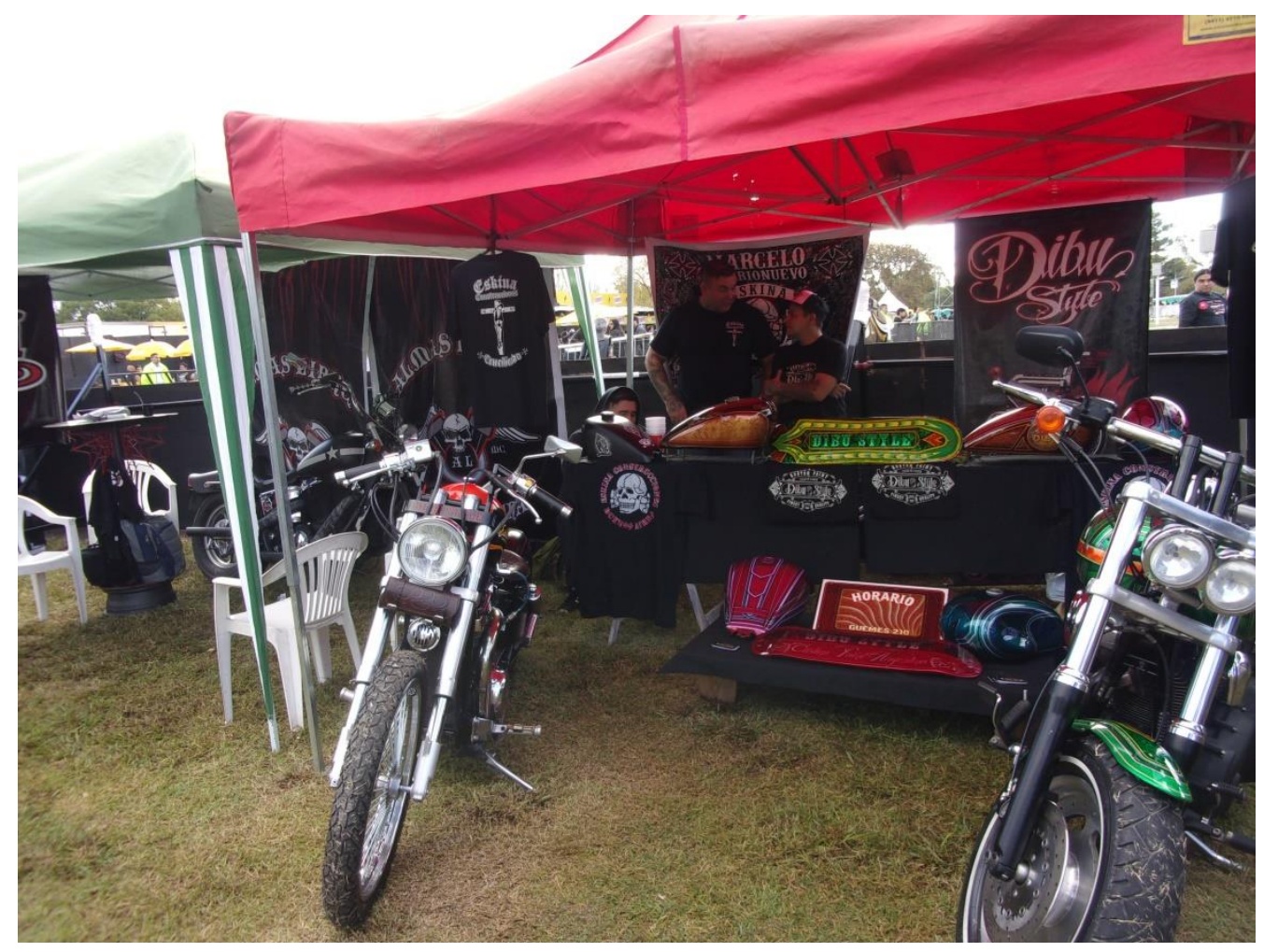

Figuras 34 y 35: Fotografías tomadas en trabajo de campo en el sector de exposición de vehículos en el festival, Monsters of Rock 2015 en CABA.

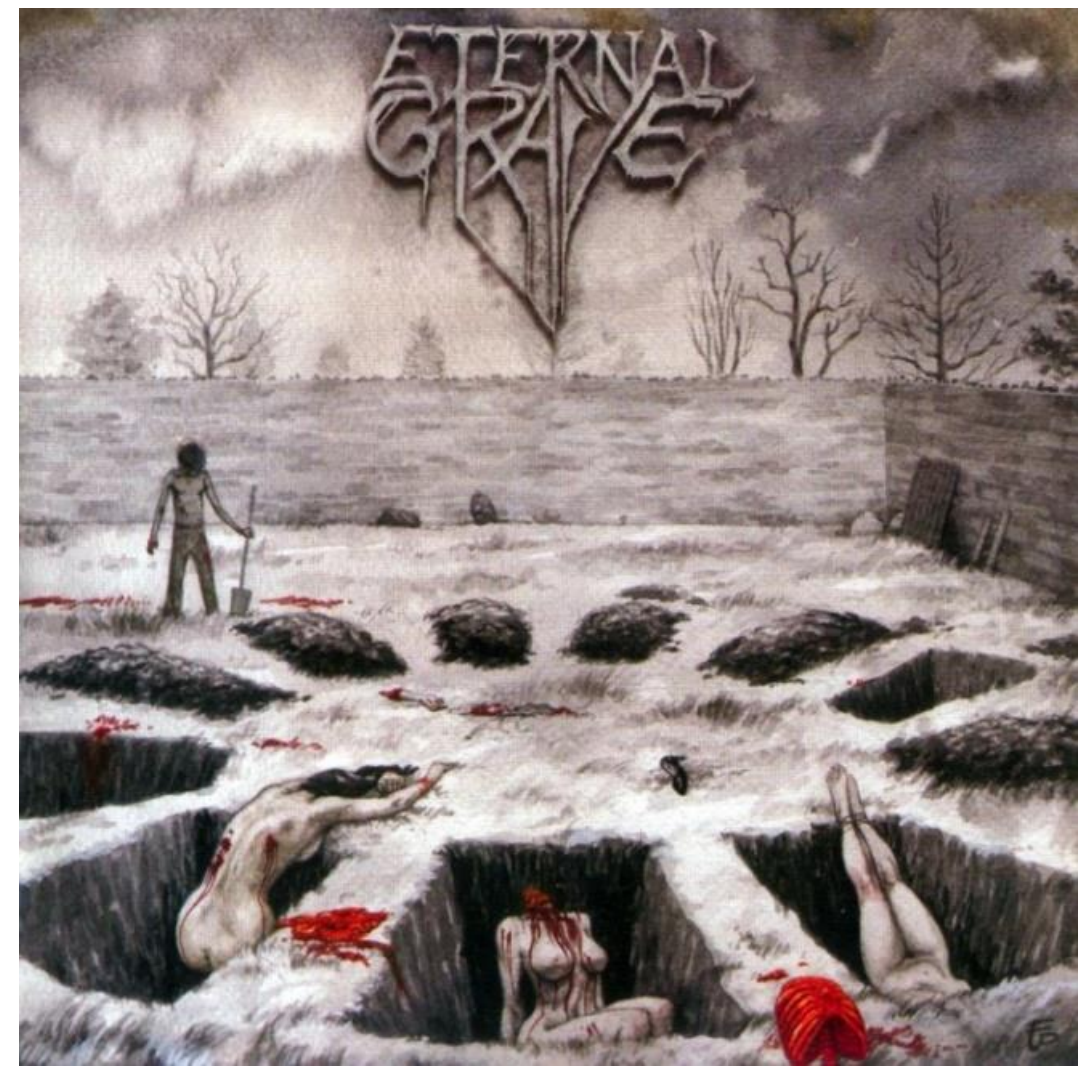

Figura 36: Portada del disco Arquitectura del horror del año 2009 de Eternal Grave. En ella aparece un femicida enterrando varios cuerpos de mujeres. 


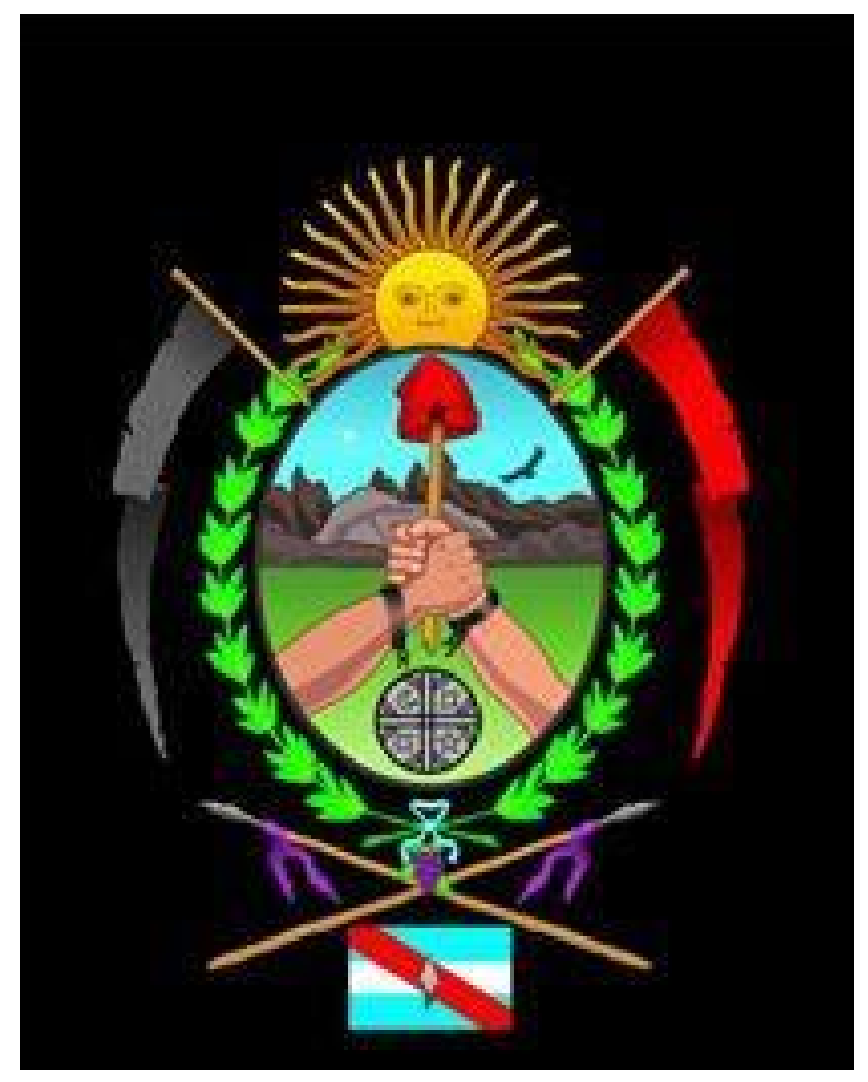

Figura 37: Imagen de perfil de la fanpage de la banda de Tres Arroyos, Rotas Cadenas.

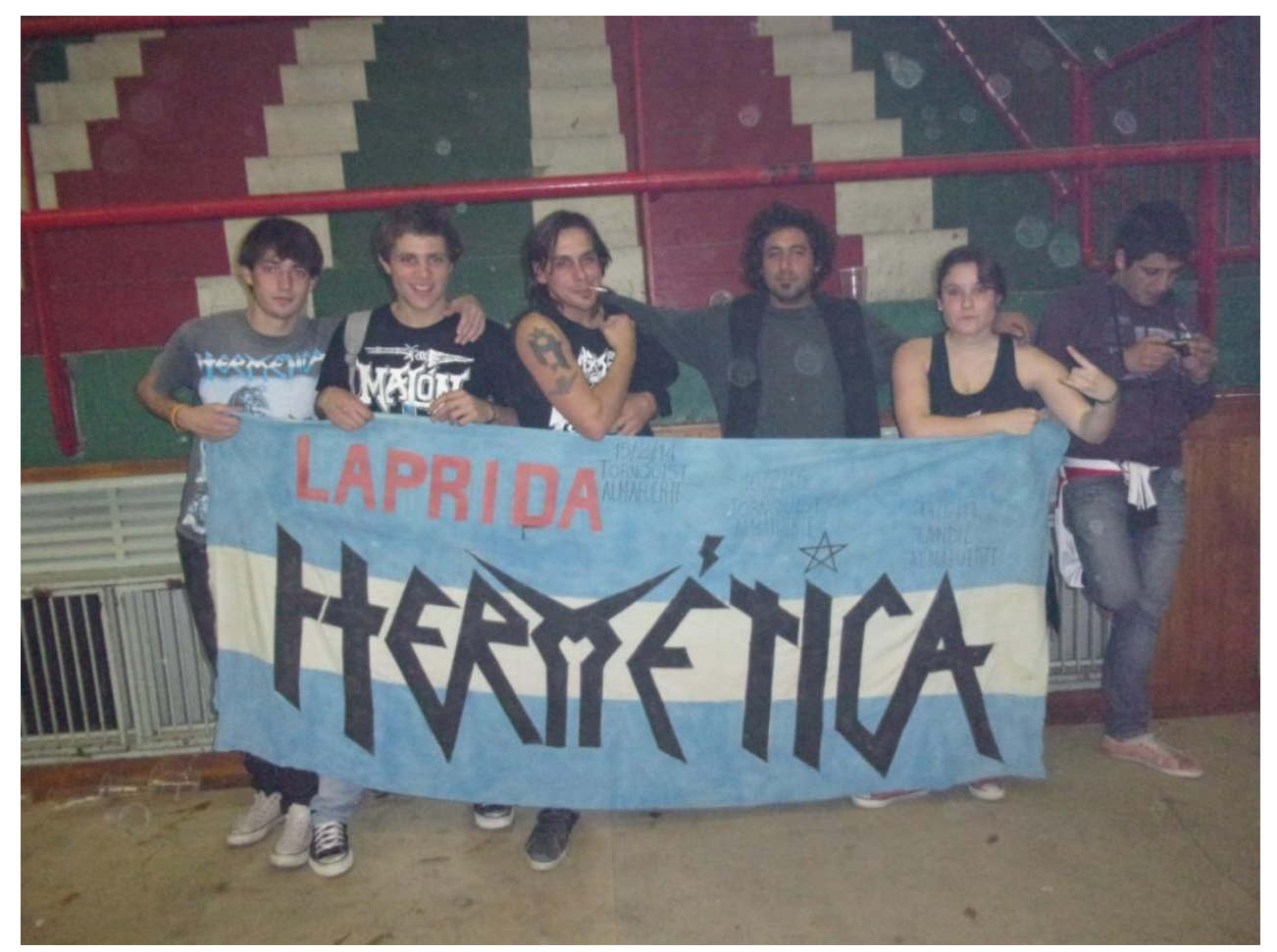

Figura 38: Fotografía tomada en trabajo de campo en recital de Malón en la ciudad de Tandil en el año 2015. 


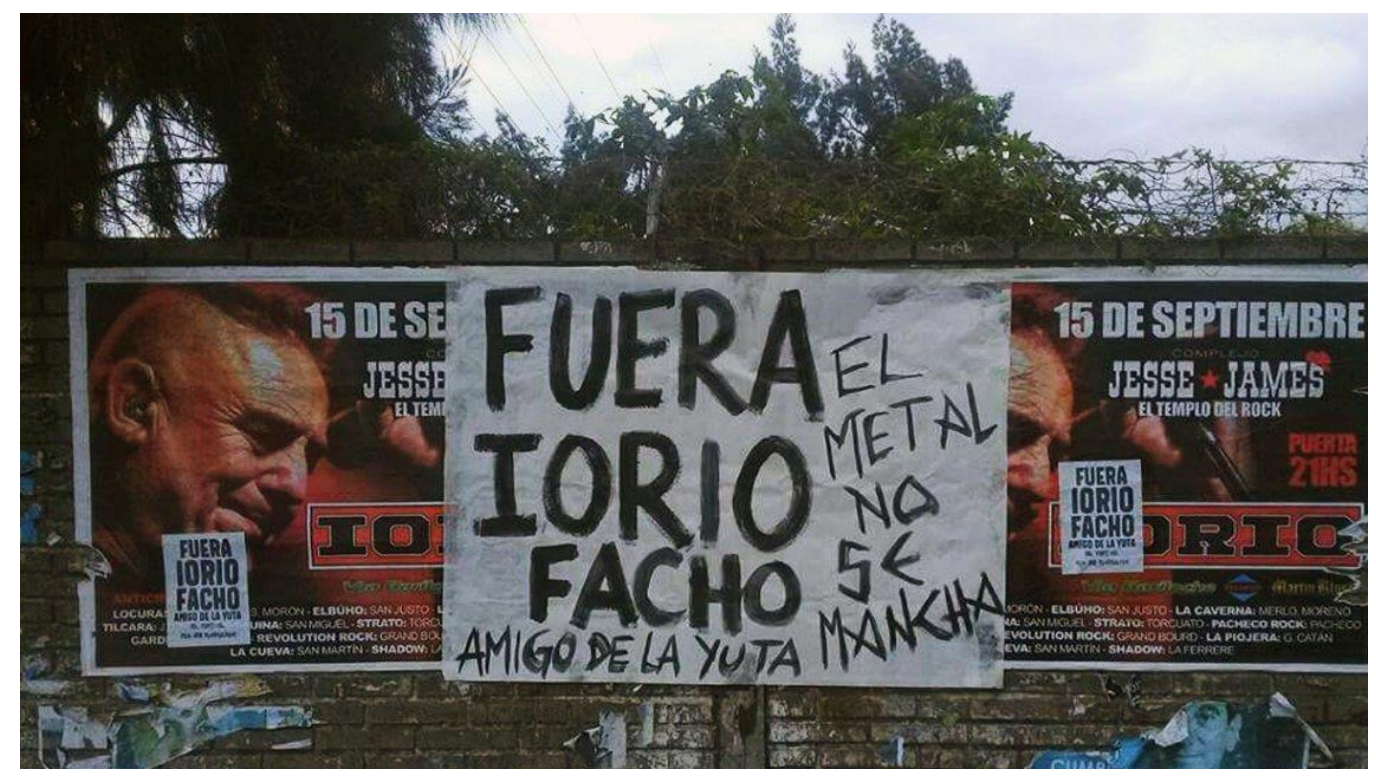

Figura 39: Imagen que apareció en distintos medios de comunicación informando acerca del escrache realizado a Iorio en Isidro Casanova en septiembre de 2017.

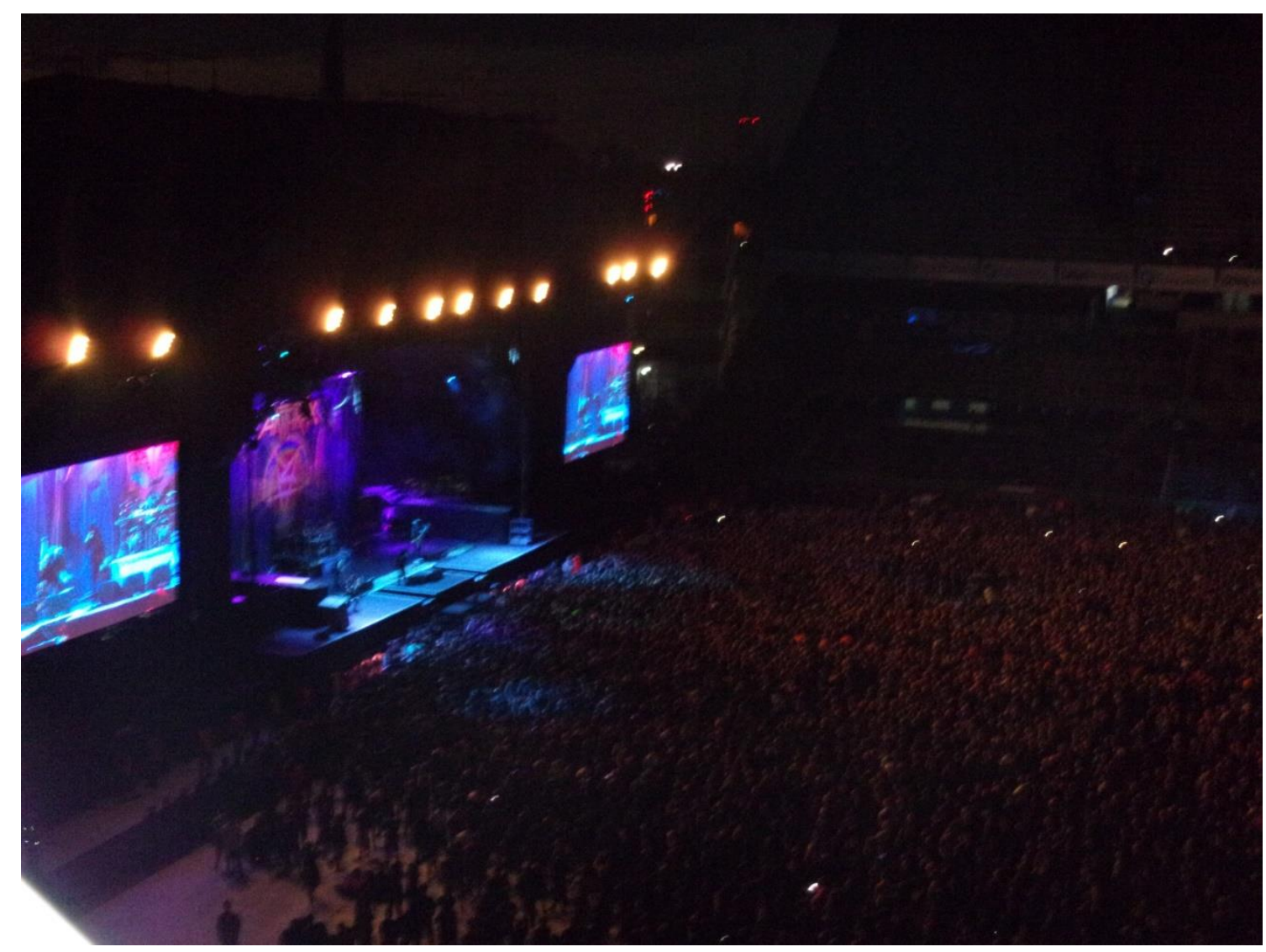

Figura 40: Fotografía tomada en trabajo de campo desde el sector de la platea del Estadio Boca Juniors durante en recital de la banda estadounidense, Anthrax y la británica, Iron Maiden. En ella se puede observar en despliegue escenográfico y la gran cantidad de asistentes. 


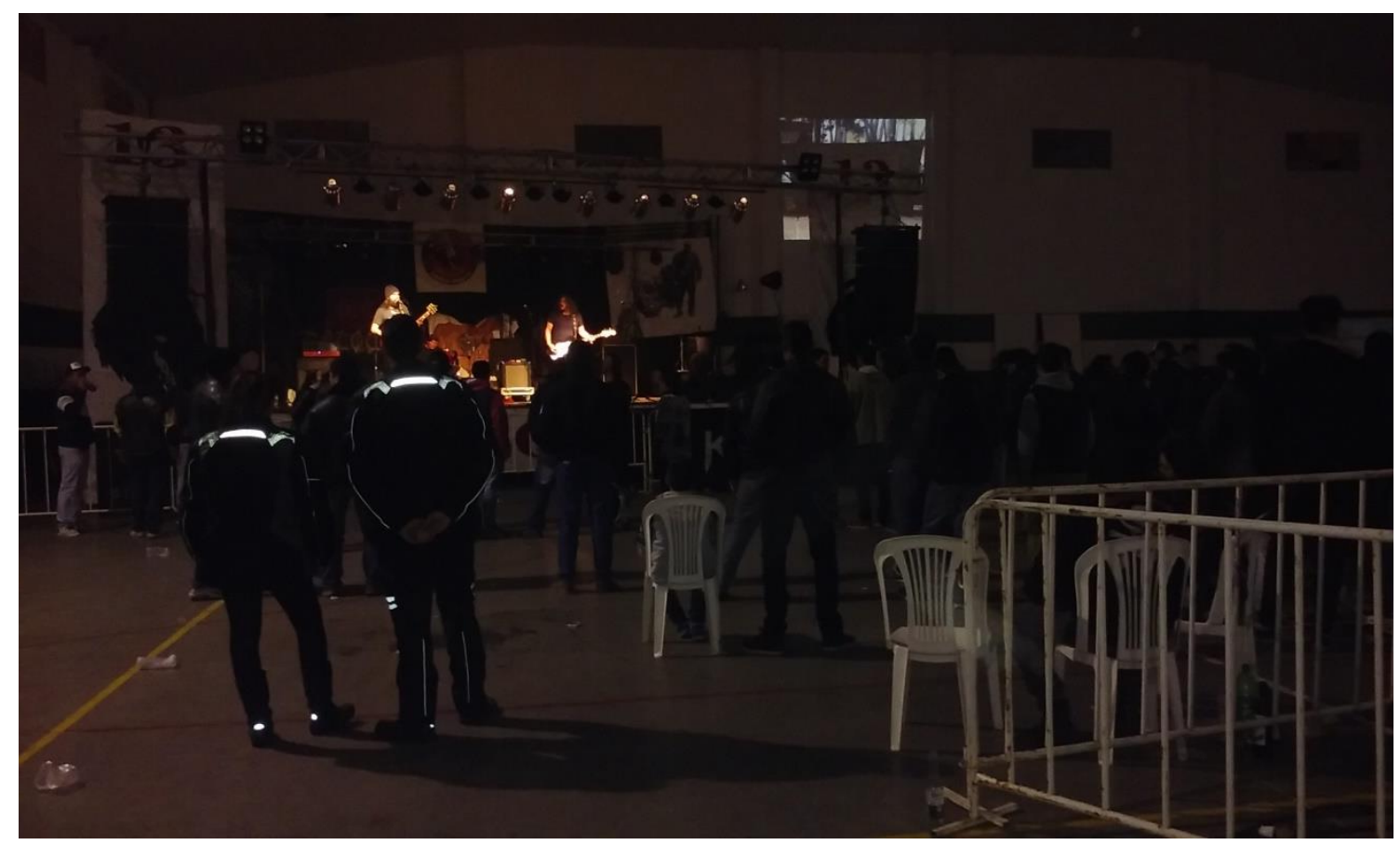

Figura 41: Fotografía tomada en trabajo de campo en motoencuentro en Trenque Lauquen en el año 2016, realizado en el Club Ferrocarril Oeste de dicha localidad. En ella se pueden observar la poca cantidad de asistentes, la cual es más visible ante la infraestructura espaciosa. Sobre el escenario se encuentra una banda underground de metal.

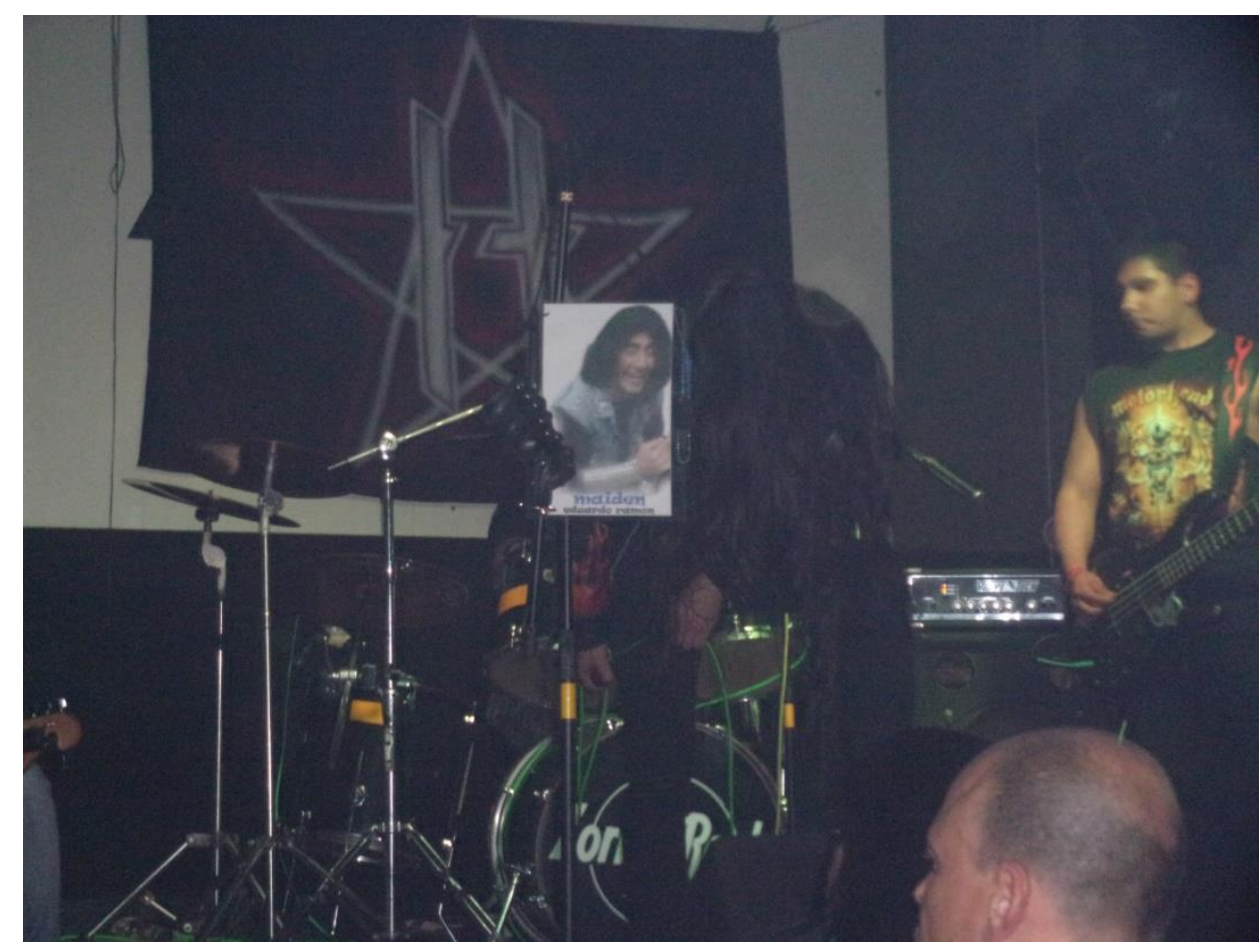

Figura 42: Fotografía tomada en trabajo de campo en festival en José C. Paz en la cual la banda dedica su performance a un amigo recientemente fallecido. 


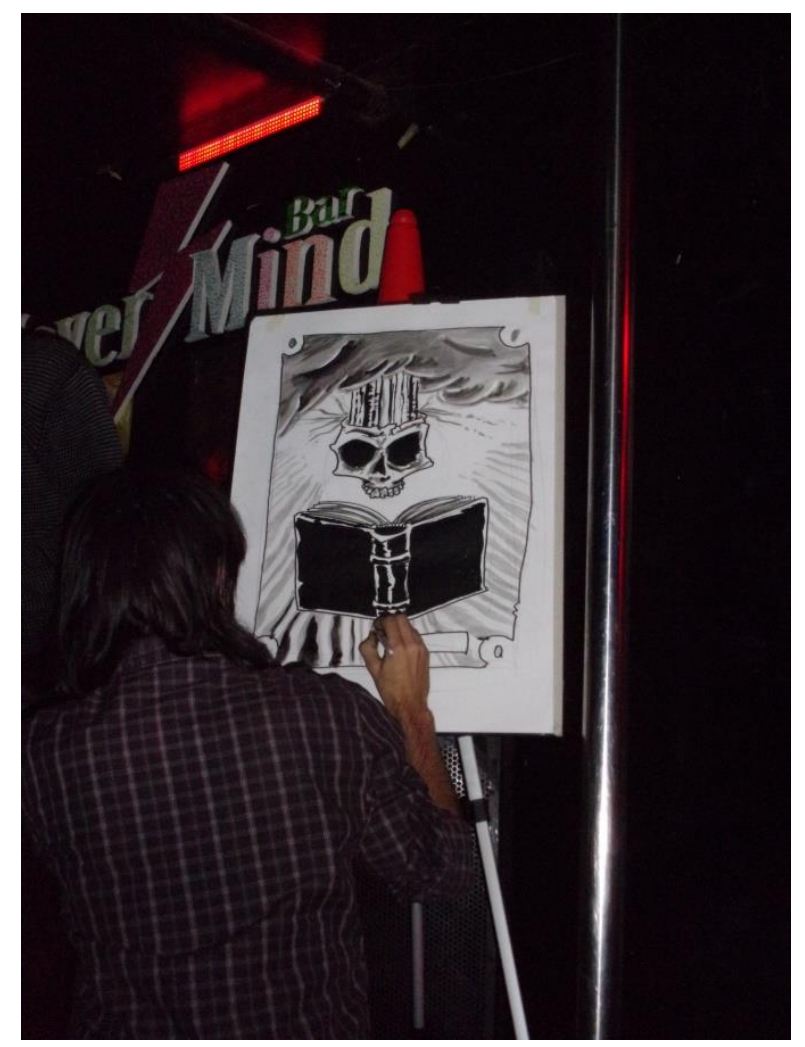

Figura 43: Fotografía tomada en trabajo de campo en la Feria del Libro Heavy de Mar del Plata de 2014. En ella se ve a un dibujante realizando una ilustración en la cual aparece una calavera, simbología característica del metal, junto a un libro.

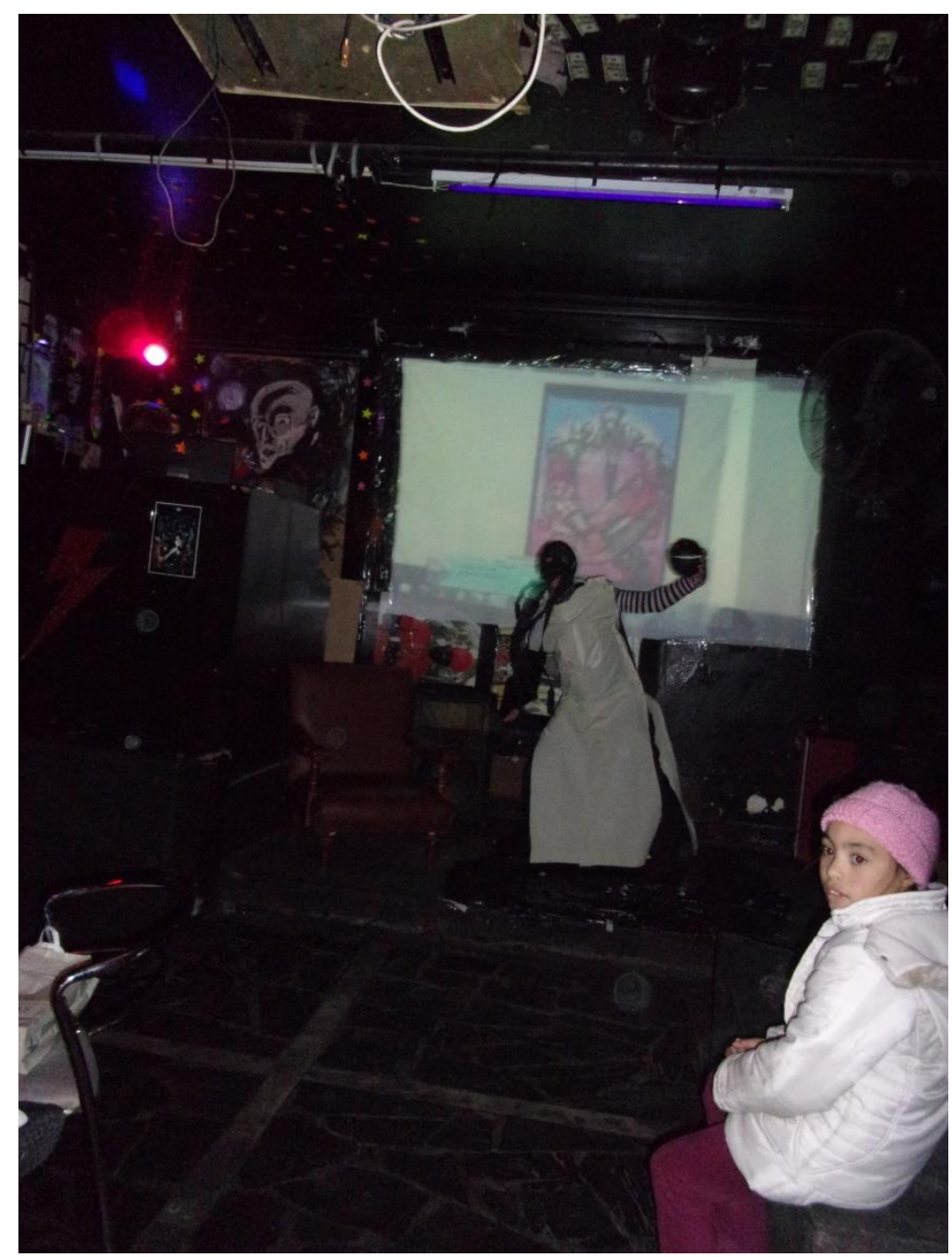

Figura 44: Fotografía tomada en trabajo de campo en Feria del Libro Heavy de Mar del Plata del año 2016 durante la performance artística de Vampire Destroy. 


\section{Gráficos}

\section{Instrumentos ejecutados por mujeres metaleras de la provincia de Buenos Aires}

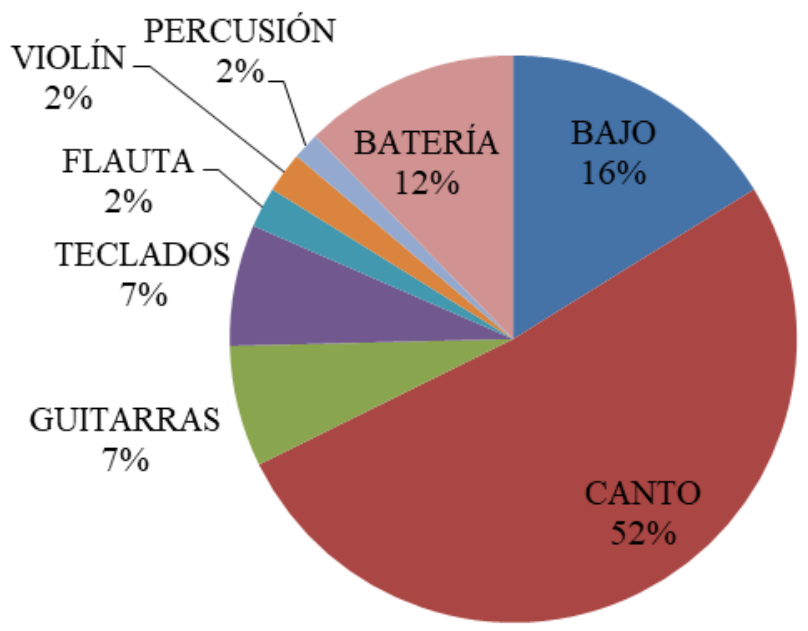

Gráfico 1: Desarrollado a partir de los datos proporcionados por "Enciclopedia Metallum. The Metal Archives"

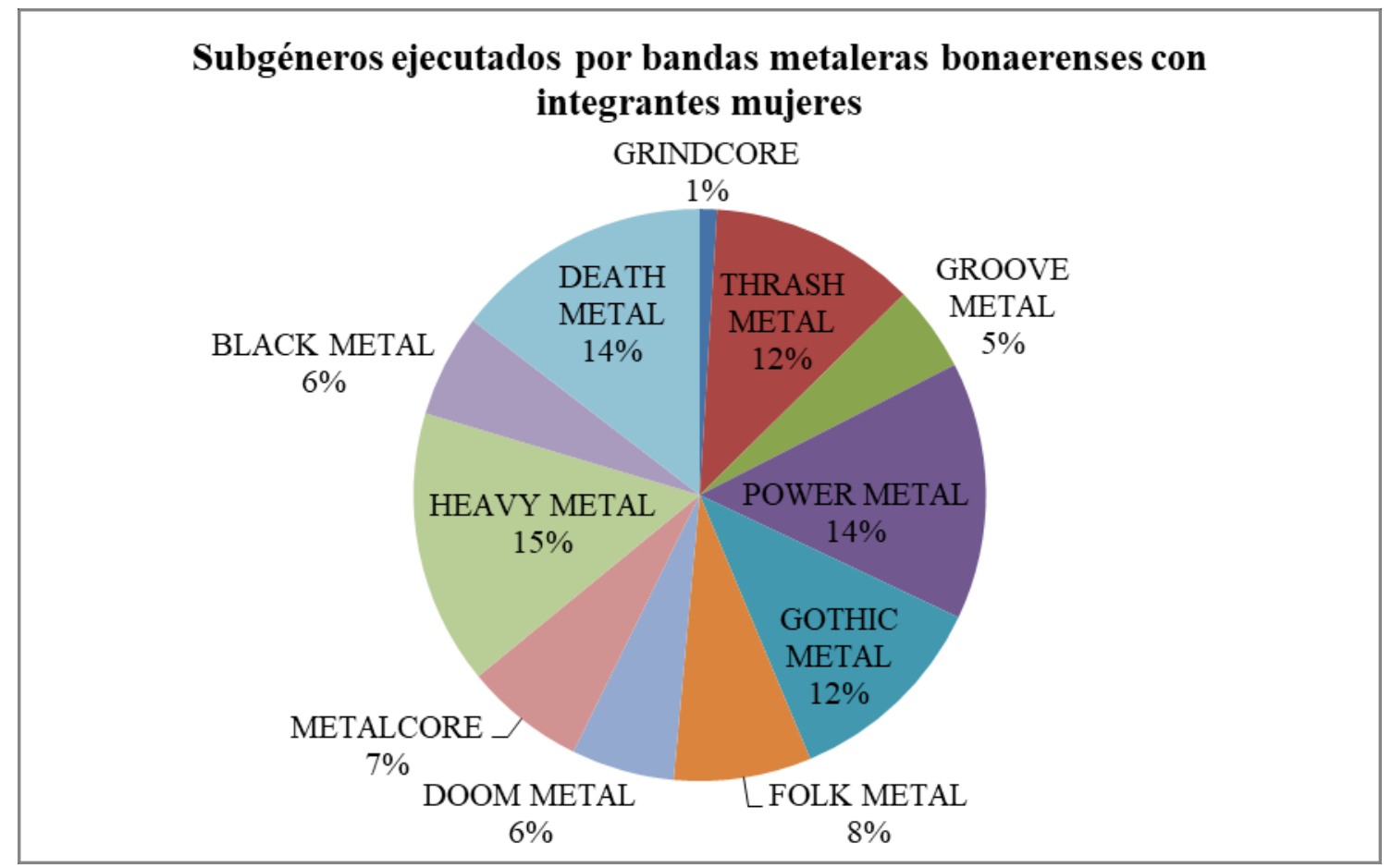

Gráfico 2: Desarrollado a partir de los datos proporcionados por "Enciclopedia Metallum. The Metal Archives") 


\section{Mapas}

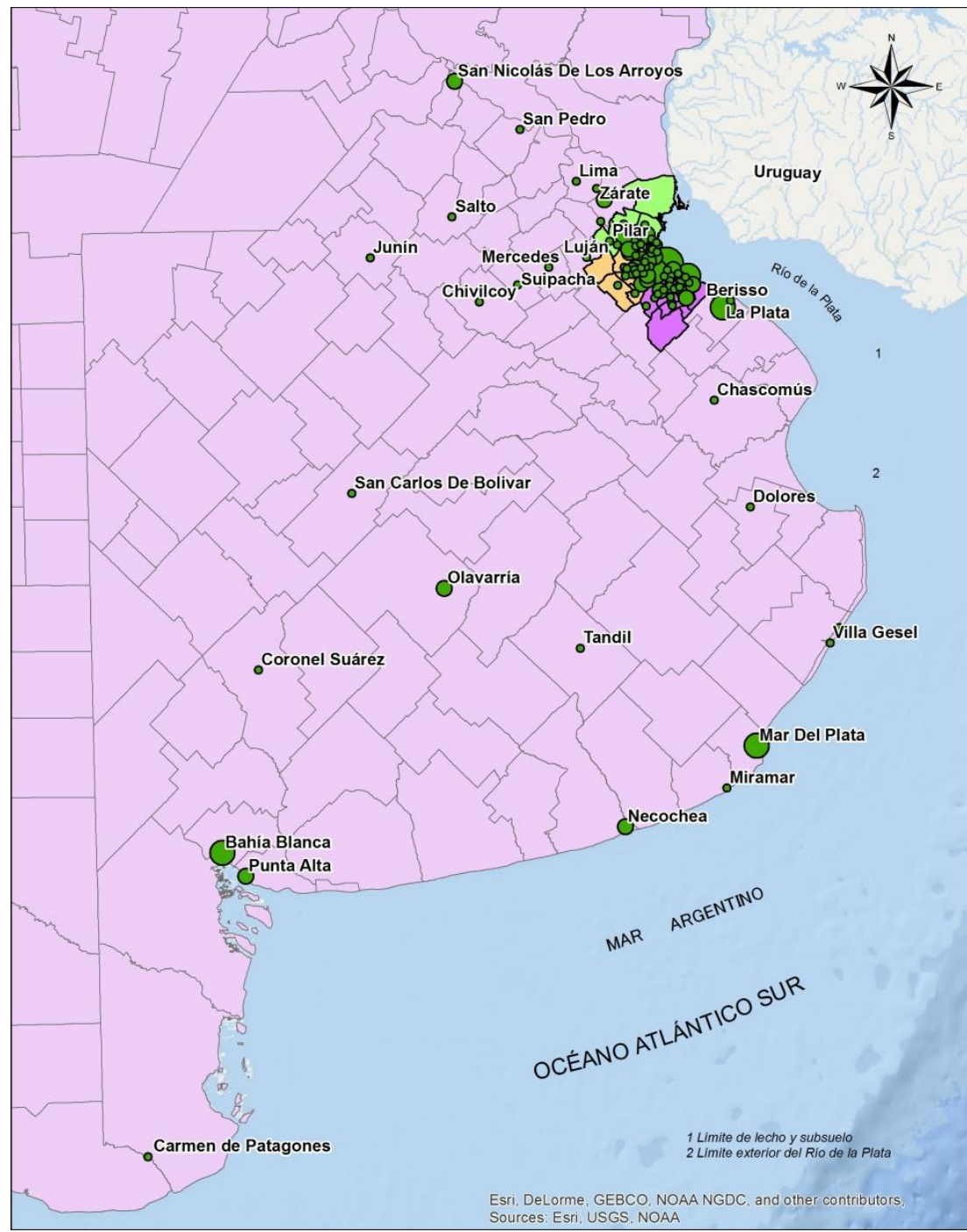

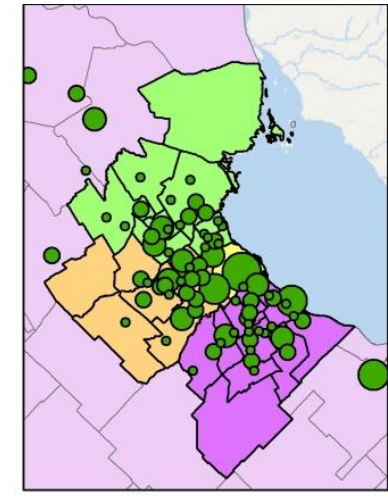

$\underline{\text { Referencias }}$

Bandas Prov. Buenos Aires. 2011-2017

Número de bandas

- 1 - 4 bandas

- 5 - 11 bandas

12 - 36 bandas

463 bandas

$\square$ Zona Norte GBA

$\square$ Zona Sur GBA

$\square$ Zona Oeste GBA

$\square$ Capital

$\square$ Partidos Bs. As

CIG Givise

Escala gráfica

$\begin{array}{llll}0 & 25 & 50 \quad 100\end{array}$

Mapa 1: Detalle de bandas metálicas de acuerdo a la información obtenida en "Enciclopedia Metallum. The Metal Archives". 


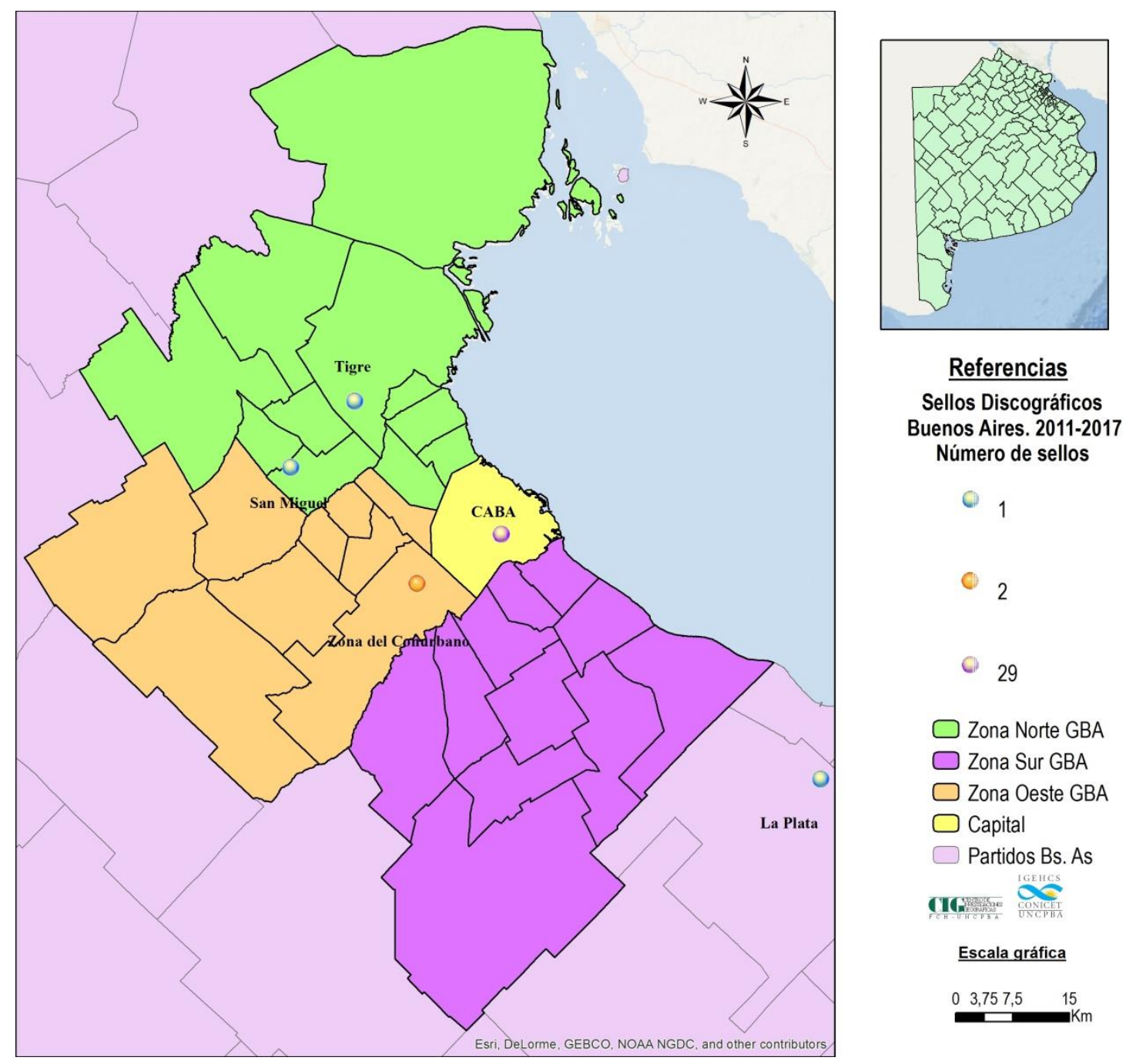

Mapa 2: Detalle de sellos discográficos metálicos de acuerdo a la información obtenida en "Enciclopedia Metallum. The Metal Archives". 


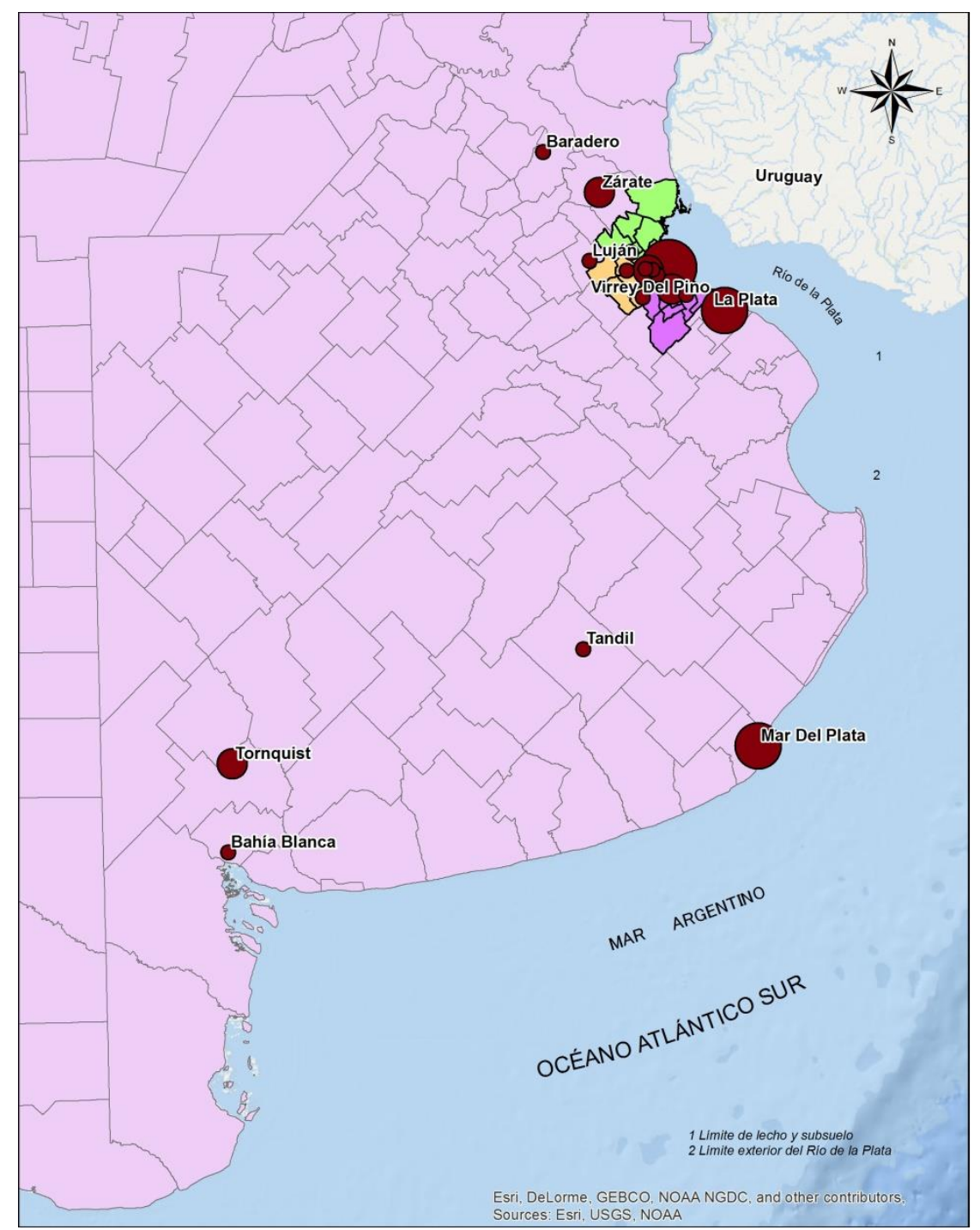

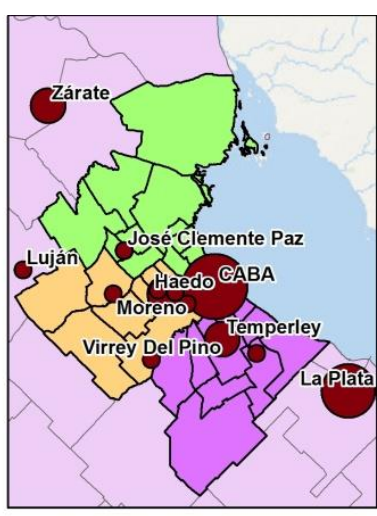

Referencias

Recitales de Almafuerte 2011-2016

\section{Cantidad}

- 1 - 2 recitales

$3-5$ recitales

$6-8$ recitales

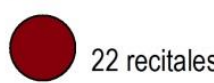

$\square$ Zona Norte GBA

$\square$ Zona Sur GBA

$\square$ Zona Oeste GBA

$\square$ Capital

$\square$ Partidos Bs. As

$$
\text { OIG }
$$

Escala gráfica

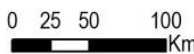

Mapa 3: Recitales de Almafuerte en la escena metálica bonaerense entre 2011 y 2016.

\section{Anexo audiovisual}

Se adjunta a esta tesis un CD con los tres discos de estudio de Hermética en formato MP3 y el video Hermética en vivo, 1993, Argentina, en formato MP4. 


\section{Siglas}

AMBA: Área Metropolitana Bonaerense

ASiMM: Asociación Sindical de Motociclistas, Mensajeros y Servicios

BDSM: Bondage, Disciplina, Dominación, Sumisión, Sadismo y Masoquismo

CABA: Ciudad Autónoma de Buenos Aires

CD: Compact Disc (Disco compacto)

CGT: Confederación General de Trabajo de la República Argentina

DAIA: Delegación de Asociaciones Israelitas Argentinas

DIY: Do it yourself (Hazlo tú mismo)

EIESHM: Equipo Interdisciplinario de Estudios Sociales sobre Heavy Metal

EP: Extended Play

FMI: Fondo Monetario Internacional

ISMMS: International Society for Metal Music Studies

GIIHMA: Grupo de Investigación Interdisciplinario sobre Heavy Metal Argentino

LGTBIQ: Lesbianas, Gays, Transexuales, Bisexuales, Intersexuales y Queers.

NWOBHM: New Wave of British Heavy Metal (Nueva Ola del Heavy Metal Británico)

PMRC: Parent's Music Resource Center

PSR: Partido Segunda República

RAM: Resistencia Ancestral Mapuche

SADAIC: Sociedad Argentina de Autores y Compositores

TICs: Tecnologías de la Información y la Comunicación

VIP: Very Important Person 


\section{Bibliografía}

“Capítulo 1. La historia año por año" (Julio 2014), Efecto metal Especial. Hermética. ii;Sigue Vivo!!!, 2 (2), 7-41.

"Impunidad total: Un cantante denunciado por violencia se autoincrimina en una canción" (18 de diciembre 2017), Rock and Ball. Recuperado de: https://rockandball.com.ar/archivo/impunidad-total-ramiro-arias-148934/

"Las damas del heavy" (Septiembre 1990), Metal, 7 (148).

\#YaNoNosCallamosMas! (7 de diciembre 2017) "Ramiro Arias ex Cantante de Anomalía Misógino, Golpeador, Violento!” [Publicación en blog], recuperado de: $\quad$ https://yanonoscallamosmas.wordpress.com/2017/12/07/ramiro-ariascantante-de-anomalia-misogino-golpeador-violentoyanonoscallamosmas/comment-page-2/\#comments

AA.VV. (1987) "Estudios sobre el mundo rural", Anuario IEHS, N. 2. Universidad Nacional del Centro de la Provincia de Buenos Aires, 21-2013.

Adamo, Noelia y Naamin Tellis, Paula (2017) “Gritar o morir. En torno a la voz de las mujeres en el metal”, en Minore, Gito (comp.) Cultura metálica 4: ponencias, debates y exposiciones de la $4^{\circ}$ Feria del Libro Heavy de Buenos Aires (pp. 5560). Ciudad Autónoma de Buenos Aires: Clara Beter Ediciones.

Adamo, Noelia (2018) "Mujeres Metálicas. Reflexiones en torno a la mujer en el heavy metal argentino", en Scaricaciottoli, Emiliano (comp.) Parricidas: mapa rabioso del metal argentino contemporáneo (pp. 47-77). Ciudad Autónoma de Buenos Aires: La Parte Maldita.

Addisi, Federico G. (2008) San Martín, Rosas, Perón. Un Homenaje a Fermín Chávez. Buenos Aires: Editorial Fabro.

Adorno, Theodor W. (2009) Disonancias. Introducción a la sociología de la música. Madrid: Ediciones Akal, 1973.

Alabarces, Pablo (1995) Entre gatos y violadores. El rock nacional en la cultura argentina. Buenos Aires: Ediciones Colihue.

Alabarces, Pablo (2006) "Fútbol, violencia y política en la Argentina: ética, estética y retórica del aguante", Esporte e Sociedade, 2 (marzo 2006), 1-14.

Alabarces, Pablo (2008) “Introducción. Un itinerario y algunas apuestas", en Alabarces, P y Rodríguez, M. G. (comps.), Resistencias y mediaciones. Estudios sobre cultura popular (pp.15-28), Paidós, Buenos Aires. 
Aliano, Nicolás (2010) "Culturas populares: orientaciones y perspectivas a partir del análisis de un campo de estudios", Sociohistórica/Cuadernos del CISH, (primer semestre 2010), 185-209.

Álvarez, Paula y Lot calabró, Lucas (2014) El Heavy Metal en Buenos Aires (tesina de grado). Licenciatura en Comunicación Social. Facultad de Periodismo y Comunicación Social. Universidad Nacional de La Plata.

Amat, Joaquín (2017) "Ricardo Iorio: la amistad, el video y el metal”, en Minore, Gito (comp.) Cultura metálica 4: ponencias, debates y exposiciones de la $4^{\circ} \mathrm{Feria}$ del Libro Heavy de Buenos Aires (pp. 95-100). Ciudad Autónoma de Buenos Aires: Clara Beter Ediciones.

Anderson, Benedict (1993) Comunidades imaginadas. Reflexiones sobre el origen y la difusión del nacionalismo. México: Fondo de Cultura Económica, 1983.

Angenot, Marc. (2012) El discurso social: Los límites históricos de lo pensable y lo decible. Buenos Aires: Siglo XXI.

Annoni Binotto, Daniel (2004) Música y transdisciplinariedad (tesis de maestría) Facultad de Artes, Universidad de Chile.

Archetti, Eduardo (2007) "Masculinity, Primitivism, and Power: Gaucho, Tango, and the Shaping of Argentine National Identity”, en French, William E. y Bliss, Katherine E. (eds.) Gender, sexuality, and power in Latin America. (pp. 212229). Maryland: Rowman \& Littlefield.

Archetti, Eduardo (2016) Masculinidades: fútbol, tango y polo en la Argentina. Ciudad de Buenos Aires: Deldragón, 2003.

Arfuch, Leonor (2010) El espacio biográfico. Dilemas de la subjetividad contemporánea. Buenos Aires: Fondo de Cultura Económica, 2002.

Arias, Luis (1998) "Una mirada antropológica sobre los procesos identitarios en jóvenes urbanos: el caso del heavy metal". IV Jornadas de Investigadores de la Cultura. Instituto Gino Germani de la Facultad de Ciencias Sociales de la UBA. Recuperado de: https:/es.scribd.com/document/70571370/Una-miradaantropologica-sobre-los-procesos-identitarios-en-jovenes-urbanos-El-casoheavy-metal-1

Aristóteles (2004) Poética. Buenos Aires: Gradifco.

Attali, Jacques (1995) Ruidos. Ensayo sobre la economía política de la música. Madrid: Siglo XXI Editores. 
Avelar, Idelber. (2003) "Heavy Metal Music in Postdictatorial Brazil: Sepultura and the Coding of Nationality", Sound. Journal of Latin American Cultural Studies, 12 (3), 141-52.

Azevedo, Claudia (2007a) "Fronteiras do metal" (ponencia). En Anais XVII Congresso ANPPOM. São Paulo 2007, 1-17. Recuperado de: http://hugoribeiro.com.br/biblioteca-digital/Azevedo-Fronteiras_do_Metal.pdf

Azevedo, Claudia (2007b) "Subgêneros de metal no Rio De Janeiro a partir da década de 1980", Cadernos do Colóquio, 7 (1), 18-30.

Bajtin, Mijail (2003) La cultura popular en la Edad Media y el Renacimiento. Madrid: Alianza Editorial, 1987.

Baranger, Denis (1992). Construcción y análisis de datos. Posadas: UNAM.

Basadre Ayulo, J. (1989), "Algunas consideraciones sobre el yanaconaje en la legislación indiana peruana", Revista Chilena de Historia del Derecho, 15, 19197

Beck, Ulrich (1998) ¿Qué es la globalización? Falacias del globalismo, respuestas a la globalización. Barcelona: Paidós.

Becker, Howard S. (2008) Los mundos del arte: sociología del trabajo artístico. Bernal: Universidad Nacional de Quilmes, 1982.

Bennett, Andy (2004) “Consolidating the music scenes perspective”. Poetics, 32, 223 234.

Bennett, Andy y Peterson, Richard A. (2004) Music scenes. Local, translocal and virtual. Nashville: Vanderbilt Univresity Press.

Bennett, Andy y Hodkinson, Paul (eds.) (2012) Ageing and Youth Cultures: Music, Style and Identity. Londres: Bloomsbury Publishing.

Bennett, Andy y Rogers, Ian (2016) Popular Music Scenes and Cultural Memory. Londres: Palgrave Macmillan.

Bernal, Manuel y Caballero, Diego (2016) “Andar andando sólo andando por andar: el viaje como ethos en la poética de Ricardo Iorio", en Scaricaciottoli, Emiliano (comp.) Se nos ve de negro vestidos (pp. 77-92). Ciudad Autónoma de Buenos Aires: La Parte Maldita.

Berger, Harris M. (1999b) Metal, Rock and Jazz: Perception and the Phenomenology of Musical Experience. Middletown: Wesleyan University Press.

Berta, Gisele; Britez, Claudio e Iglesias, Mario (2016) "Sobre la 3ra. Feria del Libro Heavy en Mar del Plata", en Minore, Gito (comp.) Cultura metálica 3: 
ponencias, debates y exposiciones de la $3^{\circ}$ Feria del Libro Heavy de Buenos Aires (pp. 99-110). Ciudad Autónoma de Buenos Aires: Clara Beter Ediciones.

Besoky, Juan Luis (2016) ““En la Patria de Perón, Ni judío ni masón’. Aproximaciones a la cultura política de la derecha peronista en los años setenta", História e Cultura, Franca, 5 (3), 199-223.

Bianchi, Susana (1996) "Catolicismo y Peronismo: la religión como campo de conflicto", Anuario del IEHS, 11, 147-178.

Bianculli, Soledad (2016) El homenaje H (e-book). Balcarce: La Autora. Recuperado de: https://issuu.com/facu88/docs/el_homenaje_libro_de_la_h

Biddle, Ian y Jarman-Ivens, Freya (2007) "Introduction. Oh Boy! Making Masculinity in Popular Music", en Jarman-Ivens, Freya (ed.) Oh Boy! Masculinities and Popular Music (pp. 59-75). Nueva York: Routledge.

Blanco, Oscar y Scaricaciottoli, Emiliano (2014) "Barrio, amistad, aguante. Prácticas barriales de resistencia". En Las letras de rock en Argentina: de la caída de la dictadura a la crisis de la democracia 1983-2001 (pp. 209-221). Buenos Aires: Editorial Colihue.

Blázquez, Gustavo (2008) "Nosotros, vosotros y ellos. Las poéticas de las Masculinidades Heterosexuales entre jóvenes cordobeses", Trans. Revista Transcultural de Música, 12 (julio 2008). Recuperado de: https://www.redalyc.org/articulo.oa?id=82201206

Blázquez, Gustavo (2012) "Masculinidades cool. Hacer género y clase en los clubs electrónicos", ESTUDIOS, 27 (Enero-Junio 2012), 45-57.

Blázquez, Gustavo (2014) ;Bailaló!: género, raza y erotismo en el cuarteto cordobés. CABA: Gorla.

Blázquez, Gustavo y Liarte tiloca, Agustín (2018) "De salidas y derivas. Anthropological Groove y 'la noche' como espacio etnográfico”, Íconos. Revista de Ciencias Sociales, 6 (enero 2018), 193-216.

Bloom, Harold (1994) El canon occidental: la escuela y los libros de todas las épocas. Barcelona: Editorial Anagrama.

Blumetti, Frank y Parise, Carlos (1993) Heavy metal argentino. Buenos Aires: Ediciones Karma.

Blumetti, Frank y Violante, Andrés (Octubre de 1993), "Biografía”, Madhouse Extra, 1 (2). 
Boffa, Natalia. (2005) "Heavy Metal: "Memoria de siglos"” (ponencia). Universidad Nacional del Sur. Recuperado de: http://www.jornadashumha.com.ar/PDF/2005/Heavy\%20Metal\%20Memoria\%2 0de\%20Siglos\%20-\%20Natalia\%20Boffa.pdf

Boholavsky, Ernesto (2009) El complot patagónico. Nación, conspiracionismo y violencia en el sur de Argentina y Chile (siglos XIX y XX). Buenos Aires: Prometeo.

Boix, Ornela (2015) 'Relajar, gestionar y editar: Haciendo música 'indie' en la ciudad de La Plata", en Gallo, Guadalupe y Semán, Pablo (comp.) Gestionar, mezclar, habitar. Claves en la música independiente (pp. 71-138). Ciudad Autónoma de Buenos Aires: Gorla.

Bourdieu, Pierre (1990) "El campo literario. Prerrequisitos críticos y principios de método", Criterios, La Habana, 25-28 (enero 1989-diciembre 1990), 20-42.

Bourdieu, Pierre (1998) La distinción. Criterios y bases sociales del gusto. Madrid: Taurus, 1979.

Bourdieu, Pierre (2000) La dominación masculina. Barcelona: Editorial Anagrama, 1998.

Bourdieu, Pierre (2002) Campo de poder, campo intelectual. Itinerario de un concepto. Capital Federal: Editorial Montressor.

Bourdieu, Pierre (2005) Las reglas del arte. Génesis y estructura del campo literario. Barcelona: Editorial Anagrama, 1995.

Bourdieu, Pierre (2006) "1. Le capital social. Notes provisoires", en Bevort, Antoine et al. Le capital social, La Découverte "Recherches/MAUSS », 29-34.

Brown, Andy (2011) "Heavy Genealogy: Mapping the Currents, Contraflows and Conflicts of the Emergent Field of Metal Studies, 1978-2010", Journal for Cultural Research, 15 (3), 213-242, DOI: 10.1080/14797585.2011.594579

Bubello, Juan Pablo (2017) “'Jesus no es Dios!' versus 'Jesús es Dios!'. Esoterismo occidental y política en argentina: espiritismo y catolicismo durante el peronismo (1946-1955)", Hist. R., Goiânia, 22 (1), 35-55.

Burroughs, William S. (1959) Naked Lunch. Francia: Olympia Press.

Butler, Judith (2007) El género en disputa. El feminismo y la subversión de la identidad. Barcelona: Paidós, 1990.

Butler, Judith (2009) Dar cuenta de sí mismo. Violencia ética y responsabilidad. Buenos Aires: Amorrortu. 
Caballero, Diego y Bernal, Manuel (2016) "El metal es el mensaje. Reflexiones sobre el rol de los medios alternativos en el heavy metal argentino" (entrevista), en Minore, Gito (comp.) Cultura metálica 3: ponencias, debates y exposiciones de la $3^{\circ}$ Feria del Libro Heavy de Buenos Aires (pp. 45-51). Ciudad Autónoma de Buenos Aires: Clara Beter Ediciones.

Calvo, Manuela B. (2012) Un análisis socio-semiótico comparativo de los discursos que conforman el metal pesado argento de Almafuerte (tesis de maestría). Facultad de Lenguas, Universidad Nacional de Córdoba.

Calvo, Manuela B. (2014). "Diálogos que construyen un modo de nacionalismo argentino en el metal pesado argento de Almafuerte", en Dalmagro, M.C. y Parfeniuk, A. (eds.), Encuentros, tránsitos y desplazamientos. Culturas y literaturas en tensión y en diálogo (II) (pp. 120-137). Colección "Lecturas del Mundo”. Facultad de Lenguas. Universidad Nacional de Córdoba. Córdoba. Buena Vista Editores.

Calvo, Manuela B. (2015) "La historia argentina en las portadas de los discos de la banda Hermética" (ponencia), II Congresso Internacional de Estudos do Rock, Unioeste Brasil, Cascavel. ISSN: 2318-3861. Recuperado de: http://www.congressodorock.com.br/evento/anais/2015/artigos/1/artigo_simposi o_1_885_nuna.calvo@gmail.com.pdf

Calvo, Manuela B. (2016a) “Acerca de la heterogeneidad del rock: el "aguante" en el heavy metal en Argentina", El oído pensante 4 (2). http://ppct.caicyt.gov.ar/index.php/oidopensante

Calvo, Manuela B (2016b) "Almafuerte: Metal pesado argento and its construction of Argentinian nationalism", Metal Music Studies, 2 (1), 21-38.

Calvo, Manuela B. (2018a) "Perspectiva indigenista en la música metal de Argentina", $\begin{array}{lllll}\text { Metal } & \text { Music } & \text { Studies } & 4 & \text { (1), }\end{array}$ DOI: https://doi.org/10.1386/mms.4.1.147_1

Calvo, Manuela B. (2018b) "Metal extremo y globalización en América Latina: los casos de Hermética (Argentina), Masacre (Colombia) y Brujería (México)”, en Dalmagro, M.C. y Parfeniuk, A. (eds.) Reflexiones comparadas: desplazamientos, encuentros y contrastes (pp. 170-190). Córdoba: Facultad de Lenguas. Disponible en: http://hdl.handle.net/11086/5735 
Calvo, Manuela B. (2018c) "Las escenas de la música metal: discusión teórica a partir del caso de la provincia de Buenos Aires", Question 1 (60), 2018: DOI: $10.24215 / 16696581 \mathrm{e} 110$

Campoy, Leonardo Carbonieri (2008) Trevas na cidade. O underground do metal extremo no Brasil (tesis de maestría), Programa de Pós-graduação em Sociologia e Antropologia, Instituto de Filosofia e Ciências Sociais, Universidade Federal do Rio de Janeiro.

Cancino, Hugo (2003) "Modernidad y tradición en el pensamiento latinoamericano en los siglos XIX y XX”, Sociedad y Discurso, 3.

Canclini, Néstor (2012) Culturas hibridas. Estrategias para entrar y salir de la modernidad (1ra. ed. y 5ta. reimp). Buenos Aires: Paidós

Cañizares, Rubén G. (2015) Cuando éramos reyes: memorias del Heavy Argentino de los ।'80s/. Ciudad Autónoma de Buenos Aires: Jedbangers.

Cañuqueo, Lorena y Kropff, Laura (2007) “MapUrbe'zine: Los cuerpos de 'la lucha' en el circuito Heavy-Punk Mapuche”. E-misférica, 4(2). Recuperado de: http://www.hemisphericinstitute.org/journal/4.2/esp/es42_pg_canuqueo_kropff.h tml

Capote González, Armando (1999) "La subjetividad y su estudio. Análisis teórico y direcciones metodológicas", La Habana: CIPS. Recuperado de: http://bibliotecavirtual.clacso.org.ar/ar/libros/cuba/cips/caudales05/Caudales/AR TICULOS/ArticulosPDF/07C119.pdf (Último acceso noviembre 2018)

Cardoso Filho, Jorge y Xavier de Oliveira, Luciana (2013) "Espaço de experiência e horizonte de expectativas como categorias metodológicas para o estudo das cenas musicais". Trans. Revista Transcultural de Música/Transcultural Music Review, 17, 1-19.

Carretero, Andrés M. (1999) El compadrito y el tango. Buenos Aires: Ediciones Continente.

Carrizo, Paula (Noviembre 2017) "Ya no sos igual, ya no sos igual, sos el vigilante del heavy metal", Enterrado vivo, 4.

Castañeda, Mario (2005) "Bajo el resplandor del metal: un intento por explicar la historia del heavy metal”, en Zúñiga Núñez, Mario (comp.) Cuaderno de Ciencias Sociales 136: Culturas Juveniles. Teoría, historia y casos (pp. 21-40). Costa Rica: FLACSO Sede Costa Rica. 
Castillo Bernal, Stephen (2007) El cuerpo humano como instrumento subcultural. De los inicios del heavy metal al simbolismo ritual del black metal, Fuentes humanísticas, México 2007, 19 (34), 43-57.

Castelnuovo, Enrico y Ginzburg, Carlo (1979) "Centro e periferia", en Previtali, Giovanni (ed.) Storia dell'arte italiana, Parte i, vol. I (pp. 285-352). Turín: Einaudi.

Cattaruzza, Alejandro (2003) "El revisionismo: itinerarios de cuatro décadas", en Cattaruzza, Alejandro y Eujanian, Alejandro. Políticas de la Historia: Argentina, 1860-1960. (pp. 103-182). Buenos Aires: Alianza.

Chang, Heewon (2008) Autoethnography as metod. California: Left Coast Press.

Chindemi, Julia y Vila, Pablo (2017) "La música popular argentina entre el campo y la ciudad: música campera, criolla, nativa, folklórica, canción federal y tango", ArtCultura, 19 (34), 9-26.

Christe, Ian (2005) El sonido de la bestia. La historia del heavy metal. Barcelona: Ediciones Robinbook.

Citro, Silvia. (2008) "El Rock como un ritual adolescente. Trasgresión y realismo grotesco en los recitales de Bersuit”, en Trans. Revista Transcultural de Música, 12 (julio 2008). Recuperado de: http://www.redalyc.org/articulo.oa?id=82201203

Clarke, John (2010) "Estilo", en Hall, Stuart y Jefferson, Tony (eds.) Resistencia a través de rituales: subculturas juveniles en la Gran Bretaña de la posguerra (pp. 310-325). La Plata: Universidad Nacional de La Plata. Facultad de Periodismo y Comunicación Social; Observatorio de Jóvenes, Comunciación y Medios.

Clarke, John; Hall, Stuart; JEFFERSON, Tony y ROBERTS, Brian (2010) "Subculturas, culturas y clase", en Hall, Stuart y Jefferson, Tony (eds.) Resistencia a través de rituales: subculturas juveniles en la Gran Bretaña de la posguerra (pp. 67-165). La Plata: Universidad Nacional de La Plata. Facultad de Periodismo y Comunicación Social; Observatorio de Jóvenes, Comunicación y Medios.

Coba Baque, Héctor O. y Vinueza Merizalde, Dayana S. (2012) Influencia de la música heavy metal en la ideología de los jóvenes de los colectivos al sur del cielo y colectivo norte de Quito (tesis de licenciatura) Carrera de Comunicación Social. Universidad Politécnica Salesiana. Sede Quito. 
Cohen, Stanley (2014) Demonios populares y "pánicos morales": delincuencia juvenil, subculturas, vandalismo, drogas y violencia. Barcelona: Editorial Gedisa.

Connell, R. W. (1997) “La organización social de la masculinidad”, en Valdés, Teresa y Olavarría, José (eds.) Masculinidad/es. Poder y crisis (pp. 31-48). Santiago de Chile: Isis Internacional, FLACSO Chile.

Conte, Silvia (2007) Historia, evolución y actualidad de la música heavy metal: entre la identidad transgresora y la industria cultural (tesina de grado). Licenciatura en Ciencias de la Comunicación. Facultad de Ciencias Sociales. UBA.

Corrado, Omar (2004) “Canon, hegemonía y experiencia estética: algunas reflexiones”, Revista Argentina de Musicología, (2004-2005), 16-44.

Cortés Morales, Yelotzin (2018) Respuesta emocional a la música extrema en situaciones controladas: estudio con escucha y no-escuchas del metal (tesis de licenciatura). Centro Universitario UAEM ECATEPEC, Universidad Autónoma del Estado de México.

Corti, Berenice (2007) "Las redes del disco independiente: apuntes sobre producción, circulación y consumo", Concurso de ensayos 2007: Las industrias culturales en la Ciudad de Buenos Aires (pp. 55-79). Ministerio de Producción, Gobierno de la Ciudad de Buenos Aires.

Corti, Berenice (2009) "Redefiniciones culturales en la Buenos Aires post Cromañón. El debate sobre el vivo de la música independiente", VIII Reunión de Antropología del MERCOSUR (RAM). Disponible en Internet en: http://www.academia.edu/700280/Redefiniciones_Culturales_En_La_Buenos_A ires_Post_Croma\%C3\%B1\%C3\%B3n_El_Debate_Sobre_El_Vivo_De_La_M\% C3\%BAsica_Independiente

D’Amore, Pablo A. (2016) Historias de metal marplatense. Mar del Plata: Pablo Antonio D Amore.

Da Silva Catela, Ludmila (2005) "Variaciones sobre las memorias", Estudios, 16 (otoño 2005), 11-20.

Dawes, Laina (2013) What Are You Doing Here? Canadá: Bazillion Points.

De Aguilera, Miguel. (2008) "El encuentro entre la comunicación y la música: razones, criterios, enfoques", en De Aguilera, Miguel; Adell, Joan E. y Sedeño, Ana (eds.) Comunicación y música I. Lenguaje y medios (pp. 9-47). Barcelona: Editorial Advisory Board.

De Beauvoir, Simone (1998) El Segundo Sexo. Madrid: Cátedra. 
De Farias Silva, Wlisses James (2014) Heavy metal no Brasil: Os incômodos perdedores (década de 80) (tesis doctoral). Universidade do São Paulo; Faculdade de Filosofia, Letras e Ciências Humanas; Programa de pós-graduação em História Social.

Del Fresno, Miguel (2011) Netnografía. Investigación, análisis e intervención social online. Barcelona: Editorial UOC.

De la Torre, Fabián (Abril 2016) "Editorial”, Metalica Fanzine, 30 (79).

DeNora, Tia (2004) Music in Everyday life. Cambridge: Cambridge University Press, 2000 .

DeNora, Tia (2003) After Adorno. Rethinking music sociology. Cambridge: Cambridge University Press.

DeNora, Tia (2012) "La música en acción: constitución del género en la escena conciertística de Viena, 1790-1810”, en Benzecry, Claudio E. (comp.) Hacia una nueva sociología cultural. Mapas, dramas prácticos (pp.215-248). Quilmes: Universidad Nacional de Quilmes Editorial.

De Val Ripolles, Fernan (2014) Rockeros insurgentes, modernos complacientes: juventud, rock y politica en España (1975-1985) (tesis doctoral), Facultad De Ciencias Políticas y Sociología. Departamento de Sociología I. Universidad Complutense de Madrid.

Díaz, Claudio F. (2005) Libro de viajes y extravíos: Un recorrido por el rock argentino (1965-1985). Unquillo: Narvaja Editor.

Díaz, Claudio F. (2009) Variaciones sobre el "ser nacional". Una aproximación sociodiscursiva al "folklore" argentino. Córdoba: Ediciones Recovecos.

Díaz, Claudio F. (2011) "Música popular, investigación y valor”, en Sanz, Juan F. y López Cano, Rubén (comps.) Música popular y juicios de valor: una reflexión desde América latina. Caracas: Fundación Centro de Estudios Latinoamericanos Rómulo Gallegos.

Domínguez Prieto, Olivia (2016) "Destrucción mutuamente asegurada”, Revista Digital Universitaria, 17 (6), (junio de 2016), 1-14.

Domínguez Prieto, Olivia (2017) Transhumancias musicales. El metal no tiene fronteras. Ciudad de México: Editorial Plaza y Valdés.

Dunaway, David K. (1992) "Music as Political Communication in the United States", en Lull, James (ed.) Popular music and communication (pp. 36-52). Londres: Sage Publications. 
Echeverría, Olga (1997) "Volver a Rosas: los intelectuales autoritarios y la compleja herencia positiva en la rehabilitación histórica del rosismo", en Anuario del IEHS "Prof. Juan C. Grosso", 12. Tandil: UNCPBA, 443-467.

Echeverría, Olga (2009) Las voces del miedo. Los intelectuales autoritarios argentinos en las primeras décadas del Siglo XX. Rosario: Prohistoria Ediciones.

Echeverría, Olga (2012) "Los intelectuales de derecha frente a lo popular: ¿axiomas estéticos como argumento político? Argentina, primera mitad del siglo XX" (ponencia), Cuarto Taller de Discusión "Las derechas en el Cono Sur, siglo $X X$ ”, Universidad Nacional de General Sarmiento, Los Polvorines, 31 de mayo de 2012. Disponible en: https://www.ungs.edu.ar/wpcontent/uploads/2018/07/Echeverria.pdf

Echeverría, Olga (2013) "Los intelectuales antidemocráticos frente a lo popular. Argentina, primera mitad del siglo XX”, Historia y Espacio, 40 (febrero-junio 2013), 49-73.

Echeverría, Olga (2017) "El surgimiento y diversificación de las derechas de Argentina y Uruguay en la primera mitad del siglo XX", Nuevo Mundo Mundos Nuevos [en línea], Colloques. Recuperado de: https://journals.openedition.org/nuevomundo/71846

Eco, Umberto (1984) Apocalípticos e integrados. España: Editorial Lumen, 1968.

Efecto metal Especial. Hermética. ¡¡iSigue Vivo!!! (Julio 2014), 2 (2).

Ellis, Carolyn; Adams, Tony E. y Bochner, Arthur P. (2015) "Autoetnografía: un panorama", Astrolabio. Nueva época, 14, 249-273.

Epstein, Jonathon S. y Pratto, David J. (1990) "Heavy Metal Rock Music: Juvenile Delinquency and Satanic Identification", Popular Music and Society, 14 (4), 6776.

Espíndola, Pablo y Morales, Germán (2013) "Evitando el ablande”: Cambios y permanencias de la identidad metalera argentina. Análisis a partir del Correo de Lectores de la revista Metal (1988-1989) y del foro Jedbangers (2011-2012). (tesina de grado) Licenciatura en Ciencias de la Comunicación. Facultad de Ciencias Sociales. UBA.

Fêo, Ingrid F.; Rossi, Andressa K. y Mendes, Isabella F. (2015) "A influência do heavy metal na moda contemporânea" (ponencia), $1^{\circ}$ Colóquio de Moda, $2^{\circ}$ Congresso Brasileiro de Iniciação Científica em Design e Moda, 1-7. 
Fernández, Ana María (1993) La mujer de la ilusión. Pactos y contratos entre hombres $y$ mujeres. Buenos Aires: Paidós.

Fernández, María Alejandra (2007) "Las razones de la violencia y la fundamentación del castigo: una aproximación a las formas de acusación y de defensa en la justicia criminal colonial (Buenos Aires, 1776-1810)", en Gayol, Sandra y Madero, Marta (eds.) Formas de historia cultural (pp. 275-303). Buenos Aires: Prometeo Libros; Los Polvorines: Universidad Nacional de General Sarmiento.

Ferrante, Natalia (2003) “Cultura popular, tácticas del margen”, en Saintout, Florencia (ed.) Abrir la comunicación. Tradición y movimiento en el campo académico (pp. 65-74). La Plata: Ediciones de Periodismo y Comunicación.

Firestone, Shulamit (1976) La dialéctica del sexo. Barcelona: Kairós.

Fischerman, Diego (2004) Efecto Beethoven. Complejidad y valor en la música de tradición popular. Buenos Aires: Paidós.

Folgueira Lombardero, Pablo (2010-2011) "La idea de historia en el heavy metal español”, en López Fernández, Ma. Isabel (ed.) Tiempo y Sociedad, 3, España, $5-41$.

Ford, Aníbal; Rivera, Jorge y Romano, Eduardo. (1984) Medios de Comunicación y Cultura Popular. Buenos Aires: Legasa.

Foucault, Michael (1992) Microfísica del poder (3ra. Ed.). Madrid: Las Ediciones de La Piqueta.

Frith, Simon (1989) “Why do songs have words?”, Contemporary Music Review, 5 (1), 77-96.

Frith, Simon (1996) “Música e identidad”, en Hall, Stuart y Du Gay, Paul. Cuestiones de identidad cultural (pp. 181-213). Buenos Aires: Amorrortu Editores.

Frith, Simon (2014) Ritos de la interpretación sobre el valor de la música popular. Buenos Aires: Paidós, 1996.

Frith, Simon y McRobbie, Angela (1978) "Rock and Sexuality”, Screen Education, 29, 3-19.

Galicia Poblet, Fernando (2005) Espíritus rebeldes: el heavy metal en España. Madrid: Fundación Autor.

Galicia Poblet, Fernando (2015) El Heavy Metal en España, 1978-1985: fases de formación, cristalización y crecimiento (tesis doctoral). Departamento de Musicología. Faculta de Historia y Geografía. Universidad Complutense de Madrid. 
Galicia Poblet, Fernando (2017) Inoxidable. Formación, cristalización y crecimiento del heavy metal en España, 1978-1985. Apache Libros. Madrid.

Gallegos Perez, Karina (2004) "Al estilo de vida metalero: resistencia cultural urbana en Quito", Íconos. Revista de Ciencias Sociales, 18, 24-32.

Gallo, Guadalupe y Semán, Pablo (2015) “Gestionar, mezclar, habitar. Claves en los emprendimientos musicales contemporáneos”, en Gallo, Guadalupe y Semán, Pablo (comp.) Gestionar, mezclar, habitar. Claves en la música independiente (pp. 15-69). Ciudad Autónoma de Buenos Aires: Gorla.

Garavaglia, Juan Carlos (2003) "Gauchos: identidad, identidades”, América: Cahiers du CRICCAL, 1 (30), 143-151.

García Angelo, Miguel (2006) "Un Nuevo Desafío en la Investigación: Enfoque Transdisciplinario en Comunicación y Desarrollo", Razón y palabra, 49. Recuperado de: http://www.razonypalabra.org.mx/anteriores/n49/mgarcia.html (Último acceso noviembre de 2018)

García Canclini, Néstor (1984) "Cultura y organización popular. Gramsci con Bourdieu", Cuadernos Políticos, 38, (enero-marzo 1984), 75-82.

García Canclini, Néstor (2012) Culturas híbridas. Estrategias para entrar y salir de la modernidad. Buenos Aires: Paidós, 1990.

García Fanlo, Luis (2010) Genealogía de la argentinidad. Buenos Aires: Gran Aldea Editores.

García, Hugo (Marzo 2014) "Hermética. 20ªniversario Víctimas del vaciamiento", Jedbangers, 79, 50-60.

Garriga Zucal, José. (2008) “Ni 'chetos' ni 'negros': roqueros”, en Trans. Revista Transcultural de Música, 12. Recuperado de: http://www.sibetrans.com/trans/a89/ni-chetos-ni-negros-roqueros

Garriga Zucal, José y SALERNO, Daniel (2008) "Estadios, hinchas y rockeros: variaciones sobre el aguante" en ALABARCES, Pablo y RODRÍGUEZ, Ma. Graciela (2008) Resistencias y mediaciones: estudios sobre cultura popular. Buenos Aires: Paidós.

Gasparri, Javier. (2011) "Che, varón. Masculinidades en las letras de tango", Caracol, $2,174-215$.

Gayol, Sandra y Madero, Marta (2007) “Introducción”, en Gayol, Sandra y Madero, Marta (eds.) Formas de historia cultural (pp. 11-27). Buenos Aires: Prometeo Libros; Los Polvorines: Universidad Nacional de General Sarmiento. 
Geertz, Clifford. (2003) "Después de la revolución: el destino de los nacionalismos en los nuevos estados", en La interpretación de las culturas (pp. 203-218). Barcelona: Editorial Gedisa.

Gendler, Martín y Prado, Horacio (2016) “De los fierros y la resistencia al campo y la tradición: Regularidades, desplazamientos y discontinuidades en el Heavy Metal argentino", Revista Trazos Universitarios, 1-38.

Gibson, James J. (1966) The Senses Considered as Perceptual Systems. Boston: Houghton Mifflin.

Giménez Montiel, Gilberto (2002a) "Identidad y memoria colectiva", en Giménez Montiel, Gilberto. Teoría y análisis de la cultura. Vol. 1 (pp. 89-111). México: CONACULTA.

Gobello, José y Oliveri, Marcelo H. (2001) Tangueces y lunfardismos del rock argentino. Buenos Aires: Ediciones Corregidor.

Gobello, José y Oliveri, Marcelo H. (2010) Novísimo diccionario de lunfardo. Buenos Aires: Corregidor.

Goebel, Michael. (2004) "La prensa peronista como medio de difusión del revisionismo histórico, 1955-1958”, Prohistoria, 8, 251-266.

Goebel, Michael. (2013) La Argentina partida. Nacionalismos y políticas de la historia. Buenos Aires: Prometeo.

Goffman, Erving (2001) La presentación de la persona en la vida cotidiana. Buenos Aires: Amorrortu.

González Zymla, Herbert (2014) "La danza macabra", Revista Digital de Iconografía Medieval, VI(11), 23-51.

Gramsci, Antonio (2018) Los intelectuales y la organización de la cultura. Ciudad Autónoma de Buenos Aires: Editorial Cooperativa de Libreros.

Gravano, Ariel (1996) "Imaginario urbano, barrios mancha y calidad de vida en la ciudad intermedia, hacia un modelo de análisis", Intersecciones, 2, 51-61.

Gravano, Ariel (2015) "Tres hipótesis sobre la relación entre Sistema urbano e imaginarios de ciudades medias", en Gravano, Ariel; Silva, Ana y Boggi, Silvia M. (eds.) Ciudades vividas: sistemas e imaginarios de ciudades medias bonaerenses (pp. 69-90). Ciudad Autónoma de Buenos Aires: Café de las Ciudades.

Grinberg, Miguel D. (1977-2014) Cómo vino la mano: orígenes del rock argentino. Buenos Aires: Gourmet Musical Ediciones. 
Gross, Robert L. (1990) "Heavy Metal Music: A New Subculture in American Society”, Journal of Popular Culture, 24 (1), 119-129.

Grupo de investigación interdisciplinaria sobre el heavy metal argentino (2017a) "Iorio, el auto-parricida metalero", La Résistance. Recuperado de: https://laresistanceweb.com/2017/07/18/iorio-el-auto-parricida-metalero/

Grupo de investigación interdisciplinaria sobre el heavy metal argentino (2017b) (Actualización de estado de Facebook). Recuperado de: https://www.facebook.com/giihmargentino/posts/como-grupo-deinvestigaci\% $\% 3 \% \mathrm{~B} 3 n$-que-asume-sus-propias-especificidades-hemos-dejado$\mathrm{d} / 673467266182248 /$

Gruzelier, Jonathan (2007) "Moshpit Menace and Masculine Mayhem”, en JarmanIvens, Freya (ed.) Oh Boy! Masculinities and Popular Music (pp. 59-75). Nueva York: Routledge.

Guber, Rosana (2001) La etnografía, método, campo y reflexividad. Bogotá: Grupo Editorial Norma.

Guerrero Muñoz, Joaquín (2014) "El valor de la auto-etnografía como fuente para la investigación social: del método a la narrative". AZARBE, Revista Internacional De Trabajo Social Y Bienestar, 3. Recuperado de: http://revistas.um.es/azarbe/article/view/198691

Guibert, Gérôme y Hein, Fabien (2006) "Les Scènes metal: Sciences sociales et pratiques culturelles radicales", Copyright Volume!, 5 (2), 5-18.

Guibert, Gérôme y Sklower, Jedediah (2013) "Dancing with the Devil: Panorame des "metal studies", La Vie des idées. ISSN: 2105-3030. Recuperado de: http://www.laviedesidees.fr/Dancing-with-theDevil.html

Hall, Stuart (1996) “Introducción: ¿quién necesita identidad?”, en Hall, Stuart y Du Gay, Paul. Cuestiones de identidad cultural (pp. 13-39). Buenos Aires: Amorrortu Editores.

Halperín Donghi, Tulio. (2005) El revisionismo histórico argentino como visión decadentista de la historia nacional. Buenos Aires: Siglo XXI.

Harvey, David (s/f) Breve historia del neoliberalismo (e-book).

Hebdige, Dick (2004) Subcultura. El significado del estilo. Barcelona: Paidós, 1979.

Hein, Fabien y Kahn-Harris, Keith (2006) "Études metal/metal studies: Une bibliographie”, Copyright Volume!, 5 (2), 19-30.

Hennion, Antoine (2002) La pasión musical. Buenos Aires: Editorial Paidós, 1993. 
Hennion, Antoine (2009) “Réflexivités. L'activité de l'amateur”, Réseaux, 153(1), 5578.

Hennion, Antoine (2012) "Melómanos: el gusto como performance", en Benzecry, Claudio E. (comp.) Hacia una nueva sociología cultural. Mapas, dramas prácticos (pp. 215-248). Quilmes: Universidad Nacional de Quilmes Editorial.

Hermética, a 20 años del Obras 1994 (revipóster) (diciembre 2014), Efecto Metal. Colección Ídolos del rock, 1 (5).

Hernández, José (2000) Martín Fierro. Barcelona: EDIMAT Libros.

Hernández Salgar, Óscar (2012) "La semiótica musical como herramienta para el estudio social de la música”, Cuadernos de Música, Artes Visuales y Artes Escénicas, 7 (1), 39-77.

Hertz, Gabriel F. (2007) Pura fusión: heavy metal y nacionalismo (tesis de licenciatura). Facultad de Ciencias Sociales, Universidad Nacional de Buenos Aires.

Hertz, Gabriel F. (2008) "Pura fusión: eugenesia, nacionalismo y (cierto) heavy metal", en Ugarte, Mariano y Sanjurjo, Luis (coord.). Emergencia: cultura, música y política (pp. 145-160). Buenos Aires: Ediciones del Centro Cultural de la Cooperación Floreal Gorini.

Hesmondhalgh, David (2015) Por qué es importante la música. Ciudad Autónoma de Buenos Aires: Paidós.

Hill, Rosemary Lucy (2013) Representations and Experiences of Women Hard Rock and Metal Fans in the Imaginary Community (tesis doctoral). Estudios de las mujeres: Universidad de York.

Hill, Rosemary Lucy (2016) Gender, Metal and the Media: Women Fans and the Gendered Experience of Music, Londres: Palgrave Macmillan.

Hjelm, Titus; Kahn-Harris, Keith y Levine, Mark (2011) "Heavy metal as controversy and counterculture", Popular Music History, 6 (1)/6 (2), 5-18.

Hoffstadt, Christian y Nagenborg, Michael (2010) “You're too Fuckin' Metal for Your Own Good! Controlled Anger and the Expression of Intensity and Authenticity in Post-Modern Heavy Metal". En Scott, Nial e Imke Von Helden (eds.) The Metal Void: First Gatherings (pp. 37-46). Oxford: Inter-Disciplinary Press.

Iorio, Ricardo (1992) "Hermética. Ni víctimas ni cambio" (entrevista), Metal.

Iorio, Ricardo (1994a) “Soledad Nativa. Ricardo Iorio habla de Hermética” (entrevista), RNS Magazine, 1 (3), 14-15. 
Iorio, Ricardo (1994b) "Ricardo Iorio. Sin Vaselina” (entrevista), RNS Magazine, 1 (4), 4-7.

Iorio, Ricardo (Octubre de 1993), "Hermética desde el interior" (entrevista), Madhouse Extra, 1 (2)

Janotti Jr., Jeder (1994) Heavy metal: o universo tribal e o espaço dos sonhos (tesis de maestría), Programa de Pós-Graduação em Multimeios, Instituto de Artes, Universidade Estadual de Campinas.

Janotti Jr., Jeder (2004) Heavy Metal com Dendê. Rock pesado e mídia em tempos de globalização. Rio de Janeiro: E-Papers editora.

Janotti Jr., Jeder (2013) "Rock with the devil: Notas sobre géneros e cenas musicais a partir da performatização do feminino no heavy metal", en Pereira de Sá, Simone y Janotti Jr., Jeder (orgs.) Cenas musicais (pp. 73-89). Guararema: Livraria Da Ana.

Jelin, Elizabeth (1985) "Los movimientos sociales en la Argentina contemporánea: una introducción a su estudio", en Jelin, Elizabeth (comp.), Los nuevos movimientos sociales (pp. 13-39). Buenos Aires: Centro Editor de América Latina.

Jelin, Elizabeth (2012) Los trabajos de la memoria. Lima: Instituto de Estudios Peruanos, 2002.

Kahn-Harris, Keith (2000) "'Roots'?: the relationship between the global and the local within the Extreme Metal scene". Popular Music, 19 (1), 13-30.

Kahn-Harris, Keith (2002) “'I Hate This Fucking Country': Dealing with the Global and the Local in the Israeli Extreme Metal Scene", en Young, R. (ed.) Music, Popular Culture, Identities (pp. 133-151). Berkeley: University of California.

Kahn-Harris, Keith (2007) Extreme Metal. Music and Culture on the Edge. Oxford: Berg.

Kahn-Harris, Keith (2011) "Metal Studies: Intellectual Fragmentation or Organic Intellectualism?", Journal for Cultural Research, 15 (3), 251-253, DOI: $10.1080 / 14797585.2011 .594582$

Keightley, Keir (2006) "Reconsiderar al rock", en Frith, Simon; Straw, Will y Street, John. La otra historia del rock (pp. 155-194). Barcelona: Ediciones Robinbook.

Koselleck, R. (2006) Futuro-passado: contribuição à semântica dos tempos históricos. Rio de Janeiro: Contraponto (PUC RIO).

Kreimer, Juan Carlos et al. (1970) Agarrate. Testimonios de la música joven argentina. Buenos Aires: Editorial Galerna. 
Krenske, Leigh y McKay, Jim (2000) “'Hard and heavy”: gender and power in a heavy metal music subculture"; Gender, Place and Culture: A Journal of Femiist Geography; 7 (3), 287-304.

Kropff, Laura (2011) "Los jóvenes mapuche en Argentina: entre el circuito punk y las recuperaciones de tierras", Alteridades, 21 (42), 77-89.

Kimmel, Michael S. "Homofobia, temor, vergüenza y silencio en la identidad masculina”, en Valdés, Teresa y Olavarría, José (eds.) Masculinidad/es. Poder y crisis (pp. 49-62). Santiago de Chile: Isis Internacional, FLACSO Chile.

"Las damas del heavy. Informe especial" (1990), Metal, VII (148).

Laclau, Ernesto. "La construcción del pueblo", en La razón populista (pp. 91-218). Buenos Aires y México: Fondo de Cultura Económica, 2005.

Lamacchia, María (2015) "Música y autogestión”, en Minore, Gito (comp.) Cultura metálica 2: ponencias, debates y exposiciones de la $2^{\circ}$ Feria del Libro Heavy de Buenos Aires (pp. 27-35). Ciudad Autónoma de Buenos Aires: Clara Beter Ediciones.

Lamas, Marta (2013) “Usos, dificultades y posibilidades de la categoría 'género'”, en Lamas, Marta (comp.) El género. La construcción cultural de la diferencia sexual (pp. 327-366). México: M.A. Porrúa, UNAM.

Leite Lopes, Pedro A. (2006) Heavy metal no Rio de Janeiro e dessacralização de símbolos religiosos: a música do demônio na cidade de São Sebastião das terras de Vera Cruz (tesis doctoral). Universidade Federal do Rio de Janeiro, Programa de Pós-graduação em Antropologia Social.

Levine, Lawrence (1988) Highbrow/Lowbrow. The Emergence of Cultural Hierarchy in America. Cambridge (Mass.): Harvard University Press.

Lévi-Strauss, Claude (1995) Antropología estructural. Barcelona: Ediciones Paidós.

López Ramírez Gastón, José I. y Risica Carella, Giuseppe (2019) Espíritu del metal: La Conformación de la Escena Metalera Peruana (1981-1992). Perú: Sonidos latentes producciones.

Lotman, Iuri (1996) La semiosfera I. Semiótica de la cultura y el texto. Madrid: Ediciones Cátedra.

Lovecraft, Howard P. (2012) El horror de Dunwich. Barcelona: Libros del Zorro Rojo.

Lull, James (1985) "On the communicative properties of music", Communication Research. Sage Journals, 12 (3), 363-372. 
Lull, James (1987a) "Popular Music and Communication: An Introduction", en Lull, James (ed.) Popular music and communication (pp. 10-35). Londres: Sage Publications.

Lull, James (1987b) “Listeners's Communicative Uses of Popular Music·, en Lull, James (ed.) Popular music and communication (pp. 140-174). Londres: Sage Publications.

Lunardelli, Laura. (2002) Alternatividad, divino tesoro. El rock argentino en los 90. Buenos Aires: Biblos.

Lvovich, Daniel. (2003) Nacionalismo y antisemitismo en la Argentina. Buenos Aires: Javier Vergara Editor.

Mancusi, Diego (14 de julio 2016) "Iorio se corta solo", Rolling Stone. Recuperado de: https://www.lanacion.com.ar/1918368-iorio-se-corta-solo

Mandrini, Raúl (1987), "La sociedad indígena de las pampas en el siglo XIX”, en Lischetti, M. (ed.) Antropología (pp. 309-36). Buenos Aires: Eudeba.

Mandrini, Raúl (1993), 'Guerra y paz en la frontera bonaerense durante el siglo XVIII', Ciencia Hoy, 4 (23), 26-35

Manzano, Valeria (2011) “Tiempos de contestación: cultura del rock, masculinidad y política, 1966-1975”. En Elizalde, Silvia (coord.) (2011) Jóvenes en cuestión: configuraciones de género y sexualidad en la cultura (pp. 23-57). Buenos Aires: Biblos.

Marafioti, Roberto (2008), "La comunicación de masas desde las críticas al sistema”, en Sentidos de la comunicación. Teorías y perspectivas sobre cultura y comunicación. (2da. Edición) (pp. 181-232). Buenos Aires: Biblos.

Marchi, Sergio (2014) El rock perdido. De los hippies a la cultura chabona. Ciudad Autónoma de Buenos Aires: Booket.

Márquez, Nicolas y Laje, Agustín (2016) El libro negro de la nueva izquierda. Ideología de género o subversión cultural. Buenos Aires: Unión Editorial.

Martín, Eloísa (2011) "La cumbia villera y el fin de la cultura del trabajo en la Argentina de los 90", en Semán, Pablo y Vila, Pablo. Cumbia: nación, etnia y género en Latinoamérica (pp. 209-244). Buenos Aires: Gorla, Facultad de Periodismo de la Universidad Nacional de La Plata.

Martín, María Victoria (2003) “Diásporas de sentido en torno a la cultura mediática”, en Saintout, Florencia (ed.) Abrir la comunicación. Tradición y movimiento en el 
campo académico (pp. 157-176). La Plata: Ediciones de Periodismo y Comunicación.

Martín-Barbero, Jesús (1987) "Retos a la comunicación en América Latina”, en Procesos de comunicación y matrices de cultura. Itinerario para salir de la razón dualista (pp. 99-114). México: Gustavo Gili.

Martín-Barbero, Jesús (1988) Procesos de comunicación y matrices de cultura. Itinerario para salir de la razón dualista. México: Gustavo Gili.

Martín-Barbero, Jesús (1991) De los medios a las mediaciones. Comunicación, cultura y hegemonía. México: Gustavo Gili, 1987.

Martín-Barbero, Jesús (1996) "Comunicación fin de siglo: para dónde va nuestra investigación", en Telos, 47.

Martínez, Ana Teresa (2013) "Intelectuales de provincia: entre lo local y lo periférico", Prismas. Revista de historia intelectual, 17, 169-180.

Martínez, Gabriel (Julio 2015) "6 de los festivales más importantes de Rock en Latinoamérica", A 33 Revoluciones en el Rock. Recuperado de: http://a33revoluciones.com/6-de-los-festivales-mas-importantes-de-rock-enlatinoamerica/

Martínez García, Silvia (1997) “El heavy metal a Barcelona: aportacions a l'estudi d'una música popular", Revista d'etnologia de Catalunya, 120-123.

Martínez García, Silvia (1999) Enganxats al heavy. Música, cultura i trangressió. Lleida: Pagès.

Martínez García, Silvia (2003) "Decibelios y testosterona: una aproximación a las imágenes de género en el rock y el heavy metal”, Dossiers feministes, 101-117.

Martínez García, Silvia (2004) “Heavies: ¿una cultura de transgresión?”, Revista de estudios de Juventud. De las tribus urbanas a las culturas juveniles, 64, 75-86.

Martínez García, Silvia (2006) "La production de genres: analyses depuis les périphéries du heavy metal”, Volume !, 5 (2), 91-113.

Masciandaro, Nicola (2011) "Metal Studies and the Scission of the Word: A Personal Archaeology of Headbanging Exegesis", Journal for Cultural Research, 15 (3), 247-250.

Maxwell, Ian (2002) “The curse of fandom: insiders, outsiders and ethnography”, en Hesmondhalgh, David y Negus, Keith (eds.) Popular Music Studies (pp. 103142). Londres: Arnold. 
Mayer, Adam y Timberlake, Jeffrey (2014) “'The Fist in the Face of God': Heavy Metal Music and Decentralized Cultural Diffusion”, Sociological Perspectives, 57 (1), 27-51.

Mendívil, Julio (2016) En contra de la música: herramientas para pensar, comprender $y$ vivir las músicas. Ciudad Autónoma de Buenos Aires: Gourmet Musical Ediciones.

Mendívil, Julio y Spencer Espinosa, Christian (2016) "Epilogue. Reconsidering Music Scenes from a Latin American Perspective". En Mendívil, Julio y Spencer Espinosa, Christian (eds.) Made in Latin American. Studies in Popular Music (pp. 160-164). Nueva York: Routledge.

Metalica Fanzine (Abril 2016), 30 (79), Capital Federal.

Miguélez, Miguel M. (2007) “Conceptualización de la transdisciplinariedad”, Polis. Revista Latinoamericana, 16.

Miguez, Daniel y Seman, Pablo. (2006) Entre santos, cumbias y piquetes. Las culturas populares en la Argentina reciente. Buenos Aires: Biblos.

Mileo, Julian (2017a) "Ricardo Iorio: 'un puñado de indemnizados, de desaparecidos, por destruir nuestra nación, son superiores"”, Revista Soy Rock, 13 de julio de 2017. Recuperado de: https://revistasoyrock.com.ar/noticia/un-punado-deindemnizados-de-desaparecidos-por-destruir-nuestra-nacion-son-superiores/

Mileo, Julian (2017b) "Iorio se juntó con el dirigente neonazi Alejandro Biondini”, Revista Soy Rock, 18 de agosto de 2017. Recuperado de: https://revistasoyrock.com.ar/noticia/iorio-se-junto-con-biondini/

Millet, Kate. (1975) Política Sexual. México: Aguilar.

Minore, Gito (comp.) (2014) Cultura metálica. Ponencias, debates y exposiciones de la $1^{\circ}$ Feria del Libro Heavy de Buenos Aires, Ciudad Autónoma de Buenos Aires: Clara Beter Ediciones.

Minore, Gito (2014) “Cultura metálica”, en Minore, Gito (comp.) Cultura metálica. Ponencias, debates y exposiciones de la $1^{\circ}$ Feria del Libro Heavy de Buenos Aires (pp. 7-13), Ciudad Autónoma de Buenos Aires: Clara Beter Ediciones.

Minore, Gito (2014) “La recepción de Iorio en la academia” (entrevista), en Minore, Gito (comp.) Cultura metálica. Ponencias, debates y exposiciones de la $1^{\circ} \mathrm{Feria}$ del Libro Heavy de Buenos Aires (pp. 23-38), Ciudad Autónoma de Buenos Aires: Clara Beter Ediciones. 
Minore, Gito (comp.) (2015) Cultura metálica 2. Ponencias, debates y exposiciones de la $2^{\circ}$ Feria del Libro Heavy de Buenos Aires, Ciudad Autónoma de Buenos Aires: Clara Beter Ediciones.

Minore, Gito (2015) "Reafirmado nuestro sentir y pensar", en Minore, Gito (comp.) Cultura metálica 2. Ponencias, debates y exposiciones de la $2^{\circ}$ Feria del Libro Heavy de Buenos Aires (pp. 7-11), Ciudad Autónoma de Buenos Aires: Clara Beter Ediciones.

Minore, Gito (comp.) (2016) Cultura metálica 3. Ponencias, debates y exposiciones de la $3^{\circ}$ Feria del Libro Heavy de Buenos Aires, Ciudad Autónoma de Buenos Aires: Clara Beter Ediciones.

Minore, Gito (comp.) (2017) Cultura metálica 4. Ponencias, debates y exposiciones de la $4^{\circ}$ Feria del Libro Heavy de Buenos Aires, Ciudad Autónoma de Buenos Aires: Clara Beter Ediciones.

Minore, Gito (2017) “Ampliando horizontes”, en Minore, Gito (comp.) Cultura metálica 4. Ponencias, debates y exposiciones de la $4^{\circ}$ Feria del Libro Heavy de Buenos Aires (pp. 7-9), Ciudad Autónoma de Buenos Aires: Clara Beter Ediciones.

Minore, Gito (Septiembre 2017) "Los delirios del defacto. Iorio, Biondini y banalidad", Nan, 1780. Recuperado de: http://anan.com.ar/iorio-biondini-heavymetal/

Molyneaux, Maxine (2002) "Ni Dios, Ni Patrón, Ni Marido. Feminismo anarquista en la Argentina del siglo XIX." La voz de la mujer. Periódico comunista anárquico (2da. ed.) (pp. 11-40). Buenos Aires: Universidad Nacional de Quilmes.

Montanero Vico, Luis. (2005) "The new wave of british heavy metal. Desarrollo, expansión y muerte de un movimiento juvenil", Ex novo: revista d'història $i$ humanitats 2. Barcelona: Comitia Rei Novae, 123-139.

Morandini, Marcelo M. (2016) Metal Pesado Argentino: historia de una contracultura durante la Argentina Menemista. Ciudad Autónoma de Buenos Aires: El autor.

Morandini, Marcelo M. (2017) “Las fotos, las grietas, y los desafíos latentes” (ensayo). Recuperado de: https://eieshm.wordpress.com/2017/08/22/las-fotos-las-grietasy-los-desafios-latentes/

Mux, Damián Andrés (2016) "En el Siglo del gran reviente: construcciones identitarias a partir del Metal Pesado en los jóvenes marplatenses" (ponencia). $1^{\circ}$ Jornadas de Estudios Sociales de la Música, Facultad de Trabajo Social, Universidad 
Nacional de La Plata. Recuperado de: http://sedici.unlp.edu.ar/bitstream/handle/10915/56667/Documento_completo__ pdf-PDFA.pdf?sequence $=1$

Nicolás Alba, María del Carmen (2016) La Narrativa Indigenista en Argentina (tesis doctoral). Departamento de Español y Portugués, Universidad de Arizona. Recuperada de: http://hdl.handle.net/10150/605110

Ochoa, Ana María (2002) "El desplazamiento de los discursos de autenticidad: Una mirada desde la música”, Trans. Revista Transcultural de Música, 6, junio 2002. Recuperado de: https://www.redalyc.org/articulo.oa?id=82200608

Palihue (5 de mayo 2016) “"Malón’ frenó un recital en Bahía Blanca para proteger a hijos descuidados por algunos espectadores", Diario Lider, Trenque Lauquen. Recuperado de: http://diariolider.medios.com.ar/noticia/56/malon-freno-unrecital-en-bahia-blanca-para-proteger-a-hijos-descuidados-por-alg

Palkowski, Germán (2017) "Presa fácil: Ricardo Iorio y el malestar en la cultura" (ensayo). Recuperado de: https:/eieshm.wordpress.com/2017/08/28/presa-facilricardo-iorio-y-el-malestar-en-la-cultura/

Panzini, Ariel (2018) Heavy metal argentino: la clase del pueblo que no se rindió: análisis y diagnóstico del movimiento metalero argentino para la construcción de un marco teórico de entendimiento. Ciudad Autónoma de Buenos Aires: Clara Beter Ediciones.

Pascuchelli, María Natalia (2012) "Las performances Rock como ámbito de construcción de identidades. Los jóvenes seguidores de V8 en Argentina" (ponencia), en VII Jornadas de Sociología. Universidad Nacional de General Sarmiento. Recuperado de: http://www.ungs.edu.ar/ms_ici/wpcontent/uploads/2012/11/Pascuchelli-Mar\%C3\%ADa-Natalia.pdf

Pascuchelli, María Natalia (2014) Avatares metaleros. Procesos de resignificación del "ser metalero" en jóvenes asociados al universo evangélico del Área Metropolitana de Buenos Aires (tesis de maestría). Centro Argentino de Etnología Americana. Área Transdepartamental de Folklore. Universidad Nacional del Arte.

Pascuchelli, María Natalia (2016) "Elaboración poética en las canciones de V8. Narrativa Creencia e identidad" (ponencia). $1^{\circ}$ Jornadas de Estudios Sociales de la Música, Facultad de Trabajo Social, Universidad Nacional de La Plata. Recuperada de: 
http://sedici.unlp.edu.ar/bitstream/handle/10915/56619/Documento_completo pdf-PDFA.pdf?sequence $=1$

Pasolini, Ricardo (2013) "La historia intelectual desde su dimensión regional: algunas reflexiones", Prismas. Revista de historia intelectual, 17, 187-192

Pease, Allan y Pease, Barbara (2007) El lenguaje del cuerpo. Barcelona: Amat Editorial.

Perón, Juan Domingo (1958) Los vendepatria. Las pruebas de una traición. Buenos Aires: Editorial Liberación.

Pisano, Juan Ignacio (2016) "La pasión y la ética: un lugar para la palabra y la tradición en las letras de Iorio", en Scaricaciottoli, Emiliano (comp.) Se nos ve de negro vestidos (pp. 93-111). Ciudad Autónoma de Buenos Aires: La Parte Maldita.

Pisano, Juan Ignacio (2017) "Heavy metal nacional: cómo matar al padre", Código y frontera, UBA-CBC. Recuperado de: http://www.codigoyfrontera.space/2017/10/06/heavy-metal-nacional-comomatar-al-padre/

Pisano, Juan Ignacio (2018) "Voces irreverentes profanan. Mutantes y enmascarados asaltan el tesoro de los cielos", en Scaricaciottoli, Emiliano (comp.) Parricidas: mapa rabioso del metal argentino contemporáneo (pp. 153-183). Ciudad Autónoma de Buenos Aires: La Parte Maldita.

Pizarnik, Alejandra (2009) La condesa sangrienta. Barcelona-Madrid: Libros del Zorro Rojo, 1966.

Plano, Eduardo R. (2011)... Y metales brillan al sol. Las estrategias discursivas de la música heavy metal en Argentina: una aproximación a su construcción ideológica (1981-1995) (tesina de licenciatura) Escuela de Comunicación Social, Facultad de Relaciones Internacionales, Universidad Nacional de Rosario.

Plesch, Melanie (2013) "Demonizing and redeeming the gaucho: social conflict, xenophobia and the invention of Argentine national music", Patterns of Prejudice, 2013, 47 (4-5), 337-358.

Poleto Dos Santos, Ivison (2013) “A utilização da Historia como temática para canções populares: caso do Heavy Metal", en Vargas, Herom (ed.) Enfoques interdisciplinarios sobre músicas populares en Latinoamérica: retrospectivas, perspectivas, críticas y propuestas. Actas del X Congreso de la IASPM-AL (pp. 99-110). Montevideo: IASPMAL/CIAMEN (UdelaR). 
Provéndola, Juan Ignacio (2015) Rockpolitik: 50 años de rock nacional y sus vínculos con el poder político. Ciudad Autónoma de Buenos Aires: Eudeba.

Pujol, Sergio A. (2007a) Las ideas del rock: genealogía de la música rebelde. Rosario: Homo Sapiens.

Pujol, Sergio A. (2007b) "La anunciación del rock. Identidad, divino tesoro", en Tram[p]as de la Comunicación y la Cultura, 52, 14-20.

Pujol, Sergio A. (2013) Rock y Dictadura (3ra. Edición). Buenos Aires: Booket, 2005.

Rafanelli, Cristina (2015) “Aleister Crowley: ¿Mago o demonio? Una leyenda del rock", en Minore, Gito (comp.) Cultura metálica 2. Ponencias, debates y exposiciones de la $2^{\circ}$ Feria del Libro Heavy de Buenos Aires (pp. 97-102), Ciudad Autónoma de Buenos Aires: Clara Beter Ediciones,.

Ratier, Hugo (2009) Poblados bonaerense. Vida y milagros. Buenos Aires: La Colmena.

Reina Rodríguez, Carlos Arturo (2009) Bogotá: Mucho más que pesado, Metal con historia. Bogotá: Ediciones Letra Oculta.

Regev, Motti (2013) Pop-rock music. Gran Bretaña: Polity Press.

Remedi, Roberto Antonio (2010) "Medios, clase y género en el contexto de los productores y públicos heavy metals de Santiago del Estero en los años'80 y '90”, en Gutiérrez, Edgardo (comp.). Rock del país: estudios culturales de rock en Argentina (1ra. Ed.) (pp. 39-56). San Salvador de Jujuy: Universidad Nacional de Jujuy. Universitaria de Jujuy. Facultad de Humanidades y Ciencias Sociales.

Resistiré fanzine (2017), 20 (37), Bahía Blanca.

Reynolds, Simon (2012) Retromanía: la adicción del pop a su propio pasado. Buenos Aires: Caja Negra.

Ribeiro, Hugo L. (2007) Dinâmica das identidades: análise estilística e contextual de três bandas de Metal da cena Rock Underground de Aracaju (tesis de doctorado), Escola de Música, Universidade Federal da Bahia.

Ribeiro, Hugo L. (2010) Da Fúria à Melancolia: a dinâmica das identidades na cena rock underground de Aracaju. São Cristóvão: Editora UFS; Aracaju: Fundação Oviêdo Teixeira.

Riches, Gabby; Lashua, Brett y Spraklen, Karl (2014) "Female, Mosher, Transgressor: A 'Moshography' of Transgressive Practices within the Leeds Extreme Metal Scene", IASPM Journal, 4 (1), 87-100. 
Riesman, David (1950) "Listening to Popular Music", American Quarterly, 2 (4), 359371.

Rivera-Segarra, Eliut; Mendoza, Sigrid y Varas-Díaz, Nelson (2015) "Entre el orden y el caos: El papel del mosh en la comunidad metalera de Puerto Rico". Revista de Ciencias Sociales, 28, 104-121.

Roccor, Bettina (1998) Heavy Metal: Kunst, Kommerz, Ketzerei. IP Verlag Jeske, Berlin.

Rodríguez, Javier A. (2017) "De Pacheco a la Paternal, de Dock Sud a Tres de Febrero: una aproximación cuantitativa al fenómeno del heavy metal en la sociedad argentina", en Minore, Gito (comp.) Cultura metálica 4: ponencias, debates y exposiciones de la $4^{\circ}$ Feria del Libro Heavy de Buenos Aires (pp. 29-36). Ciudad Autónoma de Buenos Aires: Clara Beter Ediciones.

Rosas Pineda, Karla L. (2013) “Genealogía de los estudios culturales”, Razón y Palabra. Comunicación y derechos humanos, 81. Recuperado de: http://www.razonypalabra.org.mx/N/N81/V81/26_Rosas_V81.pdf

Rozitchner, Alejandro (2003) Escuchá qué tema. La filosofía del rock nacional. Buenos Aires: Planeta.

Rubio, Salva (2011) Metal Extremo. 30 años de oscuridad (1981-2011). Lleida: Editorial Milenio.

Samiguel, Diego (2011) "Una música demasiado pesada para la báscula de la nación" (ponencia). V Jornadas de Política y Cultura, Escuela de Ciencias de la Información, Universidad Nacional de Córdoba.

Said, Edward (1990) "Figures, configurations, transfigurations", Race \& Class, 32 (1), $1-16$.

Said, Edward (1996) Representaciones del intelectual. Barcelona: Ediciones Paidós Ibérica, 1994.

Saintout, Florencia (2003a) "La nominación del campo de estudios de comunicación. Notas para reconstruir un proceso de institucionalización", en Saintout, Florencia (ed.) Abrir la comunicación. Tradición y movimiento en el campo académico (pp. 19-27). La Plata: Ediciones de Periodismo y Comunicación.

Saintout, Florencia (2003b) "La ruptura. Un campo en movimiento", en Saintout, Florencia (ed.) Abrir la comunicación. Tradición y movimiento en el campo académico (pp. 75-85). La Plata: Ediciones de Periodismo y Comunicación. 
Salerno, Daniel (2008) "La autenticidad al palo: los modos de construcción de las alteridades rockeras", Oficios Terrestres, 23, 128-138.

Salerno, Daniel y Silba, Malvina (2005) “Guitarras, pogo y banderas: el 'aguante' en el rock" (ponencia), VI Congreso de la Rama Latinoamericana de la IASPM-AL, Buenos Aires.

Salerno, Daniel y Silba, Malvina (2006) "Juventud, identidad y experiencia: las construcciones identitarias populares urbanas". Revista Question, 1 (10). La Plata: Facultad de Periodismo y Comunicación Social. Recuperado de: https://perio.unlp.edu.ar/ojs/index.php/question/article/view/1103/981

Salmerón Infante, Miguel (2015) "Satán negro y Lucifer blanco: el diablo en el blues", Herejía y belleza: Revista de estudios culturales sobre el movimiento gótico, 3 , 129-140.

Sánchez Mondaca, Maximiliano (2007) Thrash metal: del sonido al contenido. Origen y gestación de una contracultura (tesis de grado), Departamento de Sociología, Facultad de Ciencias Sociales, Universidad de Chile.

Sánchez Mondaca, Maximiliano (2014) Thrash Metal: del sonido al contenido. Origen y gestación de una contracultura chilena. Santiago de Chile: RIL editores.

Sánchez Trolliet, Ana (2017) “'Haciendo el amor en la cocina': mujeres, espacio doméstico y cultura rock en los tempranos ochenta", Cuadernos de Música, Artes Visuales y Artes Escénicas, 13 (1), 85-102

Santos Maynard, Dilton Cândido (2013) “A rede ao sul da América: um ensaio sobre a argentina e a extrema-direita na internet (1996-2007)", Boletim do Tempo Presente, 4, 1-22.

Scaricaciottoli, Emiliano (comp.) (2016) Se nos ve de negro vestidos: siete enfoques sobre el heavy metal argentino. Ciudad Autónoma de Buenos Aires: La Parte Maldita.

Scaricaciottoli, Emiliano (2017) "Vivir sin los padres, dilema del metal criollo", Andén, 87. Recuperado de: http://andendigital.com.ar/2017/03/vivir-sin-los-padresdilema-del-metal-criollo-anden-87/

Scarrone, Luciano (2016) "Violencia de género. El heavy metal argentino en el mercado de la música”, en Scaricaciottoli, Emiliano (comp) Se nos ve de negro vestidos: siete enfoques sobre el heavy metal argentino (pp. 35-50). Ciudad Autónoma de Buenos Aires: La Parte Maldita. 
Schechner, Richard (2011) "Restauración de la conducta", en Taylor, Diana y Fuentes, Marcela (2011) Estudios avanzados de performance (pp. 31-49). México D.F.: Fondo de Cultura Económica.

Schmucler, Héctor (1984) “Un proyecto de comunicación cultura”, en Comunicación y Cultura, 12, 3-8.

Scott, Niall (2012) “The International Society for Metal Music Studies.”, Volume !, 9 (2), 205-206. Recuperado de: http://www.cairn.info/revue-volume-2012-2-page205.htm

Scott, Niall_(2013) "Heavy metal and the deafening threat of the apolitical", en Hjelm, Titus; Kahn-Harris, Keith y LeVine, Mark (eds.) Heavy metal. Controversies and countercultures (pp. 229-243). Bristol: Equinox Publishing Ltd..

Scott, Niall y Von Helden, Imke (eds.) (2010) The Metal Void: First Gatherings. InterDisciplinary Press: Oxford.

Spracklen, Karl; Brown, Andy R. y Kahn-Harris, Keith (2011) "Metal Studies? Cultural Research in the Heavy Metal Scene”, Journal for Cultural Research, 15 (3), 209-212.

Semán, Pablo y Vila, Pablo (1999) "Rock chabón e identidad juvenil en la Argentina neo-liberal". En AA.VV. Los noventa. Política, sociedad y cultura en América Latina y Argentina de fin de siglo (pp. 225-258). Buenos Aires: Eudeba.

Semán, Pablo; Vila, Pablo y Benedetti, Cecilia (2011), "Neo-liberalism and rock in the popular sectors of contemporary Argentina", en Pacini Hernandez, D.; Fernández L’Hoeste, H. D. y Zolov, E. (eds.) Rockin' las Américas: The Global Politics of Rock in Latin/o America (pp. 261-98). Pittsburgh: University of Pittsburgh, Digital Research Library.

Semán, Pablo (2006) “El pentecostalismo y el 'rock chabón’ en la transformación de la cultura popular", en Miguez, Daniel y Seman, Pablo. Entre santos, cumbias y piquetes. Las culturas populares en la Argentina reciente (pp. 197-219). Buenos Aires: Biblos.

Semán, Pablo (2006) Bajo continuo. Exploraciones descentradas sobre cultura popular y masiva. Buenos Aires: Gorla.

Setton, Damián (2016) “Jasidismo, cábala y rock en el proyecto musical de Atzmus", Alteridades, 25 (51), 96-107.

Shuker, Roy (2009) Rock total. Todo lo que hay que saber. Barcelona: Ediciones Robinbook. 
Silva, Wlisses James de Farias (2014) Heavy metal no Brasil: os incômodos perdedores (década de 1980) (tesis de doctorado), Programa de Pós-Graduação en História Social, Faculdade de Filosofia, Letras e Ciências Humanas, Universidade de São Paulo.

Silva Da Silva, Bernard A. y Silva de Oliveira, Franknaldo (2013) "Por uma história social do Heavy Metal na Amazônia: o caso de Belém do Pará”, VARGAS, HEROM, et al. (eds.) Enfoques interdisciplinarios sobre músicas populares en Latinoamérica: retrospectivas, perspectivas, críticas y propuestas. Actas del X Congreso de la IASPM-AL (pp. 78-79). Montevideo: IASPMAL/CIAMEN (UdelaR).

Simonetto, Patricio (2016). "La moral institucionalizada. Reflexiones sobre el Estado, las sexualidades y la violencia en la Argentina del siglo XX”, e-l@tina 14 (55), abril-junio 2016, 1-22.

Spracklen, Karl, Brown, Andy y Kahn-Harris, Keith (2011) "Metal Studies? Cultural Research in the Heavy Metal Scene”, Journal for Cultural Research, 15 (3), 209-212, DOI: http://dx.doi.org/10.1080/14797585.2011.594578

Straw, Will (1991) "Systems of Articulation, Logics of Change: Scenes and Communities in Popular Music", Cultural Studies, 5 (3), 368-388.

Straw, Will (1993) “Characterizing Rock Music Culture: The Case of Heavy Metal”, en DURING, S. (ed.) The Cultural Studies Reader, Routledge, London, pp. 368381.

Straw, Will (1996) "Scenes and Communities in Popular Music.", en Gelder, Ken y Thornton, Sarah (eds.) The Subcultures Reader (pp. 494-505). Londres: Routledge.

Straw, Will (2002) 'Scenes and sensibilities', Public, 22/23, 245-257.

Straw, Will (2004)“Cultural Scenes”, Loisir et société/Society and Leisure, 27 (2), 411-422.

Straw, Will (2013) “Cenas Culturais e as consequências imprevistas das políticas públicas”, en Pereira de Sá, Simone y Janotti Jr., Jeder (orgs.) Cenas musicais (pp. 9-23). San Pablo: Anadarco.

Svampa, Maristella (2000) "Identidades astilladas. De la Patria Metalúrgica al Heavy Metal", en Svampa, M. (comp.) Desde Abajo. La transformación de las identidades sociales (pp. 121-155). Buenos Aires: Biblos. 
Tajfel, Henri (1984) Grupos humanos y categorías sociales. Barcelona: Editorial Herder.

Tajfel, Henri, y Turner, John C. (2004) "The Social Identity Theory of Intergroup Behavior", en Jost, J. T. y Sidanius, J. (eds.) Key readings in social psychology. Political psychology: Key readings (pp. 276-293). Nueva York: Psychology Press.

Torreiro, Gustavo. (2016) "El heavy en la Argentina como subcultura: identidad y resistencia", en Scaricaciottoli, Emiliano (comp) Se nos ve de negro vestidos: siete enfoques sobre el heavy metal argentino (pp. 19-34). Ciudad Autónoma de Buenos Aires: La Parte Maldita.

Torres, Ariel O. (2012) El perro Cristiano. Buenos Aires: el autor, 2008.

Thorne, Stephen B. y Himelstein, Philip (1984) "The Role of Suggestion in the Perception of Satanic Messages in Rock and Roll Recordings", Journal of Psychology, 11 (6), 245-248.

Thompson, Kenneth (2014) Pánicos morales. Bernal: Universidad Nacional de Quilmes.

Ulloa Brenes, Gilbert (2013) "La blasfemia como resistencia en la canción Raza odiada", Cuadernos Inter.c.a.mbio, Año 10, 10 (2), 149-173.

Ulloa Brenes, Gilbert (2014). "Esbozo metodológico cualitativo para el estudio de objetos artísticos desde consideraciones éticas y estéticas en dos expresiones de la cultura Heavy Metal” (ponencia), Actas IV Encuentro Latinoamericano de Metodología de las Ciencias Sociales, 27 al 29 de agosto de 2014, Heredia, Costa Rica, Ensenada: Facultad de Humanidades y Ciencias de la Educación. Universidad Nacional de La Plata. Recuperado de: http://www.memoria.fahce.unlp.edu.ar/trab_eventos/ev.8284/ev.8284.pdf

Urban, Greg (2001). Metaculture: How Culture Moves Through the World. Minneapolis: University of Minnesota Press.

Varas-Díaz, Nelson y Scott, Niall (2016) "Heavy Metal Music and the Communal Experience. An Introduction", en Varas-Díaz, Nelson y Scott, Niall (eds.) Heavy metal music and the comunal experience (pp. vii-xiii). Londres: Lexington Books

Varas-Díaz, Nelson; Mendonza, Sigrid y Morales, Eric (2016) "Porous Communities. Critical Interactions Between Metal Music and Local Culture in the Caribbean 
Context”, en Varas-Díaz, Nelson y Scott, Niall (eds.) Heavy metal music and the comunal experience (pp. 101-123). Londres: Lexington Books.

Vattimo, Giani (1994) “Posmodernidad: ¿una sociedad transparente?”, en Vattimo, Giani y otros. En torno a la Posmodernidad (pp. 9-19). Bogotá: Editorial Anthropos.

Vidal Vargas, Pablo (2016) "El metal extremo como fenómeno de vinculación local e internacional". $1^{o}$ Jornadas de Estudios Sociales de la Música, Facultad de Trabajo Social, Universidad Nacional de La Plata. Recuperado de: http://sedici.unlp.edu.ar/bitstream/handle/10915/56669/Documento_completo.pd f-PDFA.pdf?sequence $=1$

Vila, Pablo (1985) “Rock Nacional. Crónicas de la resistencia juvenil”, en Jelin, Elizabeth (comp.), Los nuevos movimientos sociales (pp. 8-12). Buenos Aires: Centro Editor de América Latina.

Vila, Pablo (1987) “Tango, folklore y rock : apuntes sobre música, política y sociedad en Argentina”, Cahiers du monde hispanique et luso-brésilien, $n^{\circ} 48$, Musiques populaires et identités en Amérique latine, 81-93.

Vila, Pablo (1989) “Argentina's 'Rock Nacional': The struggle for meaning, Latin American Music Review / Revista de Música Latinoamericana, 10 (1), 1-28.

Vila, Pablo (1992), "Rock national and dictatorship in Argentina”, Popular Music, 6 (2), 129-148.

Vila, Pablo (1997) "John Shepherd y Peter Wicke: Music and Cultural Theory” (reseña de Music and cultural theory, por John Shepherd y Peter Wicke), en Trans. Revista transcultural de música, 4. Recuperado de: https://www.sibetrans.com/trans/article/258/john-shepherd-y-peter-wicke-musicand-cultural-theory

Villalobos Albornoz, Omar y Miranda González, Alfredo (2011) Entre cuerdas de metal. Etnografia del metal en la provincia de Iquique. FNDR.

Villalobos Albornoz, Omar (2015) “'Pampa endiablada’ y extreme metal: sociología visual y hermenéutica del diseño, Revista de Estudios Cotidianos - NESOP, 3 (1), 253-286.

Villarino, Julio y Bercovich, Fernando (2014) Atlas Cultural de la Argentina. Buenos Aires: Secretaría de Cultura de la Presidencia de la Nación.

Violante, Andrés (Julio 2014) Efecto Metal Especial. Hermética. iiSigue Vivo!!!, 2 (2).

Violante, Andrés (2015) Hermética, las fotos. Villa Domínico: Dama Editora. 
Vitagliano, Miguel (2012) "Prólogo", en VITAGLIANO, Miguel. Boedo. Políticas del Realismo (pp. 9-11). Buenos Aires: Título.

Viteri Morejón, Juan Pablo (2011) Música y globalización. Hardcore y metal en el Quito del siglo XXI (tesis de maestría) Programa de Antropología. FLACSO, Sede Ecuador.

Vokey, John R. y READ, John D. (1985) "Subliminal Messages: Between the Devil and the Media", American Psychologist, 40 (11), 1231-1239.

Wallach, Jeremy; Berger, Harris M. y Greene, Paul D. (eds.) (2011) Metal rules the globe. Heavy metal music around the world. Estados Unidos: Duke University Press.

Wallach, Jeremy et al. (2011) "Affective overdrive, scene dynamics, and identity in the global metal scene", en Wallach, Jeremy et al. (eds.) Metal rules the globe. Heavy metal music around the world (pp. 3-33). Estados Unidos: Duke University Press.

Wallach, Jeremy y Levine, Alexandra (2013) "I want you to support local metal. A theory of metal scene formation", en Hjelm, Titus; Kahn-Harris, Keith y LeVine, Marc (eds.) Heavy metal. Controversies and countercultures. (pp. 117-135). Reino Unido: Equinox Publishing Ltd.

Walser (2014) Running with the Devil: Power, Gender, and Madness in Heavy Metal Music. Estados Unidos: Wesleyan University Press, 1993.

Wanamaker, Catherine E. y Reznikoff, Marvin (1989) "Effects of Aggressive and NonAggressive Rock Songs on Projective and Structured Tests", Journal of Psychology, 123 (6), 561-570.

Weinstein, Deena (2000) Heavy metal. The Music and Its Culture (revised edition). United States: Da Capo Press, 1991.

Weinstein, Deena (2011a) “How Is Metal Studies Possible?”, Journal for Cultural Research, 15 (3), 243-245, DOI: 10.1080/14797585.2011.594580

Weinstein, Deena (2011b) “The globalization of metal”, en Wallach, Jeremy et al. (eds.) (2011) Metal rules the globe. Heavy metal music around the world (pp. 34-59). Estados Unidos: Duke University Press.

Weinstein, Deena (2016a) "Reflections on Metal Studies", en Brown, Andy; Spracklen, Karl; Khan-Harris, Keith; Scott, Niall (eds.) Global Metal Music and Culture. Current Directions in Metal Studies (pp. 22-31). New York: Routledge. 
Weinstein, Deena (2016b) "Player with gender in the key of metal", en Heesch, Florian y Scott, Niall. Heavy Metal, Gender and Sexuality: Interdisciplinaries Approaches (e-book). Abingdon: Routledge, pp. 39-61.

Willis, Paul E. (2014) Profane culture. Reino Unido: Princeton University Press, 1978.

Yépez Aguirre, Jimmy Renzo (2013) "Política cultural neoliberal y la música heavy metal en la ciudad de Huánuco, Perú, 1990-2010”, Investigaciones sociales 17 (30), 279-290.

Young, Jack (2011) "El pánico moral. Su origen en la Resistencia, el ressentiment y la traducción de la fantasía en realidad", Delito y sociedad: revista de ciencias sociales, 31, 1-2.

Zapiola, Carolina (2007) "Niños en las calles: Imágenes literarias y representaciones oficiales en la Argentina del Centenario", en Gayol, Sandra y Madero, Marta (eds.) Formas de historia cultural (pp. 305-332). Buenos Aires: Prometeo Libros; Los Polvorines: Universidad Nacional de General Sarmiento.

Zona de obras (2005) Diccionario de heavy metal latino (España y Latinoamérica). Madrid: Zona de obras. 


\section{Discografía}

2 Minutos (1994) "Ya no sos igual”, Valentín Alsina [CD] Buenos Aires: Polydor Aleación [Disco] (1985). Buenos Aires: Umbral.

Almafuerte (1996) "Rubén Patagonia”, Del entorno [CD] Buenos Aires: DBN.

Almafuerte (1996) "Los delirios del defacto", Del entorno [CD] Buenos Aires: DBN.

Almafuerte (1998) “Almafuerte”, Almafuerte [CD] Buenos Aires: Interdisc.

Almafuerte (1999) "Convide rutero", A fondo blanco [CD] Buenos Aires: Interdisc.

Almafuerte (1999) "El visitante", A fondo blanco [CD] Buenos Aires: Interdisc.

Almafuerte (2001) "Cumpliendo mi destino", Piedra libre [CD] Buenos Aires: Interdisc.

Almafuerte (2006) “Donde está mi corazón”, Toro y Pampa [CD] Buenos Aires: Dejesú.

Almafuerte (2006) “Toro y Pampa”, Toro y Pampa [CD] Buenos Aires: Dejesú.

Aonikenk (2014) Sentir metalero [CD] Buenos Aires: Ícarus Music.

Avernal (2011) Réquiem para los rebeldes/Necrología Parte 1 [Digital] Buenos Aires:

Dont Pay Music

Deep Purple (1971) Fireball [Disco] Reino Unido: Harvest Records.

De la Tierra (2014) De La Tierra [CD] Los Ángeles: Roadrunner Records.

De la Tierra (2016) De La Tierra II [CD] California: Sony Music Latin.

Guarany, Horacio (1972) "Si se calla el cantor".

Güemes (2017) Güemes y los infernales [Digital]

Helker (2013) En algún lugar del círculo. Alemania: AFM Records.

Helker (2013) Somewhere in the circle. Alemania: AFM Records.

Hermética (1989) Hermética [Disco] Buenos Aires: Radio Tripoli Discos.

Hermética (1990) Intérpretes [EP] Buenos Aires: Radio Tripoli Discos.

Hermética (1991) Hermética. Intérpretes [CD] Buenos Aires: Radio Tripoli Discos.

Hermética (1991) Ácido argentino [CD] Buenos Aires: Radio Tripoli Discos.

Hermética (1994) Victimas del vaciamiento [CD] Buenos Aires: Radio Tripoli Discos.

Hermética (1995) Lo último [CD] Buenos Aires: DBN

Hermética (1996) En concierto parte I \& II [CD] Buenos Aires: DBN

Horcas (1990) Reinará la tempestad [Disco] Buenos Aires: Radio Tripoli Discos.

Iorio, Ricardo y Cianciarulo, Flavio (1997) Peso argento [CD] Buenos Aires: Resiste!

Iorio, Ricardo (2005) Ayer deseo, hoy realidad [CD] Buenos Aires: Dejesu Discos. 
Iorio, Ricardo (2014) Tangos y Milongas [CD] Buenos Aires: Dejesu Discos. Iorio, Ricardo (2015) Atesorando en los cielos [CD] Buenos Aires: Dejesu Discos. Iron Maiden (1983) "The trooper", Piece of Mind [Disco] Reino Unido: EMI. Iron Maiden (2000) "Bloodbrothers", Brave new world [CD] Reino Unido: EMI. Judas Priest (1978) Stained Class. Reino Unido: CBS Records. Judas Priest (1980) British Steel [Disco] Reino Unido: Columbia Records. La Pesada del Rock and Roll (1971) "Salgan al sol”, Billy Bond y La Pesada del Rock and Roll. Volumen 1 [Disco] Buenos Aires: Music Hall.

La Venganza (2011) "Q.E.P.D.”. Recuperado de: https://www.youtube.com/watch?v=m801MsShMY8

Larralde, José (1970) "De los pagos del tiempo", Amigo [Disco] Argentina: RCA Víctor.

Las Brujas (2013) La reencarnación [CD] Portugal: Metal Soldiers Records.

Lennon, John (1970) John Lennon/Plastic Ono Band [Disco] Reino Unido: Apple.

Lennon, John (1971) “Gimme some truth”, Imagine [Disco] Reino Unido: Apple.

Malón (1995) Espíritu Combativo [CD] Buenos Aires: EMI.

Malón (1996) Justicia o resistencia [CD] Buenos Aires: EMI.

Manal (1970) "Porque hoy nací", Manal [Disco] Buenos Aires: Mandioca.

Mayhem (1995) Dawn of the Black Hearts [Disco] Colombia: Warmasters Records.

Megadeth (1992) "Symphony of destruction", Countdown to extinction [CD] Estados Unidos: Capitol Records.

Metal Vol. I, Latinos y Metálicos [Disco] (1991) Argentina: Halley Records.

Metallica (1987) The \$5.98 E.P.: Garage Days Re-Revisited [EP] Los Ángeles: Elextra Records.

Motörhead (1979) "No class”, Overkill [Disco] Reino Unido: Bronze Records.

O’Connor (2004) “Deseo”, El tiempo es tan pequeño [CD] Buenos Aires: PELO.

Pappos's Blues (1973) “Sucio y desprolijo”, Pappo’s Blues Volumen 3 [Disco] Buenos Aires: Music Hall.

Patricio Rey y sus redonditos de ricota (1987) "Vencedores vencidos", Un baión para el ojo idiota [Disco] Argentina: Del Cielito Records.

Profecium (1997) Socialismo satánico [CD] Buenos Aires: el autor.

Radio Olmos [CD] (1993) Buenos Aires: Tommy Gun Records.

Renacer (2013) Espíritu inmortal [CD] Buenos Aires: Ícarus Music.

Riff (1981) Ruedas de metal [Disco] Buenos Aires: Tonodisc. 
Rubén Patagonia (1998) Cutral-Có [CD] Buenos Aires: EMI.

Santos Discépolo, Enrique (1934) "Cambalache”.

Steppenwolf (1968) "Born to be wild”, Steppenwolf [Disco] Nueva York: ABC.

Sumo (1987) “Mañana en el Abasto”, After Chabón [Disco] Buenos Aires: Sony Music.

Testament (1988) "Into the pit", The New Order [Disco] Nueva York: Megaforce Records.

Thrash, Metal Argentino [Disco] (1991) Buenos Aires: Radio Tripoli Discos.

V8 (1983) Luchando por el metal [Disco] Buenos Aires: Umbral Discos.

V8 (1985) "Ideando la fuga", Un paso más en la batalla [Disco] Buenos Aires: Umbral Discos.

V8 (1986) El fin de los inicuos [Disco] Buenos Aires: Umbral Discos.

Vibrion (2016) Bacterya [CD] Madrid: Xtreem Music 


\section{Filmografía}

Astrain, Juan. (Prod. y Dir.) (2010) Heavy Mental Metal Pensado. [Documental] Córdoba.

Benedek, László (Dir.) y Kramer, Stanley (Prod.) (1953) The Wild One [Película] Estados Unidos: Columbia Pictures.

Brenes, Jeff y González, Indira (Dir. y Prod.) (2008) Cadáver exquisito: la Cultura Metal en América Latina [Documental].

Carcavallo, Lisandro (Dir. y Prod.) (2017) Cemento, el documental [Documental] Argentina.

De Jorquera, Alexis (Dir. y Prod.) (2014) Sueños de rock [Documental] Argentina.

Díaz, Fernando (Dir.) (2015) Antena metálica [Documental] Argentina.

Dunn, Sam y McFadyen, Scot (Dir.) (2008) Global metal [Documental] Canadá: Banger Productions.

Fernández, Germán y Montllau, Pablo (Dir.); Fernández, Mariano y Cala, Rodrigo (Prod.) (2014) Relámpago en la oscuridad [Documental] Argentina.

Ford, John (Dir.) (1939) Corazones indomables [Película] Estados Unidos: 20th Century Fox.

Hermética (1993) Hermética en vivo, 1993, Argentina [VHS] Buenos Aires: Radio Tripoli Discos.

Led Zepellin; Clifton, Peter y Massot, Joe (Prod.) (1978) The song remains the same [Película] Nueva York: Warner Bros.

Lojo, Matías y Patrono, Gabriel (Prod. y Dir.) (2017) Alguien más en quien confiar [Documental] Argentina: SME.

Loreti, Nicanor (2011) La H [Documental] Argentina.

Lot Calabró, Lucas y Álvarez, Paula (Dir. Y Prod.) (2015) Sucio y desprolijo [Documental] Argentina.

Malón (2012) El regreso más esperado [DVD] Buenos Aires: Malón.

Parés, Pablo; Soria, Paul y Sáez, Hernán (Dir.) (2009) Kapanga Todoterreno [Película] Argentina: Farsa Producciones.

Salbuchi, Andrián en Iorio Channel (2016 julio 8) \#Bicentenario [Archivo de video]. Recuperado de: https:/www.youtube.com/watch?v=qeoqQgbAd4M

Soria, Paulo y Patrono, Gabriel (Dir.) y Suárez, Mariano (Prod.) (2013) El blues de los plomos [Documental] Argentina: Farsa Producciones. 
Varas-Díaz, Nelson (Prod.) y González Sepúlveda, Osvaldo (Dir.) (2015) The Distorted Island: Heavy Metal and Community in Puerto Rico [Documental]

Varas-Díaz, Nelson (Prod.) y González Sepúlveda, Osvaldo (Dir.) (2016) The metal islands [Documental]

Varas-Díaz, Nelson (Prod.) (2018) Songs of Injustice: Heavy Metal Music in Latin America [Documental] 